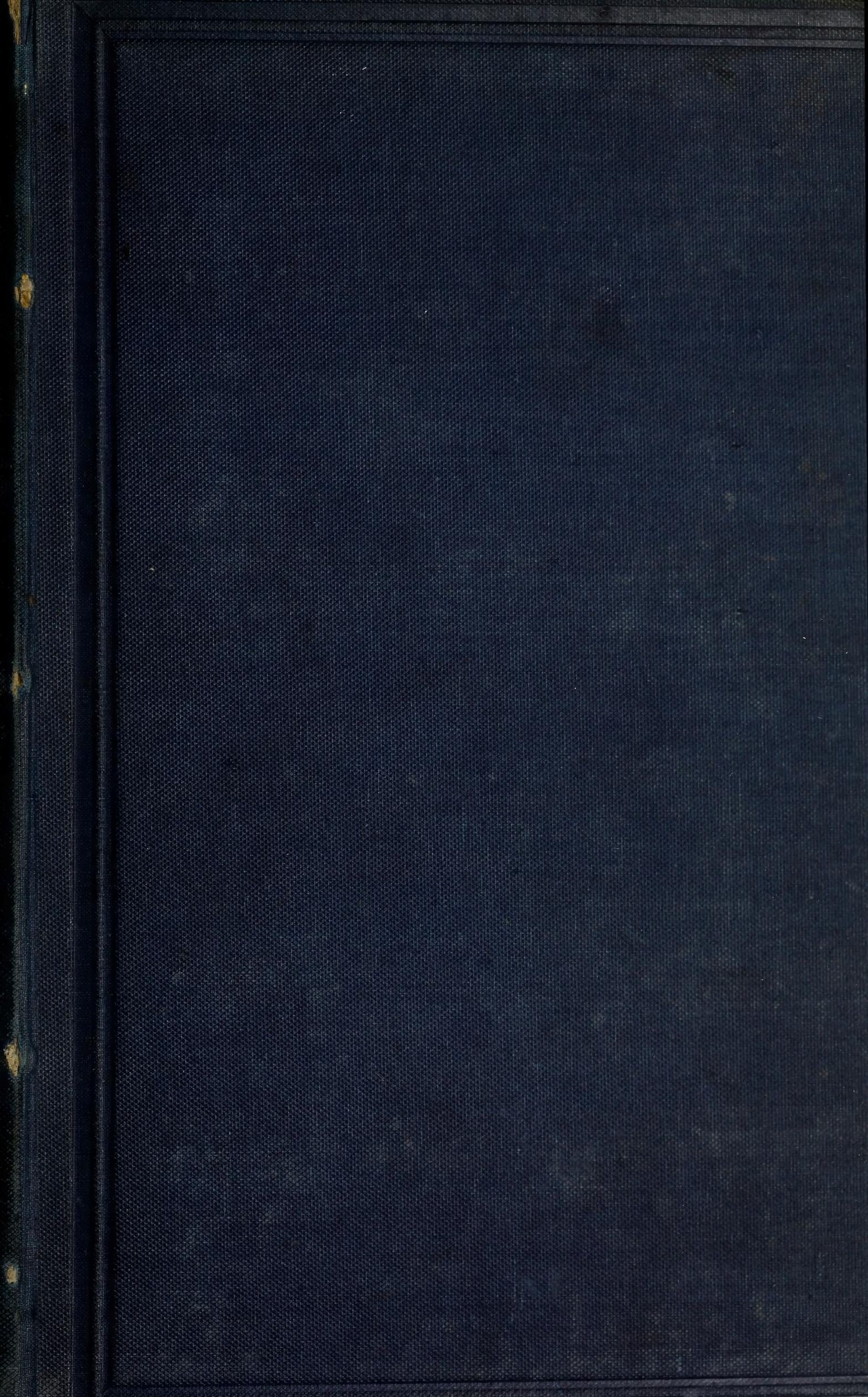


Clealli Cosme

plí

FIELD COLUMBIAN MUSEUM

LIBRARY.

Chicago.

FROM Eduvard E. ayyer

CLASS 470.543

B00रो85 




\section{PLANCHES COLORIÉES}

DES

\section{OISEAUX DE LA BELGIQUE}

ET

DE LEURS OEUFS;

PAR

CH. F. DUBOIS,

MEMBRE DE PLUSIEURS SOCIÉTÉS SAVANTES

TOME II.

AVEC 10 PEANCHES.

19018

BRUXELLES - LEIPZIG - GAND. ·

C. MUQUARDT.

1857 


$$
\begin{aligned}
& \text { R.B } \\
& \text { Ayer } \\
& P_{1} 181 \\
& 12 \\
& 7,2
\end{aligned}
$$




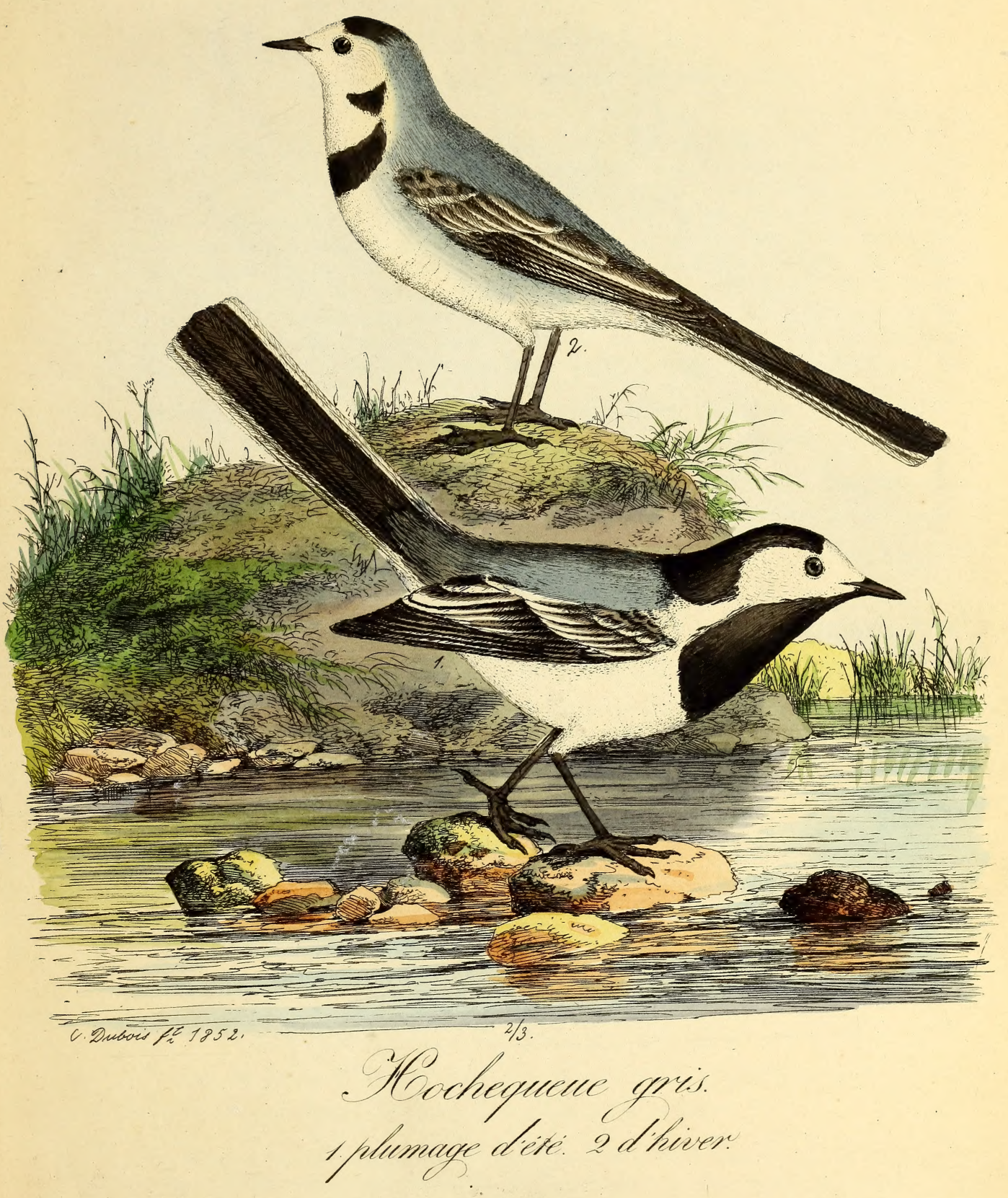





\section{FAMILLE XII. MOTACILLES-MOTACILLIDE. \\ Cense Hochequene. - Mutuciller, Linné.}

\section{0 C II E Q U E U E G R I S. MOTACILLA CINEREA, BRISSON.

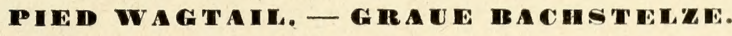

LAVANDIÈRE. Buff., t. V, p. 261. - Buff., pl. él., 652. - Briss., t. III, p. 461. - Lath., t. IV, p. 396. - Temm., t. I, p. 258 , et t. III, p. 178. - Gould, t. II, pl. 84. - Naumann, t. III, pl. 86. - Brehm., p. 347. - Glog., t. I, p. 253. - Kays. et Blas., no 172. - Schleg., p. 37. - Degl., t. I, p. 433. - Thienem, II. Abt., pI. VIII, fig. 4. - Meis. et Schinz., VG. Schweiz., no 106. - Mey. Vg. Liv u. Esthlands, p. 110. - Faber, Isländische Ornith., p. 17. - Glog., Fauna Schlesiens., n 830. -Savi, Ornith. Toscana, t. II, p. 28.-Landb., Vg. Würtembergs, $n^{0}$ 125. - Dr Hons. et $\mathrm{D}^{\mathrm{r}}$ Schill., Vg. Pommerns, $n^{\circ} 85$. - v. Homey., Vg. Pommerns, $n^{\circ} 115$. - De Selys-Longch., Faune Belge, $n^{0}$ 100. - Malh., Faune Sicile, p. 92. - Mühle, Vg. Grieghenlands, no 118. - Doubl. Brit. Birds, p. 10. - Rüppell, Vg. Nord-ost-Afrika's, no 173. - v. Müller, Ornith. Afrika’s. - Strickl., Ois. de l'Asie mineure. - Motacilla alba, Linne. M. albida, Jacq. - M. Lotor, Rennie.

Habite toute l'Europe, jusqu'en Norwége et en Finlande; cet oiseau se trouve en Sibérie, au Kamtschatka, en Égypte, en Abyssinie et en Algérie, et est très-commun en Belgique. Il fréquente les lieux bas et humides les prairies, les bords des eaux, les villages et les villes. Cet oiseau est extrêmement confiant, il suit le laboureur derrière la charrue et ramasse les insectes et les larves qui sont mis à découvert. Il poursuit avec acharnement et en poussant de grands cris les oiseaux de proie qui viennent dans leur circuit en volant bas; il donne ainsi l'alarme aux autres petits oiseaux et les préserve de la voracité de ces rapaces. Le Hochequeue gris arrive vers le commencement de mars et émigre en octobre; il y en a pourtant qui passent l'hiver en Italie, même il en reste en Belgique, lorsque cette saison n'est pas rigoureuse.

Variétés accidentelles, tout blanc, pâle jaunâtre, ou blanc grisâtre.

Nourriture : mouches, cousins, phalènes, petits limaçons, mille-pieds et autres insectes, ainsi que leurs larves (I).

Il niche entre les racines des arbres riverains, dans les masures, dans des tas de bois ou dans les trous des arbres, entre les fentes de murailles, sous les ponts et sous les toits des maisons; son nid est composé de brins d'herbe, de paille et de mousse, et à l'intérieur il est bourré avec des radicules et de la laine. Il pond de quatre à six oufs.

(1) Quoique l'utilité de cet oiseau soit appréciée surtout des laboureurs qui les aime et les protége, il y en a toujours une grande quantité de ses pauvres jeunes oiseaux aux marchés, ainsi que beaucoup d'autres espèces qui, pour la plupart, meurent quelques heures après qu'ils ont été enlevés de leurs nids; il est vraiment incroyable comment on permet un commerce aussi barbare. 
Digitized by the Internet Archive in 2015 


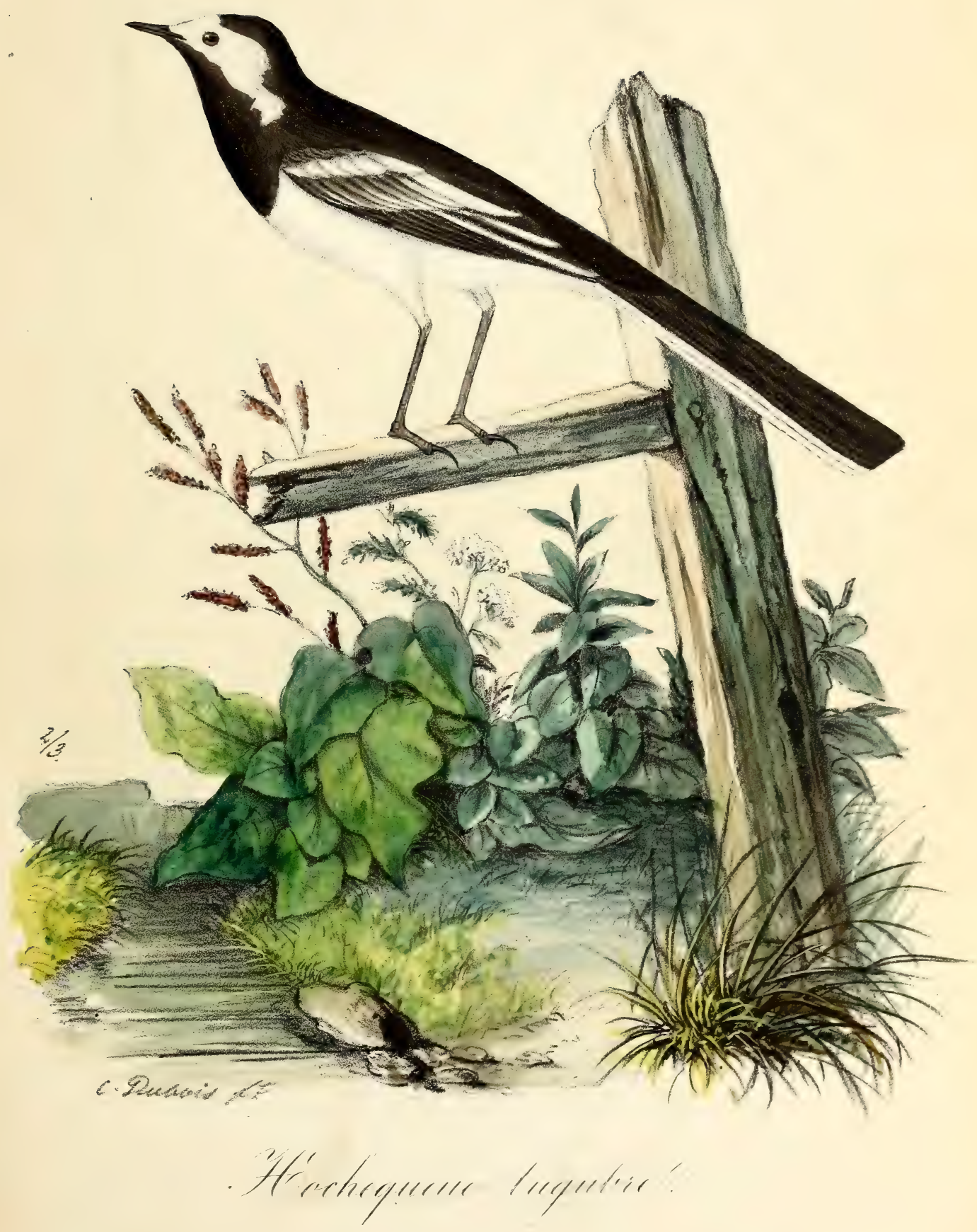





\title{
HOCHEQUEUE LUGUBRE.
}

\author{
MOTACILLA LUGUBRIS, TEMMINCK.
}

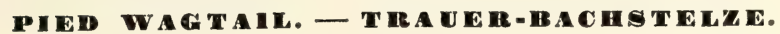

Teniminck, Man. D’Ornith, t. 1, p. 253, et t. III, p. 177. - Gould., Birds of Europe, t. II, pl. 141. - v. Kittlitz, Kupfertafeln, pl. XXI, fig. 1. - Schleg., Revue, p. 37. - Keys. et Blas., no 173. - Cabanis, Mus. Hein., no 90. - Lesson, Man. Ornith., t. I, p. 501. - Degland, Ornith. Europ., t. I, p. 435. - Doubl., Brit. Birds, p. 10. - De Selys-Longch., Faune Belge, $\mathrm{n}^{\circ}$ 101.Motacilla Yarrellit, Gould. - M. albeola, var. Pallas. - M. lugens, Illiger. - M. alba leGubris, Schlegel.

Ce hochequeue se trouve plus abondamment aux îles Britanniques que les hochequeues gris; il parait plus rarement en France et il est très-rare en Belgique. En Allemagne on en a tué quelques-uns pendant leurs migrations; en Italie, en Hongrie, en Suède, en Norwége et en Russie, il ne parait qu'accidentellement, tandis qu'il est très-abondant dans la Crimée et au Kamtschatka; en hiver il est commun au Japon et aux îles Luçon. Les hochequeues lugubres se plaisent beaucoup dans le voisinage de l'eau claire, surtout de l'eau courante, telle que les ruisseaux et les rivières; mais ils aiment particulièrement les bords montagneux de la mer; on trouve aussi cet oiseau dans les prairies et dans les champs où il suit la charrue du laboureur pour ramasser les insectes qui sont mis à découvert par l'instrument. Les hochequeues sont des oiseaux très-éveillés, ils ne sont presque jamais en repos, mais ils courent presque continuellement en agitant la queue; ils aiment beaucoup à se quereller avec les oiseaux de leur espèce ou avec d'autres; ils ne sont point farouches et laissent approcher l'homme très-près d'eux, ce n'est que lorsque celui-ci n'en est plus éloigné que de quelques pas qu'ils s'envolent pour se poser un peu plus loin.

La nourriture de ces hochequeues consiste en mouches et en petits insectes et leurs larves que ces oiseaux trouvent dans la fange et sur la terre aux bords des étangs, des ruisseaux et des rivières.

Ils construisent leurs nids dans des cavités, dans des crevasses de rochers, de vieilles murailles ou dans des trous qui se trouvent en terre; le nid n'est fait ni solidement ni adroitement; il se compose de mousse, de brins d'herbe et de radicules; dans l'intérieur du nid se trouvent des poils de vache et de renard bleu, ainsi que du duvet; il contient de quatre à cinq œufs. 



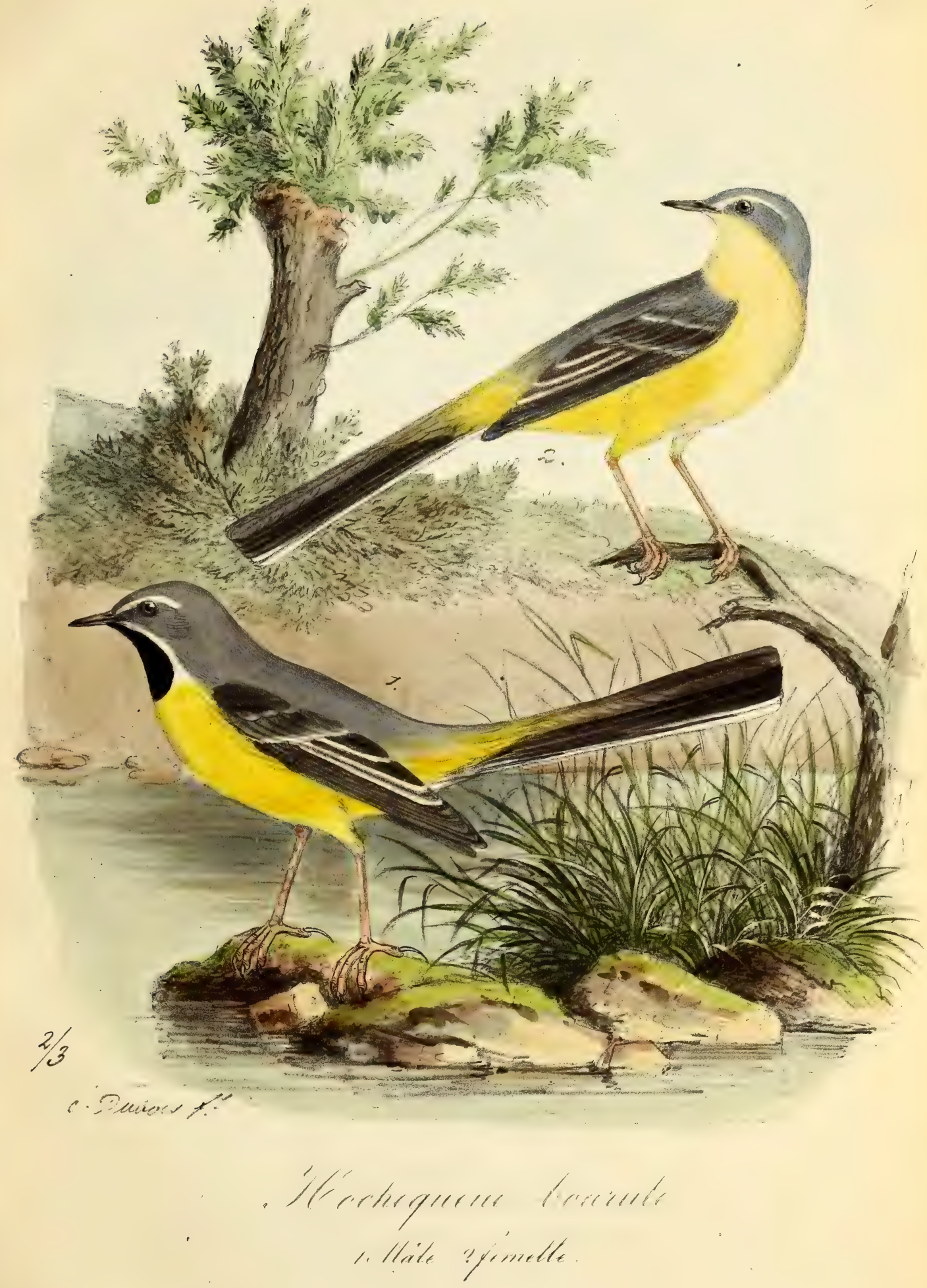





\section{H 0 C H E Q UEUE B 0 A R U L E.}

MOTACILLA BOARULA, GMELIN.

GREY WAGTAL. - GEITGA-HACHSTEZE.

BERGERONNETT E DE PRINTEMPS, Buff, pl. enl. 674. - Temm., t. I, p. 257.-Naum , t. III, pl. 187. - Gould, t. II, pl. 147. - Degl., t. I, p. 436 - Thien., FonTP., pl. VIII, fig. 5. - Selys-Longch, Faune belge, n 99. - v. d. Mühle, Vg. Griechenlands, no 119 . Malh., Ois. d’Agérie, p. 11. - Rupp., Vg. N. O. Afrika's, no 177. - Motacilla flava, Briss. - M. sulfurea, Bechst. - M. melanop, Pallas. - M. longicaudata, Hermann.

Habite l'Europe tempérée et méridionale ; il ne s'avance vers le nord que jusqu'au Danemark; il se trouve en Algérie, en Égypte et en Nubie ainsi que dans quelques parties de l'Asie; en Allemagne, en Hollande, en Belgique et en France il parait toujours dans les parties montueuses. Il arrive ordinairement quelques jours plus tôt que le hochequeue gris; quelques-uns restent ici en hiver, surtout s'il n'est point très-rigoureux. Les hochequeues boarules aiment beaucoup les ruisseaux pierreux des forêts, et ils se tiennent volontiers entre les montagnes et les bords des fleuves où il y a des pierres; on le trouve aussi près des moulins et des cascades, même dans le voisinage de l'eau; ils ne s'avancent jamais dans les champs; cependant ils se posent sur les arbres et sur les toits des maisons; la plupart de ces oiseaux sont confiants et plus prudents que les hochequeues gris; ils sont intolérants envers leurs semblables; en volant ils font entendre un son court et perçant comme : $z i z i, z i, z i s$, zissis; le mâle chante doucement et d'une manière agréable, quoique le chant soit court et monotone; dans le temps de l'accouplement, ils sont très-tendres et voltigent souvent autour de la femelle, le plumage soulevé, la queue pendante et élargie et les ailes tremblantes.

Nourriture : mouches, cousins, insectes aquatiques et leurs larves que ces oiseaux cherchent dans l'eau et sur les bords fangeux des fleuves.

Ils nichent dans les crevasses des rochers et des murailles, dans les trous de terre ou entre les racines; ils font ordinairement deux couvées. Le nid est composé de petites racines, de radicules, de mousse, d'herbe sèche et de morceaux de gazon; tous ces matériaux sont plus fins à l'intérieur, et enfin il est bourré de laine et de crins; il contient en avril cinq ou six cufs. 

0.3

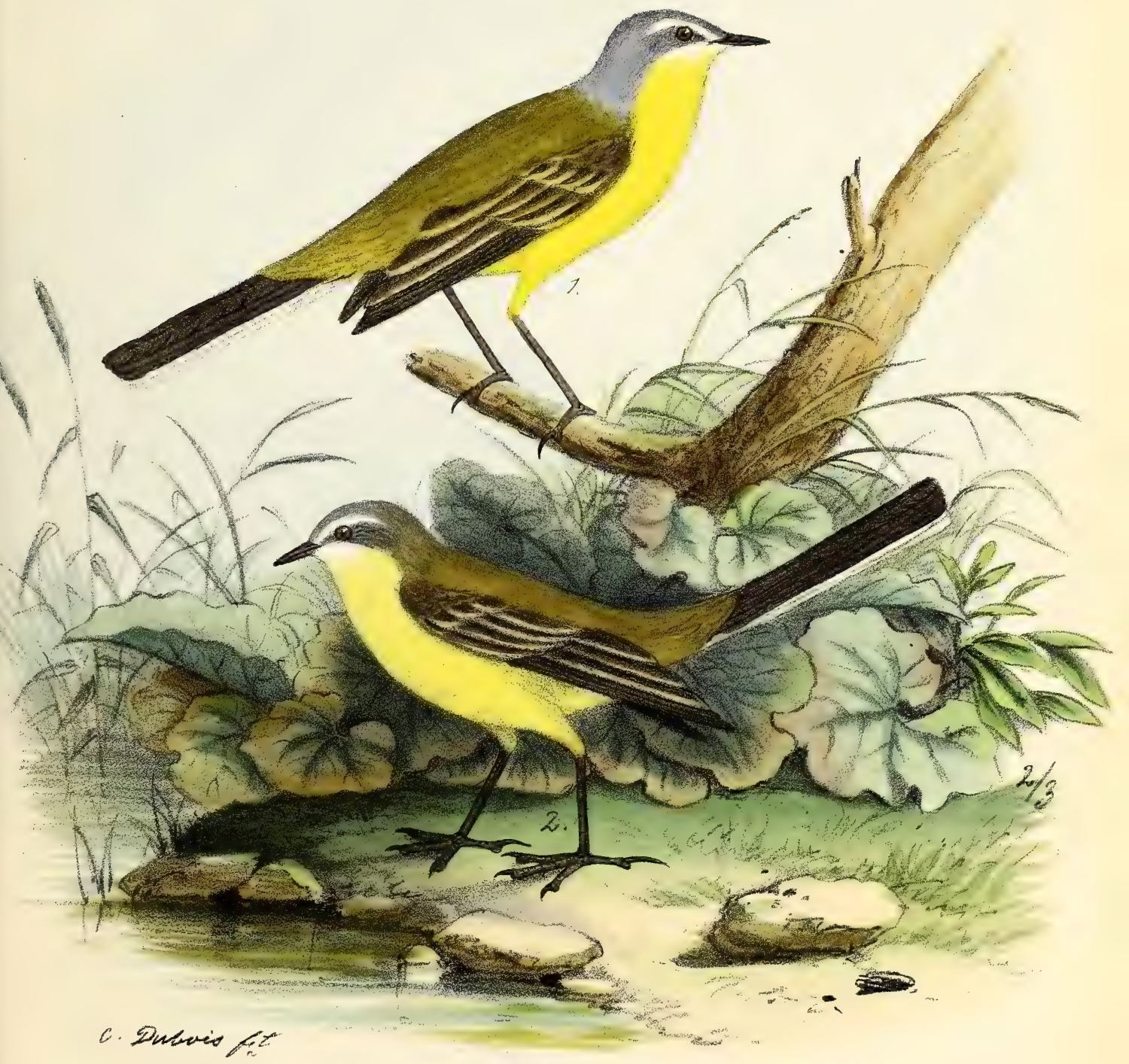

YCochequeue jaune
"White sfonetle. 



\title{
HOCHEQUEUE JAUNE.
}

\author{
MOTACILLA FLAVA, LINNE.
}

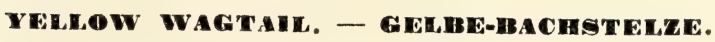

LA BERGERONNETTE DE RRINTEMPS. Buff., t. V, p. 265.-Briss., t. III, p. 468. Temm., t. I, p. 260. - Gould., t. Il, pl. 88. - Maum., t. III, pl. 88. - Brehm., p. 344.-Glog, p. 257.-Schleg., p. 38.-Degl., t. I, p. 438.-Thien., pl. 8, fig.6.-Meis., Vg. Schweız., no 108. -Mey. VG. Liv.-u. Esthlands, p. 111 - Bes., Vg. Kuhrlands, nº 180.-Glog., Fauna Schlesiens., $n^{\circ} 87$. - Savi, Ornith. Toscana, t. II, p. 34. - Landb., Vg. Wurtembergs, $n^{\circ} 121$ - - v. Homey, Vg. Pommerns, no 117.-De Selys-L., Faune Belge, no 95.-Malh., Faune Sicil., p. 94.-v. d. Mühl., Vg. Griechenlands, no 120. - Doubl., Brit. Birds, p. 10.-Malb., Ois. d'Algérie, p. 11. - Rüpp., V. N.-0. Afrika's, n 176. - Sylvia littorea, Lath. - Budytes flavus, Brehm. B. flava, Cuv. - B. beema, Sykes. - Motacilla verna, Briss. - M. neglecta, Gould. - M. chrysogastra, Bechst. - M. javanica el tschutshensis, Gml.

Cet oiseau se trouve dans toute l'Europe, dans une grande partie de l'Asie et de l'Afrique; en Europe il n'est que pendant l'été; il y arrive au mois d'avril et en part au mois d'octobre. Les hochequeues jaunes sont fort communs dans quelques contrées. Ils vivent dans les plaines unies et libres, ayant des marais, des prairies et des campagnes humides; on les voit aussi aux bords des étangs et des fossés; ils aiment particulièrement les pâturages; jamais on ne les rencontre ni aux bords des fleuves, ni dans l'intérieur des bois, quoiqu'ils en fréquentent souvent les lisières. En automne ils vont ensemble par petites sociétés ou par troupes; ils vivent beaucoup à terre, mais ils se posent aussi volontiers sur les joncs et les buissons. Pendant les couvaisons, ils dorment à terre près de leur nid et alors ils sont très-doux et point farouches, ce qui ne les empêche pas d'être très-vigilants; les jeunes oiseaux même font attention à la voix des vieux quand ils courent un danger.

Varietés accidentelles: blanc, taché·de blanc, gris rougeâtre avec le ventre blanc.

Nourriture : mouches, cousins, phalènes, de petits coléoptères, que ces oiseaux becquètent sur la terre, ou bien qu'ils saisissent en faisant un bond.

Leur nid, qui est très-mal construit, se trouve à la fin du mois de mai sur la terre dans une petite cavité. Ils le font ordinairement dans une prairie, sur les bords d'un fossé ou d'un étang, et le cachent sous l'herbe, sous des plantes ou un buisson. Le nid est fait de tiges d'herbe sèche, de petites racines, de feuilles et de plus ou moins de mousse, quelquefois il n'y en a pas du tout; dans l'intérieur du nid se trouvent des poils de vache et des crins, parfois ils y ajoutent quelques plumes. Il contient de quatre à six oufs. 



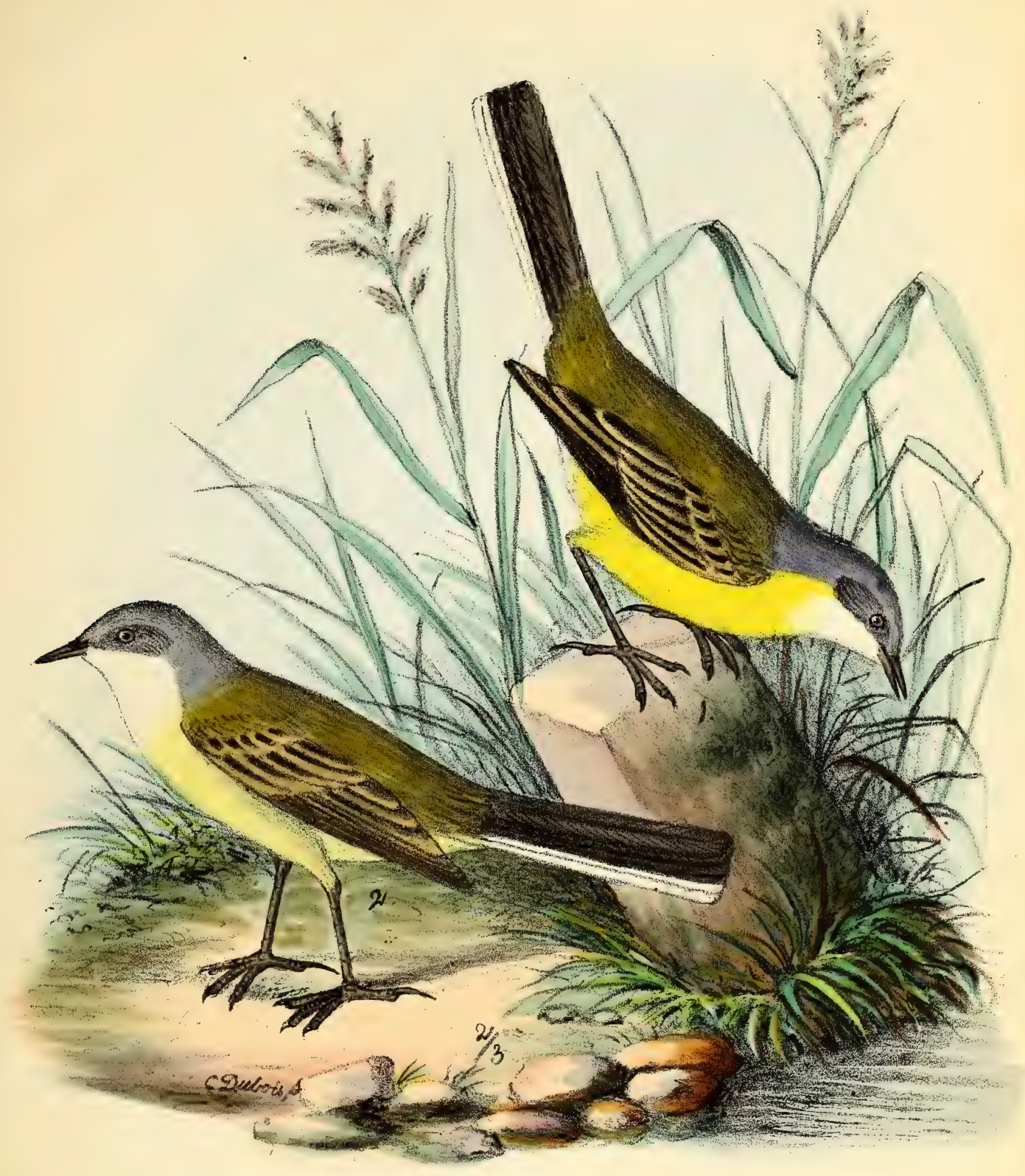

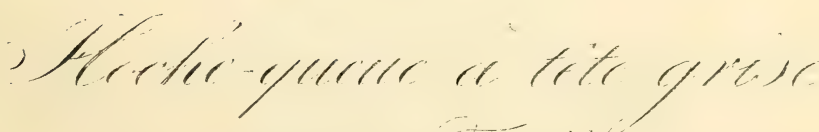

1. Hirte". Heonetle 



\section{HOCHE-QUEUE A TETE GRISE.}

MOTACILLA CINEREOCAPILLA, SAVI.

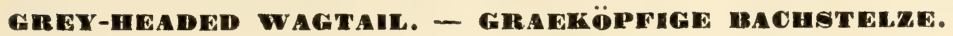

Savi, Ornith. Toscina, t. III, g. 216. - Schlegel, Revue, p. 38. - Bonaparte, Revue, p. 143. Cabanis, Mus. Hein., p. 15. - Baron Muller Syst. Verz. dans Cabanis, Journal Ornith., 185̌5̌, p. 386. - Selys-Longch., Faune Belge, no 96. - Malh., Faune Sicile, p. 94.-Motacilla flava cinereocapilla, Schleg. - M. Feldeggi, Mich. - M. dalmatica, Bruch. - Budytes cineroocaPILLA, Nobis.

Cet oiseau habite les pays chauds de l'Europe, tels que la Dalmatie, la Toscane, la Sicile, la Sardaigne, le midi de la France et l'Espagne. On le voit aussi en Egypte et même en Nubie; il se montre rarement en Belgique. M. le baron Selys-Longchamps en possède cependant un exemplaire qui a été pris dans les environs de Liége, et, moi-même, j’ai eu occasion d'en voir un vivant, dans une cage chez un oiseleur, mais il était tellement endommagé, qu'il n'aurait pas été possible à un amateur d'en tirer le moindre parti pour le faire figurer dans une collection. Cet oiseau se distingue du Hoche-queue jaune par une gorge blanche et une tête grise, et par l'absence complète du cercle blanchâtre autour des yeux.

Les grandes plaines, les pâturages et les marais sont les lieux où ces oiseaux préfèrent séjourner; il leur faut un sol humide, entrecoupé d'osiers, de roseaux et autres plantes aquatiques, parmi lesquelles le mâle, dans la saison de l'accouplement, se tient des heures entières pour appeler la femelle par ses cris tendres. Ils ont beaucoup d'agilité dans tous leurs mouvements, mais ils sont d'une timidité excessive, et le moindre bruit les met en fuite. Néanmoins, on en prend beaucoup en Italie, où l'on ne considère guère leur utilité et où l'on préfère s'en servir pour les plaisirs de la table.

lls placent leurs nids à une très-petite élévation du sol, soit dans l'herbe ou dans le grain; ce nid est fait de petites racines, de brins d'herbe et de mousse; dans l'intérieur, ils ont soin de le garnir de laine pour le rendre plus doux ; quatre ou cinq est le nombre des oufs qu'ils y déposent ordinairement. Ces oufs ne diffèrent absolument en rien de ceux du Hochequeue jaune. 



\section{git.}

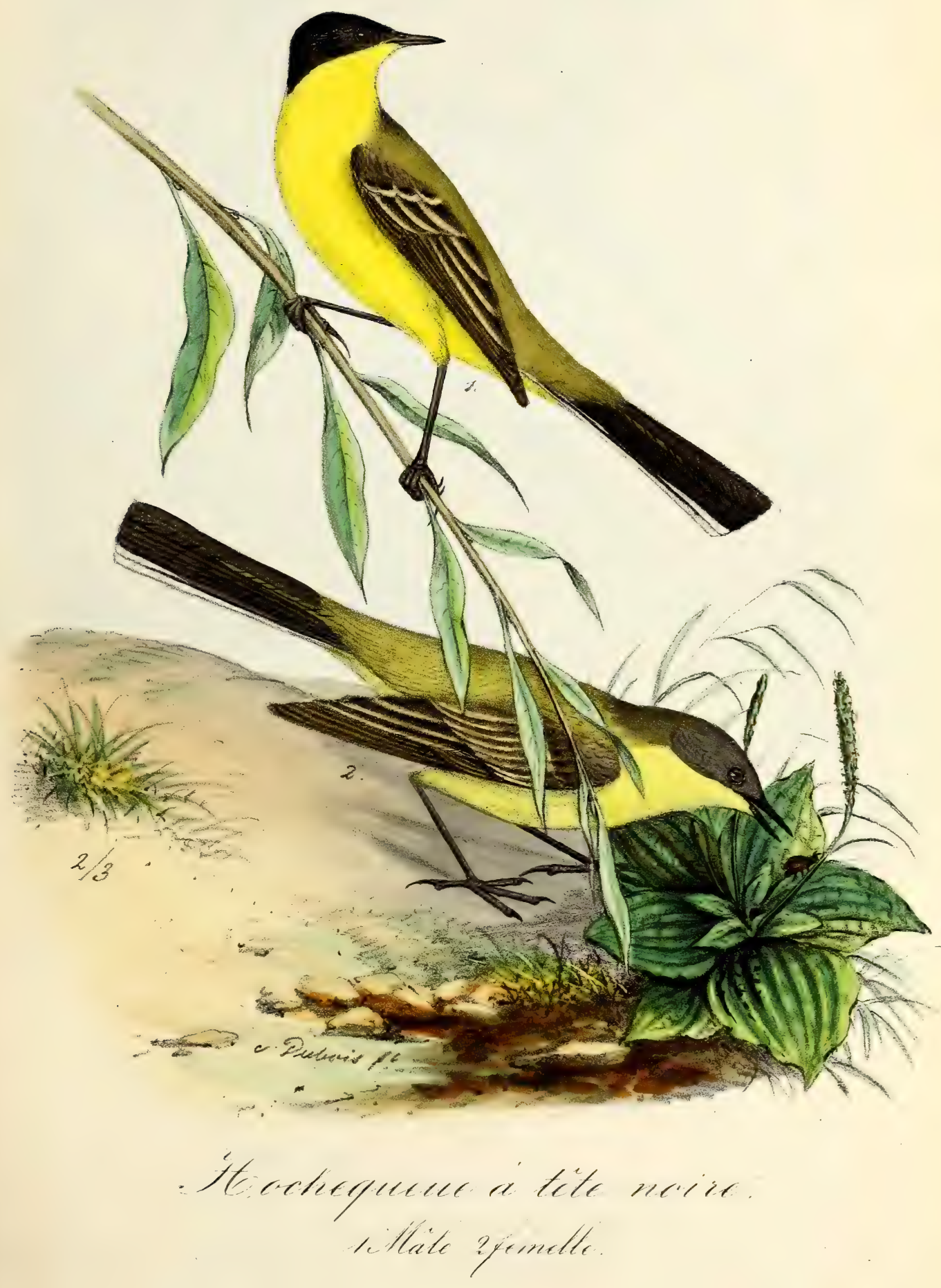





\section{HOCHEQUEUE A TETE NOIRE.}

MOTACILLA MELANOCEPHALA, LICHTENSTEIN.

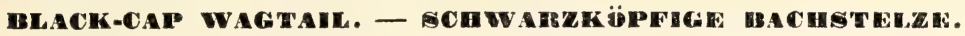

BERGERONNETTE DE PRINTEMPS A TÊTE NOIRE. Schleg., Revue, p. 38. Eversman, Reise, p. 129. - Licht. Cat. Doubl., p. 36. - Degl., t. I, p. 443. - De SelysLongch., Faune Belge, n 97. - v. d. Mühle, Vg. Griechenlands, no 121. - Malh., Faune Sicıl., p. 9ö. - Rüpp., Vg. N. 0. Afrika's, no 178. - Budytes melanocephala, Ménétr. Motacilla flava melanocephala, Schleg. - M. Feldeggit, Michapllis.

Ce bel oiseau habite l'Algérie, l'Égypte, la Nubie, l'Arabie, la Syrie, la Perse et la Bucharie; il est commun dans la Grèce, la Dalmatie et la Sicile; et ne parait qu'accidentellement en Allemagne, en Belgique et en France. Il aime les plaines herbeuses, les champs, les prairies et les marais; il se tient beaucoup à terre; cependant il se pose aussi sur les rameaux des buissons, sur les tiges de roseaux ou d'osiers. Ces oiseaux sont très-vifs dans leurs mouvements, farouches et sauvages; ils font souvent entendre de petits cris perçants.

Plusieurs naturalistes tiennent ce hochequeue pour une variété de la Motacilla flava, mais M. le comte von der Mühle nous donne là-dessus plusieurs éclaircissements, parce qu'il a observé les deux différents oiseaux en Grèce ; jamais il n'a trouvé la $M$. flava dans la société de la $M$. melanocephala, mais dans quelques districts il ne vit que ces oiseaux-ci, tandis que, dans d'autres, il ne trouva que les premiers. Dans tes parties où parait la $\boldsymbol{M}$. flava, on trouve aussi ordinairement la $\boldsymbol{M}$. cinerea, tandis que celle-ci ne se rencontre jamais avec la $M$. melanocephala; il est aussi à remarquer que cette dernière espèce part très-tôt, et que la $\boldsymbol{M}$. flava reste pendant une partie de l'hiver. Le 8 mai 1853 j'obtins au marché de Bruxelles, pour la première fois, un couple de ces beaux hochequeues, et le marchand m'assura que dans l'endroit où il avait pris ceux-ci, il y en avait d'autres; en effet, au bout de quelques jours, il m'apporta encore deux femelles et un mâle.

Ces oiseaux se nourrissent de mouches, de cousins, de phalènes, de petits coléoptères, d'insectes et de leurs larves.

Ils nichent à terre dans l'herbe ou sous un buisson, sur les bords des champs et des prairies; leur nid est fait de brins d'herbe sèche, de petites racines et de mousse; dans l'intérieur ils mettent une herbe plus fine et ils y ajout ent un peu de laine. Ils pondent aussi de quatre à six œufs. 



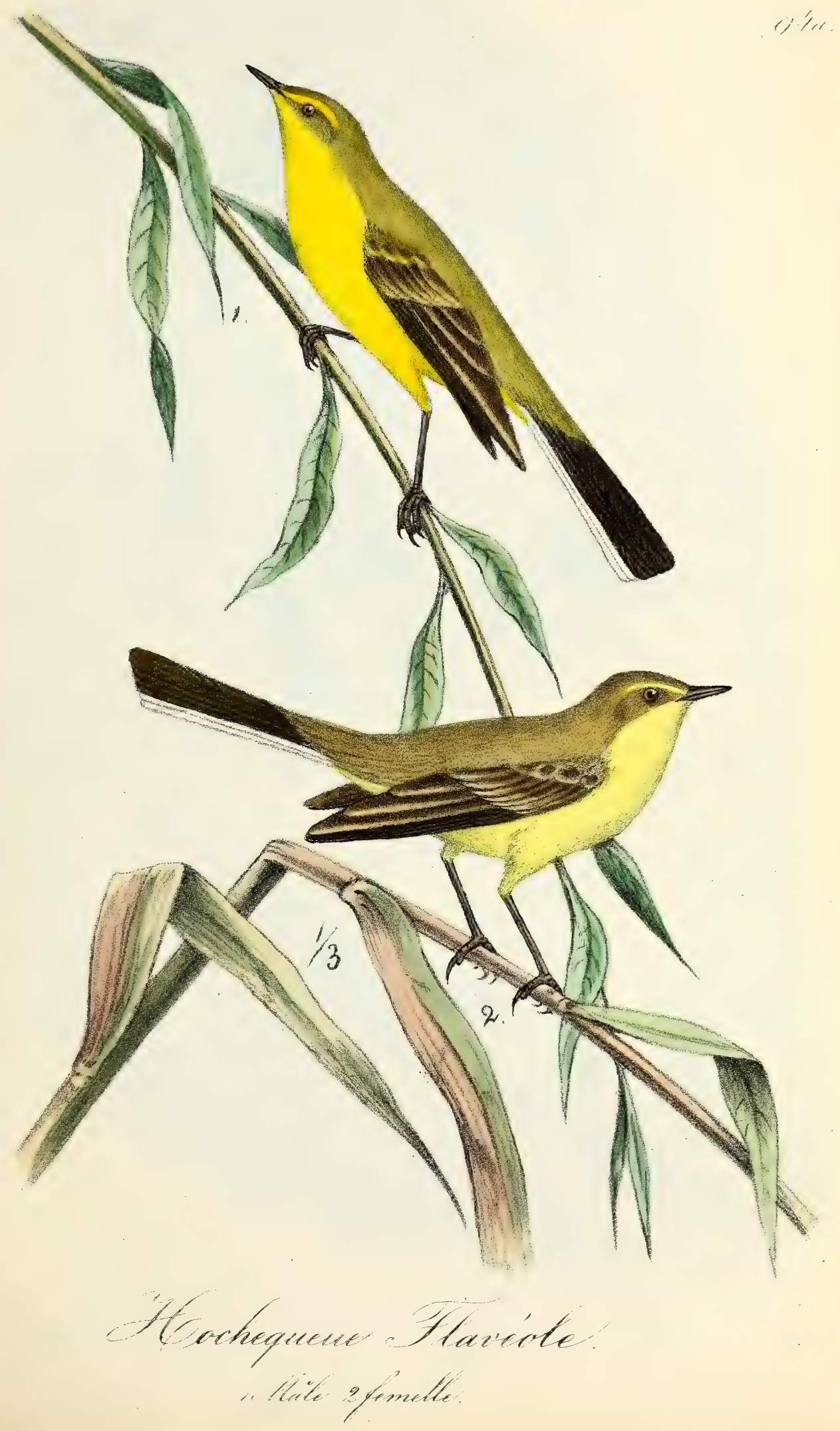





\section{HOCHEQUEUE FLAVÉOLE.}

MOTACILLA FLAVEOLA, GOULD.

YELLOW WAGTAT. - GELRGR̈̈UE-BACHSTELE.

Temminck, Man. d’Ornith., t. I, p. 253, et t. III, p. 183. - Gould., Birds of Europe, t. II, pl. 145. - Schleg., Revue, p. 38. - Keys. et Blass., n 176. - Degland, Ornith. Eunop., t. 1, p. 441. - Malh., Oiseaux de l'Algérie, p. 11. - De Selys-Longch., Faune Belge, no 98. - Doubl., Brit. Birds, p. 10. - Motacilla campestris, Pallas. - M. Anglorum, Prévost. - M. flata Rayi, Schleg. - Budytes Rayi, Gould.

Ces oiseaux sont assez abondants dans les îles Britanniques, ils sont rares en France et ne paraissent en Belgique que pendant leurs migrations; on en a aussi attrapé dans l'île d'Helgoland; pendant leurs migrations on en a tué en Allemagne où ils sont regardés comme étant des oiseaux extrêmement rares; j'y ai reçu, il y a quelques années, une couple de ces hochequeues qu'un amateur de Flosdorf avait tués près de la Rohr. Cette espèce arrive en Europe au mois d'avril et en part en octobre. La manière de vivre de ces oiseaux est presque semblable à celle des hochequeues jaunes; ils montrent une grande préférence pour les marais ayant des roseaux et des joncs, pour les prairies humides, les champs et les pâturages; ils courent vite et se réfugient sur de petites élévations, ainsi que sur les branches d'un arbre ou d'un bosquet. Ce sont des oiseaux farouches desquels on ne peut approcher qu'avec beaucoup de peine; pendant les couvaisons ils sont moins farouches; ils se querellent beaucoup entre eux et avec d'autres oiseaux; leur chant est désagréable; ils crient beaucoup et s'appellent toujours les uns les autres.

Leur nourriture consiste en mouches, petits insectes et leurs larves, et en chenilles; aux pâturages ils enlèvent les insectes parasites qui sont sur les animaux.

Ils nichent volontiers dans des endroits marécageux, ainsi que dans les prairies humides ou bien sur les bords des fossés, et aussi sur la terre, dans l'herbe, daris un petit enfoncement. Le nid est mal bâti et se compose de mousse, de brins d'herbe, de radicules et de quelques feuilles mortes; l'intérieur cst doublé de laine, de crins; quelquefois il s'y trouve des plumes; ils y pondent quatre ou cinq oufs.

Les nids de ces oiseaux seraient fort difficiles à trouver s'ils n'avaient soin de les signaler eux-mêmes par la crainte qu'ils montrent lorsqu'on en approche. 



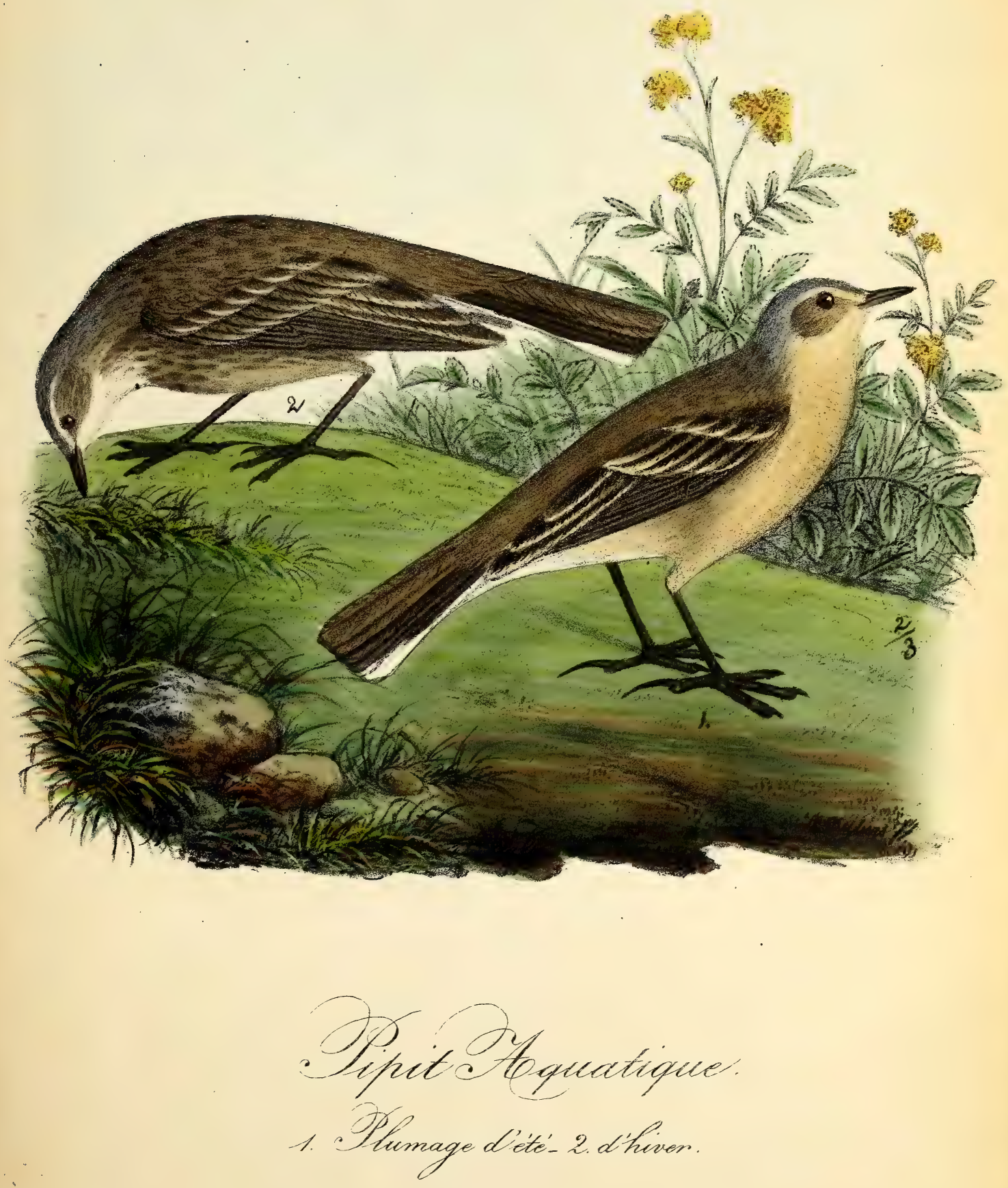



Cenre Pipit. - Amthens, Bechstein.

\section{P I P I T A Q U A TI Q U E.}

ANTHUS AQUATICUS, BECHSTEIN.

AUATIC PIPIT. - WASSEIE-PIETEIR.

LA SPINOLETTE. Buff., t. V, p. 43 ; pl. enl. 661 . - Temm., t. I, p. 265. - Naum., t. III, pl. 85. - Gould., t. II, pl. 138. - Degl., t. I, p. 425. - Savi, Ornith. Toscana, t. II, p. 39. Thienem., Fortp., pl. VIII, fig, 7.-Selys-Longch., Faune Belge, nº 91.-v. d. Mühle, Ornith. Griechenlands, no 112. - Malh., Faune Sicile, p. 97. - Rüpp., Vg. N. 0. Afrika, no 183. Alauda spinoletta, Linné. - A. campestris spinoletta, Gmel. - Anthus montanus, Koch. A. spinoletta, Key. et Blas.

Habite pendant l'été l'Europe tempérée jusqu'en Suède; on le trouve beaucoup sur les montagnes de la Bavière, et particulièrement sur celles qui bordent le Rhin; il parait aussi sur les montagnes d'Italie, sur les Pyrénées, mais rarement en Belgique. Pendant leurs migrations, en automne, ces oiseaux arrivent par petites troupes dans les plaines, dans les pâturages humides, dans les prés, ainsi qu'aux bords des ruisseaux et des étangs. Ils sont très-farouches; ce n'est que pendant les couvaisons qu'ils volent ou courent autour de celui qui les observe ou les dérange. Le mâle fait entendre assidùment son chant assez simple; pour l'exécuter il s'élève dans les airs et chante d'abord lentement, puis toujours plus vite: tingh, tingh, tingh, et finit en descendant par un long si-si-si-sisi, ayant les ailes étendues et se posant sur un arbuste ou sur une pierre, toujours en ligne oblique; il chante rarement étant perché.

Nourriture : mouches, cousins, insectes aquatiques et leurs larves.

Ils nichent à terre, ayant pour soutien une pierre, de l'herbe ou de petits arbustes, quelquefois aussi tout à fait sans soutien; le nid est composé de mousse, de brins d'herbe, de quelques racines et de tiges, l'intérieur est bourré de brins d'herbe, de radicules, quelquefois aussi d'un peu de laine ou de plumes; il contient de quatre à six ceufs. 

$19.2=$

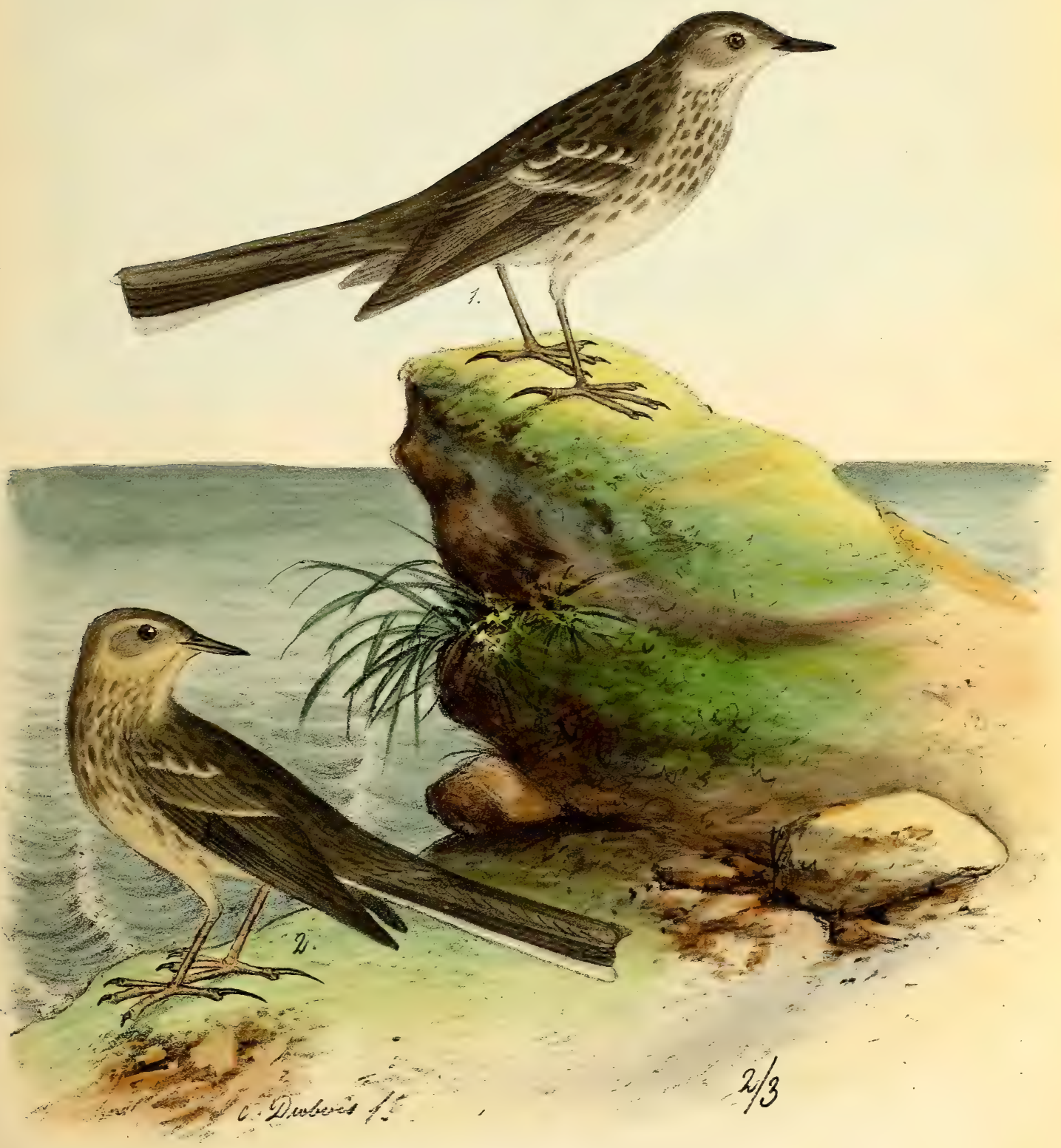

$$
\begin{aligned}
& \text { Jifieit de eractecs }
\end{aligned}
$$

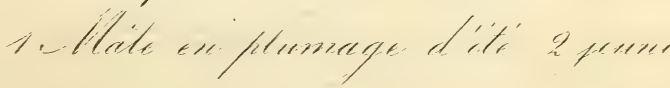





\title{
PIPIT DES ROCHES.
}

\author{
ANTHUS RUPESTRIS, NIELSON.
}

OHORE PIPIT. - FELSENPIEPER.

Temm., t. IV, p. 628. - Gould, t. II, pl. 138. - Schleg., p. 33̈. - Brehm, p. 330. - Degl., t. I, p. 428. - Cabanis, Journal Ornith. extra heft 1853, p. 62. - Selys-Longch, Faune belge, no 92. - Doubl., Britr. Birds, p. 10. - Alatda petrosa, linné. - A. obscura, Pennant. - Anthus obscurus, Temm. - A. petrosus, Flem. - A. littoralis, Brehm. - A. aquaticus, Selby. - A. Campestris, Bewick. - A. immutabilis, Degl.

Cet oiseau est tenu par quelques ornithologues pour une variété de climat du pipit aquatique; mais après de nouvelles recherches il a été reconnu pour être une véritable espèce. Ce pipit diffère toujours du pipit aquatique par la penne externe de la queue qui est grise. II habite particulièrement en été les parties septentrionales de l'Europe, telle que la Norwége, la Suède, le Danemark et les Iles Britanniques, surtout l'Écosse. Dans ces pays il vit sur les bords de la mer et sur les rochers qui la bordent ainsi que dans les dunes. Ils courent très-vite sur les pierres; le mâle chante beaucoup, son chant n'est point indifférent et ressemble assez à celui du bec-fin sylvicole; ils voltigent dạns les airs en répétant continuellement sist, sist; il se pose ensuite sur un rocher, sur lequel il court sans crainte, même s'il est parfois baigné par les vagues; en automne il est de passage sur les bords de la mer, en Allemagne, en Hollande, quelquefois en Belgique et en France; mais seulement là où il y a des rochers et des pierres.

Nourriture : mouches, cousins, insectes aquatiques et leurs larves que ces oiseaux cherchent sur les pierres et au bord de l'eau.

Les pipits nichent entre les pierres et dans les crevasses de rochers où se trouve de la mousse et de l'herbe entre lesquelles le nid se trouve à une certaine profondeur; il est composé de brins d'herbe, de feuilles de jonc et d'un peu de mousse; l'intérieur est bourré de laine de mouton et de crins; les pipits y déposent quatre ou cinq œufs. 



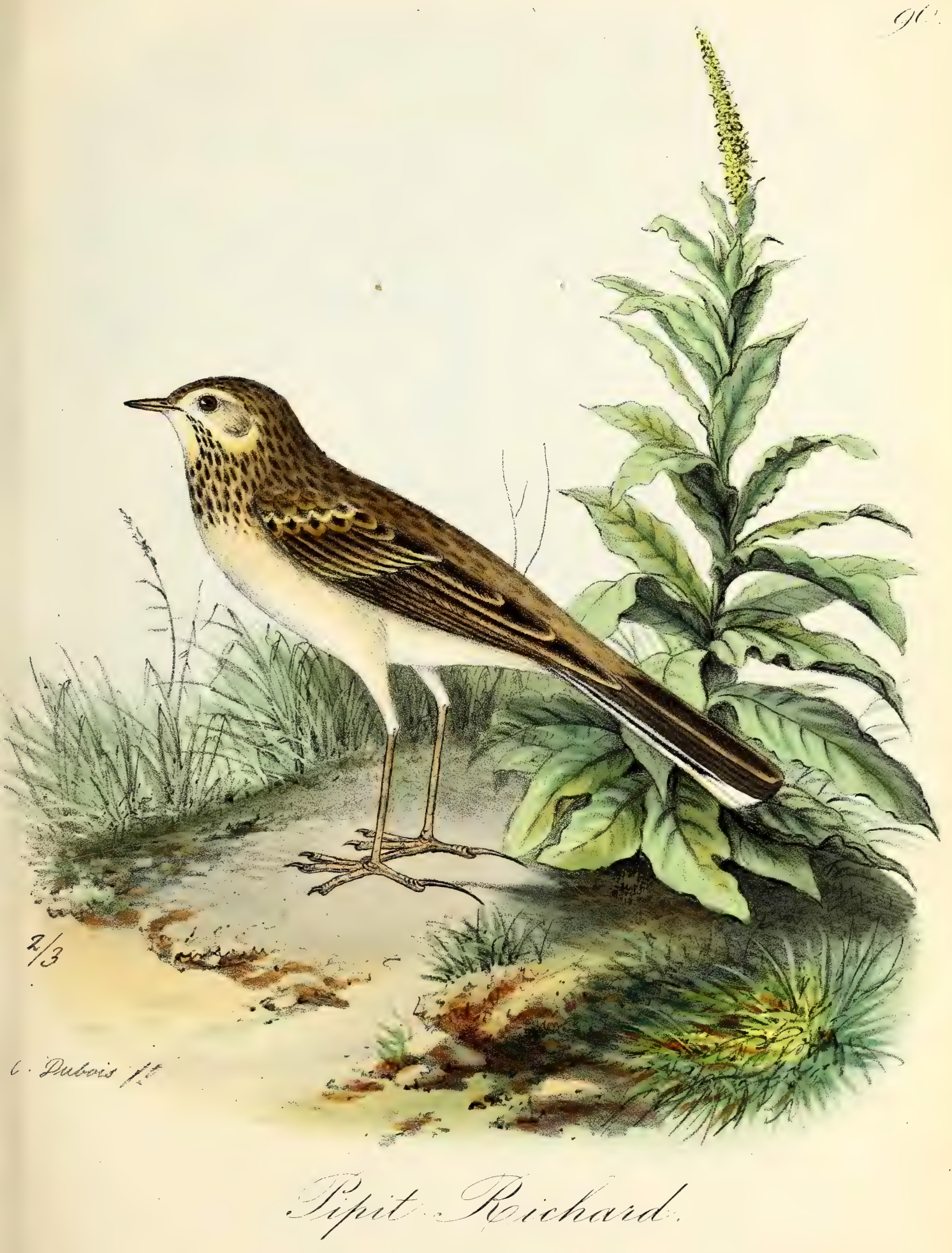





\title{
PIPIT RICHARD.
}

\author{
A NTHUS RICHARDI, VIELLOT.
}

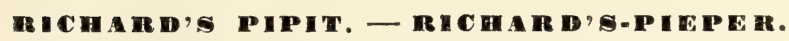

PIPIT RICHARD. Temm., pl. color., 101.-Temm. Ma., i. I, p. 263 - Gould., t. II, pl. 1330 - Brehm., Handr., p. 322. - Glog., t. I, p. 322. - Schleg., p. 36. - Keys. et Blas., p. 48. Degl., t. 1, p. 416. - Savi, Ornitu. Toscana, t. II, p. 53. - De Selys-Longch., Faune Belge, no 89. - Malh., Faune Sicil., p. 296. - v. d. Mühle, Vg. Griechenlands, n¹17. - Doubl., Brit. Birds, p. 10. - Corvdalla Richard, Vigors. - Anthus pupestris, Ménétr. - A. lonGiPes, Hollandre. - A. MaCronyx, Glog.

Le Pipit Richard habite la Grèce, la Sardaigne, l'Espagne et la France, particulièrement dans les environs des Pyrénées, de la Picardie et de la Provence; en Belgique et en Angleterre il est rare; en Autriche et dans d'autres parties de l'Allemagne il ne vient qu'accidentellement. On le trouve aussi dans l'Asie occidentale. Cet oiseau préfère les pays montagneux aux pays plats. Il court avec facilité sur le sol entre les broussailles sur lesquelles il se met souvent pour se reposer en agitant continuellement la queue et en faisant entendre sa voix perçante. Il est très-adroit et sait se soustraire à la vue du chasseur qui le guette. Au printemps on les trouve par couples, et lorsque la femelle couve, le mâle jaloux ne s'en éloigne jamais. Il s'élève ordinairement en chantant dans les airs, mais il ne reste pas à cette hauteur et en descend immédiatement.

Leur nourriture consiste en mouches, en cousins ef d'autres petits insectes et leurs larves.

Il niche dans un petit enfoncement sur la terre, contre une pierre ou caché par un buisson ou une touffe d'herbe; son nid est fait de brins d'herbe et de mousse, et lintérieur est bourré de poil de vache et de quelques crins; la ponte est de quatre ou cinq œufs. 



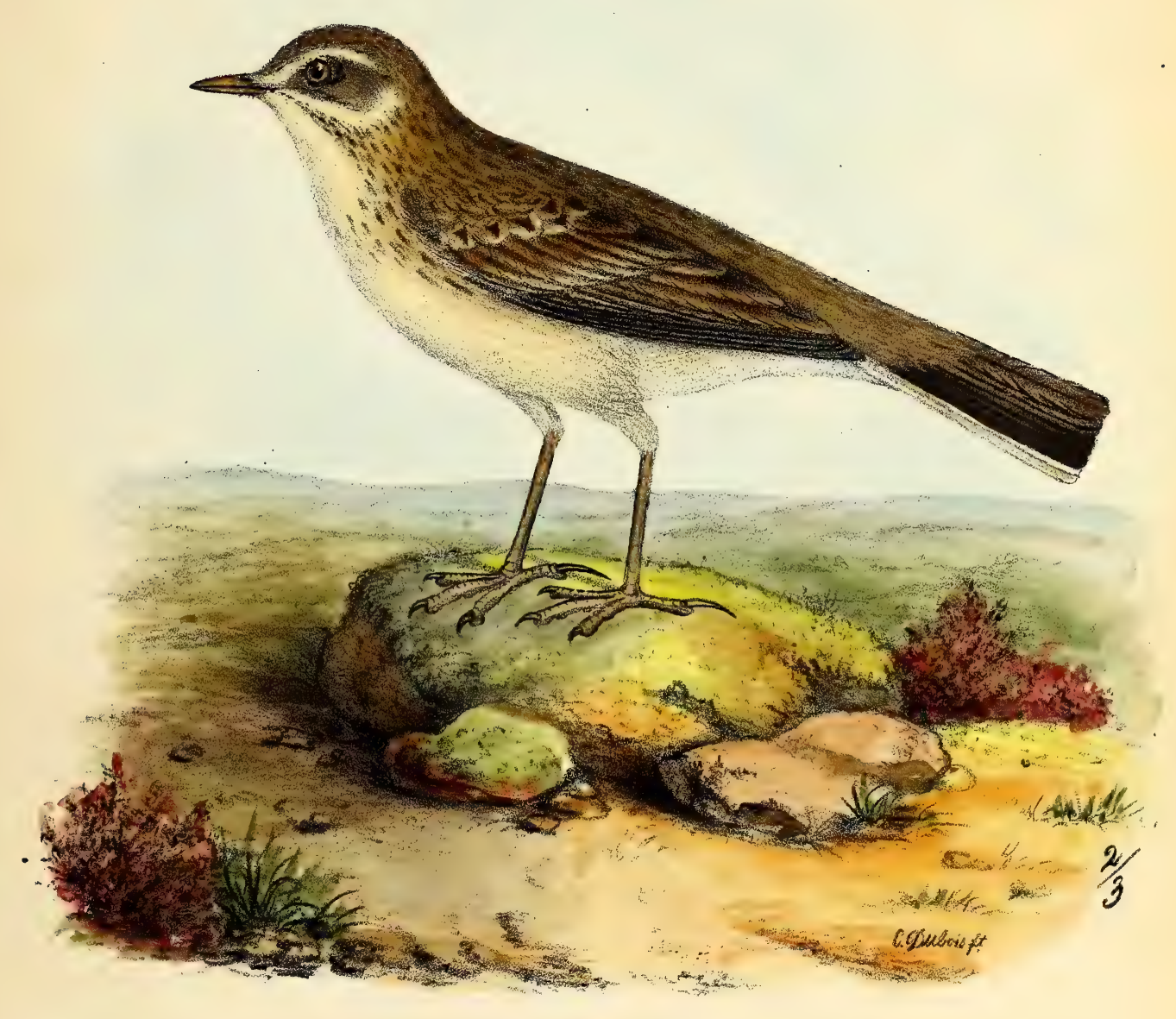

OHint das chamylas. 



\section{PIPIT DES CHAMPS.}

ANTHUS CAMPESTRIS, BECHSTEIN.

TA UNY PIPIT. - IRIRACH-PIEPEIR.

LA ROUSseline. Buff., pl. enl. 661. - Temm., t. I, p. 267. - Gould, t. II, pl. 137. Naum., t. III, pl. 84. - Brehm, p. 84. - Degl., t. I, p. 418. - Thienem, pl. VIII, fig. 9. v. d. Mühle, Ornith. Griechencands, no 116. - Savi, Ornith. Toscana, t. II, p. 45. - Malh., Faune Sicile, p. 98. - Selys-Longch., Faune Belge, no 91. - Malh., Ois. de l'Algérie, p. 11. - Rüpp., Vg. N. 0. Afrika's, no 182. - Anthus rufescens, Temm. - A. Rufus, Vieill. A. agrorum et subaquatus, Brehm. - Agrodroma Campestris, Swains.

Cet oiseau habite les contrées tempérées et surtout les contrées méridionales de l'Europe; cependant il parait encore en Suède et en Finlande; il n'est pas rare non plus dans l'Asie tempérée, ainsi que dans l'Égypte et la Nubie. Il n'est abondant ni en Allemagne, ni en Belgique; en Hollande il est une rareté et il ne paraît jamais dans les Iles Britanniques. Le Pipit des champs montre de la préférence pour les grandes plaines sèches à peine pourvues d'un peu d'herbe et de quelques arbustes; il aime beaucoup à vivre en pleine compagnie, aussi fuit-il l'herbe haute et les buissons; il court presque toujours à terre, quelquefois il se pose sur un monticule, une pierre ou un arbrisseau, rarement il se met sur un arbre. Il est trèsfarouche, prudent et vif dans ses mouvements. Le mâle a un chant assez singulier, composé de tons courts, uniformes et mélancoliques, qu'il fait entendre en volant; en automne, il vient en petites sociétés sur les champs en jachère.

Nourriture : petits coléoptères, araignées et beaucoup d'autres insectes, ainsi que leurs larves.

Le nid se trouve à terre dans un petit enfoncement, abrité par un arbuste; il est composé de brins d'herbe et de mousse; l'intérieur en est bourré de radicules, et il contient quatre ou cinq œufs. Les jeunes quittent le nid même avant de savoir voler; car ils courent toujours assez bien pour pouvoir se cacher dans l'herbe, dans les blés ou dans les broussailles. 


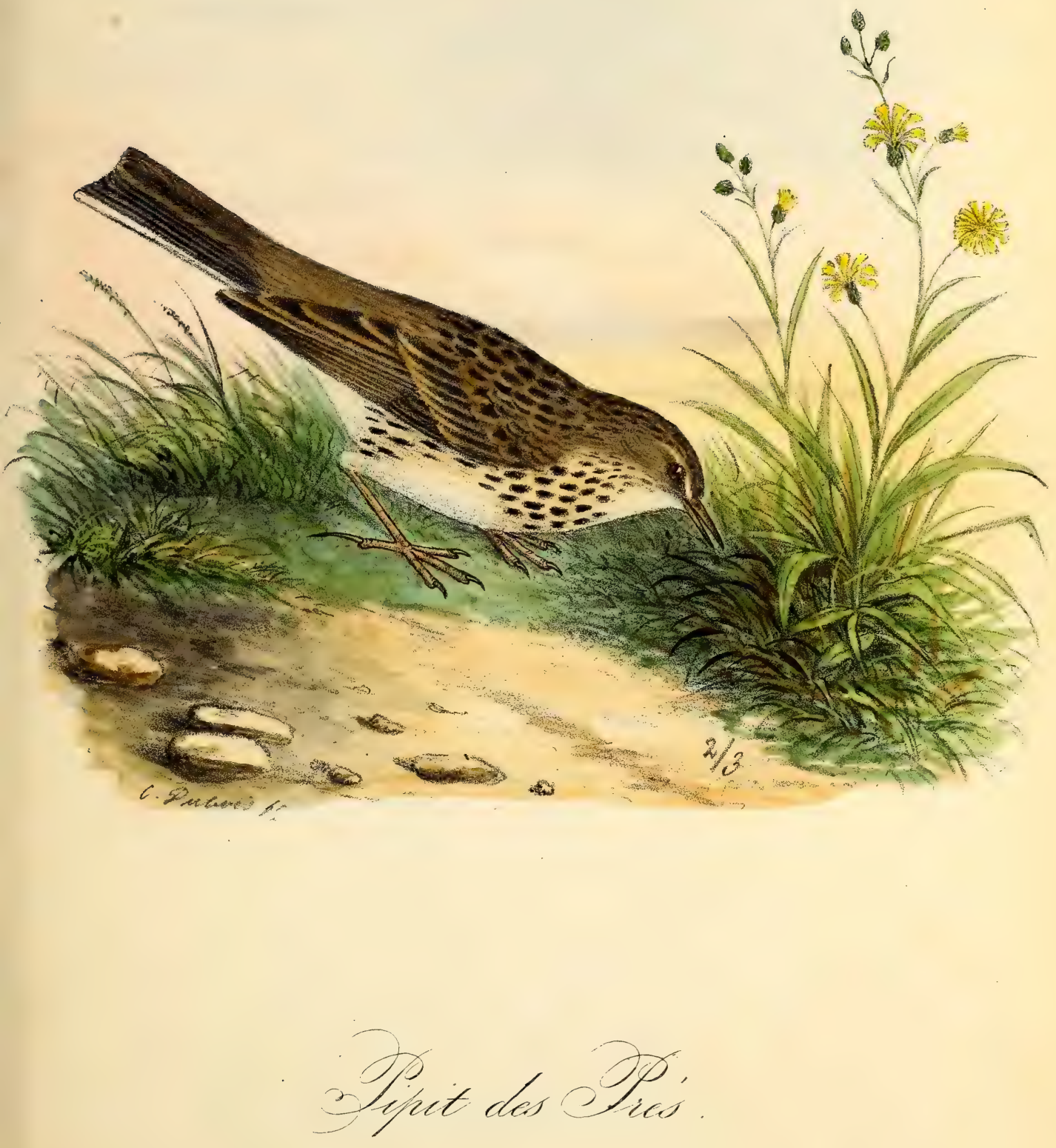



\section{PIPIT DES PRES。}

ANTHUS PRATENSIS, BECHSTEIN.

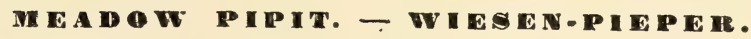

FARLOUSE. Buff., t. V, p. 31 ; pl. enl. 660. - Temm., t. I, p. 269. - Gould, t. Il, p. 136. Naum., t. III, pl. 84. - Degl., t. I, p. 419. - Thienem, FortP., pl. VIII, fig. 8. - Savi, Ornith. Toscana, t. II, p. 42. - Malh., Faune Sicile, p. 99. - v. d. Mühle, Ornith. Griechenlands, p. 113. - Selys-Longch., Faune belge, n 93. - Faber, Isländische Ornith., p. 19. - Alauda pratensis, Linné. - A. Sepiaria, Briss. - Anthus sepiarius, Vieill. - A. tenuirostris, musicus, stagnatilis, Danices, pratorum, palustris, alticeps, Virescens, Lichtensteinit, desertorum et MONTANELLUS, Brehm.

Cet oiseau habite une grande partie de l'Europe, vers le nord jusqu'en Islande et en Laponie, ainsi qu'en Sibérie et au Kamtschatka; on le trouve même dans le Groenland. Il se tient particulièrement dans les endroits pourvus de tourbières ou dans les prairies marécageuses entrecoupées de fossés et ayant par. ci par-là quelques arbres ou quelques arbustes. Après la couvaison, ils quittent ces endroits et se rendent par grandes masses dans les pâturages, dans les champs des pommes de terre et de navets, et enfin dans les champs de chaume et vivent alors comme l'alouette sur des terrains secs et sablonneux, jusqu'au mois de novembre, où ils nous quittent pour se rapprocher des contrées méridionales; il y en a qui émigrent même jusqu'en Afrique et en Syrie. Ils se tiennent de préférence à terre, mais se posent aussi sur les arbustes peu élevés. Leur chant n'est point aussi agréable que celui du Pipit des arbres; il s'élève en chantant, nage quelques instants dans l'air et puis redescend à terre pour se reposer; chantant rarement à terre et encore plus rarement sur un arbuste. Ils se tiennent peu cachés, et sont toujours inquiets et se querellent volontiers avec les autres espèces d'oiseaux; cependant le Pipit des prés est très-sociable et affectueux pour ses semblables; aussi hors le temps de la ponte, ne les trouve-t-on jamais isolés, mais se tiennent toujours ensemble, quelquefois par plusieurs centaines; c'est alors qu'on en attrape une grande quantité, car ils forment un mets très-délicat.

Variétés accidentelles : blanc ou irrégulièrement taché de blanc.

Nourriture: mouches, cousins et beaucoup d'autres insectes et leurs larves, ainsi que de petites chenilles.

Ils nichent à terre sur une place sèche, enfoncée dans l'herbe ou sous l'abri d'une pierre. Le nid est composé de brins d'herbe, de mousse, et l'intérieur de quelques crins et de laine; on y trouve de quatre à six oufs; ils font ordinairement deux couvées. 



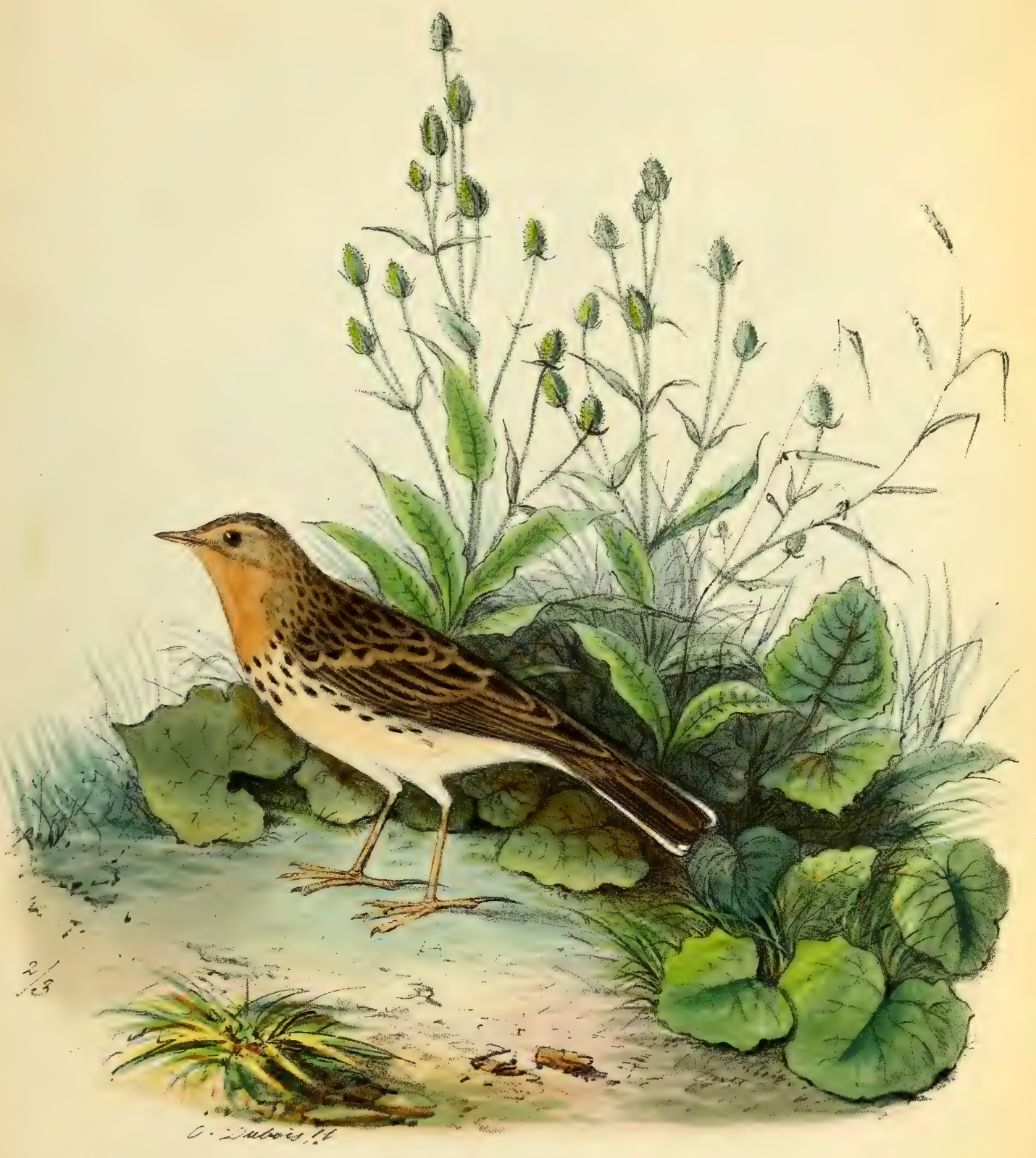

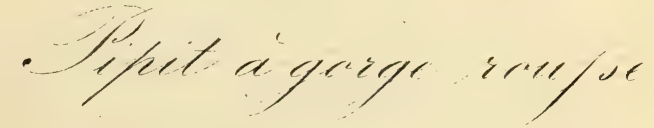





\section{PIPIT A GORGE ROLSSE.}

ANTHUS RUFOGULARIS, BREHM.

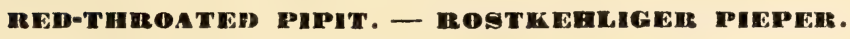

Temm., t. III, p. 192. - Gould, t. II, pl. 140. - Brehm., p. 340. - Schleg., p. 36. - Naumann, t. III, pl. 85, fig. 1.- Degl., t. I, p. 421.- Faune de Sicile, p. 99.-Vg. N.-0. Afrika's, no 181. - Ornith. Grieghenlands, no 114. - Cabanis, Jounnal Ornith., p. 64. - Motacilla Cervina, Pallas. - Anthus cervinus, Keys. et Blas. - A. Cecilit, Audouin. - A. rosaceus, Hodgs. A. pratensis rufigularis, Schleg. - A. aquaticus, Blyth.

Cet oiseau est regardé par beaucoup d'ornithologues comme une variété ou comme un vieux mâle, parfaitement coloré, de l'Anthus pratensis, pour lequel M. Naumann l'a aussi pris, et l'a représenté sur sa Pl. 85, fig. 1. Cependant le pipit à gorge rousse est reconnu maintenant pour être une espèce véritable. Il appartient à l'extrême Nord, à la Russie et à la Laponie; il est plus rare en Suède; il se trouve aussi dans les parties du nord de l'Asie, telles que la Sibérie, le Kamtschatka et les îles du nord de l'Amérique; on le rencontre abondamment en Égypte, en Nubie, en Grèce, en Turquie et en Barbarie, où il va passer l'hiver. Pendant leurs migrations, ces oiseaux viennent en très-petite quantité, et le plus souvent seuls de leur espèce, dans la société de l'Anthus pratensis jusqu'en Allemagne et en Belgique; c'est ainsi qu'on en prit un mâle le 5 octobre 1831 ; il se trouve maintenant dans la collection de M. Isidore Bovie, à Louvain, à l'obligeance de qui je doit ce bel exemplaire qui m'a servi de modèle pour la planche ci-jointe. Ces oiseaux vivent particulièrement dans de vastes plaines, surtout dans les marais, dans les places marécageuses, entre les montagnes, ainsi que dans les pâturages et les champs, mais jamais dans les forêts; ils se posent souvent sur l'extrémité des arbustes. Ils font entendre leur chant en se balançant et en nageant dans l'air ; ils le finissent ordinairement en se perchant. Leur chant et leur cri d'appel diffèrent tout à fait de ceux de l'Anthus pratensis. Ils sont peu farouches; ils volent ordinairement en s'élevant un peu, puis se reposent à une petite distance du lieu d'où ils sont partis; leur vol est incertain, ils s'élèvent et s'abaissent tour à tour.

Leur nourriture se compose de mouches, d'araignées, d'autres insectes et de leurs larves, ainsi que de petites chenilles.

Ils nichent à terre dans de petits enfoncements abrités par un arbuste ou une pierre; le nid est composé de mousse et de brins d'herbe; l'intérieur est bourré de poils de vache et contient quatre ou cinq œufs. 

(j)

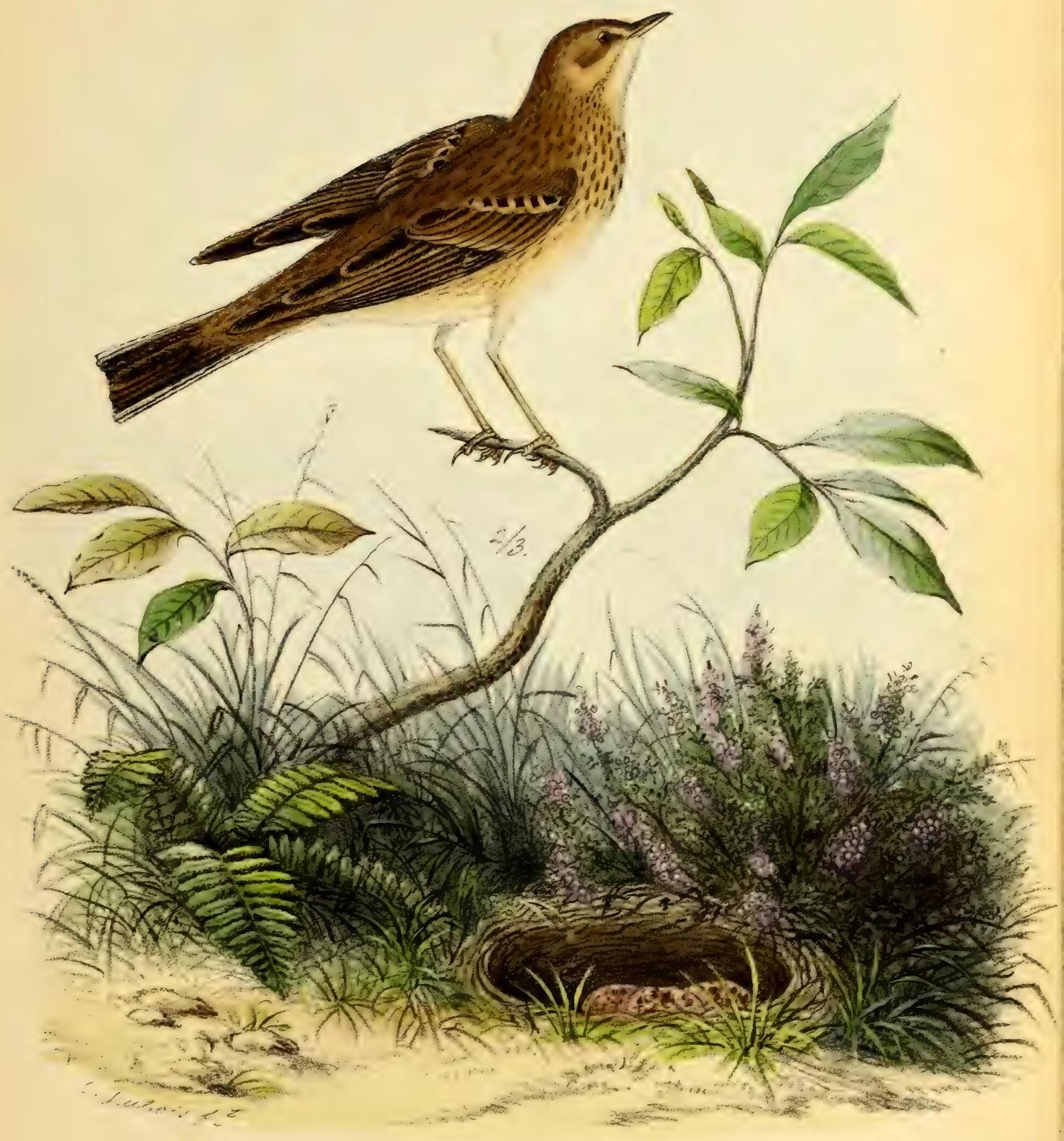

$$
\text { Sifuet des revliose. }
$$





\section{PIPIT DES ARBRES.}

ANTHUS ARBOREUS, BECHSTEIN.

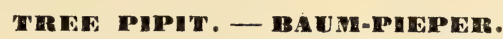

FARLouse. Buff., t. V, p. 25. - Buff., pl. él. 660. - Briss., t. III, p. 340. - Temm., t. I, p. 271, et t. III, p. 194. - Gould̀, t. II, pl. 136. - Naumann, t. III, pl. 84, fig. 2.- Brehm., HandB., p. 326. - Glog., t. I, p. 266 - Schleg., p. 36. - Degl., t. 1, p. 423. - Thienem., ForTP., pl. VIII, fig. 10. - Meisn. et Schinz. Vg. Schweiz, n 134. - Glog., Fauna Schlesiens, no 90. - Savi, 0rnith. Toscana, t. II, p. 40. -Landb., Vg Wurtembergs, no 118. - v. Homey, Vg. Pommerns, no 120. - De Selys-Longch., Faune Belge, no 94.- Malh., Faune Sicile, p. 100. v.d. Mühle, Vg. Griechenlands, no 115.-Doubl. Brit. Birds, p. 10.-Math., Ois. de l’Algérie, p. 11.-Rüpp., VG. N.-O. Afrika's, no 179.-Motacilla maculata, Gmel.-M. spipola, Pallas.M. arborea, Hempr. - Sylvia maculata, Lath. - Alauda arborea, Willough. - A. trivialis, Linné. - A minor? - A pratensis, Briss. - Anthus trivialis, Licht.

Habite la Sibérie et une grande partie de l'Afrique; il est très-commun en Algérie, en Égypte et dans toute l'Europe; il fréquente les forêts situées sur des montagnes et les bruyères. En automne il visite quelquefois la campagne, mais toujours celle où il y a le plus de végétation; aussitôt que quelque chose l'effarouche, il vole sur un arbre où il se met de préférence. Ces oiseaux vivent ordinairement séparés; en automne seulement ils se réunissent par famille de dix ou douze individus, mais lorsqu'on les fait fuir, ils se séparent. Au printemps, ils sont encore moins sociables; aussi chaque couple défend-il avec acharnement contre toute tentative d'invasion le circuit qu'il a choisi pour sa résidence.

Le mâle a un chant très-retentissant et supérieur à celui de tous les oiseaux de son genre; ce chant, qui est agréable, ressemble beaucoup à celui du canari. On l'entend pendant les beaux jours, depuis son arrivée jusqu'au mois de juillet, du haut d'un arbre sur lequel il répète souvent sa chanson, et tout à coup il s'élève dans les airs en chantant comme l'alouette des champs, puis il se remet sur un autre arbre où il finit sa chanson. Il arrive vers le commencement de mars et émigre à la fin de septembre pour l'Afrique.

Nourriture : mouches, cousins, coléoptères et autres insectes et leurs larves.

Il niche à terre, dans les forêts, dans les bruyères, sur les bords des prairies, aux environs des bois, dans les touffes d'herbe, sous les buissons ou entre les racines, et sur les revers des fossés. Son nid est composé de brins d'herbe, de radicules, quelquefois aussi de mousse; l'intérieur est bourré de laine et de crins; il pond de quatre à six oufs. 



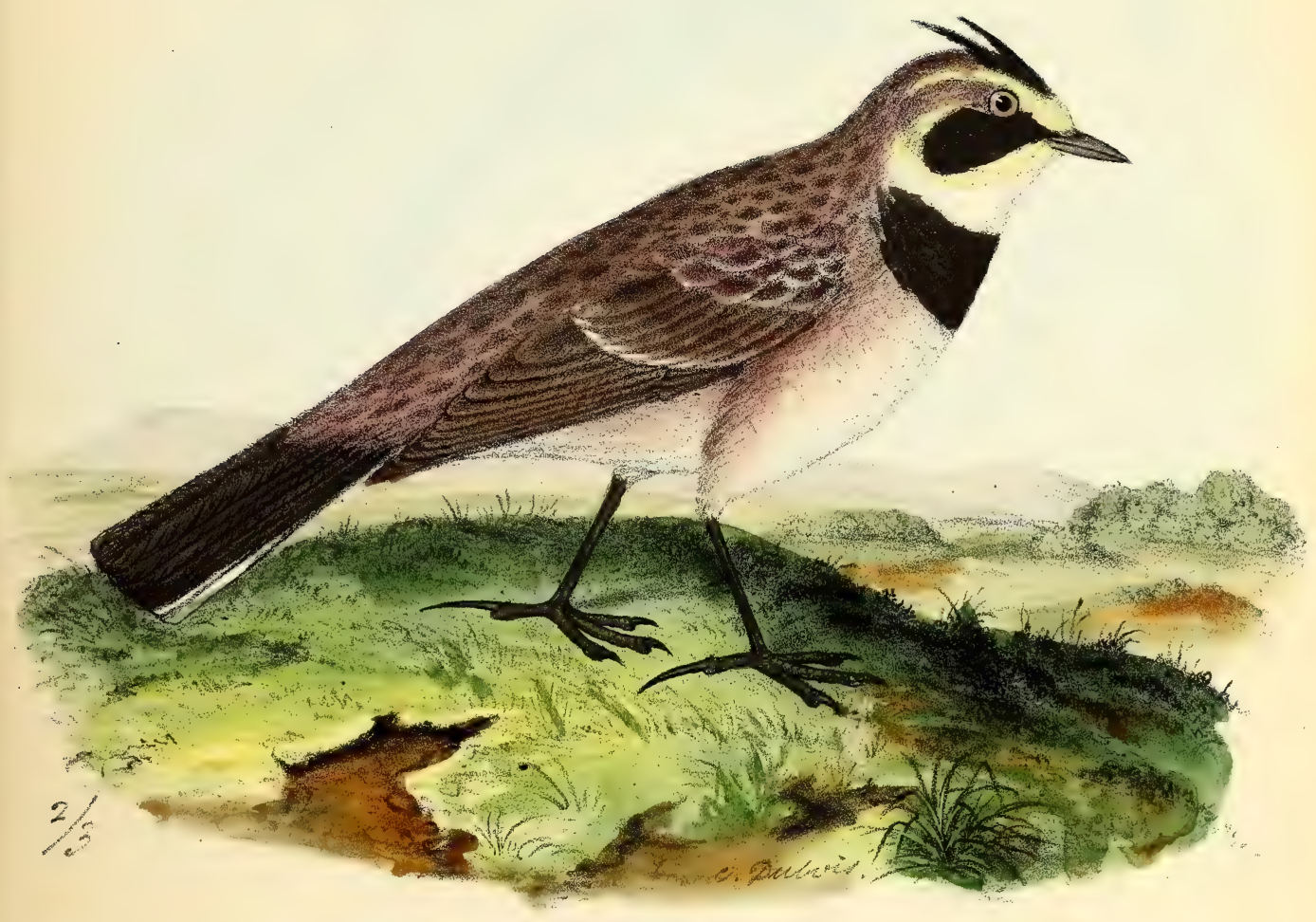

ctobrette eylpine? 

cense Alomette. - Almata, Linné.

\title{
A L 0 U E T T E A L P I N E.
}

\author{
ALAUDA ALPESTRIS, LINNÉ
}

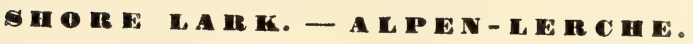

HAUSSE-COL NOIR. Buff., t. V, p. 55; pl. enl. 650.-Temm., t. I, p. 279. - Gould, t. III, p. 164. - Naum., t. IV, pl. 99. - Degl., t. I, p. 398. - Thienem, pl. XXVI, fig. 3. Schleg., Revue, p. 60. - Selys-Longch., Faune belge, no 85. - Meis. et Schinz., Vg. Schweiz., no 141. - Glog., Fauna Schlesiens, no 92. - Landb., Vg. Wurtembergs, no 112. - Alauda flava, Gml. - A. nivalis, Pallas. - Otoconys alpestris, Bonap. - Phileremos alpestris,
Brehm.

Cette alouette habite les montagnes du nord de l'Asie, où elle est fort commune dans quelques contrées; elle est aussi abondante en Russie et en Hongrie; elle paraît en Allemagne pendant ses migrations d'automne, mais très-rarement dans les Iles Britanniques et en Belgique. J'en ai reçu une de M. Croyart, receveur à Anvers; elle avait été prise près de cette ville. Pendant leurs migrations, elles suivent volontiers les rivages de la mer ou les bords des fleuves, sinon elles ont beaucoup d'analogie avec l'alouette des champs; elles voltigent souvent en rasant la terre. Le mâle s'élève d'une pierre ou d'un monticule dans les airs en chantant, il y fait quelques évolutions, puis redescend à terre; son chant n'est point aussi beau ni aussi soutenu que celui de l'alouette des champs, cependant il est encore très-mélodieux. Ce sont des oiseaux fort sociables; on les trouve en société des alouettes, des plectrophanes, des bruants et des moineaux dans les basses-cours et même près des villes et des villages; ils vivent constamment réunis en grandes et petites troupes, leur unique soin est d'être aussi près les uns des autres que possible; ce besoin de société est si grand chez cet oiseau, qu'en captivité il montre ce désir en faisant entendre son cri d'appel le jour et la nuit.

Leur nourriture consiste en insectes et en semences.

Ces oiseaux recherchent pour y nicher les penchants des rochers couverts de mousse et de quelques arbustes, afin que la femelle soit cachée lorsqu'elle couve. Le nid, assez légèrement bâti, se trouve dans un petit enfoncement; il est composé de brins d'herbe, de mousse et de quelques feuilles sèches; il est bourré parfois de quelques crins et de laine; il contient de cinq à six oufs. 



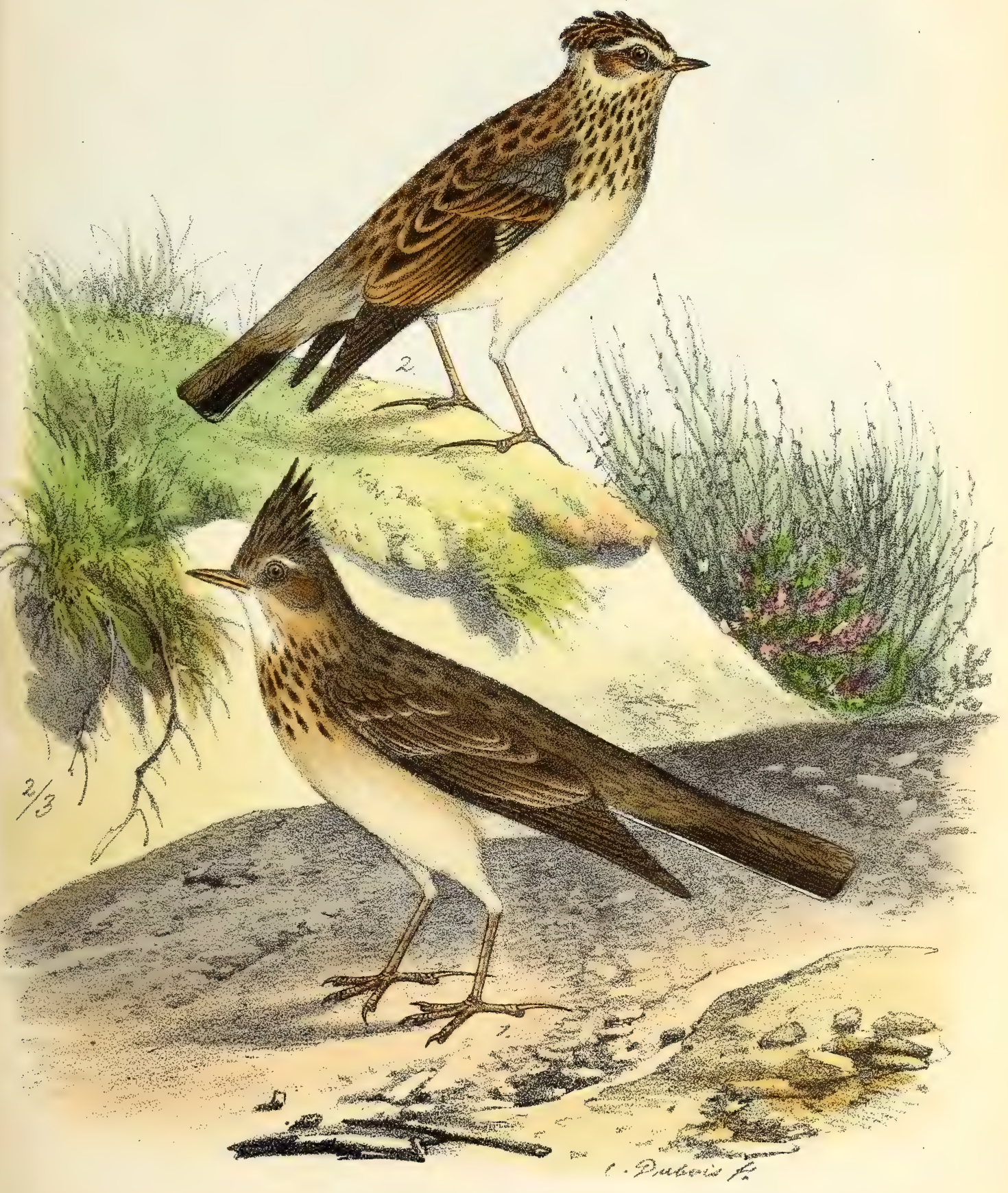

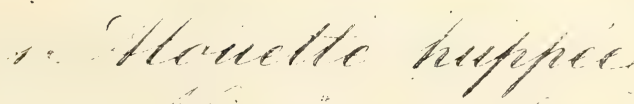

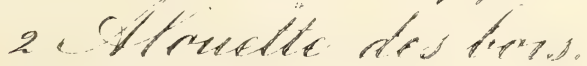





\section{A L O UE T TE II UP PÉE.}

ALAUDA CRISTATA, LINNÉ.

CURSTED LARK. - HAUBRV-LERCHE.

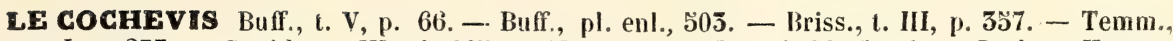
t. I, p. 277. - Gould̀., t. III, pl. 165̆. - Naumann, t. IV, pl. 99, fig. 1. - Brehm., Hande., p. 315. - Glog., HandB., p. 273. - Schleg., p. 59. - Degl., p. 400. - Thienem., ForTP., pl. VIII, fig. 12. - Meisn. el Schinz. Vg. Schweiz, n" 140. - Mey., Vg. Liv -u. Esthlands, no 133. - Glog., Fauna Schlesiens., no 93. - Savi, Ornith. Toscana, t. II, p. 53. - Landb., Vg. Wurtembergs, no 113. - v. Homey., Vg. Pommerns, no 123. - De Selys-Longch., Faune Belge, no 86. - Malh., Faune Sicil., p. 108. - V. d. Mühle, Vg. Grieghenlands, no 57 . Malb., Ois. de l'Algérie, p. 12. - Strickl., Ois. de l'Asie Mineure. - Alauda undata et senegalensis, Gmel. - A. galerita, Pallas. - A. nemorosa, Dumont. - A. cristatella, Vieill. - Galerida cristata, Bojé.

Habite l'Allemagne, la Belgique, la Hollande, les îles Britanniques et les autres parties de l'Europe méridionale et tempérée. Cette alouette a une prédilection particulière pour les plaines sablonneuses et unies; elle se trouve aussi dans les plaines qui sont entrecoupées de carrières de sable ou de montagnes; dans les pays boisés elle ne parait presque jamais. Les alouettes huppées ne vivent point en grandes troupes comme les alouettes des champs, mais elles se tiennent dans le voisinage de l'homme sur les grandes routes, dans les champs de légumes, ainsi que dans les cours des fermes; en hiver, lorsqu'il y a beaucoup de neige, elles arrivent même dans les villes; le froid cependant ne leur est point nuisible, elles supportent parfaitement les rigueurs de l'hiver. Cette alouette vole avec lenteur et ordinairement à une hauteur peu élevée, cependant parfois elle s'élève précipitamment dans les airs; elle ne vole jamais sur les arbres, mais d'autant plus sur les murs et sur les pieux. Le mâle a un chant agréable et varié; il ne chante pas beaucoup, ordinairement le matin de bonne heure, et parfois même dans la nuit; pour chanter il se pose souvent sur une hauteur, étend les ailes et fait des mouvements continuels avec le corps; il chante aussi en s'élevant dans les airs au-dessus de la place où se trouve son nid. Lorsqu'on prend ces oiseaux jeunes, on peut facilement leur apprendre à chanter différentes mélodies; en liberté ils essayent souvent de contrefaire le chant des autres oiseaux. On les trouve aussi dans la Sibérie, en Daourie, et ils sont en grande quantité dans tout le nord de l'Afrique.

Variétés accidentelles : blanc, mélangé de blanc et de couleur isabelle claire ou avec le bec croisé.

Nourriture : insectes et leurs larves et des semences.

Quelques-uns nichent très-tôt, quelquefois déjà au mois de février; ordinairement ils nichent au mois de mars dans les jardins peu fréquentée et sur les lisières des champs dans de petits enfoncements. Le nid se compose de brins d'herbe, de petites racines et d'un peu de mousse; dans lintérieur se trouvent des crins et des plumes; il contient de quatre à six œeufs. 



\section{ALOUETTE DES BOIS.}

ALAUDA ARBOREA, LINNÉ.

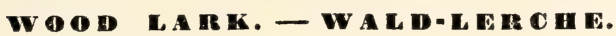

LE CUJELIER. Buff., t. V, p. 25. - Buff., pl enl., 503, fig. 2. - Briss., t. III, p. 340. Temm., t. I, p. 282. - Gould., t. III, pl. 167. - Naumann, t. IV, pl. 100. - Brehm., HandB., p. 317. - Glog., p. 275. - Schleg., p. 59. - Degl., t. I, p. 402. - Thienem., FortP., pl. VIII, fig. 14. - Meisn., VG. Schweiz., no 139. - Mey., Vg. Liv.-U. Esthlands, p. 132. Glog., Fauna Schlesiens., $1^{\circ}$ 94. - Savi, Ornith. Toscana, t. II, p. 65. - Landb., Vg. Wurtembergs, no 114. - v. Homey., VG. Pommerns, n 122. - De Selys-Longeb., Faune Belge, n 87. Malh., Faune Sigil., p. 108. - v. d. Mühle, Vg. Griechenlands, no 58. - - Doubl., Brit. Birds, p. 13. - Malh., Ois. de l'Algérie, p. 11. - Strick., Ois. de l'Asie Mineure. - Alauda nemorosa, Gmel. - A. Cristatella, Lath. - A. nemoralis, Roux. - A. picta, Herm. - GaleRIDA ARBOREA, Bojé.

Celte alouette-ci se trouve dans presque toute l'Europe, depuis les îles Britanniques jusque dans les bois de pins de la Norwége; elle est en France, en Belgique, en Allemagne et en Italie. Il y en a beaucoup dans les forêts de cèdres du Liban; on la trouve aussi dans la Sibérie, au Kamtchatka, dans l'Asie Mineure et en Algérie. Les alouettes des bois sont le plus souvent dans les plaines stériles, sablonneuses et sèches; elles se tiennent aussi dans les parties montagneuses, et ne sont jamais dans l'intérieur des forêts, quoiqu'elles en recherchent les lisières. Ces oiseaux vivent presque constamment sur la terre où ils restent cachés dans les bruyères ou dans l'herbe; on ne les voit jamais sur les grands chemins ou dans d'autres places libres; mais ils volent souvent sur les arbres, et ne sont point farouches. Pendant la couvaison, le mâle chante beaucoup; son chant est extraordinairement doux et mélancolique; il émeut, plus que le chant de tout autre oiseau, le cœur de l'homme impressionnable, surtout lorsque dans le silence majestueux de la nuit l'alouette fait entendre du haut des airs ou du sommet d'un arbre sa voix suave et harmonieuse. L'alouette des bois a aussi le don de contrefaire différents sons du chant des autres oiseaux.

Variétés accidentelles : blanc, taché de blanc, plus pâle qu'ordinairement ou plus foncé, et couleur isabelle.

Nourriture : insectes, leurs larves et différentes semences.

Ils commencent ordinairement au mois de mars à construire leur nid qui est toujours à terre dans les bruyères, ou dans l'herbe dans de petits enfoncements; leurnid est construit sans soins; il est fait de brins d'herbe et de petites racines; il est passablement profond; dans l'intérieur se trouvent parfois des poils d'animaux; il contient à la fin de mars ou au commencement d'avril de quatre à six oufs. 



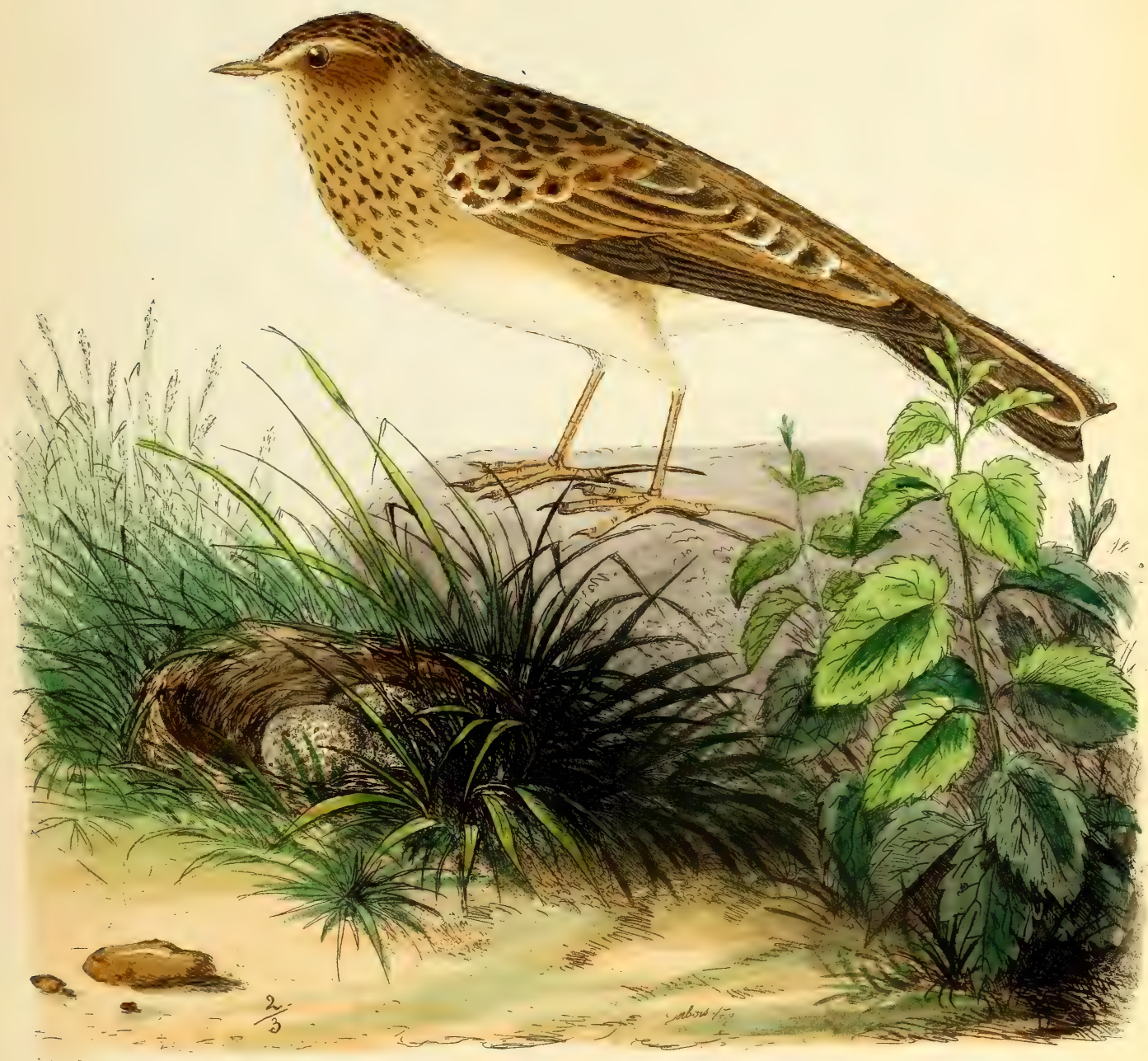

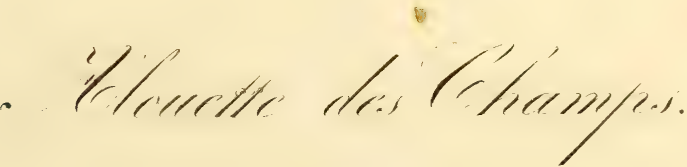





\section{ALOUETTE DES CHAMP.}

ALAUDA ARVENSIS, LINNE.

SHY LAMK. - FELD-LERCHE.

L'ALOUeTTE. Buff, t. v, p. 1. - Buff., pl. él., 363. - Briss., t. III, p. 349. - Temm. t. I, p. 281, et t. III, p. 205. - Gould, t. III, pl. 166. - Naumann, t. IV, pl. 100. - Brehm., HANDB., p. 318. - Glog. t. I, p. 276. - Schleg., p. 59. - Degland, t. I, p. 396. - Thienem., Fortp., pl. VIII, fig. 14. - Meisn. et Schinz. Vg. Schweiz, no 138. - Glog., Fauna Schlesiens., n 95. - Savi, Ornith. Toscana, t. II, p. 5̌5.-Landb., Vg. Wurtembergs, no 116. - v. Homey, VG. Pommerns, n' 124. - De Selys-Longch., Faune Belge, no 88. - v. d. Mühle, Vg. Griechenlands, no 59. - Doubl. Brit. Bikds, p. 13. - Malh., Ors. de l’Algérie, p. 11. - Rüpp., VG. Nord-ost-Afrika's, no 310. - Strickl, 0ts. de l'Asie Mineure. - Muscicapa tertia, Jonst. alauda novalium, Frisch. - A. Agrestis el A. longipes, Sleph. - A. italica, Gmel. - A. granDior, Pallas. - A. provingialis, Schran. - A. vulgaris, Willoug.

Habite la Sibérie, le Kamtschatka, l'Asie Mineure, l'Arabie, la basse Égypte et toute l'Europe excepté l'Islande. Elle vit dans les champs de grains, de colzas et d'autres végétaux. Cette alouette est cette chanteuse si universellement connue et estimée, qui remplit le cœur de l'homme sensible de tant de délicieux sentiments lorsque au printemps elle fait entendre sa voix suave et harmonieuse et semble vouloir, par ses divins accents, faire admirer à toutes les créatures la beauté de la nature renaissante. Dès les premiers rayons du crépuscule du matin, lorsque tout parait encore plongé dans les ténèbres de la nuit, l'alouette s'élève dans les airs, et aussitôt que la première s'est fait entendre, cent voix répètent sa chanson. Elle chante le plus souvent en volant, quelquefois pendant des heures entières sans interruption; il arrive parfois qu'on l'entend encore et que l'ouil nu ne peut plus l'apercevoir. La première chanson du matin et la dernière chanson du soir se fait ordinairement entendre quand elle est à terre. Elle voyage au mois d'octobre, par grandes bandes; on prend, à cette époque, un nombre considérable de ces oiseaux au moyen de grands filets; sa chair est fort délicate, et par cela même très-estimée; elles reviennent déjà au commencement du mois de février et sont à cette époque très-recherchées par les amateurs à cause de leur chant; il y en a cependant beaucoup qui l'hiver restent au sud de l'Europe.

Varie accidentellement : tout blanc, ou tapiré de blanc, jaunâtre, ou tout à fait noir, aussi avec le bec croisé.

Nourriture : insectes, petites sauterelles, coléoptères et leurs larves, et différentes sortes de semences et de graines, aussi des feuilles vertes trèstendres et du sable pour faire la digestion.

Elle niche à terre dans les champs, habituellement dans un petit enfoncement ou dans des tas d'herbes. Son nid est composé de racines et de brins d'herbe; à l'intérieur il est bourré avec des radicules et quelquefois aussi avec un peu de laine; pond de quatre à six œufs. 



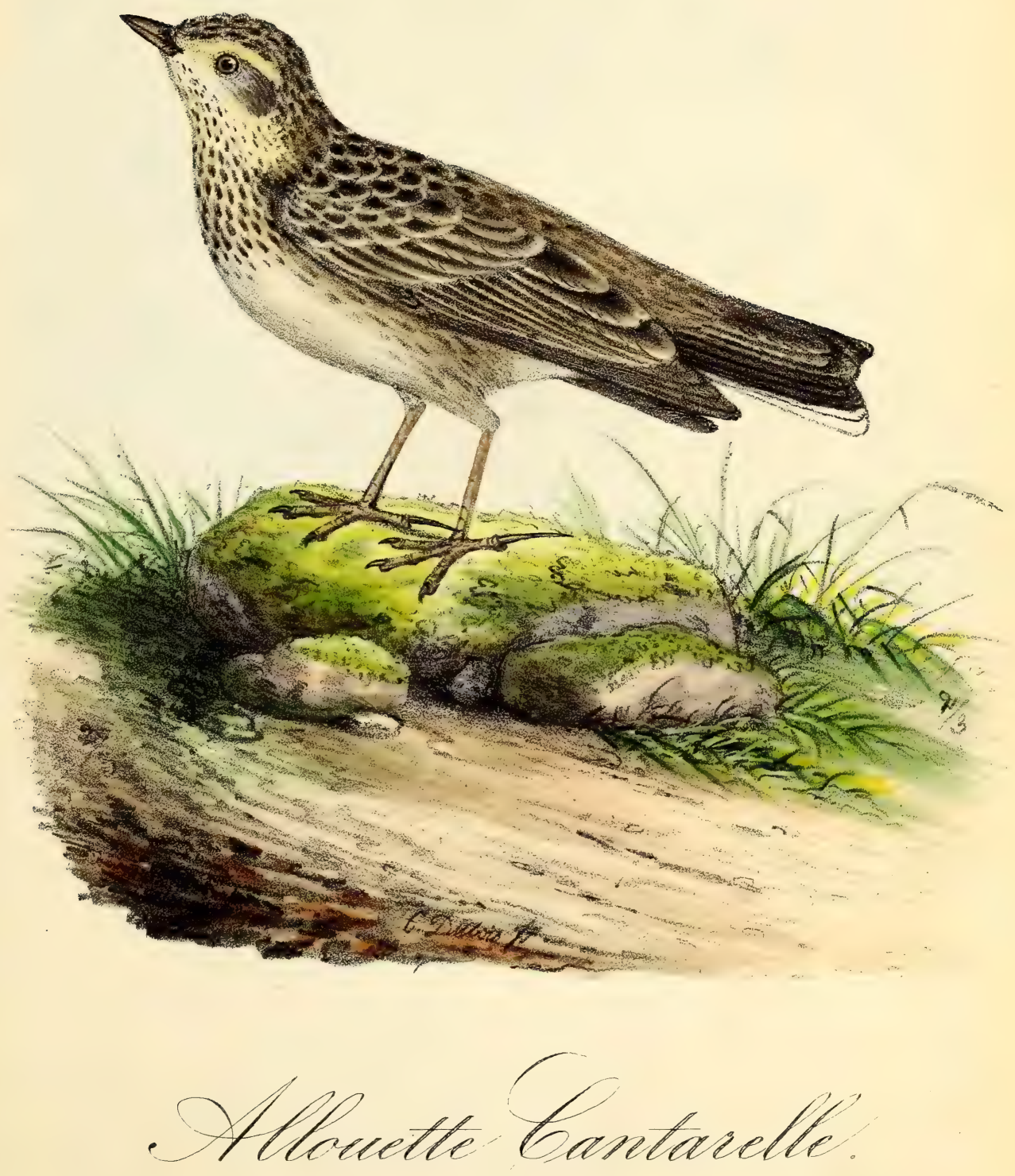





\title{
ALOUETTE CANTARELLE.
}

ALAUDA GaNTARELLA, bonaparte.

\begin{abstract}
CAN'A AELL LARK. - CANTAMERL LERCAE.
Bonaparte, List., p. 37. et Icon. D. Faun. Ital. - Bonap., Revue, p. 75. - Keyserling et Blasius, Wirbelthiere, p. 37. - Schlegel, Revue, 75.
\end{abstract}

Le prince Charles-Lucien Bonaparte est le premier qui ait observé et décrit cette alouette, qui habite l'Italie. Dans la belle collection de M. le baron Selys-Longchamps, il y en a une qui a été prise dans les environs de Liége. L'alouette cantarelle est plus petite que l'alouette des champs; son plumage en diffère également.

Comme beaucoup d'ornithologues en connaissent cette alouette que de nom, et que même plusieurs n'ont pas encore voulu admettre l'espèce, une représentation fidèle de celle prise dans les environs de Liége ne sera donc pas hors de propos ici. Bien que j’aie moi-même des doutes s'il convient de considérer cette alouette comme formant une espèce particulière, ou s'il ne la faut regarder que comme une variété de l'alouette des champs, j’ai cru devoir la distinguer ici. Si elle avait été observée en Italie par un naturaliste avec attention, et qu'elle s'y fût trouvée en assez grand nombre, on aurait pu en tirer la conclusion qu'elle forme une espèce à part, et nos doutes auraient été complétement dissipés. Cette alouette n'ayant encore jamais été représentée, les ornithologues me sauront gré d'en donner une gravure fidèle, car c'est la première qui en soit faite. 

1016.

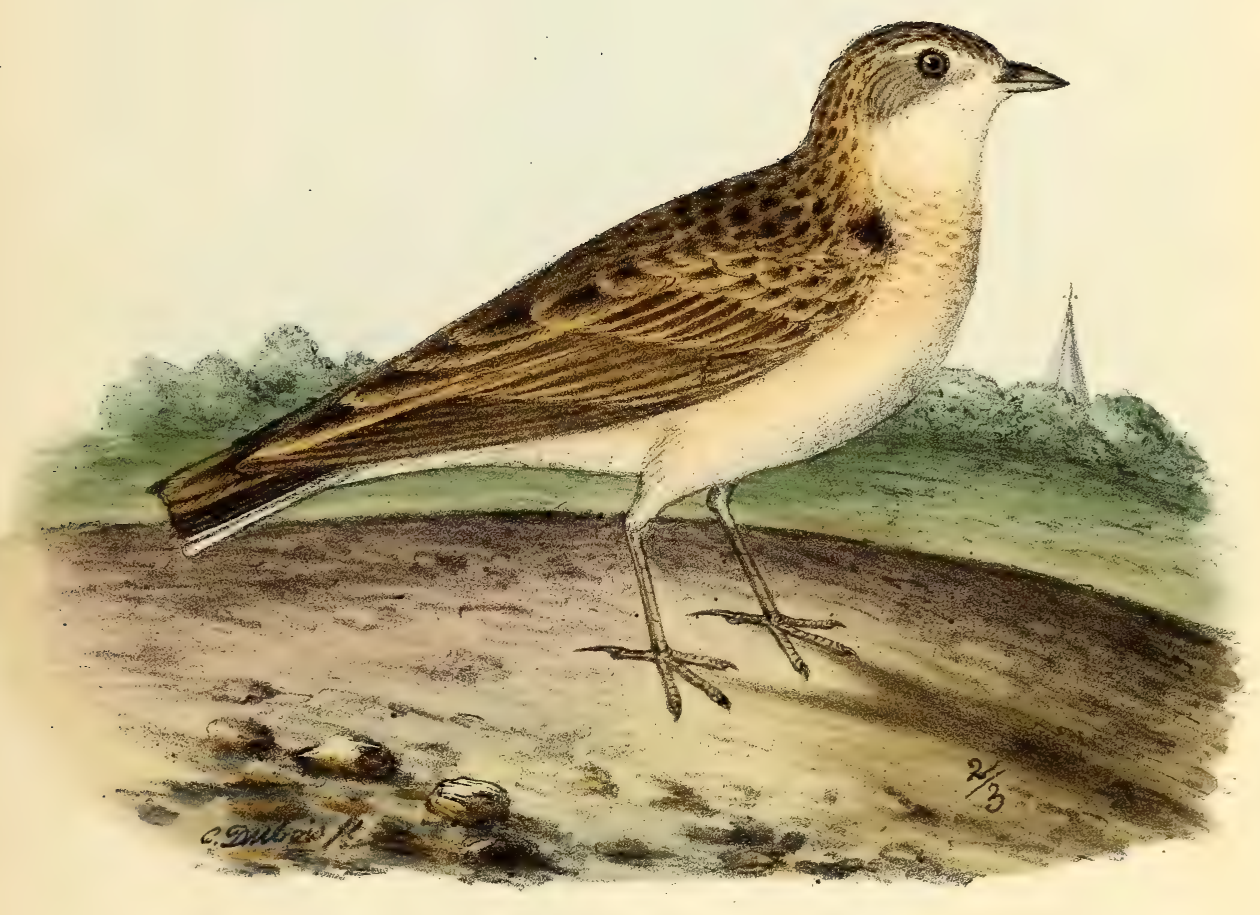

Oblouidte Galandudle. 



\section{ALOUETTE CALANDRELLE.}

ALAUDA CALANDRELLA, SAVI.

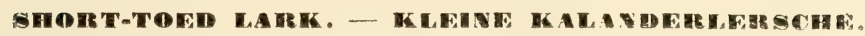

Temm. Man., t. I, p. 284. - Naum., t. IV, pl. 94. - Gould, t. III, pl. 163 - Degl., t. I, p. 404. -Thien., pl, XXVI, fig. 7. - Malh., Faune Sigile, p. 109. - Savi, Ornith. Toscana, t. II, p. 67. - V.d Mühle, Ornith. Grieghenlands, nº 60. - Rüpp. Vg. N. O. Afrika's, no 306. - Malh., Ois. d’Algérie, p. 12. - Alauda arenaria, Vieill. - A. Brachydactyla, Leisl. - Melancurypha arenaria, Bonaparte. - M. Brachydactyla deserti el obsoleta, Brehm. - Galerida calandrella, Bonelli. - Phileremos brachydactyla, Keys et Blas.

De grands terrains arides, dénudés, exposés à un soleil continuel, d'immenses bruyères, sont le séjour favori de cet oiseau. En troupeaux, ces alouettes aiment aussi à se répandre dans les plaines du midi de l'Europe, dans les steppes de l'Asie exposées à un soleil ardent. On les rencontre encore fréquemment sur les rives du Don, du Volga et dans les déserts qui entourent la mer Caspienne. Elles fréquentent aussi l'Égypte, la Nubie, l'Abyssinie, même la Grèce, la Dalmatie, l'Espagne et le midi de l'Allemagne. En France, elles ne se montrent guère qu'en Provence et en Champagne, et très-rarement en Belgique. Quant à leurs mœurs, elles sont absolument les mêmes que celles de l'alouette des champs, avec laquelle on les trouve souvent réunies. Dispersées dans les campagnes pendant la belle saison, ces alouettes se rassemblent en grandes troupes, en automne et en hiver. Elles deviennent alors fort grasses, parce que, le temps des amours, du chant et des couvées étant passé, elles se tiennent à terre, et. n'ont d'autre occupation que de chercher leur nourriture. Au printemps, elles se réunissent de nouveau. Parmi toutes les espèces d'alouettes qui habitent l'Europe, le chant de celle-ci est le plus insignifiant. Ordinairement, l'alouette calandrelle se pose sur une pierre ou sur une motte de terre lorsqu'elle veut chanter : son cri ressemble à un didli didli souvent répété; et c'est aussi le sifflet du mâle quand il veut appeler la femelle. Sa nourriture consiste en insectes, larves, araignées, petits vers; elle aime aussi les graines et les semences farineuses.

Variétés accidentelles, dont le plumage est blanc ou tacheté de blanc, avec des ailes blanches.

La femelle fait son nid par terre, dans une petite excavation, au pied d'un arbre ou entre deux mottes de terre; il est promptement fait, d'herbes et de petites racines sèches, presque plat, et sans consistance. Ce nid contient, au mois de mai ou de juin, quatre à cinq œufs. 


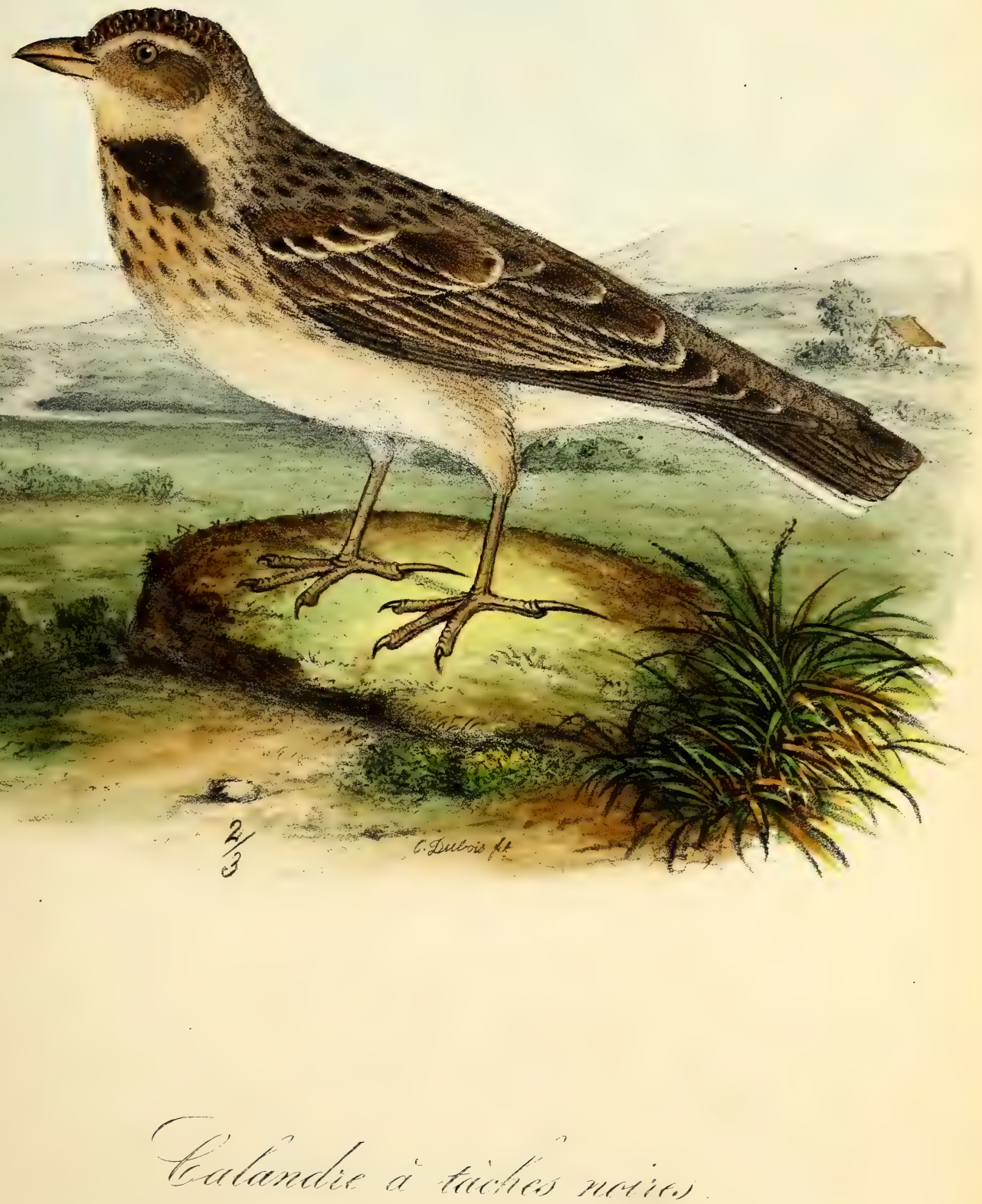



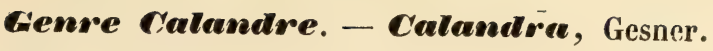

\section{CALANDRE A TACHES NOIRES.}

CALANDRA BIMACULATA, dubors.

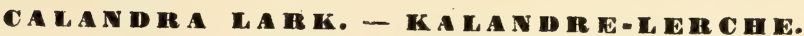

LA CALANDRE. Buff., t. V, p. 49 ; pl. enl. 363. - Temm., t. I, p. 276. - Gould, t. IIl, pl. 162. - Naum., t. IV, pl. 98. - Degl., t. I, p. 406. - Schleg., Revue, p. 60. - Thienem, pl. XXVI, fig. 5. - Glog., Fauna Schlesiens, no 96. - Savi, Ornith. Toscana, t. II, p. 50. Malh., Faune Sicile, p. 110. - v. d. Mühle, Vg. Griechenlands, n 62. - Malh., Ois. de l'AlGÉRIE, p. 12. - Rüpp., Vg. N. 0. Afrika's, no 305. - Alauda Calandra, Linné. - A. undata, Gml. - A. sibirica, Pallas. - Melancorypha calandra, Bojé.

Habite la Grèce, la Turquie, les États de l'Église, la Sicile, la Sardaigne, l'Espagne, le Portugal, la France méridionale et souvent aussi les steppes de l'Asie, l'Arabie, et le nord de l'Afrique. Cet oiseau est une grande rareté dans l'Allemagne centrale, ainsi qu'en Belgique; j'en reçus un pour la première fois au mois d'octobre 18504 ; il était vivant et avait été pris dans les environs de Bruxelles. Ces calandres vivent en grand nombre dans les champs les terrains plats et arides; ils sont moins souvent dans les prairies et les champs fertiles; en automne ils quittent l'Europe, à l'exception de l'Italie, où beaucoup d'entre eux passent l'hiver. Les mœurs de cet oiseau ressemblent tout à fait à celles des alouettes des champs; ils volent souvent ensemble en grandes troupes, et ils ont un chant clair, beau et varié, qu'ils font entendre tant dans leur vol qu'en repos; malgré la perfection de leur chant, il est impossible aux amateurs de les tenir dans les chambres, car leur voix est trop pénétrante. Pris jeunes, on peut leur apprendre à imiter toutes espèces de voix d'autres oiseaux; ils entremêlent souvent le chant de la grive chanteuse, des pinsons, des chardonnerets, des mésanges, des cailles, etc.; ils contrefont même les coassements des grenouilles.

Nourriture : insectes et leurs larves et des semences.

Ils nichent à terre dans un petit enfoncement sous l'abri d'un buisson ou dans les blés; leurs nids ressemblent beaucoup à celui de l'alouette huppée; il est fait de brins d'herbe et de racines, et à l'intérieur se trouvent des radicules et de la mousse; quelquefois il y a un peu de laine animale et des plumes; il contient quatre ou cinq oufs. 



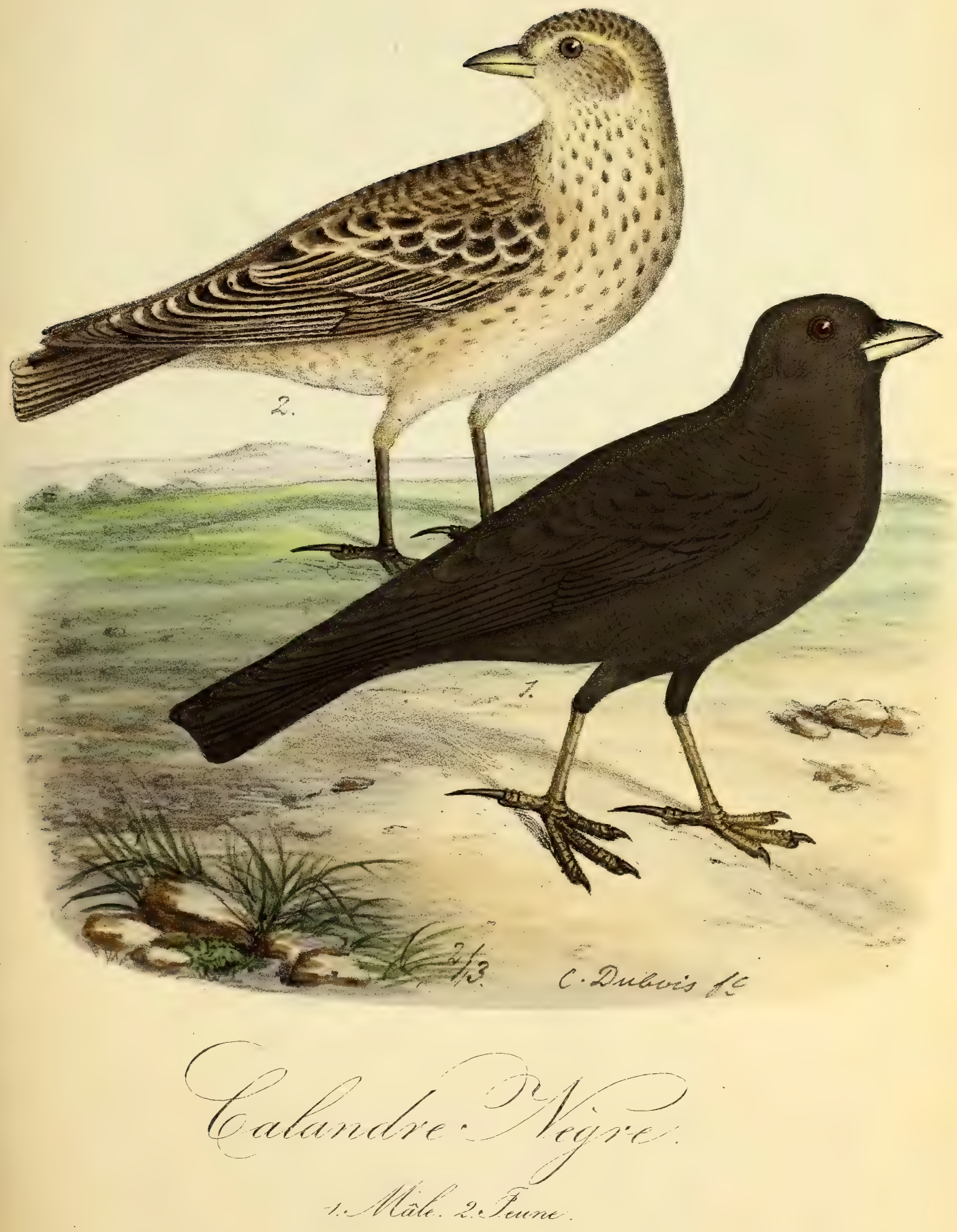





\section{CALANDRE NËGRE.}

CALANDRA NIGRA, DUboIs.

MLACK YARK. - MOEREA-TEITCHE.

Buff., pl. enl. 6500. - Temm., t. I, p. 275. - Gould, t. III, pl. 161. - Degl., I. I, p. 408. Schleg., Revue, p. 60. - Glog., Handb., p. 281. - Brehm, p. 312. - Naumannia, Nalım., 1852, p. 97. - Tanagra sibirica, Sparm. - Alauda tatarica, Pall. - A. nigra, Falk. - A. yeltoniensis, Forst. - A. mutabilis, Gmel. - Melanocorypha tatarica, Bojé.

Cet oiseau vit dans les steppes en Asie et dans la Russie d'Europe ainsi que dans l'Afrique du sud. Il est assez commun près du Wolga et l'Irtych, sur les steppes des Kirghiz, des Dsungares et des Tartares. Il parait rarement dans les différentes contrées de l'Allemagne, et bien plus rarement encore en Belgique. J'ai trouvé une de ces calandres nègres vers la mimars 1850 sur le marché de Bruxelles chez un oiseleur qui l’avait attrapée dans les environs de cette ville, et il m'a assuré en avoir vu plusieurs ensemble, mais n'avoir pu en prendre qu'une seule; d'après l'assurance de M Croegaert, on en aurait aussi pris une dans les environs d'Anvers en 1852 et on a pu la tenir vivante pendant plusieurs semaines.

Cet oiseau habite l'été en grande quantité les grandes plaines maigres et décharnées où l'on ne voit que de temps en temps des montagnes de sáble; ils émigrent en automne, et arrivent pendant les hivers rigoureux sur les routes des villes et des villages, où ils pénètrent quelquefois jusqu’à lintérieur. Ils retournent sur les steppes pendant les premiers jours du printemps. Son vol est de petites distances, pas très-vite et assez bas; c'est en général un oiseau nonchalant; son chant n'est pas beau, et il le fait entendre ordinairement assis sur un monticule, il fait très-rarement entendre son cri d'appel lorsqu'il s'élève dans les airs.

Nourriture : insectes et leurs larves, vers et des semences.

Il niche sur la terre, dans un petit enfoncement et sait, malgré la grande aridité du sol, très-bien cacher son nid qui est difficile à trouver; ce nid est fait sans art, il se compose de brins d'herbe, de racines et de mousse; à l'intérieur il s'y trouve des radicules, des brins d'herbes molles, et quelquefois des plumes; il contient quatre à cinq œufs. 

1021
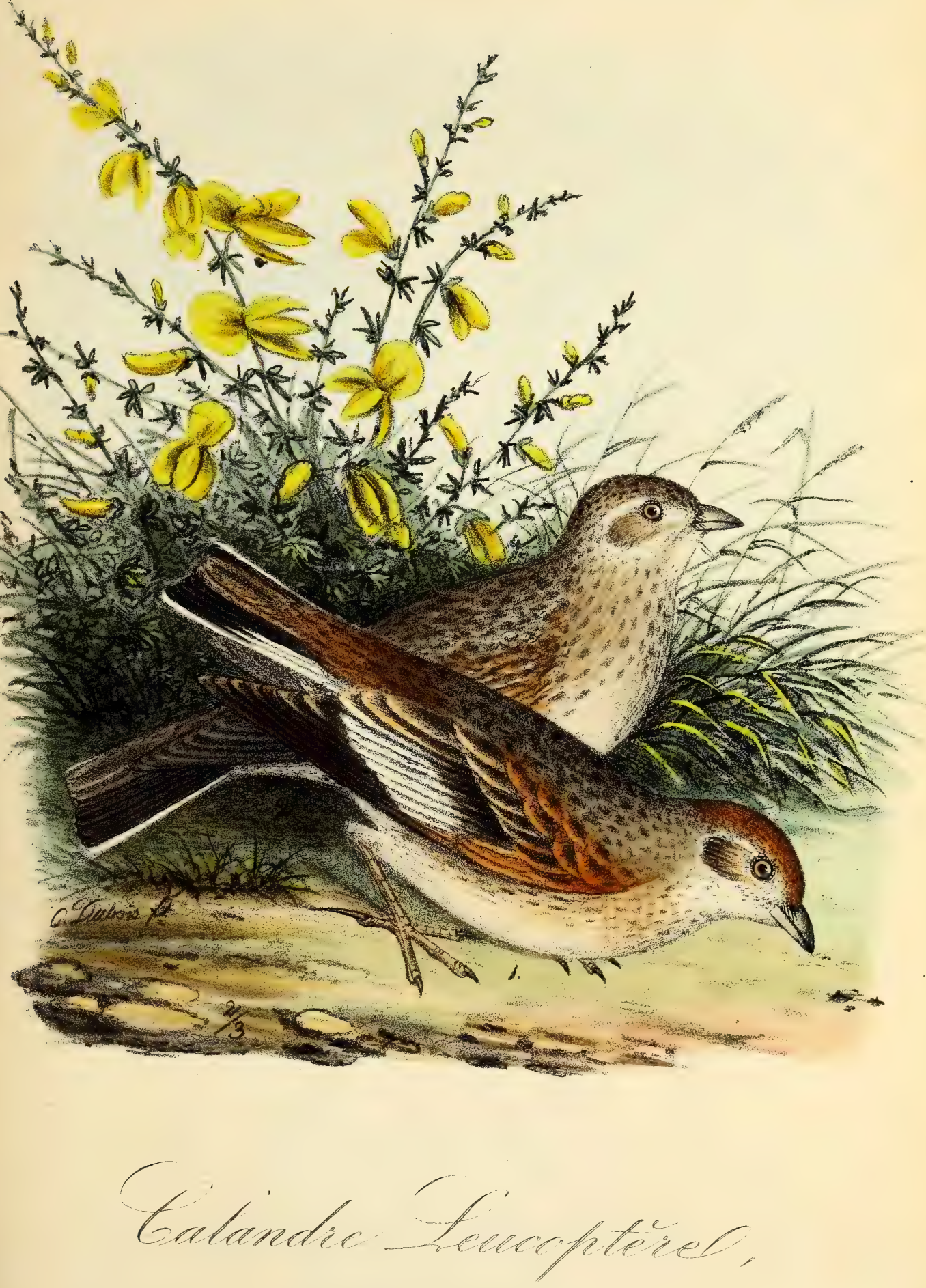

- Dicice-2. Emune 



\title{
CALANDRE LEUCOPTËRE.
}

\author{
CALANDRA LEUCOPTERA, DUBOIS.
}

WHITE-WINGED CARK. - WEISSFLÜGGLIGE KALANDERLECHE.

Latham, par Bechstion, t. IV, p. 384. - Pallas, Zoogr., t. I, p. 518. - Keys. et Blas, Wirb., p. 37. - Schleg., Revue, p. 50. - Degl., Ornith., t. I, p. 410. - Alauda. calandrae affinis et Aleucoptera, Pallas. - Alauda sibirica, Gmel. - Melanocorypha leucopterae, Bonap.

Cet oiseau est rare en Europe, et on ne le voit guère qu'en Sibérie, où il se trouve en grand nombre; il fréquente les plaines qui s'étendent le long du fleuve Irticsh; il vit aussi sur les bords de l'Obi, dans tout son parcours depuis les mont Altaï. On le voit aussi en Tartarie, dans les steppes du Kirghis et sur les bords du fleuve Oural. Rarement on en voit en Crimée, en Russie et en Pologne. Quoique cet oiseau soit si rare en Europe, M. le baron Selys-Longchamps en possède un qui a été pris dans les environs de Liége, au mois de décembre 1855. L'ayant fait empailler, il eut la bonté de me l'apporter pour l'ajouter à la table supplémentaire avant que la famille des alouettes fût close. Le genre de vie et la manière de se propager de la Calandre Leucoptère sont encore fort peu connus; sa voix n'est pas aussi agréable que celle de l'alouette des champs, quoiqu'elle ait la même légèreté que celle-ci dans ses mouvements et ses amours ; comme elle, elle niche à terre, dans un petit enfoncement. Elle est peu timide et se laisse approcher d'assez près sans s'effaroucher.

Sur la planche $\mathrm{n}^{\circ} \mathrm{XXXII}$, je représente un œuf qu'on dit appartenir à cette espèce, mais je n'ose le garantir. 



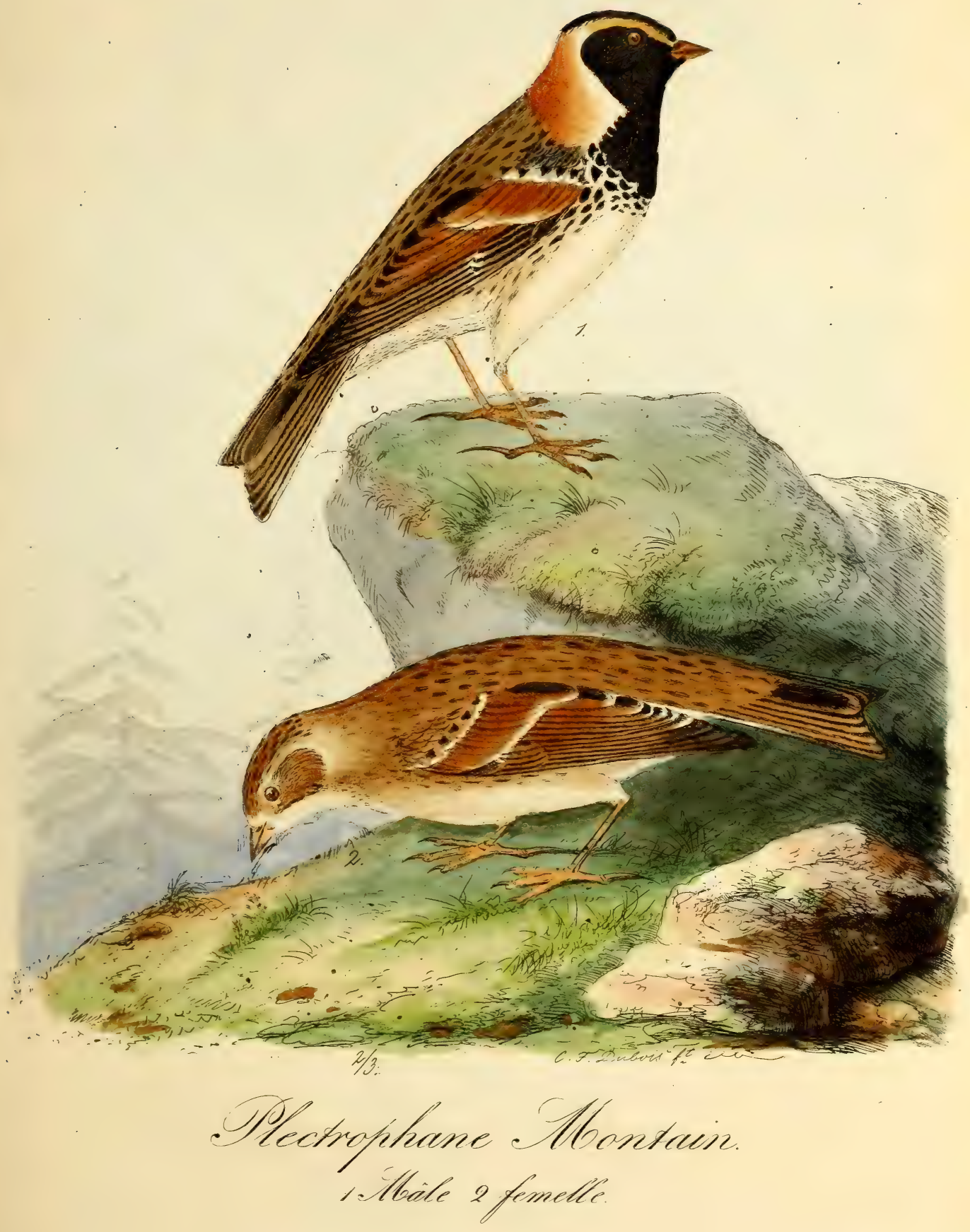



Genere plectrophane. - Plectsophanes, Neyer.

\section{PLECTROPHANE IIONTAIN.}

PLEGTROPHANES CALGARATUS, MEYER.

LARK-HEELED HUNTIG. - CERCHEN-SPORNAMMER.

LE GRAND-MONTAIN. Buff., t. IV, p. 134. - Briss., t. III, p. 160.- Temm., t. III, p. 160. - Gould, 1. I, pl. 322. - Brehm., Hande., p. 306. - Glog., t. I, p. 302. - Schleg., p. 72. - Degland, t. I, p. 278. - Savi, Ornith. Toscana, t. II, p. 73. - Glog. Fauna Schlesiens., no 104. - Landb., Vg. Wurtembergs, no 111. - Faber, Islandische Ornith, p. 14. - v. Homey. Vg. Ponmerns, n 129. - De Selys-Longch., Faune Belge, n" 84. - Doubl., Brit. Birds, p. 13. - Holböll, Ornith. Groenlands, p. 26. - D $\mathrm{D}^{\mathrm{r}}$ Richard. el Swains, Fauna Boreali-Americana, p. 248. - Passer calcaratus, Pall. - Passerina laponica, Vieill. - Fringllla montana, Briss. - F. lapponica, linné. - Montifrigille congener, Aldrov. - Carduelis lapponica, Linné. - Alauda calcarata, Cuvier. - Emberiza calcarata, Temm. - E. lapponica, Nils. - Plectrophane lapponica, Selby. - Pl. lapponicus, Bonap.

Habite les pays du Nord, la Sibérie, les États-Unis, le Groenland, la Laponie et l'Oural; vient en certains hivers par petites troupes aux lles Britanniques, en Allemagne, en Hollande et en Belgique au commencement d'octobre et retournent au commencement de mars(1); en général il est plus rare ici que le plectrophane de neige, aussi n'aime-til pas autant que celui-ci les sites sauvages et rocheux, mais il préfère les grandes plaines montagneuses, les surfaces des montagnes qui n'ont point d'arbres, mais seulement des buissons et des bruyères; il aime aussi beaucoup les champs, même les campagnes humides, les marais et les bords de la mer; pour cette raison, les Groenlandais le nomment narksamatak (habitant des plaines), nom qui le caractérise et le distingue de l'autre plectrophane. Il est aussi plus sensible au froid que celui-ci. Le mâle chante très-vaillamment sa claire et mélodieuse, mais courte chanson, le plus souvent en volant dans les airs; le thème de son chant ressemble assez à celui des alouettes des champs avec des modulations du chant de la linotte; plus rarement chantet-il perché sur un monticule, et, selon M. Holböll, le mâle chanterait aussi quelquefois perché sur une branche et se balançant, quoique dans son état naturel il vive comme les alouettes dont ces oiseaux aiment beaucoup la société; ils sont très-éveillés, pas trop timides et supportent mieux la captivité que l'autre.

Nourriture : semences qu'ils ôtent de la terre ou qu'ils épluchent des arbustes; ils mangent aussi les insectes et leurs larves.

Ils nichent comme les alouettes dans l'herbe ou entre les plantes et les arbrisseaux. Le nid se compose de brins d'herbe, de petites racines et de mousse, et l'intérieur est bourré de plumes de lagopèdes; la femelle pond au commencement du mois de juin cinq ou six oufs.

(1) Nous recevons cependant toujours ces oiseaux en plumage d'hiver qui ressemble tout à fait à celui de la femelle; seulement au mâle on voit le noir à travers les plumes de la tête. 



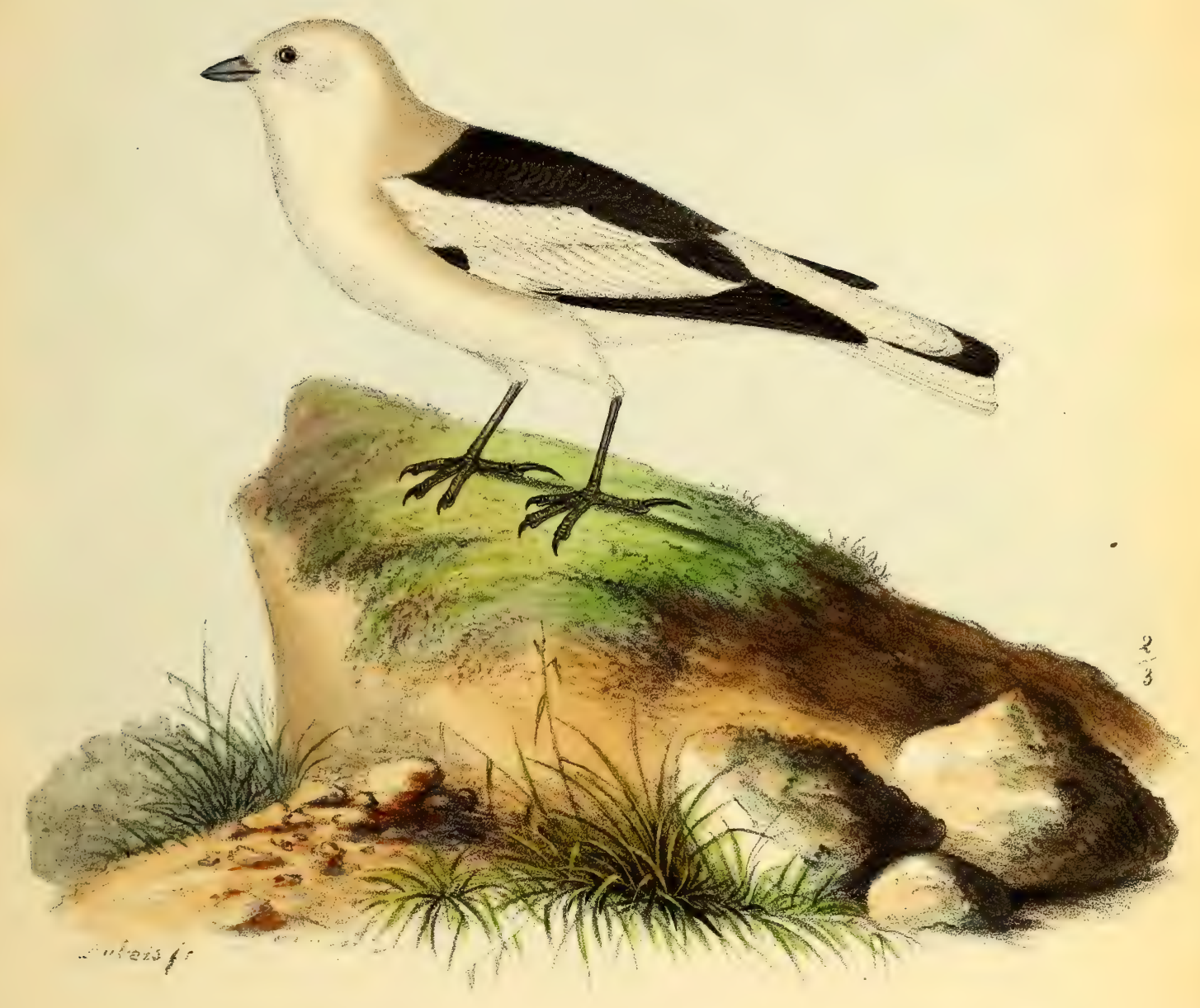

$$
\begin{aligned}
& \text { Pectrofhane de neige } \\
& \text { on plumage diété. }
\end{aligned}
$$





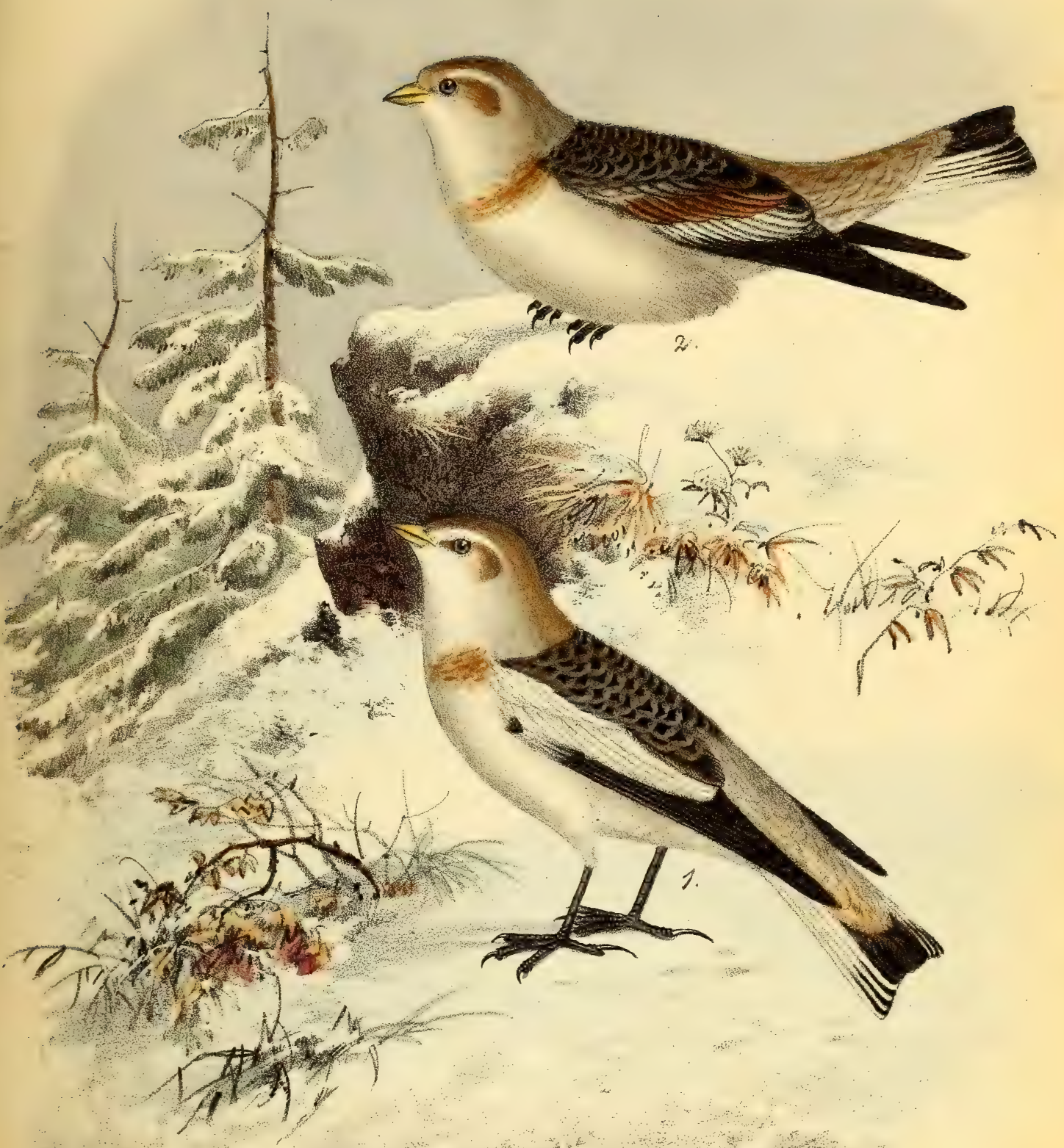

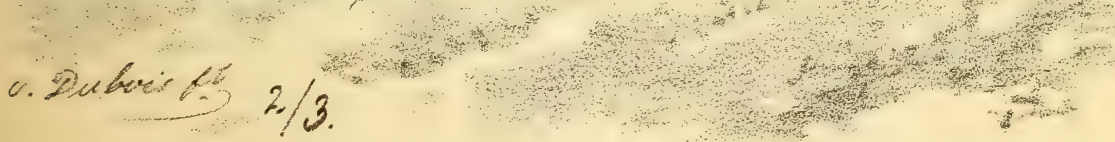

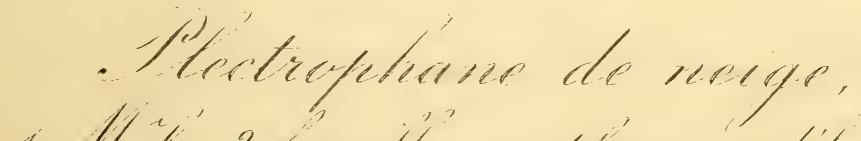

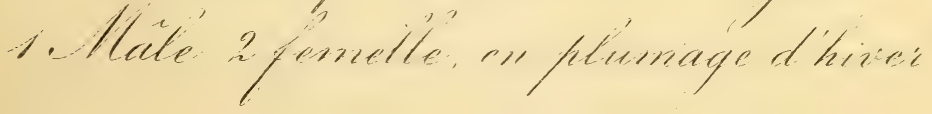





\section{PLEGTROPIANE DE NEIGE.}

PLECTROPHANES NIVALIS, MEYER.

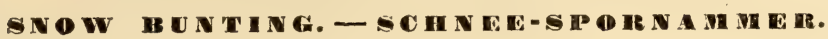

L'ORTOLAN DE NEIGE. Buff., t. IV. p. 329. - Briss., t. III, p. 283. - Temm., l. l, p. 319. - Gould., t. III, pl. 183. -- Naumann, t. IV, pl. 106. - Brehm., p 503. - Glog., I. I, p. 303. - Schleg., p. 72. - Degl ., t. I, p. 275. - Thienem., pl. IX, fig. 13. - Meisn. et Schinz., VG. Schweiz, no 91. - Meyer, Vg. Liv.-u. Estulands, p. 93. - Glog., Fauna SchleSiens., $n^{n} 105$. - Savi, Ornith. Toscana, I. II, p. 75. - Landb., VG. Wurtembergs, no 110 . Faber, Islandische Orn., p. 15. - v. Homey, Vg. Pommerns, n 13. - De Selys-Longch., Faune Belge, no 83. - Doubl., Brit. Birds, p. 13. - Holb., Vg. Groenlands, p. 25. - D Rich. et Swains, F. americana, p. 246. - Wilson, t. III, p. 36. - Passerina nivalis, Vieill. - Fringillla albicans, Aldrov. - Miliaria nivis, Frisch. - Hortulanus nivalis, Briss. - Emberiza varia, Schwenk. - E. nivalis, Linné. - E. mustetina et E. montana, Gmel. - E. glicialis, Lath.

Habite les plus hautes montagnes couvertes de neige, dans le nord de la Sibérie, du Kamtschatka, du Groenland, du Spitzberg, de l'Islande, de la Laponie et de la Norwége; dans ces pays il est toujours sur les monts isolés et arides, qui ne produisent qu'avec peine quelques maigres brins d'herbe; de manière que ces oiseaux se trouvent toujours entourés d'amas de neige et d'une terre glacée où la mousse et les lichens couvrent à peine la pierre nue. Là où toute grande végétation périt par la rigueur du climat, on le trouve seule créature vivante; il ne quitte pas en hiver les pays du Nord qui sont plus tempérés. Dans les pays froids, ces oiseaux se dirigent vers le Midi en hiver, arrivent chaque année en grande masse en Russie, en Suède et en Irlande, et parviennent quelquefois en grande quantité sur les bords de la mer d'Allemagne, en Hollande et en Belgique. Au commencement de décembre de 1849,1850 et 1851 , ils étaient ici très-communs. Ce n'est que la grande neige, et non pas le froid même le plus rigoureux, qui les fait émigrer pour chercher leur nourriture; ce qu'ils font par petites troupes en se répandant dans les plaines. Il arrive parfo:s que ces oiseaux, par manque de nourriture, s'égarent jusque dans les villes; ils nous quittent vers la fin de février. Le mâle gazouille déjà au mois de mars sa chanson mélancolique dans les tristes solitudes; son chant se compose de tons très-courts. Les habitants du Nord mangent ces oiseaux en grande quantité. En captivité il périt ordinairement, car il ne souffre pas la chaleur des chambres.

Varie accidentellement, tout à fait blanc, blanc-jaunâtre, bec croisé.

Nourriture : semences, insectes et leurs larves dont ils nourrissent principalement leurs petits.

Il niche entre les morceaux de pierre et dans les crevasses de rochers, mais ordinairement sous les endroits couverts. Le nid se compose de brins d'herbe, de petites racines de plantes. L'intérieur est bourré de poils de renard, de plumes, particulièrement de celles de lagopèdes. La femelle pond vers la fin de mai cinq ou six oufs; le mâle prend quelquefois la place de la femelle pour couver les oufs, afin que celle ci n'éprouve point une trop grande fatigue. 



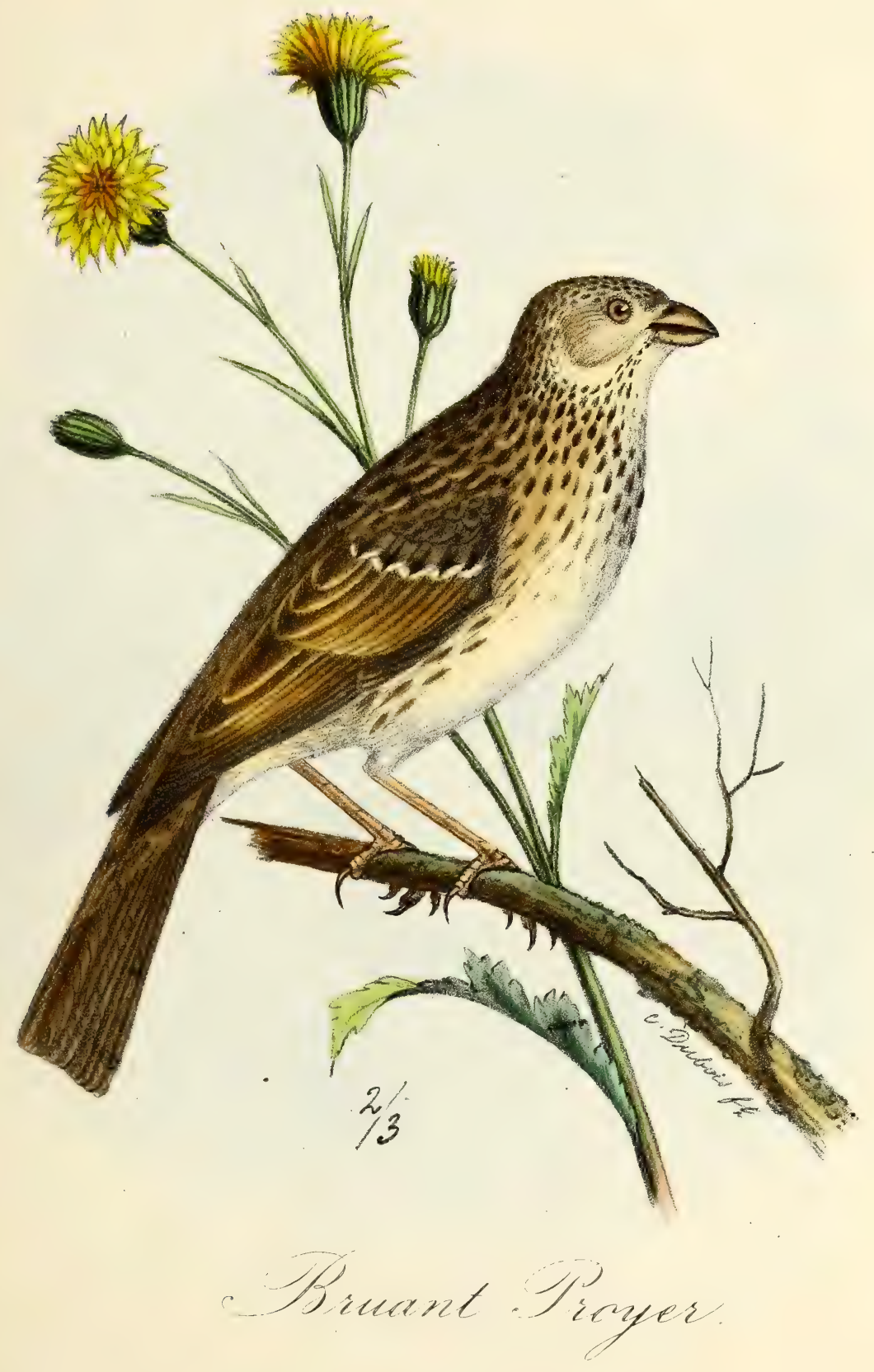





\section{B R U A N T P R 0 Y ER.}

EMBERIZA MILIARIA, LINNÉ.

CONIIDN BUNTING. - GIEAU-ANMER.

LE PROYER. Buff., t. IV, p. 555. - Buff, pl. enl., 233. - Briss., t. III, p. 292. - Temm., t. I, p. 306. - Gould., t. III, pl. 171. - Naumann, t. IV, pl. 101. - Brehm., HandB., p. 288. - Glog., Handв., p. 290. - Schleg., p. 71. - Degl., t. I, p. 270. - Thienem., FortP., pl. IX, fig. 10. - Meisn., Vg. Schweiz, no 88. - Mey., Vg. Liv.-v. Esthlands, p. 91. - Glog., Fauna Schlesiens., no 99. - Sayi, Ornith. Toscana, t. II, p. 79. - Landb., Vg. Wurtembergs, n 104. - v. Homey., Vg. Pommerns, no 125. - De Selys-Longch., Faune Belge, no 18. - Malh., Faune Sicil., p. 113 . - v. d. Mühle, Vg. Griechenlands, no 68. - Doubl., Brit. Birds, p. 13. Malh., Ois. de l'Algérie, p. 14. - Strickl., Ois. de l'Asie Mineure. - Rüpp., Vg. N. O. Afrika's, n. 297. - Miliaria cana, Frisch. - M. germanica, Brehm. - Cynchramus Bellonil, Aldrov.C. miliaria, Bonap.

Cet oiseau se trouve répandu dans presque toute l'Europe; dans certains pays il est commun, dans d'autres il est plus rare; mais dans les pays montagneux et boisés il ne parait jamais; on le trouve aussi dans l'Asie Mineure, en Syrie, en Arabie, en Egypte; il est commun en Algérie. Les bruants n'habitent pour ainsi dire que les pays plats dans lesquels il y a des plaines et des champs fertiles entrecoupés d'arbres; ils aiment particulièrement les endroits marécageux où se trouvent des saules et d'autres arbustes sur lesquels ces oiseaux se perchent ordinairement près de la terre et en évidence; on les voit très-rarement sur le sommet d'un arbre élevé. Les bruants courent beaucoup à terre dans l'herbe; ils y dorment aussi comme les alouettes derrière des monticules ou de petites broussailles. En hiver, ils émigrent en société d'autres oiseaux, parfois avec les bruants jaunes; pendant les hivers rigoureux, ils viennent dans les villages avec les moineaux et ordinairement ils se chamaillent sans cesse. En volant ils font souvent entendre de petits cris saccadés; le mâle chante toujours près de l'endroit où se trouve le nid; il se pose ordinairement sur un pieu ou sur une pierre; son chant se compose de tons faibles, enroués et ayant un singulier son; lorsqu'il chante, il enfle beaucoup son plumage et de temps en temps, d'un vol incertain, il va prendre une nouvelle place. Beaucoup d'entre ces oiseaux laissent encore entendre leur voix en hiver par le plus grand froid.

Les variétés accidentelles de ces oiseaux sont: blanc, taché de blanc, brun-jaunâtre et ayant les taches moins marquées.

Leur nourriture se compose en été d'insectes et de leurs larves, en hiver et en automne de semences.

Ils nichent sur la terre dans de petits enfoncements entre les fortes plantes, dans l'herbe ou dans des buissons de saules contre la terre; le nid est grossièrement construit et se compose de tiges de paille et de forts brins d'herbe; celle qui est en dedans est plus délicate; dans l'intérieur se trouve aussi plus ou moins de crins. Le nid contient de quatre à six oufs. 



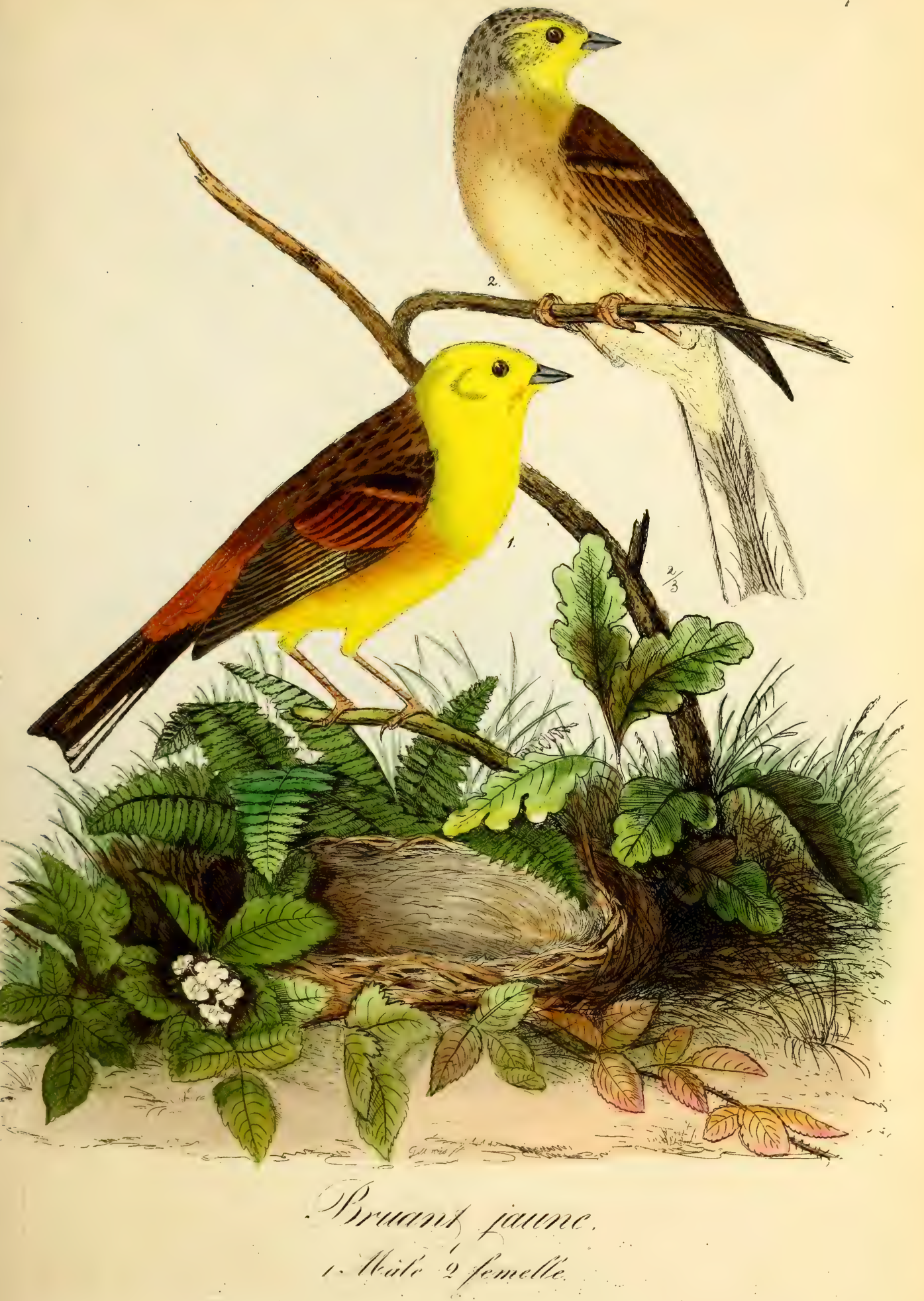





\title{
BRUANT JAUNE.
}

\author{
EM B E R IZ A C I T R I NEL L A， LINNÉ.
}

YELTOW BUNTING. - GoLD-AMmere.

BRUANT. Buff., Ors., t. IV, p. 340. - Buff., pl. él., 30. - Brisson, t. III, p. 258. - Lath. pr. Bechst., t. III, p. 167. - Gould, Birds of Europe, t. III, pl. 173. - Temm., Man., t. I, p. 304, et t. III, p. 218. - Naumann, t. IV, pl. 102. - Brehm. HANDB., p. 294. - Glog. HANDB., t. I, p. 293. - Schleg., Revue, p. 68. - Degland, Ornith., t. I, p. 240. - Thienem., Fortp., III. Abt., pl. IX, fig. 9. - Meisn. et Schinz. VG. Schweiz, no 85. - Mey., VG. Liv-u. Esthlands, p. 90. - Savi, Ornith. Toscana, t. II, p. 83. - Glog., Fauna Schlesiens., no 100 . - Landb. Vg. Wurtembergs, no 105. - v. Homey, Vg. Pommerns, n' 126. - De Selys-Longch., Faune Belge, no 81. - Malh., Faune Sicile, p. 114. - Doubl., Brit. Birds., p. 13. - v. d. Mühle, Vg. Griechenlands, n 67. - Strichl., Ois. de l'Asie Mineure.

Habite une grande partie de l'Asie et est répandu dans presque toute l'Europe jusque fort avant dans le Nord, comme la Finlande, Norwége, Suède, Russie, est très-commun en Belgique, en France et en Allemagne. Se tient dans les bois montueux et en plaines, dans les haies, dans les jardins, et dans les champs bordés de buissons. Le mâle perche le plus souvent sur une branche morte, et fait entendre son chant mélancolique et fort simple pendant une grande partie de la journée jusqu'en automne. II se rapproche des habitations pendant l'hiver et vient jusque dans les villes et les villages où il se mêle aux bandes de moineaux, de pinsons et des alouettes huppées; sa chair est délicate et recherchée en automne.

Variétés accidentelles, tout blanc, tapiré de blanc, tout jaune, ou le bec croisé.

Nourriture : toutes sortes de graines farineuses, chenilles, insectes et leurs larves.

Il niche le plus souvent à terre, quelquefois pourtant dans les buissons, dans les herbes, dans les bruyères ou entre les racines des buissons; son nid est composé de tiges, de brins d'herbes, quelquefois aussi de mousse, et l'intérieur est bourré de radicules et de laine; il pond de quatre à six oufs. 

118

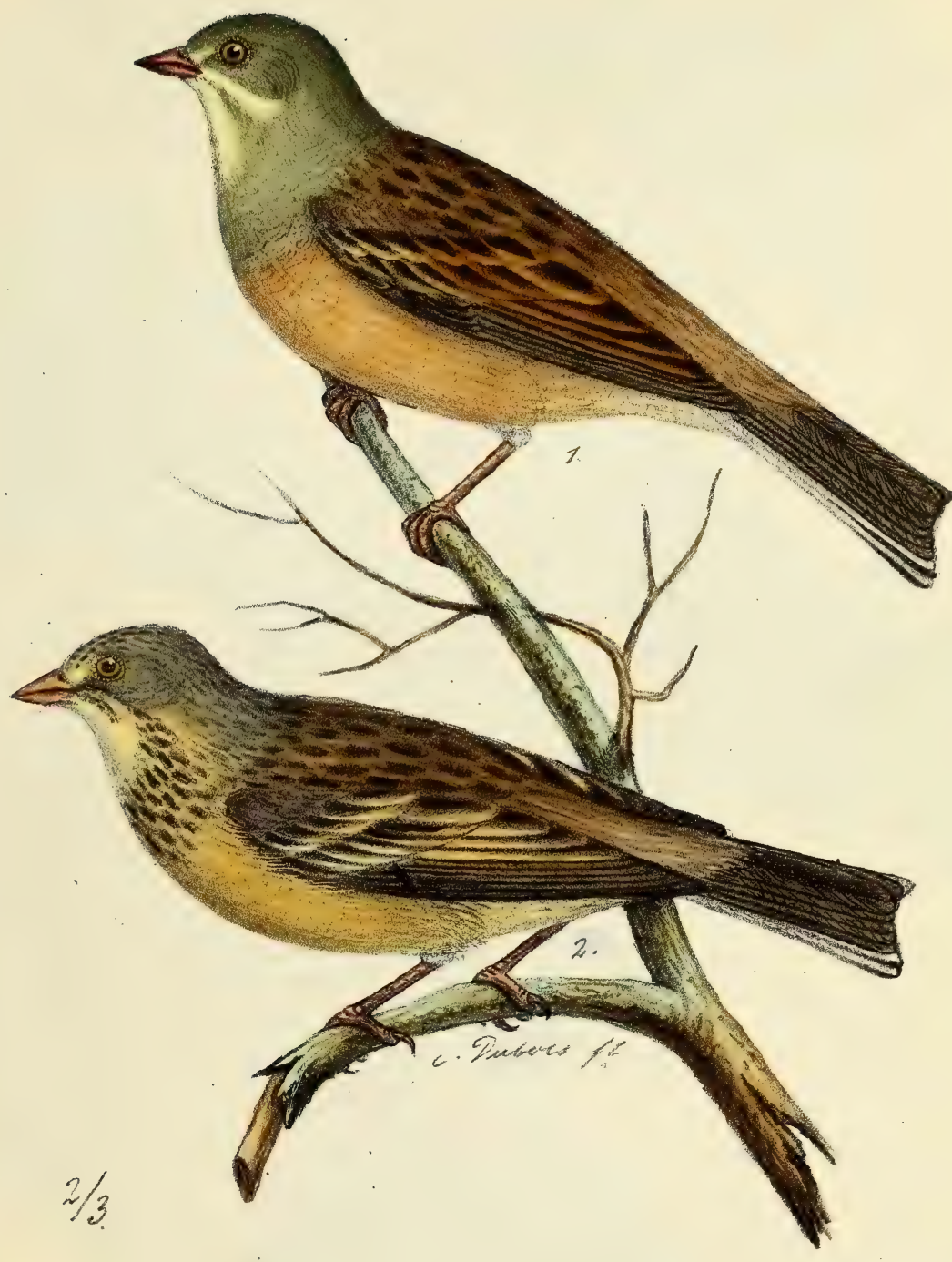

- Precruel Coldeleié,

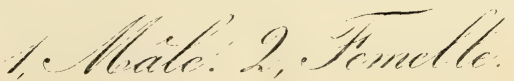





\title{
B R U A N T O R T O L A N.
}

\author{
EMBERIZA HORTULANA, LINNE.
}

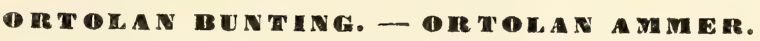

\begin{abstract}
ORTOLAN. Buff., pl. enl. 247. - Temm., t. I, p. 311. - Gould, t. III, pl. 176. - Degl., t. l, p. 254. - Naumann, t. IV, pl. 103. - Schleg., p. 69. - Thienem., Fortp., pl. IX, f. 12. Savi, Ornith. Toscana, t. II, p. 87. - De Selys-Longch, Faune belge, no 80. - Malh., Faune Sigile, p. 116. - v. d. Mühle, Vg. Griechenlands, nº 64. - Rupp., Vg. N. O. Afrika's, no 296. Emberiza badensis, et E. chlorocephala, Gml. - E. malbeyensis, Spar. - E. Tunstalli, Lath. - E. Pinguescens, Brehm. - Citrinella hortulana, Kanp.
\end{abstract}

Cet oiseau-ci habite une grande partie de l'Asie et le nord de l'Afrique; en Europe on le voit plus souvent dans les parties du sud que dans celles du nord; en Allemagne il n'est abondant que dans quelques parties, dans d'autres il est rare et même très-rare; en Italie, en France et en Belgique, il est en abondance. Le bruant se tient particulièrement dans de grandes plaines libres. et de préférence dans les plaines de sable, dans les bruyères ou sur les lisières des bois; il se trouve aussi dans les petits bois et dans les jardins, se posant rarement haut sur les arbres. Ce bruant est paresseux et aime beaucoup à rester à une même place; il est pacifique, confiant et simple. Le mâle a un chant monotone que l'on entend depuis le matin de bonne heure jusque tard au soir. La manière de vivre de cet oiseau est tranquille et retirée. En automne ces oiseaux sont très-gras, aussi les attrape-t-on en grande quantité, car ils forment un mets très-délicat, et se payent fort cher. En Belgique on en prend beaucoup dans la Campine; l'époque pour les attraper est fixée par la loi. On peut encore engraisser ces oiseaux lorsqu'on les tient dans une chambre continuellement éclairée par une lampe pour qu'ils ne s'aperçoivent pas de la différence du jour et de la nuit, afin qu'ils puissent toujours manger; aussi en peu de temps deviennent-ils excessivement gras. Au midi de l'Europe, avant de les expédier, on les laisse bouillir un instant dans l'eau, puis on les met dans de petits tonneaux avec du vinaigre et des épices. La plupart viennent de l'île de Chypre, d'où l'on expédie en une année de 80,000 à 100,000 ortolans.

La nourriture de ces oiseaux est tout à fait la même que celle des autres bruants.

Variétés accidentelles : blanc, blanc mélangé et vert foncé.

Le nid des ortolans est ordinairement caché sous un arbuste, sous la bruyère ou d'autres plantes semblables. Le nid est composé de brins d'herbe, de racines et souvent de mousse; à l'intérieur il y a des radicules et des crins, il contient de quatre à six oufs. 

ICY.

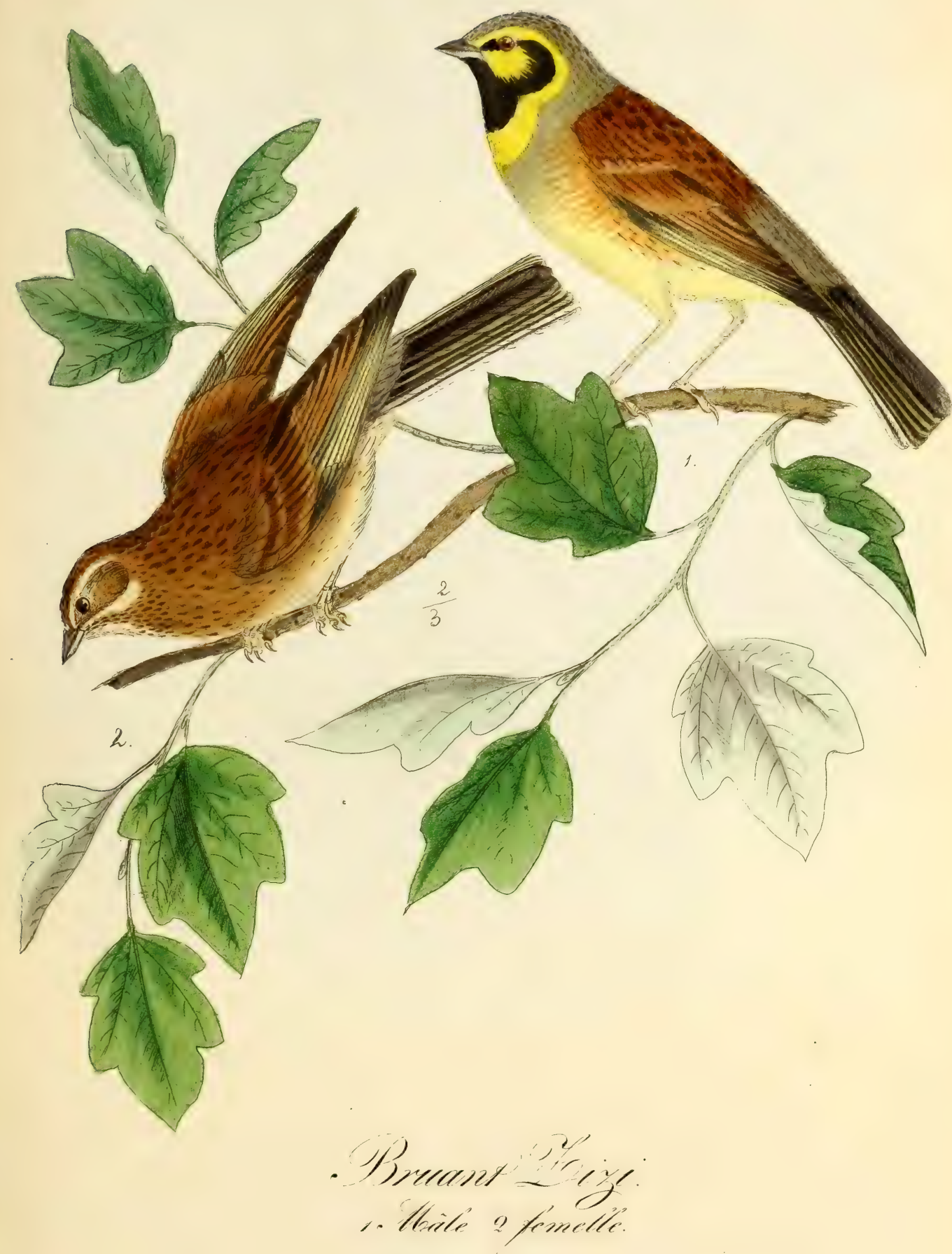





\title{
BRUANT ZIZI.
}

\author{
EM B ERIZA GIRLUS, LINNÉ.
}

CIRT RUNTKN. - ZIRI-AMMER.

BRUANT DE HAIE. Buff., 0is., t. IV, p. 347. - Buff., pl. él., 633. - Briss., t. III, p. 263. Lath., pr. Bechst., t. III, p. 184. - Temm. Man., t. I, p. 313, et t. III, p. 227. - Gould, t. III, pl. 175. - Naumann, t. IV, p. 102 , fig. 3. - Brehm., HandB., p. 297. - Glog., t. I, p. 294. - Keys. et Blas, p. 68. - Schleg., p. 68. - Degl., t. I, p. 247. - Meisn. et Schinz., VG. Schweiz., no 89. - Savi, Ornith. Toscana, t. II, p. 81. - Landb., Vg. Würtembergs, $n^{\circ}$ 107. De Selys-Longch., Faune Belge, no 78. - Malh., Faune Sicile, p. 117. - v. d. Mühle, Vg. Griechenlands, no 66. - Doubl., Brit. Birds, p. 13. - Malh., Oiseaux de l'Algérie, p. 14. - Strickl., Ois. de l'Asie Mineure. - Emberiza sepiaria, Briss. - E. eleathorax, Bechst. E. badensis, Sander. - E. tunstalli? - E. chorocephala, Gmel.

Habite l'Asie Mineure et l'Algérie, est abondant en Italie, en Suisse, en Bavière, dans le midi de la France; très-commun en Sicile, mais très-rare en Belgique. Il se tient de préférence dans les lieux montueux et dans les bois, près des champs. Le mâle perche le plus souvent sur une branche morte, sur laquelle il fait entendre son chant qui est assez semblable à celui de la sauterelle; pendant l'hiver il se tient dans les villes et les villages en compagnie des bruants jaunes, des pinsons et des moineaux dans la société desquels il est très-peu timide, mais querelleur et impatient.

Nourriture : toutes sortes de graines farineuses, baies, chenilles, insectes et leurs larves; mais sa nourriture favorite, ce sont les baies de morelles.

Il niche dans les haies et dans les buissons, près de la terre, entre les racines ou dans les herbes; son nid est composé de tiges, de brins d'herbe, quelquefois aussi de mousse, et l'intérieur est bourré de laine; pond de trois à cinq œufs. 



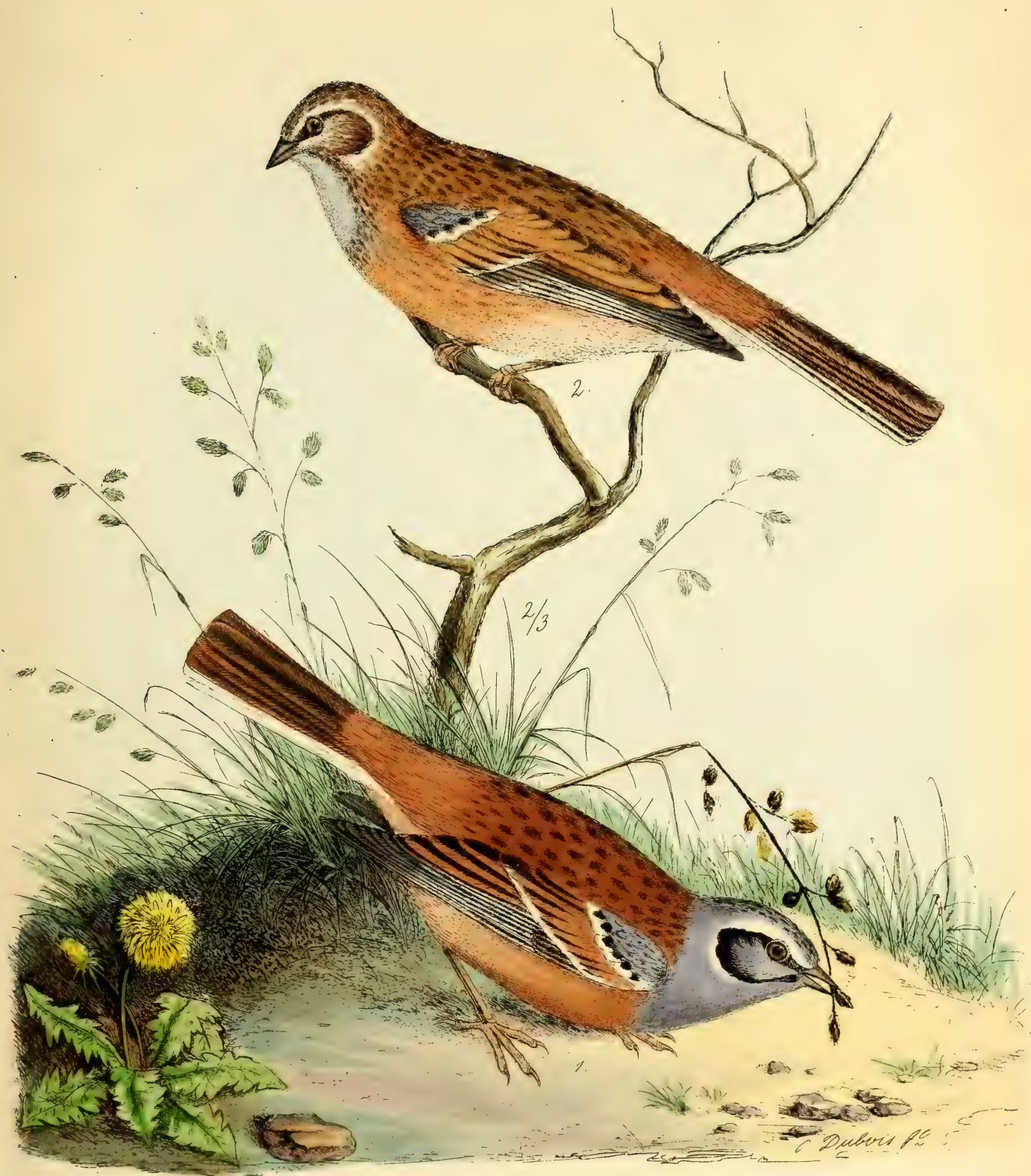

- Pryerast Frore.

r. Whate. a femelle. 



\section{B R U A N T F O U.}

EMBERIZA CIA, LINNÉ.

M A DOU IENTIG. - Z IP-AMMEET.

L'ORTOLAN DE LORRAine. Buff., Ois., t. IV, p. 323. - Buff., pl. él., 30. - Briss., t. III, p. 266. - Lath. pr. Bechst., t. III, p. 173. - Temm., t. I, p. 315, et t. III, p. 227. - Gould, Birds of Europe, t. III, pl. 179. - Naumann, t. IV, pl. 104. - Brehm., p. 298. - Glog., HavdB., t. I, p. 298. - Schleg., Revue, p. 69. - Kays. et Blas, p. 69. - Degl., t. I, p. 25ั0. - Meisner et Schinz., Vg. Schwerz, no 192. - Glog., Fauna Schlesiens., no 102. - Landb., Vg. Wurtembergs, no 108. - Savi, Ornith. Toscana, t. II, p. 83̈. - De Selys-Longch., Faune Belge, no 79. - Malh., Faune Sicile, p. 118 . - v. d. Mühle, Vg. Griechenlands, n 69. - Strickl., Ois. de L'Asie mineure. - Emberiza pratensis, Briss. - E. Lotharingica, Gmelin. - E. barbata, Scopoli. - Fringilla cinerea, Gmelin. - F. sylvatica, Lacépède.

Habite une grande partie de l'Asie, la Syrie, l'Arabie, Daourie, se trouve aussi en Algérie et en Europe, dont il habite les parties méridionales; il est très-abondant en Italie et en Espagne, commun en Sicile, rare en Allemagne, de temps en temps on le voit en Autriche et en Bavière, plus rare encore en France, et très-rare et accidentellement en Belgique. Il vit dans les endroits montagneux, pierreux et sauvages, mais ils doivent être fertiles et l'eau doit y être abondante. Il se tient de préférence dans les jardins et prairies près des lieux habités. Il se perche ordinairement bas dans les buissons ou sur de petits arbres sur lesquels il chante avec courage sa petite chanson insignifiante. Il s'entend parfaitement avec le Bruant jaune, vit souvent en automne, dans sa société, et parfois même il se mêle avec les Fringilles voyageuses.

Nourriture : les insectes et leurs larves, et différentes sortes de graines farineuses.

Il niche dans les forêts et dans les haies, ainsi que dans les buissons, mais il se tient toujours près de la terre; son nid se compose de brins d'herbe, de mousse, et de quelques feuilles mortes; à l'intéricur il est bourré de laine. Pond trois à cinq oufs. 



$$
\text { 跑 }
$$





\title{
BRUANT DES ROSEAUX.
}

\author{
EMBERIZA SCHOENICLUS, LINNÉ.
}

IEED TUNTING. - ROER-AMMER.

ORTOLAN DE ROSEAdX. Buff., pl. enl. 247.-Temm., t. I, p. 307.-Gould, t. III, pl. 183. - Degland, I. I, p. 260. - Schlegel, p. 70. - Naumann, t. IV, pl. 70. - Thienem., ForTP., pl. IX, fig. 11. - Savi, Ornith. Toscana, t. II, p. 89. - De Selys-Longch., Faune Belge, no 76. - Malh., Faune Sicile, p. 115.- v. d. Mühle, Vg. Griechenlands, n 71. - Malh. Ois. de l'Algérie, p. 14. - Emberiza passerina, Pall. - E. arundinacea, Gm. - Cynchramus schoeniclus, Boje. - C. stagnatilis et septentrionalis, Brehm.

Cet oiseau habite presque toute l'Europe et les parties tempérées de la Sibérie. En Belgique et en Hollande il est très-commun; il a une préférence marquée pour les endroits environnés d'eau, les rochers situés dans des lieux humides, les marais qui sont pourvus dherbes hautes, de roseaux et d'osiers sur lesquels il se pose parfois, quoique plus ordinairement il se pose à terre; il est très-craintif; son cri d'appel est un zich ou tschu élevé et étendu; le chant que le mâle fait entendre depuis le mois de mars, de bonne heure et tard, quelquefois pendant la nuit jusque vers la fin de l'été, est mauvais et monotone; en automne ils volent en grande société sur les champs de mil et de colza dont ils aiment beaucoup la semence; ils mangent encore les semences de joncs et de roseaux, les insectes et leurs larves.

Variétés accidentelles : blanc, dans son plumage ordinaire, toutes les couleurs sont pâles.

Ils nichent sur les rivages ou près de l'eau, sur la terre entre de l'herbe. de l'osier ou d'autres arbustes; le nid est composé de brins d'herbe, de feuilles sèches et quelquefois de mousse; à l'intérieur ces mêmes matériaux sont beaucoup plus fins; quelquefois ils y ajoutent un peu de laine d'animaux ou de plantes; il contient quatre ou six oufs 



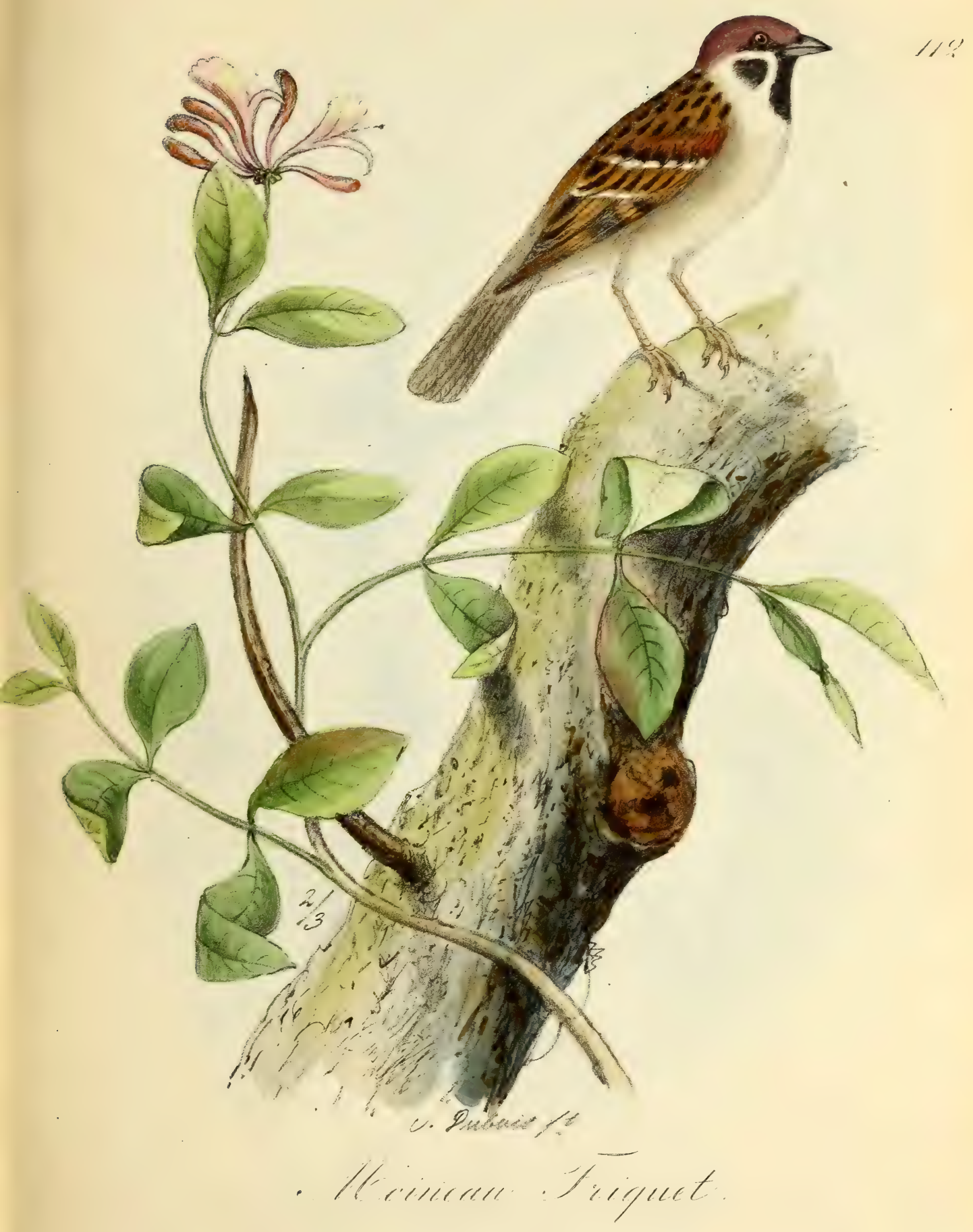



Cempe Moimeau. - Passer, Brisson.

\section{0 I N E A U F R I Q U E T.}

PASSER CAMPESTRIS, BRISSON.

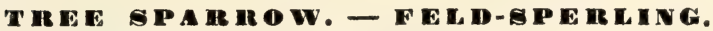

FRIQUET. Buff., pl. enl. 267. - Temm., t. I, p. 554. - Gould, t. III, pl. 184. - Naum., t. IV, pl. 116. - Degl., t. I, p. 211. - Thien., pl. X, 6. - Vg. Liv.-U. Esthlands, p. 85. - Ornith. Toscana, t. II, p. 107. - Faune Sicile, p. 122. - Vg. Griechenlands, no 73. - Vg. N. 0. Africa's, no 294. - Fringilla campestris, Schrak. - F. montana, Linné. - Pyrgita montana, Cuvier. - Py. campestris, Brehm. - Passer montanus, Koch. - P. montanina, Pallas.

Le moineau Friquet est répandu dans toute l'Europe, mème dans le Nord, jusqu'en Laponie et en Sibérie; il se trouve aussi dans le Japon, en Chine et en Égypte. On le voit dans le voisinage des villages et des villes, sur les lisières des bois qui ont de grands arbres creux, dans les vergers, dans les pâturages où se trouvent de vieux saules; en hiver il arrive jusque dans les villes où il vit dans la société des bruants, des alouettes et des pinsons. Au commencement de la saison tempérée, ces oiseaux émigrent en volée compacte sur les champs et retournent dans leurs résidences d'été. Leur cri d'appel est court et doux; malgré leur sociabilité, ce sont des oiseaux querelleurs et colériques; ils sont circonspects quoique peu farouches, mais ils sont beaucoup moins artificieux et prudents que les moineaux domestiques, cependant ils sont plus adroits et plus vifs que ceux-ci. Ils passent la nuit dans les touffes d'arbres ou dans les creux et dans les tas de rameaux; en automne ils se tiennent volontiers dans les roseaux, et vont au repos en faisant toujours un immense tapage.

Variétés accidentelles : blanc, blanc-jaunâtre, taché de blanc et presque tout noir.

Leur nourriture se compose d'insectes et de leurs larves, et particulièrement de chenilles qu'ils prennent sur les branches et les troncs des arbres auxquels ces oiseaux s'accrochent; ils y montent et en descendent en bidis; ils vont aussi sur les champs de grains où ils font quelque dommage, cependant ils nous sont plus utiles que nuisibles.

Ils commencent ordinairement dès le mois de mars la bâtisse de leur nid qu'ils mettent dans des creux, particulièrement dans ceux des vieux arbres, des crevasses de rochers 'et de vieilles murailles. Le nid est tout simple et se compose de paille. de petits rameaux, de radicules et de mousse; si la place du nid est humide, le fondement en est plus solide, il s'y trouve de la laine et surtout une fine couche de plumes sur laquelle ces moineaux posent de quatre à sept œufs; ils font ordinairement chaque été deux ou trois couvées pour lesquelles le même nid sert toujours s'il n’a pas été détruit. 



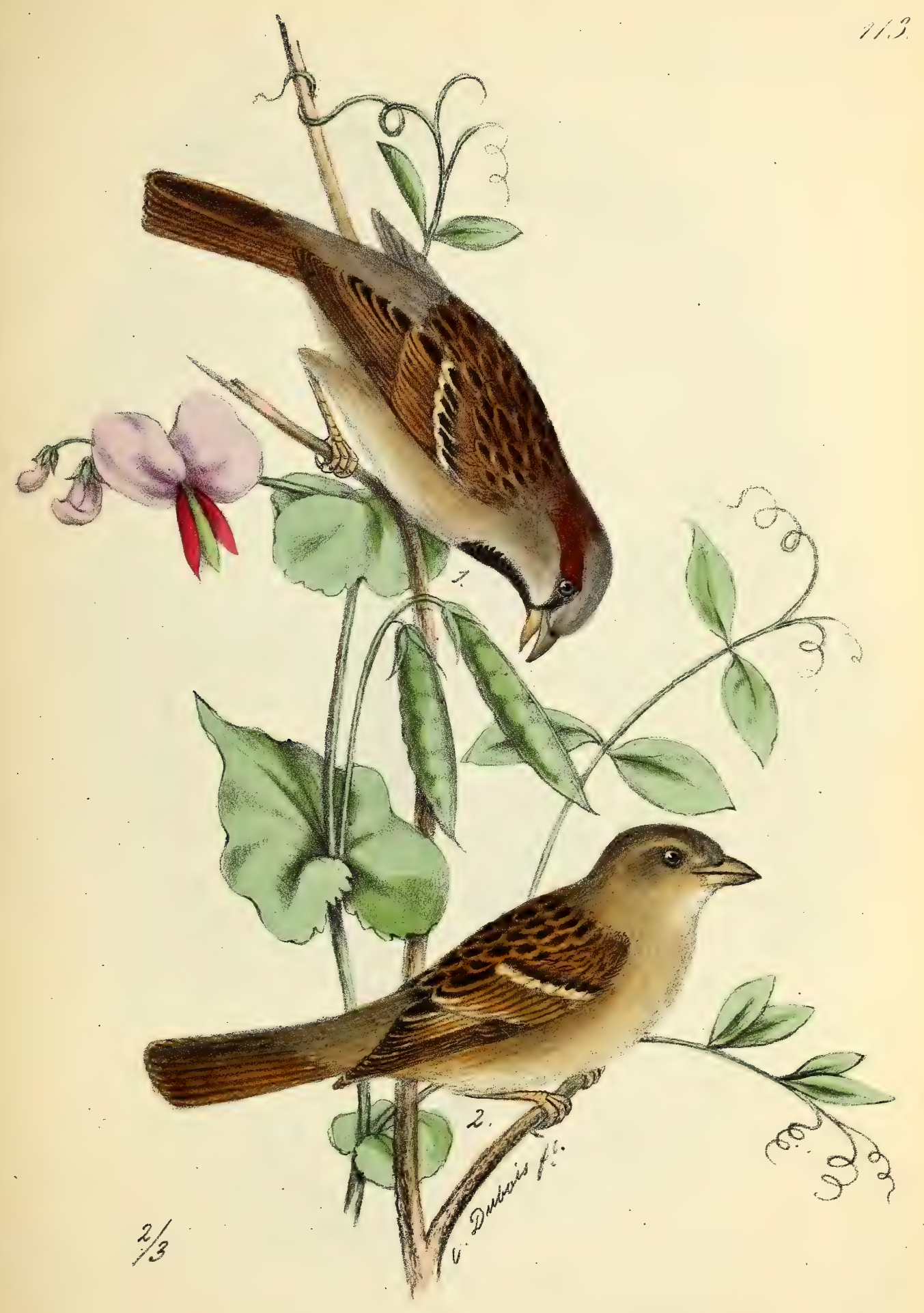

- Aleivenere drunedigué,

r. Elate a fonclle. 



\title{
MOINEAU DOMESTIQUE.
}

\author{
PASSER DOMESTICUS, BRISSON.
}

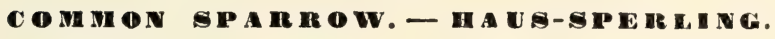

Buff., pl. enI. 6. - Temm., t. I, p. 350. - Gould, t. III, pl. 184. - Naum., t. IV, pl. 115. Degl., t. I, p. 205. - Thien., pl. X, 4. - Vg. Liv.-U. Esthlands, p. 84. - Ornith. Toscana, t. II, p. 105. - Vg. Griechenlands, no 74. - Vg. N. 0. Africa's, no 291. - Fringilla donestica, Linné. - Pyrgita domestica, Cuvier.

Cet oiseau-ci se trouve dans une grande partie de l'Europe et est commun dans beaucoup de pays; on le trouve aussi dans la Russie d'Asie jusqu'en Sibérie; il abonde en Égypte et en Arabie. 11 habite les villes les plus grandes et les plus peuplées, car loin de fuir l'homme il recherche sa présence : on le trouve aussi dans les villages isolés et dans les fermes. En automne et en hiver ces oiseaux vivent en société, souvent en fort grandes bandes. Par suite des attaques incessantes de l'homme, cet oiseau a acquis un caractère aussi méfiant et circonspect qu'il était confiant, et au lieu de s'apprivoiser il est devenu d'une prudence extrême. En hiver les moineaux dorment dans tous les réduits des maisons, et en été dans les châtaigniers et les tilleuls, où l'on entend le soir leur voix querelleuse jusqu'à ce qu'il fasse tout à fait obscur.

Variétés accidentelles : blanc, blanc-jaunâtre, taché de blanc et gris cendré clair.

La nourriture de ces oiseaux est composée d'insectes et de leurs larves, de grains, de baies et de cerises; en hiver ils mangent tout mets préparé qu'ils peuvent attraper.

Ils nichent dans tous les trous et coins des maisons, ils chassent souvent par force les hirondelles de leurs nids pour y faire leurs couvées, il arrive même que ces moineaux s'approprient une partie du nid des cigognes pour y faire conjointement le leur. Leur nid est fait légèrement et sans art avec de la paille, du foin, de vieux chiffons, du papier, etc. L'intérieur est doublé de laine, de cheveux et de plumes. On y trouve de quatre à six oufs; ils font ordinairement deux ou trois couvées. Souvent ils posent aussi leur nid librement sur un arbre; il forme alors une grande masse de foin en forme de boule ayant l'ouverture sur le côté; chose singulière. lorsqu'un couple a fait cette déviation, les autres moineaux suivent son exemple, car on trouve parfois des allées d'arbres toutes remplies de nids pareils. 



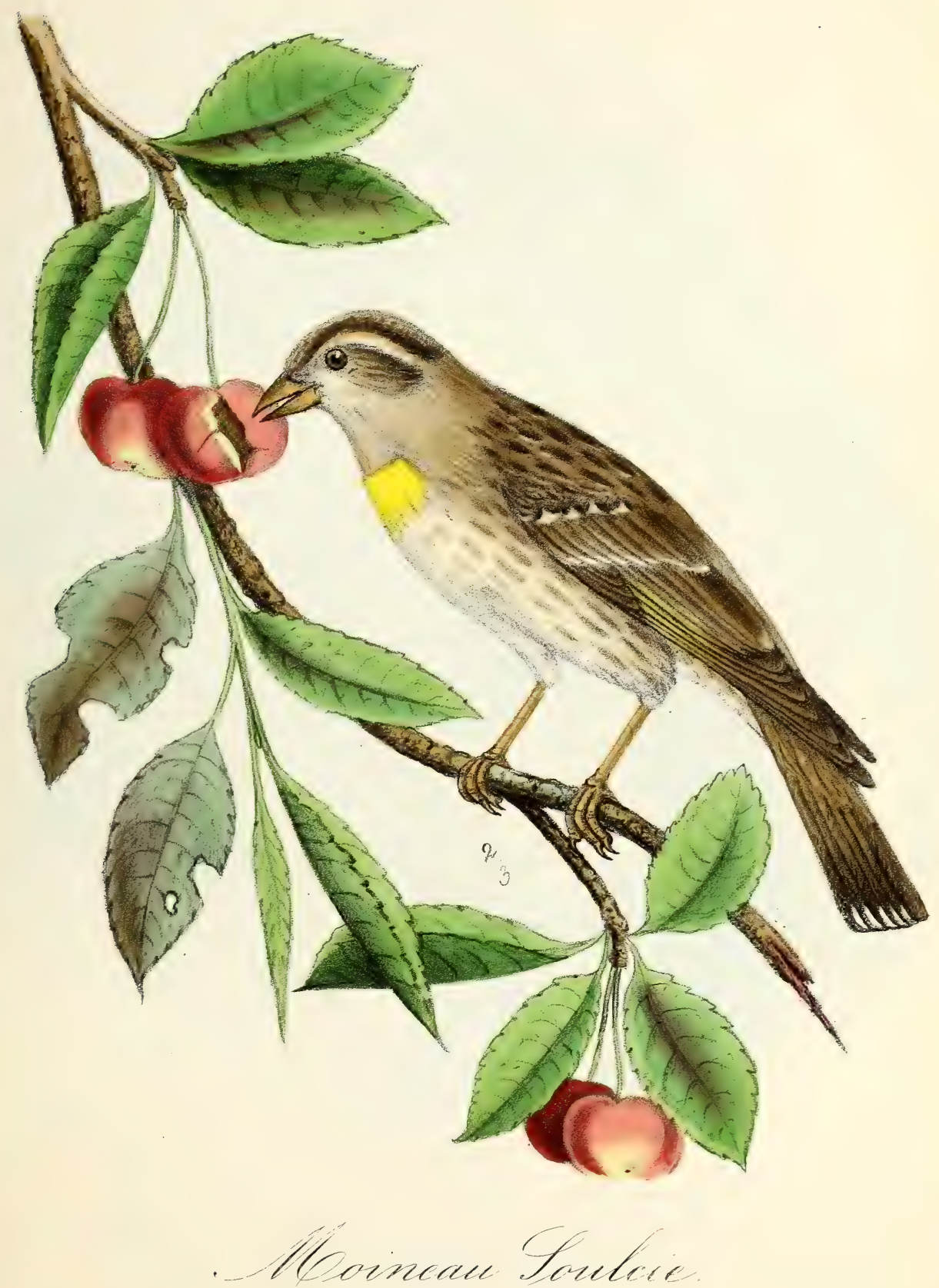





\section{OINEAU SOULCIE.}

PASSER PETRONIA, косн.

MOUITEUT, SPAIR ROW. - STEIV-SPERLING.

MOINEAU DES BOIS OU SOULCIE. Buff., Ors., t. III, p. 498. - Briss., t. III, p. 88. Temm., Man, t. I, p. 348. - Gould, Birds of Eur., pl. 186. - Naumann, pl. 116. - Brehm., Handb., p. 263. - Glog., Handb., p. 322. - Schleg., Revue, p. 63. - Degland, Ornith, t. I, p. 213. - Thienem, FortP , pl. X, fig. 3. - Meisn. et Schinz, VG. Schweiz., $n^{\circ}$ 78. - Glog., Fauna Schlesiens., $n^{\circ} 110$. - v. Homeyer, Vg. Ponmerns, $n^{\circ} 135$. - Savi, Ornith. Toscana, t. II, p. 138. - Landb., Vgl. Wurtemberg, no 91. - De Selys-Longch., Faune Belge, no 65. Malh., Faune Sicile, p. 120. - Pyrgita petronia, Brebm. - Coccothraustes petronia, Cuv. - Fringilla petronia, linné. - F. stulta, leugura el Boloniensis, Gml. - Petronia marina, Willug. - P. nupestris, Bonap. - P. stulta, Strickl. - Passer sylvestris, Brisson.

Habite l'Afrique du Nord, la Syrie et toute l'Europe méridionale, l'Espagne, le midi de la France, les Hautes-Pyrénées et la Suisse; on le trouve aussi parfois en Allemagne aux bords du Rhin, de l'Aar et de la Saal; il n'est que très-rarement de passage en Belgique, ordinairement au mois d'octobre et de novembre. Ces moineaux choisissent pour demeures de vieilles tourelles désertes, d'autres de hautes tours, des endroits montagneux et des rochers; pendant le jour ils s'en éloignent souvent pour voler dans les champs, les chaussées, et même dans les villages; le soir ils retournent dans leurs demeures pour y jouir du repos. Ils sont farouches et craignent l'homme comme le moineau domestique avec lequel ils ont du reste beaucoup de ressemblance quant à la manière de vivre.

Variétés : blanc-jaunâtre, ou blanc taché.

Les cerises sont leur nourriture préférée, surtout les cerises aigres; ils mangent aussi d'autres baies molles, ainsi que des insectes, leurs larves, des chenilles et des vers.

Ils nichent dans des crevasses de rochers, dans les murailles des hautes ruines ou dans les arbres creux; il paraît qu'à Madère ils nichent sous les toits des maisons comme nos moineaux. Le nid est plat et fait sans art; il se compose d'herbe sèche, de petites racines et quelquefois d'un peu d'écorce d'arbre; dans l'intérieur se trouvent de la laine et des plumes qui y sont légèrement déposées; il y a toujours trois ou quatre oufs; comme ils ne font qu'une couvée, leur propagation n'est point grande. Les œufs de ces oiseaux sont rares dans les collections, aussi se distinguent-ils fort peu de ceux des moineaux domestiques. 



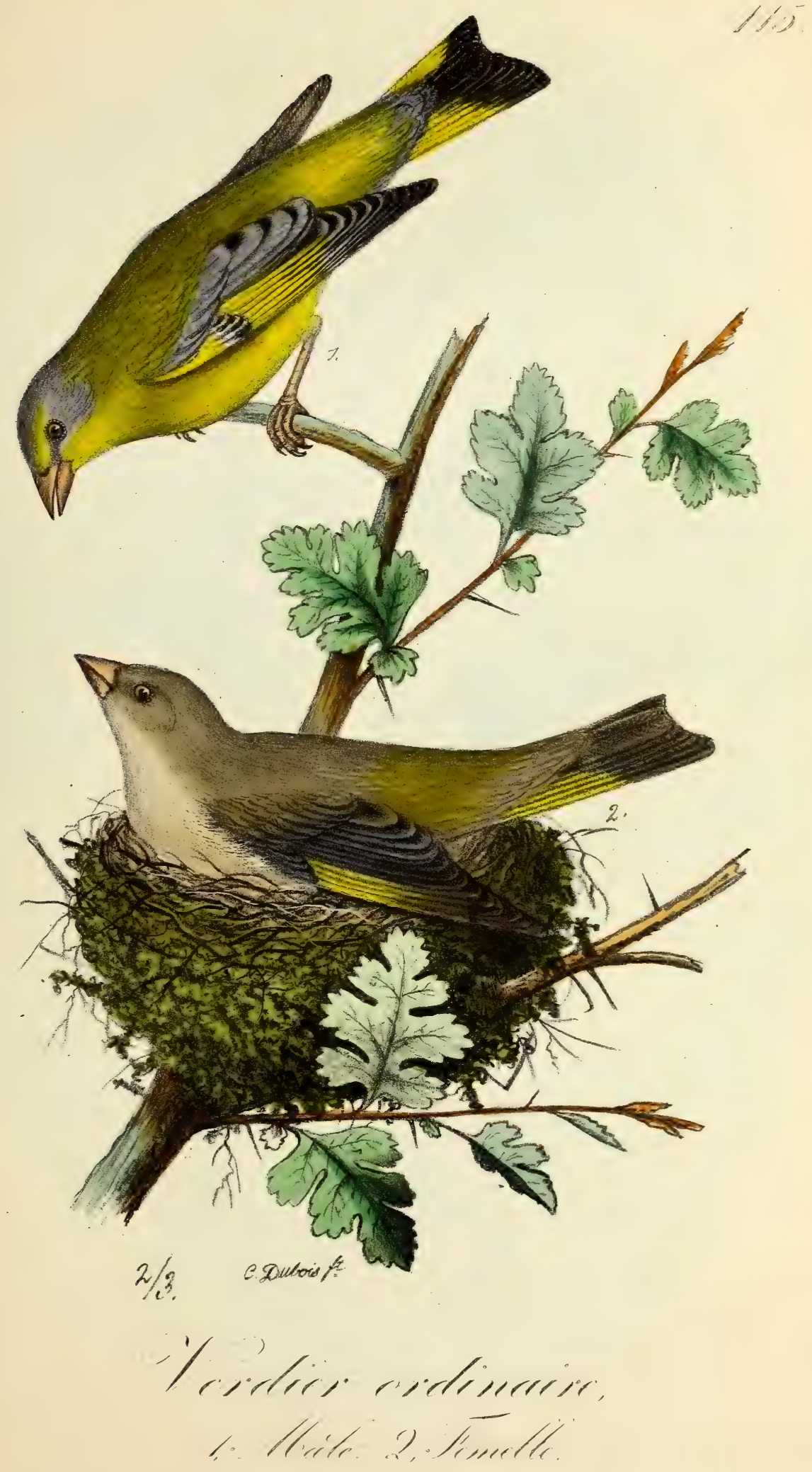



Genre Verdier. - Eigmenus, Koch.

\section{E R D I E R O R D I N A I R E.}

LIGURINUS CHLORIS, косн.

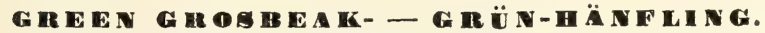

VERDIER. Buff., pl. enl. 267. - Temm., t. I, p. 346. - Gould, t. III, pl. 200. - Degl. t. I, p. 199. - Schleg., p. 61. - Naum., t. V, pl. 120. - Thienem., Fortp., pl. X, f. 2.-Savi, Ornith. Toscana, t. II, p. 134. - De Selys-Longch., Faune belge, n 64. - Malh., Faune Sicile, p. 120. - v. d. Mühle, Yg. Grieghenlands, p. 83. - Malh., Ois. de l'Algérie, p. 14. - Loxia chloris, Linné. - Coccothraustes chloris, Pall. - Chloris flavigaster, Sws. - Chlorospiza chloris, Bonap. - Fringilla chloris, III. - Linaria chloris, hortensis, pinetorum et septentrícnalis, Brehm.

Ce verdier est répandu dans la plus grande partie de l'Europe, de la Finlande et jusqu'en Grèce; de cette contrée il s'étend en Asie jusqu'au Kamtschatka, ainsi que dans l'Afrique du Nord. En Allemagne, aux lles Britanniques, en Belgique et en France, il appartient aux oiseaux com. muns. On le trouve partout où il y a des plantations d'arbres, mème dans les grandes villes; partout où il trouve de la nourriture, il est abondant et il aime beaucoup les endroits fertiles et marécageux, les prairies et les champs bordés d'osiers, ou les environs des villages où se trouvent des fossés remplis d'eau, des étangs ou des arbres. Ce verdier est un oiseau grossier et maladroit; il n'est vif que pendant la nitation; lorsqu'elle est passée il redevient paisible et tranquille, mais aussi plus farouche; en automne ces oiseaux vont par petites ou par grandes volées dans la société des bruants, des pinsons et des moineaux pour chercher leur nourriture qui consiste en semences de différentes sortes de plantes, ainsi qu'en baies de genévrier, quelquefois des faînes. Son cri d'appel est gik qu’il fait particulièrement entendre lorsqu'il vole; le chant du mâle est peu agréable et consiste en tons perçants et saccadés.

Variétés accidentelles : blanc, blanc jaunâtre ou taché de blanc; quelquefois aussi le bec croisé.

Ils nichent au mois de mars dans un buisson épais, particulièrement dans les haies ou sur un arbre contre le tronc; le nid est composé de mousse, de brins d'herbe, de radicules; l'intérieur est doublé de plumes, de laine et de crins, il contient de quatre à six oufs. 



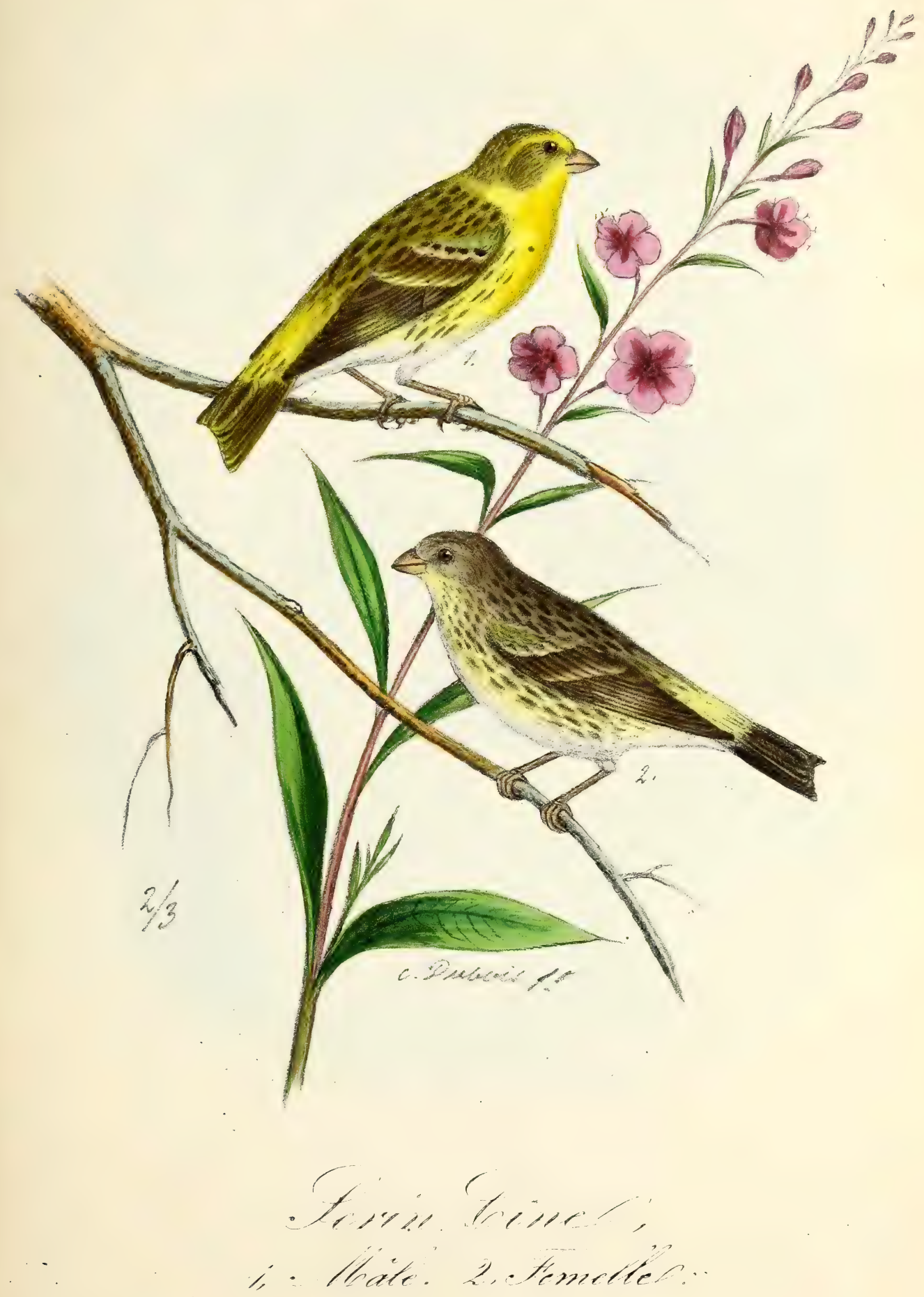



Genre Serim. - Serimus, Koch.

\section{SERIN CINE.}

\section{SER I NUS FLAVESGENS, GOULD.}

SERIN FINCF, - GMÜN-GIREITZ.

LE CINI. Buff., pl. enl. 658. - Briss., Ornith. t. III, p. 179. - Temm., t. I, p. 556. - Gould, t. III, pl. 185. - Degl., t. I, p. 192. - Schleg., p. 56.- Naumann, t. V, pl. 123. - Thienem., FortP., pl. XXXV, fig. 15. - Savi, Ornith. Toscana, t. II, p. 132. - De Selys-Longch., Faune belge, no 73. - Malh., Faune sicile, p. 123. - v. d. Mühle, Vg. Griechenlands, no 78. Malh., Ois. de l’Algérie, p. 14. - Fringilla serinus, linné. - Pyrrhula serinus, Degl. Dryospiza serinus, Cab. - Serinus hortulanus, Koch. - S. Brumalis, Strichl. - S. islandicus, Bonap. - S. MERIDionalis, Brehm.

Le serin cine se trouve dans toute l'Europe du sud, où il est presque partout commun, tel qu'en Espagne, en Portugal, en Italie, dans la France méridionale ainsi qu'en Suisse et à Baden; il est déjà plus rare en Autriche et dans quelques autres parties de l'Allemagne; il est très-rare en Belgique et en Hollande. On trouve aussi ce serin en Syrie, dans l'Asie Mineure et dans le nord de l'Afrique; cet oiseau aime particulièrement les endroits montagneux où il $\mathrm{y}$ a des jardins, des champs et des prairies bien pourvus d'arbres, ainsi que les fossés d'eau et les ruisseaux où se trouvent des plantes; dans les vignobles, sur les lisières des bois. Au printemps il est un des oiseaux les plus vifs et les plus joyeux; il se fait plus remarquer alors parce qu'il se tient sur le sommet des arbres et qu'il vole en chantant d'un arbre à l'autre. Le mâle est très-caressant et folâtre envers la femelle, vers l'automne il devient plus tranquille et vole fréquemment en société des linottes, des verdiers et des tarins. Il chante beaucoup; son chant ressemble à celui du chardonneret et du verdier, mais le serin a la voix plus souple; il chante tantôt en volant, tantôt étant posé, en s'élevant parfois dans les airs comme le pipit des arbres et descend toujours en chantant. Son cri d'appel est à peu près comme guirri ou guirrili.

Leur nourriture est composée de semences, principalement des semences de l'orme et de l'aune.

Ils nichent sur les arbres, sur les arbustes élevés et aussi sur les espaliers; leur nid est joli et composé de tiges de plantes et d'herbe sèche; à l'intérieur on trouve de la laine de plante ou d'animal et des plumes; il contient de quatre à six oufs. 



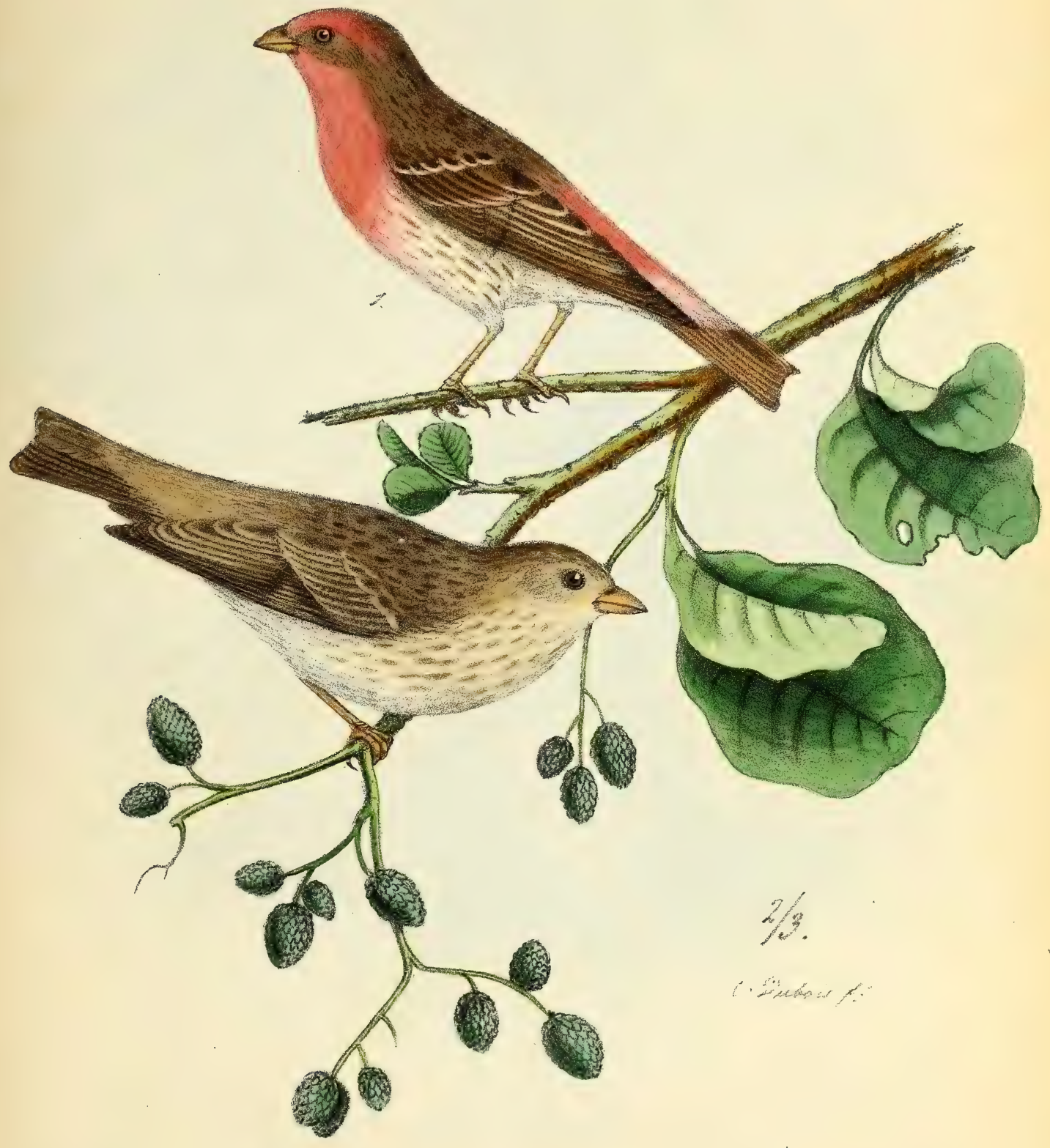

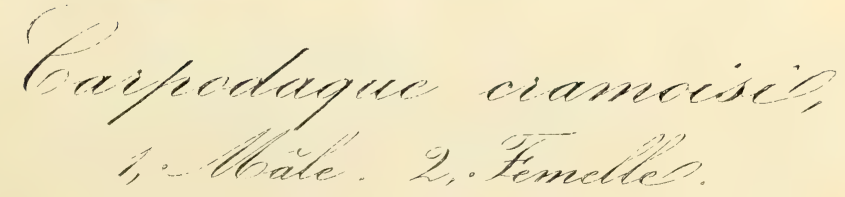





\section{CARPODA Q U E CRA M OISI.}

CARPODACUS ERY'THRINUS, GRAY.

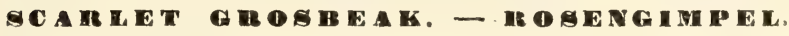

Temm., t. I, p. 336. - Gould, t. III, pl. 206. - Degl.,t. I, p. 489. - Naumann, t. IV, pl. 113. Bonap .el Schleg., Monogr. Des Loxiens., pl. 14. - Kitt. Kupf., pl. 31, f. 1.-Thienem., ForTPflanzungsg, pl. XXXV, f. 15. - De Selys-Longch., Faune Belge, no 72 . - Meyer, Vg. Lief-U. Esthland, p. 77. - Beseke, Vg. Kurlands, p. 77. - Loxia obscura, Gml. - L. erythrina, Pall. - L. cardinalis, Beseke. - L. rosea, Vieill. - L. Erythrea, Endler. - Fringilla flammea, Linné. - F. erythrina, Meyer. - F. Gristata, Briss - Coccothrautes rosea, et C. erythrina, Vieill.-Pyrrhula erythrina, Pall. - Pyrrhulinota roseata, Hodgs. - Frythrothorax rubrifrons. Brehm. - Erythropiza erythrina, Bonap. - Propasser sordidus, Hodgs.

Cet oiseau habite les endroits fertiles de la Finlande, de la Russie, de la Sibérie, du Kamtschatka et de la Daourie, mais il se trouve particulièrement aux bords des fleuves Volga, Ouda, Samara, Lena et du Danube. On le voit habituellement en Fsthonie et en Livonie; il est plus rare dans la Courlande et parvient quelquefois en automne, pendant ses migrations, jusqu'en Allemagne, en France et en Belgique, où l'on a tué, dans les environs de Tournay, un mâle qui se trouve maintenant dans la riche collection de M. le baron de Selys-Longchamps. Il aime beancoup les arbustes de marais, tels que l'osier, l'aune, le roseau, le jonc et d'autres buissons marécageux, ainsi que les lisières humides des forêts; on le trouve aussi dans les endroits stériles qui ne sont pourvus que de quelques plantes. Ce carpodaque n'est point du tout farouche, il se mêle volontiers aux moineaux avec lesquels il va jusque dans les fermes pour y chercher de la nourriture; dans ses poses et dans son vol il a beaucoup de ressemblance avec le verdier, dont il a aussi le chant mélangé avec celui du bruant des roseaux; pour chanter il se pose sur l'extrémité d'une branche libre, son chant est long, entremêlé de pauses fréquentes; son cri d'appel ressemble à celui du moineau. La nourriture du carpodaque cramoisi consiste en différentes graines, particulièrement les huileuses, ainsi que les semences de l'orme et de l'aune.

Il niche sur les arbres peu élevés, particulièrement dans les buissons. Le nid est composé de petites branches sèches, de radicules, de mousse, de laine et de lichens, à l'intérieur se trouve de la laine, du crin; il contient quatre ou cinq oufs. 



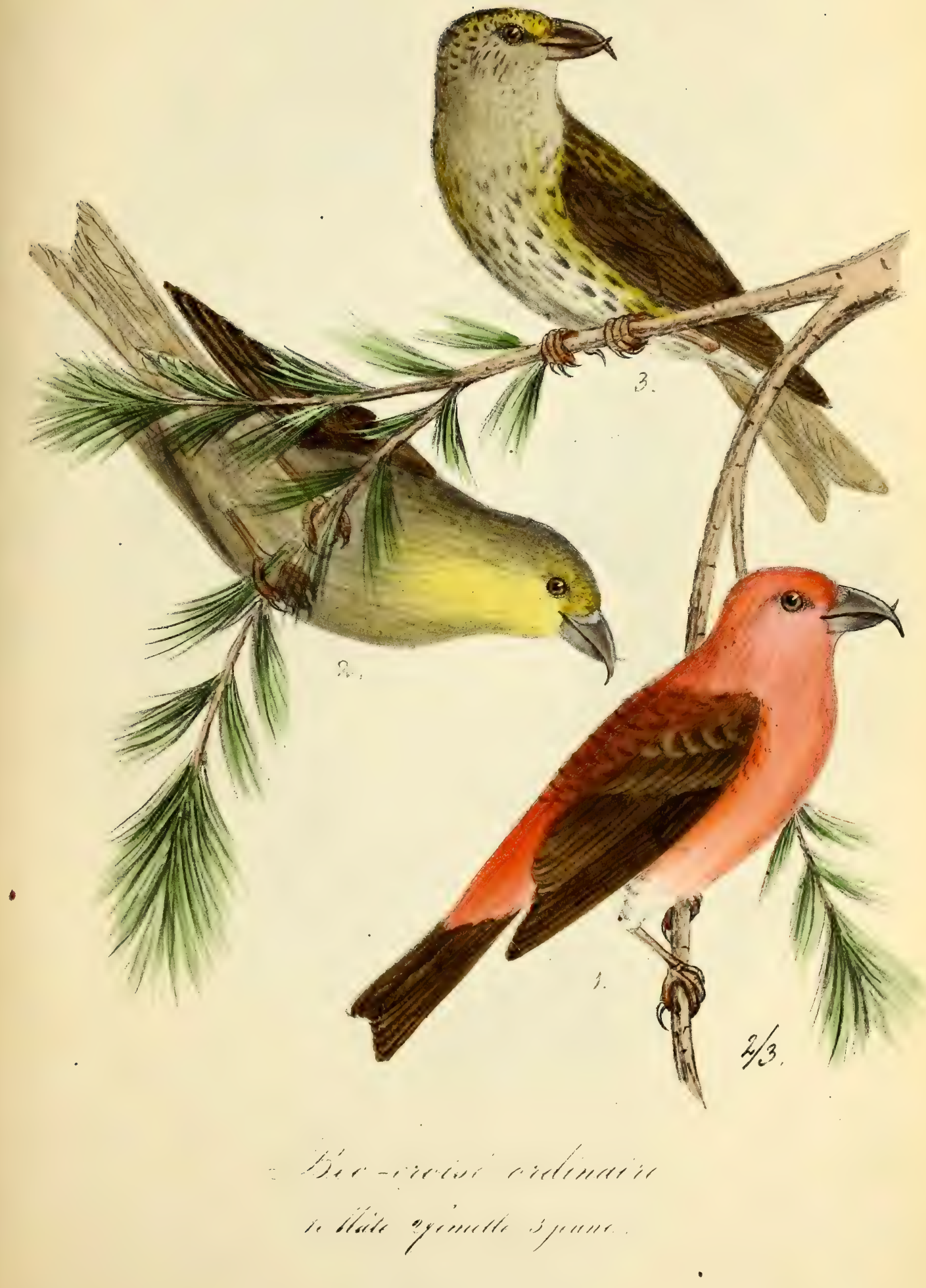





\title{
BEC-CROISÉ ORDINAIRE.
}

\author{
CRUCIROSTRA VULGARIS, STEPHENS.
}

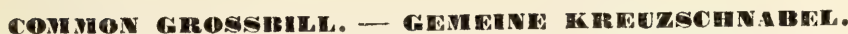

BEC CROISE D'ALLEMAGNE, Buff., pl. enl. 218. - Temm , t. I, p. 328. - Gould, t. III, pl. 197. - Naum., t. IV, pl. 110. - Bonap. et Schleg. Monog. des Loxiens, pl. 2, 3 et 4. Degl, t. I, p. 176. - Thienem., pl. IX, p. 15. - Savi, t. II, p. 147. - Vg. Liv.-U. Esthlands, p. 71. - Faune Sicile, p. 129. - Vg. Griechenlands, no 81. - Loxia curvirostra, Linné. L. Pinetorum, Meyer. - L. Crucifera, Olto. - Crucirostra montana, paradoxa, media, pinetorum, macrorhynchos et minor, Brehm. - Gurvirostra vulgaris, Dumont.

Il habite toutes les régions l'Europe septentrionale et tempérée, telles que la Russie, la Suède, les lles Britanniques, l'Allemagne et la Suisse; il est de passage en Italie, en France, en Belgique et en Hollande; il se trouve aussi en Sibérie, dans le Kamtschatka et dans le Japon (1).

Ces oiseaux vivent aussi bien dans les endroits montagneux que dans les plaines ayant des forêts de pins et de sapins, dans lesquelles ils sont parfois très-abondants, car pendant leurs migrations ils s'y réunissent par grandes volées. Ce sont des oiseaux stupides et indifférents, mais ils sont vifs, agiles et très-sociables. Leur chant n'est point désagréable, le mâle le fait entendre perché sur une branche d'arbre et l'accompagne par des mouvements continuels du corps. Leur cri d'appel peut se rendre à peu près par kip kip ou kup kup. Le bec-croisé se trouve bien en captivité, et apprend facilement à connaitre son maitre qu'il salue par son cri d'appel quand il le voit venir de loin; il ne souffre point la chaleur ni l'air corrompu d'une chambre, il est aussi très-sensible à l'électricité, car pendant un orage il se montre très-inquiet.

Nourriture : semences de pins, de sapins, d'aunes, de larix, et des noyaux de fruits; les becs-croisés mangent aussi des bourgeons d'arbres, mais peu d'insectes.

Ces oiseaux s'accouplent ordinairement déjà au mois de janvier, quoiqu'ils fassent peu d'attention aux saisons, car on les a vus couver dans toutes; mais en général ils couvent au mois de février et de mars. On trouve ordinairenient le nid sur un pin élevé, dans les branches les plus touffues, de manière qu'il soit caché par les branches supérieures, ce qui le rend fort difficile à découvrir. lls font leur nid avec de petits rameaux du pin, des brins d'herbe, de bruyères et de mousse d'arbre; à l'intérieur ils mettent de petites radicules, des brins d'herbe molle, et quelquefois des plumes; il contient ordinairement trois oufs.

(1) Crucirostra americana, Loscia americana, Audubon, et Cr. minor., Brehm., ne se distinguent du bec-croisé ordinaire que parce qu'ils sont un peu plus petits, mais comme la grandeur de ces oiseaux n'est point stable, il y en a qui ont la taille des becs-croisés ordinaires d'Europe; il en est de même du Cr. himalayana, Loxia himalayana, Hodgson, mais comme ces deux-ci ne montrent point une différence constante, on ne peut en former une espèce. 



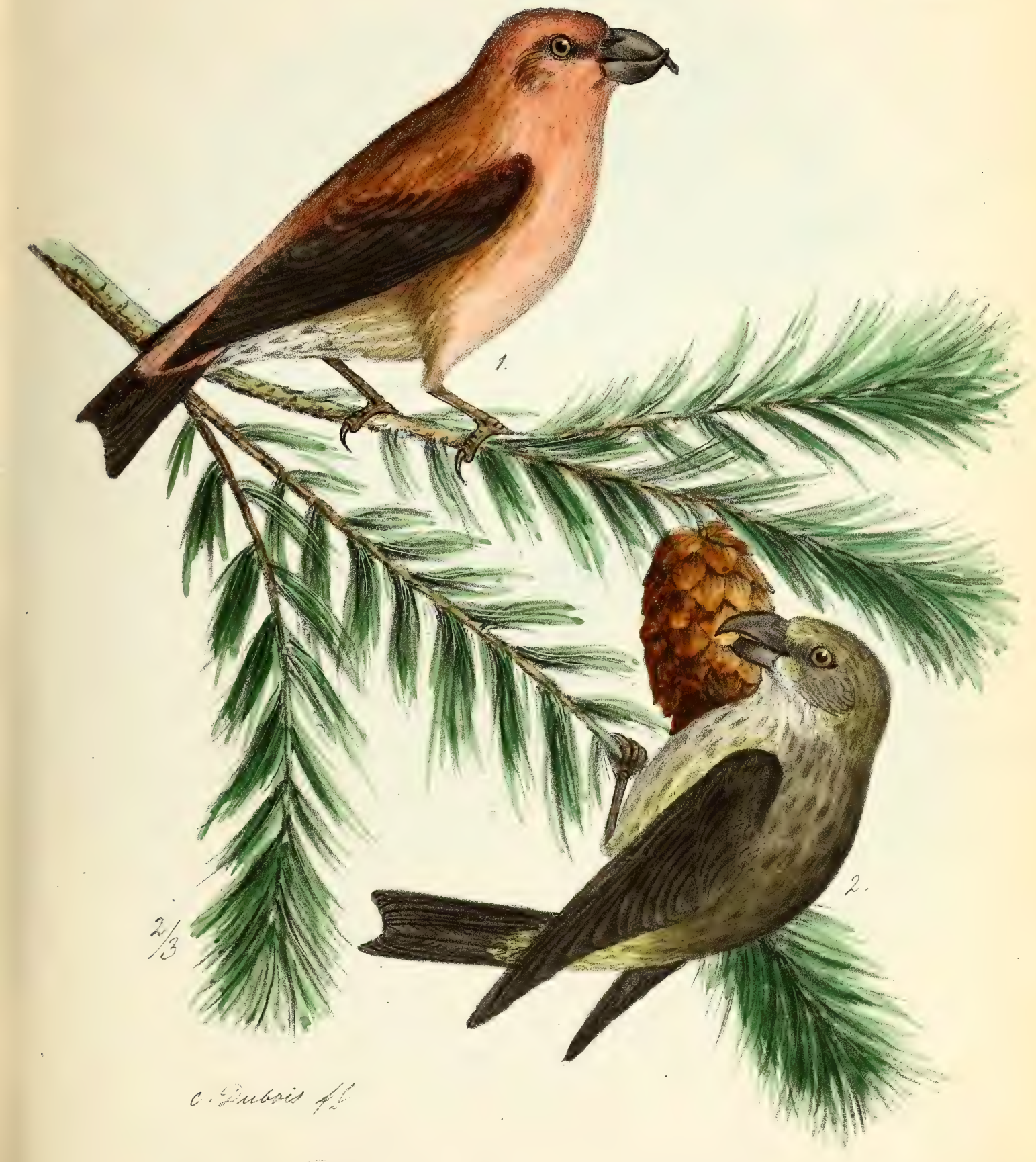

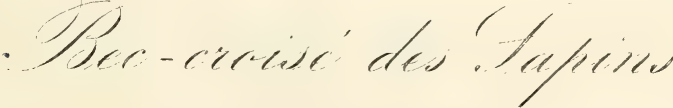

$$
\begin{aligned}
& \text { whith a jirrer }
\end{aligned}
$$





\title{
BEC-CROISÉ DES SAPINS.
}

\author{
CRUCIROSTRA PITYOPSITTACUS, вREHм.
}

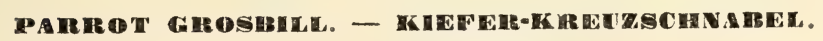

BeC-croisé PERrogueT. Temm., Man., t. I, p. 325. - Gould., Birds of Eur., pl. 201 - Naumann, t. IV, pl. 109. - Brehm., HandB., p. 241. - Schleg., Revue, p. 68. - Glog., Hande, p. 357. - Degl., Ornith., t. I, p. 179. - Bonap. et Schleg., Monogr. Lox., pl. I. Thienem., Fortp., pl. IX, fig. 14. - Meis. et Schinz., Vgl. Schweiz, n 68. - Mey., Vg. Liv.-U. Esthlands, p. 71. - Lamdb., VG. Wurtemberg, nº 84. - Glog., Fauna Schlesiens., no 124. v. Homey., Vg. Pommerns, no 138 . - Savi, Ornith. Toscana, t. II, p. 150. - Loxia pytiopsittacus, Bechs. - L. curvirostra major, Gml. - Curvirostra pytiopsittacus, Brehm. - Crucirostra pinetorum, Meyer. - C. pityopsittaci, C. subpityopsittacus. - C. brachyrhynchos et C. interCEDENS, Brehm.

Ces oiseaux habitent les régions du nord de l'Asie et de l'Europe, telles que la Norwége, la Suède, le Danemark, la Russie, la Pologne et différentes parties de l'Allemagne; ils paraissent aussi en petite volée aux IlesBritanniques, en France et en Hollande. En 1849, $\mathrm{M}^{\mathrm{r}}$ Croegaert, receveur à Anvers, m'a cédé un bec-croisé femelle qui avait été pris aux environs de cette ville. Ces oiseaux se trouvent autant dans les pays montagneux que dans les pays plats; mais ils se tiennent particulièrement dans les forêts de pins et de sapins. lls sont lourds et montrent peu de courage; lorsqu'ils se trouvent sur un pin qui a beaucoup de semences, ils ne le quittent pas même lorsqu'on tire après eux. Aussi peu d'autres oiseaux leur ressemblent-ils sous ce rapport Leur chant est assez agréable; le mâle le fait entendre non-seulement perché sur le sommet d'un arbre élevé dans le voisinage du nid, mais aussi dans les airs, en volant, d'un vol incertain, d'un arbre à un autre.

Ils nichent très-tôt, au mois de février et de mars, quelquefois même en janvier; ils bâtissent leurs nids assez haut sur les pins et les sapins, ordinairement vers la partie extérieure d'une branche, mais toujours de manière que les rameaux supérieurs les préservent en hiver de la neige qui tombe. Le nid, fait de rameaux durs de pin, de mousse, de lichens et de brins d'herbe, a ordinairement plus de profondeur qu'une demi-boule; tout ceci est si compacte et si bien cimenté que l'on se demande, en le voyant, comment un oiseau d'un aspect si grossier a pu faire cela avec son bec; dans l'intérieur du nid se trouvent de fins brins d'herbe et de lichens; il contient trois ou quatre oufs. 



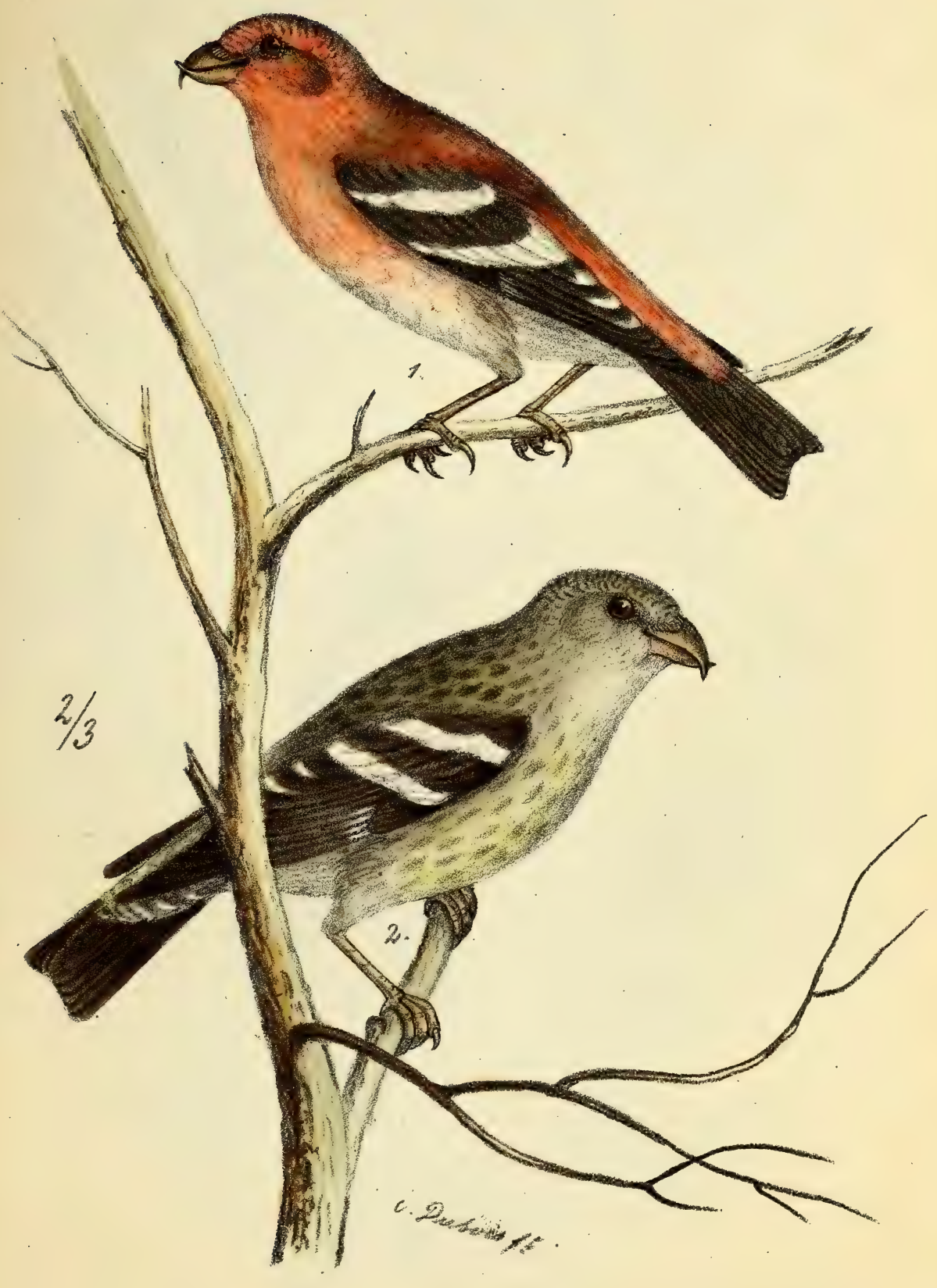

- Peccivisé a deux bandes.

$$
\text { 1. Hate. } 2 \text { jeune. }
$$





\title{
BEC-CROISÉ A DEUX BANDES.
}

\author{
CRUCIROSTRA BIFASCIATA, вREHм.
}

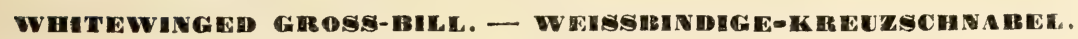

Temm., Man , t. III, p 243. - Brehm., HandB , p. 244. - - Glog., Handb., p. 354. - Gould., pl. 203. - Schleg., Revue, p. כ28. - Degl., Ornith., p. 180. - Bonap. et Schleg., Monogr. des loxiens, p. 8. - Bonap., Revue, no 282. - Glog., Fauni Schlesiens., no 122 . - SelysLongch., Faune belge, no 68. - Doubl., Brit. Birds, p. 14. - Loxia bifasciata, Nilsson. L. tenioptera, Glog - L. falgirostra, Lath. - L. Leugoptera, Gmel. - Crucirostra tae NIOPTERA, Brehm.

Cet oiseau si rare en Belgique habite le nord de l'Asie, mais on ne peut donner des notions certaines sur les contrées où on le rencontre; probablement se trouve-t-il en Sibérie et d'autres pays du Nord qui ne sont pas encore explorés. Il a déjà été pris en Russie, aux îles Britanniques, en Hollande et en Allemagne, dans la Silésie, en Saxe, dans la forêt Hercynienne, ainsi qu'en Belgique. Au mois de janvier de l'année 1827, une volée de becs-croisés s'abattit à Longchamps près de Liége, on en tua un mâle; vers la même époque on en prit aussi un près d'Anvers. Plusieurs années après, on en tua encore un près de cette dernière ville. En 1819, vers la fin de septembre, M. Isidore Bovie, de Louvain, remarqua une vollée assez nombreuse de ces oiseaux à un quart de lieue de cette ville; on en prit aussi trois mâles et une femelle dont un couple se trouve dans la belle collection de M. Bovie; les autres oiseaux sont restés dans ces environs pendant trois ou quatre semaines, mais le mauvais temps et d'autres circonstances ont empèché M. Bovie de pouvoir s'en procurer encore. Pendant leurs migrations, ces oiseaux cherchent leur nourriture dans les bois de pins et de sapins, et ils s'abattent ordinairement sur les plus hauts sommets des arbres. Le bec-croisé n'est pas farouche, et on le prend ou on le tue avec une grande facilité, ce dont on peut conclure que sa véritable patrie est une contrée où il est peu en rapport avec l'homme. Il se laisse aussi facilement prendre lorsqu'on imite son cri. Par leur vol, leur manière de grimper et de sautiller, ces oiseaux ont beaucoup de ressemblance avec les autres espèces du même genre. Le chant du mâle est varié et clair, même en captivité il chante beaucoup. Ils ne souffrent point la grande chaleur; aussi se baignent-ils très-souvent, quelques-uns même pendant les gelées plusieurs fois par jour, ce qui fail présumer qu'ils sont habituées à un climat rigoureux.

Quant à ce qui concerne leur propagation, on ne sait encore rien de positif.

Jusqu'à présent cet oiseau fut confondu avec le B. leucoptera de l'Amérique du Nord, mais ces différentes espèces ont été séparées en 1842 par notre savant naturaliste M. de Selys-Longchamps dans sa Faune belge; les deux copies ci-jointes ont été faites d'après les oiseaux de la collection de M. de Selys, qui eut la complaisance de me les env oyer pour l'achèvement de ce travail. 



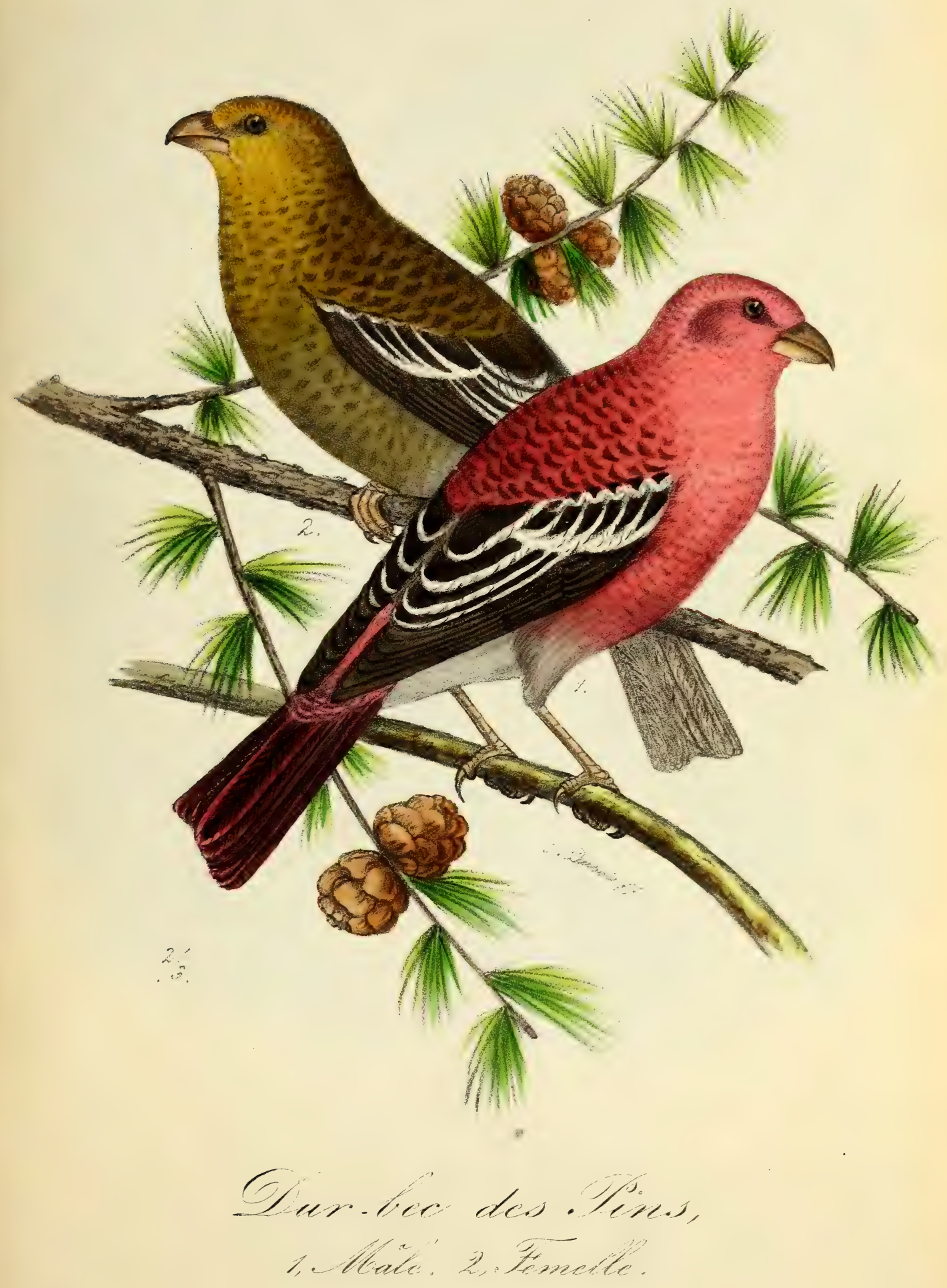



Cenre Durbec. - Corythms, Cuvier.

\section{UR-BEC DES PINS.}

CORYTHUS ENUCLEATOR, GUVIER.

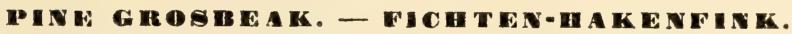

Buff., pl. enl. 135. - Cuvier, Reg. AN., t. I, p. 392. - Temm., t. I, p. 333. - Naumann, t. IV, pl. 110. - Gould, t. III. pl. 195. - Degl. t. I. p. 183. - Bonap. et Schleg., Mon. Loxiens.,

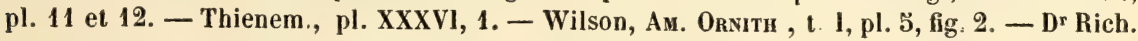
et Swain., Fauna bor. Am., p. 262, pl. 63. - Meyer, VG. Liv-u. Esthlands, p. 74. - Beseke, Vg. Kurlands, p. 76. - Selys-Longch., n 69. - Loxia enucleator, Linné. - L. PSittacea, Pall. - L. flamengo, Sparrm. - Rubicilla maxima canadensis, Edw. - Coccothraustes canadensis. Briss. - Fringllla enucleator, Meyer. - Strobllophaga enucleator, Vieill. - Pinicola enucleator, Cabanis. - Pyrrhula enucleator, Temm.

Habite l'Asie et l'Europe septentrionale, comme la Sibérie, la Laponie, la Norwége, la Suède; en hiver, il est de passage en Allemagne, aux Iles Britanniques et rarement en Belgique. Vers la fin de novembre 184. je reçus ici au marché un jeune mâle; cet oiseau est aussi abondant à la baie d'Hudson, au Canada et dans les contrées septentrionales des États-Unis. Les durs-becs vivent dans les bois de pins et de sapins ou dans les autres grandes forêts tranquilles, particulièrement là où il $\mathrm{y}$ a beaucoup de buissons de genévrier; ce sont des oiseaux très-sociables, ils se réunissent en grande volée pendant leurs migrations. Ils grimpent assez facilement sur les branches, presque aussi bien que les becs-croisés. Ce sont des oiseaux simples et sans malice; le danger leur est inconnu, aussi les tuet-on avec une grande facilité, car un coup de fusil même ne les effraye pas: ce qui fait qu'on les prend par milliers; en captivité, ils s'apprivoisent vite, mais ils ne souffrent point la chaleur d'une chambre. Les mâles sont des chanteurs très-assidus; leur chant est varié et changeant; ils le font entendre en partie bas et en partie haut, même en criant, et ont quelques tons ressemblant au chant de la grive-chanteuse et du tarin; les femelles chantent aussi.

Variétés accidentelles : blanc, blanchàtre ou taché de blanc.

Nourriture : semences de pins, de sapins, de larix, de hêtre, des baies de genévrier et des merises, même les noyaux durs de différentes baies, des semences et des bourgeons d'arbres.

Ils nichent au nord dans les bois de pins peu fréquentés; le nid se trouve à une hauteur de huit à quinze pieds; il est tout contre le tronc de l'arbre et couvert de branches épaisses; le nid se compose de branches de pin, et l'intérieur est bourré de brins d'herbe fine; il contient trois ou quatre œufs. 



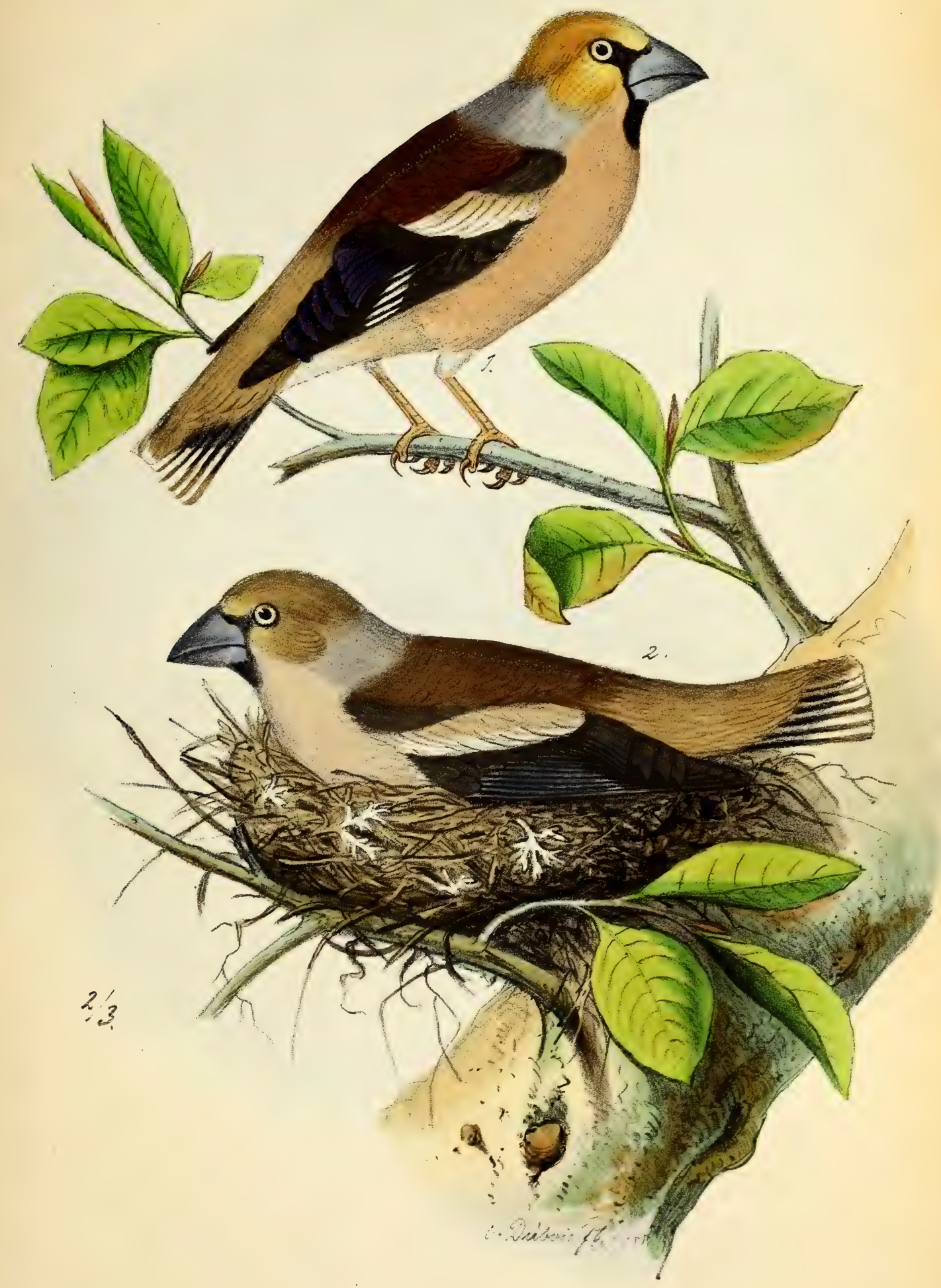

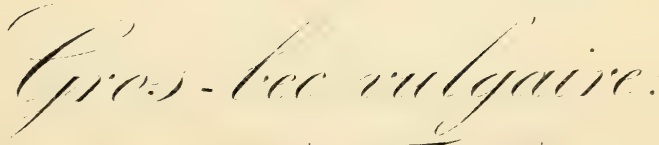

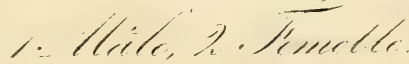



Geme Qros-bec. - Coccothorastes, Gesner.

\section{GROS-BEC V ULG A I RE.}

COCCOTHRAUSTES VULGARIS, GESNER.

HAWFUNCH, - KMRECR-K ERNBEISGER,

GROS-BEC. Buff., pl. enl. 99. - Temm., t. I, p. 344. - Gould., t. III, pl. 199. - Degl., t. I, p. 196. - Naumann, t. VI, pl. 114. - Schlegel, p. 6D. - Thienem., ForTP., pl. X, fig. 1. Savi, Ornith. Toscana, t. II, p. 139. - De Selys-Longch., Faune belge, n ${ }^{\circ} 66$. - Malh., Faune Sicile, p. 119. - v. d. Mühle, Vg. Grieghenlands, n 87 - Fringilla coccothraustes, III. loxia coccothraustes, Linné. - Coccothraustes deformis, Koch. - C. europeus, Selby. C. atrigularis, Megill. - C. simpliciter, Klein. - C. Flaviceps, sagoruir et Cerasorum, Brehm.

Cet oiseau habite toute l'Europe depuis le milieu de la Suède; en Belgique il n'est pas rare; on le trouve aussi dans la Sibérie méridionale et dans le Japon. Il se tient sur les lisières des bois, dans les vergers et en général dans tous les endroits fertiles, de préférence sur les hauts arbres bien épais; il vient peu à terre où il se montre du reste fort maladroit; cependant il est vif, surtout le mâle, au printemps; son cri d'appel ordinaire est un son aigu et criard ressemblant à ziks ou knips, son cri d'avertissement est zilk qu'il répète plusieurs fois de suite; son chant est entremêlé de ces tons; il le fait entendre parfois pendant des heures en faisant de continuels mouvements de corps. Le gros-bec est un oiseau prudent, rusé et farouche; il craint surtout l'homme et se tient toujours caché lorsqu'il est dans le voisinage de celui-ci; hormis le temps de la nitation, ces oiseaux vivent en société et en petites volées.

Variétés accidentelles : blanc, blanc grisâtre, blanc jaunâtre ou taché de blanc.

Cet oiseau est très-gourmand; il fend les cerises avec une dextérité remarquable pour arriver jusqu'au noyau, car il ne fait aucun cas de la chair de la cerise; aussi pour parvenir à sa nourriture favorite, fait-il de grands ravages aux cerisiers; il fait de même pour les raisins et autres petites baies; il mange aussi les faines et d'autres semences huileuses; au printemps il mange des pois, les bourgeons des arbres, des insectes et leurs larves; avec ces derniers il nourrit ses petits. Comme ces oiseaux causent beaucoup de dommages, on leur fait une guerre acharnée; mais comme ils sont très-farouches, on les attrape difficilement.

Ils nichent sur les arbres élevés, rarement sur les arbres fruitiers et sur de hauts buissons; le nid se trouve ordinairement à une hauteur de la terre de 8 à 30 pieds. Le nid est légèrement fait de branches sèches, de racines et de lichens; quelquefois ils y ajoutent un peu de mousse; tous ces matériaux sont tellement entrelacés avec ce qui entoure le nid qu’il est difficile de le prendre sans le détruire. L'intérieur est bourré de radicules et souvent de laine animale ou végétale; il contient quatre ou cinq oufs. 



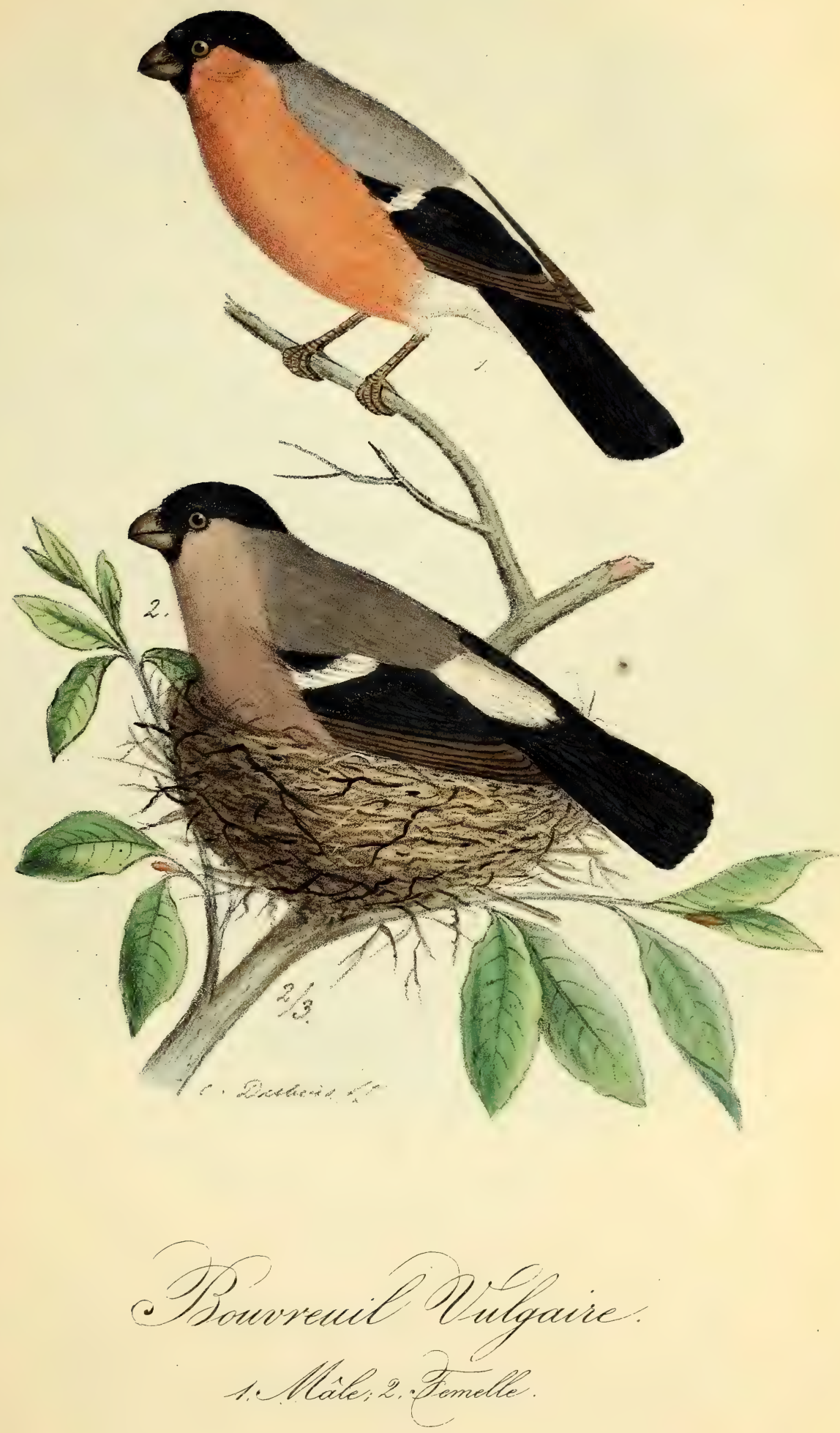



Genve Rourreadx. - Pyrmholes, Cuvier.

\title{
BOUVREUIL VULGAIRE.
}

\author{
PYRRHULA VULGARIS, тEMmincK.
}

COMMON BUELIINCM. CEMEINE-GMMERE.

Buff., t. IV, p. 372; - pl. enl. 146. - Temm., t. I, p. 338. - Gould, t. I, pl. 209. - Naum., t. IV, pl. 111. - Degl., t. I, p. 185. - Thienem., pl. IX, fig. 16. - Selys-Longch., Faune belge, no 70. - Mejer, Vg. Liv.-v. Esthlands, p. 18. - Savi, Ornith. Toscana, t. II, p. 142. - Malh., Faune Siglle, p. 128. - Loxia pyrrhula, Linné. - Fringilla pyrrhula, Meyer. - Pyrrhula europea, Vieill. - P. rubicilla, Pall. - P. rufa, Koch. - P. pileata, Macgill. - P. vulgaris Minor, Schleg. - P. GerManica, Brehm.

Ce bouvreuil habite l'Europe et quelques parties de l'Asie; cependant il est en plus grand nombre dans les pays du Nord, il n'est que de passage pendant ses migrations dans les pays chauds. Il aime particulièrement les endroits montueux, les forêts ayant des parties non boisées ou des groupes d'arbres; on le trouve aussi dans les jardins. Cet oiseau est confiant, doux et sociable; hors du temps des couvaisons, on le trouve en grande société, mais ordinairement les sexes sont séparés, surtout en automne où les vieux mâles émigrent ensemble. Les bouvreuils supportent bien le temps rigoureux, mais ils aiment beaucoup la liberté, car la perte de celle-ci les fait souvent mourir. Ils sautillent avec difficulté à terre, ils se pendent aux branches comme le tarin; leur cri d'appel, mélancolique et peu perçant, qui résonne comme din et finit accompagné par des sons plus doux, tels que but, but. Leur chant n'a rien d'agréable; mais pris jeunes ils apprennent non-seulement à contrefaire différents oiseaux, mais aussi à chanter des airs qu'on joue devant eux.

Variétés accidentelles : blanc ou blanc grisâtre, taché de blanc, quelquefois aussi tout noir, les ailes et la tête se distinguent seulement par un noir bleuâtre brillant.

Nourriture : semences de différentes plantes, particulièrement semences d'arbres et des bourgeons.

$\mathrm{Au}$ printemps, après l'accouplement, les couples vivent ensemble et se donnent, pendant la bâtisse du nid, des marques d'attachement et d'affection. Le nid se trouve ordinairement sur une branche en fourche de hêtre, de pin ou de sapin ou dans d'autres broussailles élevées à une hauteur de 8 à 20 pieds. Le nid est composé de fines branches de pin, de sapin, de bouleau et d'une masse de minces racines; à l'intérieur il est bourré de radicules et de lichens, quelquefois aussi d'un peu de laine ou de crins; il contient quatre ou cinq oeufs; ils font ordinairement deux couvées. 



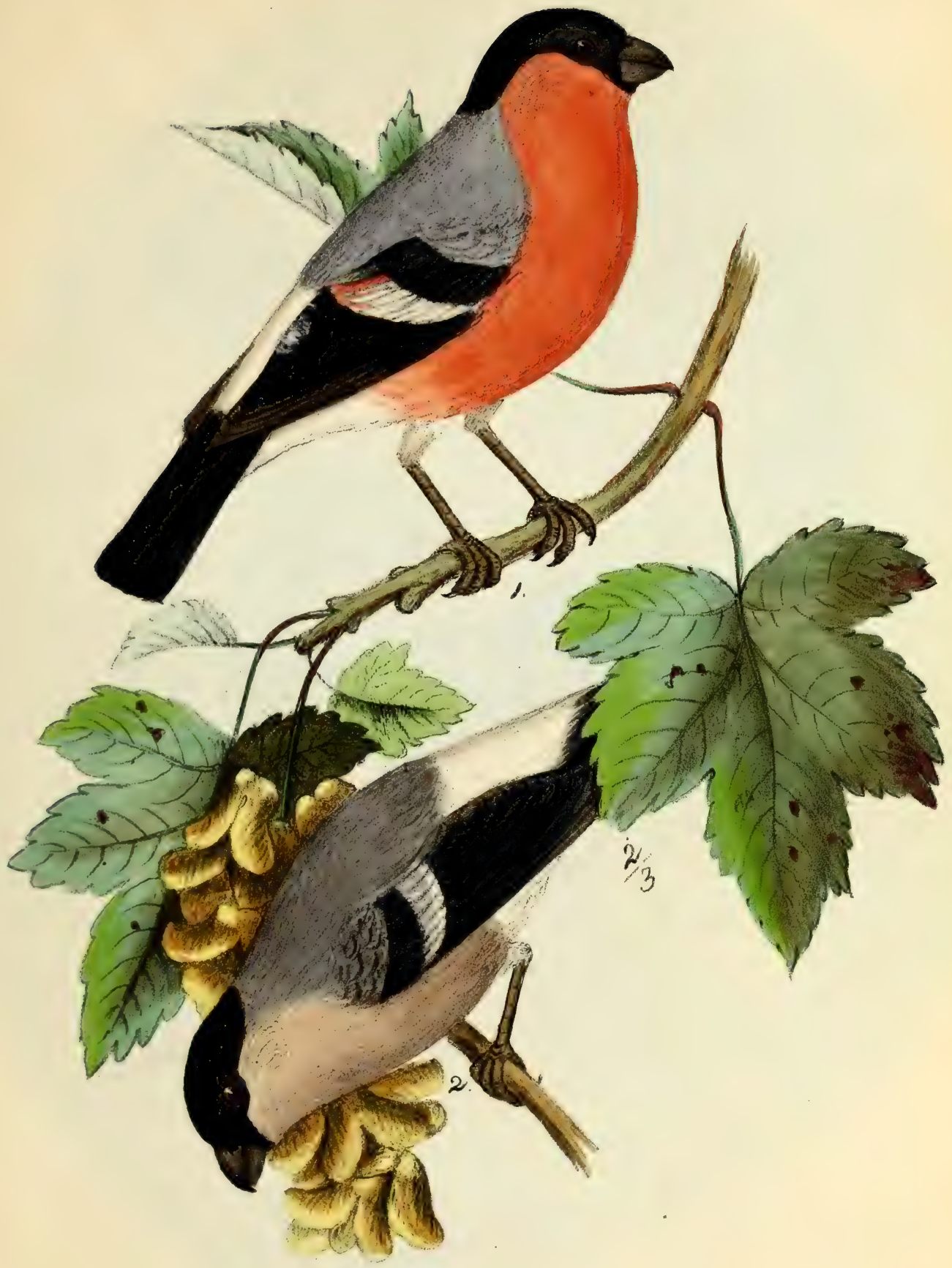

- Sourrenil icarlate 1. Alate. 2. Fomelle. 



\title{
BOUVREUIL ÉCARLATE.
}

\author{
PYRRHULA COCGINEA, NOBIS.
}

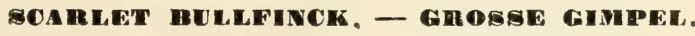

Sander, Naturf , t. XIII, p. 199. - Selys-Longch., Faune belge, no 71. - Guvier, Règne animal, t. I, p. 414. - Degl., I. I, p. 187. - Brehm, Handb., p. 452. - Bonap., Revue, p. 169. Schleg., Revue, p. 80. - Emberiza coccinea, Sander. - Pyrrhula major, Brehm.

Cet oiseau a beaucoup de rapports avec le jaseur garrule; on ne le voit que de temps en temps; souvent il reste plusieurs années sans faire d'apparition, puis il se montre en grand nombre. Ces bouvreuils ont leurs migrations périodiques, et se réunissent tantôt par petites, tantôt par grandes volées pour se mettre en route. On les a remarqué en Belgique pendant les années 1836, 1840, 1846, 1850; mais dans l'automne de $185 \%$, on en prit un si grand nombre que chez tous les marchands de gibier on pouvait les acheter à la douzaine. Notre savant naturaliste M. le baron SelysLonchamps a l'honneur d'être le premier qui, de nouveau, ait représenté cet oiseau dans sa Faune belge; d'autres naturalistes ont suivi son exemple.

Ce bouvreuil est connu depuis longtemps des oiseleurs, qui le désignent sous le nom de grand bouvreuil. Des naturalistes le confondaient aussi avec le bouvreuil vulgaire. bien que, par sa grosseur, il dût former une espèce à part et qu'on ne le voit jamais se joindre aux bouvreuils vul gaires quand ils s'assemblent pour leurs migrations périodiques. Le bou. vreuil écarlate se distingue par un rouge plus vif et par le plus grand développement de la tache blanche qui lui couvre le croupion.

L'espèce, selon toute apparence, appartient au nord de l'Europe; mais, comme elle a toujours été confondue avec le bouvreuil vulgaire, il n'est plus possible de lui assigner une patrie fixe. Peut-être parviendra-t-on à savoir quelque chose de plus précis à cet égard pendant que le présent ouvrage est en cours de publication. Dans ce cas, je pourrais y revenir. 



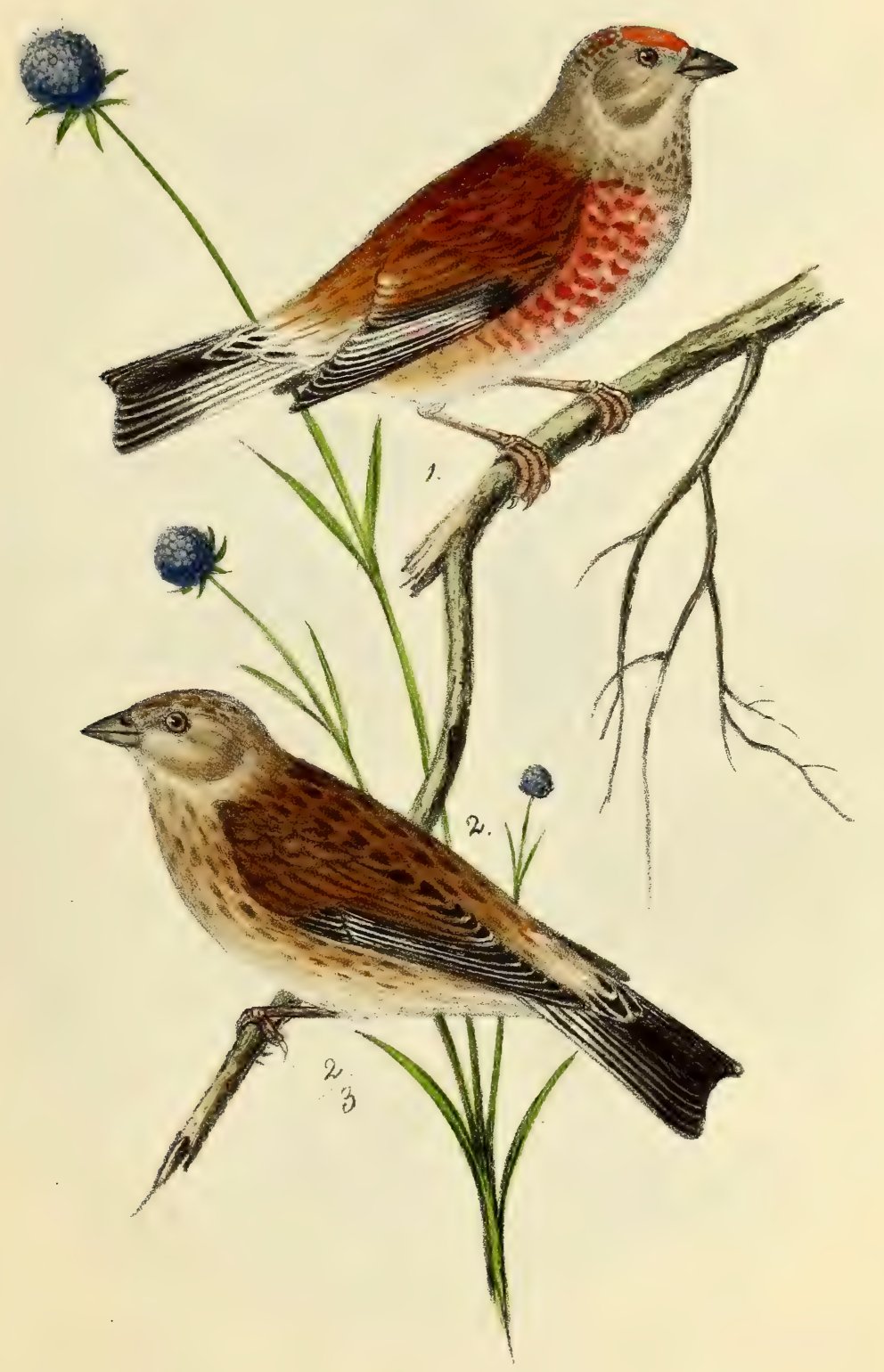

- Giverde riedivereiver

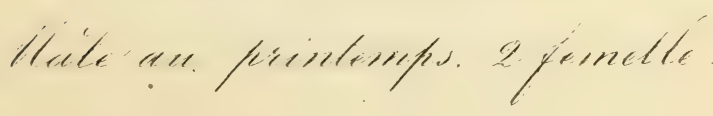





\section{I N 0 T T E 0 R D I N A I R E.}

LINOTA CANNABINA, ch. Bonaparte.

CONMON LINNET. - GEMEINE HÄNTLNG.

GRANDE LINOTTE. Buff., pl. enl., 151. - Temm.. t. I, p. 364. - Gould., t. III, pl. 19 I.

- Naum., t. V, pl. 121. - Ch. Bonap. et Schleg., Monog. des Loxiens, pl. 48. - Degl.,

t. I, p. 231. - Thienem., pl. X, fig. 9. - Faune Sicile, p. 125. - Ornith. Toscana, I. II, p. 128.

- Vg. Grieghenlands, no 81. -VG. Liv.-v. Esthlands, p. 86. - Vg. N.-0. Africa's, no 290.

- Ois. de l'Algérie, p. 14. - Fringilla cannabina, Linné. - F. linota, Gmelin. - Ligurinus gannabinus, Koch. - Carduelis gannabinus, Dumont. - Passer cannabina et papanerina, Pallas. - Cannabina linota, Gray. - C. arbustorum, Brehm. - C. sanguinea, Landheck.

Cet oiseau-ci habite toute l'Europe, à l'exception de l'extrême nord; on le trouve aussi dans l'Asie Mineure, dans le Liban, en Syrie, en Perse, en Egypte et en Nubie; il vit dans les lieux plats et les endroits montueux qui sont richement pourvus de buissons; il se trouve aussi dans les vignobles, dans les haies; pendant ses migrations en hiver, on le voit en petites ou en grandes volées. Ces oiseaux vivent par couples, et le mâle et la femelle montrent beaucoup de tendresse l'un pour l'autre; ils sont sociables, vifs, aussi adroits sur la terre que dans l'air, et ils exécutent parfaitement les changements de direction en plein vol; en volant ils font entendre un cri d'appel bref; ils sont très-prudents et surtout farouches. Le chant des linottes est agréable; aussi les classe-t-on parmi les oiseaux chanteurs les plus estimés; elles commencent à chanter en mars, et même déjà en février lorsque le temps est favorable, et continuent jusqu'à la fin de l'été; elles chantent particulièrement le matin, mais aussi vers le soir, en se posant sur l'extrémité d'un arbre ou d'un arbuste, souvent aussi envolant. Pris jeunes, on peut apprendre à cet oiseau à imiter différentes mélodies.

Variétés accidentelles : blanc, blanc jaunâtre, taché de blanc. En chambre ils changent, en noir ou en jaune, le rouge de la poitrine et de la tête.

Nourriture : semences, différentes petites plantes et particulièrement des graines de millet, de lin, de rabette et de chènevis.

Ces oiseaux nichent vers la fin de mars ou au commencement d'avril dans les broussailles, les tas de fagots, dans les genêts et les bruyères; même dans les jardins, dans les buissons de groseilliers et dans les berceaux de verdure; quelquefois aussi sur un arbre jusqu'à une hauteur de vingt pieds. Le nid est fait de brins d'herbe, de radicules et de mousse, quelquefois ils y ajoutent un peu de bruyère; en dedans, ils le bourrent avec de la laine de mouton, des poils de vache et des crins, quelquefois aussi avec des plumes; ils y mettent cinq ou six œufs et font chaque année deux ou trois couvées. 



$$
\text { S }
$$





\section{LINOTTE DE MONTAGNE.}

LINOTA MONTIUM, CH. BONAPARTE.

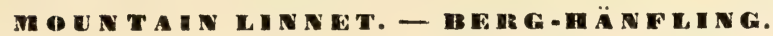

Temm., t. I, p. 368. - Naumann, t. V, pl. 122. - Gould, t. III, pl. 194. - Schleg , p. 62. Degl, t. I, p. 233. - Bonap. et Schleg.. Mon. Loxiens., pl. 50. - Thienem, Fortp., pl. X, fig. 10. - Selys-Longch., Faune belge, no 60. - Canabina montium et flavirostris, Brehm. - L. montium, Leach.-L. palustris, Landbeck. - Linaria montana, Briss.-Fringllla montium, Gmel. - F. flavirostris, Linné. - Carduelis montiun, Dumont. - Acanthis montium, Blyth.

Cette linotte habite en été les parties septentrionales de l'Asie et de l'Europe, telles que la Sibérie, la Russie, la Laponie, la Norwége, la Suède et l'Écosse, où elle vit sur les montagnes arides ou sur les rochers dénués d'arbres et couverts de broussailles qui croissent entre les masses de pierres ou des quartiers de rochers; c'est dans ces places arides que se trouve en été la linotte de montagne; en automne elle paraît dans des parties plus basses et enfin elle vient dans les plaines. La linotte, en émigrant des contrées septentrionales, vient en Allemagne, en Hollande, en Italie, en France et en Belgique, où certaines années on la rencontre en abondance. Cet oiseau est extrêmement vif, prudent et adroit; il vit en société même avec d'autres espèces de cette lamille d'oiscaux. Le chant n'en est, de loin, pas aussi agréable que celui de la linotte ordinaire, quoique le mâle chante beaucoup étant posé sur une pierre ou sur des broussailles.

Nourriture : les semences de beaucoup de plantes sauvages, ainsi que de millet, de lin et de chènevis.

Ils nichent au nord dans les parties sauvages, inhabitées et pierreuses, sur la terre, dans des broussailles peu élevées; le nid est bâti solidement et avec art; il est composé de quelques tiges de plantes, de radicules, de mousse et de lichens; tout cela est recouvert de filage d'insectes; l'intérieur en est doublé de duvet de plantes, particulièrement de laine d'osier; il contient de quatre à six oufs. 


denre Pinson. - Froingillas, Linné.

\section{PIN S O N O R D INAIRE.}

FRINGILLA COELEBS, LINNE

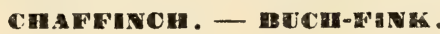

PINSON. Buff, pl. enl. 54. - Brisson, t. III. p. 148. - Temm., t. I, p. 357. - Naumann, 1. V, pl. 118. - Gould, t. III, pl. 187. - Degl., t. I, p 216. - Thienem., FortP., pl. X, fig. 7. v. d. Mühle, Vg. Griechenlands, $n^{\circ}$ 8ö. - Malh., Ors. d'Algérie, p. 14. - Fringilla sylvia? F. Coelebs, Scopoli, Annus, $n^{0} 217$, p. 147. - F. nobilis, Schranck. - F. hortensis et sylvesrris, Brehm. - Passer spiza, Pallas. - Struthus coelebs, Bojé.

Cet oiseau est répandu dans toute l'Europe et se trouve en Sibérie et dans l'Afrique méridionale. Il vit dans les jardins, dans les vergers, dans les allées ou d'autres groupes d'arbres, même au milieu des villes, où ils restent pendant tout l'été. Le pinson est au nombre des chanteurs les plus connus; au printemps il doit toujours étudier son chant et ne parvient à le savoir qu'après quelques efforts; le chant de cet oiseau diffère beaucoup de l'un à l'autre, aussi sert-il aux amateurs pour désigner les différentes espèces. En Belgique il y a beaucoup d'amateurs de pinsons, ils forment des sociétés qui décernent des prix pour les oiseaux qui chantent le mieux; par exemple à Grammont on a donné un premier prix pour un pinson qui répète en une heure $\mathbf{6 2 1}$ fois son chant, le second prix pour celui qui le répète כૅ 58 fois, le troisième prix pour celui qui le répète $\check{4} 48$ fois; en un mot l'ardeur de ces pauvres oiseaux dans la lutte est si grande qu'ils tombent parfois morts de fatigue. Quelques amateurs ont encore la cruelle habitude de les priver de la vue, afin que rien ne les puisse distraire en chantant. Le pinson ordinaire nous quitte vers la fin d'octobre en grandes volése; les femelles partent entre elles et plus tôt que les mâles; ils émigrent en Afrique. Au commencement de mars les femelles reviennent une quinzaine de jours après les mâles; jendant les hivers doux il en reste beaucoup ici. Ce sont des oiseaux peu sociables, et pendant le temps de l'accouplement ils sont très-jaloux : lorsqu'un mâle paraît dans un endroit yu'un de ces oiseaux s'est choisi, celui-ci le poursuit avec une colère aveugle qui est souvent cause de la perte de leur liberté et les fait facilement tomber entre les mains des oiseleurs. Ils montrent beaucoup de tendresse pour leurs femelles, et dans le temps de l'accouplement ils voltigent autour d'elles avec un vol tantôt tremblant, tantôt folâtre, ou bien ils sautillent autour d'elles en prenant des poses affectées et bizarres.

Variétés accidentelles : blanc, blanc-jaunâtre, taché de blanc, ou toutes les couleurs moins vives.

Leur nourriture est composée d'insectes, de semences, de faînes, de chanvre, de navets, de lin, de salade et de beaucoup d'autres plantes.

Ils nichent vers la fin d'avril, la plupart sur les arbres dans les forèts, dans les vergers et dans les jardins; le nid est ordinairement posé au milieu d'une branche fourchue ou sur une branche horizontale; il est fait avec art, et composé de mousse, de foin, d'herbes ou de radicules ; l'extérieur est couvert de lichens qui sont unis par du filage d'insecte; l'intérieur en est bourré de laine, de plumes et de crins; ils y posent cinq et six oufs et font deux couvées. 



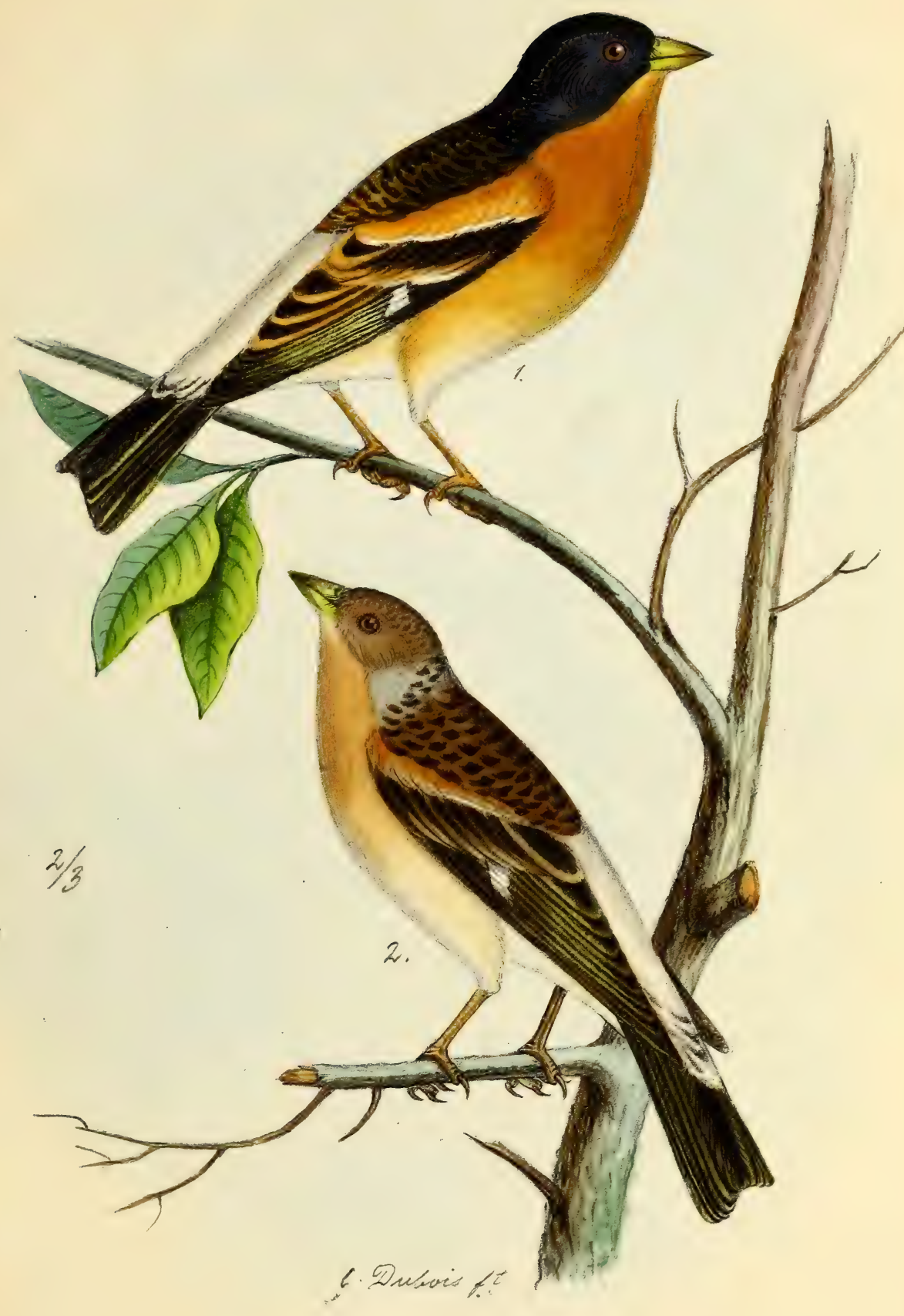

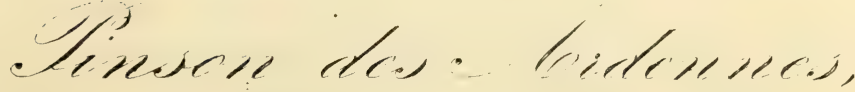

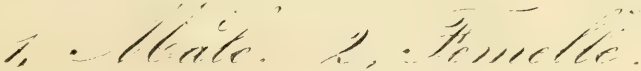





\title{
PINSON DES ARDENNES.
}

\author{
FRINGILLA MONTIFRINGILLA, LINNÉ.
}

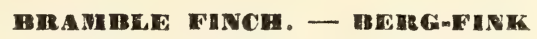

PINSON DES ARDENNes. Buff, pl. enl. 54. - Temm., t. I, p. 360. - Gould, t. III, pl. 188. - Degl., t. I, p. 219 - Naum., t. V, p. 119. - Schleg., p. 61. - Thien., FortP., pl. X, f. 9. - Savi, Ornith. Toscana, t. II, p. 113. - De Selys-Longch, Faune Belge, no 62. - Malh., Faune Sicile, p. 124 - v. d. Mühle, Vg. Griechenlands, no 86. - Fring: lla flammea, Beseke.

- F. lulensis, Linné. - F. septentrionalis, Brehm. - Struthus montifringilia, Boje.

Habite l'Asie et l'Europe septentrionale, ainsi que les forêts de hêtres, de pins et de sapins de la Norwége, de la Finlande, de la Laponie, de la Russie et de la Sibérie; vers la fin du mois d'août, ces oiseaux se rassemblent en grandes troupes pour émigrer; ils viennent alors aux mois d'octobre et de novembre en Allemagne, aux Iles Britanniques, en Hollande, en Belgique et en France. La volée est quelquefois si grande qu'elle forme comme un nuage long et épais; au mois d'avril, ils retournent dans les pays froids, mais en plus petite volée, car le nombre de ces oiseaux s'est amoindri par la captivité et d'autres circonstances. Ces pinsons passent la nuit rassemblés sur un ou sur plusieurs arbres; ils ne sont ni prudents, ni adroits, ni artificieux, mais en société ils prennent beaucoup d'attachement les uns pour les autres; ils vivent aussi en bonne harmonie avec les moineaux, les linottes, les bruants, etc., etc., et paraissent quelquefois avec ceux-ci dans les fermes, mais seulement par un froid rigoureux. En captivité ils deviennent méchants, se disputent la nourriture, et se mordent entre eux, ainsi que les autres oiseaux.

Le chant de ces pinsons est mauvais et criard, il a beaucoup de ressemblance avec celui du pinson ordinaire, quoiqu'il soit moins pur et mélodieux que le chant de ce dernier.

Les variétés accidentelles de ces oiseaux sont le blanc, blanc taché, ou toutes les couleurs blanchâtres.

Le pinson des Ardennes niche, particulièrement dans le Nord, sur les pins et les sapins; son nid a aussi beaucoup de ressemblance avec celui du pinson ordinaire; il est composé de brins d'herbe, de mousse et de lichens; l'intérieur en est mollement bourré de plumes, de poils de renne, de filaments d'osier et de chardons; il contient de cinq à sept oufs. 


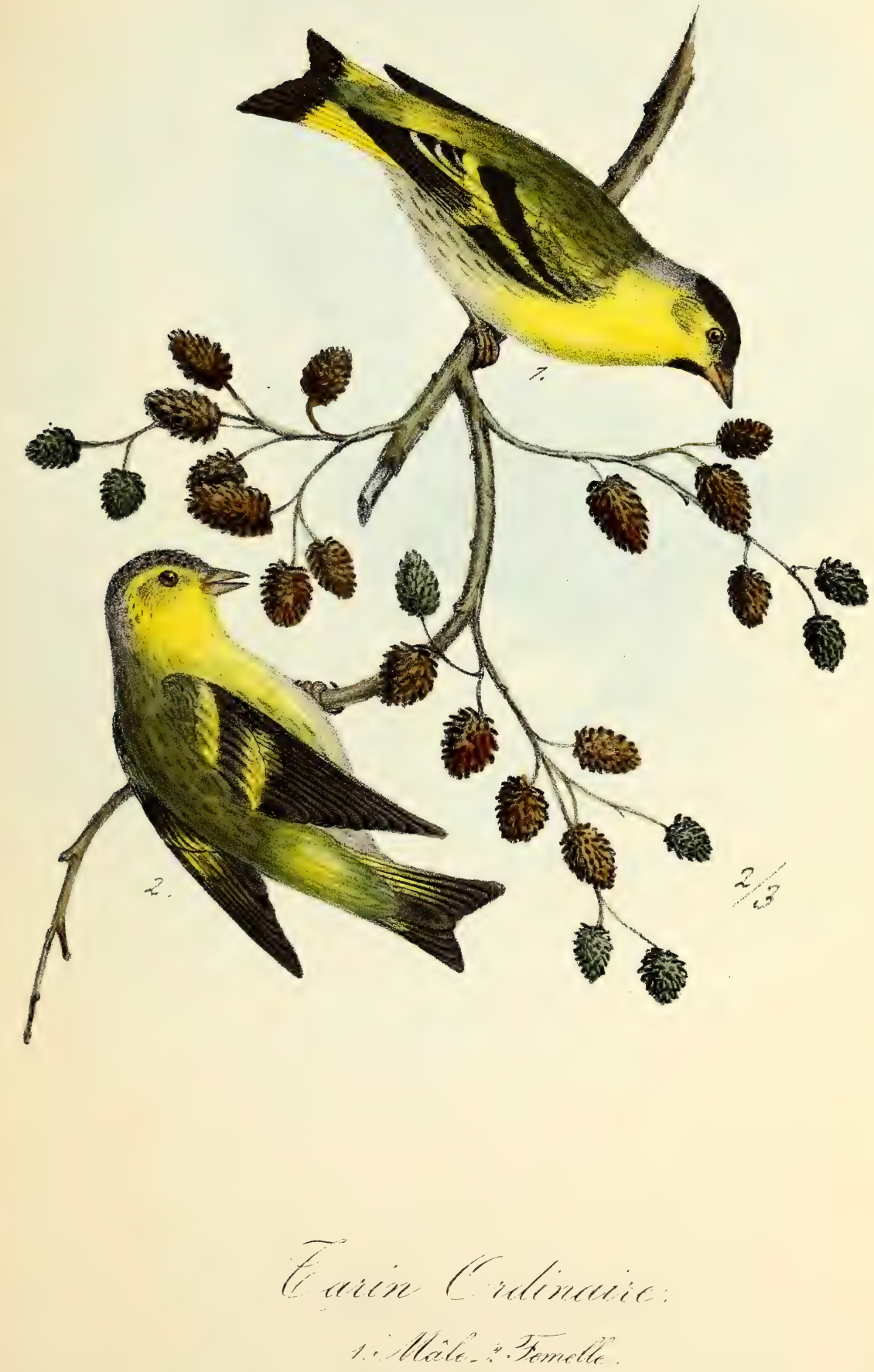

Cenme Tamin. - Camalocelis, Cuvier.

T A R I N O R D I N A I R E.

CARDUELIS SPINUS, STEPHENS.

COM MON SISKIN. - EREN-ZEIGIG.

TARIN. Buff., t. IV, p. 221 ; pl. enl. 485. - Temm., t. I, p. 371. - Degland, t. I, p. 227. Naumann, t. V, pl. 125. - Brehm, p 284. - Gould., t. III, pl. 197. - Thienem., FortP., pl. X, fig. 12. - Malh., Faune Sicile, p. 126. - De Selys-Longch., Faune belge, n ${ }^{\circ}$ 56. - Meyer, Vg. Liv.-u. Esthlands, p. 88. - Fringilla spinus, Linné. - Passer spinus, Pall. - Linaria spinus, Leach. - Cirrsomitris spinus, Bojé. - Spinus viridis, Koch. - S. alnorum, nedius et Betulanus, Brehm.

Cet oiseau si connu habite pendant l'été, l'Écosse, la Suède, la Norwége et le nord de l'Allemagne; en automne il se répand dans toutes les contrées de l'Europe, tantôt en abondance, tantôt plus rarement; ils s'assemblent par petites volées et vont partout où ils trouvent des semences de pin, de bouleau et d'aune; ils se posent volontiers sur le sommet des plus hauts arbres.

Ce tarin est un oiseau inoffensif; il est peu farouche et se familiarise avec l'homme; aussi parait-il dans les jardins, au milieu des villes et des villages, où l'on peut les prendre en les touchant avec de longs bâtons enduits de glu. Au commencement du printemps, le mâle fait déjà entendre son chant joyeux et trainant, commençant par son cri d'appel di, die, dei, deidel, didlei, et contenant des tons grésillants; il finit ordinairement par un long didelhei, doeh. En chantant ils sont ordinairement en mouvement; lorsqu'ils restent à la même place ils balancent le corps; ils volent aussi en chantant dans les airs. En captivité ils sont fort agréables et montrent beaucoup de tendresse pour leurs maitres qu'ils accueillent en les voyant venir, par des mouvements joyeux, en ouvrant les ailes et en faisant entendre leur phrase favorite : die, dielei; pendant presque toute l'année ils font entendre ce chant peu agréable.

Nourriture : particulièrement des semences de l'aune et du bouleau; ils mangent cependant aussi toutes les autres semences huileuses; au printemps ils consomment aussi de petits insectes.

Les tarins ordinaires nichent souvent dans le voisinage de l'eau et particulièrement haut sur les pins et les sapins, ordinairement en se cachant. Le nid est composé de mousse, de radicules et de lichens qui sont cimentés avec de la toile d'araignée; à l'intérieur se trouvent de la laine d'osîer ou d'animal et quelques plumes; il contient cinq ou six oeufs. 



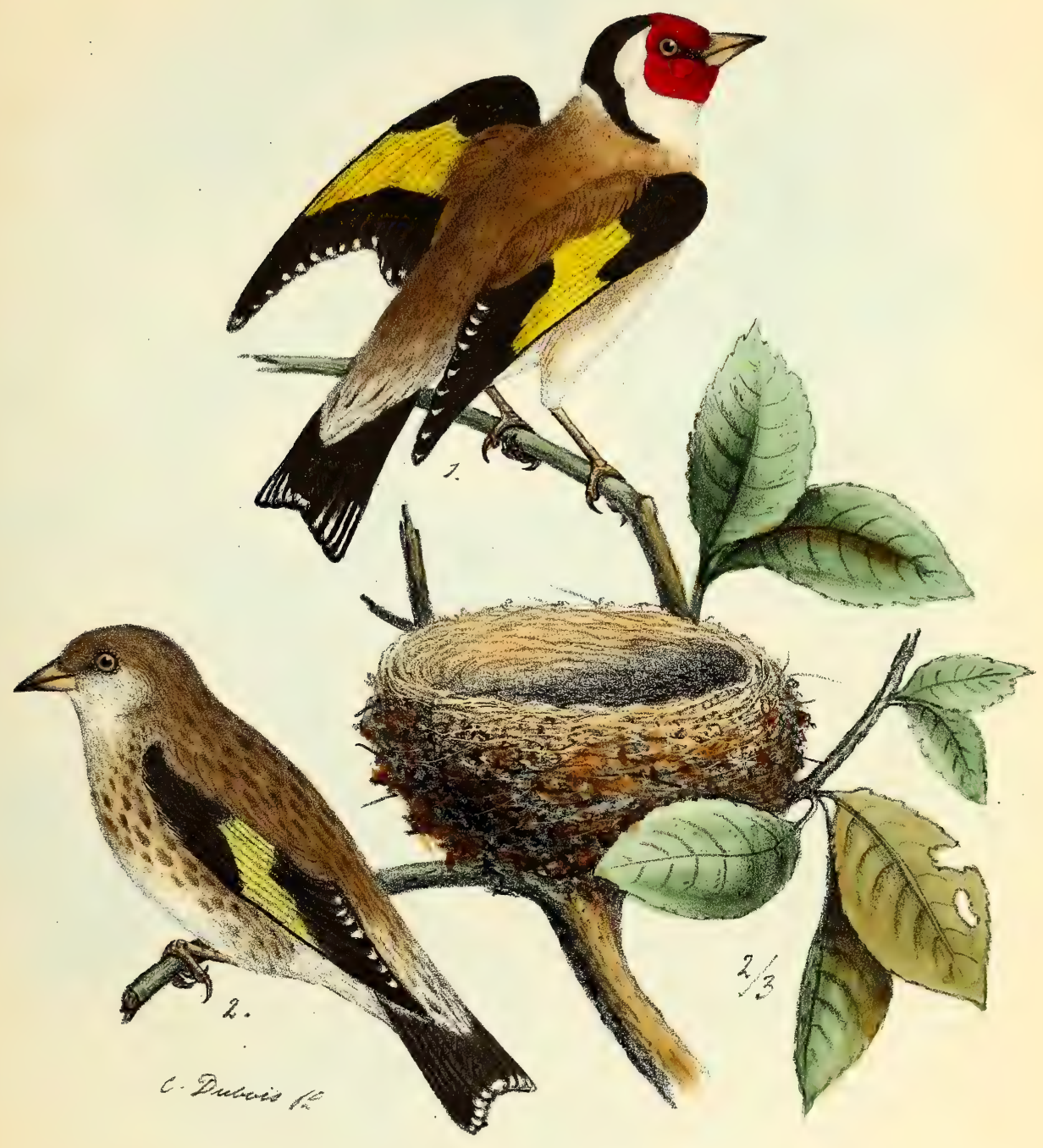

\footnotetext{
Savin Cofardonneref, 1 lacite 2 Teune.
} 



\title{
TARIN CHARDON NERET.
}

\author{
CARDUELIS ELEGANS, STEPHENS.
}

GOLDEINCH. - DISTEL-ZEIEIG.

ChaRdonneret. Buff., t. IV, p. 187; pl. enl. 4. - Temm., t. I, p. 376. - Gould, t. III, pl. 196. - Naum., t. V, pl. 124. - Degl., t. I, p. 225. - Thienem, pl. X, fig. 13. - SelysLongchamps, Faune belge, no כొ. - Savi, Ornith. Toscana, t. II, p. 117. - Malh., Fauke Sicile, p. 127. - v. d. Mühle, V. Griechenlands, n 79. - Malh., OIS. de L'Algérie, p. 14. - Rüpp., Vg. N. 0. Afrika's, no 3̃̃6. - Fringilla carduelis, Linné. - F. ochracea, Gml. - Passer carduelis, Pallas. - Spinus carduelis, Koch. - Acanthis Carduelis, Keys. et Blas. - Carduelis auratus, Eyton. - C. europoeus, Swains. - C. Germanicus et Septentrionalis, Brehm.

Habite, outre l'Europe, la Sibérie occidentale, l'Asie Mineure, la Syrie et la Perse; le nord de l'Afrique et les îles Canaries. Il vit de préférence dans les endroits fertiles et pourvus d'eau; aussi le trouve-t-on souvent dans les plaines ayant de grands courants d'eau; il aime aussi les vergers et surtout ceux dans lesquels se trouvent les pruniers lorsque leã environs ne sont point dépourvus d'arbres ou d'arbustes. Il se tient ordinairement haut sur les arbres; il est prudent, artificieux, très-vif et toujours en mouvement; son cri d'appel est sticklitt, pickelnick, mais en volant il fait entendre pick, pick, pickelnick. Pendant l'automne et le printemps ils vont par troupes de vingt à cinquante, et paraissent alors dans les pâturages et dans les champs pour y trouver des chardons et des glouterons. En captivité il se montre très-intelligent, et l'on peut lui apprendre plusieurs tours, tels que faire la sentinelle, tirer un petit canon, se laisser pendre par les jambes, etc., etc.

Le mais, les semences de chardons, de glouterons et de bluets forment leur nourriture favorite.

Ils nichent sur les arbres ou arbustes élevés, rarement en dessous de la hauteur d'un homme; le nid, qui est fort gracieux et gentil, consiste en brins d'herbe, fins et flexibles, en radicules, mousse et en lichens, tout cela est cimenté par des toiles d'araignées; l'intérieur est bourré de laine d'animaux et de bourre de plantes; il s'y trouve quatre ou cinq œufs; ces oiseaux font ordinairement deux pontes. 



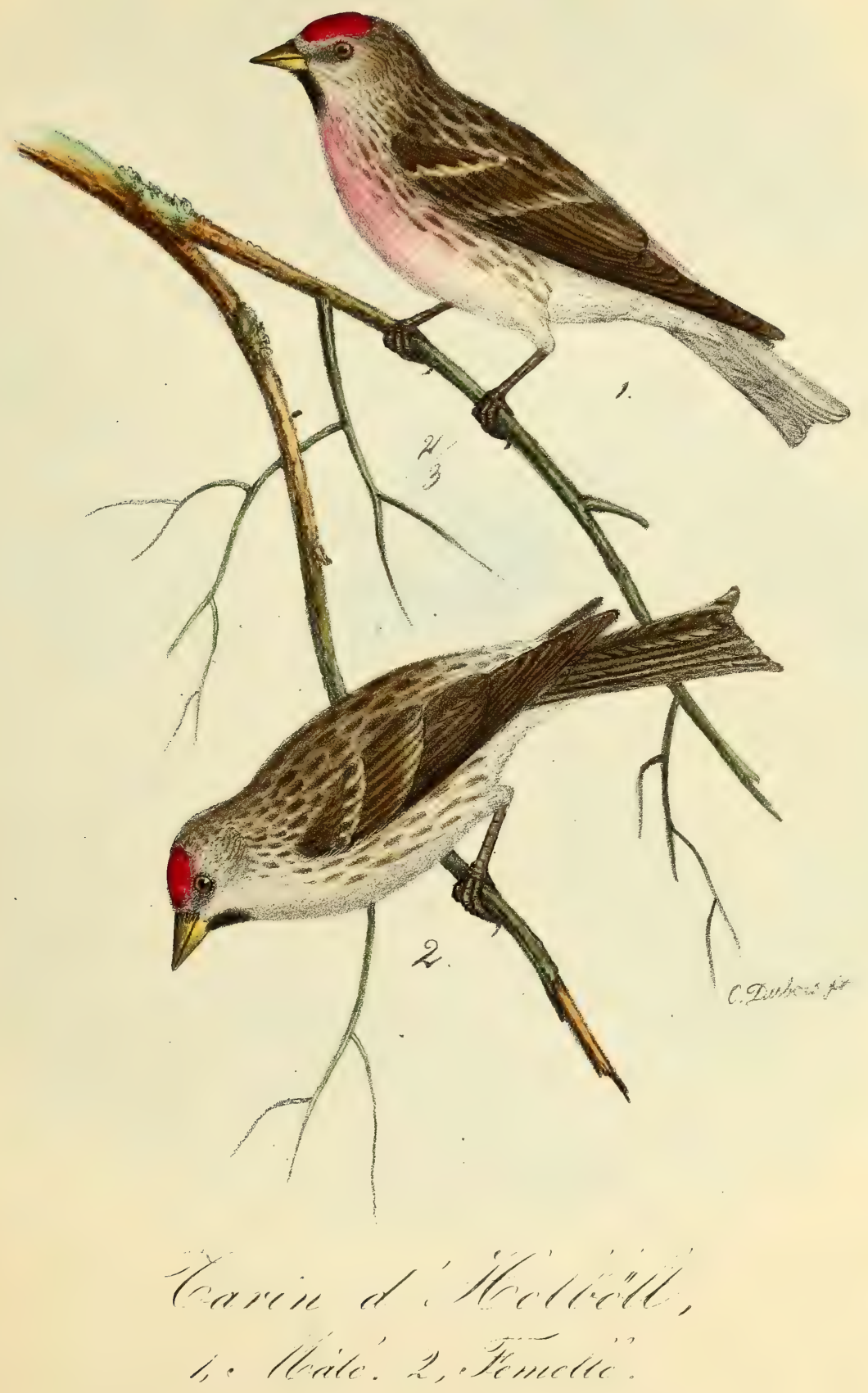





\section{T A R I N D'II 0 L B Ö L L.}

CARDUELIS HOLBOELLII, DUBOIS.

HOLB̈̈r. SI:

Brehm, Hande., p. 28. - Ch. L. Bonap. et Schleg., Moxogr. Lox., pl. 53. - Ch. L. Bonap., Revue critique, p. 172, no 293. - De Selys-Longch., Faune beige, n* 59. - Fringilla Holboeldi et linaria Holboelli, Brehm. - Acanthis Holbolli, Bonap. - Aglothus Holboflli, Cabanis.

Ce tarin est très-rare, et l'on n'a que des notions très-vagues sur lui; on ignore quelle est sa véritable patrie; on sait seulement qu'il vient du Nord et qu'il parait en Allemagne et en Belgique. On ne connait rien de la manière de vivre et de la propagation de ces oiseaux; cela ne diffère probablement pas des autres espèces du même genre. Si plus tard on apprend quelque chose de plus certain sur ce tarin, je le communiquerai à la fin de cet ouvrage. Le tarin d'Holbôll se distingue des autres par le corps et le bec qui sont plus forts et les ailes plus longues.

Beaucoup de naturalistes ont fait un genre particulier de ce tarin, ainsi que des deux suivants que nous décrivons ici; mais nous ne pouvons admettre cette distinction, attendu que ces tarins ne differrent en rien, sinon par la couleur du plumage, des autres tarins dont ils ont le caractère du bec, les habitudes, la nourriture et les instincts de propagation.

Ces deux oiseaux se trouvent dans la collection de M. le baron de Selys-Longchamps; aussi je ne puis assez remercier ce savant naturaliste, au nom de la science, pour l'extrême complaisance avec laquelle il a mis à ma disposition toute la collection qu'il possède de ces oiseaux; ce qui m’a permis de rendre aussi fidèlement les figures ci-jointes. 



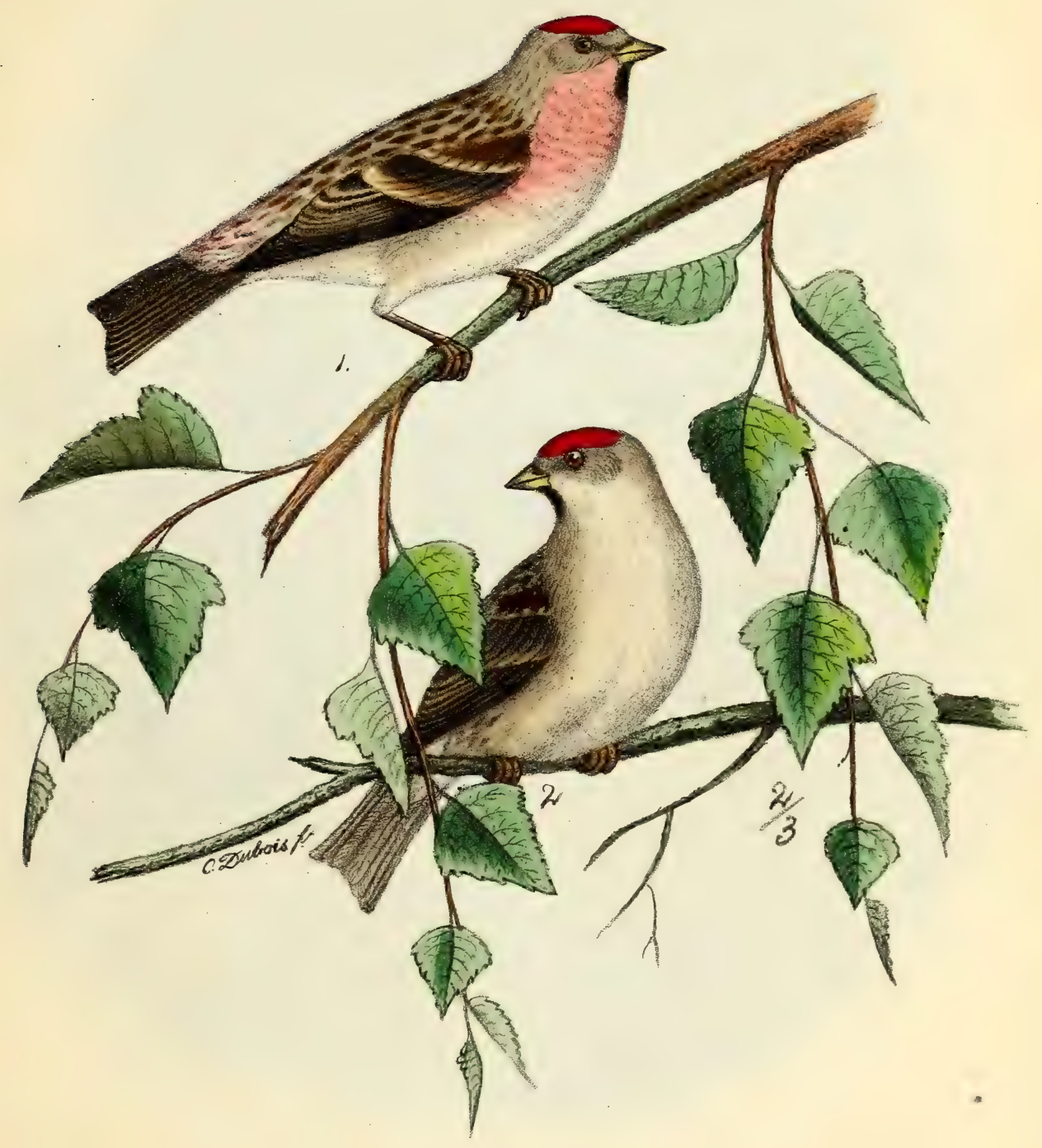

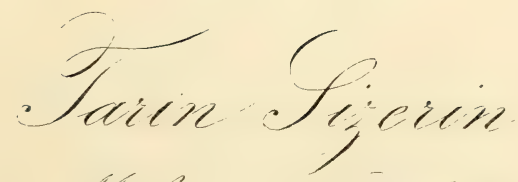

$$
\begin{aligned}
& \text { 1. Naile, } 2 \text { Enrndels? }
\end{aligned}
$$





\section{T A R I N S I Z E R I N.}

CARDUELIS LINARIA, RISSo.

CRSAEIR SISKIN. - IIIKEN-ZEISIC.

SIzERIN. Buff., t. IV, p. 216. - Buff., pl. enl. 151. - Temm., t. I, p. 573. - Naum., t. V, pl. 126. - Gould, t. III, pl. 194. - Ch. L. Bonap. et Schleg., Monogr. Lox., pl. 52. - Degl., I. I, p. 237. - Thien., Forte., pl. X, fig. 14. - Selys-Longch., Faune Belge,no 57. - v. d. Mühle, Vg. Griechenland, no 80. - Holbóli, Ornith. Groengand, p. 30. - Wilson, Amerigan Ornith., t. IV, pl. 30, fig. 4. - Audubon, t. III, pl. 178. - Rüp., Vg. N.-0. Afrika's, no 290.Passer linaria, Pall. - Fringilla linaria, Linné. - F. borealis, Temm.-Spinus linaria, Koch. - Llnaria rubra minor, Briss. - L. borealis, Vieill. - L. alnorum, Brehm. - Linota linaria, Bonap. - Acanthis linaria, Key. et Blas. - Egiothus linarius, Nob.

Cet oiseau habite, en été, la Norwége, la Laponie, la Finlande, les îles Foeroë, l'Islande, la Russie, la Sibérie, le Japon, le Groenland, le Labrador et le Canada; dans les hivers très-rigoureux, il parait jusqu'en Pensylvanie; on le voit en novembre et en décembre en Allemagne, en Hollande, en Belgique et en France dans les endroits où il trouve le plus de nourriture; ce qui fait qu'ils ne paraissent pas aussi abondamment d'un côté que de l'autre; certaines années on les rencontre dans une contrée par grandes volées, tandis que dans d'autres ils ne viennent qu'en petite quantité ou pas du tout. Aux mois de mars et d'avril ils retournent vers le Nord; quelques couples restent parfois aux Iles Britanniques et en Allemagne, particulièrement en Bohême. Ce sont des oiseaux très-sociables, qui se mêlent souvent aux volées du tarin ordinaire; leurs migrations se font ordinairement pendant le crépuscule du matin, mais aussi pendant le jour, le plus souvent très-haut dans les airs. Le tarin sizerin habite particulièrement dans les forêts de bouleaux et d'aunes; il se hasarde aussi dans les campagnes s'il aperçoit seulement quelques buissons. Son chant est le plus mauvais de tout le genre.

Variétés accidentelles : d'un blanc pur avec le front rouge, quelquefois aussi avec la poitrine rouge; souvent il est taché de blanc et a le front rouge.

Leur nourriture favorite consiste en semences d'aunes et de bouleaux; pour les prendre ils se suspendent aux branches les plus délicates et y grimpent de toutes les façons; ils mangent aussi d'autres graines huileuses, mais rarement de petits insectes.

Les tarins nichent dans le Nord, sur les arbres ou les buissons peu élevés, où l'on trouve leur nid vers la mi-juin; ce nid se compose d'herbes sèches, de bruyères et de radicules; l'intérieur en est bourré de laine d'osier ou de plumes; il contient trois ou quatre oufs. 



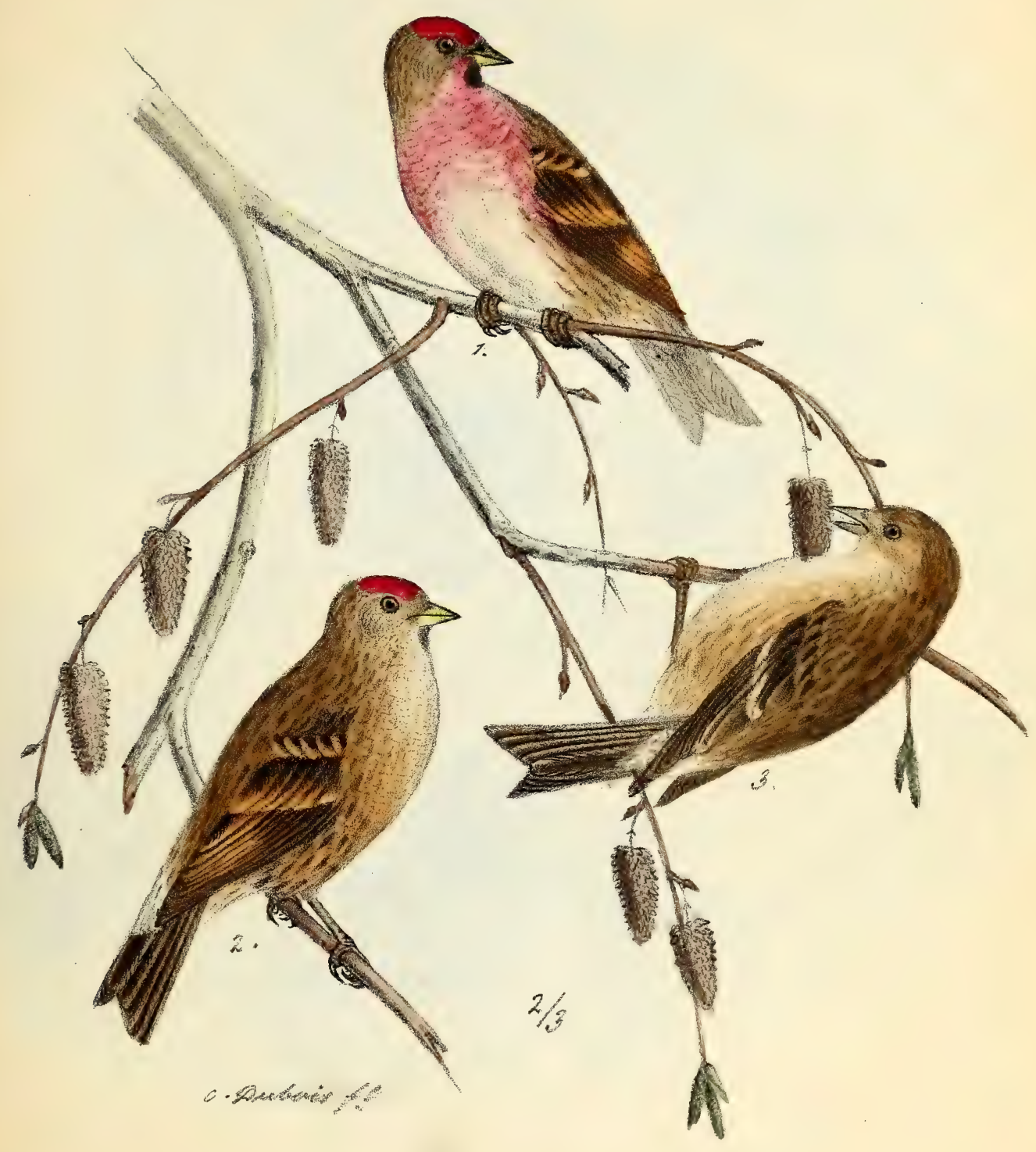

$$
\begin{aligned}
& \text { Favin Prowsatie }
\end{aligned}
$$

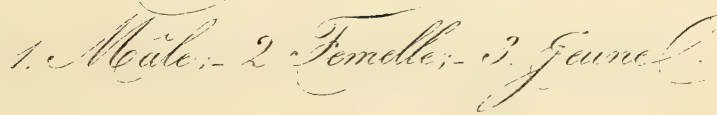





\title{
TARIN ROUSSATRE.
}

\author{
CARDUELIS RUFESCENS, DUBoIS.
}

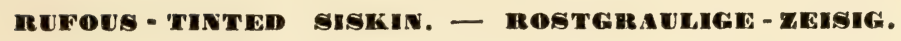

LiNOTTE CABARET. Brisson, ORnith., t. III, p. 142. - Gould., t III, pl. 194. - Naum., t. V, pl. 126, fig. 4, var. - Brehm, p. 282. - Degl., I. I, p. 239.-Bonap. et Schleg, Monogr. Lox., pl. 51. - Cabanis, Mus. Hein., ${ }^{\circ}$ 813. - Selys-Longch., Faune Belge, no 57. - Savi, Ornith. Toscana, I. II, p. 124. - Fringilla linaria, var. Lalh. - F. flavirostris, Linné. F. rufescens, Vieill. - Linaria minima, Briss. - L. rubra, Gmel. - L. flavirostris, Brehm. - L. minor, Gould. - Acanthis rufescens. Bonap - Aegiothus rufegens, Nob.

Ce tarin labite en été l'islande, le Danemark, la Suède, la Norwége, la Pologne et la Gallicie; en automne, pendant ses migrations, il parait en Allemagne, en Hollande, en Belgique et en France; dans les hivers rigoureux, il va jusqu'en Italie et en Grèce. Cet oiseau vient ici beaucoup plus tôt que le tarin sizerin, parce qu'il n'habite pas des contrées aussi avancées vers le nord. Le tarin roussâtre est un petit oiseau doux et inoffensif qui se trouve, pendant ses migrations, aussi bien dans les montagnes que dans les plaines et dans les vallées sèches ou marécageuses. Sa manière de vivre ainsi que sa nourriture sont les mêmes que celles du précédent; son chant est tout aussi insignifiant, cependant on le dit un peu mieux; mais ce n'est qu'une exception, comme il arrive chez tous les oiseaux.

Les mâles n'ont pas la poitrine rouge pendant l'automne et ils ressemblent alors fort à la femelle.

Variétés accidentelles : blanc avec le front rouge ou taché de blanc avec le front rouge. En captivité ils perdent souvent les plumes rouges et en reçoivent de jaunes.

Ils nichent sur les arbres peu élevés ou dans les buissons, et leur nid si gracieux est composé de radicules, de brins d'herbe sèche, de mousse et de lichens; à l'intérieur se trouve de la laine d'osier et d'autres plantes; il contient de quatre à six œu?s. 



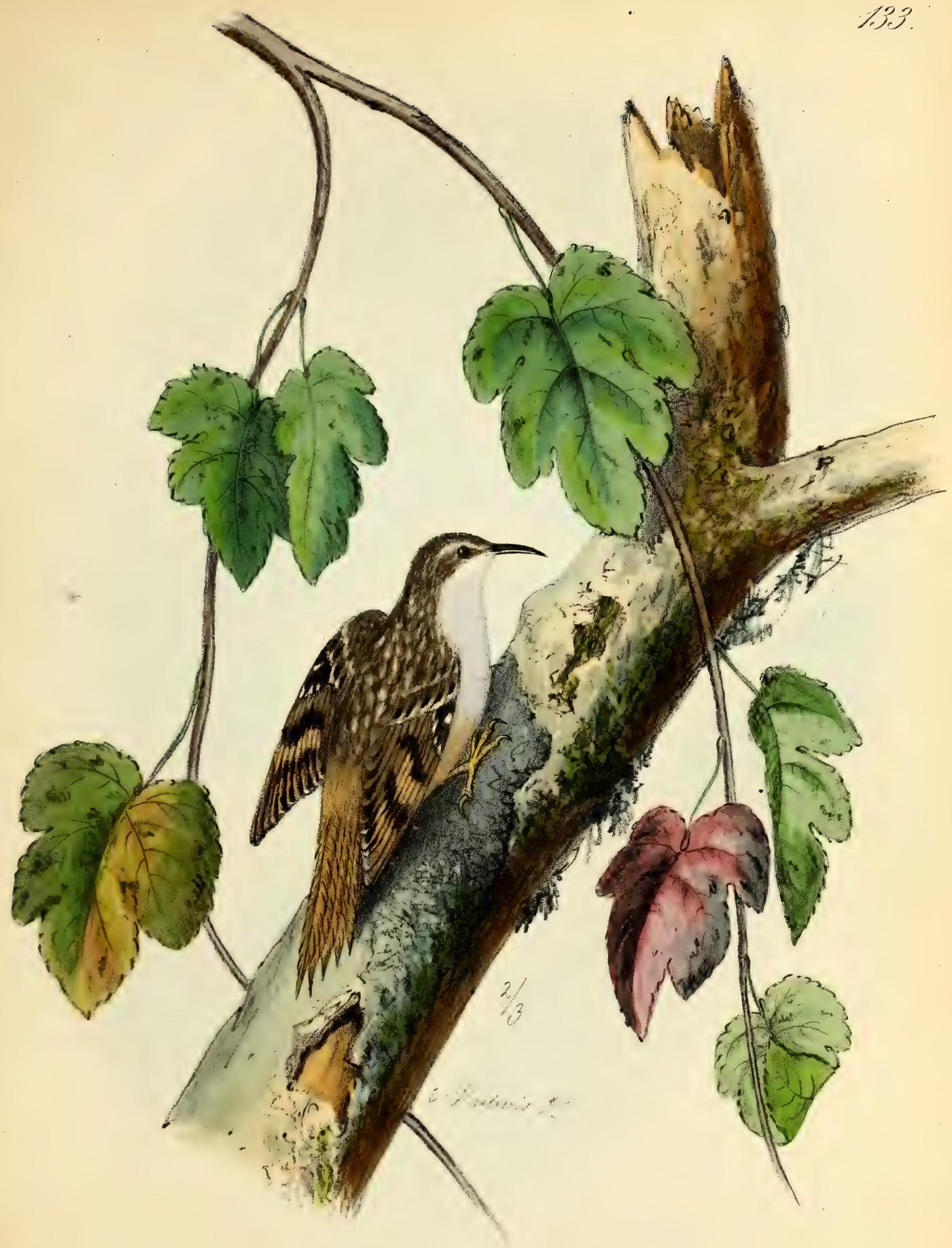

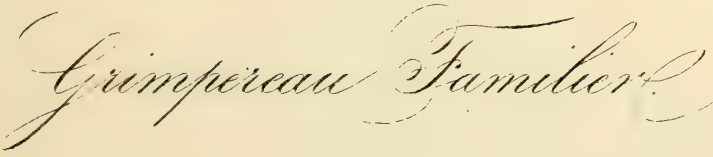



Cense crimpercas. - Certhia, Linné.

\section{GR R II PEREA U FA MILIER.}

CERTHIA FAMILIARIS, LINNÉ.

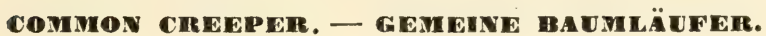

GRIMPEREAU. Buff., t. V, p. 481 ; pl. enl. 691. - Temm., t. I, p. 410. - Gould, t. III, pl. 237. - Naum., t. V, pl. 140. - Schleg., Revue, p. 48. - Degl., t. I, p. 604. - Thienem, pl. XI, f. 9 et 10. - Savi, Ornith. Toscana, t. I, p. 187. - Malh., Faune Sicile, p. 139. v. d. Mühle, Vg. Griechenlands, n 109. - Selys-Longch., Faune belge, n 146 . - Malh., Ors. de l'Algérie, p. 17. - Certhia scandulaca, Pallas. - C. Coste, Gerbe. - C. macrodactyla et SEPTENTRIONALIS, Brehm.

Cet oiseau habite presque toute l'Europe et la Sibérie; il est abondant dans quelques districts, tandis qu'il est rare dans d'autres. En été et au printemps on le rencontre dans les grandes et les petites parties boisées et dans les jardins; en hiver il se répand d'avantage, car là où se trouvent des arbres isolés ou des allées, on le voit en compagnie du roitelet et de la mésange. Il grimpe perpendiculairement sur les troncs et les branches des arbres avec une vitesse incroyable, en se soutenant avec la queue; parfois en ligne droite et parfois en spirale; est-il au haut de l'arbre, il vole sur un autre et recommence depuis le bas jusqu'au sommet; il ne le fait jamais de haut en bas; rarement il se pose en biais sur les branches minces, et encore plus rarement sur la terre. Ce grimpereau est très-pacifique et point farouche, plutôt confiant, car on peut souvent l'approcher de très-près; cependant il lui est facile de se cacher en allant de l'autre côté du trone, d'où il vole sur un autre arbre, ce qu'il fait ordinairement en laissant entendre sa voix, comme zit-zit, zit-zit.

Sa nourriture consiste en insectes et en larves, qu'il cherche dans les crevasses de l'écorce des arbres ou dans la mousse qui les recouvre.

Il niche dans les cavités et les crevasses des arbes, tantôt bas, tantôt élevé. Le nid est composé de feuilles sèches, de petits morceaux de bois pourri et de fine écorce; à l'intérieur il est bourré de plumes; la femelle y pond huit ou neuf œufs. Il n'y a ordinairement qu'une couvée. 



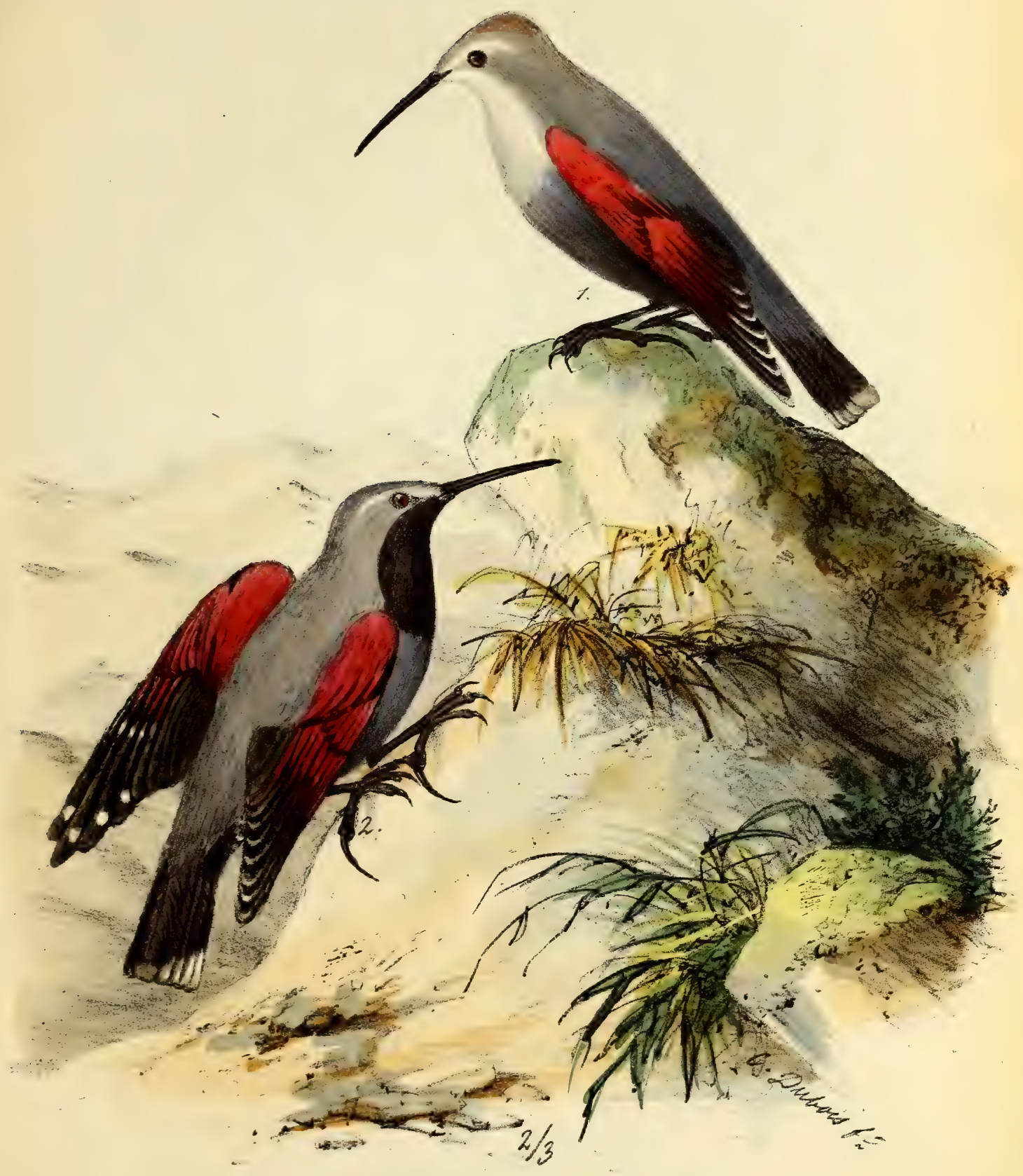

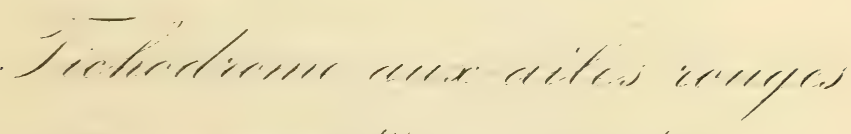

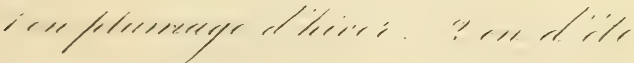



Genne Tichodnome. - Thehodroma, Illiger.

\section{TICHODRONE AUX AILES ROUGES.}

TICHODROMA PHOENICOPTERA, TEMMINCK.

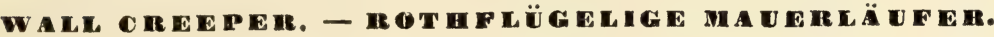

GRIMPEREAU DE MURAILLE. Buff., pl. enl. 372.-Temminck, t. I, p. 412.-Naumann, t. I, pl. 141. - Brehm., p. 213. - Gloger, p. 378. - Gould, t. III, pl. 239. - Schlegel, p. 47. - Degland, t. I, p. 607. - Savi, t. I, p. 185. - Schinz., VG. Schweız, no 46. - Selys-Longch., Faune belge, no 147. - Rüppel, Vg. N.-0. Afrika's, no 114. - v. d. Mühle, Vg. Griechenlands, $n^{\circ}$ 110. - Pigus muralis, Gesner. - Silvia longirostris, Stephens. - Gerthia muraria, Linné. - C. muralis, Briss. - Petrodroma muraria, Vieill. - Tichodroma muraria, Ch. Bonap. -

T. brachyrhynchos et macroruynchos, Brehm. - Europea, Stephens.

Le tichodrome habite particulièrement les contrées méridionales de l'Europe et les parties occidentales de l'Orient, depuis la Perse jusque sur le Caucase, dont il n'habite en été que les hautes cimes; en Europe il parait sur les sommets des montagnes de la Grèce, de l'Espagne, de l'Autriche, de la Bavière, de la Suisse et de la France; il s'avance même vers les régions froides, mais il les quitte cependant en automne, lorsque le froid commence ou par les premières neiges Alors il se tient sur les flanes des rochers ou dans les ruines des vieux châteaıx; il se tient aussi sur les murailles basses près de la terre. Dans ses migrations, le tichodrome vient encore souvent dans d'autres contrées; ainsi il a paru plusieurs fois en Belgique, notamment à Namur et à Huy et près d'Aubel dans la carrière de M. Talpot. Cet oiseau ne se pose jamais près des arbres ni dessus; rarement à terre; il est indifférent au froid et à la gelée, il est insociable et, hors les temps des couvaisons, il vit seul. Au printemps seulement on les voit émigrer par couples, autrement ils ne souffrent point leurs semblables dans leur voisinage. Le tichodrome n'est point farouche, il s'occupe principalement à grimper, ce qu'il fait ordinairement en tenant les ailes levées et en faisant un cri d'appel. Le chant de cet oiseau est composé de plusieurs tons courts et perçants que fait entendre non-seulement le mâle, mais aussi la femelle.

Leur nourriture est composée d'insectes, de leurs larves et de leurs œufs, mais particulièrement d'araignées que ces oiseaux cherchent dans toutes les crevasses.

Ils nichent dans les creux des rochers escarpés ou dans les trous des vieilles murailles. Le nid est bâti très-légèrement et se compose d'herbe sèche et tendre et de quelques feuilles sèches qui sont unies par des toiles d'araignées; à l'intérieur il est mollement bourré de plumes. Le nid contient quatre ou six oufs. 



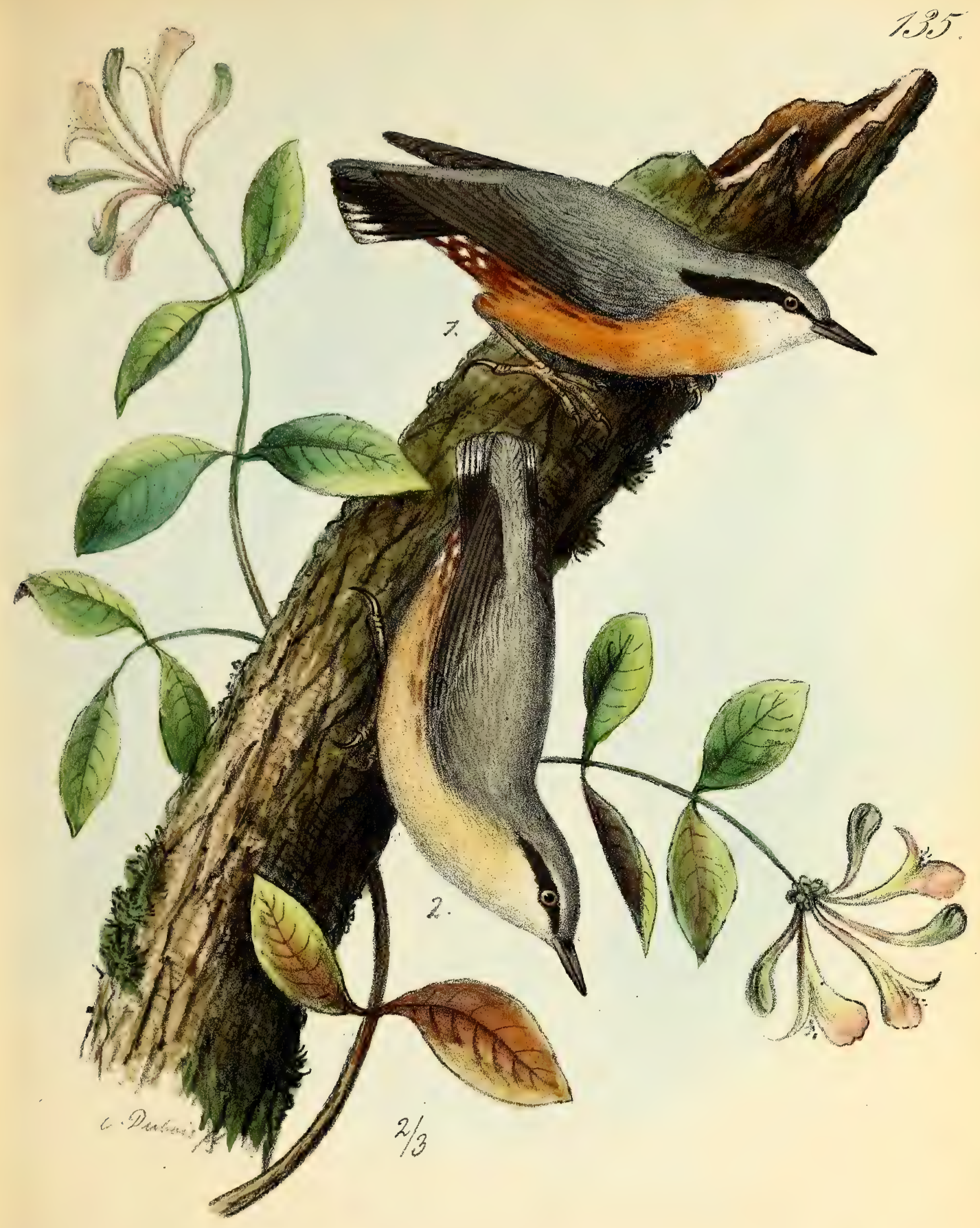

$$
\begin{aligned}
& \text { Sitele Sedinavie } \\
& \text { 1. Vlate-2. Foncle }
\end{aligned}
$$



Gemre sttelle. - sulk, Linné.

\section{SITTELLE ORDIN A IRE.}

SITTA CAESIA, MEYER.

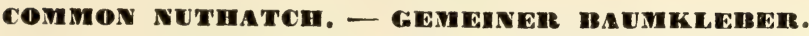

SITTELLE ou TORCHEPOT. Buff., t. V, p. 460 ; pl. enl. 625 . - Temm., t. I, p. 407. Naumann, t. V, pl. 139. - Gould, t. III, pl. 234. - Degl., t. I, p. 600. - Brehm, p. 205.Thienem., FortP., pl. XI, fig. 8. - v. d. Mühle, Vg. Griechenlands, nº 96. - Savi, Ornith. TosCana, t. I, p. 122. - Malh., Faune Sicile, p. 138. - De Selys-Longch., Faune Belge, n 145. Sitta Eunopea, Linné. - S. pinetorum, folionum et septentrionalis, Brehm.

La sittelle ordinaire est répandue dans toute l'Europe, quoiqu'elle ne soit nulle part en abondance; en Écosse elle ne parait jamais. Elle fréquente en été et au printemps les forêts qui sont dans les plaines ou celles qui sont sur les hautes montagnes; en automne on la voit isolée ou par couples dans les jardins et dans tous les endroits pourvus d'arbres; elle vient quelquefois, en société d'autres oiseaux, jusque dans les villes. Toujours occupé, sociable et pacifique, cet oiseau n'est jamais en repos. Il est rusé, mais il n'est point farouche; au contraire, il se montre plutôt curieux. II grimpe avec beaucoup d'habileté sur les arbres, en montant et en descendant. Au printemps les couples vont à la place qu'ils se sont choisie pour faire leur nid; le mâle se pose ordinairement sur le sommet des arbres pour chanter; son chant n'est qu'une continuité de tons perçants ressemblant à sit, sit, auxquels la femelle répond par quelques cris semblables. Il n'est point rare de voir des mâles se battre pour une femelle, tout en jetant des cris perçants et en se poursuivant avec rage. On peut fort bien les conserver en captivité.

Variélés accidentelles : blanc, ou blanc avec une bande noire au-dessus des yeux.

Nourriture : coléoptères et beaucoup d'autres insectes, leurs larves et leurs chenilles, que ces oiseaux cherchent dans les crevasses de l'écorce des arbres; ils se nourrissent aussi de la semence de hêtre et de tilleul, et de beaucoup d'autres semences, ainsi que de noisettes qu'ils cherchent à ouvrir en donnant des coups de bec réitérés, afin d'en prendre le noyau; en hiver, lorsqu'ils ont faim, ils mangent aussi de l'avoine.

Ils nichent dans le creux des arbres et ils se servent souvent des nids abandonnés des pics; lorsque l'entrée du nid est trop grande, ils l'amoindrissent avec de la terre que le mâle et la femelle vont chercher, et qu'ils travaillent de manière qu'en séchant elle acquiert la solidité d'un mur; l'entrée forme un petit trou rond qui se trouve toujours placé au milieu. Dans le creux se trouve le nid qui est composé d'une masse de feuilles sèches, de pelures d'écorces d'arbres, de laine et de plumes; tous ces matériaux sont légèrement posés les uns sur les autres et l'on y trouve, vers la fin d'avril, de six à neuf ocufs. 



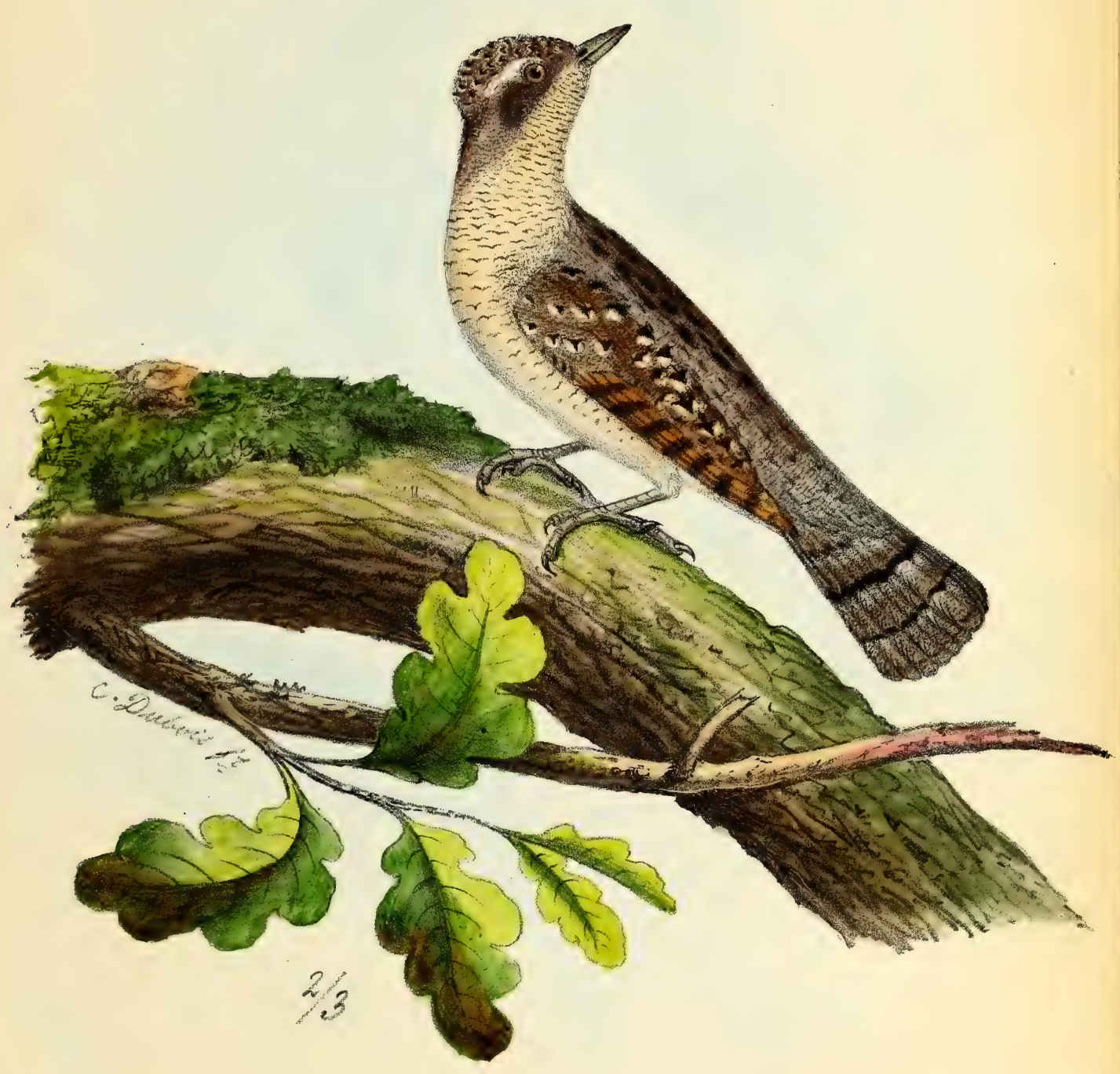

Bunal Proticille 

Gevere Torcol. - Jymx, Linnć.

\section{TO RCOL VERTIGILLE.}

JYNX TORQUILLA, LNNE.

WRYNECK. - GEMEINER WENDEMALS.

TORCOL. Buff., t. VI, p. 84 ; pI. enl., n $n^{0} 698 .-$ Temm., t. I, p. 403. - Naum., t. V, pl. 138. Brehm, p. 208. - Degl., t. I, p. 163. - Gould., t. III, pl. 233. - Thienem, FortP., pl. XI, fig. 7. - Savi, Ornith. Toscana, 1. I, p. 146. - Malh, Faune Sicrle, p. 145̃. - v. d. Mühle, Vg. Griechenlands, no 41. - Selys-Longeh., Faune belge, no 157. - Nalh., Ois. de l'Algérae, p. 17. - Rüpp., Vg. N.-0. Afrika's, no 347. - Picus toroullla, Klein. - P. Jyvx, Pall. - Jyxx arBOREA el PUNCTATA, Brehm.

On trouve cet oiseau dans toute l'Europe, mais nulle part en grande quantité; en Hollande, il est même une rareté. On le trouve aussi dans I'Asie septentrionale. Cet oiseau vient ici vers la fin d'avril et nous quitte au commencement de septembre, pour émigrer le plus souvent vers l'Afrique septentrionale; quelquefois il en reste dans les contrées du sud de l'Europe. Le torcol choisit pour sa résidence les grandes forêts, les vergers, les vieux arbres et de petits groupes d'arbres dans les champs où se trouvent des fourmilières. Il se pose rarement sur le sommet des arbres, mais ordinairement sur les branches inférieures, souvent aussi sur la terre; il vole presque toujours très-bas et se distingue beaucoup par la lenteur avec laquelle il déploie ses ailes, et par les inflexions de son cou; en même temps il déploie la queue, et les plumes de la tête se redressent. En captivité, lorsqu'on le prend en main, il tourne les yeux et fait entendre un cri singulier et sourd tandis qu'il tourne le cou en formant des cercles comme un serpent afin de recouvrer par ces manéges sa liberté. Dès son arrivée le mâle fait entendre sa voix forte qui résonne presque comme weid ou weib, et qu'il répète le plus souvent de dix à douze fois en faisant de grands mouvements avec le corps et le bec; aussitôt qu'il a attiré une femelle par son chant, il se choisit une place pour faire un nid; lorsqu'ils couvent, le mâle ne chante plus autant, et il se tait tout à fait dès que les petits sont éclos.

Variétés accidentelles : d'un blanc pur, d'un blanc rougeâtre ou jaunâtre, ou comme toujours, mais toutes les couleurs plus pâles.

Nourriture : de petits insectes et leurs larves, particulièrement les œufs de fourmis, aussi des chenilles, rarement des baies molles.

Ils nichent dans le creux d'un arbre tantôt élevé, tantôt bas, mais rarement plus élevé que de $\mathbf{3 0}$ pieds; la femelle y dépose de sept à onze œufs sur du bois pourri; le mâle relève la femelle pendant le milieu du jour et il couve lui-même les oufs pendant quelques heures. 



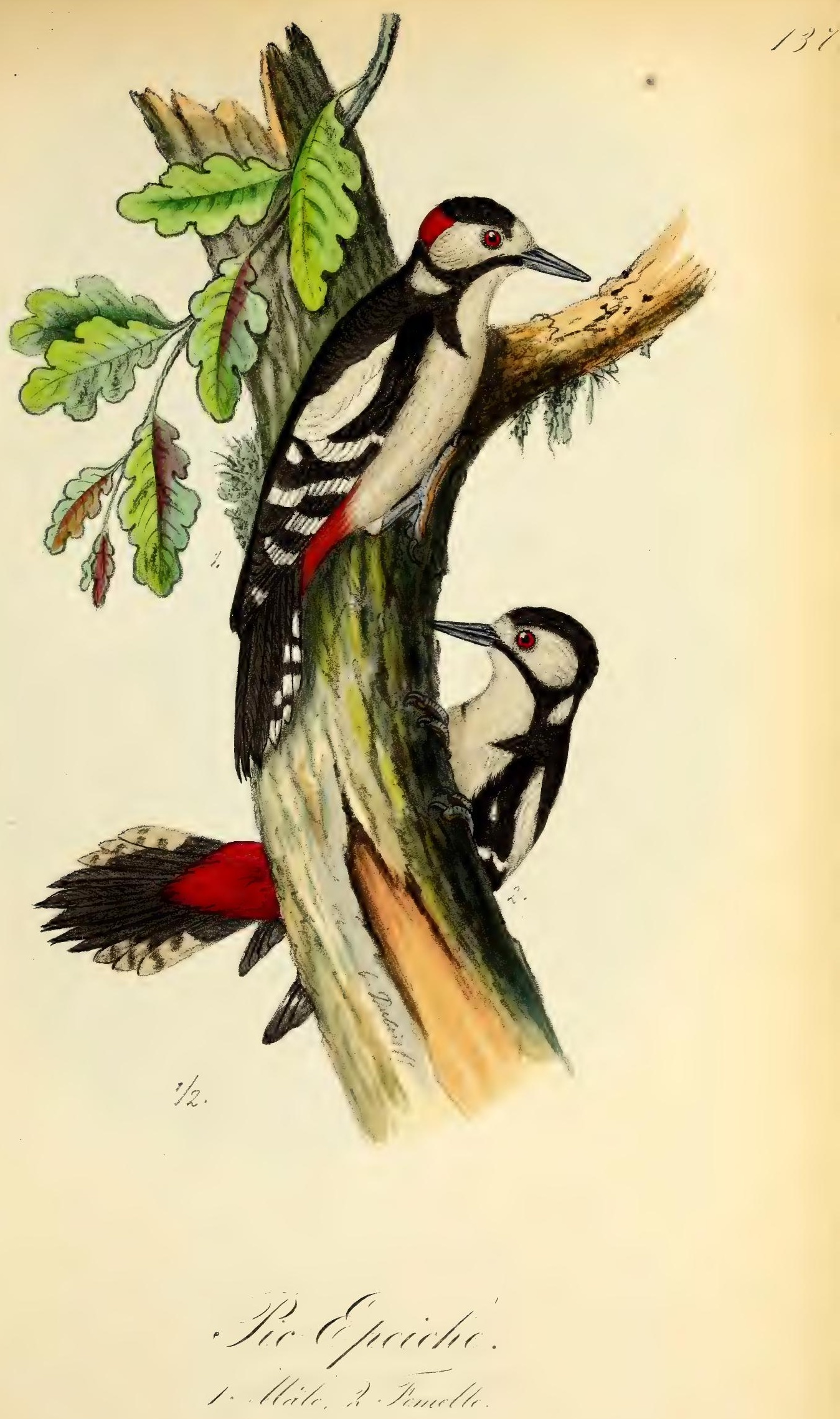



Genre Pic. - Plens, Linné.

\section{P I G E P E I C II E. \\ PICUS MAJOR, LINNÉ.}

GREAT SPotTen Woow. - GRosge huntspecht.

GRAND ÉPEICHE. Buff, $\iota$ VII, p. 57 ; pl. enl. 196. - Temm., t. I, p. 393. - - Degl., t. I, p. 15̈6. - Brehm, p. 187. - Naumann, t. v, pl. 136. - Gould, t. III, pl. 150. - Thienem., Fortp., pl. XI, fig. 4. - v. d. Mühle, Vg. Griechendands, no 48 - Malh., Faune Sicile, p. 144. - Meyer, Vg. Liv.-U. Esthlands, p. 62. - Meis. et Schinz., Vg. Schweiz, no 39. - De SelysLongch., Faune belge, ${ }^{0}$ 152. - Picus cissa, Pall. - P. pinetorum, pityopicus, frondium et montanus, Brehm. - Dendrocopus majoR, Koch.

Cet oiseau habite la plus grande partie de l'Europe, ainsi que la Sibérie et jusqu'au Kamtschatka, vivant dans les forèts, dans les plaines, et sur les hautes montagnes; en hiver il visite tous les endroits pourvus d'arbres; on le voit de temps en temps dans les jardins des villes et des villages. Toujours éveillé et actif, rarement farouche, il grimpe avec beaucoup de facilité sur les arbres, même sur les branches et les arbustes. Le pic fait entendre un ton perçant et court comme tgik, kgik ou kix, mais toujours isolé ou entrecoupé de longues pauses; il chante ordinairement en grimpant ou en volant d'un arbre à un autre. Dans le temps de l'accouplement, il rend un son sourd et rauque en frappant avec le bec contre les troncs d'arbres. Souvent les mâles se querellent et se poursuivent jusqu'à ce que l'un d'eux ait quitté les lieux, objet de leur querelle.

Variétés accidentelles: blanc, le crâne et les sous-caudales rouges, ou toutes les plumes, ordinairement noires, d'un brun rougeâtre.

Nourriture : fourmis et beaucoup d'autres insectes, ainsi que leurs larves, que ce pic cherche sous l'écorce et dans les crevasses des arbres; il mange aussi des semences de hêtre et de sapin, des glands et des noisettes qu'il ouvre à coups de bec.

Ces oiseaux sont très-difficiles dans le choix d'une place pour la nitation. Les divers arbres des forêts leur conviennent, ainsi que les pommiers et les poiriers, où ils trouvent une branche ou un tronc pourri dans lequel ils font un trou rond qui sert d'entrée, tâchant autant que possible d'unir ce creux; ils commencent souvent à creuser des trous sans les achever. La femelle pond, sur quelques fins copeaux, de quatre à six œufs. Ces oiseaux montrent une grande tendresse pour leurs petits, et les nourrissent de petites chenilles et de larves. 


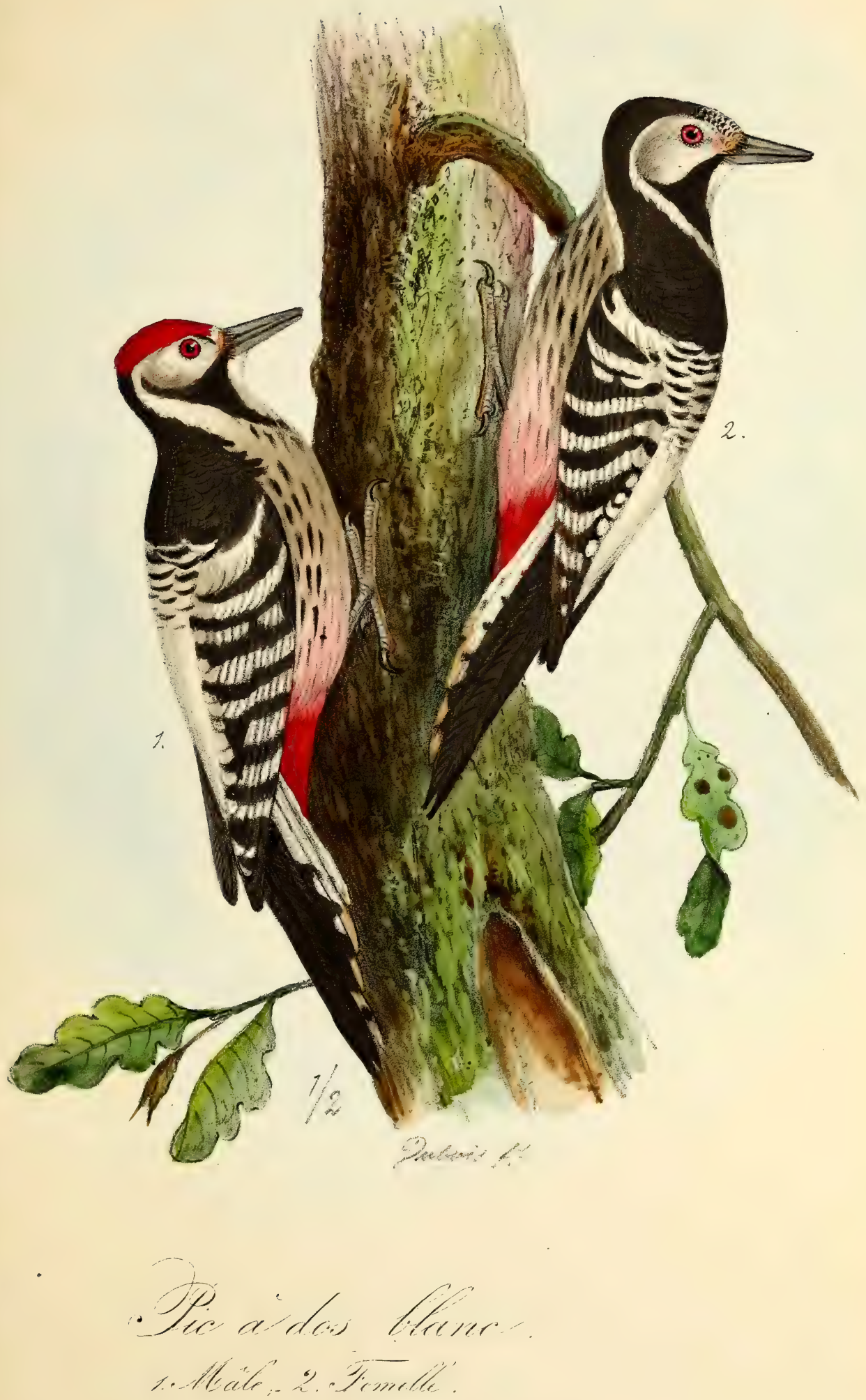



\section{PIC A DOS BLANC.}

PICUS LEUCONOTUS, MEYER.

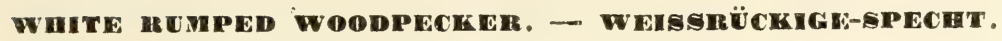

Temm., t. I, p. 397. - Gould, t. III, pl. 228. - Naum., t. V, pl. 135. - Degl., t. I, p. 157 Bechst. Ornith., тaschenbuch, p. 66. - Thienem., Gesam. Vg., pl. XIII, fig. 8. - Beseke, Vg. Kurlands, p. 38. - Meyer, Vg. Liv.-U. Esthlands, p. 60.- Zawadzki, Fauna galizien's, no 167. v. d. Mühle, Gg. Griechenlands, no 47. - Picus leucotus, Bechst.- P. cirnis, Pallas. - P. meDius, Beseke.

Ce pic se trouve en grand nombre en Europe et dans le nord de l'Asie; il est abondant en Sibérie, au Kamtschatka, dans toute la Russie et la Pologne, il est déjà plus rare en Suède et en Norwége et n'est qu'accidentellement en Allemagne, en Prusse, en Saxe, en Autriche et en Bavière. Au mois de novembre de 1840 cet oiseau si rare en Belgique fut abattu par M. Talpot près d'Aubel qui me l'envoya avec la chair; un autre fut abattu aux frontières de la Belgique près d'Aix-la-Chapelle et se trouve là dans la collection de M. A. Nutten. Ce pic aime particulièrement les forêts en montagnes pourvues abondamment de chênes et de hêtres; en hiver il parait aussi dans le voisinage des maisons, sur des groupes d'arbres ainsi que dans les jardins; il est peu farouche et par conséquent facile à abattre, aussi peut-on l'attirer facilement en contrefaisant le bruit qu'il fait en donnant des coups de bec contre les arbres.

Variétés accidentelles : tout blanc, et les sous-caudales rouge rosâtre.

Nourriture : insectes, leurs larves et leurs œufs; des vers et des chenilles qu'ils cherchent sous l'écorce des arbres; ils mangent aussi des semences, particulièrement celles du hêtre.

Ils nichent dans les forêts ou d'autres groupes d'arbres, dans un tronc ou une branche pourrie où il se font un trou rond servant d'entrée; la femelle dépose, sur quelques copeaux, quatre ou cinq œufs. 



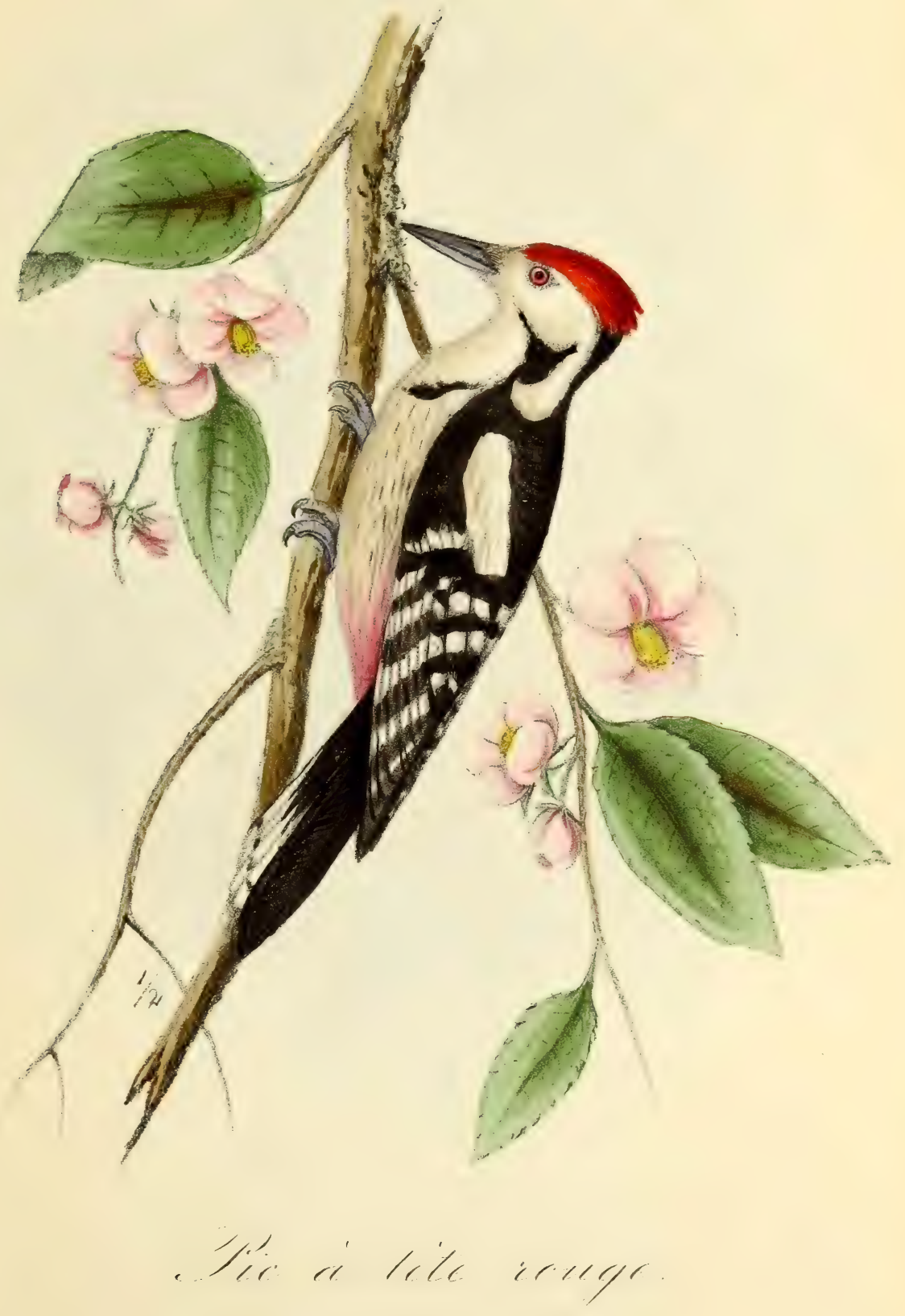





\section{PIC A TETE ROUGE.}

PICUS MEDIUS, LINNE.

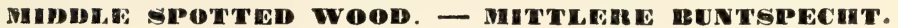

LE PIC VARIE், Buff., pl. enl., 611. - Temm., t. I, p. 398. - Gould, t. III, pl. 130. Naumann, t. V, pl. 136. - Degl., t. I, p. 159. - Thienem., pl. XI, p. 5. - Ornith. Toscana, t. I, p. 143. - Faune Sicile, p. 145. - Pigus varius, Brisson. - P. Quercuum, Brehm.

Le pic à tête rouge est rare en Norwége, en Suède, en Finlande, en Russie, aux Iles Britanniques et en Hollande; en Allemagne on le rencontre assez souvent ; il n'est rare ni en Belgique, ni en France dans la Provence, ni en Italie; en général il est plus répandu dans l'Europe du sud que dans l'Europe du nord; il n'est abondant que dans peu de contrées. Ce pic, dont le mâle et la femelle sont tout à fait semblables par le plumage, se tient dans les forêts en plaines pourvues de vieux arbres; en hiver, il erre dans les forêts de pins et de sapins, ainsi que dans les vergers et les jardins; alors, il est ordinairement accompagné par les mésanges, les roitelets, les grimpereaux, les sitelles, etc. qui semblent lui confier la recherche de leur nourriture. Cet oiseau se distingue par sa vivacité, son agilité et son adresse; il se chamaille souvent avec ses semblables; son cri d'appel est aigu et perçant; lorsqu'il le fait entendre, il le répète toujours plusieurs fois en le liant tant soit peu; au printemps, lorsque les mâles se disputent pour les femelles, ils mêlent à leur cri d'appel un son criard ; ils forment aussi un son en frappant avec le bec contre les troncs d'arbres. En général cet oiseau n'est pas farouche.

Sa nourriture consiste en fourmis et en quantité d'autres insectes qu'il cherche sous l'écorce des arbres; il mange aussi des glands, des faines et des semences de pins et de sapins.

Dans le temps de l'accouplement, qui a lieu à la fin de mars ou au commencement d'avril, ces oiseaux sont extrêmement vifs; les mâles et les femelles, ainsi que les mâles entre eux, chassent ensemble près des arbres, dans les airs, jusqu'à ce qu'ils se soient accouplés, car alors commence la nitation qui a lieu dans un trou que le pic pratique avec le bec dans un arbre ayant une place vermoulue; il agrandit le trou et, sur le bois détaché, il pose de cinq à sept œufs. La place du nid est toujours choisie avec soin par le pic qui adopte à cet effet un arbre assez élevé. 



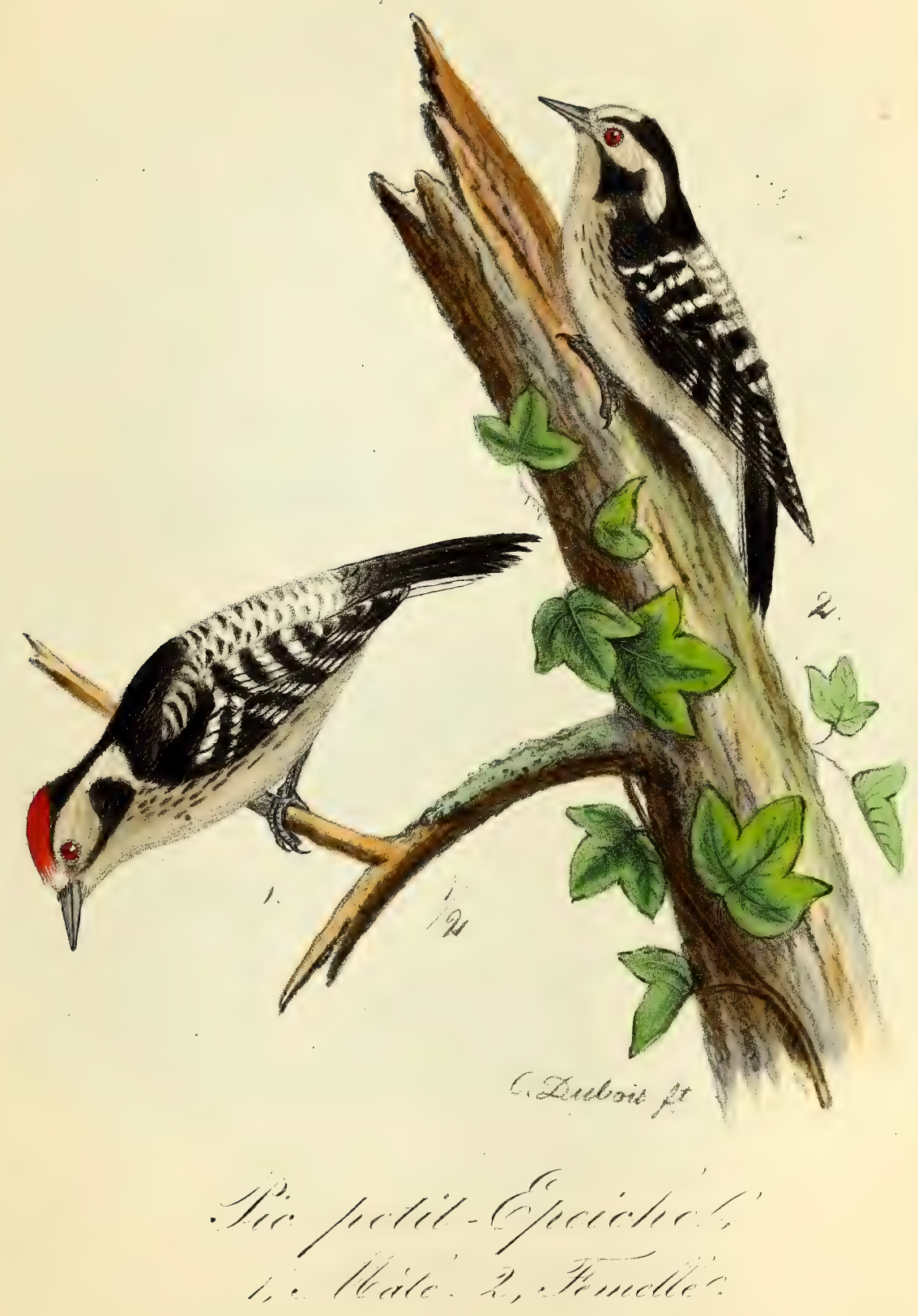





\section{PIC PETIT-EPEICHE.}

PICUS MINOR, LINNE.

LESEIER SPOTTED WOOD. - KMEUNE BUNTSPECHT.

ÉPEICheTTE. Buff., pl. enl. 598. - Temm., t. I, p. 399. - Naumann, t. V,pl. 136, fig. 1. - Gould, t. III, pl. 231. - Degl., t. I, p. 160. - Thienem., FortP., pl. XI, fig. 6. - Glog., t. I, p. 461. - Schinz, Vg. Schweiz, no 11. - De Selys-Longch, Faune belge, no 154. - v. d. Mühle, Vg. Griechenland, no 49. - Malh., Ois. de l'Algérie, p. 17. - Pigus varius minor, Briss. - Pigus hortorum, Brehm. - P. pipra, Pallas. - Dendrocopus minor, Koch.

Ce petit pic se trouve dans toute l'Europe et dans une grande partie de l'Asie; cependant il ne parait être commun nulle part, quoiqu'on le rencontre dans plusieurs districts en Norwége, aux lles Britanniques, en Allemagne, en Suisse, en France et en Belgique; ce n'est qu'en Hollande qu'il paraît bien rarement. Il vit dans les forêts et aime particulièrement celles debouleaux ; on le trouve aussi dans la forêt Noire ainsi que dans les endroits plantés d'arbres, particulièrement d'arbres fruitiers sur lesquels il grimpe autour des grosses branches et parvient même jusqu'aux plus petites. Ce pic est un oiseau querelleur, remuant et envieux envers ses semblables, mais il est confiant envers l'homme. La voix de cet oiseau est plus fine, plus élevée et moins sèche que celle du pic à tête rouge; au printemps il chante vite et avec persévérance, il fait aussi entendre un son faible en frappant avec le bec sur les troncs d'arbres.

Nourriture : plusieurs sortes d'insectes et leurs larves qu'il trouve dans les crevasses des arbres et sur les branches; cet oiseau mange aussi beaucoup de semences d'arbres, tels que des pins, des hêtres et d'autres.

Les pics choisissent ordinairement pour y placer leurs nids un trou vers le haut d'un arbre ou d'une autre place pourrie; s'ils n'en trouvent point qui leur soit convenable, ils s'en arrangent une, ayant pour entrée un trou rond; ils font ce travail avec facilité, car ils en commencent toujours plusieurs avant d'en finir un. Dans ce nid ils posent cinq ou six oufs sur quelques petits morceaux de bois; le mâle remplace quelquefois la femelle pour les couver; ils nourrissent leurs petits en commun, les aiment beaucoup, les entretiennent encore lorsqu'ils savent déjà voler, et ne cessent que lorsqu'ils s'éloignent peu à peu. 


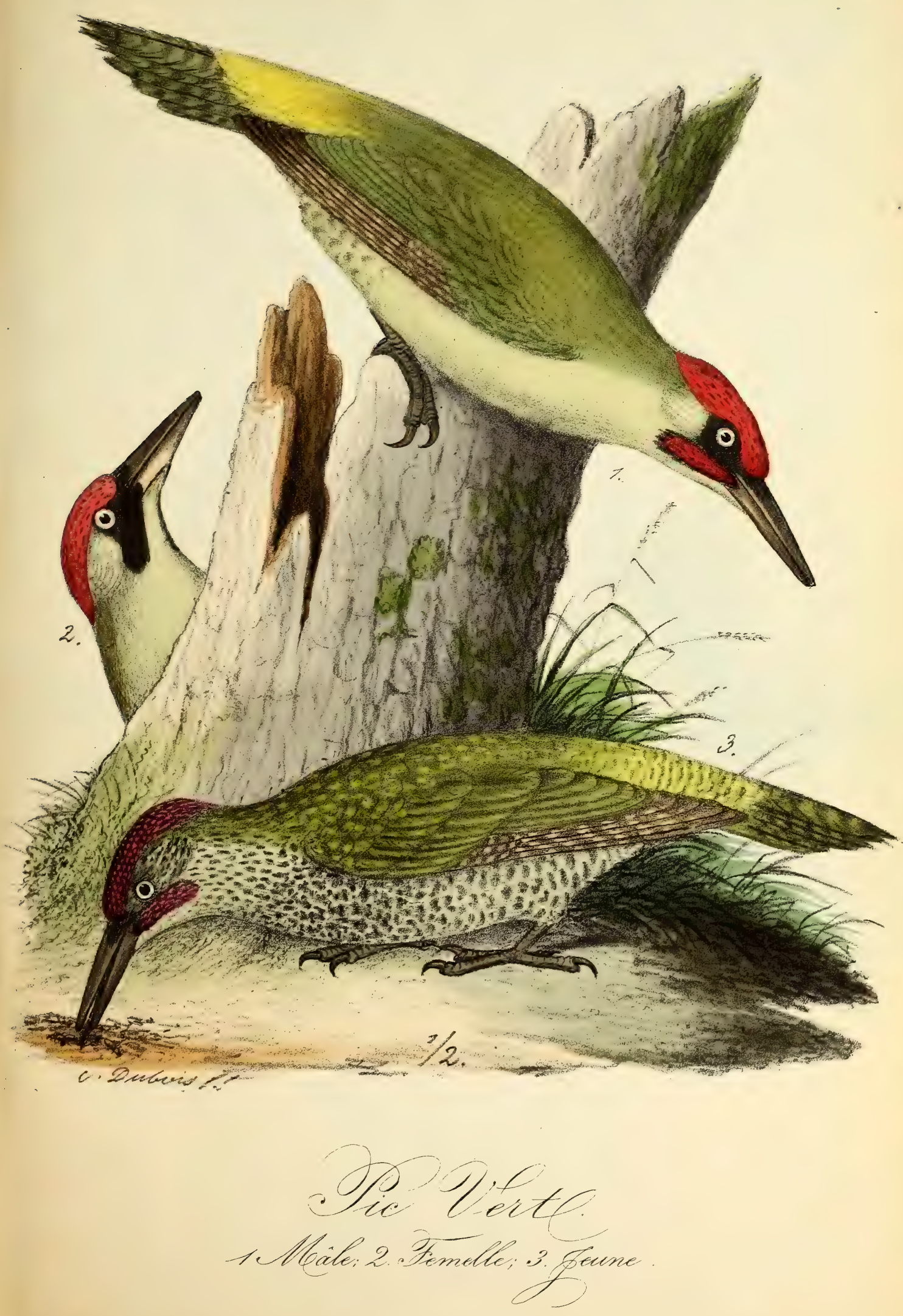



\title{
PIC VERT.
}

\author{
P I G U S VIR I D IS, LINNÉ.
}

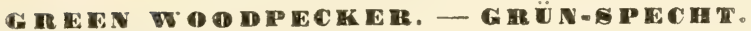

Buff., t. ViI, p. 23; - pl. enl. 693. - Temm., t. I, p. 391.-Gould, t. III, pl. 226. - Naum., t. V, pl. 132. - Degl., t. I, p. 153. - Thienem, pl. XI, fig. 2. - Selys-Longch., Faune Belge, n 155. - Savi, Ornith Toscana, t. I, p. 140. - Malh., Faune Sicile, p. 143. - Mey., Vg. Liv.-U. Esthlands, p. 59. - Beseke, Vg. Kurlands, p. 37. - Malh., Ois. dé l'Algérie, p. 17. - Gecinus viridis, Bojé. - G. virescens, pinetorum et frondium, Brehm. - Chloropicus viridis, Malh. BRACHYLOPHUS VIRIDIS, Swainson.

Cet oiseau est répandu dans toute l'Europe jusqu'en Laponie et en Sibérie. Pour son séjour il choisit les prairies et autres endroits libres entrecoupés de bois; recherchant particulièrement les endroits où se trouvent beaucoup de fourmis. En automne il se retire bien avant dans les forêts ou autour des vergers; il ne vole ordinairement qu'à de petites distances, comme d'un arbre ou d'une forêt à l'autre; c'est un oiseau éveillé, farouche et téméraire; lorsqu'on s'approche de lui, il se met toujours au côté opposé de l'arbre, de manière qu'on ne puisse le voir et puis il s'envole; en grimpant il fait entendre le cri de gik, gik ou gluk, et au printemps, dans le temps de l'accouplement, le mâle pousse son cri d'appel d'abord lentement, puis plus vite et ressemblant alors à gluh, gluh, gluk gluck gluck gluckgluckgluckgluck. Le pic vert cherche sa nourriture qui consiste en chenilles de bois, en insectes et leurs larves, dans les fentes des arbres et dans les crevasses profondes il se sert de sa longue langue pour en retirer les insectes. On le trouve aussi beaucoup à terre dans les prairies et dans les champs, recherchant les nids de fourmis dont il aime les oufs; il mange aussi parfois quelques baies.

Variétés accidentelles : blanchâtre ou taché de blanc.

Tout arbre creux ayant une branche ou une autre place pourrie lui est agréable pour y faire son nid; cependant il le recherche toujours d'une hauteur de 20 pieds au moins; rarement plus bas; il agrandit la place qu'il a trouvée et dépose, sur quelques petits copeaux, de cinq à huit œufs; il nourrit d'abord les petits avec des oufs de fourmis; aussitôt qu'ils ont des plumes, ils grimpent et regardent hors de l'ouverture du nid. 



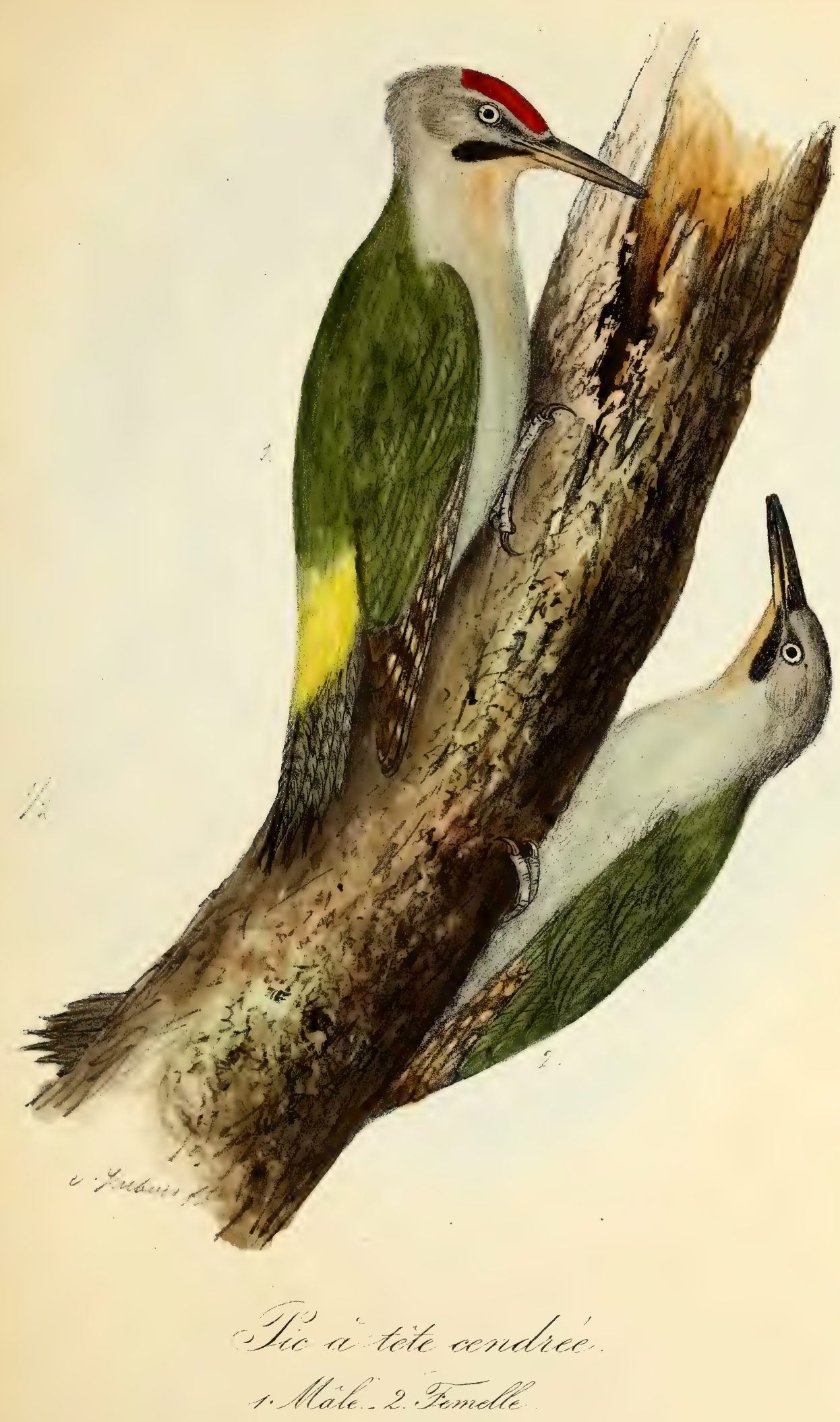





\section{PIC A TETE CENDRÉE.}

PICUS CANICEPS, NILSSON.

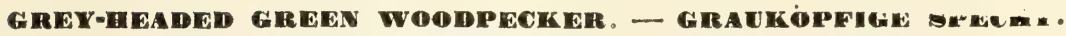

Temm., t. I, p. 593. - Gould, t. III, pl. 227. - Naum., t. V, pl. 133. - Degl., t. 1, p. 154. Thienem., pl. XI, fig. 3. - Selys-Longch., Faune BeLGe, no 156. - Meyer, Vg. Lrv.-u. Estulands, p. 59. - v. d. Mühle, Vg. Grieghenlands, no 45. - Malh., Ois. de l'Algérie, p. 17. Chloropicus canus, Malh. - Gecinus canus, Bojé. - G. viridicanus et caniceps, Brehm. - Picus canus, Gmelin. - P. norwegicus, Lath. - P. viridis norwegicus, Briss. - P. viridj-canus, Meyer. - P. chloris, Pallas.

Cet oiseau séjourne dans les pays du milieu et du nord de l'Europe, ainsi que dans les parties de l'Asie avoisinantes, où il se trouve en grande quantité; il est très-commun en Sibérie, en Norwége, en Suède, en Finlande et en Russie; en Allemagne il est déjà plus rare, dans quelques provinces on n'en trouve même pas. Aux Iles Britanniques, en France et en Belgique il est aussi très-rare, et en Hollande il n'en a pas été trouvé. Pendant l'été il se tient le plus souvent dans les forêts, aux bords des fleuves et des ruisseaux, et particulièrement dans ceux où se trouvent des prairies et des pelouses. En automne et en hiver il voltige autour des vergers dans les villages, surtout dans ceux où se trouvent beaucoup de fourmis. Cet oiseau est vif, éveillé et adroit; il grimpe fort lestement; presque toujours du bas d'un arbre, il grimpe jusqu'au sommet, puis de là vole à un autre arbre où il fait la même chose. Le mâle fait entendre au printemps son chant clair qui commence par klih, klih, et finit par des notes plus basses, telles que gluk, gluk; il se distingue du pic vert en ce qu'il chante plus lentement.

Il cherche ordinairement les insectes au pied d'un arbre sous l'écorce, mais les fourmis et leurs oufs sont toujours sa nourriture favorite; il mange aussi parfois des baies de sureau et des raisins, par là il commet quelques dommages.

On trouve son nid dans différents arbres dont certaines parties sont pourries, à une hauteur de 20 à 50 pieds; il se sert aussi parfois du nid de l'année précédente qu'il agrandit encore un peu; il dépose ordinairement, sur du bois pourri, de cinq à huit œufs. 

143

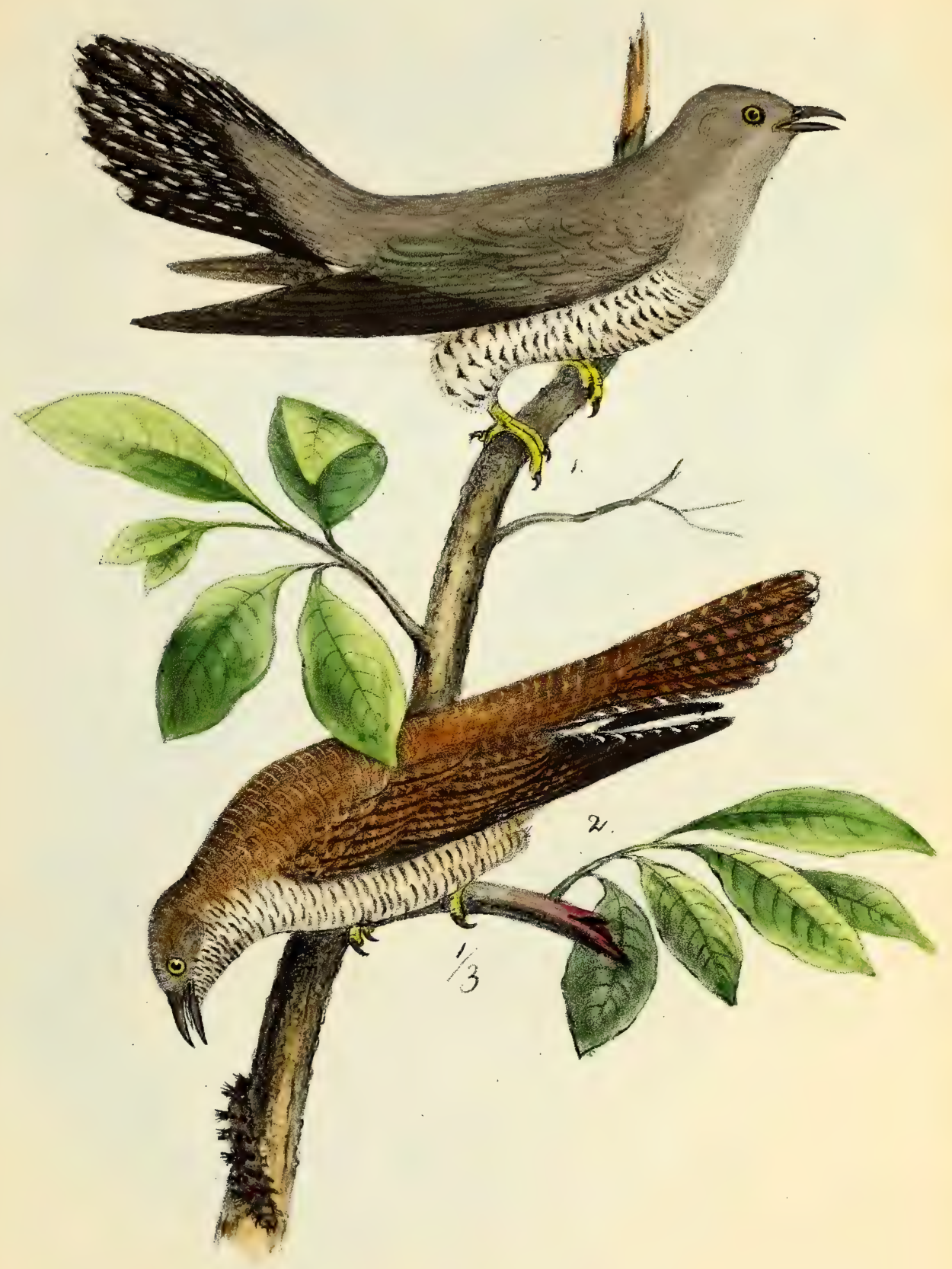

$$
\text { Counario funs. }
$$





\section{COUCOU GRIS. \\ G U G U L U C A N O R US, LIN É. \\ COMMON CUCKO⿻. - GEMEINE KUCKEK.}

Coucou. Buff., t. VI, p. 305̆; pl. enl. 81. - Temm., t. I, p. 453. - Gould, t. III, pl. 240. Naum., t. V, pl. 127. - Degl., t. I, p. 167. - Thienem, pl. X, fig. 15 et 16. - Selys-Longch., Faune belge, no 158. - Savi, Ornith. Toscana, t. I, p. 149. - Malh., Faune Sicile, p. 146. v. d. Mühle, Vg. Griechenlands, no 42. - Malh., Ois. de l'Algérie, p. 15. - Cuculus cinereus, Brehm. - C. Canorus rufus, Gml. - C. rufus, Bechstein.

Ce remarquable oiseau n'habite l'Europe que pendant l'été; il émigre vers la fin d'août ou au commencement de septembre en Afrique et dans l'Asie septentrionale, son séjour habituel. Il se tient de préférence dans les bois avoisinant les champs, les prairies et les jardins qui se trouvent près des marais dans lesquels se tiennent les rousserolles, car le coucou recherche le voisinage de ces oiseaux. Au printemps il se tient ordinairement sur le sommet d'un arbre élevé, caché dans le feuillage; sa voix, connue de tout le monde, consiste dans le cri de coucou qu'il répète souvent et dont il tire son nom.

Nourriture: insectes et particulièrement les chenilles, rases ou velues.

Ce coucou ne bâtit point de nid, mais la femelle dépose ses oufs dans le nid des autres oiseaux, particulièrement dans celui de ceux qui appartiennent à la famille des Sylviadées; ce n'est que dans les cas rares qu'il recherche ceux de la famille des Fringillidées. La femelle pond de quatre à six oufs petits, comparativement à la taille de l'oiseau; ordinairement un tous les sept jours, ce qui la met dans l'impossibilité de les couver, car, lorsque le dernier ouf est pondu, le premier est déjà corrompu depuis longtemps. Aussi le coucou se met-il à temps à la recherche d'un nid; l'at-il trouvé, il observe ce nid avec une persévérance étonnante; aussi cette observation continuelle influe-t-elle sur la formation des oufs, car ordinairement l'ouf du coucou est semblable aux oufs qui se trouvent dans le nid qu'il a observé. Y a-t-il trop d'œufs dans le nid, il en jette dehors (1); cet oiseau rencontre-t-il un nid dans lequel il ne peut pondre, il le fait dans le voisinage et porte l'œuf dans le bec pour le déposer dans le nid. Lorsqu'il voit que la propriétaire du nid couve son ouf, il se met à la recherche d'un autre nid pour l'avenir. Il arrive aussi parfois que le nid choisi est détruit, alors le coucou en cherche un nouveau de la même espèce que le précédent; s'il n'en trouve pas, il prend le premier venu. Voilà pourquoi il arrive aussi souvent que l'œuf du coucou ressemble peu aux autres œufs qui se trouvent dans le nid ou en diffère même tout à fait.

Lorsque le coucou est sorti de l'œuf, il donne beaucoup d'embarras à sa mère adoptive, à cause de sa grande voracité; aussi il arrive souvent que les petits oiseaux qui se trouvent avec lui meurent de faim, car le coucou s'empare de tout ou bien il jette les autres petits hors du nid.

(1) Sur la planche XXIV, fig. 143, se trouvent différents œufs de coucou qui ont été trouvés dans les nids des oiseaux suivants : $a$. Rousserolle des roseaux; $b$. Rubielte rouge-gorge; $\boldsymbol{c}$. Fauvelte grise; $d$. Fauvette des jardins; $c$. Hippolais contrefaisant; $f$. Rousserolle turdide; $g$. Piegrièche à tête rousse; $h$. Alouette des champs; $i$. Pipit des arbres; $k$. Traquet tarier. 



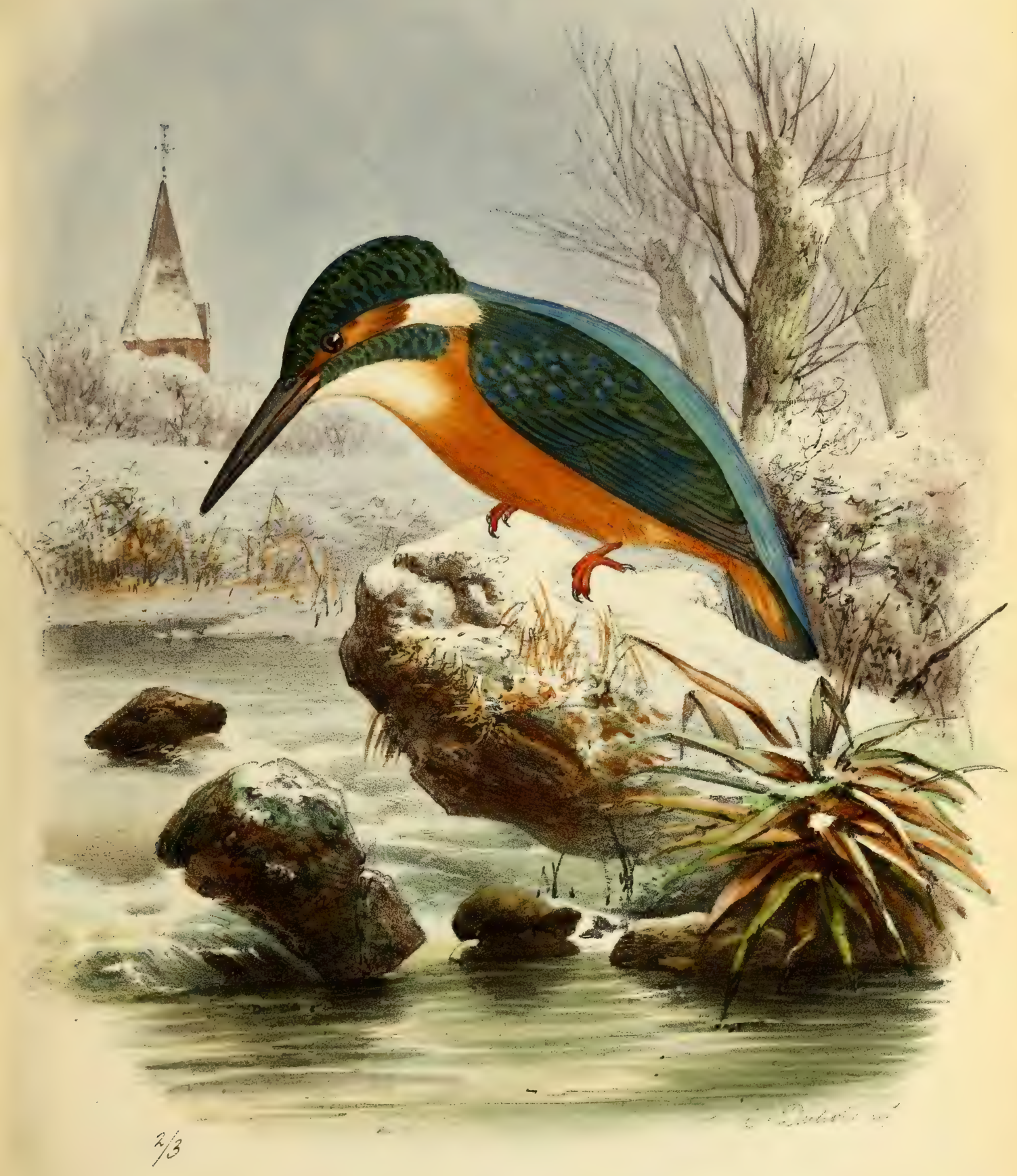

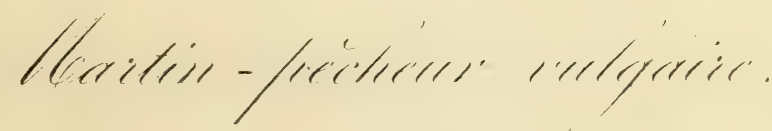



Gense Martin-Péchens. - Alcedo, Linné.

\section{MARTIN-PECGHEUR VULGAIRE.}

ALCEDO ISPIDA, LINNE.

KINGg-TISHER. - GEMEIVE EISTQGR.

MARTIN-PÊChEUR, Buff., pl. enl. 77. - Temm., t. I, p. 424. - Gould., t. III, pl. 61. Naum., t. V, pl. 144. - Degl., t. I, p. 620. - Thie., pl. XI, 13. - VG. Liv.-v. Esthlands, p. 69. - Ornith. Toscana, t. I, p. 178. - Faune Sicile, p. 142. - Vg. Griechenlands, n ${ }^{0}$ 51 . - Ois. de l'Algérie, p. 17. - Vg. N. O. Africa's, n0 91. - Alcedo subisp.da, Brehm.

Ce martin-pêcheur est répandu dans toute l'Europe et se perd dans le Nord; on le trouve aussi dans une grande partie de l'Asie et de l'Amérique. Il choisit pour son séjour les endroits plats et montueux pourvus de fleuves, de fossés et d'étangs; il aime aussi particulièrement l'eau claire et les rives escarpées et touffues; il se tient caché au-dessus ou près de l'eau sur une pierre ou sur une branche. Il vole en ligne droile, très-vite et en rasant l'eau. Lorsqu'il vole, il fait entendre un son aigu et perçant qu'il répète souvent. Le martin-pêcheur est craintif et farouche, querelleur et envieux envers ses semblables, qu'il chasse avec fureur lorsqu'ils paraissent dans la place que cet oiseau s'est choisie. Il se perche souvent pendant des heures entières sur une branche commode, s'y tient immobile, ou bien y guette les petits poissons sur lesquels il se précipite aussitôt qu'ils se montrent à la surface de l'eau, parce que cette manière lui est plus facile que d'entrer dans les profondeurs de l'eau. Lorsque cet oiseau aperçoit un poisson, il se jette dans l'eau avec une grande précipitation, le sasisit avec le bec et se remet avec sa proie sur une branche où il l'avale en commençant par la tête. En volant, il cherche aussi à attraper des poissons; lorsqu'il en aperçoit un, il voltige quelques instants au-dessus de l'endroit où il se trouve, puis s'élance sur lui. Pendant les hivers rigoureux il cherche les ouvertures dans les glaçons, et arrive alors jusqu'au milieu des villes à cause du manque de nourriture qui le fait souvent périr; dans une disette pareille je vis un jour un martin-pêcheur attraper un troglodyte et le dévorer. Dans le besoin il se nourrit aussi de sangsues, d'insectes aquatiques et de leurs larves.

Ces oiseaux nichent ordinairement dès le mois d'avril, lorsque le temps est favorable, parfois encore plus tôt; ils choisissent à cet effet les rives escarpées, près de l'eau; la femelle creuse dans la terre, avec le bec et les pieds, un étroit tuyau de deux à quatre pieds de profondeur; il est élargi au bout où se trouve le nid dans lequel on rencontre au milieu du mois de mai ou au commencement de juin de cinq à sept, quelquefois jusqu'à onze œufs. La femelle est approvisionnée par le mâle dans les temps des couvaisons. Ces oiseaux rejettent les arètes des poissons et les rassemblent pour les faire servir de couches inférieures aux oufs. 



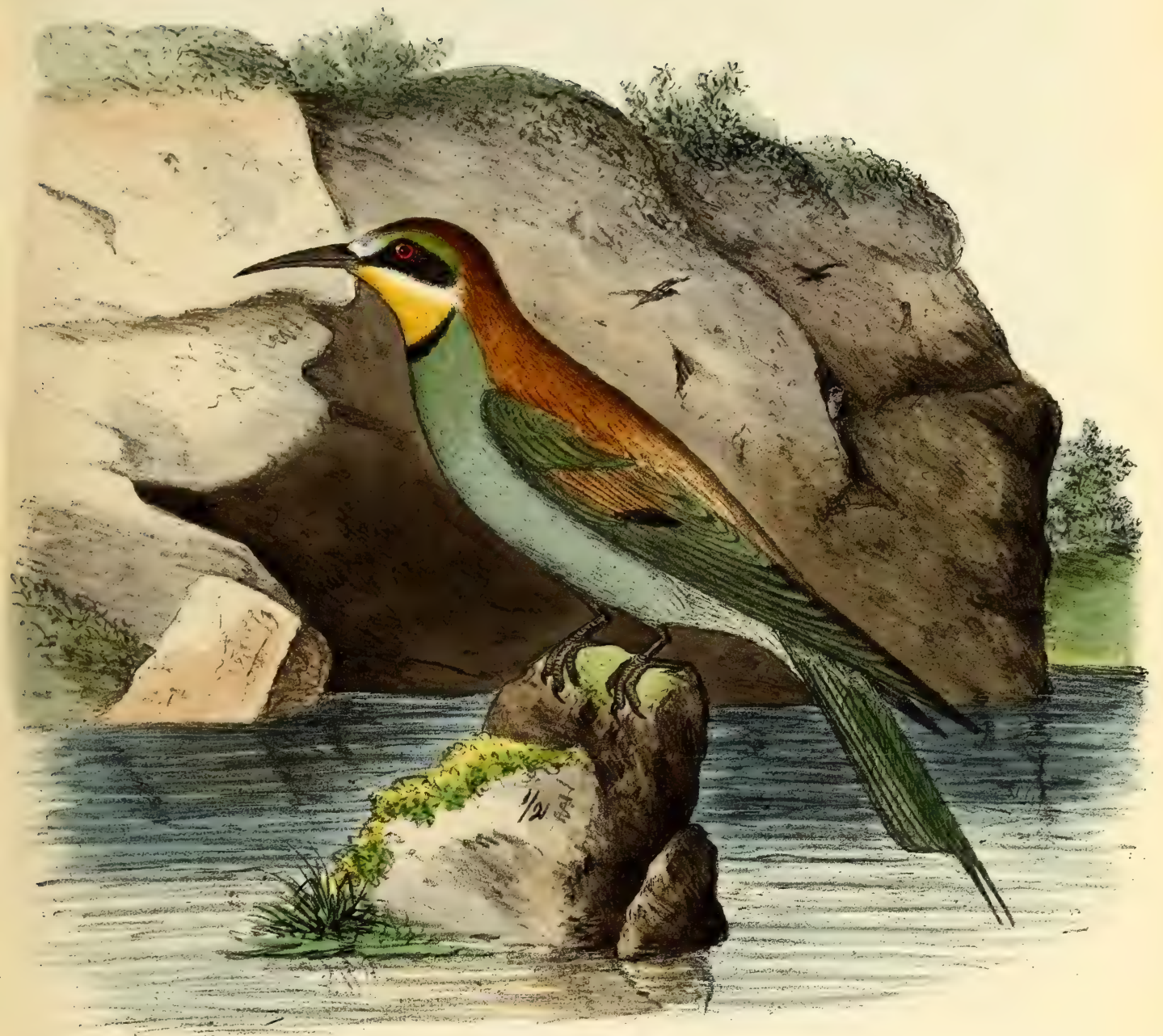





\title{
G U ÉPIER A P I V O R E.
}

\author{
MEROPS APIASTER, LINNE.
}

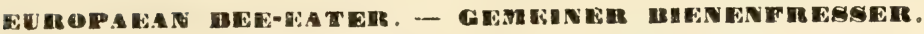

Buff., pl. enl. 938. - Temm., Man., t. 1, p. 420. - Naum., t. V, pl. 145. - Gould, I II, p. 59. Degl., t. I, p. 616. - Thien., pl. XI, fig. 12. - Malh., Faune Sicule, p. 140. - Savi, Ornitr. Toscava, 1. I, p. 174. - V. d. Mühle, Ornith. Griechenlands, no 53. - Merops schaeghagha Forsk. - M. Chrysocephalus, Lath. - M. Congener, Gmel. - M. Galilaeus, Hafselq. - M. Hungariae el Elegans, Brehm.

Le séjour favori de cet oiseau est le midi de la France et de l'Allemagne, la Suisse, l'Italie, la Hongrie, la Grèce, la Turquie et la Russie, jusqu'au fleuve Irtisch en Asie. Mais il quitte ces pays en automne, pour émigrer en Afrique, où on le rencontre à peu près partout, jusqu'au cap de BonneEspérance. Quelquefois on le voit aussi dans l'Allemagne centrale, mais bien rarement dans la Grande-Bretagne et en Belgique. - II y a quelques années, M. Tichon, de Laeken, en tua un près de Dinant; un autre fut tiré près de Tongres, le 23 mai 1850 ; il y en avait trois ensemble, mais l'on n'a pu en abattre qu'un seul, autour duquel les autres ont tournoyé quelques instants avant de partir. On ne les a plus revus. Cet oiseau se trouve actuellement dans la riche collection de M. Duvivier, bourgmestre à Vliermael.

Les guépiers apivores recherchent surtout les contrées montagneuses, les rivages escarpés des fleuves et des lacs; ils aiment aussi les bords de la mer, et on les trouve également le long des grandes rivières, mais rarement dans les pays plats. Ils sont en grand noinbre sur les rives du Don, du Volga et de la Samara, et s'étendent jusqu'à la grande chaine de l'Oural, qui sépare la Russie de la Sibérie. Ils passent la journée à voltiger en troupes nombreuses dans les champs, les prairies, les jardins et les montagnes, à la manière des hirondelles. Quant à leur voix, ce n'est guère que le matin, ou vers le soir pendant qu'ils volent, qu'on peut l'entendre : elle ressemble à un croui, croui, croui qui n'est pas sans une certaine harmonie. Ils ne sont pas timides et se laissent même approcher d'assez près sans s'effaroucher. Une température humide, sans soleil, leur est très-contraire, et, pour s'en garantir, ils passent des jours et des nuils entières dans les trous et les excavations qu'ils trouvent sur les berges des rivières. IIs se nourrissent principalement d'insectes, même de ceux pourvus d'un dard, comme les abeilles, les taons, qu'ils attrapent en volant, avec beaucoup d'adresse.

Les femelles nichent sur les bords des rivières profondément encaissées, à pic, ou dans les rebords des fossés, où elles font, comme les martinspêcheurs, des excavations d'une profondeur de cinq à six pieds, dont l'intérieur est assez spacieux, garni d'herbes et de mousses sèches. Leur ponte est ordinairement de cinq à sept œufs, rarement de plus. 



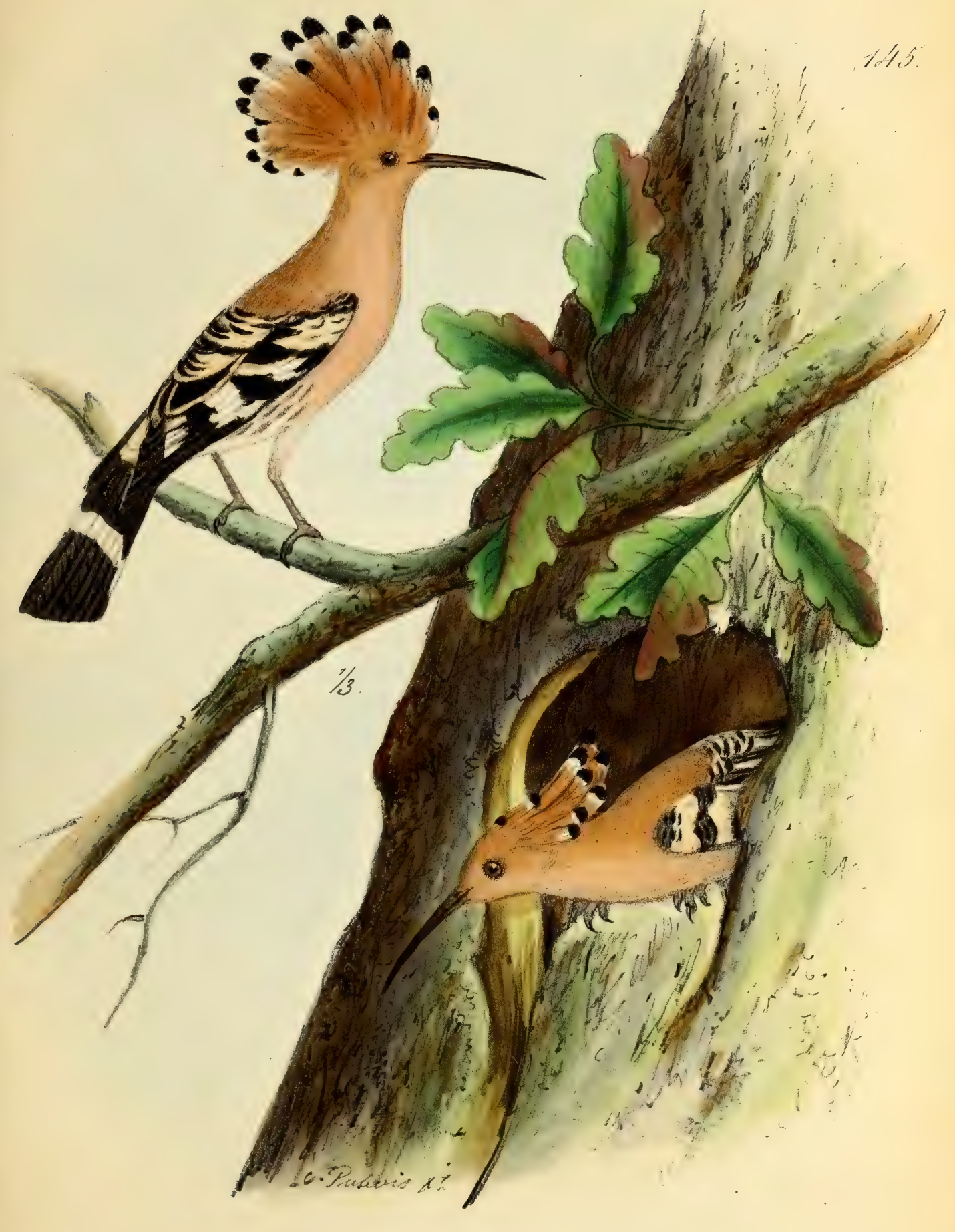

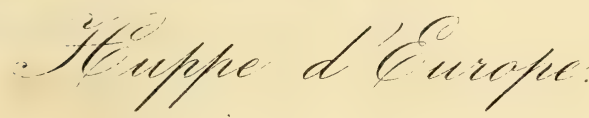



Cenve Toppe. - Upmpa, Linné.

\section{IIUPPE D'EUROPE.}

UPUPA EPOPS, LINNÉ.

hoOPOE. - EUHOPÄISCHE WIEDEHOPF.

HUP PE. Buff., pl. enl. 52. - Temm., t. 1, p. 415. - Gould., p. III, pl. 238. - Naum., t. V, pl. 142. - Degl., t. 1, p. 610. - Thien., pl. XI, 11. - Vg. Liv.-U. Esthlands, p. 56. - ORnith. Toscana, t. I, p. 182. - Faune Sicile, p. 139. - Ois. de l'Algérie, p. 17. - Vg. Griechenlands, $n^{\circ}$ 55. - Vg. N. 0. Africa's, no 102. - Upupa bifasciata, Brebm.

Cet oiseau habite toute l'Europe, à l'exception des parties les plus froides; il n'est abondant que dans les pays du Sud. Il arrive ici au commencement d'avril et émigre en septembre pour l'Asie et l'Afrique. Il choisit pour son sëjour des plaines, des parties montueuses avec des buissons et les lisières des forêts dans lesquelles il ne pénètre pourtant jamais; il aime aussi les environs boisés des villages et les bords des champs et des prairies. La huppe d'Europe est très-farouche et craintive, et par conséquent d'une extrême prudence, aussi se choisit-elle toujours un lieu de retraite. Tout grand oiseau qui vole près d'elle l'effraye; pour échapper à la vue des oiseaux de proie, elle se jette plat à terre, élargit les ailes et la queue, et pose la tête de manière que le bec soit levé; dans cette position elle reste aussi longtemps que l'ennemi réel ou supposé se soit éloigné. Lorsque cet oiseau vole, il rejette la huppe en arrière; lorsqu'il est perché, il l'agite ou la tient droite. En sé reposant sur une branche cachée, il fait entendre son cri retentissant d'appariement, houp houp, ou houp houp houp, en ayant le gosier gonflé; il continue ainsi pendant des heures entières s'il n est point dérangé, faisant des poses régulières, accompagnant chaque syllabe d'un baissement de tête.

La nourriture des huppes se compose de coléoptères, de taupes-grillons, de fourmis et de leurs oufs, de hannetons et de beaucoup d'autres insectes, ainsi que de leurs larves.

Cet oiseau niche dans les arbres creux, dans les trous des murailles, dans les crevasses des rochers, dans les creux des rives, ou sur la terre entre les racines des arbres; il y porte quelques rameaux durs et des brins d'herbe, un peu de mousse, de la fiente de vache et des plumes dont il fait un nid très-léger; il y a ordinairement quatre ou cinq, quelquefois sept œufs, que la femelle couve. La place où se trouve le nid commence dès la couvaison à répandre une mauvaise odeur, parce que la femelle ne quitte jamais son nid dans lequel elle dépose ses immondices; cette odeur ne fait qu'augmenter lorsque les jeunes sont éclos, parce que les vieux ne cherchent point à débarrasser le nid des excréments des jeunes; cette odeur se communique au plumage de ces oiseaux et ne se perd que longtemps après qu'ils sont éclos. 



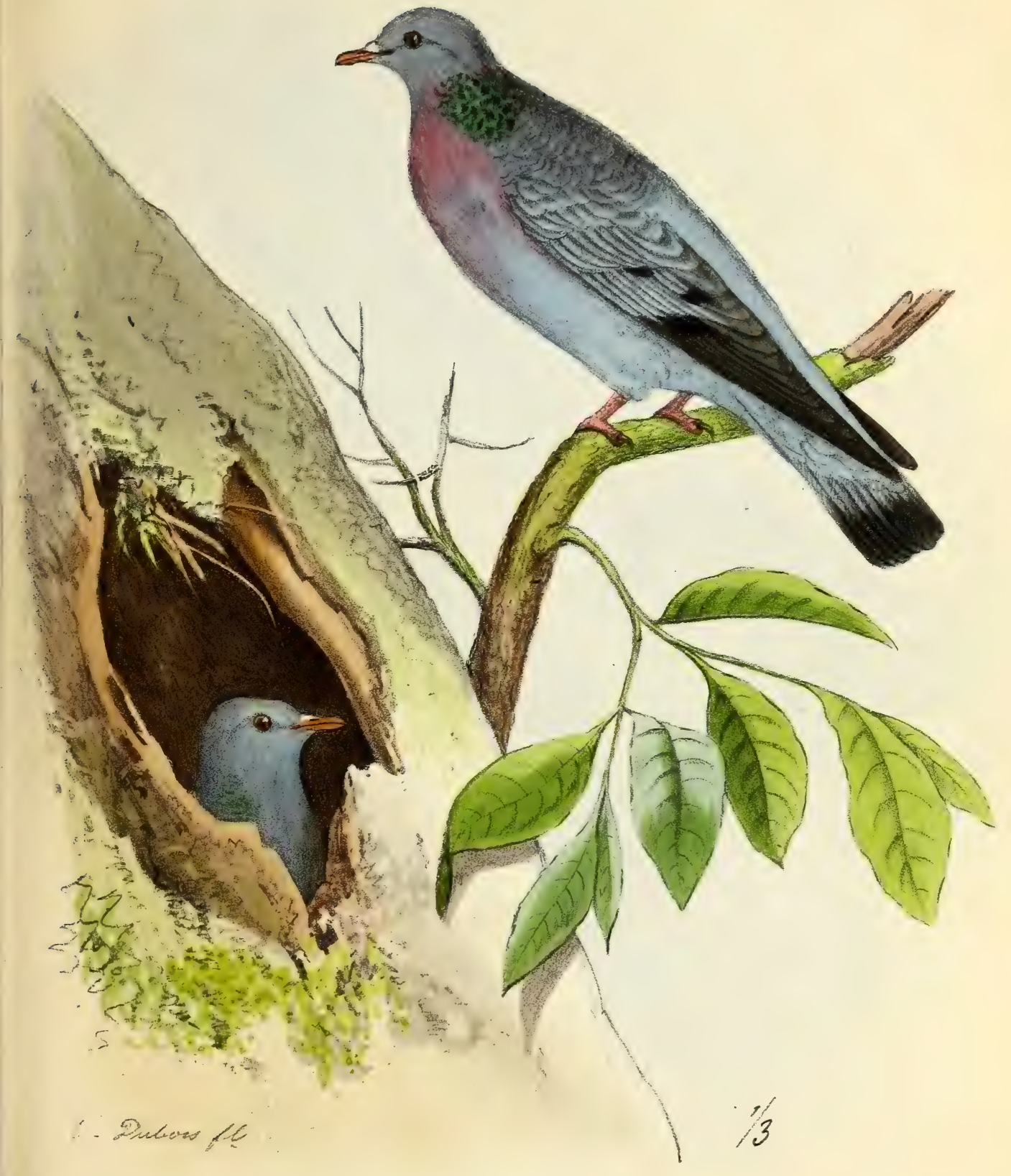

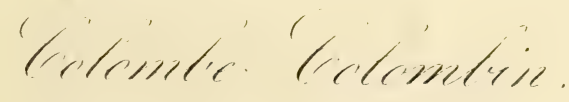



Cenve Colombe. - Columber, Linné.

\section{0 L 0 M B E COL 0 M B IN.}

COLUMBA OENAS, LINNÉ.

STOCK DOVE. - MOHK-TAWEE.

PETIT RAMIER. Buff., pl. enl. 316. - Teum., t. I, p 445. - Naumann, t. vi, pl. 151. Brehm, p. 492. - Gould., t. IV, pl. 244. - Gloger, p. 485. - Schlegel, p. 73. - Degl., t. II, p. 6. - Thienem., Fortp., pl. XII, fig. 5. - Selys-Longch., Faune balge, $n^{0}$ 160. - v. d. Mühle, Vg. Griechenlands, nº 185. - Malh., Ois. d’Algérie, p. 18.

Cette colombe habite toute l'Europe depuis le midi de la Norwége et le centre de la Suède et de la Finlande; en Allemagne elle est commune dans toutes les forêts qui ont des arbres creux; en Belgique, on la rencontre plus rarement; on la trouve aussi dans quelques parties de l'Asie, depuis la Perse jusqu'en Égypte et en Algérie. Ces oiseaux aiment les parties boisées, les petits et les grands bosquets dans le voisinage desquels se trouvent des campagnes et des prairies, car ils volent au-dessus des champs et se posent volontiers sur l'extrême sommet des arbres; lorsqu'ils veulent se tenir cachés, ils se mettent dans les branches épaisses. La nuit, ils dorment dans les troncs creux. La voix du mâle sonne comme houhkouk ou hourkouh avec des tons plus ou moins forts, ordinairement plusieurs fois de suite, comme houh houh houh houh houh. Ils émigrent en société, souvent en grandes volées, arrivent ordinairement au commencement de septembre, et restent alors jusqu'à la fin d'octobre ou au commencement de novembre; lorsque l'hiver est doux, quelques-uns restent même ici.

Leur nourriture se compose de blé, de plusieurs sortes de graines, de baies, de glands et de faînes. Ces oiseaux sont nuisibles dans les endroits où ils paraissent souvent, car ils mangent la semence de navets, de chanvre, de lin et de lentilles, ainsi que beaucoup d'autres.

Ils nichent dans les arbres creux, tantôt haut, tantôt bas; le nid est composé de branches sèches, de racines, quelquefois de mousse et de feuilles sèches; ils y déposent deux œufs; ordinairement ils font trois couvées, la première vers la fin d'avril; lorsqu'ils couvent ils ne quittent point le nid et se laissent quelquefois prendre sur les œufs; on recherche beaucoup les nids pour les jeunes oiseaux qui sy trouvent, car ils constituent un mets fort délicat. 



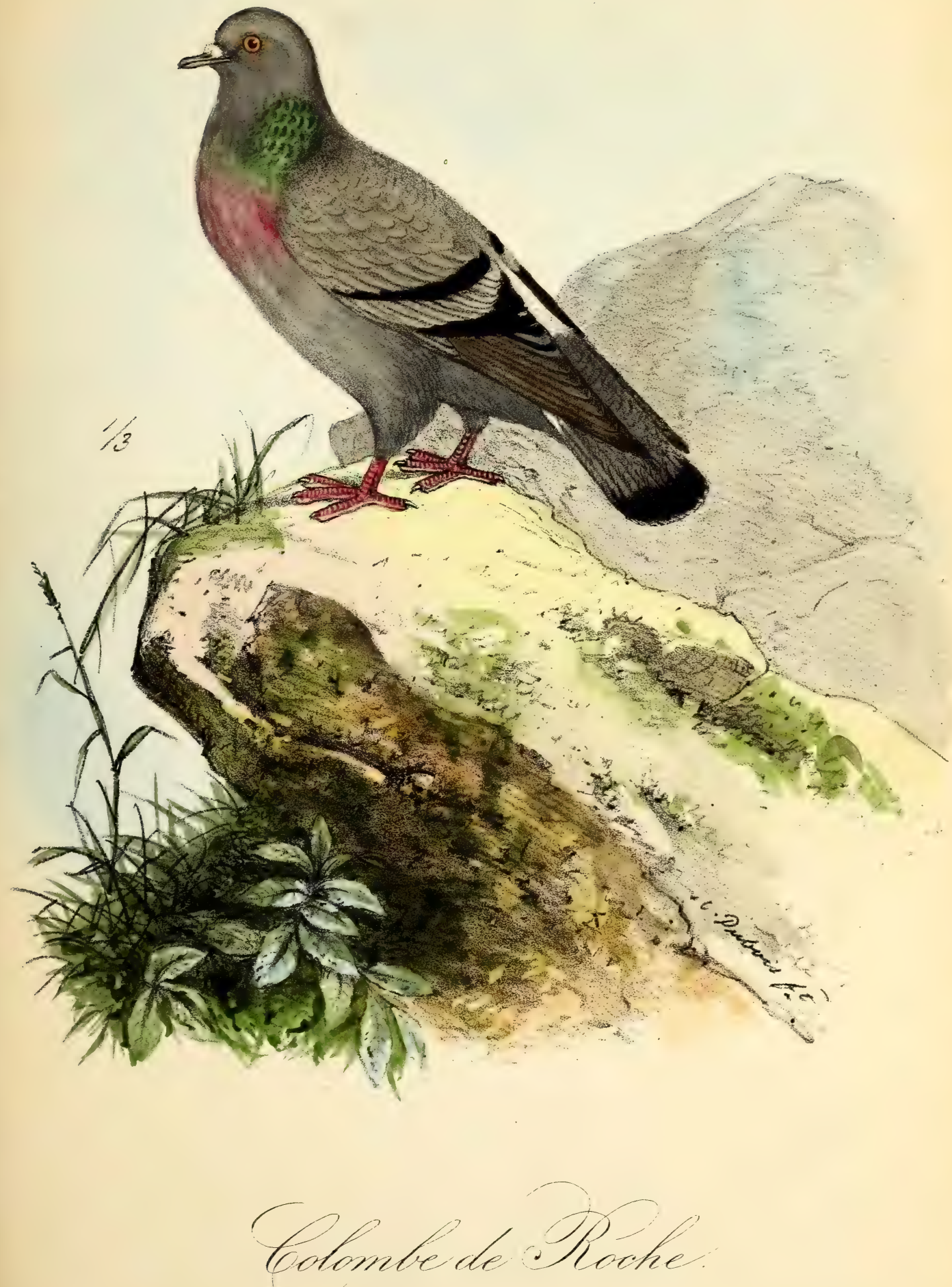





\section{COLOMBE DE ROCHE.}

COLUMBA LIVIA, BRisson.

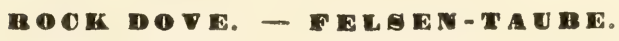

COLOMBE BISET, Buff., pl. enl. 510. - Temm., t. II, p. 446. - Gould, t. IV, pl. 245. Naum., t. VI, pl. 150. - Degl., t. II, p. 8. - Thienem, pl. XII, fig. 6. - Selys-Longch., Faune belge, no 161. - Savi, Ornith. Toscana, t. II, p. 160. - Malh., Faune Sigile, p. 158 . - v. d. Mühle, Vg. Griechenlands, no 186. - Rüpp., Vg. N. O. Afrika, nº 361. - Columba domestica, Gmelin. - C. vulgaris, Gesn.

Cette espèce primitive de la colombe domestique ne se trouve en Belgique que sur quelques rochers aux bords de la Meuse; on la rencontre aussi dans l'Allemagne, au sud de la France, aux îles Britanniques et aux îles Foeroë; elle est en abondance sur les rochers de la Sardaigne, de la Toscane, de Naples, de Sicile, des îles Canaries, en Égypte ainsi que dans quclques parties de l'Asie. Ces oiseaux vivent pour la plupart sur les rochers, dans les crevasses des rocs et dans des grottes profondes et obscures; ils sont rarement sur les ruines, mais ils marquent de la préférence pour les rochers calcaires. Ils ont le vol extrêmement vif et sont farouches; ils se posent rarement sur les arbres; seulement en hiver ils recherchent les forêts montagneuses à cause de leur nourriture qui se compose de semences de hêtre, de pin, de sapins larix et de vesces, ainsi que de beaucoup d'autres graines; ils mangent aussi des racines bulbeuses de plantes, de petites limaces de rivage même avec leurs coquilles, ainsi que des larves dinsectes.

Ils nichent en commun dans les crevasses de rochers, dans les grottes et. même dans les cratères des volcans malgré l'odeur du soufre et la grande chaleur qui au contraire parait attirer ces colombes parce que cette chaleur leur facilite la couvaison. Dans les îles Canaries elles nichent en grande quantité dans les grottes; on se fait même un plaisir de les y poursuivre; les chasseurs entrent dans ces grottes avec des torches, ils en bouchent l'entrée et frappent avec des bâtons au milieu des colombes effrayées dont on attrape un grand nombre vivantes; chaque année on en abat ainsi une grande quantité. Au printemps le jeune mâle se choisit une compagne avec laquelle il reste réuni pendant toute sa vie; il choisit une place pour déposer le nid et fait entendre alors son cri d'appel pour attirer la femelle qui vient aussitôt; le mâle la reçoit avec de grandes démonstrations en enflant le cou, et tourne autour d'elle dans une attitude fière, accompagnant de sourds roucoulements les baisers qu'il lui prodigue. Après quelques jours il conduit la femelle au lieu où il a rassemblé les matériaux pour faire le nid, tels que des branches sèches que la femelle arrange pour y déposer deux cufs. Pour la couvaison le mâle soulage parfois la femelle en la remplaçant sur les œufs jusqu’à ce qu'elle revienne, ils nourrissent tous deux leurs petits. 



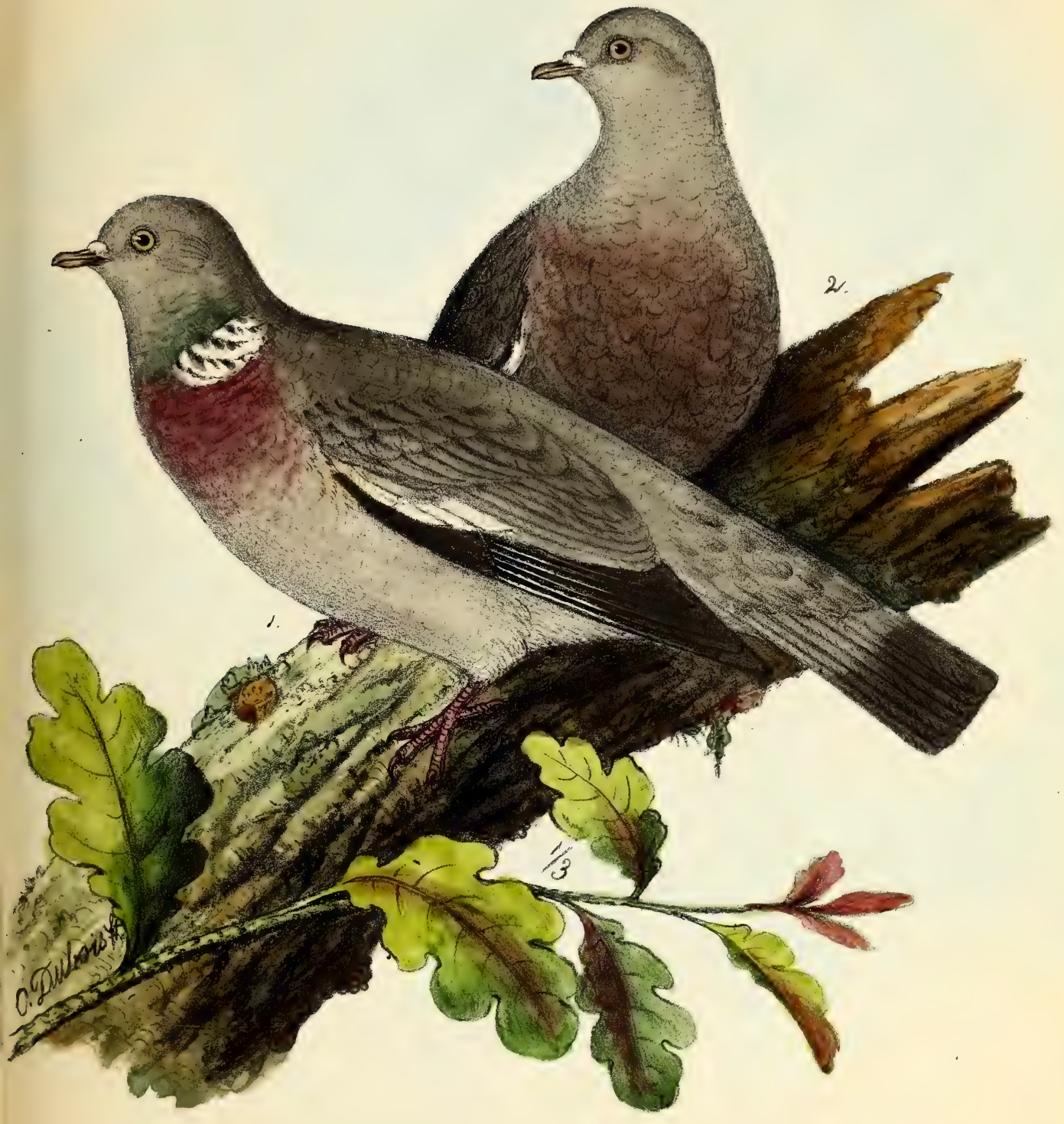

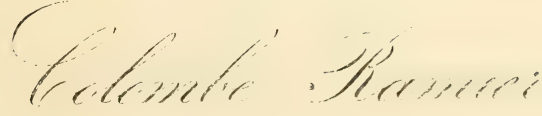

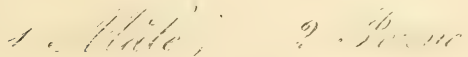





\section{0 L 0 M B E R A II I E R.}

COLUMBA PALUMBUS, LiNNÉ.

IXYG DOVE. - RINGEI,-TAUIBE.

PIGEON RAMIER. Buff., t II, p. 531 ; pl. enl. 316. - Temm., t. II, p. 444. - Brehm, p. 487. - Naum., t. VI, pl. 149. - Degl., t. II, p. 4. - Gould, t. IV, pl. 243. - Thienem., Fortp., pl. XII, fig. 4. - v. d. Mühle, Vg. Griechenlands, no 184. - Savi, Ornith. Toscana, t. II, p. 154. - Malh., Faune Sigile, p. 157. - De Selys-Longch., Faune belge, no 159. Malh., Ois. de l’Algérie, p. 18. - Culumba palumbes, Pall. - C. torquata, Frisch.

Cette colombe, qu'on trouve en Sibérie à l'automne, est répandue dans toute l'Europe; elle émigre en Afrique pour y passer l'hiver, mais celles qui habitent les contrées les plus méridionales restent en Europe et n'émigrent pas; seulement elles voyagent par couples ou par petites volées l'hiver pour chercher leur nourriture, comme cela est le cas en Belgique. Cet hiver-ci, 1855, il en est resté beaucoup ici; aussi la grande quantité de neige qui est tombée a-t-elle été cause de la grande destruction qui s'est faite parmi elles, faute de nourriture. En été on les trouve dans les forêts et dans tous les endroits tranquilles et pourvus d'arbres; quelquefois cependant on les trouve dans les jardins des villes; ici, par exemple, il se trouve au Parc un couple de ramiers qui fait chaque année sa ponte sans se laisser embarrasser par la foule des promeneurs, ni par la musique; tandis que les autres, qui se tiennent dans les endroits écartés, sont extrêmement prudents et farouches. Quoique leur vol soit rapide, il est un peu lourd et bruyant par le claquement des ailes. Le mâle s'élève souvent d'un arbre près du nid, fait un grand cercle dans les airs, puis se laisse descendre, tenant les ailes immobiles et la queue écartée; il fait entendre le cri de houhouh, houhouh, auquel la femelle répond par un autre cri dans le genre de houh ou pouh.

Nourriture : des glands, des semences de hêtre, des myrtilles, ainsi que plusieurs autres baies sauvages; aussi des pois, des semences de lentilles, des vesces, du millet, de l'orge, du seigle; à cause de leur nourriture, les ramiers sont très-nuisibles dans quelques pays, parce qu'en hiver ils s'abattent dans les champs.

Ces colombes nichent ordinairement sur des arbres très-élevés, vers la mi-avril; elles commencent souvent dès le mois de mars, car elles font leur nid longtemps avant. Ce nid se compose de branches sèches et de racines, il contient deux oufs; le ramier choisit souvent des nids abandonnés des corneilles et des écureuils. 



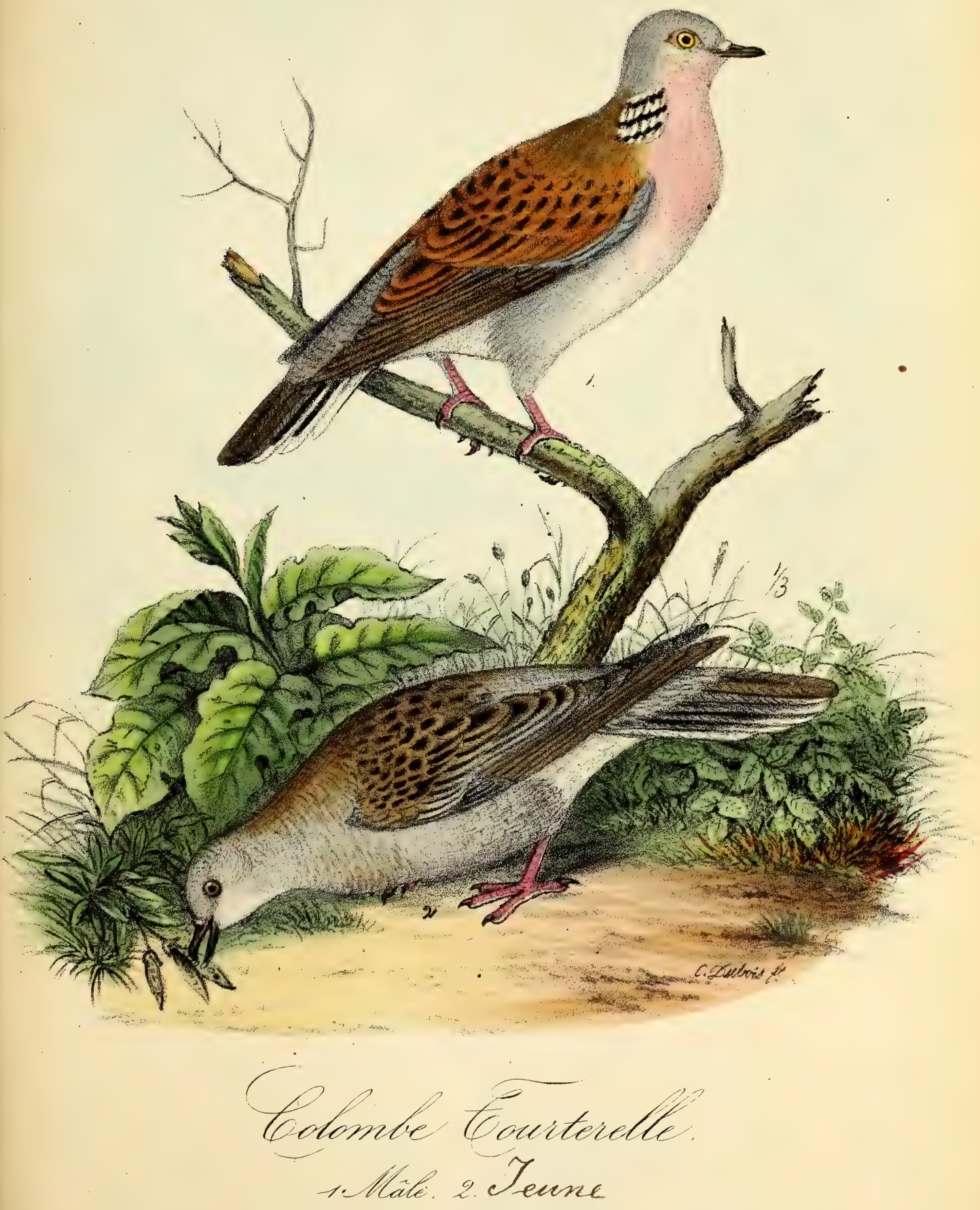





\section{COLOMBE TOURTERELLE.}

COLUMBA TURTUR, LINEE.

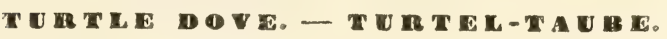

TOURTERELLE. Buff., t. II, p. 545; - pl. ent. 394. - Temm., t. II, p. 448.-Gould, t. IV, pl. 246. - Naum., t. VI, pl. 152. - Degl., t. II, p. 9. - Thienem., pl. XIl, fig. 7. - SelysLongch., Faune belge, no 162. - Savi, Ornith. Toscana, t. II, p. 163. - Malh., Faune Sichle, p. 159. - v. d. Mühle, Vg. Griechenzands, n 167. - Beseke, Vg. Kurlands, p. 71. - Meyer, Vg. Liv.-U. Esthlands, p. 147. - Malh., Ois. de l’Algérie, p. 18. - Rüpp., Vg. N. 0. Afrika's, n³66. - Peristera turtur, Bojé。 - Turtur auritus, Ray.

Cette tourterelle est répandue dans la plus grande partie de l'Europe; l'Écosse et la Suède méridionales forment sa frontière au nord; il est oiseau de passage dans peu de pays chauds, mais pourtant il en reste dans l'Europe du Sud pour y passer l'hiver; il n'est pas rare en Belgique; il se trouve aussi dans une grande partie de l'Afrique et de l'Asie. Ces charmants oiseaux vivent particulièrement dans les parties pourvues de fleuves, de ruisseaux et d'étangs; ils choisissent aussi pour leur résidence d'été des groupes d'arbres, des jardins où ils s'habituent à la vue de l'homme; à part cela, ils sont très-farouches et se tiennent ordinairement cachés dans les arbres touffus; la tourterelle est une charmante créature, gracieuse et douce de mours, mais peu sociable; ces oiseaux vivent par couples, ce n'est qu'en automne qu'on les trouve réunis en petites volées. Le mâle, étant perché, fait entendre sa voix qui ressemble à tourrtourr, tourrtourr, tourrtourr, qu'il répète parfois longtemps, parfois pendant un court espace de temps. Pris jeunes, ils s'apprivoisent à la captivité et sont même enclins à se reproduire.

Nourriture : semences de hêtres, de pins et de sapins, ainsi que beaucoup d'autres.

Ils posent leur nid, le plus souvent bien caché, sur un arbre touffu ou sur des broussailles élevées et ordinairement à une hauteur de 8 à 20 pieds. Le nid est composé de plusieurs couches de petites branches sèches; lorsque ces oiseaux sont dérangés pendant la bâtisse du nid ou la couvée, ils le quittent presque toujours, et comme le mâle fait constamment entendre sa voix dans le voisinage du nid, il n'est pas difficile de le découvrir. Ils pondent deux oufs. 



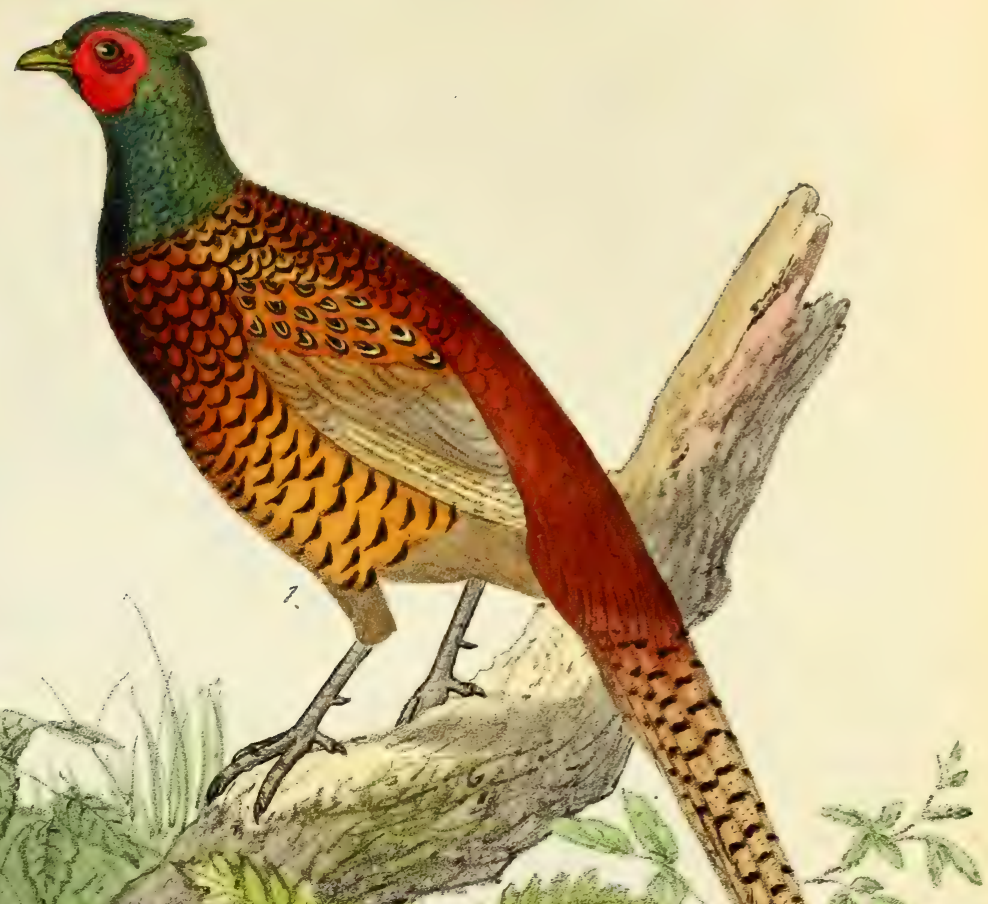

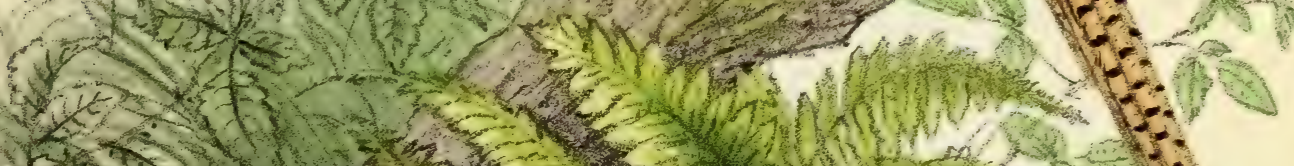

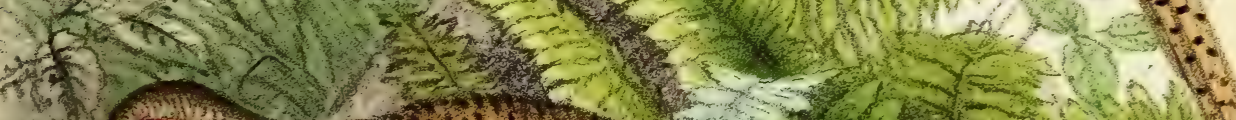

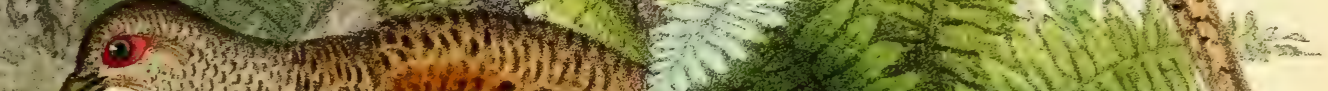

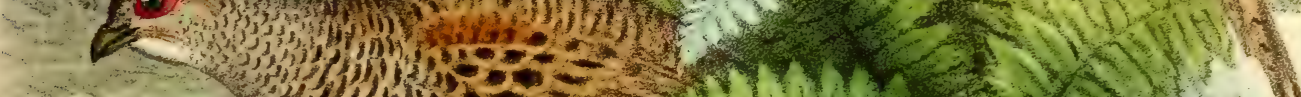

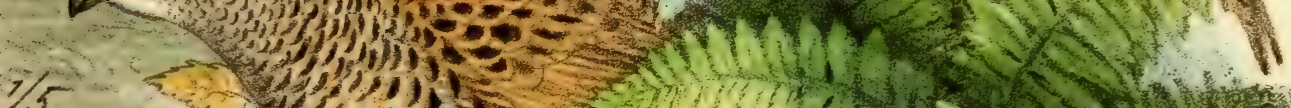

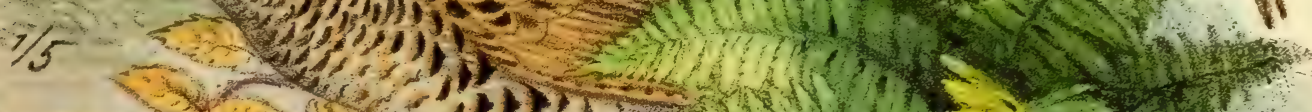

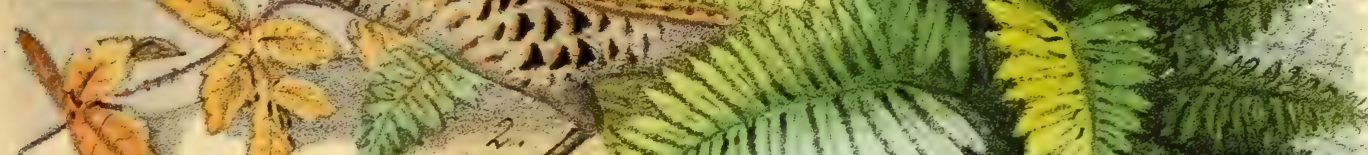
- 15 .

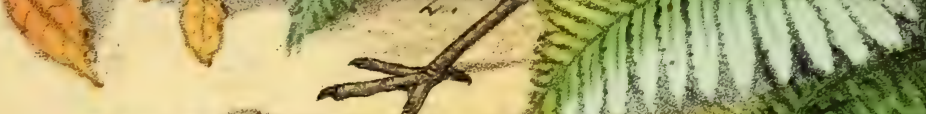

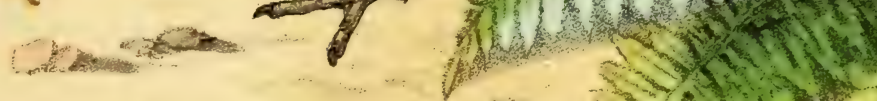

C. 2uxkers:-
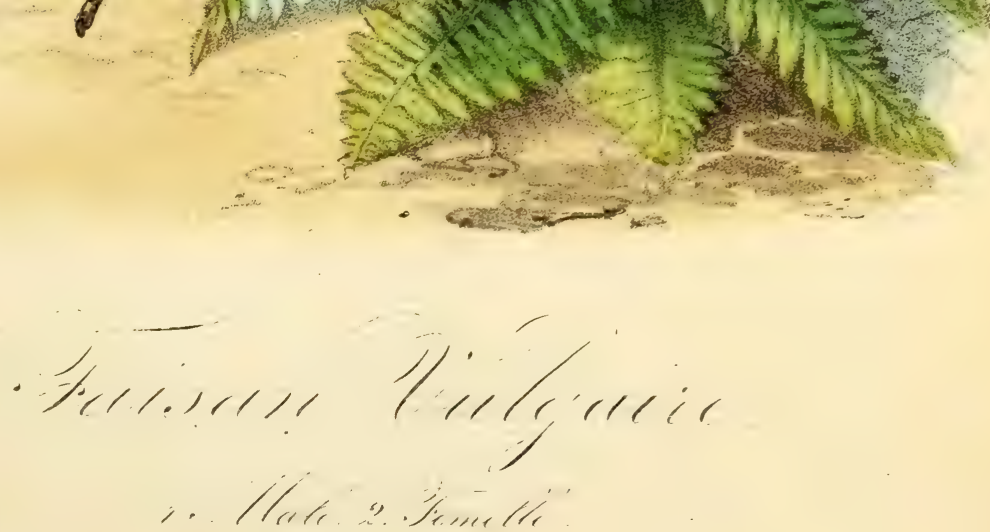

Gemere Ferisane.- Fonsianens, Linné.

\section{FAISAN VULGAIRE.}

PHASINNUS VULGARIS, dubors

COMDON PHEASANT. - GEMEMNE FASAN.

LE FAISAN, Buff., t. II, p. 328 ; - Temm., t. II, p. 453. - Gould, t. IV, p'. 247. - Naum., t. VI, pl. 162. - Degl., t. II, p. 40 - Thienem., Gesam. Vg pl. VII, fig. 3. - Savi, Ornith. Toscana, t. II, p. 174 - v. J. Mühle, V. Griechenlands, no 192. - Phasianus simpliciter, Klein. - Ph. marginatus, Wolf - Ph. colchigus, Linné.

La véritable patrie de cet oiseau est près de la mer Noire, de la mer Caspienne, dans la Tartarie, en Perse, dans la Mongolie, en Chine, et particulièrement dans le Caucase et en Grèce. Dans l'état sauvage, il est également répandu dans l'Europe méridionale et tempérée comme en Hongrie, Autriche, Bohême, Italie, France, dans les lles Britanniques et en Belgique, particulièrement dans la province de Hainaut où on l'a souvent abattu; aussi a-t-on le droit de le classer parmi les oiseanx de la Belgique comme il est rangé parmi les oiseaux des Iles Britanniques, de la France et de l'Allemagne. Le faisan vit sur les lisières des forêts, rarement dans l'intérieur, mais il aime beaucoup les endroits marécageux, fertiles et humides, pourvus de buissons touffus et surtout de fougères et de ronces formant une masse impénétrable; les arbres cependant ne doivent pas manquer; il se tient aussi volontiers dans le voisinage des fleuves et des étangs, ainsi que dans les prairies et les champs, du moment où ceux-ci lui offrent le moyen de se cacher, car cet oiseau est craintif à l'excès; sa crainte pour le danger lui fait souvent oublier tout moyen de se cacher, ce qui permet ordinairement an chasseur de l'attraper, sinon on le prend difficilement parce qu'il se cache toujours bien. En volant on entend souvent son cri tel que hok, hok, hok; le mâle pousse assez souvent un cri qui rappelle celui du coq domestique.

Nourriture : toutes sortes de graines, de semences, des baies, des bourgeons, des insectes et des limaçons.

L'accouplement se fait au mois de mars, le mâle ne se choisit pas d'a. bord un endroit où il reste, mais vole pendant quelque temps avec la femelle, surtout s'il y a des mâles dans le voisinage; lorsque le matin il y a encore d'autres femelles près de l'arbre que le mậle s'est choisi pour y passer la nuit, il vole auprès d'elles, fait entendre son cri joyeux $h o k, h o k$, se promène entre elles, bat des ailes, prend différentes poses jusqu'à ce que les femelles se dispersent, car il se tient toujours avec une seule jusqu'à ce que celle-ci couve et alors il s'associe à une autre, puis à une troisième et à une quatrième. La femelle se choisit une place pour nicher dans un endroit très-caché dans les buissons touffus; elle y forme un creux qu'elle remplit de feuilles sèches et de mousse et y dépose de douze à vingt œufs; lorsqu'on les prend, elle pond jusqu'à trente œufs. 



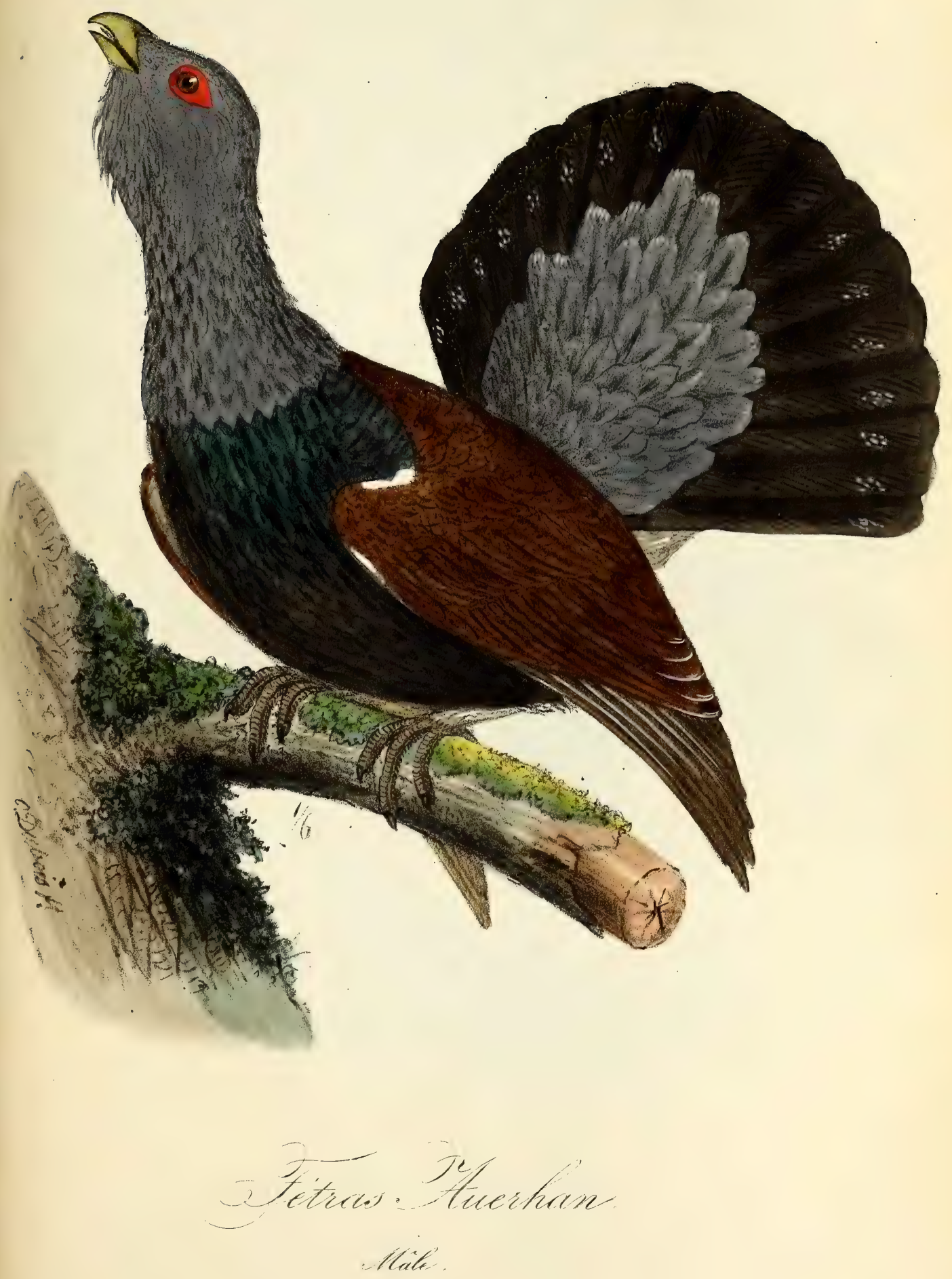



Gemare Tétress. - Telnos, Linné.

\section{TÉTRAS A U ERHA N.}

TETRAO UROGALLUS, LINEÉ.

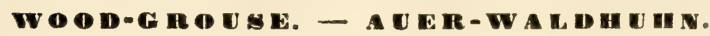

COQ DE BRUYĖRE. Buff., pl. enl. 73.- Temm. Man., t. II, p. 45T.- Naum., Vl, pl. 154.Gould, t. IV, pl. 251. - Degl., t. II, p. 23. - Thienem., pl. XII, fig. 8. - Selys-Longch., Faune belge, no 163. - V. d. Mühle, Ornith. Grieghenlands, n 191. - Savi, Ornith. Toscana, t. II, p. 181. - Urogallus major, Briss. - Tetrao major el T. crassirostris, Brehm.

Ce grand oiseau habite la Sibérie, la Laponie, la Norwége, la Suède, la Russie, la Hongrie et l'Allemagne. On le trouve principalement sur les Alpes de la Bavière, de la Suisse et en Westphalie. On l'a vu aussi dans la forêt de Hertogenwald et même jusque dans les environs de Jalhay, dans la province de Liége. Les régions élevées, couvertes de forêts, où il y a beaucoup de vieux chênes et de hêtres, sont ses lieux favoris; il aime aussi les forêts de pins et de sapins. Parfois il lui arrive de quitter les lieux élevés, et, comme fatigué de leur majesté solitaire, il recherche les endroits bas, couverts de broussailles, entrecoupés de ruisseaux ou arrosés de sources fraiches. En automne, ils se réunissent à plusieurs, pour errer à l'aventure, et alors, au lieu de se retirer dans les hautes inontagnes, ils recherchent fréquemment les sapinières les plus insignifiantes. Leur accouplement dure depuis le mois de mars jusqu'en mai, c'est-à-dire pendant le temps où les feuilles des arbres commencent à pousser ; ils se tiennent alors, le soir, presque toujours perchés sur une forte branche, à une hauteur moyenne. Le mâle devient, le matin, dans l'obscurité, dans toute l'étendue du terme, ivre d'amour; on le voit sur le tronc d'un arbre, les plumes de la tête relevées, les ailes traînantes, la queue étalée, se promener, en prenant toute sorte de postures extraordinaires. Mais il ne se borne pas à cette singulière pantomime, il exprime le besoin qui le tourmente, par un cri qui se fait entendre de loin. Ce cri commence par une espèce d'explosion suivie d'une voix aiguë et perçante, semblable au bruit d'une faux qu'on aiguise; cette voix cesse, et recommence successivement; après avoir ainsi continué à plusieurs reprises, il finit par l'explosion d'un cri très-fort. Pendant qu'il se démène ainsi, les femelles s'assemblent au pied de l'arbre ; on voit alors le mâle en descendre pour montrer à chacune d'elles sa bienvenue. Dans tout autre temps, le tétras est très-défiant et se laisse difficilement approcher; mais, lorsqu'il est agité par de violents désirs, et surtout pendant qu'il fait entendre son cri de rappel, la vue de l'homme, le bruit et même les coups de fusil, rien ne peut le distraire de son espèce d'extase : on le croit sourd et aveugle, il n'est qu'amoureux.

Leur nourriture consiste en bourgeons, en semences de hêtres, de pins et de sapins,et toute sorte de baies, plus rarement des insectes.

Les femelles nichent à l'écart dans les lorêts, sous d'épais taillis; leur nid consiste en une excavation qu'elles creusent elles-mêmes et qu'elles garnissent de quelques fenilles sèches. Leur ponte est de sept jusqu'à treize outs. 


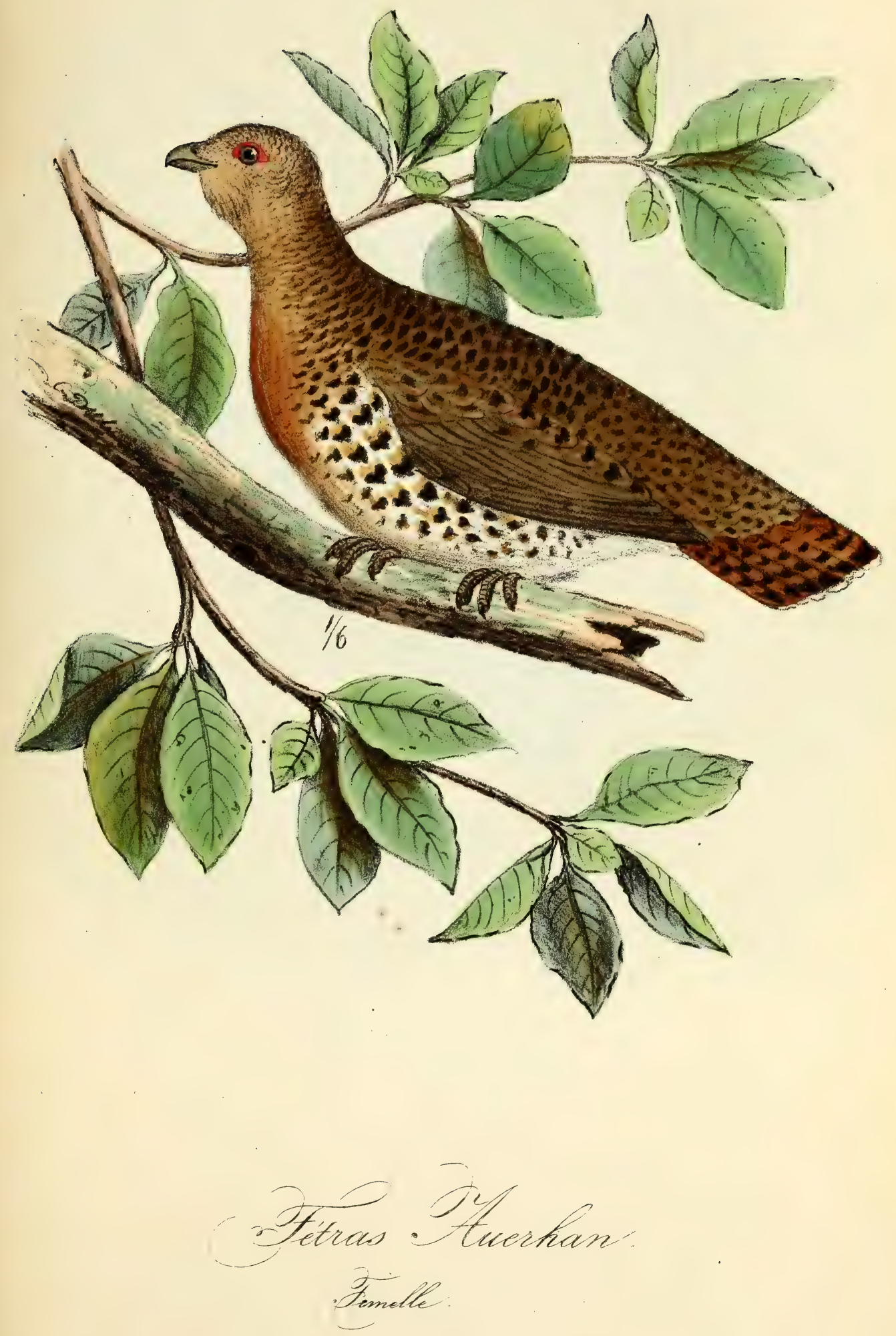


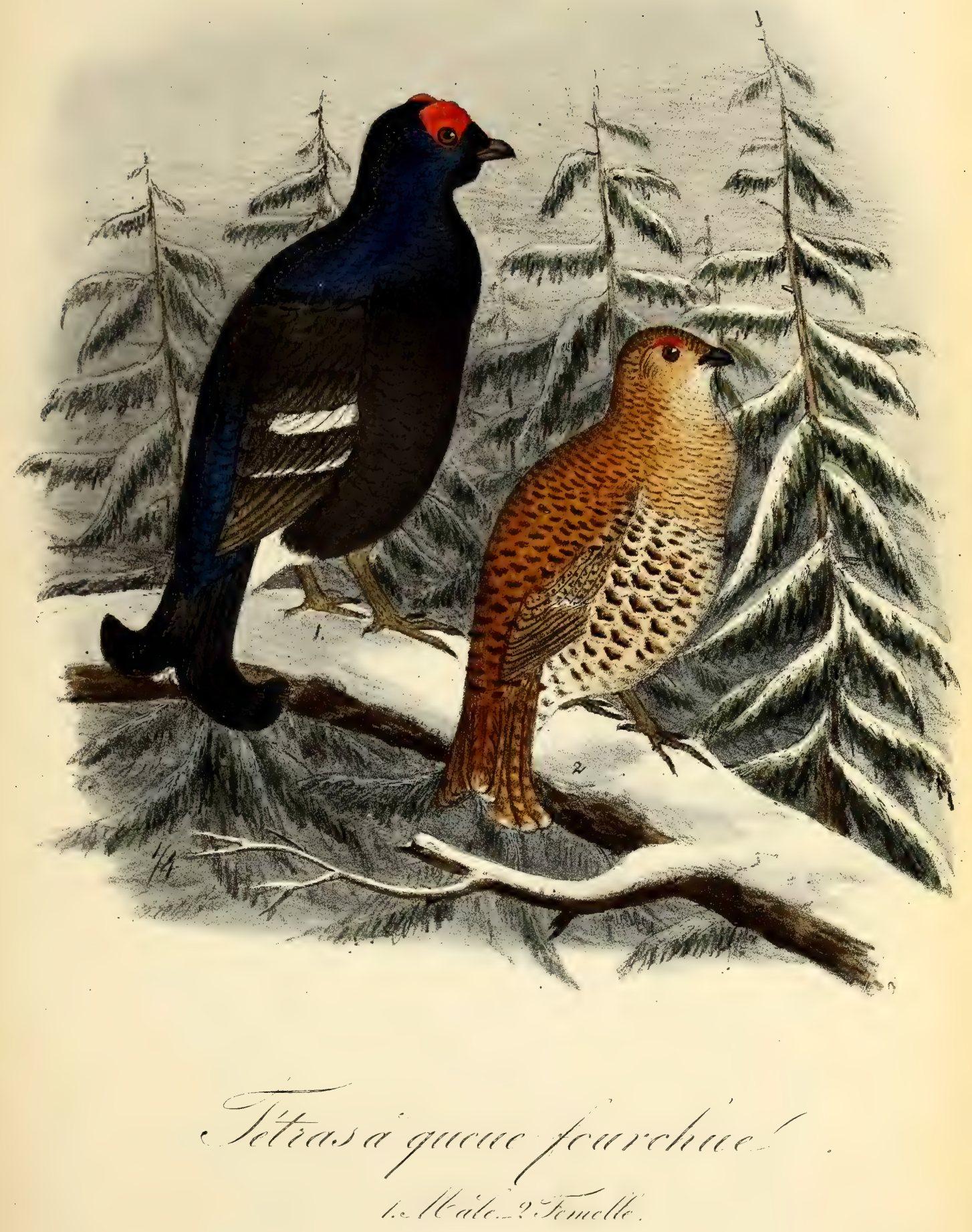



\section{TÉTRAS A QUEUE FOURCHUE.}

TETRAO FURCATUS, dUBOIS.

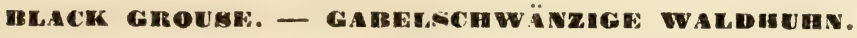

Buff., pl. enl. 172. - Temm., t. II, p. 460. - Naum., t. VI, pl.157.-Degl., t. II, p. 26. - Gould., t. IV, pl. 250. - Thien., p. XII, fig. 9. - De Selys-Longch., Faune belge, no 164. - Savi, Ornith. Toscana, t. II, p. 179. - Mey., Vg. Liv-u. Estrands, p. 150. - Beseke, Vg. Kurlands, no 145. - Urogallus minor, Briss. - Tetrao tetrix, Linné. - T. peregrinus, juniphorum et ERICEUS, Brehm.

Cet oiseau habite la partie centrale et le nord de l'Europe ; on le voit en Allemagne, en Danemark, en Écosse, en Suède et en Norwége ; mais il est rare en Hollande, en Belgique et en France. Il fréquente aussi la Russie, et, en Asie, la Sibérie. Les contrées ouvertes, boisées, un peu montagneuses et entrecoupées de marais, sont celles qu'il préfère,surtout si les hêtres y abondent; il aime aussi les grandes plaines où il y a beaucoup de bruyères, mais il évite, autant que possible, les forêts de haute futaie. II est d'un caractère remuant, volage, mais très-sociable, et il n'est pas rare de voir, en automne, depuis vingt jusqu’à trente tétras de cette espèce ensemble. Ils mènent alors une vie errante, vagabonde, et s'éloignent souvent à une grande distance de l'endroit où ils se tenaient. Ils volent très-loin, avec rapidité et légèreté. A la course, ils sont passablement agiles. Au mois de mars, le mâle se choisit, tous les soirs, un arbre propice pour y établir le théâtre de ses amours; il s'installe sur une branche à une hauteur moyenne, et prélude à ses extases par un sifflet court, saccadé, auquel succède une espèce de roucoulement comme celui du coq d'Inde; puis il commence à danser sur sa branche, en faisant les contorsions les plus folles; il va, il vient, et, s'il est seul, il prend les poses les plus drôles; mais si d'autres mâles de la même espèce se trouvent dans le voisinage, ils se réunissent pour continuer ensemble le même manége, et pour se livrer des combats acharnés, en se roulant et en se trainant par terre, sans toutefois se faire beaucoup de mal. Pendant ce temps, les femelles s'assemblent en cachette dans les broussailles au pied de l'arbre, et annoncent leur présence par des gloussements doux et cadencés ressemblant à un toc, toc. Après le lever du soleil, le mâle descend et se rend auprès de sa femelle. Ces tétras sont d'une timidité extrême, et ils sont constamment sur le qui-vive, et même au temps de leurs amours, au plus fort de leurs danses furibondes, ils sont toujours attentifs et observent ce qui se passe autour d'eux; la moindre apparence de danger les met en fuite. Ils se nourrissent de baies, de graines et des bourgeons d'arbres, mais ils paraissent aimer moins les insectes et les vers.

Au mois de mai, la femelle cherche un endroit favorable dans la forêt pour y nicher, et ordinairement elle choisit, au pied d'un arbre, une excavation tapissée d'herbe et de mousse et abritée par des broussailles. Sa ponte est de six jusqu’à seize œufs; aussitôt quils sont tous éclos, la mère conduit les petits vers une fourmilière pour leur apprendre à chercher leur nourriture. Sa tendresse et ses soins pour sa couvée sont excessifs : à l'apparence du moindre danger, elle appelle ses petits et les assemble sous ses ailes pour les cacher. Pendant la nuit et dans les grandes pluies, ils se réfugient également sous les ailes de leur mère, qui ne se lasse point de leur prodiguer ses plus tendres soins. 


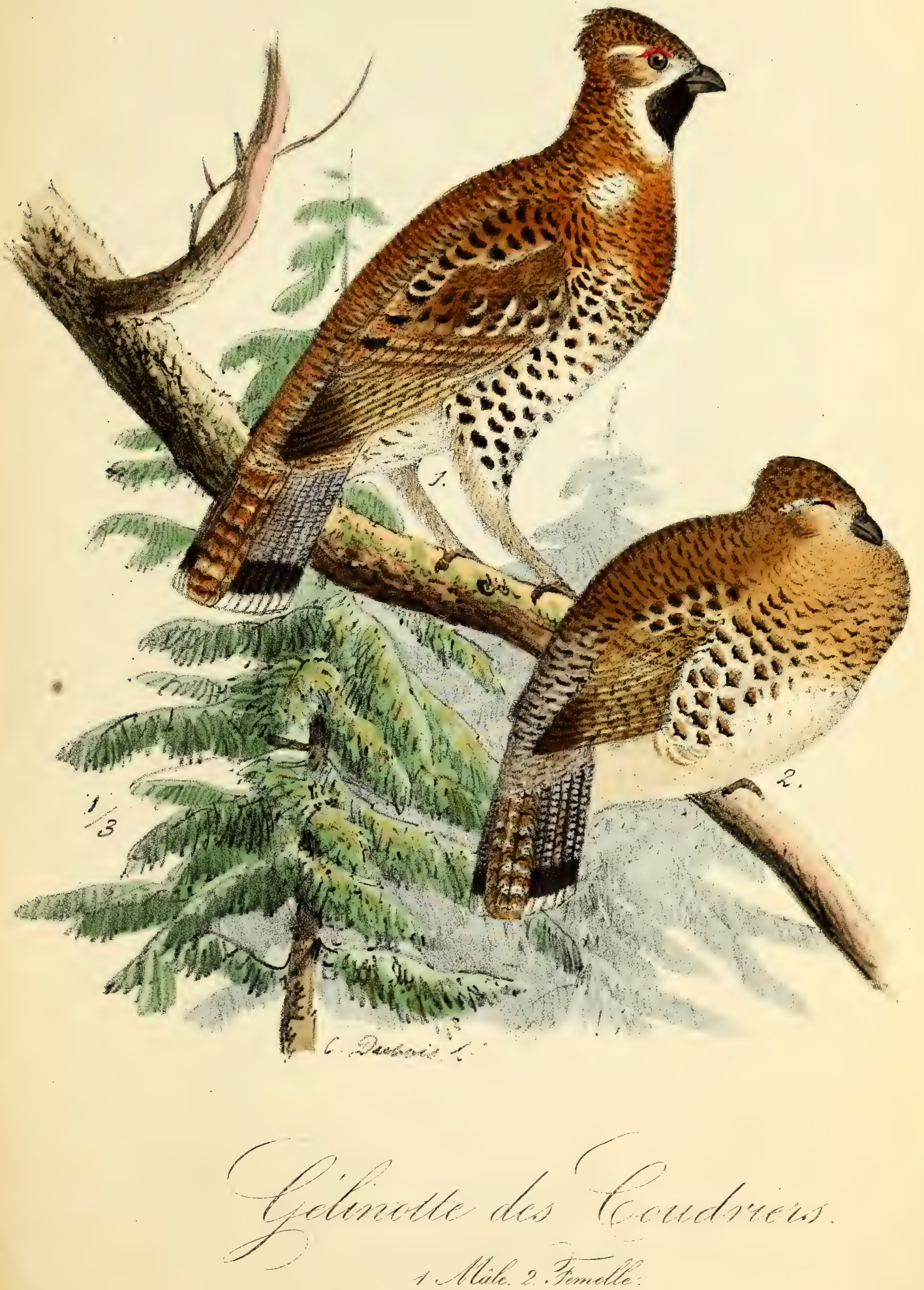

Cenre Célimotce. - Tetrastes, Keys. et Blas.

\section{GELINOTTE DES COUDRIERS.}

TETRASTES BONASIA, KEYS. et BLAS.

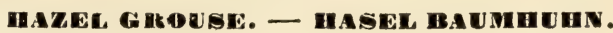

GÉLINOTTE, Buff., t. II, p. 153; - pl. enl. 474. - Temm., t. II, p. 163. - Gould, t. IV, pl. 249. - Naum., ı. VI, pl. 158. - Degl., t. II, p. 30. - Brehm., Hand, p. כ̃13. - Thienem.? pl. XII, fig. 10. - Selys-Longch., Faune Belge, no 165. - Meyer, Vg. Liv.-u. Esthlands, p. 151. Savi, Ornith. Toscana, t. II, p. 183. - Lagopus bonasia, Klein. - Tetrao bonasia, Linné. T. canus, Sparm. - Bonasia rupestris, Brehm. - B. europea, Gould. - T. svlvestris, Bonap. - B. Betulina, Strickl.

La gélinotte vit dans le nord del'Asie et est très-commune dans le nord de l'Europecommeen Suède, en Finlande, enRussie, en Pologne ; on la trouve aussi dans toute l'Allemagne, quoique plus rare d'un côté que de l'autre; elle est également en France dans les Pyrénées et dans le Dauphiné; rarement en Belgique où elle paraît parfois dans les Ardennes vers les frontières prussiennes et dans le voisinage de Malmédi ; selon M. Temmink, cet oiseau n’a jamais été remarqué en Hollande. La gélinotte habite les forêts montagneuses, particulièrement celles qui ont diverses espèces d'arbres comme des pins, des sapins, des bouleaux et des coudriers; il aime aussi les forêts ayant des places non ombragées; comme il aime assez à être caché, il se tient ordinairement dans les buissons peu élevés. En automne ces oiseaux recherchent les bois de sapins dans lesquels ils ont plus de facilité pour se cacher; leurs poses à terre sont ordinairement courtes, et on neles remarque jamais sur les arbres de haute futaie. Dans la plupart des contrées qu'habitent ces oiseaux ils y restent constamment en toutes saisons; dans d'autres on les voit pendant l'automne et l'hiver voltiger de côté et d'autre en petite société. Lorsqu'on les chasse ils ne volent jamais trèslongtemps, aussi les rappelle-t-on en contrefaisant leur voix, même après qu'on a tiré sur eux plusieurs coups de fusil; leur chair, qui est extrêmement tendre, est fort estimée.

Variétés accidentelles : presque blanc ou d'un roux pâle; quelquefois blanc ayant des plumes isolées de leur couleur ordinaire.

Nourriture : particulièrement les boutons et les bourgerons du hêtre, du bouleau, du pin, du sapin, des baies de toutes sortes et des insectes.

Les couples se réunissent au mois de mars ou d'avril; dans ce temps le mâle se perche sur un arbre et fait entendre son cri d'appel qui se compose d'un sifflement perçant et prolongé ; il le commence le matin et continue quelquefois jusque bien avant dans la nuit; la femelle y répond bientôt et ils ne tardent pas à se rapprocher l'un de l'autre; le mâle élève alors les plumes de la tête et du cou, et prend différentes poses. Au mois de mai ou au commencement de juin, la femelle cherche une place pour nicher sous une pierre aussi cachée que possible, dans un enfoncement qu'elle a trouvé ou qu'elle a fait, et elle y dépose sur des brins d'herbe sèche, des feuilles ou des branches fines, de huit à quinze oufs; elle les recouvre de feuilles sèches et d'herbe, ce qui fait qu'on les trouve difficilement. 



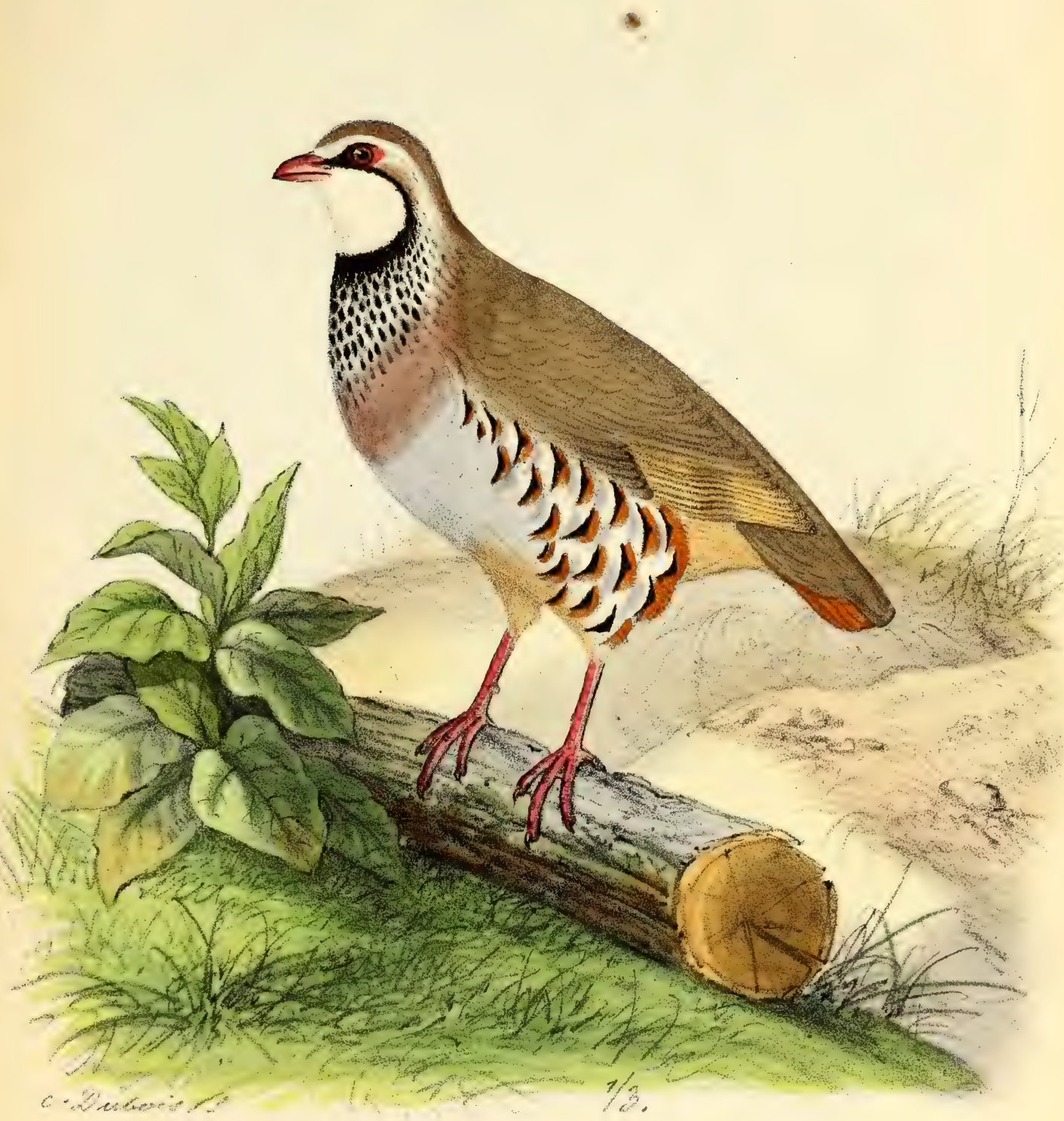

$$
\text { - Jiedix Serroge }
$$





\section{PERDRIX R0UGE.}

PERDIX RUBRA, BRISSON.

IR GD-LEGGED PARTRIDGE, - ROTHE IEPPHAHN.

Buff., t. II, p. 133; - pl. enl. 150. - Temm., t. II, p. 485. - Gould., t. IV, pl. 260. - Naum., t. VI, pl. 165. - Degl., t. II, p. 53. - Thienem., pl. XIII, fig., 2. - Selys-Longch., Faune belge, $n^{\circ}$ 166. - Savi, Ornith. Toscana, t. II, p. 193. - Malh., Faune Sicile, p. 153. - Tetrao Rufus, Linné. - Perdix Rufa, Lath.

Cette perdrix habite particulièrement la France méridionale, l'Italie et la Dalmatie; on la voit plus rarement dans le sud de l'Allemagne, aux Iles Britanniques et elle ne parait qu'accidentellement en Belgique. Pour son séjour, cet oiseau recherche les mêmes districts que la perdrix grise, mais il préfère les places sèches et pierreuses aux places humides et fertiles; il se pose sur les buissons et les arbres peu élevés, aimant particulièrement, pour s'y reposer la nuit, les petites éminences ou monticules. La perdrix rouge est moins sociable que la perdrix grise; quoique vivant par familles, les perdrix rouges sont généralement peu réunies entre elles et bien qu'élevées ensemble elles se tiennent éloignées les unes des autres, et se dispersent le matin de tous côtés; à l'exception du temps de l'accouplement, elles ne s'appellent pas. Au printemps elles se dispersent par couples, alors le mâle fait entendre souvent son cri répété et prolongé; il reste avec la femelle jusqu’à ce que celle-ci couve, alors il la délaisse sans se soucier des petits, ce n'est que lorsque ceux-ci sont déjà grands qu'il revient auprès de la femelle. On les chasse avec les chiens couchants; la chair tendre et d'un fort bon goût est estimée.

Variétés accidentelles : blanc, taché de blanc, ou tout le plumage plus clair qu'à l'ordinaire.

Nourriture : semences, grains, différentes plantes, insectes, leurs larves et des vers.

La femelle dépose son nid au bord d'un champ, d'une prairie ou dans une autre place semblable, sous l'herbe ou les buissons où elle se forme un enfoncement, s'il n'est pas tout fait, pour y déposer ses dixà vingt œufs sur de l'herbe ou des feuilles sèches. 


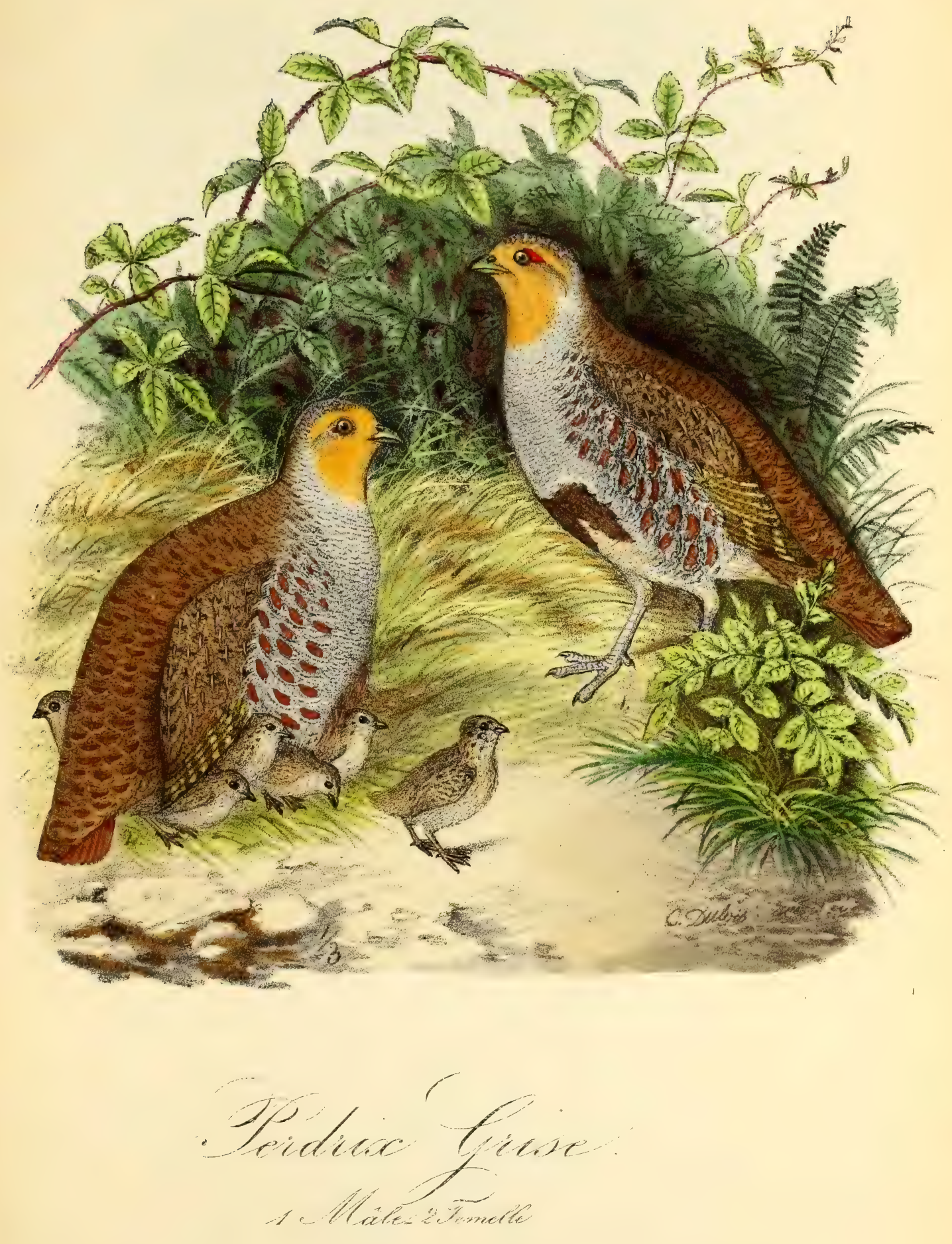



\section{PER D R I X GR ISE.}

PERDIX CINEREA, BRISSON.

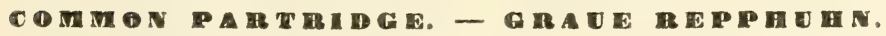

Buff., t. II, p. 401 ; - pl. enl. 27. - Temm., t. II, p. 488. - Gould., t. IV, pl. 262. - Naum., t. V, pl. 163. - Degl., t. II, p. 57. - Schleg., p. 88. - Thienem., pl. XIII, fig, 4. - SelysLongch., Faune belge, no 167. - Savi, Orinith. Toscana, t. II, p. 195. - Malh , Faune Sicile, p. 15̃4. - Beseke, Vg. Kurlands, p. 71. - Meyer, Vg. Liv.-u. Esthlands, p. 165. - Tetrao Perdix, Linné. - T. moxtanus, Gmelin. - Perdix vulgaris, Charlet. - Starna Perdix, Bonap. -St. cinereA, Key, et Blas.

Habite une grande partie de l'Europe le nord de la France, la Belgique, la Hollande, l'Allemagne, le Danemark, la Suède méridionale, la Turquie, la Russie, la Crimée et les parties occidentales de l'Asie ainsi que le nord de l'Afrique; ces oiseaux vivent dans les environs des champs, dans les parties qui ne sont pas trop boisées, de préférence celles qui sont entrecoupées de petits bois, et dans les prairies, et dans les champs de trèfles et de pommes de terre qui sont pourvus de haies ou d'autres broussailles. Après la couvaison ils se réunissent par familles, passent la nuit pressés les uns contre les autres, dans les champs et dans les prairies; à leur réveil, après s'être mutuellement appelés ils s'élèvent deux ou trois fois dans les airs pour se poser à une certaine distance où ils attendent le lever du soleil pour se mettre à la recherche de leur nourriture qui se compose de semences, de graines, de baies, de vers, d'insectes et de leurs larves; ils aiment particulièrement les larves des fourmis. Il est à remarquer que non seulement ils cherchent leur nourriture en commun, mais encore que pendant ce temps l'un d'entre eux veille à la sûreté générale en faisant sentinelle; pendant la nuit il $\mathrm{y}$ en a aussi toujours un à une petite distance qui veille pour les autres, à cause des chasses fréquentes qu'on leur fait ils sont devenus farouches.

Variétés accidentelles : blanc, taché de blanc ou couleur isabelle.

Au commencement de mars ils se réunissent par couples et se choisissent alors une place propre à y faire leur nid, quoique les différentes familles tâchent de rester autant que possible dans le voisinage; la femelle fait un enfoncement dans la terre au bord d'un champ ou d'une prairie, sous l'herbe ou des broussailles et ordinairement bien caché; elle y dépose, vers la mi-avril, de 10 à 20 oufs. S'il y a dans les environs plus de femelles que de mâles, elles se tiennent à deux près du mâle et déposent les œufs dans un nid commun, de manière qu'on en a déjà trouvé 40 dans un seul nid; lorsqu'il y a danger la femelle quitte le nid et cherche à en écarter l'ennemi. Après de longs détours, elle y retourne plus tard. Les petits sont très-développés en quittant le nid, il est même très-difficile d'en prendre un avec la main, car ils courent ayant parfois sur eux des débris de coquilles d'œufs; les vieux grattent la terre pour y découvrir les fourmis, afin de montrer à leurs petits à prendre leur nourriture. 


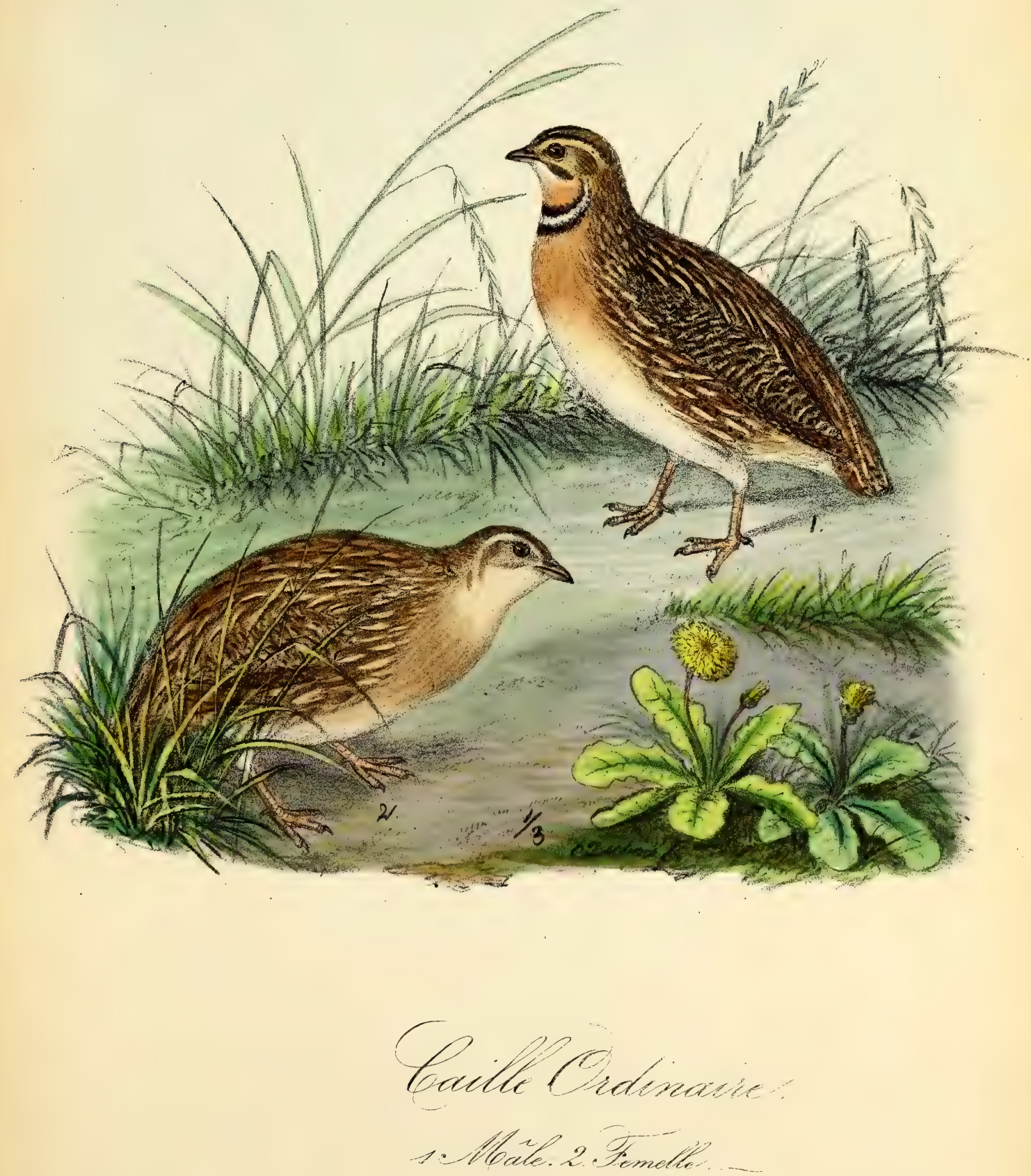



\section{Henre Coille. - Coturmix, Brisson. \\ C A I L L E O R D I N A I R E.}

COTURNIX VULGARIS, JARDINE.

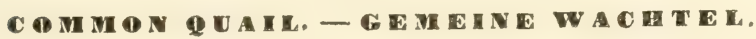

Buff., t. II, p. 449 ; - pi. enl. 170. - Temm., t. II, p. 491. - Gould, t. II, p!. 263. - Naum., t. VI, pl. 166. - Degl., t. II, p. 63. - Thienem., pl. XIII, fig. 5. - Selys-Longch., Faune belge, no 168. - Savi, Ornith. Tosgana, t. II, p. 199. - Malh., Faune Sicile, p. 15̆5̆. - v. d. Mühle, V. Griechenlands, no 196. - - Malh., Ois. de l'Algérie, p. 18. - Rüpp., Vg. N. 0. Afrika's, no 383. - Tetrao coturnix, Linné. - Perdix coturnix, Lath. - Ortygion coturnix, Key. el Blas. - Coturnix dactyusonans, Meyer. - C. major, Briss. - C. communis, Bonnat. C. europea, Swains. - C. europeus, Selby.

Elle habite, depuis le Japon, la plus grande partie de l'Asie, de l'Afrique et de l'Europe à l'exception des parties froides et des hautes montagnes; elle aime particulièrement les districts fertiles et surtout les champs de pommes de terre, de trèfles et de froment; elle fuit les terrains humides, boisés ou montagneux. Le principal cri de la caille est ordinairement pickterwick qu'elle répète tantôt de quatre à cinq fois, tantôt de six à huit et rarement de douze à treize fois. Dans les pays plus froids elles ne supportent pas bien l'hiver et quittent pour cela l'Europe en automne pour aller se diriger vers l'Afrique par la mer Méditerranée; vers ce temps presque toutes les lles du sud de l'Europe particulièrement en Grèce en sont pourvus abondamment, car les cailles s'y rassemblent par millions en attendant un vent favorable; alors elles s'élèvent pour le départ comme un immense nuage noir. Elles se reposent sur les îles et les rochers qu'elles rencontrent; la fatigue les fait tomber parfoiş par milliers sur les navires; les tempêtes en détruisent aussi un grand nombre. Arrivées en Égypte elles sont si fatiguées qu'on peut les prendre avec la main, comme cela s'est déjà vu il y a bien des siècles lorsque Moise a nourri avec des cailles son peuple mécontent. A leur retour à la mi-avril elles sont toutes aussi épuisées et restent près d'un quart d'heure sans faire le moindre mouvement; aussi les habitants des îles qui guettent leur passage les prennent et en font de grandes provisions; les enfants mèmes les abattent avec de grands bâtons: on les plume et on les met dans des tonneaux avec du sel, puis on les expédie à l'étranger, ce qui forme une grande ressource pour les habitants de ces côtes.

Variétés accidentelles : blanc, taché de blanc et d'un blanc rougeâtre.

Nourriture : principalement des insectes et leurs larves, des vers, des semences et des grains. La femelle pond dans un petit enfoncement abrité par de l'herbe, pard'autres plantes ou par un monticule, sur un peu d'herbe sèche, de huit à seize œufs. 



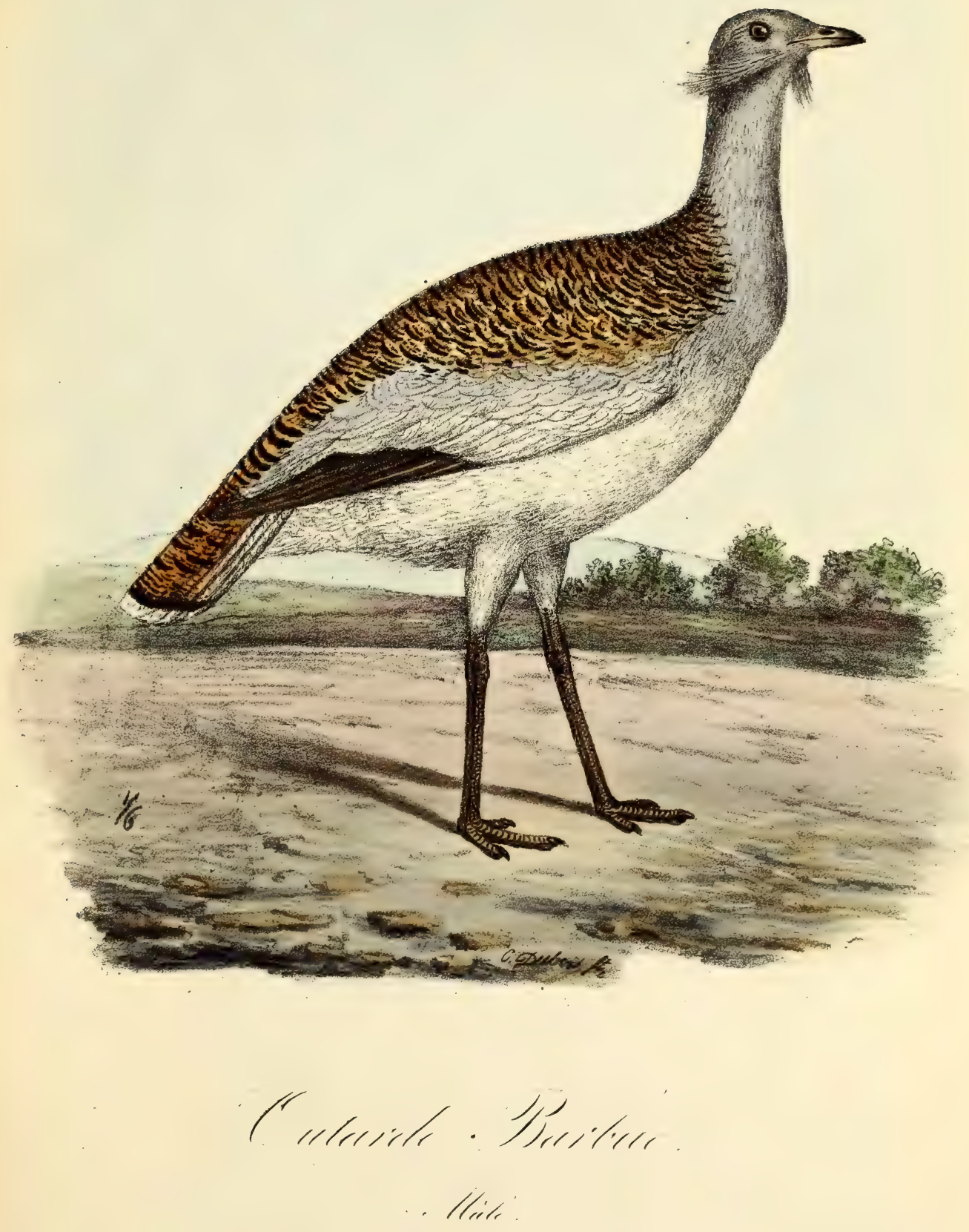



Genre Duturele. - Dlis, Linné.

\section{U T A R D E B A R B U E.}

O'TIS BARBATA, DUBOIS.

MEARIET HESTARD. - HQTE-THAPPE.

Temm., t. II, p. 506. - Gould., t. IV, pl. 267. - Naum., t. VII, pl. 167. - Degl., t. II, p. 72.-

Thien., pl. XIII, fig. 7. - De Selys-Longch., Faune belge, no 177. - Savi, Ornith. Toscana,

t. II, p. 218. - V. d. Mühle, Ornith. Griechenlands, no 198. - Otis tarda, Linné.

Ce grand oiseau habite la Sibérie, la Russie, la Hongrie, la Dalmatie, l'Italie et la Grèce; dans ce dernier pays il est même très-commun. On le rencontre aussi dans toute l'Allemagne, mais surtout dans la Poméranie, la Silésie et la Thuringe. Les grands froids et beaucoup de neige lui sont contraires, et le forcent à s'expatrier. Il cherche alors un climat plus doux, et il se dirige vers la Grande-Bretagne, la France, la Belgique et la Hollande. Les outardes barbues vivent principalement dans les champs de blé, de seigle et de mais. Elles sont craintives et d'une tinidité extrême, aussi sont-elles constamment aux aguets pour voir si quelqu'un s'approche, et tout ce qui leur parait suspect les met en fuite immédiatement. Elles ouvrent leurs ailes pour accélérer leur course, car elles ne volent que fort difficilement par rapport à leur grosseur. Les chiens de chasse surtout leur inspirent la plus grande frayeur, par la raison que, lorsqu'elles veulent voler, elles ont besoin de prendre leur élan, et les chiens profitent de cet instant pour se jeter sur elles. Elles passent la nuit dans les champs, loin de toute habitation, et, pour plus de sécurité, une d'elles se tient à quelque distance du lieu qu'elles ont choisi pour se reposer, et reste de garde pour donner, en cas de danger, l'alarme à ses camarades. Lorsqu'elles ont bien pris leur élan, elles parviennent à s'élever à une assez grande hauteur, et savent même s'y maintenir et voler pendant plusieurs heures sans éprouver aucun inconvénient. Elles se nourrissent d'herbes, de blé, de graines, d'insectes, de vers et de limaçons.

Le mâle est polygame, et c'est dans l'accouplement qu'il se montre dans toute sa beauté. Il relève alors majestueusement la tête; ses plumes se dressent et sa queue s'ouvre comme un éventail; en cet état, il s'avance vers une ou plusieurs femelles, et tourne autour d'elles pendant quelques instants, en faisant entendre un cri tout particulier. Si d'autres mâles sont présents, ils se livrent entre eux des combats acharnés pour la possession des femelles. Celles-ci creusent ensuite une excavation en plein champ, au milieu du froment, pour y faire leur ponte. Elles garnissent leur nid de brins d'herbes et de plantes sèches; elles y déposent, vers la fin de mai, deux neufs, quelquefois trois. Le mâle ne partage point avec la femelle les soins de la ponte, et celle-ci est obligée de s'en occuper toute seule. Les petits savent courir aussitôt qu'ils sont éclos, et s'il leur arrive d'être surpris par quelqu'un, la mère a recours à tous les moyens pour les défendre; elle vole çà et là, puis se met à courir et fait semblant de ne plus savoir voler, afin d'attirer l'attention et de ménager aux petits le temps de se sauver. Si ce manége ne lui réussit pas et que ses petits soient sur le point d'être pris, elle s'avance hardiment vers le ravisseur, le bec béant, les plumes redressées, en faisant entendre un sifflement aigu. 



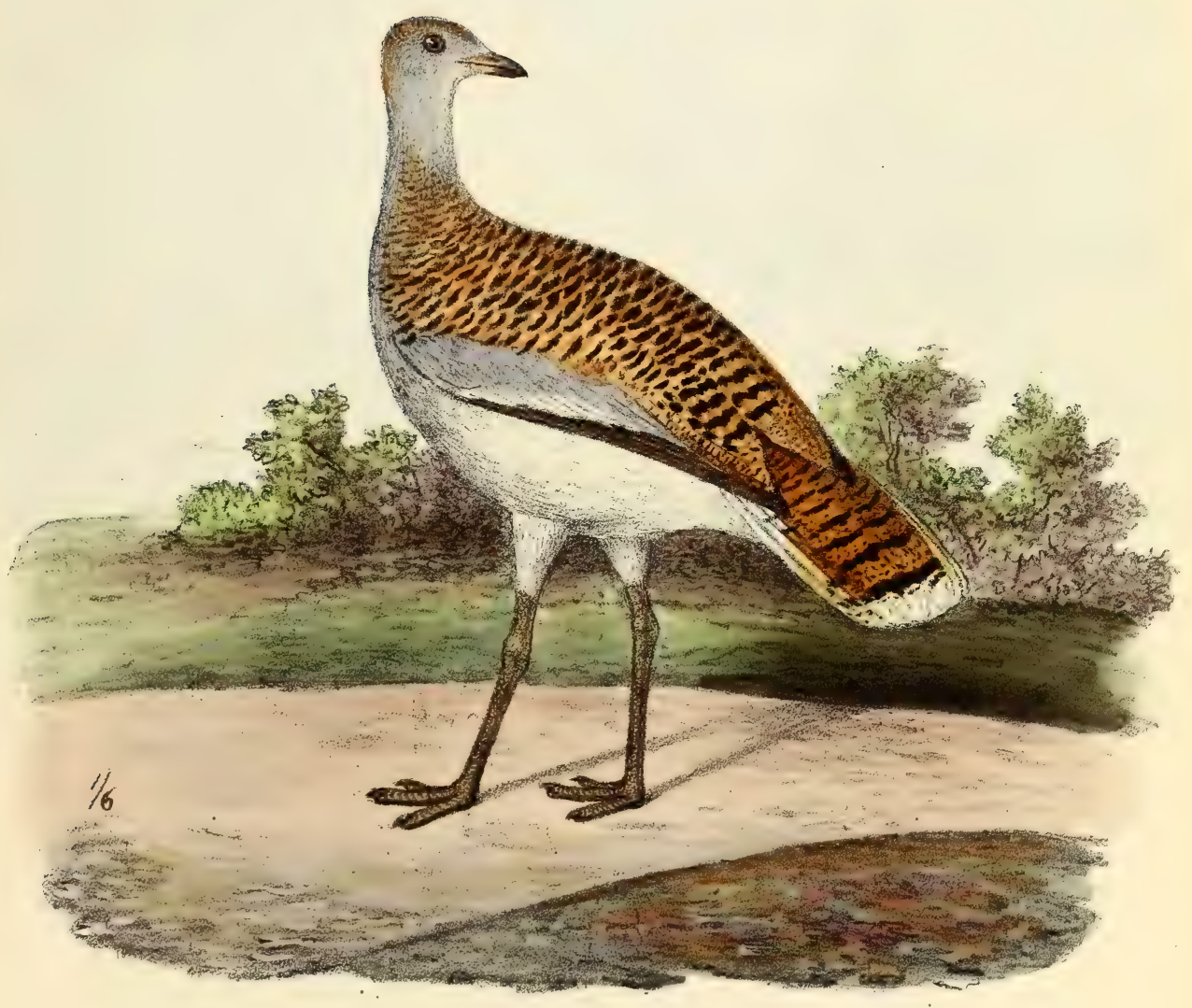

$$
\text { Centererte. Periture }
$$





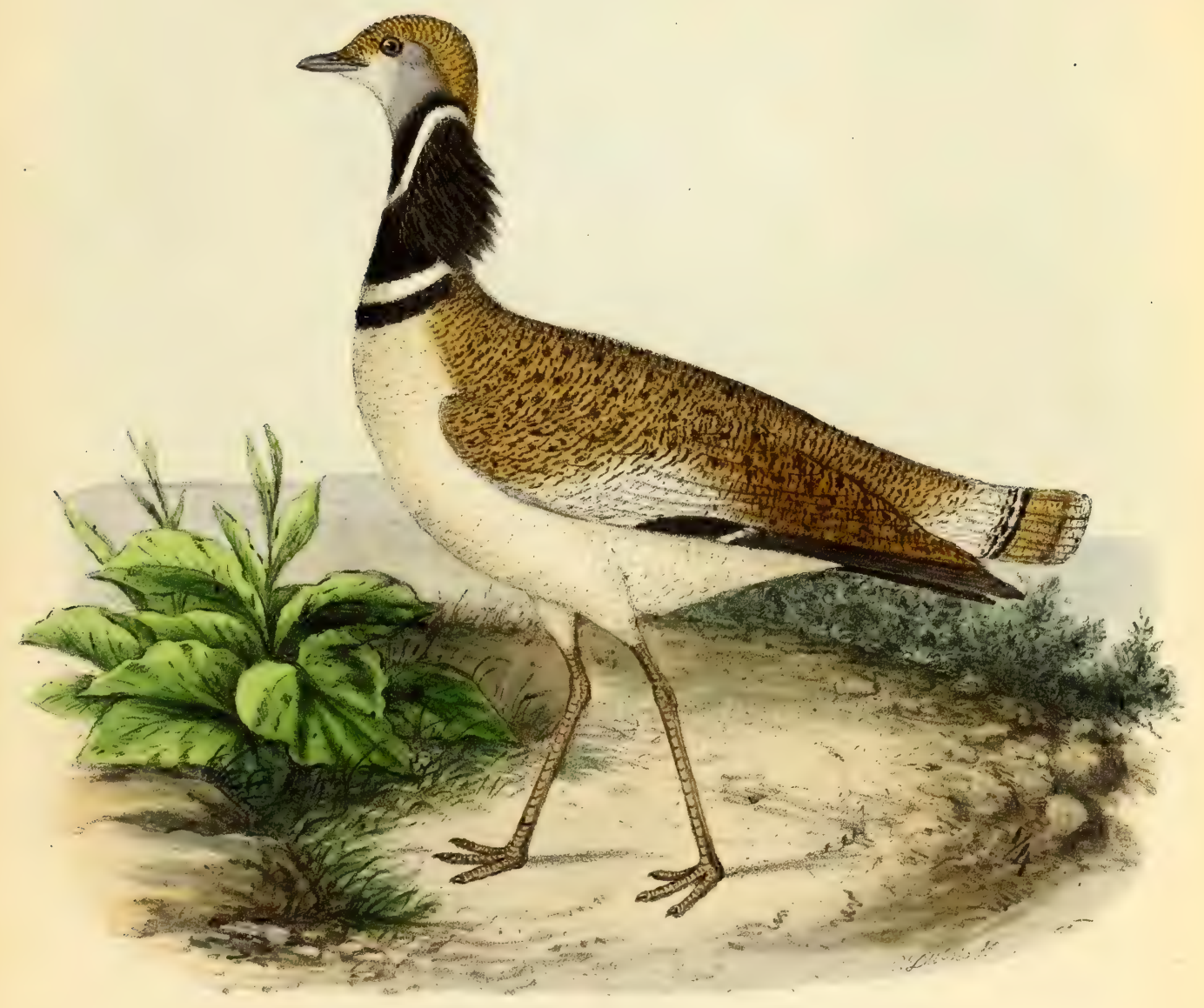

$$
\begin{aligned}
& \text { Cotarde Ifonefertieie } \\
& \text { thate. }
\end{aligned}
$$





\section{OUTARDE CANEPETIERE.}

OTIS TETRAX, LINNÉ.

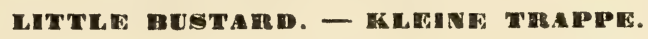

Temm., t. II, p. 507. - Gould, t. IV, pl. 269. - Naım., t. VII, pl. 167. - Degl., t. II, p. 77.

- Thien., pl. LVI, fig. 3. - De Selys-Longch., Faune belge, ${ }^{\circ}$ 177. - Malh., Faune gicile, p. 160. - Savi, Ornith. Toscana, t. II, p. 219. - V. d. Mühle, Ornith. Griechenlands, no 199. - Malh., Ois. d’Algérie, p. 19. - Tetrax campestris, Leach. - Otis campestris et 0. minor, Briss.

Le midi de l'Europe, une partie de l'Asie et le nord de l'Afrique sont la patrie de cet oiseau. On le rencontre aussi fréquemment en Tartarie, dans la Russie méridionale, en Turquie, en Grèce, en Italie, en Sicile, en Sardaigne, en Espagne et dans le midi de la France; mais il se montre rarement en Allemagne et dans la Grande-Bretagne. En Belgique, cette outarde n'est pas non plus souvent visible, bien que, à ma connaissance, on y en ait déjà tiré plusieurs, entre autres, une que M. Hubert-Lauwers a tuée, le 6 janvier 18533, près de Louvain, aux environs du château de $\mathbf{M}$. le baron de Snoy. Les outardes canepetières évitent les hautes montagnes, les districts boisés et montagneux ; elles préfèrent les contrées ouvertes, les plaines et les champs cultivés. Toutefois, elles s'éloignent, autant qu'elles peuvent, de tout lieu habité, soit villages ou fermes isolées. Elles passent l'été, la plupart du temps, dans les champs de blé, surtout lorsque le blé est arrivé à une certaine hauteur pour qu'elles puissent s'y cacher. Méfiantes et timides à l'excès, elles ont l'habitude, en cas de danger, de se coucher par terre sur le ventre et de s'aplatir autant que possible, et c'est seulement lorsqu'on n'est plus qu'à quelques pas d'elles, qu'elles se lèvent. Cette manœuvre rend leur chasse extrêmement facile. La moisson une fois achevée, il n'est plus si aisé de les tirer quand elles sont dans les champs, parce qu'alors le chasseur ne peut les approcher sans être vu, et qu'elles s'envolent à tire-d'aile à l'approche de tout ce qui leur parait suspect ; mais elles ne tardent pas à reprendre pied pour se mettre à courir avec une vitesse et une agilité tellement grande, qu'il est impossible au chasseur de les suivre. Leur vol est léger, rapide, soutenu; elles vivent, pour la plupart du temps, d'insectes, de larves et de vers; elles mangent aussi les boutons et les feuilles de certaines plantes; mais ce qu'elles aiment surtout, ce sont les graines et les semences de toute espèce. Souvent elles occasionnent de grands dégâts, quand elles s'abattent en troupes sur des champs nouvellement ensemencés. Pour cette raison, les cultivateurs les redoutent beaucoup.

Au printemps, les mâles font entendre fréquemment leur voix, et leur gosier ne semble pouvoir se lasser, même pendant la nuit, de crier: Prout, prout, prout. Ils se livrent aussi des combats acharnés pour la possession des femelles, et, comme les coqs, ils aiment à en avoir plusieurs. Alors la femelle se creuse, dans un endroit bien solitaire, une excavation abritée par quelques broussailles, où elle dépose trois ou quatre oufs. Aussitôt que les petits sont éclos, ils sortent du nid et suivent leur mère, qui a soin de les instruire dans la chasse; et, si un danger les menace, elle leur apprend à se coucher à plat ventre par terre, et à demeurer dans cette position jusqu’à ce que le danger soit passé. 


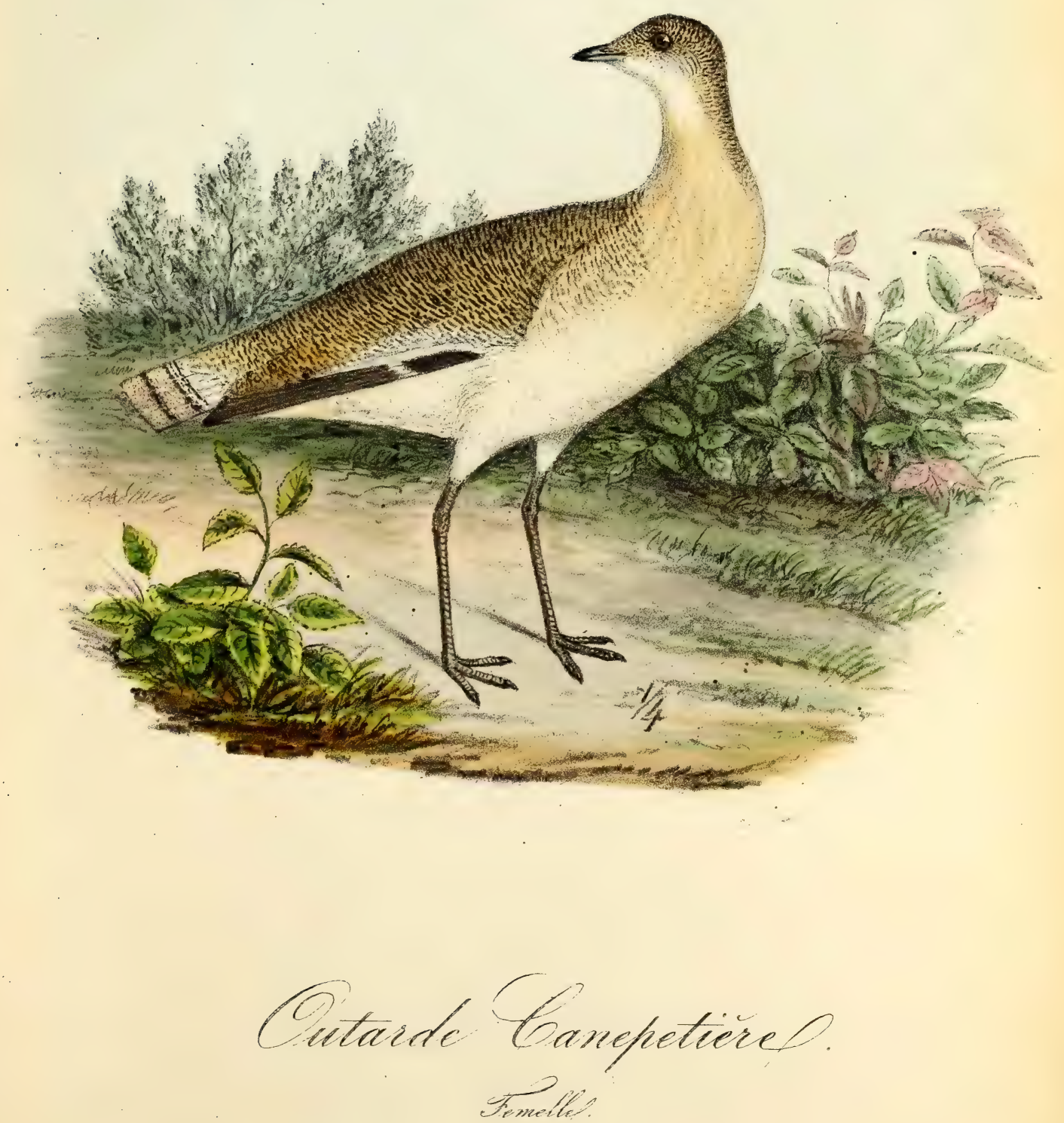

101

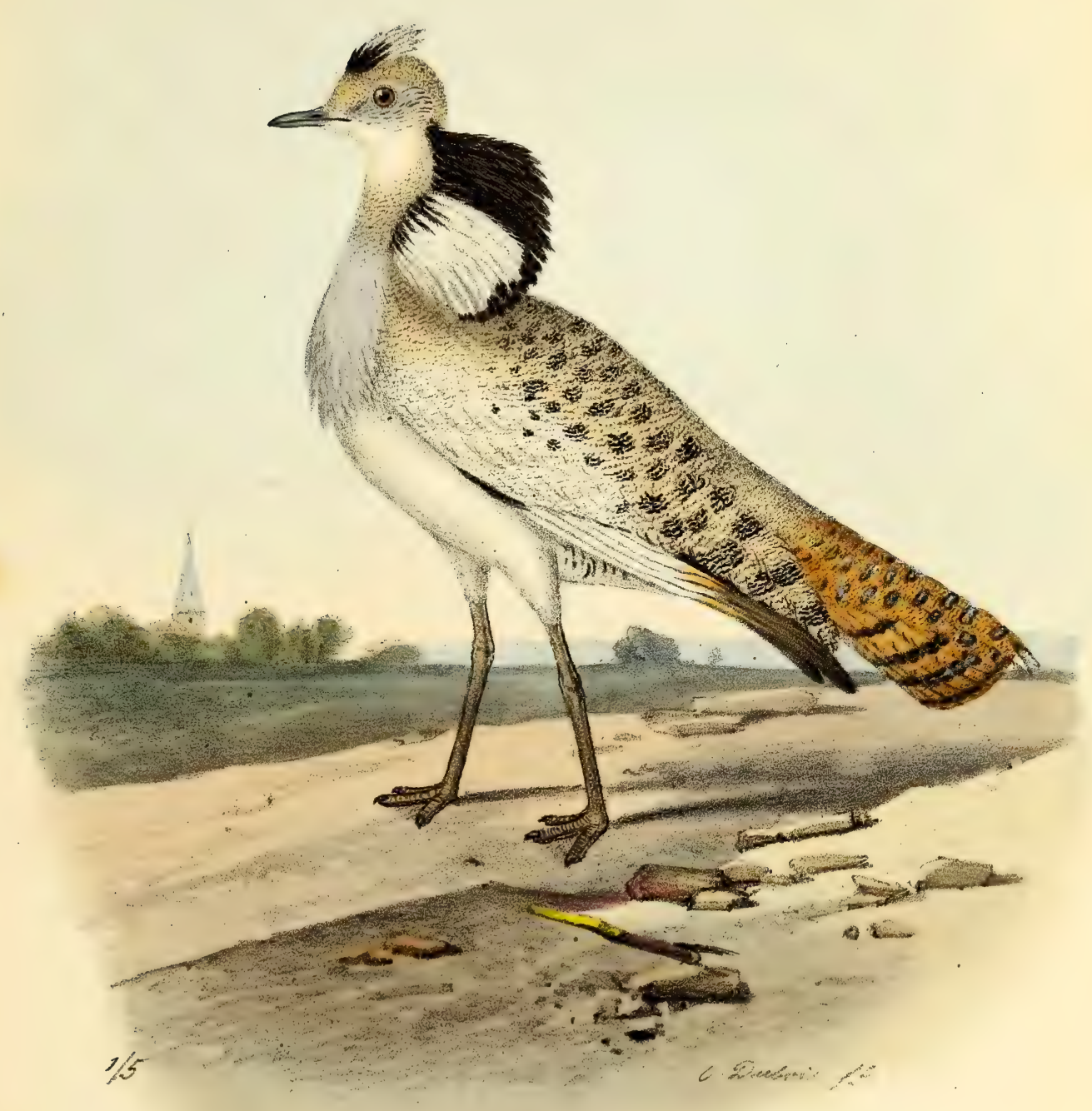

$$
\text { Cutuide do Plltarquen }
$$





\section{Cenre Dutarele. - Otis, Linné. \\ OUTARDE DE II CQUEE.}

OTIS MACQUEENI, HARUWIG.

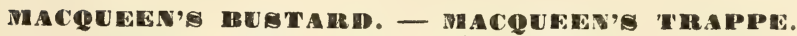

Houbara Macqueenii, List of Birds in Brit mas., part. III, p. 57. - Hulton, Journ. Asiat., soc. Beng., vol XVI. - Gould, Birds of Asia, part. III. - Bechst., Ornith. Tosc. 247. - B. Du Bus, Acad. royale de Belgique, t. XIII, $\mathbf{n}^{\circ} \mathbf{3}$ des Bulletins. - Dubois, Journal Ornith., du Dr Cabanis, 1856, pl. IV. - Eupodotis macqueeni, Gray. - Houbara ornata, Brehm.

Cette belle outarde habite principalement l'Asie, le Beloutchistan et le Caboul; on la voit aussi en Tartarie, dans la partie occidentale de la Perse, en Arabie; il n'est pas rare de la voir en Turquie. Elle se montre quelquefois dans ses voyages en Allemagne, où elle a été prise en Silésie. Diffèrentes outardes ont été tuées en Allemagne, mais il est douteux qu'elles appartiennent toutes à cette espèce; il est plus probable qu'on les a confondues avec l'Otis houbara. Un de ces beaux oiseaux fut tiré, en 1842, en Belgique, où il devint la propriété du directeur de la douane, à Virton. En 1844, M. Desmoor tira une belle outarde mâle, à Situlaer, près de Louvain; on l'aperçut d'abord au milieu d'un champ labouré, mais l'approche de M. Desmoor la mit en fuite vers une prairie voisine: dans la rapidité de sa course elle imite le paon en faisant l'éventail avec sa queue. Ce magnifique exemplaire se trouve maintenant à Louvain, dans la collection de M. Isidore Bovie, amateur distingué, qui eut la bonté de me l'envoyer pour en faire le dessin Le $\mathbf{1 3}$ décembre de la même année, le chasseur de M. Degroodt tua encore un mâle moins beau, dans la commune de Woluwe, aux environs de Bruxelles. M. le vicomte Du Bus, qui en avait fait l'acquisition pour le musée royal de cette ville, m'assura qu'il en ivait trouvé la chair excellente et d'un goût très-délicat. Le musée de la société philosophique de la ville d'York, dans la Grande-Bretagne, possède également une de ces outardes qui fut tirée dans un champ à Kirton-Lindsey, Lincolnshire, le 7 octobre 1847, par M. Hansley. On trouva la poche de son gosier remplie d'insectes, de chenilles, de petites pierres et de brins d'herbe. D'après M. Gould, la femelle n'a pas de huppe; elle est moins belle que le mâle.

La propagation et les habitudes de cet oiseau ne nous sont guère connues. 


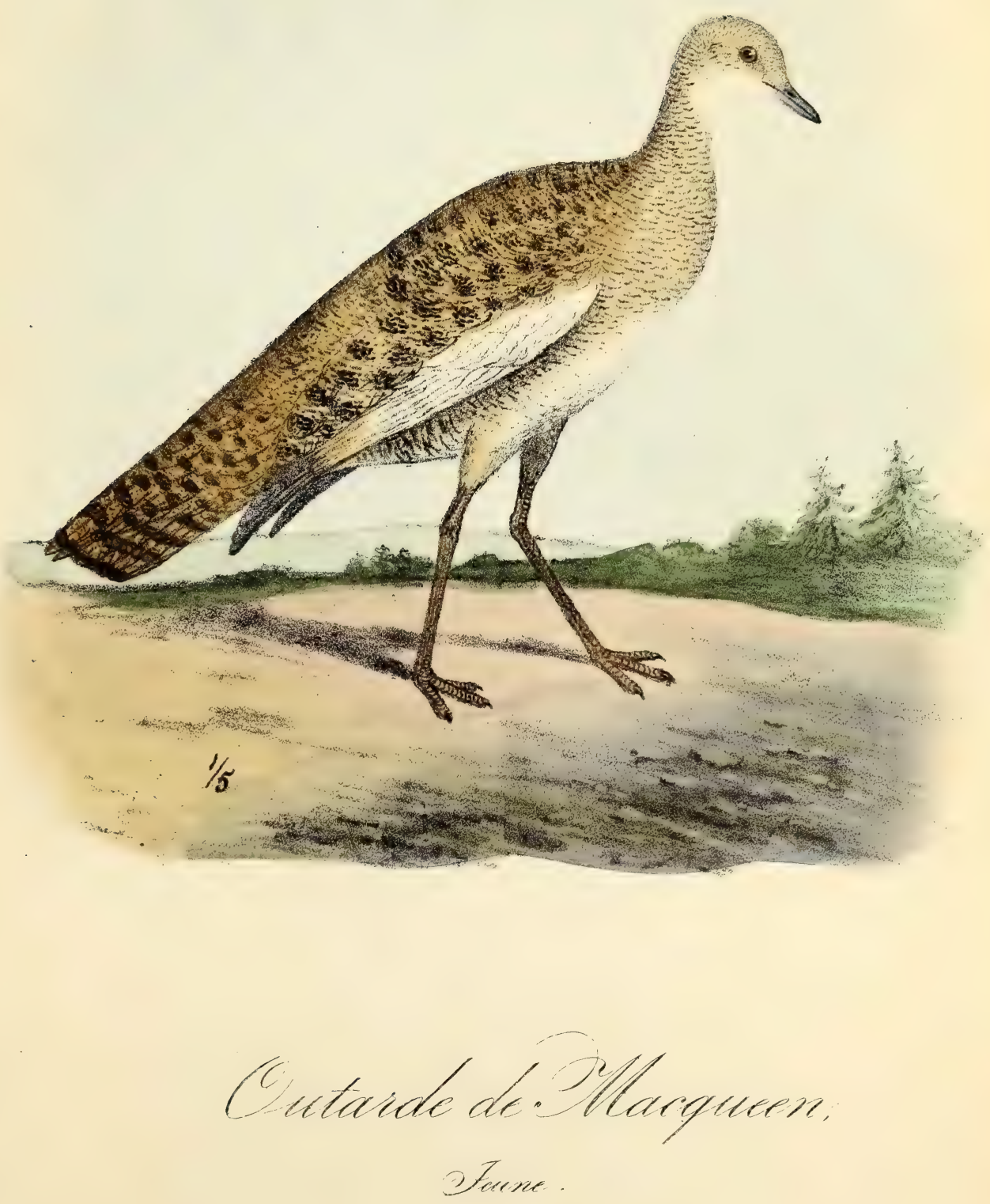


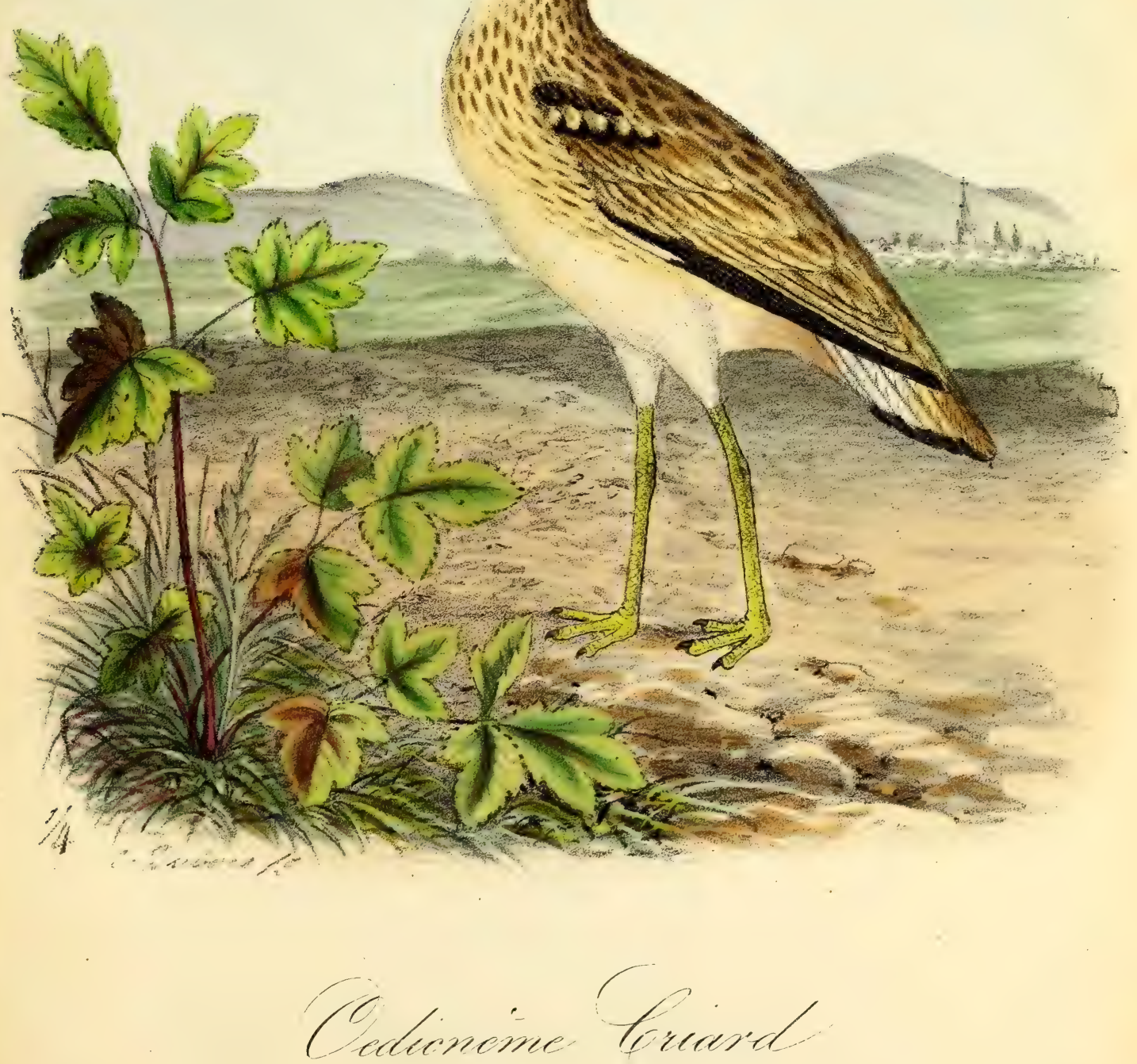

Gense OEdienème. - DEalicnemus, Temminck.

\title{
(E I I C N E II E C R I A R I).
}

\author{
OEDICNEMUS CREPITANS, TEMMINCK.
}

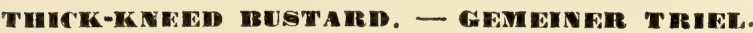

GRAND PLUVIER, Buff., t. VIII, p. 105; - pl enl. 919. - Temm., I. II. p. 521. - Gould, t. IV, 1I. 288. - Degl., t. II, p. 88. - Naum., t. VII, pl. 172. - Thienem., pl. XIV, fig. 1. Selys-Longch., Faune belge, no 179. - Savi, Ornith. Toscana, t. II. p. 225. - Malh., Faune Sicile, p. 162. - Nalh., Ois. de l'Algérie, p. 19. - Rüpp., Vg. N.-O. Afrika's, n $395 .-$ Otis oedicnemus, Lath - Charadrius oedicnemus, Linné. - oedicnemus europeus, Vieill. OE. Griseus, Koch.

Cet oiseau habite l'Europe, particulièrement vers le sud; le midi de la France, l'Espagne, l'Italie, la Sardaigne, la Turquie et la Grèce; plus rare en Belgique et en Allemagne; on le trouve en Égypte, en Abyssinie, au Sénégal et au Cap, ainsi que dans quelques contrées de l'Asie. Il vit dans les champs secs et grands ainsi que dans les plaines stériles, pierreuses et désertes; mais toujours dans le voisinage de l'eau. Cet cedicnème est très-craintif et farouche; on le trouve presque toujours isolé, ou par couples; on l'attrape difficilement; cependant on peut en approcher d'assez près lorsqu'il aperçoit un oiseau de proie parce qu'alors il se couche à plat ventre pour se cacher, ou le soir lorsqu'il sort de l'eau après avoir bu ou s'être baigné. Il court excessivement vite, mais malgré ses grandes ailes il ne vole que médiocrement.

Pendant le jour il est souvent couché sur le ventre, les jambes repliées sous lui; parfois encore il se tient sur une patte; pendant toute la nuit il est éveillé et actif; les couples et plus tard les familles se tiennent ensemble pendant leurs migrations. Leur voix est un cri assez désagréable comme tourrlui ourrlui, tourrlui ourrlui, qui se fait entendre pendant la nuit, mais les mâles et les femelles le font aussi entendre pendant le jour; lorsque cet oiseau est fâché il pousse un cri rauque. Il se laisse facilement apprivoiser et supporte fort bien sa captivité.

Nourriture : sauterelles, coléoptères, insectes, leurs larves et les vers de terre; il mange aussi de petites grenouilles, des lézards et des souris, il ne mange ces animaux qu'après leur avoir donné quelques coups de bec et leur avoir fracassé les os; il rejette les parties indigestes en forme de petites boules comme les oiseaux de proie.

Ils nichent dans les endroits secs, sablonneux ou pierreux; quelquefois aussi dans les champs, abrités par une pierre; le nid ne consiste que dans un petit enfoncement dans lequel il dépose trois ou quatre oufs. Aussitôt que les petits sont âgés de quelques jours, ils courent après les vieux, et lorsqu'il y a un danger quelconque, ceux-ci font un signe et les jeunes se mettent plat à terre, de manière qu'on les écraserait plutôt que de les voir à cause de leur couleur uniforme à celle de la terre; ils sont nourris de vers de terre et de larves que le mâle et la femelle déposent devant eux; mais aussitôt qu'ils sont un peu plus grands. les vieux les conduisent dans les champs en jachère où ils doivent chercher eux-mêmes leur nourriture. 



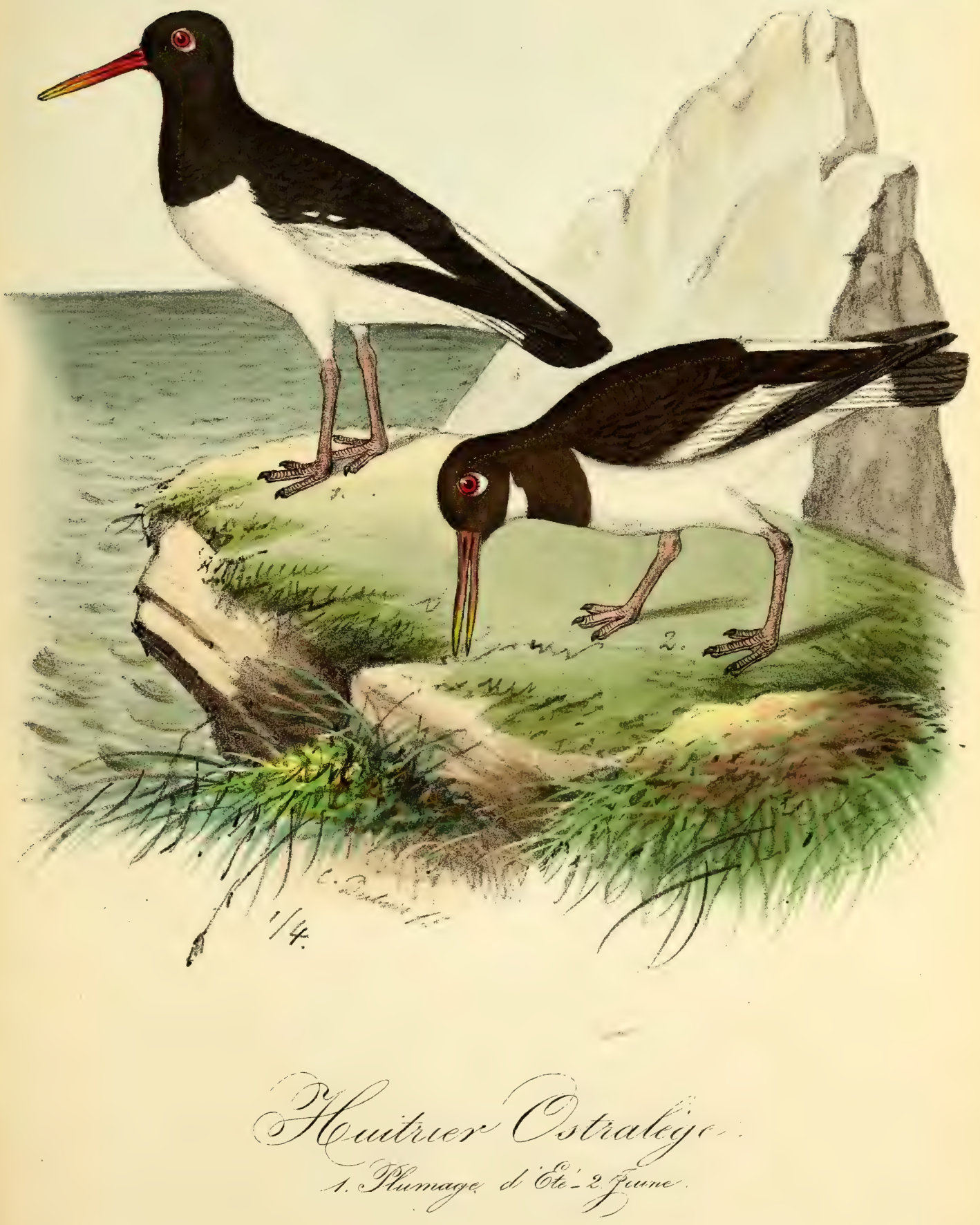



Cenre Houtorier. - Hoematopus, Linné.

\section{HUITRIER OSTRALÉGE.}

HEMATOPUS OSTRALEGUS, LINNÉ.

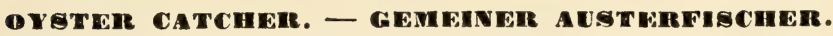

HUITRIER, Buff., t. VIII, p. 119; - pl. enl. 929. - Temm., t. II, p. 531. - Gould., t. IV, pl. 300. - Degl., t. II, p. 104. - Naum., t. VII, pl. 181. - Thienem., pl. XIV, fig., 3. Selys Longch., Faune belge, $n^{\circ}$ 188. - Savi, Onnith. Toscana, t. II, p. 229. - Malh., Faune Sicile, p. 166. - Meyer, Vg. Liv.-u. Esthlands. p. 172. - v. d. Mühle, Vg Griechenlands, no 220. - Malh., OIS. de l'Algérie, p. 20. Rüp., Vg. N.-0. Afrika's, no 417. - Hematopus hypoleuga, Pall - Ostralega europea, Briss.

Se trouve sur les bords de la mer en Europe, mais plutôt du côté du nord que du sud, en Suède, en Norwége, en Islande, en Laponie, en Sibérie aux bords de la mer Rouge et en Egypte. II arrive vers le mois de mars et il quitte les bords de la mer des lles Britanniques, de la France, de la Belgique et de la Hollande, en automne. Quelques-uns restent pendant l'hiver aux bords des eaux en France et en Belgique. Malgré son ap parence un peu lourde, cet oiseau est adroit, éveillé et farouche; il se tient ordinairement sur les rivages ou sur les morceaux de rochers qui sortent de la mer, ou bien il cherche sa nourriture dans la vase humide, aussi y fait-il souvent des trous assez profonds pour y chercher des vers ou des racines tendres; on trouve toujours de ces trous là ou sont les huitriers. Son vol est léger et entrecoupé de battements d'ailes forts et vifs; avant de se reposer, il vole toujours à une petite distance. Son cri d'appel, qu'il fait souvent entendre, est kuick, kuick. Penciant le jourils volent ordinairement haut dans les airs au nombre de vingt à trente dans un ordre parfait. Il est très-prudent et laisse rarement le chasseur approcher de son nid; lorsqu'il n'a plus d'autre moyen de se sauver, il tâche d'échapper par la nage.

Nourriture : insectes, vers, escargots, petites écrevisses et des œufs de poissons; on trouve presque toujours dans leur estomac de tendres racines d'herbe; son nom d'huitrier lui vient de ce quil tourne fort adroitement les huîtres et les moules pour retirer les insectes qui se trouvent dessous.

Ces oiseaux nichent dans le voisinage de l'eau, pas si près cependant que le flux et le reflux puissent faire du tort à la couvée ; ils nichent aussi dans les pâturages et d'autres places où se trouve de l'herbe; rarement dans le sable. Le nid n'est qu'un enfoncement dans lequel ils ont mis des racines d'herbe ; on y trouve, au mois de mai ou de juin, trois ou quatre oufs, qui ressemblent beaucoup à ceux des oedicnèmes; cependant les œufs des huitriers sont en général un peu plus petits; comme on prend souvent de ces oufs qui sont fort bons à manger, on trouve ces oiseaux couvant encore bien avant dans la saison; sa chair passe pour bonne et saine, cependant en ayant moi-même mangé, je ne lui ai trouvé rien d'agréable ni de nature à la faire rechercher. 



$$
\Leftrightarrow
$$



Gense Échesse. - Himunulopess, Brisson.

\section{ÉCHASSE A MANTEAU NOIR.}

HIMANTOPUS MELANOPTERUS, BRISSON.

LONG-LEGCED PLOVER. - SWAHZRÜKMGE GTELZENR̈̈UTER.

Temm., Max., t. II, p. 338. - Naum., t. VIIl, pl. 234. - Gould., t.IV. pl. 289. - Degl., t. V, p. 252. - Thien., pl. XIV, fig. 3. - De Selys-Longch., Faune belge, n 189. - Malh., Faune sicile, p. 192. - Savi, Ornith. Toscana, t. II, p. 232. - v. d. Mühle, Ornith. Griechenlands, " 222. - Malh., ois de l'Algérie, p. 20. - Rüpp, Vg. N. O. Afrika's, no 462. - Charadrius Himantopus, Linné. - Hypsibates Himantopus, Nitzsch. - Himantopus vulgari el rufipess, Bechst. - H. atroapterus, Mey. - H. Candidus, Bonnat. - H. albicolus, Veill. - H. longipes et melanocephala, Brehm.

Cet oiseau habite l'Égypte, la Nubie et la Sénégambie. On le trouve aussi dans l'Inde, en Chine, en 'Tartarie et dans toutes les parties du midi de l'Europe, depuis l'Espagne jusqu'au midi de la Russie. Il abonde en Hongrie et en Dalmatie, mais on ne le voit que rarement en France; c'est plus rarement encore que, dans ses émigrations, il lui arrive de traverser l'Allemagne, la Grande-Bretagne, la Hollande et la Belgique; il fréquente les bords de la mer et les marais, et, comme la plupart des oiseaux aquatiques, il a de très-longues jambes. Cette échasse est très-sociable, et ne se rencontre ordinairement que par couple. Pour émigrer, elles se réunissent par troupes quelquefois fort nombreuses, auxquelles se joignent souvent aussi les Chevaliers et les Bécasseaux. Leur cri, qu'elles font entendre rarement, est un sifflet bref et perçant, qu'elles répètent plusieurs fois et qu'on entend au loin. Leur vol est léger, majestueux et rapide; en fendant l'air, elles battent des ailes, et retirent en arrière leurs longues jambes. Elles cherchent leur nourriture au bord de l'eau, dans la vase, où, grâce à leurs échasses, elles peuvent s'avancer sans crainte de s'embourber, et où on les voit quelquefois s'enfoncer jusqu'au ventre pour chercher des vermisseaux aquatiques, des insectes et des larves; en cas de besoin, lorsqu'elles viennent à manquer pied, elles savent un peu nager. Leur timidité n'est pas fort grande; il n'est donc pas difficile au chasseur de les épier, de les approcher à portée de fusil et de les tirer au moment où elles se lèvent. Leur chair est délicate et presque toujours très-grasse, surtout quand elles sont jeunes. En Hongrie, on les apporte au marché, où elles sont fort recherchées par les amateurs de gibier.

La femelle fait ordinairement son nid dans un grand marais, où, dans un endroit sûr et inabordable, sur une légère élévation entourée d'eau et de vase, elle arrange une litière composée de racines et de brins d'herbe desséchés. Sa ponte habituelle est de quatre oufs au plus. 



Cenre Pluvier. - Charadriess, Linnć.

\section{P L U V I E R D 0 R É.}

CHARADRIUS AURATUS, MEYER.

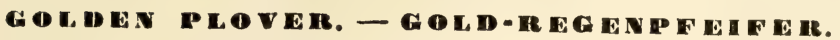

Buff., t. VIII, p. 85̃; - pl. enl. 944. - Temm., t. II, p. 535. - Gould, t. IV, pl. 294. - Degl., t. II, p. 91. - Naum., t. VII, pl. 173. - Thienem., pl. XIV, fig. 4. - Selys-Longeh., Faune belge, no 18\%. - Savi, Ornith. Toscana, t. II, p. 235. - Malh., Faune Sicile, p. 163. - Mey., Vg. Liv.-u. Esthlands, p. 173. - v. d. Mühle, Vg. Griechentands, n 214. - Holböll, ORN. Groenlands, p. 37. - Richardson, Fauna boreali americana, p. 369. - Pluvialis viridis, Willough. - P. apricarius, Bonap. - P. aurea, Brehm. - Charadrius pluvialis et apricarius, Linné, - Cir. aureus, Macgill.

Le pluvier doré séjourne en Europe, en Asie et dans le nord de l'Afrique; en automne il parait en Allemagne, et pendant certaines années, abondamment en Belgique, en Hollande et en France; il quitte ces pays au printemps afin de couver plus vers le nord. Les pluviers vivent dans les bruyères et ce n'est que pendant leurs migrations qu'on les voit paraitre dans les champs ; se tenant de préférence dans les endroits déserts et stériles, ils évitent les étangs et les ruisseaux, si ce n'est pour boire. Ce sont des oiseaux éveillés, farouches et craintifs; ils courent extrêmement vite, cependant ils restent souvent immobiles; soit pour regarder autour d'eux, suit pour se reposer; lorsqu'ils courent, ils se tiennent les uns près des autres; leur vol est léger et vif, ils forment ordinairement des cercles en volant comme s'ils voulaient se reposer, cependant ils s'éloignent toujours de plus en plus. Leur cri d'appel est tlui, tlui, ils le font entendre lorsqu'ils volent ou en se reposant. Ils sont très-vigilants et savent parfaitement distinguer le chasseur du campagnard; ils ne fuient pas ce dernier tandis quils s'éloignent toujours excessivement du chasseur qui ne peut jamais en approcher à portée de fusil ; aussi les abat-on difficilement. La chair de cet oiseau est bonne, les amateurs de bon gibier la recherchent beaucoup.

Nourriture : vers de terre, insectes et leurs larves, petites limaces ainsi que de petites baies.

Ils couvent dans le nord de l'Europe et de l'Asie; le nid est fait sans art, il est posé sur la terre unie, couverte d'un peu de bruyère ou d'herbe. Vers la fin de mai ou au commencement de juin, la femelle dépose sur une couche de feuilles sèches ou de mousse trois ou quatre oufs qui sont grands comparativement à la taille de l'oiseau; les ocufs ont la coquille grossière et sont sans lustre: Cet oiseau est aussi confiant pendant la couvaison qu'il est sauvage pendant ses migrations. 



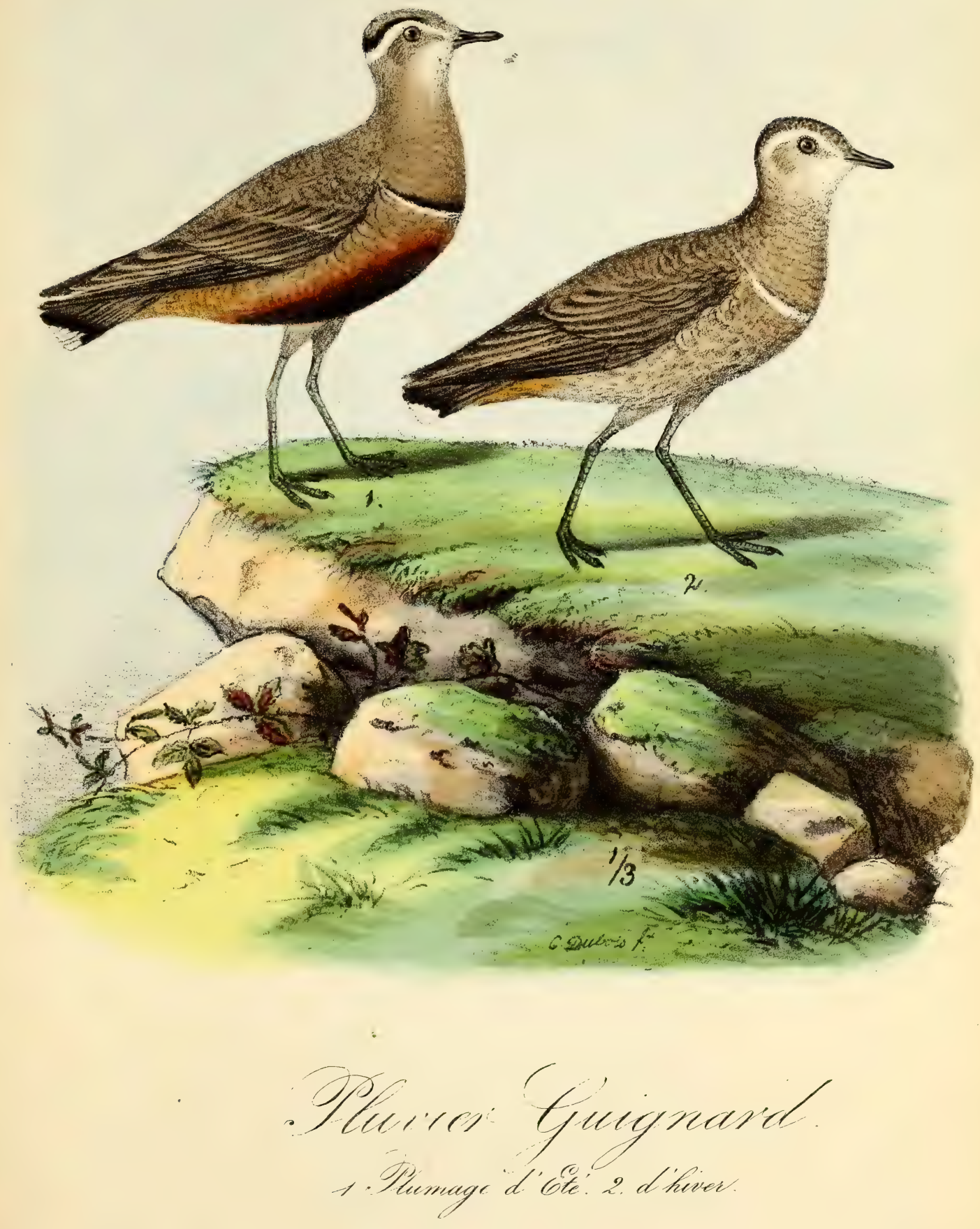





\section{P L U VIER GUIG N R D.}

CHARADRIUS MORINELLUS, LINNÉ.

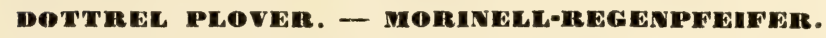

Buff., pl. enl. 852. - Temm., t. II, p. 537. - Naum., t. VII, pl. 174. - Gould, t. IV, pl. 395. Degl., ı. II, p. 93. - Thienem., pl. XIV, fig. 5. - Selys-Longch., Faune Belge, no 183. - Savi, Ornith. Toscana, t. II, p. 239. - Malh., Faune Sicile, p. 163. - v. d. Mühle, Vg. Griechenlands, p. 215 . - Beseke, Vg. Kurlands. - Charadrius tataricus, Pallas. - Ch. sibiricus, Gmel. - Eudromias morinellus, Bojé. - E stolida, Brehm.

Il habite, en été, le nord de l'Europe et de l'Asie; on le voit en Sibérie, en Russie, en Finlande, en Laponie, dans la péninsule scandinave, en Danemark et même aux îles Britanniques. Mais, à l'approche de l'hiver, il quitte ces régions septentrionales pour se diriger vers l'Allemagne, la Hollande, la Belgique et la France; il y en a même qui vont jusqu'en Espagne et en Italie. Pendant l'été, ils fréquentent les terrains secs et pierreux, les plateaux incultes des collines, les sommets des montagnes dénudées de la zone glaciale, où toute végétation cesse et où la neige, même en été, ne disparait jamais tout à fait. Dans leurs voyages, ils ne s'arrêtent que dans les grandes plaines, les champs nus et les prairies. Ils quittent les latitudes boréales déjà à la fin d'août et n'y reviennent qu'en mai; ils vont par troupeaux plus ou moins nombreux; leur vol est élevé et trèsrapide, et de temps en temps ils laissent entendre leur voix, et leurs cris un peu plaintifs ressemblent à un durr, durr, dut, dut, souvent répété ; si la nuit est fort obscure, au lieu de poursuivre leur route, ils se reposent, et, pour continuer avec plus de rapidité leur vol pendant les nuits claires, ils sommeillent pendant le jour. Leur timidité n'est pas fort grande, et ils se laissent approcher à portée de fusil. Leur chair est délicate et d'un goût fort agréable, et beaucoup de personnes la préfèrent à celle des bécasses. Leur nourriture consiste principalement en larves et vers de terre, rarement des baies ou des plantes, et, pour faciliter la digestion, ils avalent fréquemment de petites pierres.

Les sommets arides et dénudés des plus hautes montagnes, où à peine il croit quelques plantes rabougries, sont leurs endroits de prédilection pour nicher. Un petit enfoncement dans le sol est l'emplacement qu'ils préfèrent pour leur nid; ils le tapissent de mousse, de brins d'herbe et de lichens; trois ou quatre œufs forment leur ponte ordinaire. La femelle a pour sa couvée tant de soins, qu'il n'est presque pas possible de l'en éloigner, et on peut s'en approcher au point de la toucher pour ainsi dire, avant qu'elle se décide à s'éloigner, et elle ne quitte sa couvée qu'avec lenteur et en élevant les ailes. 

1)i,i,

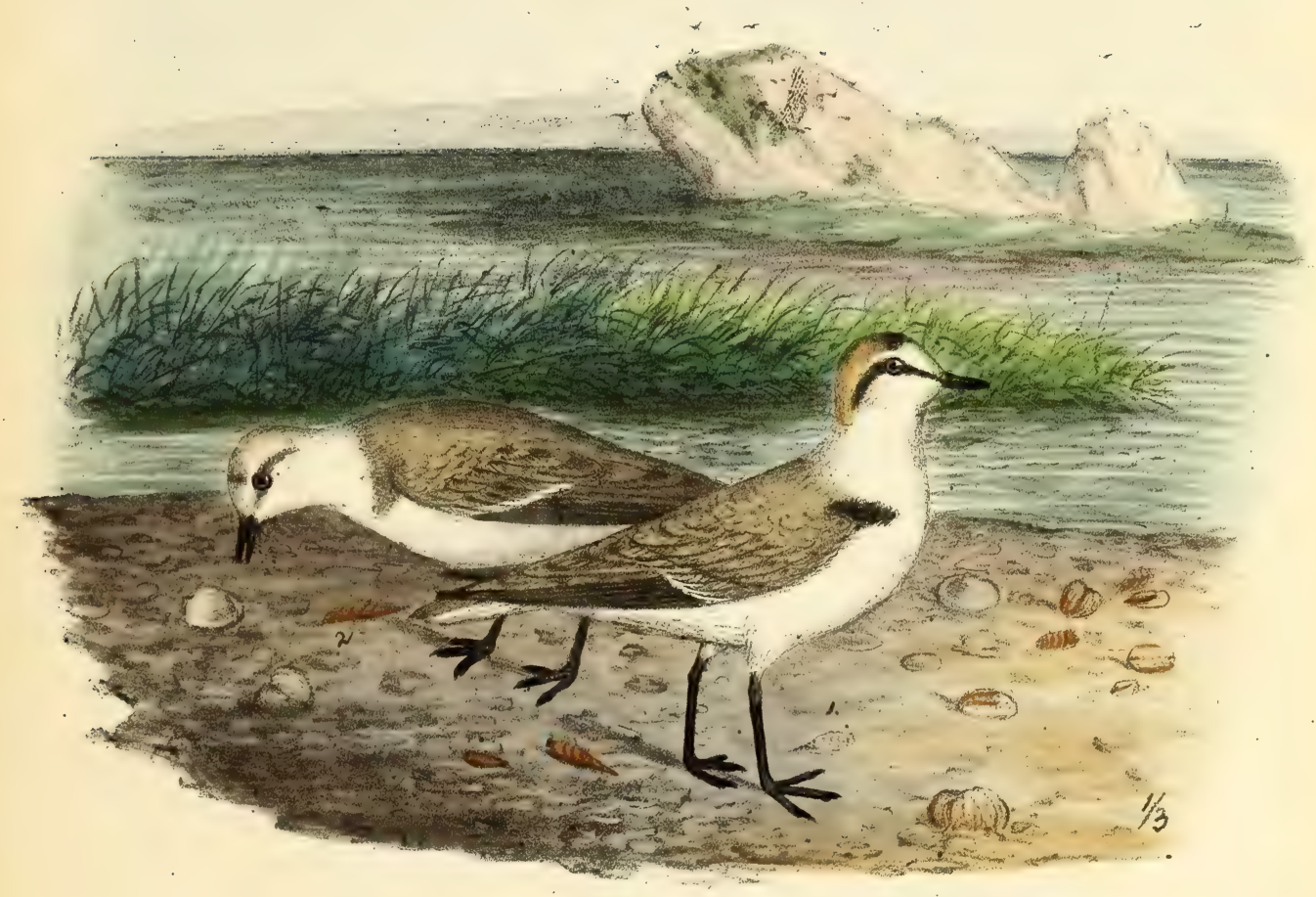

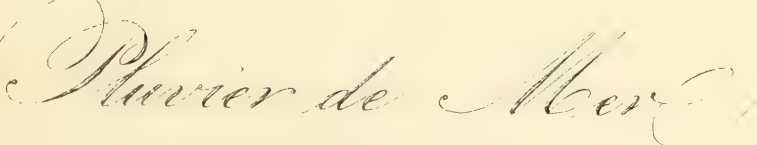

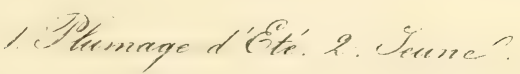





\section{$(166 a$. \\ P L U V I E R D E M ER.}

CIIARADRIUS CANTIANUS, LINNÉ.

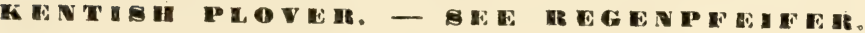

Temm., Man., t. II, p. 544. - Naumann, VII, pl. 176. - Gould., t. IV, pl. 298. - Degl., t. II, p. 101. - Thien., pl. XIV, fig. 8. - Selys-Long., Faune Belge, n 182. - Malh., Faune Sicile, p. 165. - Savi, Ornith. Toscana, t. II, p. 245 . - V. d. Mühle, Ornith. Griechenlands, no 216. - Rüpp., Vg. N. 0. Afrika's, no 411. - Malh., Ois. d’Algérie, p. 20. - Egialites cantianus, Bcjé. - Charadrius alexandrius, Lath. - Ch. littoralis, Bechst. - Ch. albifrons, Meyer.

Cet oiseau se trouve répandu en Europe et dans le nord de l'Afrique; on le rencontre également en Asie, aux bords des grands lacs de la Tartarie; il fréquente aussi les côtes de la Grande-Bretagne, de la France, de la Belgique, de la Hollande et de l'Allemagne. Ces pluviers suivent, dans leurs migrations périodiques, les bords de la mer; leurs endroits favoris sont les grandes plaines verdoyantes, entrecoupées de terrains sablonneux, couverts de coquillages; ils ne se dirigent vers l'intérieur des continents que lorsque ces plaines, où ils aiment tant à séjourner, sont envahies par les eaux de la mer. Leur vol est très-rapide; ils déploient une grande adresse dans leurs évolutions aériennes, mais ils ne s'élèvent pas fort haut et se contentent de raser le sol ou l'eau. A vant de prendre leur vol, ils ouvrent plusieurs fois leurs ailes, comme pour essayer leur force et leur souplesse, et, avant de se poser, ils planent, en quelque sorte sans mouvement, pendant quelques instants dans l'air. Ces pluviers, plus timides encore que sauvages, savent courir sur la pelouse et dans les champs avec une grande vitesse, s'arrêtent tout court après avoir couru, regardent autour d'eux avec inquiétude, puis se tiennent immobiles et se bloltissent contre terre. Poursuivis par le chasseur, ils cherchent à lui échapper par une course rapide, de sorte qu'il est presque impossible à celui-ci de les suivre; puis, las de courir, ils se lèvent et décrivent un immense cercle dans l'air, pour se tenir hors de la portée du fusil; ensuite, ils font volte-face, et, par un brusque motvement, reviennent à leur point de départ, ce qui rend leur chasse fatigante et ennuyeuse. Mais, si on les surprend dans leur nid, il est facile de les tirer; ils y montrent alors une grande tendresse sexuelle: si l'un est tué, le survivant ne peut se décider à abandonner la couvée, et, malgré l'instinct de la conservation personnelle, il préfère souvent mourir plutôt que de fuir.

Leur nourriture habituelle sont les insectes, les scarabées, les petits limaçons, ainsi que des larves et des vers.

Ce pluvier ne fait point de nid. La femelle dépose trois ou quatre œufs, dans une excavation peu profonde, sur la terre nue, dans le sable ou entre les pierres, non loin de la mer. Une litière de quelques brins d'herbe desséchés est tout ce qu'ils mettent au fond du trou qui leur sert de nid, et souvent même il n'y a rien du tout; mais, comme une compensation à cette manière de nicher, pendant et après la couvaison, le mâle ne quitte point sa compagne, lui témoigne la plus vive tendresse et l'aide à élever les petits, pour lesquels tous les deux montrent une grande sollicitude. 



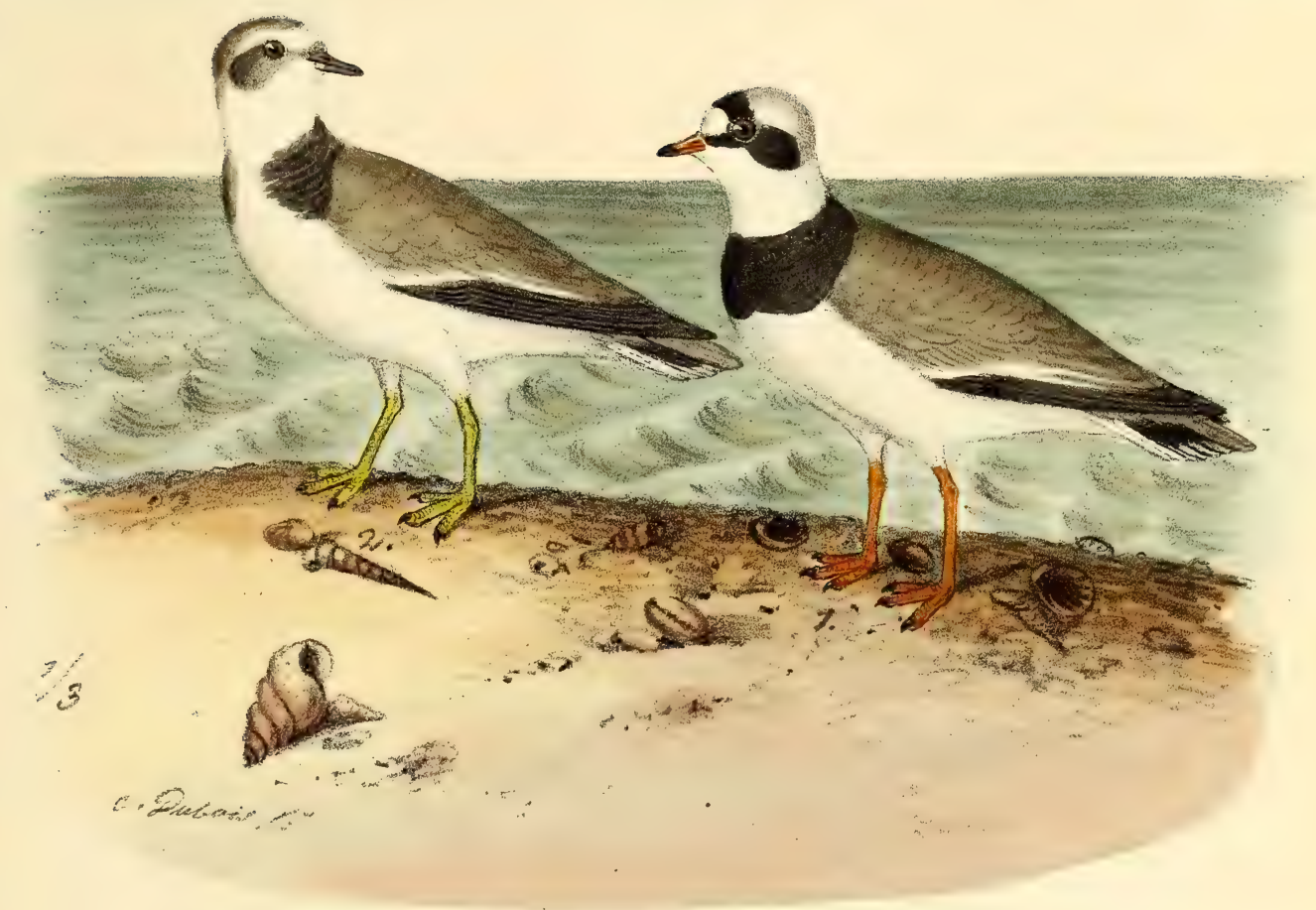

$$
\text { Doturion a Coller }
$$





\section{PLUVIER A COLLIER.}

CHARADRIUS HIATICULA, LINNE.

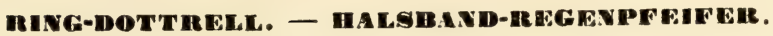

Buff., t. VIII, p. 60; - pl. enl. 920 - Temm., t. II, p. כ339. - Gould, t. IV, pl. 296. - Degl., t. II, p. 97. - Naum., t. VII, pl. 175. - Thienem., pl. XIV, fig. 6. - Selys-Longch., Faune belge, n 180. - Savi, Oanith. Toscana, t. II, p. 241. - Malh., Faune Sicile, p. 161. - Mey., Vg. L.iv.-u. Estillands, p. 170̈. - v. d. Mühle, Vg. Griechenlands, no 218. - Malh., Ois. de l'Algérie, p. 20. - Rüpp., Vg. N. 0. Afrika's, n" 410. - Holbóll, Ornith. Groevlands, p. 37. - Pluvialis torquata, Briss. - Hiatigula anvulata, Gray. - Aegialitis hiaticula, Bojé. A. Septentrionalis, Brehm.

Cet oiseau-ci est répandu dans toute l'Europe; on le trouve aussi en Egypte, dans le gouvernement du Cap, en Sibérie, dans le Groenland et dans presque toutes les contrées du nord de l'Amérique; il aime les bords sablonneux des fleuves et des mers, ainsi que les rivages pierreux et unis; c'est un oiseau vif et inquiet, qui court avec la plus grande vivacité sur les rivages, il s'y tient ordinairement près d'une proéminence de rochers où il se croit plus en sûreté; onle trouve rarement seul, il est presque toujours accompagné. Ce pluvier vole avec rapidité et ordinairement en rasant l'eau; il se repose à une distance de cent pas; court vite, et vole souvent au-dessus des eaux étroites d'un bord à l'autre; il fait peu de mouvement en volant et avant de se reposer il nage un peu dans l'air; en volant ou étant posé il crie sans cesse kuh, kuh, tull, tull, ce qu'on entend encore le soir fort tard; il arrive vers la fin de mars et retourne au mois de septembre pendant la nuit; lors des migrations on les voit encore jusqu'à la fin d'octobre; comme ces oiseaux sont très-prudents et méfiants, les chasseurs ont beaucoup de peine à les abattre.

Nourriture : insectes d'eau et leurs larves, petits coléoptères, vers et petites limaces.

Il niche une fois par an, au mois de mai ou de juin, près ou loin de l'eau, souvent aussi dans les champs en jachère, dans l'herbe haute ou simplement à terre, quelquefois aux bords de la mer; le nid consiste en un enfoncement dans la terre ou dans le sable; ils y mettent quelques petits cailloux sur lesquels ils déposent quatre œufs; en cas de danger la femelle quitte le nid avec les ailes pendantes; ils aiment beaucoup leurs petits, ils les nourrissent en commun. 



$$
\begin{aligned}
& \text { Peverene seteit? } \\
& \text { 1. Mumage di Ote.' 2. Pune. }
\end{aligned}
$$





\title{
P L U V I E R PETIT.
}

\author{
CHARADRIUS MINOR, MEYER.
}

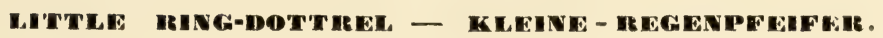

Buff., t. VIII, p. 921 ; - pl. enl. 921. - Temm., t. II, p. 542. - Goull, t. IV, pl. 297. - DegI., t. II, p. 99. - Naum., t. VII, pl. 177. - Thienem., pl. XIV, fig. 7. - Selys-Longch., FaunE belge, no 181. - Savi, Ornith. Toscana, $t$ II, p. 214. - Malh., Faune Sigile, p. 165.- Meyer, Vg. Liv.-u. Esthlands, p. 176. - v. d. Mühle, V. Griechenlands, no 217 . - Rüpp., Vg. N. 0. Afrika's, no 413. - Charadrius fluviatilis, Bechst., - Ch. curonicus, Beseke. - agialitis, curonicus, Keys. et Blas. - E. MıNor, Bojé.

Ce petit pluvier habite particulièrement l'Europe tempérée et méridionale; en Allemagne et en France il est par-ci par-là en abondance; il est plus rare en Belgique, et encore plus rare en Hollande; on l'a aussi trouvé en Egypte, en Nubie et en Abyssinie. Il vit aux bords des étangs et des fleuves; près des torrents, surtout ceux qui ont des bords pierreux. Son vol a la vitesse d'une flèche; il est toujours éveillé et en mouvement, mais il est farouche, méfiant; il fait souvent entendre sa voix perçante qu'on entend de loin. Il nous vient ordinairement aux mois de mars et d'avril et nous quitte au mois de septembre pour commencer ses migrations, ce qu'il fait pendant la nuit ordinairement par volées de cinq à douze, mais aussi par couples ou isolé. Les chasseurs doivent s'en approcher avec prudence, car ils apprennent facilement à les connaitre et s'envolent au plus vite à leur aspect.

Nourriture : insectes et leurs larves ainsi que des vers.

Pour nicher ils recherchent particulièrement les places couvertes de sable et de cailloux, les rivages unis et sablonneux, les îles de sable même lorsque ces endroits sont assez éloignés de l'eau; le nid est un simple enfoncement dans le sable, mais plutôt encore dans le gravier; ils l'arrangent toujours de manière que les inondations ne puissent lui nuire; cet enfoncement, que ces oiseaux se font s'ils ne le trouvent pas tout fait, est ordinairement raffermi par des cailloux; ils y déposent habituellement au mois de mai ou de juin trois ou quatre oufs sans lustre et la coquille unie; on les trouve difficilement, car ces œufs ressemblent beaucoup aux cailloux; moi-même j’y ai été pris plusieurs fois. Les petits sont nourris par le mâle et la femelle; en cas de danger ceux-ci font un signe et aussitôt les petits se jettent plat à terre où ils restent souvent tout à fait inaperçus. 

169.
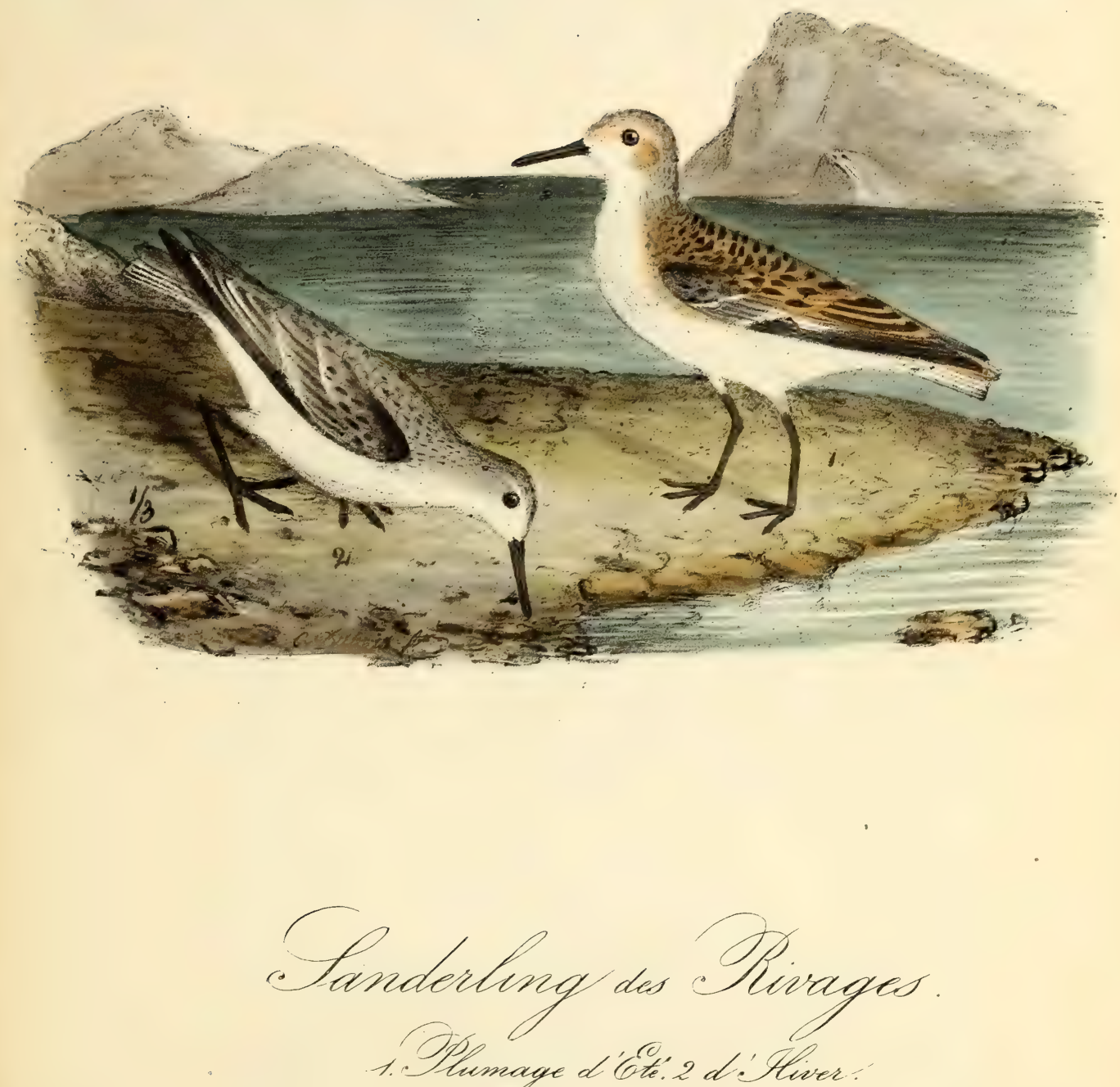

, 



\title{
SANDERLING DES RIVAGES.
}

\author{
CALIDRIS ARENARIA, ILLIGER.
}

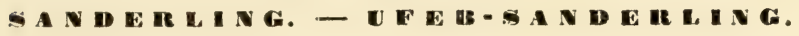

Temminck, t. II, p. 334. - Naum., t. VII, pl. 182. - Gould, t. IV, pl. 335. - Degl., t. II, p. 240. - Thiem., pl. LXII, fig. 2. - Selys-Longch., Faune belge, $n^{0}$ 193. - Malh., Faune Sicile, p. 183. - Savi, Ornith. Toscana, t. II, p. 249. - V. d. Mühle, Ornith Griechenlands, no 233. - Richardson el Schwain, Fauna Bor. Am., p. 366. - Holböll, Fauna Groenlands, p. 36. Rüpp., Vg. M. 0. Afrika's, no 468. - Max. Prinz zu Wied, Beit, v. Brasilien, t. IV, p. 750. Charadrius calidris, wils. - Tringa arenaria, Linné.-T. Tridactyla, Pall. - Calidris rubidus, Vieill. - Arenaria vulgaris, Bechst.

Cette espèce est répandue dans le nord de l'Europe, de l'Asie et de l'Amérique; on la trouve sur le littoral de la mer Glaciale, depuis l'Islande, le Groenland, la baie d'Hudson jusqu'au Labrador; on la voit aussi le long des côtes de la Sibérie. En automne, ces sanderlings quittent ces régions boréales et se dirigent vers les côtes de la GrandeBretagne, de l'Allemagne, de la Belgique, de la Hollande et de la France. A l'apparition du printemps, ils se réunissent en grand nombre, et reprennent leur vol vers les pays du Nord. Ces migrations se font pendant la nuit ; comme leur vol est très-rapide, ils parcourent de grandes distances d'un seul trait, toujours en suivant les bords de la mer, qu'ils quittent rarement : les grèves, les hautes falaises sont les lieux où ils aiment à séjourner de préférence; il est rare d'en voir sur les bords des rivières ou des lacs situés dans l'intérieur des continents. En volant, lorsqu'ils ne veulent pas parcourir de grandes distances, ilsse contentent de raser la surface de l'eau, sans s'éloigner du rivage. Leur voix, qu'ils font quelquefois entendre en cherchant leur nourriture, ressemble à un pitt pitt fort monotone d'ailleurs.

Ils se nourrissent d'insectes, de larves et de petits vers, et lorsqu'ils sont à la recherche de leur pâture, tout ce qui se passe autour d'eux leur est indifférent, et ils se laissent approcher de très-près; il est alors trèsfacile d'en tirer, mième plusieurs à la fois. On les rencontre souvent en troupeaux assez nombreux et très-serrés, errant sur la grève. Leur chair est délicate et d'une saveur agréable. En captivité, ils s'apprivoisent facilement et deviennent extrêmement familiers.

Ils nichent sur les bords de la mer, dans un petit enfoncement qu'ils garnissent de mousse et de quelques herbes sèches; leur ponte est de trois à quatre œufs. 



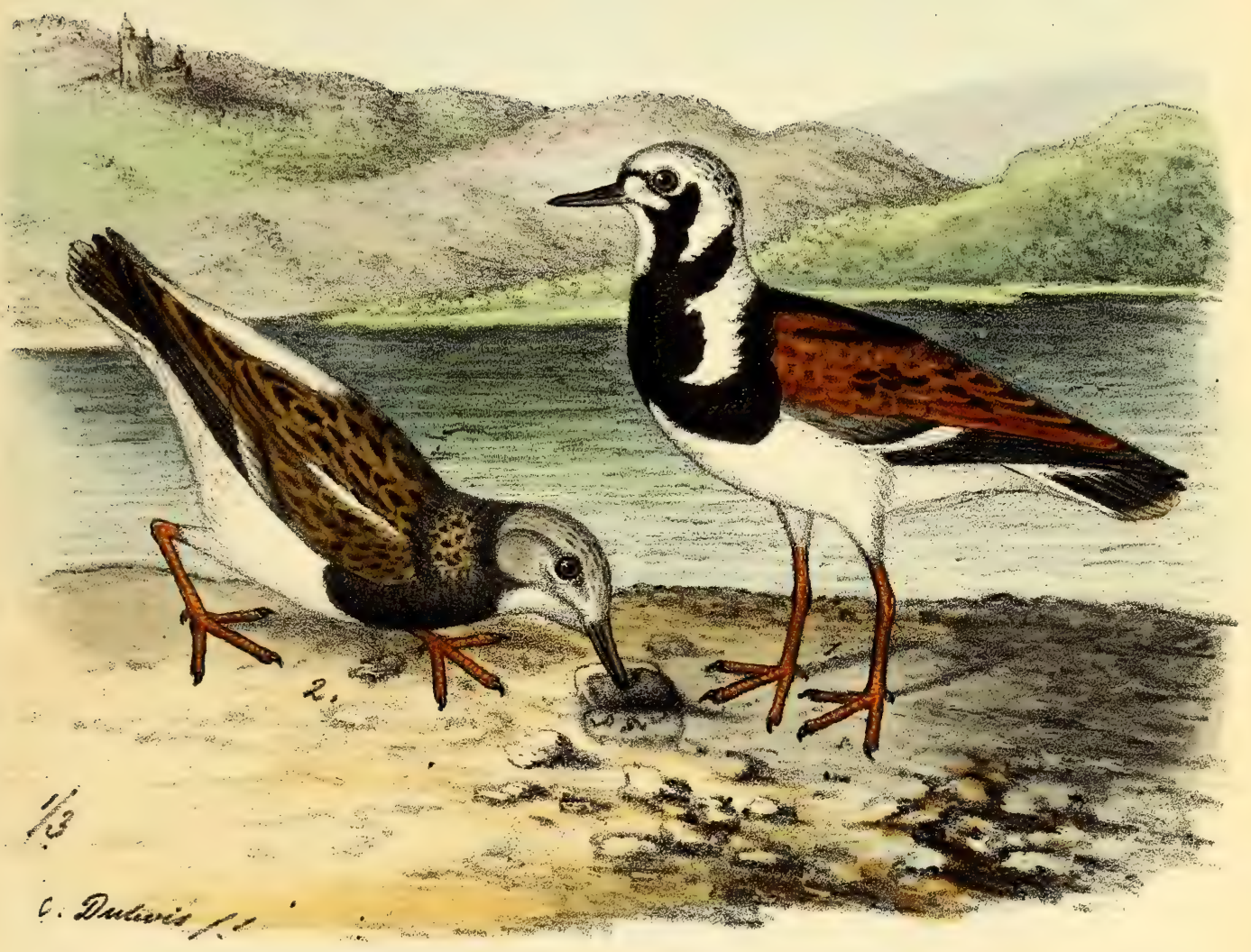

$$
\text { Eoume-fuevere a torilliep. }
$$



Genve Tourme-piense. - strepsilus, Hliger.

\section{TOURNE-PIERRE A COLLIER.}

STREPSILAS COLLARIS, TEMMINCK.

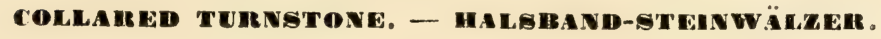

TOURNE-PIERRE, Buff., t. VII, p. 130. - Temm., t. Il, p. 55̃.-Gould, t. IV, pl. 318. Naum., t. VII, pl. 180. - Degl., t. II, p. 242. - Thienem., pl. XIV, fig.10. - Selys-Longch., Faune belge, n 187. - Mey., Vg. Liv.-u. Estulands, p. 210. - Malh., Faune Sicile, p. 187. - Savi, Onnith. Toscana, t. II, p. 260. - v. d. Mühle, Vg. Griechenlands, p. 219. - Faber, Island Ornith., p. 26. - Rüpp., Vg. N. 0. Afriks's, nº 416. - Rich. el Sws., Fauna boreali americana, p. 571. - Arenaria cinerea, Briss. - Tringa morinella el T. interpres, Linné. - Morinella collaris, Meyer. - Strepsilas interpres, Illig.

Ces oiseaux se trouvent particulièrement dans le nord de l'Europe comme en Islande, Norwége, Suède, Russie, Danemark; il est de passage en Italie, en Allemagne, aux lles Britanniques, en Hollande, en Belgique et en France; on le trouve aussi dans plusieurs parties de l'Asie, de l'Afrique et de l'Amérique. Pour leur séjour ils choisissent les bords graveleux et sablonneux des mers et des fleuves, ou les petites îles ayant peu d'herbes mais beaucoup de bruyères et de sable; ils paraissent aussi aimer beaucoup les buissons de genévrier. Ils sont très-vifs et éveillés, et en mouvement dès le matin de très-bonne heure jusqu'au soir fort tard. Leur marche est précipitée, cependant ils se reposent souvent; étant perchés ou courant ils font entendre leur voix perçante ressemblant à kuh, kih, kih, tantôt lentement, tantôt plus vite, plus fort cependant en s'élevant dans les airs et en volant; ils sont farouches et craintifs et s'aperẹoivent vite du voisinage du chasseur ; lorsque après avoir tiré on a manqué l'oiseau, celui-ci s'abaisse comme s'il se laissait tomber puis vole plus loin.

Sa nourriture se compose d'insectes, de leurs larves et de vers; il a l'habitude de chercher sa nourriture sous de petites pierres, ce qui lui a valu le nom de tourne-pierre; car il le fait avec une grande dextérité en se servant du bec.

Pour couver il cherche les îles qui ont peu d'herbe, mais beaucoup de bruyères et de sable, ainsi que des buissons de genévriers peu élevés; il ne niche pas seulement sur le rivage mais partout où il trouve une place convenable. Le nid est tout bonnement un enfoncement sous un buisson de genévriers ou de bruyères, bourré de quelques brins d'herbe sèche; on y trouve vers la fin de mai trois ou quatre oufs, grands en proportion de 'oiseau; les œufs sont un peu brillants et unis. Les petits, qui quittent le nid aussitôt qu'ils sont sortis de l'œuf, se couchent à terre à l'approche d'un danger. 



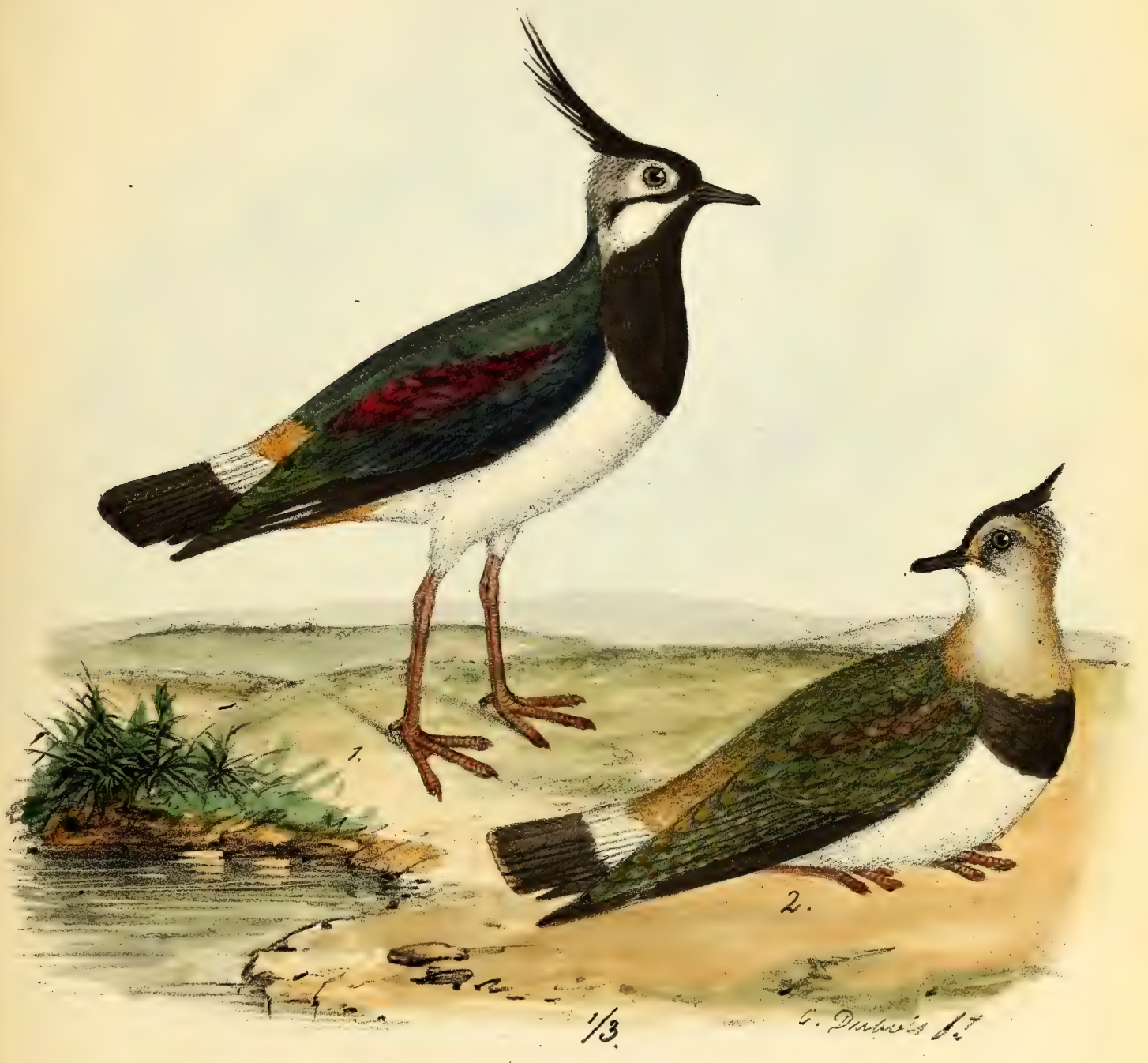

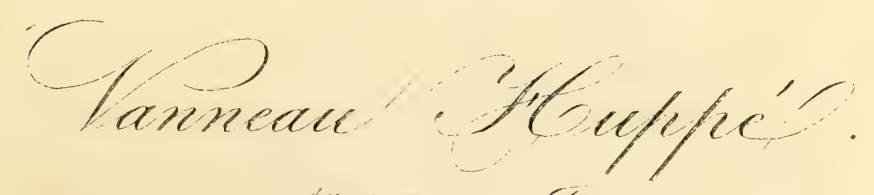

1. Nhith 2. Youmé 

Gevre Vannean. - Vasmellus, Brisson.

\title{
V I N N E A U II U P P E.
}

VANELLUS" CRISTATUS, MEYER.

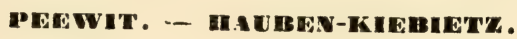

\begin{abstract}
VANNEAU, Buff., $\mathrm{t}$ VIII, p. 46 ; - pl. en!. 242. - Temm., I. II, p. 5ว̃0. - Gould, t. IV, pl. 291. - Degl., t. II, p. 112. - Naum., t. VII, pl. 179. - Thienem., pl. XIV, fig. 9. - SelysLongch., Faune belge, no 186 - Savi, Ornith. Tosgana, t. II, p. 2206. - Malh., Faune Sigile, p. 166. - Meyer, Vg. Liv.-u. Esthlands, p. 211 . - v. d. Mühle, Vg. Griechenlands, no 212. - Rüpp., VG. N. 0. Afrika's, n" 402. - Tringa vanellus, Linné. - T. Bononiensis, Gmel.
\end{abstract}

Cet oiseau est répandu de tous côtés; il habite la Sibérie jusqu'au Kamtscharka, la Per'se, la Chine, la Barbarie, le Groenland et toute l'Europe; il est en abondance en Belgique, mais nulle part aussi commun qu'en Hollande; il paraît ici dès la tin de février et nous quitte, pour la plupart, au mois de septembre alin de passer l'hiver dans les parties méridionales de l'Europe; cependant lorsque l'hiver n'est pas rigoureux, il y en a qui restent ici. Il aime les bords marécageux des mers, des fleuves, des étangs, les prairies humides, les marais; on le trouve aussi dans les pàturages et dans les campagnes en jachère. C'est un oiseau éveillé, adroit, farouche et presque toujours en mouvement pendant la nuit et le jour; il court vite, le cou en avant et les ailes élevées; son vol est léger et beau, mais il fait beaucoup de battements d'ailes; les évolutions qu'il décrit en se jouant dans les airs sont vraiment remarquables; en volant ils font souvent entendre leur voix tel que kiebich, ce qui lui a valu son nom allemand. Cet oiseau dort ordinairement vers midi en se tenant sur une palte. Ils ne dorment que pendant les nuits obscures, lorsqu'il fait clair ils volent et on peut facilement les attraper alors. La chair du vanneau est moins recherchée en Hollande que ses œufs qu'on envoie par paniers sur le marché.

Nourriture : coléoptères, et autres insectes et leurs larves, ainsi que des vers de terre et des limaces.

Ils nichent aux bords des fleuves et des étangs marécageux, particulièrement près des marais isolés et sur les rivages de la mer; mais on le trouve aussi dans les pâturages humides et dans les champs en jachère Au mois d'avril ou de mai, on trouve le nid dans l'herbe sur une place élevée s'il y a de l'eau autour; ordinairement ils déposent leurs quatre œufs sur un peu d'herbe sèche, souvent simplement sur la terre; les oufs sont sans lustre et la coquille en est unie; mâle et femelle couvent; et ils aiment beaucoup leurs petits. Lorsqu'un de ces oiseaux est en danger, il fait entendre un cri d'effroi qui rassemble tous les vanneaux qui sont dans le voisinage; ceux-ci volent tous, en jetant de grands cris, autour de l'ennemi et parviennent parfois à l'écarter du nid en faisant tant d'évolutions qu'ils lui font perdre souvent la trace des oeufs ou des petits qu'il convoitait. 

192

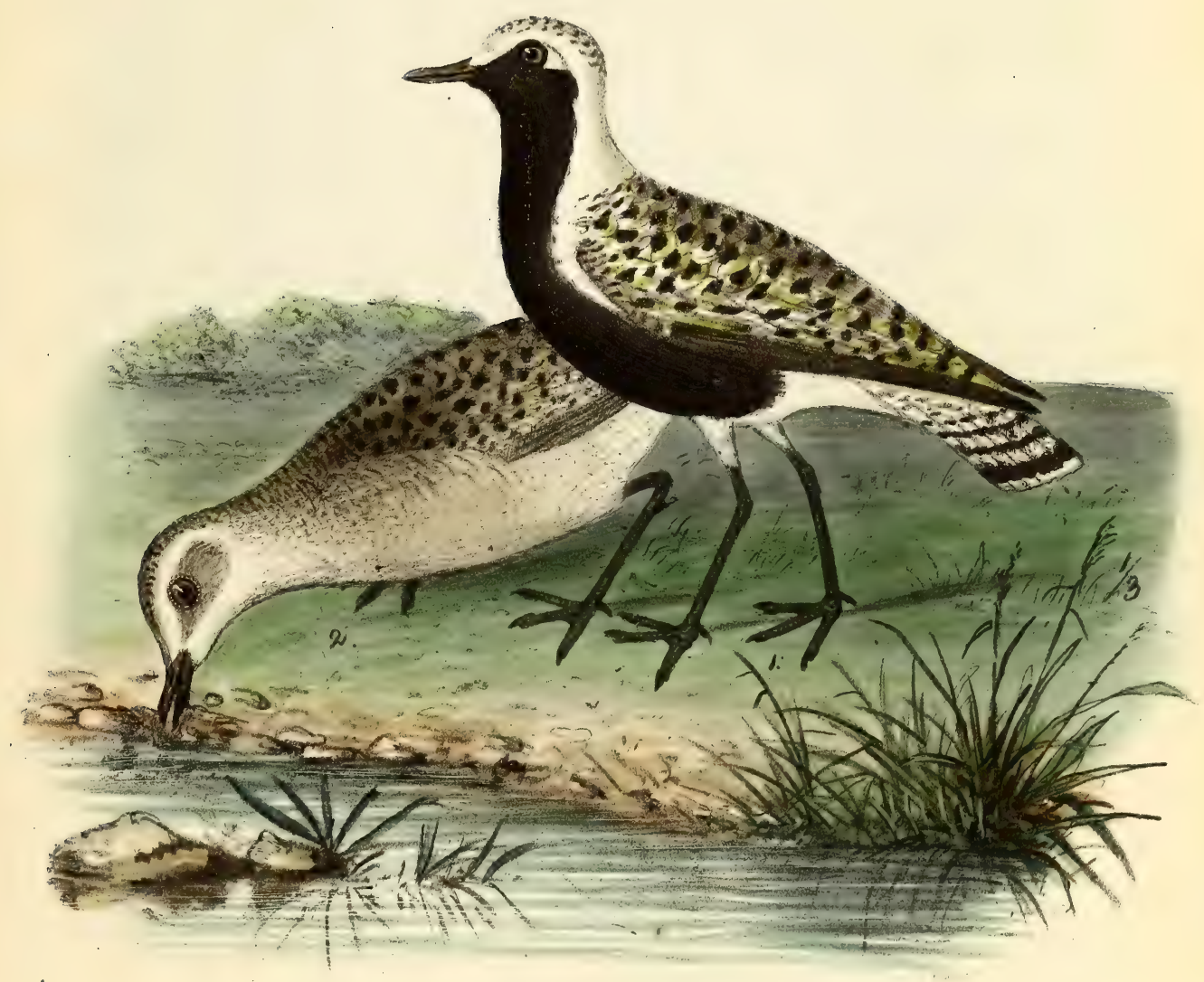

\footnotetext{
Conneau a nentie: noir'

1. Pusnaye d'E'te'. ? d hiver
} 



\section{VANNEAU A VENTRE NOIR.}

VANELLUS MELANOGASTER, BECHSTEIN.

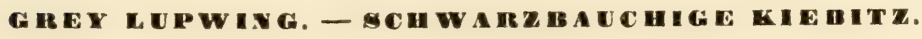

Temm., Man., I. II, p. 547. - Naum., VII, pl. 178. - Gould, t. IV, pl. 209. - Degl., t. II, p. 114. - De Selys-Lonch., Faune belge, n⿳ 185. - Malh., Faune Sigile, p. 166. - Savi, Onnith. Toscana, I. II, p. 254. - V. d. Mühle, Ornith. Griechenlands, no 213. - Hỏlb., Fauna Groenlands, p. 37. - Malh., Ors. d'Algérie, p. 20. - Rich. et Sivains., Fauna Bor. Amer., p. 370. - Charadrius apricarius, Wils. - Ch. squatarola, Naum. - Tringa squatarola, Lath.

- T. Helvetica, Linn. - Squatarola melanogaster, Swains. - S. Helvetia el varia. Brehm.

- S. cinerea, Cuv. - Vanellus Helveticus. griseus et varius, Briss.

On le trouve répandu dans toute l'Amérique septentrionale, jusqu'à la baie d'Hudson, et en Asie, il habite la Sibérie. On le voit aussi dans la Russie d'Europe. En automne, ces vanneaux émigrent et se dirigent vers l'Allemagne, la Grande-Bretagne et la Hollande, mais rarement vers les pays plus méridionaux de France, de Belgique, d'Espagne ou d'Italie. En Egypte, on en trouve quelquefois, mais ils sont isolés. Dans leurs voyages, ils suivent autant que possible les bords de la mer, qui sont leur séjour favori; car ils aiment les grandes plages et les rives des grands lacs, pourvu qu'il y ait dans le voisinage des prés et des pâturages où ils puissent se reposer et passer quelques heures, quand ils sont fatigués des bords de la mer. Les endroits montagneux, couverts de forêts, ne leur plaisent pas, et ils les évitent autant que possible. Ils sont très-sociables; en automne, ils se réunissent en troupes assez nombreuses pour se mettre en route; ils volent aussi bien la nuit que pendant le jour. Leur vol est élevé et rapide, et s'ils sont à plusieurs, ils suivent une direction oblique; mais en troupe nombreuse, ils forment deux lignes qui se touchent à leur extrémité, de manière à représenter un angle très-aigu. Ils ont du reste le vol fort aisé, s'élèvent fort haut, et se jouent dans les airs de diverses manières. D'un naturel gai, ils sont sans cesse en mouvement; mais ils sont très-défiants et se laissent difficilement approcher : ils semblent même distinguer de très-loin le chasseur, pour l'éviter et lui échapper à temps. Leur chair est très-délicate et ordinairement fort grasse. Des insectes, des vers, des vermisseaux aquatiques, des petits coquillages qu'ils trouvent dans la vase, forment leur principale nourriture.

Dans la saison de la ponte, la femelle choisit un petite butte ou motte de terre, élevée au-dessus du niveau d'un terrain humide, pour y placer son nid; elle le laisse entièrement à découvert; et pour en former l'emplacement, elle se contente de faire dans l'herbe une petite excavation recouverte de mousse ou de brins d'herbe desséchés, où elle dépose trois ou quatre oufs. 


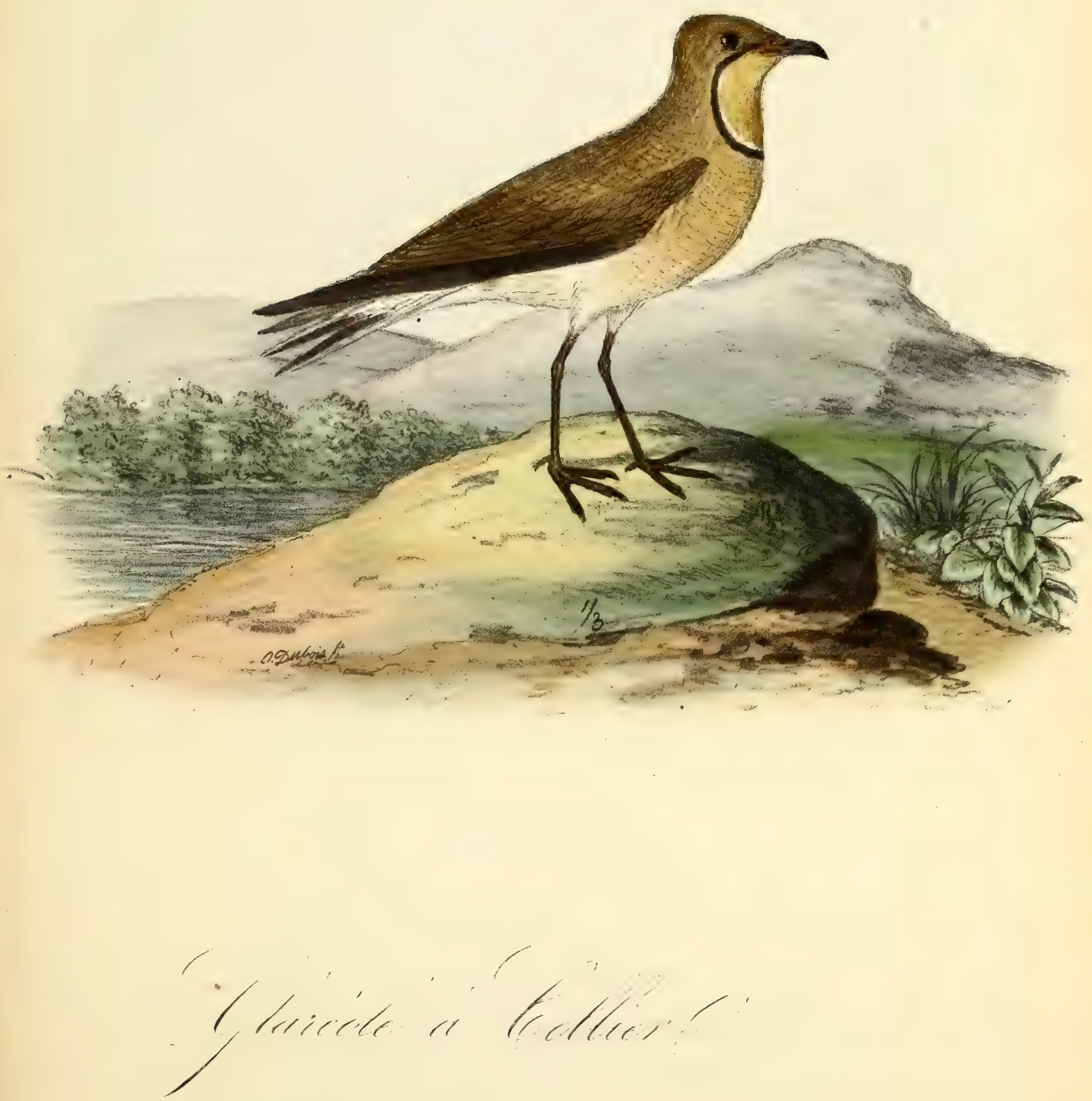

Denre Alanéole.-Clareola, Brisson.

\section{GLAREOLE A COLLIER.}

GLAREOLA TORQUATA, BRISSON.

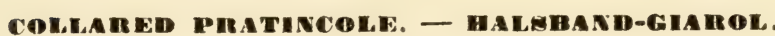

PERDRIX DE MER. Buff., pl. enl. 882. - Temm. Man., t. II, p. 500. - Naum., IX, pl. 264. - Gould, t. IV, pl. 265. - Degl., t. II, p. 107. - Thien., pl. XIII, fig. 6. - De Selys-Longch., Faune belge, no 178. - Malh., Faune Siclle, p. 200. - Savi, Ornith. Toscana, t. II, p. 214. V. d. Mühle, Ornith. Griechenlands, n 197. - Malh., Ois. de l’Algérie, p. 19. - Rüpp., Vg. N. 0. Afrika's, n' 400. - Hirundo pratincola, Linné. - Glareola Austriaca el Naevia, Gmel. - G. pratincola, Leach.

Cet oiseau se trouve répandu dans la plus grande partie de l'Asie, sur tout le littoral de la mer Caspienne et de la mer Noire, en Tartarie et dans la Sibérie méridionale. On le voit aussi dans les plaines sablonneuses de l'Arabie, en Égypte, sur les bords de la mer Rouge, dans l'Arabie Pétrée. Il se montre également en Turquie, en Hongrie et en Dalmatie. Dans ses émigrations, il traverse souvent la Suisse, l'Italie, le midi de la France, mais rarement l'Allemagne, la Hollande, la Belgique et la Grande-Bretagne. Il vit sur les bords des rivières, des étangs et des lacs dont les rives sont sablonneuses ou bordées de champs en friche, mais il fréquente peu les bords de la mer. Son vol est léger et rapide; il rase seulement la terre ou la surface de l'eau, et ne s'élève à une certaine hauteur que lorsqu'il veut prendre une direction lointaine. En volant, il laisse souvent entendre sa voix, qui est un sifflet court, aigu et saccadé. D'un caractère gai, il aime à courir et à jouer dans le sable ou dans les champs en friche situés près des rivières. On le trouve même quelquefois trèséloigné de tout cours d'eau, dans des p'aines sablonneuses, où il s'amuse à sautiller, à courir et à chercher sa nourriture. Sa timidité est assez grande, et comme il se tient presque toujours dans des lieux entièrement découverts, il est fort difficile au chasseur de l'approcher. Sa nourriture principale consiste en scarabées, mouches, moucherons et autres insectes; il mange aussi des vermisseaux aquatiques et des larves; il aime également à faire la chasse aux insectes, et sait les attraper dans leur vol avec une adresse vraiment surprenante.

La femelle niche au bord de l'eau, où elle se choisit un emplacement bien abrité dans l'herbe ou les roseaux. Quelquefois elle fait son nid dans des champs en friche ou dans le blé. Une petite excavation cachée par une motte de terre, et garnie de quelques racines et brins d'herbe bien secs, lui suffit; sa ponte est rarement de plus de trois ou quatre œufs. 


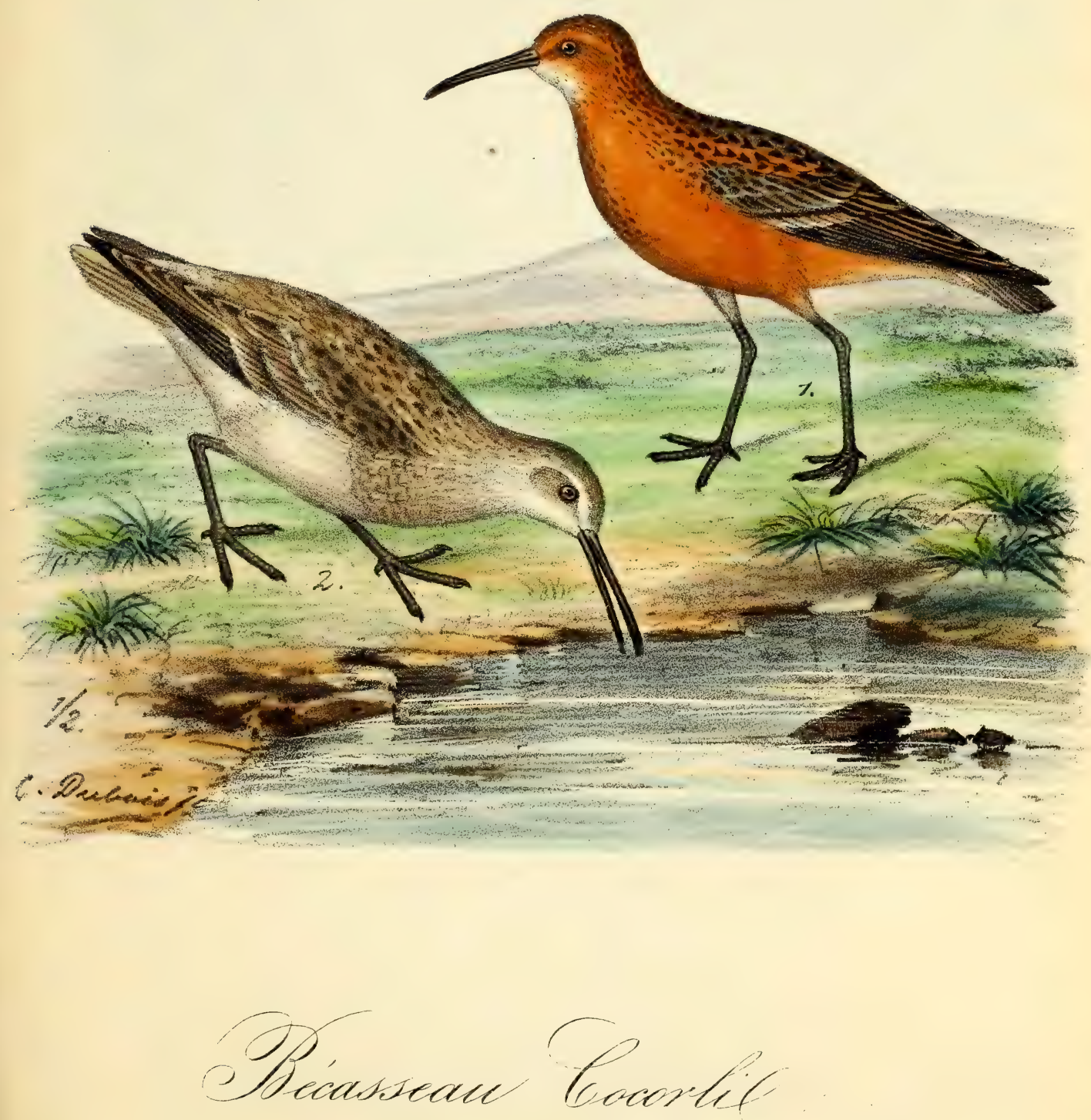

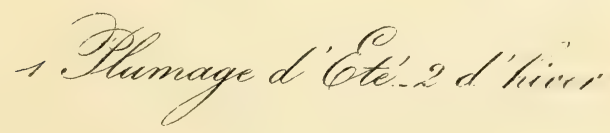





\section{Geñe Bécrsseas. - T'mongr, Linné. \\ BÉCASSEAU COCORLI.}

TRINGA SUBARQUATA, TEMMINCK.

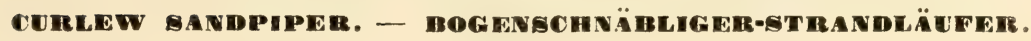

L'ALOUETTE DE MER, Buff., pl. eln. 851. - Temm., t. II, p.609. - Naum., t. VII, pl. 185. - Gould, t. IV, pl. 328. - Degl., t. II, p. 225. - Selys-Longch., Faune BELGe, n 194. Savi, Ornith. Toscana, t. II, p. 284. - Malh., Faune Siclle, p. 184. - v. d. Mühle, Vg. Griechenlands, p. 236. - Malh., Ois. L'Algérie, p. 21. - Rüpp., VG. N. O. Afrika's, nº 467. Scolopax subarquata, Gmi. - Numenius subarquata, Bechst. - N. ferrugineus, Wulf et Mey. - N. africanus, Lath. - Tringa ferrugineus, Koch. - T. cinerea, Brünn, - Pelidna subarquata, Cuvier. - Schoeniculus subarquatus, Rüpp.

Il habite l'Europe, l'Asie et l'Afrique ainsi que l'Amérique septentrionale; en Europe, il fréquente, pendant l'été, la Norwége, la Suède, le Danemark et tout le littoral de la mer du Nord et de la mer Baltique; on le voit aussi dans le nord de l'Allemagne, en Hollande, en Belgique et même en France. Ces oiseaux commencent leurs migrations périodiques, pour se diriger vers des contrées où le climat est plus tempéré, vers la mi-août, et continuent jusqu'au milieu d'octobre, et ils reviennent ordinairement à la fin d'avril. Comme ils sont très-sociables, ils se réunissent pour voyager ensemble, et souvent ils se joignent aux autres espèces de bécasseaux pour se mettre en route. Pendant le trajet, ils font souvent entendre leur voix. Ils aiment les endroits marécageux, les terrains plats et entrecoupés bordant la mer, les bords des fleuves et des ruisseaux, où il se trouve du gravier et du sable fin.

Il n'est nullement timide, et, lorsqu'il est poursuivi par le chasseur, il court devant lui, et il faut presque marcher dessus pour le faire lever; et, quand il se lève, son vol est moins rapide et il redescend bientôt. Quand ils sont réunis par troupes, comme ils se tiennent les uns près des autres en courant, il n'est pas difficile d'en tuer plusieurs d'un seul coup de fusil. Aussitôt que le chasseur a tiré, toute la troupe se lève avec rapidité, décrit une grande courbe dans l'espace et revient se poser au même endroit qu'auparavant. En captivité, le bécasseau cocorli se conserve fort bien; il semble même s'y plaire. Des insectes, des petits vers et des larves forment sa nourriture habituelle. Il aime à nicher dans le voisinage de la mer, où il choisit ordinairement un endroit légèrement élevé; son nid, assez mal construit dans l'herbe, est garni de quelques brins de paille et d'herbes desséchés; sa couvée est de trois ou quatre oufs au plus. 

$1-4$
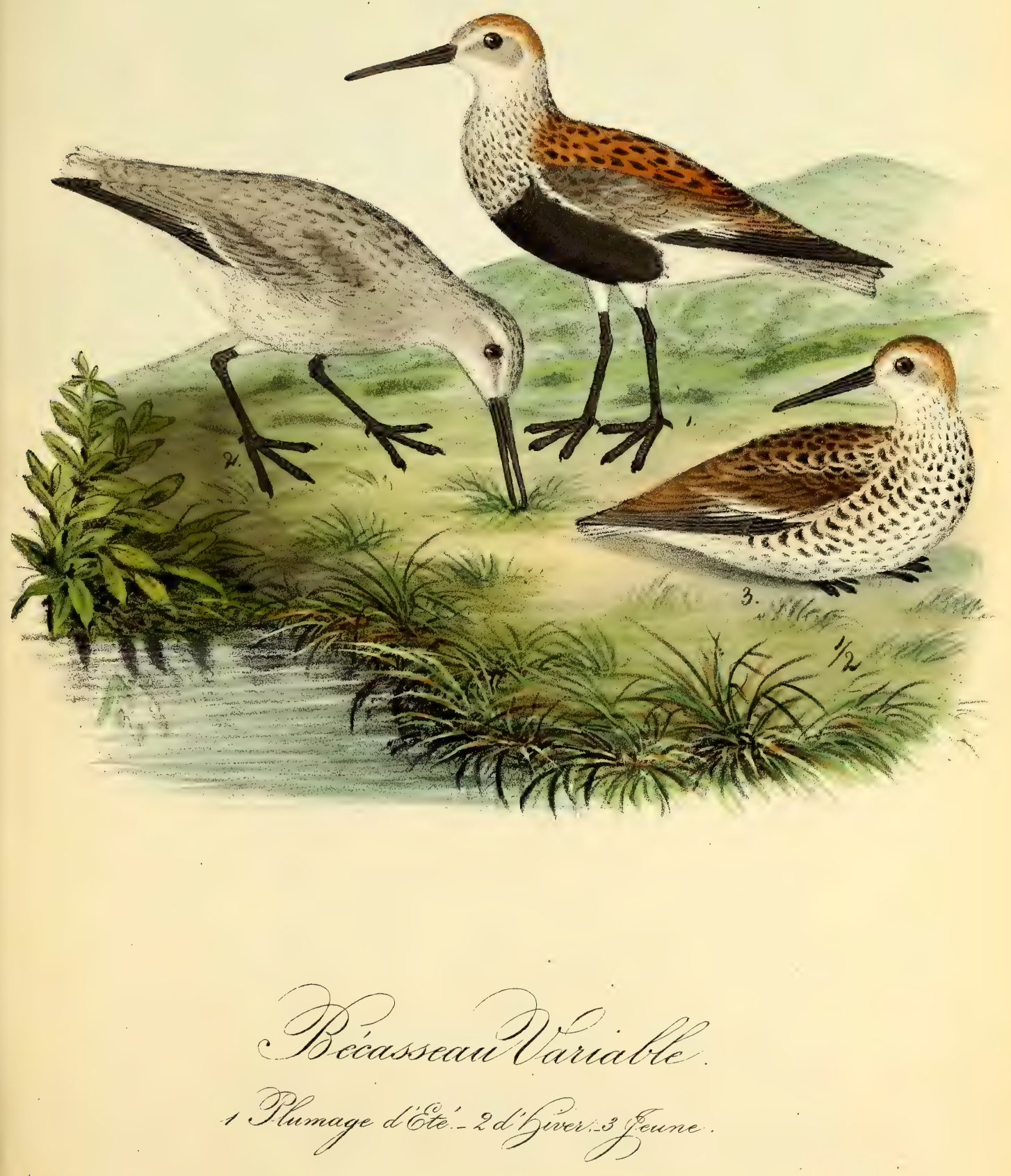



\section{(174) \\ BÉCASSEAU VARIABLE.}

TRINGA VARIABILIS, MEYER.

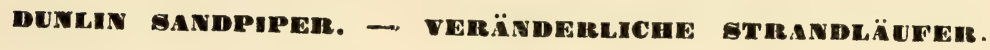

L'ALOUETTE DE MER, Buff., t. VII, p. 493 ; - pl. enl. 851. - Temm., t. II, p. 612. Gould, t. IV, pl. 328. - Degl., t. II, p. 228. - Naum., t. VII, pl. 186. - Thienem., pl. XVII, fig. 1. - Selys-Longch., Faune belge, no 195. - Savi, Ornith. Toscana, t. II, p. 282. - Malh., Faune Sicile, p. 185. - Meyer, Vg. Liv.-u. Esthlands, p. 208.-v. d. Mühle, Vg. Griechenlands, n 257.-Malh., Ois. de l'Algérie, p. 21.- Holbỏll, Ornith., Groenlands, p. 39. - Cinclus torquatus, Briss. - Numenius variabilis, Bechst. - Pelidva cinclus, Cuv. - Tringa alpina et T. cinclus, var., Ginel. - T. cuclus, Vieill.

Le becasseau variable se trouve dans presque toute l'Europe et y est très-répandu; on le trouve particulièrement en Suède, en Norwége, en Laponie, en Islande, en Sibérie, en Égypte, dans le Groenland, ainsi que dans une grande partie du nord de l'Amérique; il est très-fréquent aux bords de la mer en Hollande, aux Iles Britanniques, en France et en Belgique où il passe aussi ordinairement l'hiver, car je l'y ai rencontré dans toutes les saisons; il quitte ordinairement l'Allernagne aux mois de septembre et d'octobre. Ce bécasseau aime les marais les bords inarécageux des fleuves et les rivages des mers; il est sociable et éveillé, court en tremblant mais pourtant avec adresse sur la vase, dans les marais et sur le sable; il ne s'y enfonce pas; sur des élévations il se pose souvent pour regarder autour de lui. Pendant leurs migrations ils s'assemblent par grandes bandes et souvent en société d'oiseaux beaucoup plus grands, tels que les pluviers et les vanneaux; les bécasseaux sont peu farouches et peuvent être pris facilement. Leur vol est rapide et léger; pendant qu'ils couvent ils ne volent jamais qu'à de petites distances, tandis que pendant leurs migrations leur vol est haut et soutenu s'ils ne trouvent une place convenable pour se reposer.

Nourriture : petits insectes et leurs larves, des vers et des limaces.

Ils nichent, aux mois d'avril ou de mai, aux bords de la mer ou dans les marais, dans les prairies et pâturages, sur une hauteur dans l'herbe ou sous un buisson, de manière que le nid soit à l'abri de l'eau; aussi est-il toujours bien caché, et on le trouve difficilement; ce nid consiste en un petit enfoncement bourré d'un peu de mousse ou de brins d'herbe sèche, il contient ordinairement trois ou quatre oufs d'un lustre mat et ayant de petits pores. Lorsque la femelle est chassée de sa couvée, elle court ayant les ailes pendantes et avec anxiété autour de son nid et tâche d'en éloịgner l'ennemi; les petits qui quittent le nid de bonne heure se cachent avec beaucoup d'adresse dans l'herbe à l'approche du danger. 



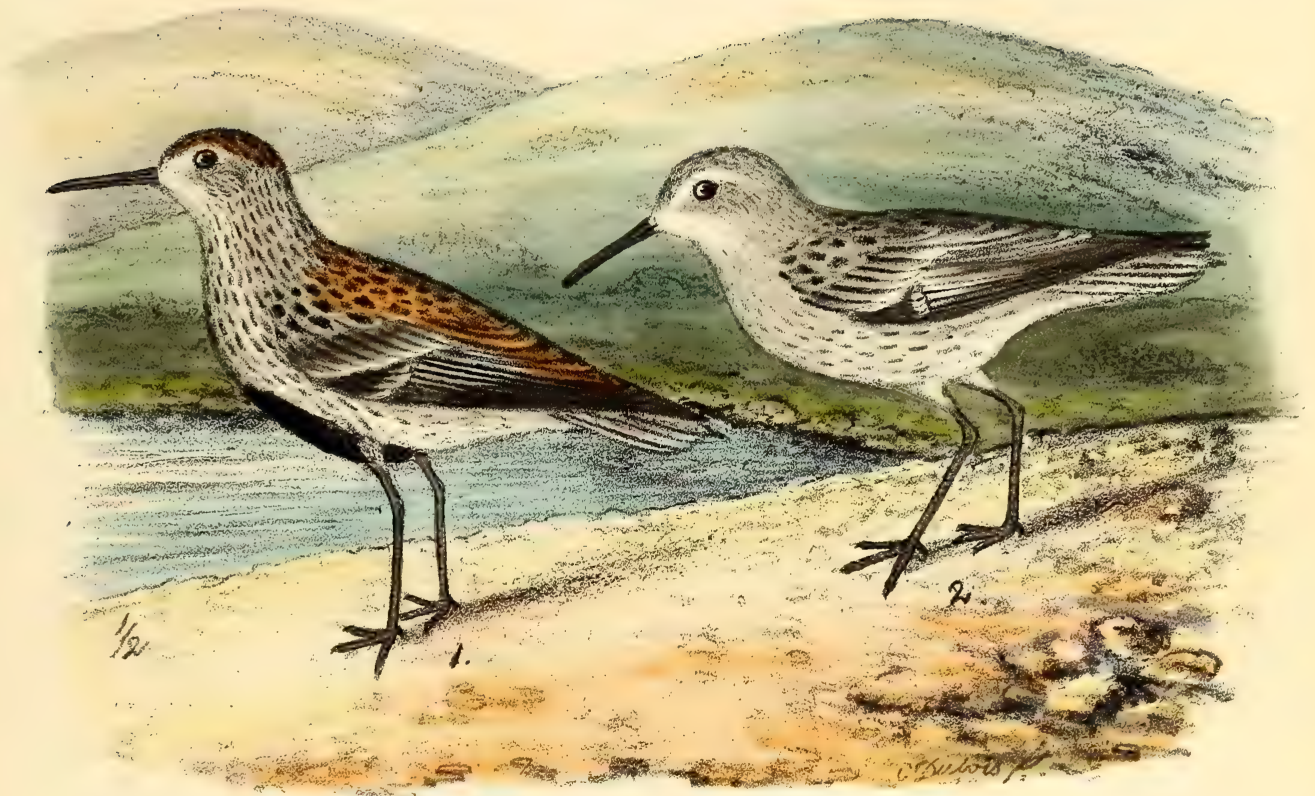

- Pricasscane de. Sining 



\section{BÉCASSEAU DE SCHINZ.}

TRINGA SCHINZII, BREHM.

MCHINZ' SANDPIPER. - GCUMNZ-STTANDLÄUFER.

Temm.. t. IV, p. 401. - Gould, t. IV, pl. 330. - Naumann, t. VII, pl. 187.-Degl., t. II, p. 231, - Brehm, Beitr., t. III, p. 355. - Brehm, Handb., p. 663 - Selys-Longch, Faune belge, no 196. - Savi, Ornith. Toscana, t. II, p. 291. - v. d. Mühle, Vg. Griechfnlands, no 238. Holboll, Faune Groenlands, p. 39. - D. Kich. et Swainson, Faune Bor. Amerigana, p. 384. Tringa pygmaca, Schinz. - T. cinclus minor, Schleg. - Pelidna Schinzü, Brehm..

Cet oiseau habite les régions septentrionales de l'Europe et on le trouve principalement sur les bords de la mer, en Danemark, en Allemagne, aux iles Britanniques, en Hollande, en Belgique et en France. Ils commencent leurs migrations périodiques rarement avant septembre et octobre, et ils s'éloignent déjà en avril et en mai. Cet oiseau fréquente les bords marécageux de la mer, les rivages plats des petites rivières et les endroits pier. reux, entre coupés de flaques d'eau; il se tient aussi dans les prairies situées le long des rivières. Ce bécasseau est éminemment sociable; et il ne recherche pas seulement son pareil, mais encore la compagnie d'autres espèces de bécasseaux. On le distingue à distance et très-facilement du bécasseau variable par sa petite taille et encore plus par ses cris modulés, ressemblant à un trri, trri ou trru, trru. Quoique méfiant, il se laisse approcher d'assez près, surtout lorsqu'il est seul; mais, s'il est en compagnie de bécasseaux d'une autre espèce et qui sont plus craintifs, il s'effarouche comme eux et s'envole très-vite. A la chasse, il est facile d'en tirer plusieurs d'un seul coup, parce qu'ils ont l'habitude de se tenir très-près l'un de l'autre.

Leur nourriture consiste principalement en insectes et en larves, ainsi qu'en petits vers.

Ils déposent leur nid près de l'eau, et choisissent à cet effet des petits trous bien secs, et de préférence ceux qui sont entourés d'eau; ils le garnissent d'herbe et de racines bien sèches; la femelle y dépose trois ou quatre oufs et se laisse approcher d'assez près avant de quitter sa couvée; et, quand elle l'abandonne, elle court alentour en jetant de petits cris et en battant des ailes. Mais, quand on s'en approche trop, elle s'envole en redoublant ses cris, le mâle partage sa frayeur, et, par leurs cris réunis et leur terreur, ils trahissent la présence de leur conuvée, objet de leurs plus tendres soins. 



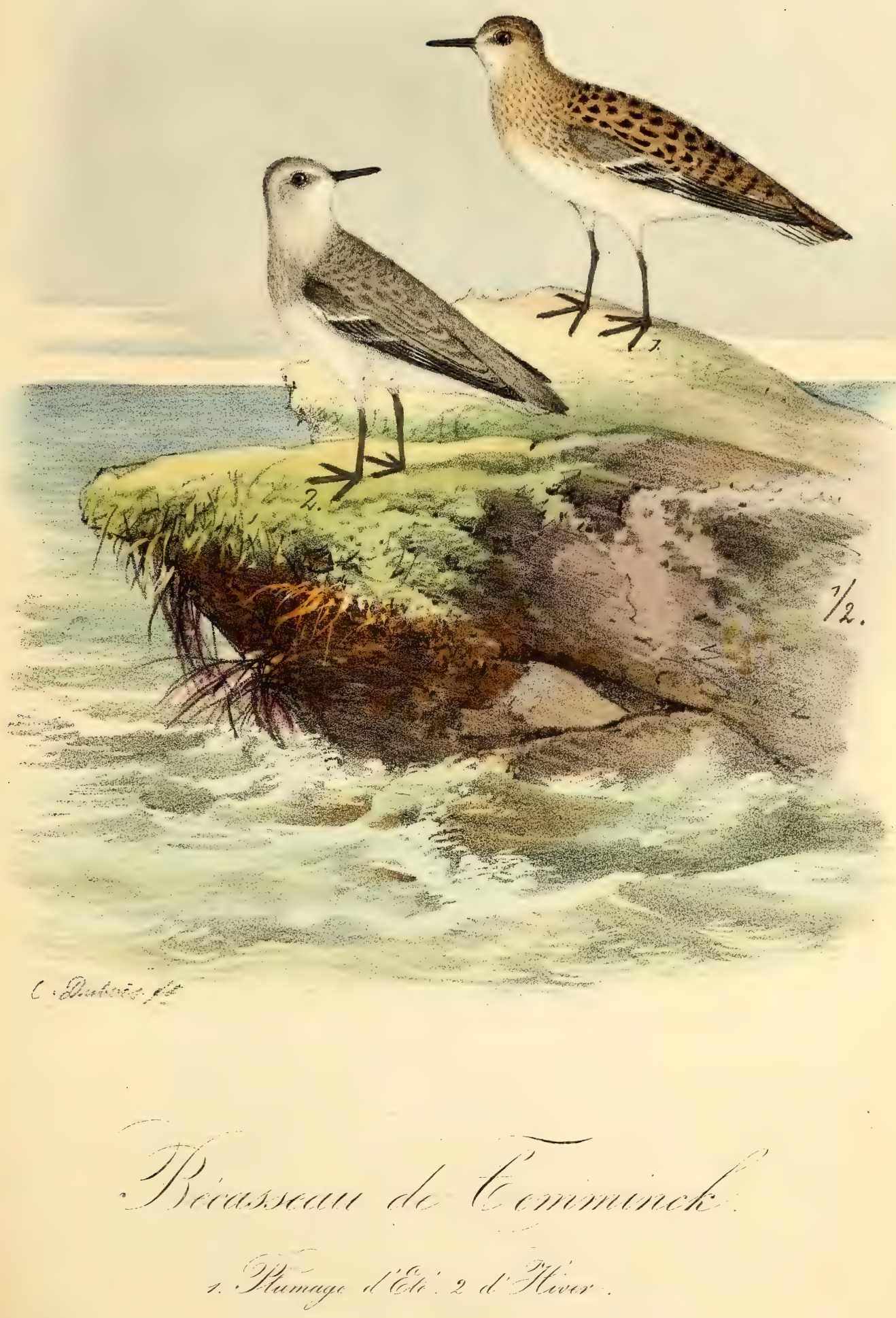





\section{BÉCASSEAU DE TEMMINCK.}

TRINGA TEMMINCKII, LEISLER.

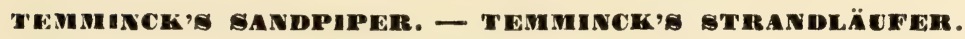

Temminck, t. II, p. 622. - Naum., t. VII, pl, 189. - Gould, t. IV, pl. 333. - Degl., t. II, p. 237. - Savi, Ornith. Toscana, t. II, p. 287. - Thien., pl. LXIII, fig. 2. - Selys-Longch, Faune belge, $n^{\circ}$ 197. - v. d. Mühle, Vg. Griechenlands, no 239. - Rüpp., Vg N. 0. Afrika's, no 466. - Tringa pusilla, Bechst. - Pelidna Temminckir, Bojé. - Schoeniculus Temminicki, Rüpp.

Il habite la Sibérie, la Norwége, l'Irlande, la Russie et la Suède, où il se trouve en grand nombre. En automne, dès les premiers frimas, il quitte les régions septentrionales pour venir habiter l'Allemagne, les îles Britanniques, la Hollande, la Belgique et la France. Au printemps, il quitte de nouveau nos climats tempérés, et se dirige vers le nord de l'Europe pour y passer l'été. On le voit aussi dans quelques parties de l'Afrique, en Egypte, en Nubie et sur les bords de la mer Rouge.

Ils voyagent pendant la nuit, volent rapidement et par petites troupes, et ne s'arrêtent que lorsque l'aurore paraît, pour se poser le plus souvent sur de grosses pierres, près de la mer, ou sur les bords des rivières et des étangs. Les rivages pierreux, entrecoupés de flaques d'eau et de vase sont leur séjour favori; ils s'y amusent à fouiller la terre molle pour y chercher des vers. Ils sont, du reste, très-sociables et se réunissent en troupes lorsqu'ils veulent prendre un vol lointain; souvent d'autres bécasseaux et des pluviers sont de la partie, et ils vivent tous en très-bonne intelligence, et cherchent leur nourriture avec beaucoup d'ardeur sans que jamais il $\mathbf{y}$ ait dispute pour s'emparer de ce qu'ils ont trouvé. En cas de danger, ils s'envolent dans toutes les directions, et se réunissent de nouveau dans un autre endroit; les plus grandes espèces même suivent cet exemple.

Il ne fait pas souvent entendre sa voix, et ce n'est guère qu'en prenant son vol. ou lorsqu'il rase la surface de l'eau, qu'il se fait entendre. Il n'est pas fort timide; on peut l'approcher, et il n'est pas difficile à la chasse d'en tuer plusieurs d'un seul coup, car ils courent très-près les uns des autres lorsqu'ils sont à terre.

Leur nourriture consiste en larves et en petits vers.

Ils nichent de préférence au bord de la mer, des lacs et des marais, où la femelle fait son nid dans l'herbe ou les roseaux, soit sur un petit monticule ou dans un enfoncement; elle le compose de mousse et d'herbes sèches, le tout rassemblé sans art, et y dépose ordinairement trois ou quatre œufs tout au plus. 



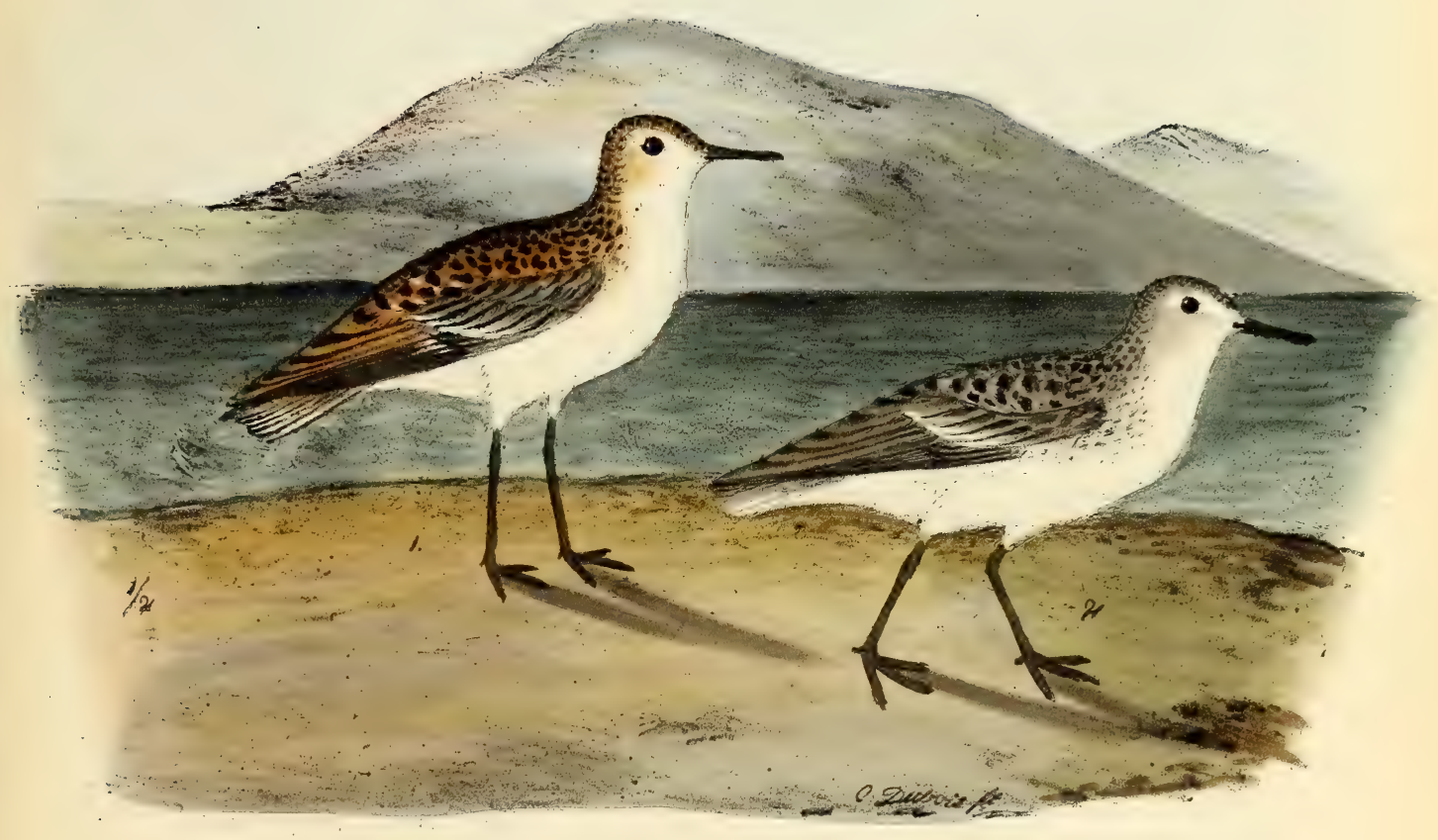

Secasseane Bunute.

1. Stumage d'oté 2 di Given 



\section{BÉCASSEAU MINULE.}

TRINGA MINUTA, LEILLER.

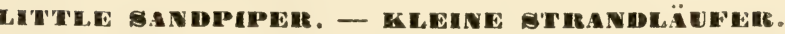

Temm., Man., t. II, p. 626. - Naum, t. VII, pl. 184. - Gould, t. IV, pl. 332. - Degl., t. II, P. 236. - Thien., pl. LXIII, fig. 1. - De Selys-Longch., Faune Belge, " " 198. - Malh., Faune Sigile, p. 186. -Savi, Ornith. Tosgana, I. II, p. 289. - V. d. Mühle, Vg. Griechenlands, n 464. - Rich. el Schwain, Fauna bor. am., p. 383.- - Rüpp., Vg. N. 0. Afrika's, no 464. - Peldda minuta. Bojé. - Schoeniculus minutus. Möhr. - Calidris minutus, Cuv. - Tringa pusilla, Vieil.

Ce bécasseau se trouve répandu dans toute l'Europe, même jusque vers les dernières extrémités du Nord; on le trouve aussi au nord et dans la partie centrale de l'Asie. On le voit également dans diverses parties de l'Afrique, dans la haute Égypte, le long des rives du Nil. Sur tout le littoral de la mer Méditerranée il est très-connu; vers la fin d'août, on le trouve en Allemagne. en Hollande, en Belgique et en France, où il se montre rarement seul. On les voit par troupeaux plus ou moins nombreux; leur vol est rapide, et ils parcourent de grandes distances. Souvent ils se joignent à d'autres bécasseaux. Ils fréquentent les rivages de la mer et des grandes rivières, se plaisent sur les bords des ruisseaux d'eau vive, volent en rasant la surface de l'eau, jettent un cri en partant et en frappant l'air par coups détachés; ils fuient les rivages où croissent des plantes. Cet oiseau est très-sociable : plutôt que de rester seul, il se joint aux autres espèces de bécasseaux, suit leur cri et les accompagne même dans leurs migrations lointaines. Ce bécasseau est aussi excessivement remuant : il ne reste pas longtemps en place; à la course il est trèsrapide, et, quand l'approche du chasseur le fait lever, il vole toujours du côté de l'eau, qu'il rase, se pose un instant sur l'autre rive, puis vient reprendre son ancienne place. Son cri, qu'il fait entendre lorsqu'il part, ressemble à un itt itt souvent répété; mais c'est surtout lorsqu'il cherche sa pâture qu'il fait entendre son sifflet, ce qui révèle sa présence au chasseur. Lorsque ces oiseaux sont nombreux, ils se tiennent très-serrés en courant ou en volant, de sorte qu'il est facile d'en tuer six ou même quelquefois dix d'un seul coup de fusil. Leur nourriture consiste en insectes, larves et petits vermisseaux aquatiques.

La femelle niche dans les marais, entre quelques mottes d'herbe un peu élevées et bien sèches; elle y dépose trois ou quatre oufs, rarement davantage. 



\section{0}
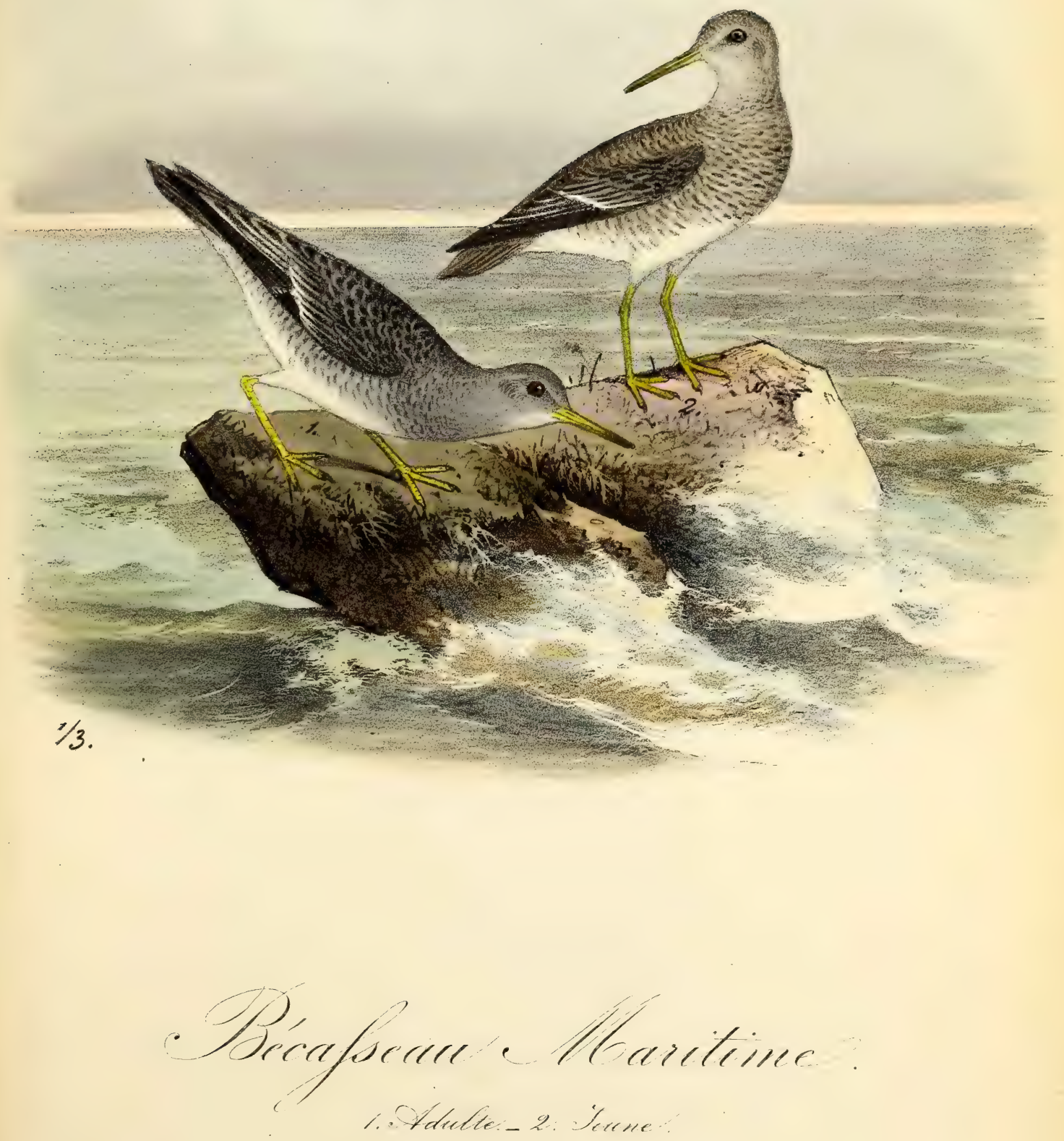



\section{BÉCASSEA U M RITIME.}

TRINGA MARITIMA, BRÜNNICH.

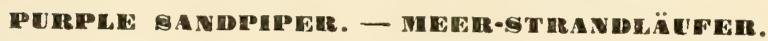

Temm., Man., t. II, p. 619. - Naum., t. VII, pl. 188. - Gould., t. IV, pl. 334. - Degl., t. II, p. 222. - Thien., pl. XVII, fig. 2. - De Selys-Longch., Faune belge, no 199. - Savi, Orvith. Toscana, t. II, p. 292. - V. d. Mühle, Ornith. Griechenlands, no 235. - Faber, Islandische Ornith, p. 28. - Holb, Fauna Groenlands, p. 39. - Rich. et Swains, Bor. Amr., p. 382. Calidris maritima, Cuv. - Tringa littoralis, Brehm. - T. nigrigans, Montagu. - T. triata, Retz.

Cet oiseau habite, pendant l'été, les pays les plus septentrionaux de l'Europe ; les régions boréales qui s'étendent, en suivant les bords de la mer, depuis la baie d'Hudson et le Labrador jusqu'au Groënland et à l'Islande, où, malgré l'âpreté du climat, on le trouve en très-grand nombre. Ses émigrations ne commencent qu'en automne; il quitte alors ces régions inhospitalières pour se diriger vers les côtes du Danemark, de l'Allemagne, de la Grande-Bretagne, de la Hollande, de la France et de l'Italie, où il trouve un climat plus tempéré, et ne quitte ces contrées qu'au mois de mai de l'année suivante, pour reprendre son vol vers les pays situés sous le cercle arctique. Les bords de la mer ou le voisinage des fleuves qui s'y jettent, les lagunes, sont les endroits où cet oiseau passe la plus grande partie de l'année; il est bien rare qu'il s'aventure dans l'intérieur des terres. Il lui faut des récifs escarpés, des plages pierreuses couvertes de fragments de rochers baignés par la mer.

Le vol de ce bécasseau est très-rapide; il déploie beaucoup d'adresse en rasant la surface de l'eau; on le voit même souvent suivre le mouvement des vagues en passant de l'une à l'autre avec une grande rapidité. Pour émigrer, ils se réunissent en troupes nombreuses, et, pendant leur $\mathrm{vol}$, ils forment une file longue, serrée et droite. Leur caractère n'est nullement timide; ils se laissent approcher sans montrer de la défiance, et il est très-facile d'en tuer plusieurs. De petites coquilles, des mollusques, des insectes et des larves, constituent leur principale nourriture.

Dans le Nord, ils font leur nid dans des vallées pierreuses, entrecoupées d'eau, souvent très-loin de la mer. La femelle choisit le plus communément dans l'herbe une place bien sèche, qu'elle garnit de quelque verdure; sa ponte ordinaire est de trois ou quatre oufs. Lorsque les petits sont éclos, rien n'égale la tendresse avec laquelle le mâle et la femelle les soignent, et si quelqu'un s'approche de leur cachette, ils font semblant d'être morts; puis, tout d'un coup, leur plumage se hérisse, et, comme frappés d'une terreur subite, ils s'enfuient, les ailes pendantes, en se trainant par terre et en jetant des cris lamentables; pendant ce temps, les petits ne bougent pas, osant à peine respirer, jusqu'à ce que le danger soit passé. 



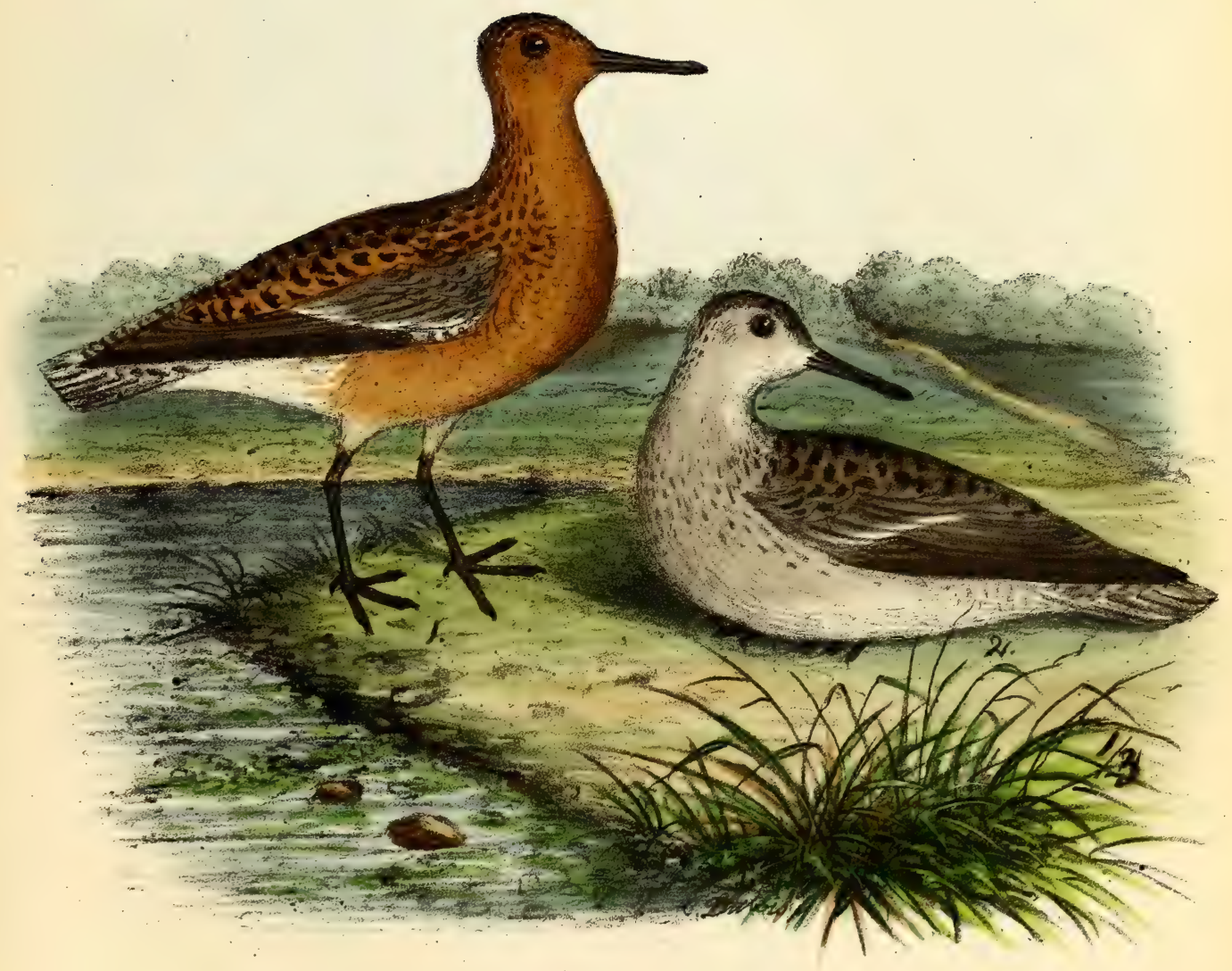

- Pecassean Panut

1. Pumage d'bte', 2. Chiver. 



\section{B ÉCA S S A U C A N U T.}

TRINGA CANUTUS, GMEL.

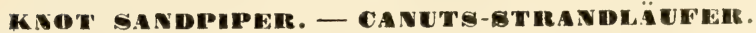

MAUBĖche GRISE. Buff., pl. 366. - Temm., t. II, 627. - Naum., I. VII, pl. 183. - Gould., t. IV, pl. 334. - Thien, pl. XVII, fig. 8. - De Selys-Longch., no 200. - Malh., Faune Sicile, p. 186. - Savi, Ornith. Toscana, t. II, p. 294 - - V. d. Mühle, Ornith. Griechenlands, no 234. - Faber, islandische Ornith., p. 27. - Holboll, Fauna Groenlands, p. 38. - Max. Prinz zu Wied, Beit. v. Brasilien, t. IV, p. 135. - Canutus Islandicus, Br. - Calidris canutus, Selby. - Tringa Ginerea, Brünn. - T. Islandicus, Gmel. - T. naevia et aestralis, Linné. - T. FerRuginea, Niison. - T. RUFA, Wils.

Cet oiseau habite pendant l'été les pays septentrionaux de l'Europe, de l'Asie et de l'Amérique; à l'approche de l'hiver, il a l'habitude d'émigrer et de se diriger vers l'Allemagne, la Grande Bretagne, la France, la Belgique et la Hollande; dans ce dernier pays surtout, il se trouve en grand nombre. Il se tient sur le rivage de la mer, les bords des rivières et des étangs; il fréquente aussi les plaines marécageuses. Ce bécasseau est d'un caractère remuant, changeant; il ne peut rester longtemps à la même place et il voltige çà et là ; mais il est sociable, et il n'est pas rare d'en voir un grand nombre ensemble dans de vastes plaines entrecoupées d'eau, où ils se plaisent à voler en tout sens; on les voit alors chercher leur pâture avec une ardeur infatigable.

Des insectes, des vers et leurs larves, ainsi que des vermisseaux, font leur principale nourriture. Cet oiseau est méfiant et difficile à approcher, même quand il ne parait occupé qu'à chercher sa nourriture; il n'oublie pas un instant sa sûreté personnelle, et s'éloigne bien vite de tout ce qui lui inspire la moindre crainte. Il exerce au plus haut degré la patience du chasseur, en passant d'une rive à l'autre, soit d'un étang, soit d'une rivière, et ce n'est guère que lorsque plusieurs sont ensemble et qu'ils se lèvent, qu'il est possible au chasseur d'en tirer plus d'un, parce qu'alors ils se tiennent assez serrés pour voler. Son cri est un sifflet clair et modulé, ressemblant à un toui toui toui qu'on entend au loin; mais ce n'est qu'en partant qu'il jette ce cri ; s'ils sont plusieurs, ils se lèvent, alors leurs cris réunis font beaucoup de bruit. La chair de ce bécasseau est fort délicate. Dans le Nord, il niche dans les endroits marécageux, à terre et dans l'herbe; un petit enfoncement garni de racines et de quelques brins d'herbe desséchés suffit à la femelle pour y déposer trois ou quatre oufs, rarement davantage. 



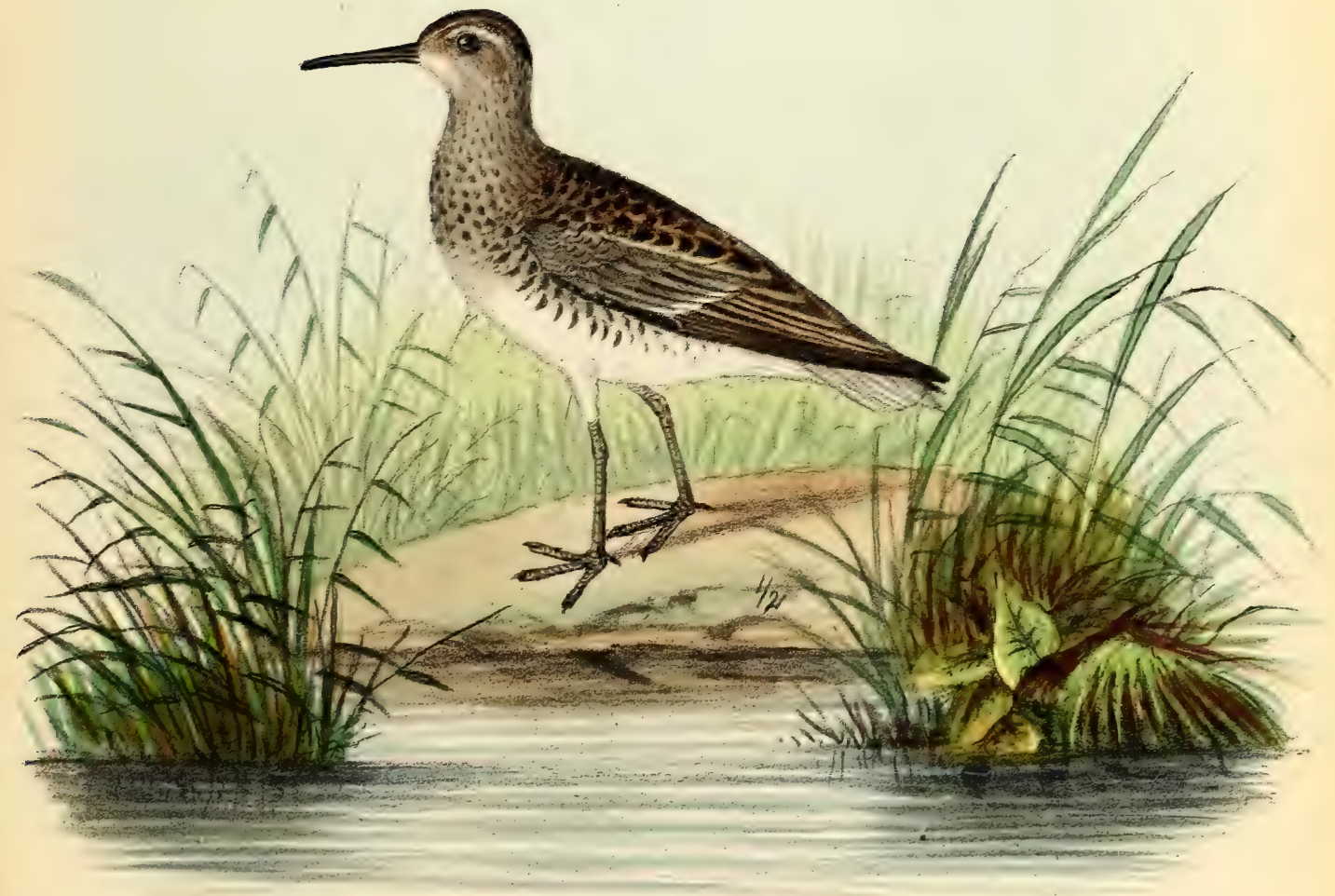

- Secrafueare futrty inymoue. 



\section{BÉCASSEAU PLATYRHYNQUE.}

TRINGA PLATYRHYNCHA, TEMmincK.

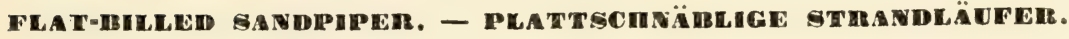

Temm., t. II, p. 616. - Gould., t. IV, pl. 331. - Naum., t. VIII, pl. 238. - Degl., t. II, p. 234. - Thien., pl. LXII, fig. 4. - v. d. Mühle, Ornitil. Griechenlands, n⿳0 241. - Malh., Faune Sicile, p. 185. - Scolopax pygmea, Gmel. - Numenius pygmeus, Lath. - N. pusillus, Becht. - Tringa pygmaza, Savi. - T. eloriodes, Vieill. - Limicola pygmal, Koch. - L. Platyrhyncha, Grai. - Pelidna platyrynchos, Brehm.

Les contrées septentrionales de l'Europe, de l'Asie et de l'Amérique sont la patrie de cet oiseau; mais, comme la plupart des oiseaux erratiques, lorsque l'époque de ses migrations, l'automne et le printemps, sont arrivés, il quitte le nord et s'avance quelquefois jusqu'en Allemagne, en Grande-Bretagne, en Belgique et en France. Dans les environs de Dunkerque ce bécasseau a été observé à différentes reprises et quelques-uns même y ont élé tués. Son bec légèrement aplati est le seul signe qui le distingue de ses congénères, car dans toutes ses autres parties il est absolument semblable aux autres bécasseaux. Il était donc inutile d'en faire un genre à part comme quelques ornithologues l'ont fait, car son nom de platyrhynque le caractérise suffisamment. Il vit principalement sur les bords marécageux des rivières et dans le voisinage des étangs où l'on conduit le bétail à l'abreuvoir, car il aime à courir dans la vase. D'un caractère tranquille et pacifique, ces bécasseaux platyrhynques se donnent rarement beaucoup de mouvement, et c'est seulement quand ils sont occupés à chercher leur nourriture qu'ils montrent quelque vivacité. On les voit alors courir sur les bords des rivières, fouillant la vase pour y trouver des insectes áquatiques, des larves et des vermisseaux dont ils font leur principale nourriture. Ils sont peu sociables, et s'il leur arrive de se trouver avec d'autres oiseaux, ils cherchent à s'en séparer au plus vite. Ils ne voyagent que pendant la nuit et ordinairement à plusieurs, ou par couple, et lorsquils se lèvent, ils font entendre leur voix tremblottante. Ils sont très-familiers, et la vue d'un homme ne leur inspire pas la moindre crainte. Leur chasse n'offre donc pas autant d'obstacles que celle de beaucoup d'autres oiseaux, et l'on peut facilement en tuer plusieurs. Lorsqu' un chasseur les surprend, ils ont l'habitude de se baisser ou de se cacher derrière un buisson, et, s'il luı arrive de passer trop près de leur cachette, ils se lèvent en sa présence et s'envolent, mais ils ne tardent à revenir à leur ancienne place. Ils nichent, dans le nord, au bord des rivières et des étangs. Leur ponte ordinaire est de trois à quatre œufs. 


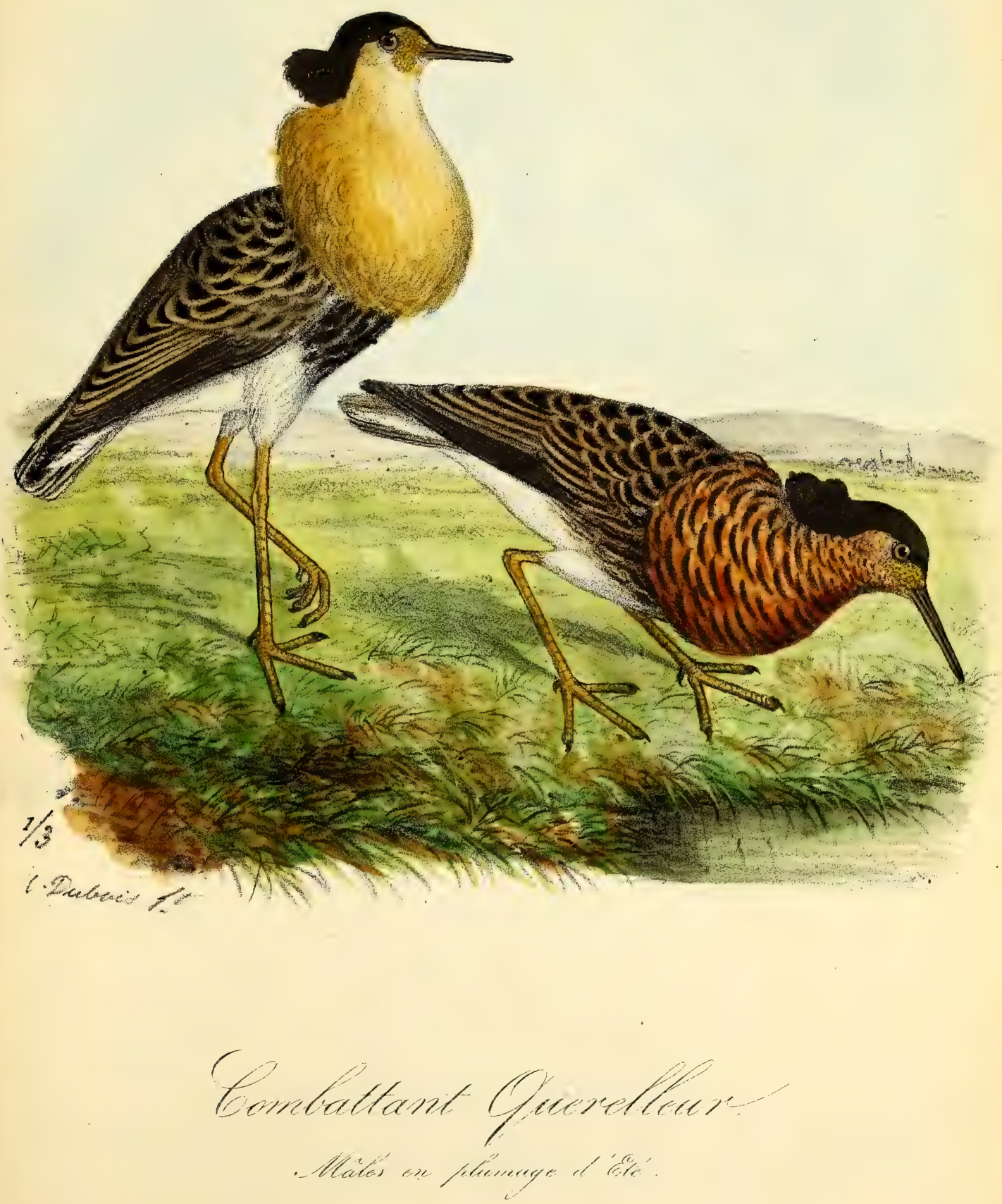

Gense Combruttant. - Irachetes, Cuvier.

\title{
COMBATTANT QUERELLEUR.
}

\author{
MACHETES PUGNAX, GUVIER.
}

IEFF。 - STIRET-KAMPFLÄUFER。

LE COMBATTANT, Buff., t VII, p. 508. - Temm., t. II, p. 631. - Gould, t. IV, pl. 324. - Naum., t. VII, pl. 190-193. - Degl., t. II, p. 201. - Thienem., pl. XVII, fig. 4. - SelysLongch., Faune aelge, no 201. - Meyer, Vg. Liv:-u. Esthlands, p. 201. - Malh., Faune SiCule, p. 186. - Savi, Ornith. Toscana, t. II, p. 263. - v. d. Mühle, Vg. Griechenlands, no 232. Tringa pugnax, Linné. - T. cinereus, Briss. - T. variegata, Brünn. - T. littorea, Gmel. T. Rufescens, Bechst. - T. equestris et grenovicensis, Lath. - Totanus pugnax, Nilson.

IIabite les contrées septentrionales et tempérées de l'Europe et de l'Asie ainsi qu'en Égypte, en Arabie et en Abyssinie; abondant en Livonie, en Esthonie, dans la Courlande, dans les îles Danoises et les parties de l'Allemagne aux bords de la mer du Nord et de la mer Baltique; on le voit aussi en Belgique, mais nulle part aussi abondant qu'en Hollande. En été ils vivent dans les grandes prairies humides, dans les pâturages avoisinant de grands étangs ou des marais; le mâle a plusieurs femelles dont il s'occupe peu cependant; les femelles et les jeunes vivent en société pendant l'automne, mais les mâles vivent isolés et partent dès le commencement du mois d'août, les femelles et les jeunes ne suivent qu'au mois de septembre, et ne reviennent que quinze jours après les mâles; ceux-ci sont un peu plus grands que les femelles; en automne leur plumage se ressemble; mais au mois de inars le mâle change; sa figure, qui l'hiver est couverte de plumes, se couvre alors, particulièrement autour des yeux, de petites verrues jaunes, et au cou il lui vient une grande fraise; il est à remarquer qu'il est rare d'en voir deux se ressemblant de plumage.

Nourriture : vers de terre, petits limaęons, insectes de marais et leurs larves.

Au printemps les mâles se battent presque toute la journée, car chacun s'approprie une petite place et tout mâle qui approche en est chassé à coups de bec; on trouve parfois en une seule place de quatre à six combattants. Avant le combat chaque mâle se tient roide, enfle le cou, puis se jette sur son adversaire lui donne des coups de bec, et lui arrache les plumes; est-il fatigué, il s'envole, retourne quelque temps auprès de sa femelle ou bien s'en va chercher sa nourriture; puis, retournant au lieu du combat ils se battent jusqu'à l'entrée de la nuit.

La femelle couve dans des prairies près des étangs et marais, à une place sèche dans un petit enfoncement, dans lequel elle met des herbes sèchées, et pond quatre œufs. Les femelles seules couvent et soignent les jeunes. 


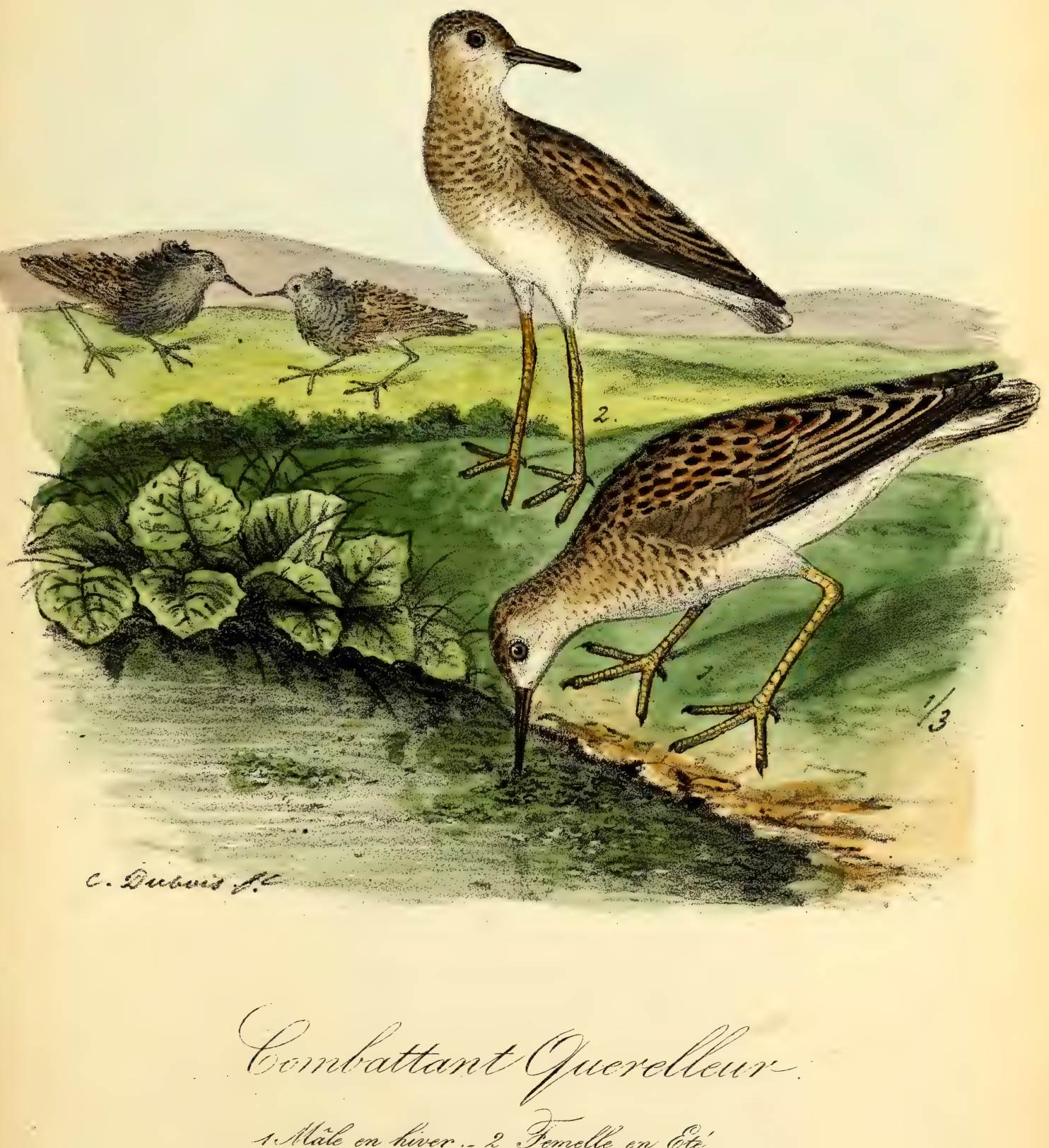


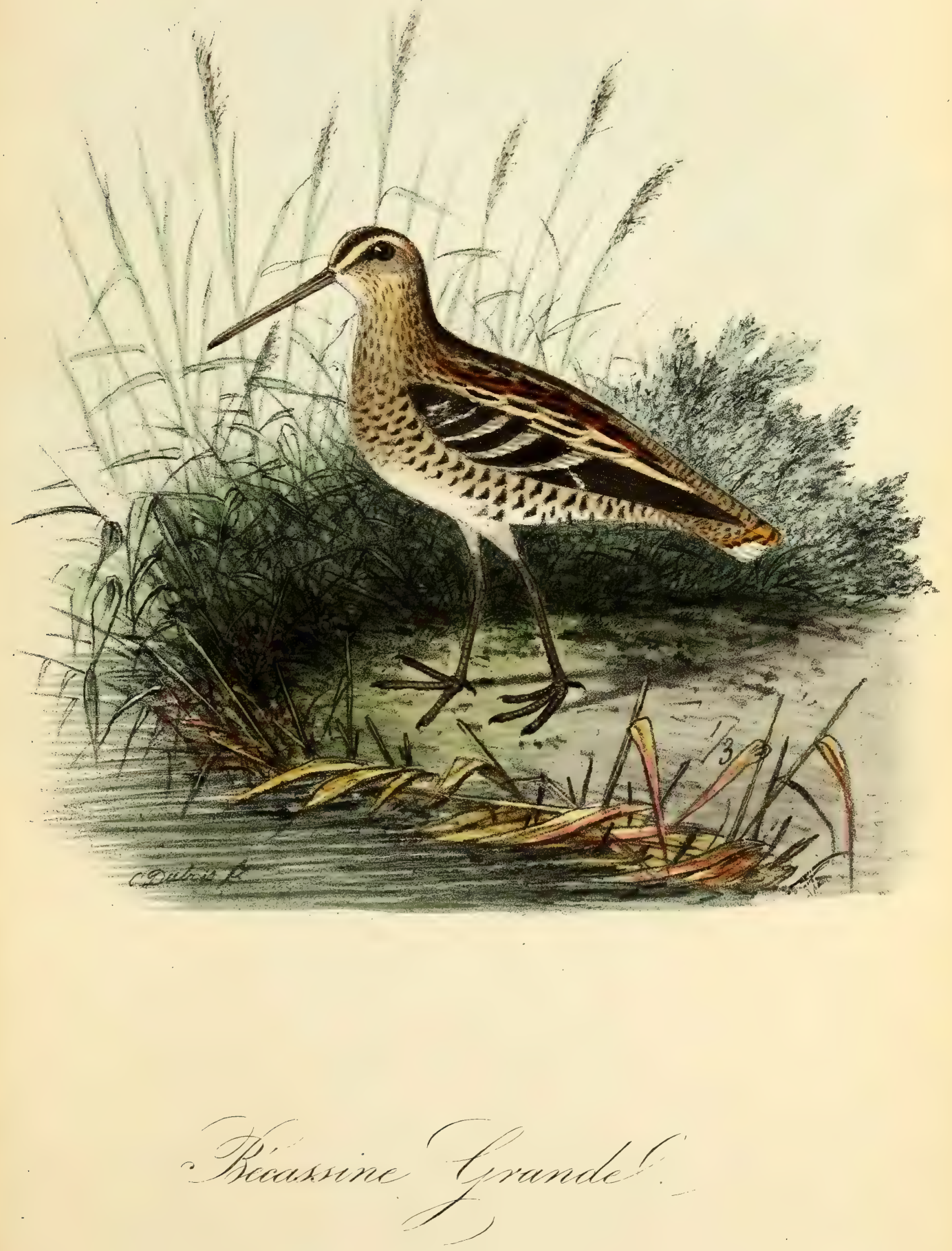



\section{BÉCASS INE GR A N E.}

GALLINAGO MAJOR, LEACH.

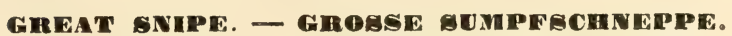

Temm. Man., t. II, p. 675. - Naum., t. VIII, pl. 239. - Gould, t. IV, pl. 334. - DegI., t. II, p. 209. - Thien., pl. IV, fig. 2. - De Selys-Lonch., Faune Berge, no 182. - Mey., Vg. Liv. u. Estrlands, p. 193. - Malh., Faune Sicile, p. 182. - Savi, Ornith. Toscana, t. II, p. 309. V. d. Mühle, Ornith. Griechenlands, no 244. - Malh., Oıs. d’Algérie, p. 21. - Rüpp., Vg., N. 0. Afrika's, no 471. - Scolopax major, Gmel. - S. media, Frisch. - Asculoapax major, Keys. el Blas. - Telmatias major, Bojè. - T. nisoria, uliginosa et brachyptera, Brehm.

Cette bécasse se voit beaucoup en Finlande, en Livonie, en Russie, en Pologne et en Hongrie; elle se montre moins en Allemagne et en Danemark, et elle est rare aux îles Britanniques, en Hollande et en Belgique, et encore plus rare en France. Elle paraît surtout beaucoup se plaire dans le nord de l'Asie, qu'elle quitte cependant à l'approche de la mauvaise saison pour se diriger vers les régions plus méridionales de cette partie du monde. On la trouve aussi quelquefois en Égypte et en Nubie. Elle aime à se tenir dans les marais ou dans les grandes plaines entrecoupées de flaques d'eau, où il n'y a ni arbres ni broussailles, mais beaucoup de plantes aquatiques; elle habite aussi les prairies basses et humides qui avoisinent les eaux; elle s'y tient cachée et passe une partie de la journée à dormir. Les bécassines grandes sont beaucoup plus sensibles au froid que les autres espèces, et elles commencent de bonne heure leurs émigrations vers un climat plus doux pour y passer l'hiver; elles voyagent de nuit, seules, ou deux à deux, et leur vol a quelque chose de plus lourd que celui des autres bécassines ; on remarque aussi que pendant le jour, leur activité est moins grande, leur manière de courir plus lente et leur vol moins vif, et elles ne quittent leur place qu'à contrecœur, et lorsqu'elles y sont forcées par la nécessité. Il n'y a que le crépuscule et la nuit qui leur rendent toute leur activité, leur besoin de mouvement; on dirait que ce n'est plus le même oiseau; elles savent même alors nager; en cas de besoin, et s'il y a grand danger, elles plongent. On entend rarement leur voix, qui parait, du reste, n'ềtre ni forte, ni mélodieuse : c'est un baid, baid, souvent répété, et très-insignifiant. Elles ne sont pas très-timides et leur chasse est facile; il n'y a que l'approche du chasseur qui puisse les faire lever, et souvent elles attendent pour fuir qu'il se trouve à quelques pas d'elles. Leur vol est très-bas et tout droit, mais pas très-rapide, et il n'est pas rare de les voir revenir se poser à la place qu'elles viennent de quitter.

Leur chair est plus délicate que celle de toutes les bécassines; leur nourriture consiste en insectes, larves, vermisseaux et limaçons.

La femelle construit son nid dans un marais, sur une petite élévation entourée d'eau; elle le garnit de feuilles sèches et d'herbe. Sa ponte ordi-naire est de quatre oufs, et tant que dure l'incubation, elle porte tant d'attachement à sa couvée, qu'elle se laisse approcher et presque toucher avant de songer à fuir. 

182

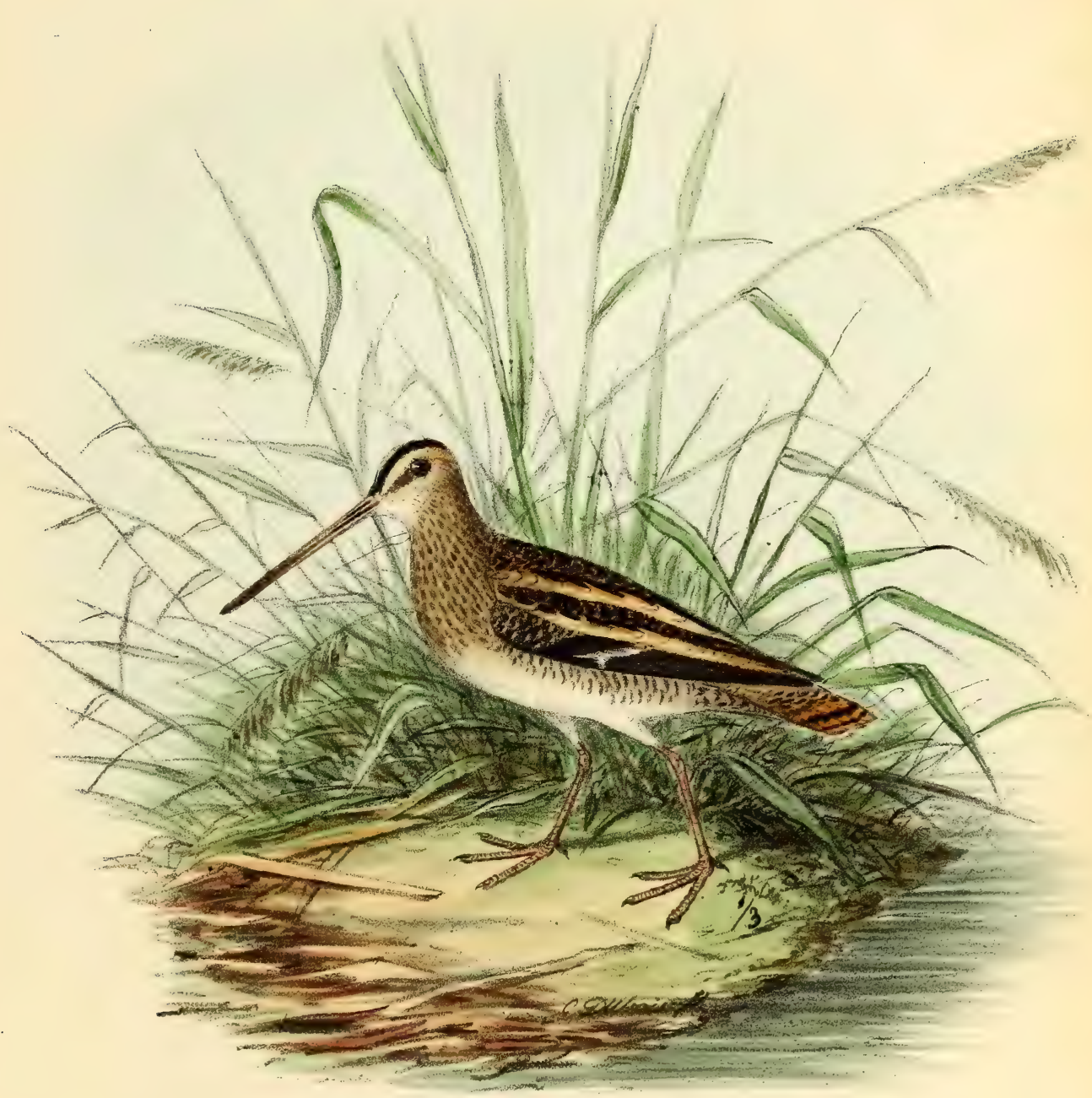

Becafoine Cratimave 



\section{BÉCASSINE ORDIN A I RE.}

GALLINAGO VULGARIS, DUBOIS.

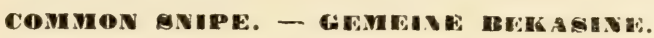

Temm., t. II, p. 676.-Gonld., t. IV, pl. 321 - Naum., t. VIII, pl 240.-Degl., t. II, P. 211. Thien., ßl. XVIII, fig. 3.-De Selys-Longch., Faune Belge, no 212.-Malh., Faune Sicile, p. 184. - Savi, Ornith. Toscana, t. II, p. 312. - V. d. Mühle, Orvith. Griechenlands, n 240 . Faber, Islandische ornith., p. 50. - Malh., Ois. d’Algérie, p. 21. - Rüpp., Vg. N.-0. Afrika's no 470. - Scolopax gallinago, Linné. - Ascolopax gallinago, Keys. - Telmatias gallinago, Bojé. - Gallinago media, Steph. - G. scolopacinus, Bonap.

Cette bécassine est connue dans toute l'Europe et aussi dans une grande partie de l'Asie, de l'Afrique et de l'Amérique. Elle vit dans les marais et sur les bords marécageux des étangs, pourvu qu'il y ait abondance d'herbe, de roseaux et de plantes aquatiques où elle puisse se cacher facilement. Elle aime aussi les prairies entourées d'aunes et de saules. On la rencontre également dans tous les pâturages bas et humides, et même fréquemment dans les forêts. Les bécassines ordinaires émigrent pendant la nuit, et, à moins d'être surprises, il est rare de les voir dans le jour, parce qu'elles se tiennent constamment cachées dans les plantes aquatiques, où elles dorment la plupart du temps. D'un caractère peu sociable, elles préfèrent vivre dans l'isolement, et, même dans les endroits qui leur conviennent le plus et où il n'est pas rare de les voir en assez grand nombre, elles s'y tiennent séparées les unes des autres et ne paraissent nullement se soucier de la compagnie de leurs semblables. Cette indifférence ou plutôt cette aversion qu'elles se montrent réciproquement paraît être un des traits saillants de leur caractère, car, même pendant qu'elles nichent, elles préfèrent la solitude. Dans le temps de l'accouplement elles rendent un son qui a quelque ressemblance avec le bêlement de la chèvre, excepté qu'il ne vient point de la gorge comme celui de cette dernière. Ces bécasses ne quittent leurs retraites dans les marais qu'au moment du crépuscule; elles s'élèvent alors obliquement dans l'air à une assez grande hauteur, puis tout à coup elles s'arrêtent et redescendent en se laissant en quelque sorte choir plutôt qu'elles ne volent; car, bien que leurs ailes soient ouvertes, leur corps est dans une position tout à fait oblique, de manière qu'une aile s'élève vers le ciel et l'autre s'abaisse vers la terre. En tombant ainsi avec impétuosité du ciel, l'air, en passant par les pennes antérieures de leurs ailes, produit ce son qui a tant de ressemblance avec le bèlement de la chèvre. C'est surtout dans les belles soirées de l'été, après le coucher du soleil, lorsque tous les travaux champêtres ont cessé et que tout dans la nature devient calme et silencieux, qu'elles se livrent à leurs évolutions aériennes et font alors quelquefois entendre leur voix rauque et peu agréable. C'est aussi pendant l'aurore et le crépuscule qu'elles cherchent leur nourriture, qui consiste principalement en larves, vers, limaçons et coquillages d'un très-petit volume.

La bécassine ordinaire niche dans toutes les contrées du nord de l'Europe et aussi dans la partie septentrionale de l'Allemagne. Au mois de mai elle bâtit son nid dans un endroit bien marécageux, où il y a beaucoup de saules et d'aunes; une petite excavation au milieu des roseaux, enlourée de vase, lui suffit: elle y fait une litière d'herbes sèches pour sa couvée, qui est ordinairement de quatre œufs, rarement davantage. 


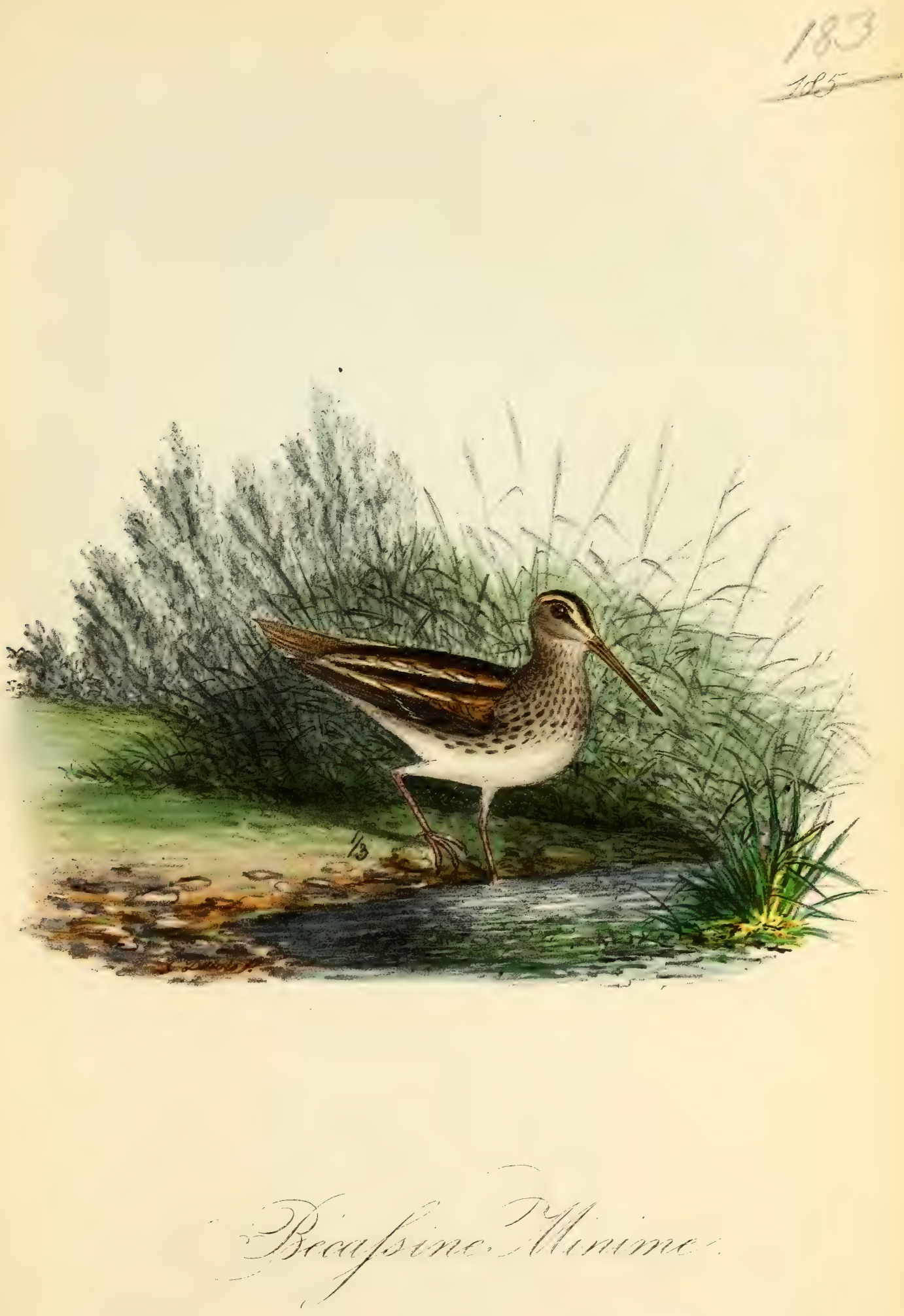



\section{BÉCASSINE M I N I M E.}

GALLINAGO MINIMA, REY.

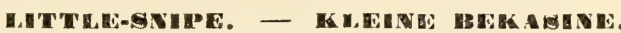

Temm., t. II, p. 678. - Gould., t. IV, pl. 322. - Naum., t. VIII, pl. 241. - Degl., t. II, p. 213. - Thien., pl. LX, fig. 1. - De Selys, Faune belge, n² 213. - Malh., Faune Sigile, p b85. - Savi, Ornith. Toscana, t. II, p. 317. - V. d. Mühle, Ornith. Griechenlands, n" 242. Malh., Ois D'Algérie, p. 21. -- Scolopax gallinula, Linné. - Ascolopax gallinula, Keys. Philolimnos gallinula et minor, Brehm. - Gallinago minor, Briss. - G. gallinula, Bonap.

Cette petite bécassine habite l'Europe, la Norwége, la Suède, la Russie et l'Asie; on la rencontre en Sibérie, en Amérique; on la trouve au Labrador et au Canada. Elle ne quitte ces latitudes élevées que lorsque ses migrations périodiques commencent; elle traverse toute l'Allemagne, la Hollande, la Belgique, la France et l'Italie. Les bécassines minimes aiment à se tenir dans les marais où il y a beaucoup de saules et d'aunes; on les rencontre aussi souvent dans les prairies et les pâturages bas et humides, entrecoupés de flaques d'eau. Elles fréquentent également les bords des lacs, pourvu quil y ait quelque végétation, soit des roseaux ou d'autres plantes aquatiques. D'un caractère peu sociable, elles fuient non-seulement la compagnie de leur espèce, mais encore celle de tous les autres oiseaux, et, bien qu'on en rencontre souvent une vingtaine dans un district de fort peu d'étendue, chaque individu vit isolément et ne parait nullement se soucier des autres. Leurs migrations se font la nuit; mais aussitôt que le jour commence à poindre, elles s'arrêtent soit dans un marais, soit au bord d'un étang ou d'une rivière, où elles s'amusent à chercher dans la vase, à l'aide de leur bec, des insectes aquatiques, des larves, des vermisseaux et de petits limaçons. Pendant le jour, elles se cachent dans les broussailles ou dans les roseaux pour y dormir, et c'est seulement vers le soir, après le coucher du soleil, qu'elles se livrent de nouveau à la recherche de leur pâture. La nuit une fois venue, elles continuent leur route. De toutes les bécassines, c'est l'espèce la moins timide, et le chasseur peut les approcher de très-près, même presque marcher sur elles avant qu'elles se décident à se lever. C'est pour cette raison qu'on a donné à cette bécassine le surnom de sourde, bien qu'elle ne soit rien moins que sourde; c'est plutôt par insouciance et ignorance qu'elle est si indifférente au danger. En Allemagne, on l'appelle la muette, ce qui me parait plus rationnel, vu qu'elle ne fait jamais entendre aucun cri en se levant. Sa voix est extrêmement faible; on l'entend peu, et ce n'est guère que le soir en quittant son gîte qu'elle jette un petit cri assez perçant, ressemblant à un kits ou kuts. Dans la saison de l'accouplement, au printemps, le mâle a un chant particulier, sonnant à peu près comme un tettettettet, se prolongeant, tout d'une haleine, pendant cinq ou six secondes. Il est donc évident qu'elle ne mérite pas plus le surnom de muette que celui de sourde.

Quoique faisant leur ponte dans toutes les contrées septentrionales de l'Europe, les bécassines nichent peu dans le nord de l'Allemagne. La femelle choisit ordinairement dans un district marécageux une petite place un peu élevée et sèche dans l'herbe, où, sans préparer aucune espèce de litière, elle dépose trois ou quatre oufs. 



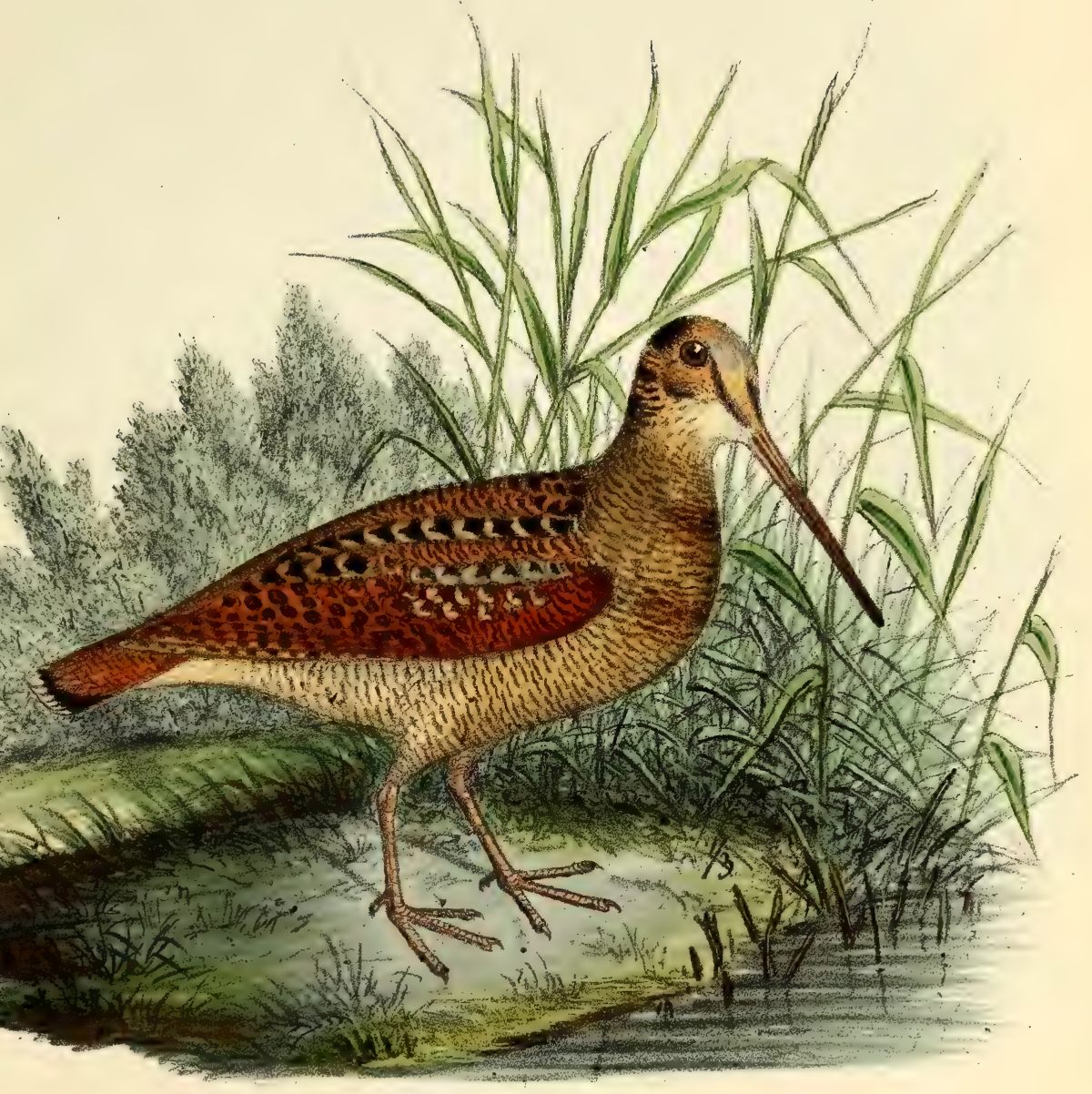

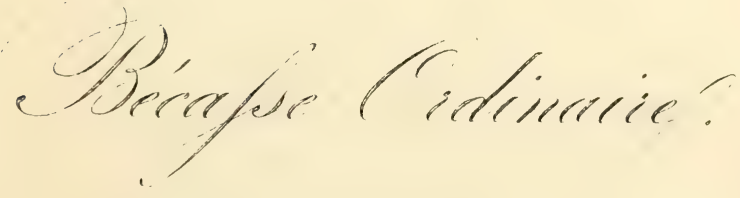



Genre Récusse. - Scotopux, Linné.

\section{B ÉCA S S E O R D I N A I RE.}

SCOLOPAX RUSTICULA, LINNE.

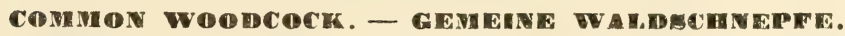

Temm., t. II, p. 675. - Gould., t. IV, pl. 319. - Naum., t. VIII, pl. 242. - Degl., t. II, p. 215. -- Thien., pl. XVIII, fig. 1. - De Selys-Longch., Faune belge, no 214 . - Malh., Faune Sichle, p. 181. - Savi, Ornith. Toscana, t. II, p. 3i5. - V. d. Mühle, Ornith. Griechenlands, no 243. Malh., Ois. d’Algérie, p. 21. - Rüpp. Vg. N. 0. Afrika's, n 473. - Rusticola vulgaris, Vieill. - R. Europæa, Less.

Cette bécasse est répandue dans toute l'Europe et dans différentes parties de l'A frique. Toutefois, il est vrai de dire qu'on ne voit les bécasses rusticoles, dans beaucoup de contrées de l'Europe, qu'au moment de leur passage, lorsqu'elles quittent le Nord pour émigrer vers le Midi. Dans les hivers peu rigoureux, un grand nombre reste en Belgique et en France. Dans leurs migrations, elles sont ou seules ou deux à deux, rarement plus, quoiqu'on en rencontre beaucoup dans la même localité. Elles ne vont donc point par troupes, comme d'autres espèces de bécasses. Dans les îles de Rügen et de Helgoland, où on les voit par masses, ces îles leur servant de pied-à-terre dans leur traversée maritime, les habitants s'amusent tous, dans l'arrière-saison, à leur donner la chasse, et en tuent, chaque année, un grand nombre. Elles voyagent pendant la nuit, et ne s'arrêtent que lorsque la nuit est fort obscure, ou qu'il y a de l'orage; elles sont alors obligées de passer la nuit dans les champs, en attendant qu'aux premières clartés de l'aurore elles puissent atteindre un buisson voisin. Mais, si la violence de l'orage n'est que passagère, elles ne suspendent leur vol qu'autant qu'il dure, et, quand il est fini, elles continuent leur route. Elles évitent, autant que possible, de voler dans une direction contraire au vent. Les districts bien boisés sont ceux qu'elles préfèrent; elles aiment aussi les marais où il y a beaucoup d'aunes, de saules et de sources vives. Elles cherchent, le matin de bonne heure, et le soir au crépuscule, leur nourriture, qui se compose d'insectes, de larves, de vermisseaux et de petits limacons. Vers le soir, elles vont aussi, dans les prairies et les pâturages, chercher dans les excréments du bétail les vers et les larves. Elles ont aussi l'habitude de creuser avec leur bec des trous dans les terres molles ou détrempées par la pluie pour attraper les vers qui s'y tiennent à une petite profondeur. Pendant le jour, elles restent dans une inactivité complète; elles dorment dans les broussailles. Leur méfiance et leur timidité sont extrêmes, et le moindre bruit les met en fuite. La chasse aux bécasses est une des plus amusantes qui existent, et leur chair est partout aimée et recherchée comme un met très-délicat.

Au printemps, les mâles se livrent des combats acharnés pour la possession des femelles. Celles-ci nichent de préférence dans les bois marécageux, où elles choisissent un endroit bien sec, abrité par des broussailles. Une petite excavation qu'elles creusent avec soin, et garnissent de quelques feuilles sèches et de graminées, leur sert de nid. Leur ponte ordinaire est de quatre oufs. 


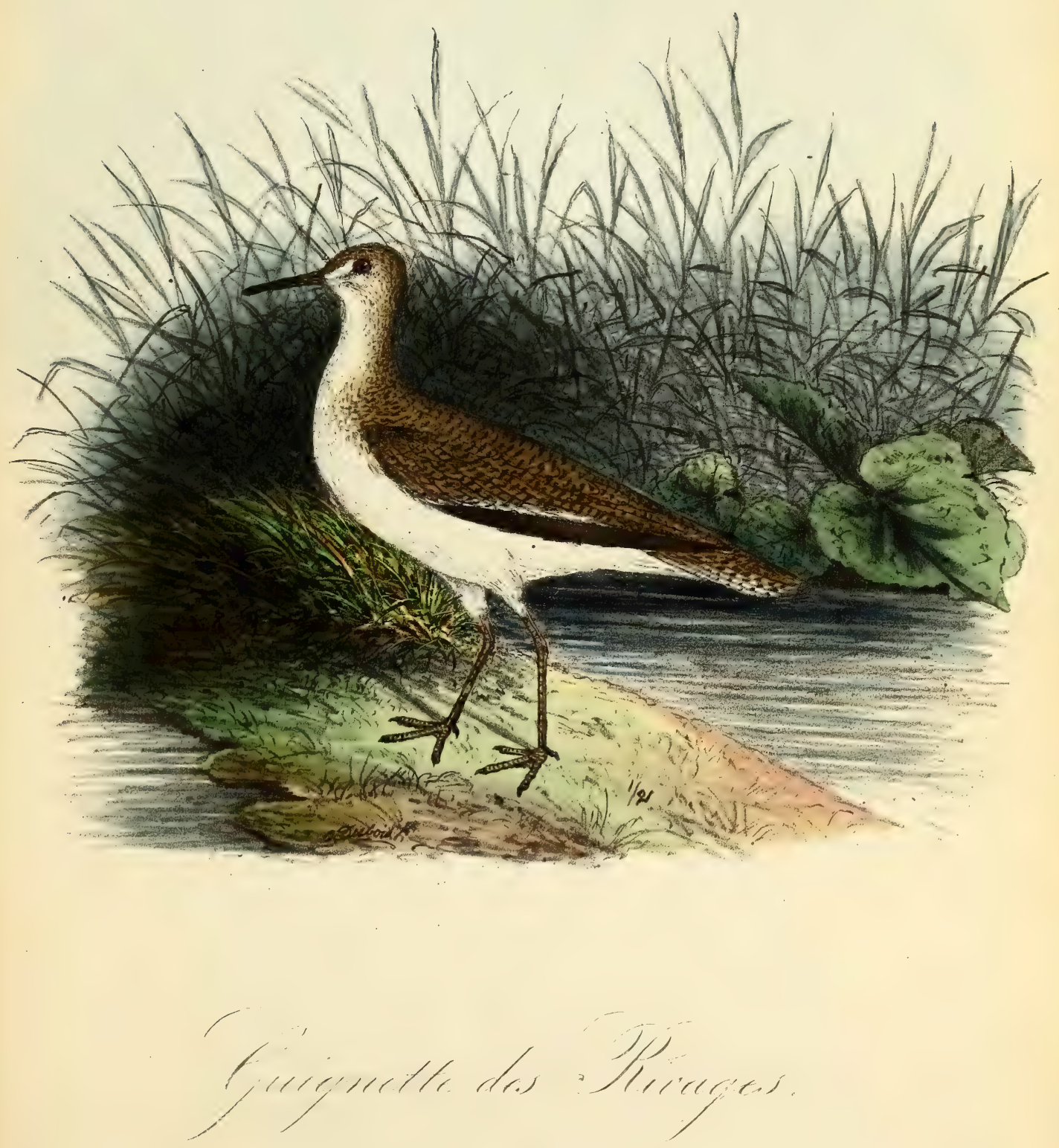



\section{Genere Guignetle. - Aolihis, Bojé. \\ GUIGNETTE DES RIVAGES.}

ACTITIS HYPOLEUCOS, воJE.

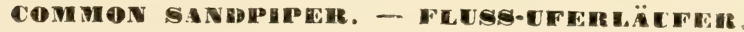

PETITE ALOUETTE DE MER, Buff., pl. en!. 850.-Temm., t. II, p.657.-Naum., t. VIII, pl. 225. - Gould, t. IV, pl. 115. - Degl., t. II, p. 194. - Thien., pl. LXV, fig. 3.-SelysLongch., Faune belge, no 202. - Malh., Faune Sicile, p. 190. - Savi, Ornith. Toscana, t. II, p. 275. - V. d. Mühle, Ornith. Grieghenlands, no 229.- Rüpp., VG., N. 0. Afrika's, nº 458.

- Tringa hypoleugos, Linné. - T. leucoptera, Pall. - Totanus hypoleucos, Tem.

Cet oiseau habite le nord de l'Asie, depuis les monts Oural jusqu'au Kamschatka. On le trouve encore dans le nord de l'Afrique, en Egypte et en Nubie. On le rencontre également dans toute l'Amérique septentrionale. En Europe, il habite la Norwége. la Suède, la Finlande, l'Allemagne, la Grande-Bretagne, la Hollande, la Belgique, la France et l'Italie. Comme on le voit, tous les climats conviennent à peu près à la guignette, mais nulle part on ne la voit en grand nombre. Elle vit sur les grèves et rives de sable; elle aime aussi à séjourner dans les terrains boisés, arrosés de rivières, dans les prairies entourées de saules ou de bois de futaie, où elle puisse au besoin s'abriter et trouver une retraite pour se cacher. Une pierre au bord de l'eau, ou s'avançant au milieu de l'eau, est son endroit favori pour se poser; elle aime aussi à se percher sur des branches basses, suspendues au-dessus de l'eau, car elle sait nager en cas de besoin, et plonge rapidement et avec beaucoup d'adresse, en tenant ses ailes ouvertes. Vers la fin d'août et de septembre, ces oiseaux émigrent et se dirigent vers le Midi pour y passer la manvaise saison. lls se réunissent au nombre de six; quelquefois ils sont jusqu’à vingt, et alors on les voit, vers le soir, prendre leur vol ensemble, s'élever à une petite hauteur, redescendre subitement, pour s'élever de nouveau et continuer ainsi ce manége jusqu’à ce que le soleil soit couché. Le crépuscule une fois arrivé, on les voit alors s'élever à une grande hauteur et s'éloigner à tire-d'aile : leurs migrations nocturnes commencées, ils s'en vont pour ne revenir que l'année suivante. Leur vol est rapide et léger, ils s'élèvent à une grande hauteur, et il est difficile de les tirer, car ils sont très-circonspects et d'une timidité excessive. Leur chair est délicate, tendre et d'un goût très-agréable. Des insectes, des larves et des vers sont leur nourriture habituelle; on les voit souvent fouiller la vase jusqu'à mi-corps pour y chercher leur pâture.

La femelle place son nid dans des trous de rives où elle cherche un endroit bien sec, un peu élevé, qu'elle garnit de feuilles, d'herbes, de ro. seaux hachés menu, pour y déposcr ordinairement quatre ou cinq oufs. Quelquefois aussi elle dépose ses outs tout bonnement dans le nid abandonné d'une grive que le hasard lui fait trouver. 


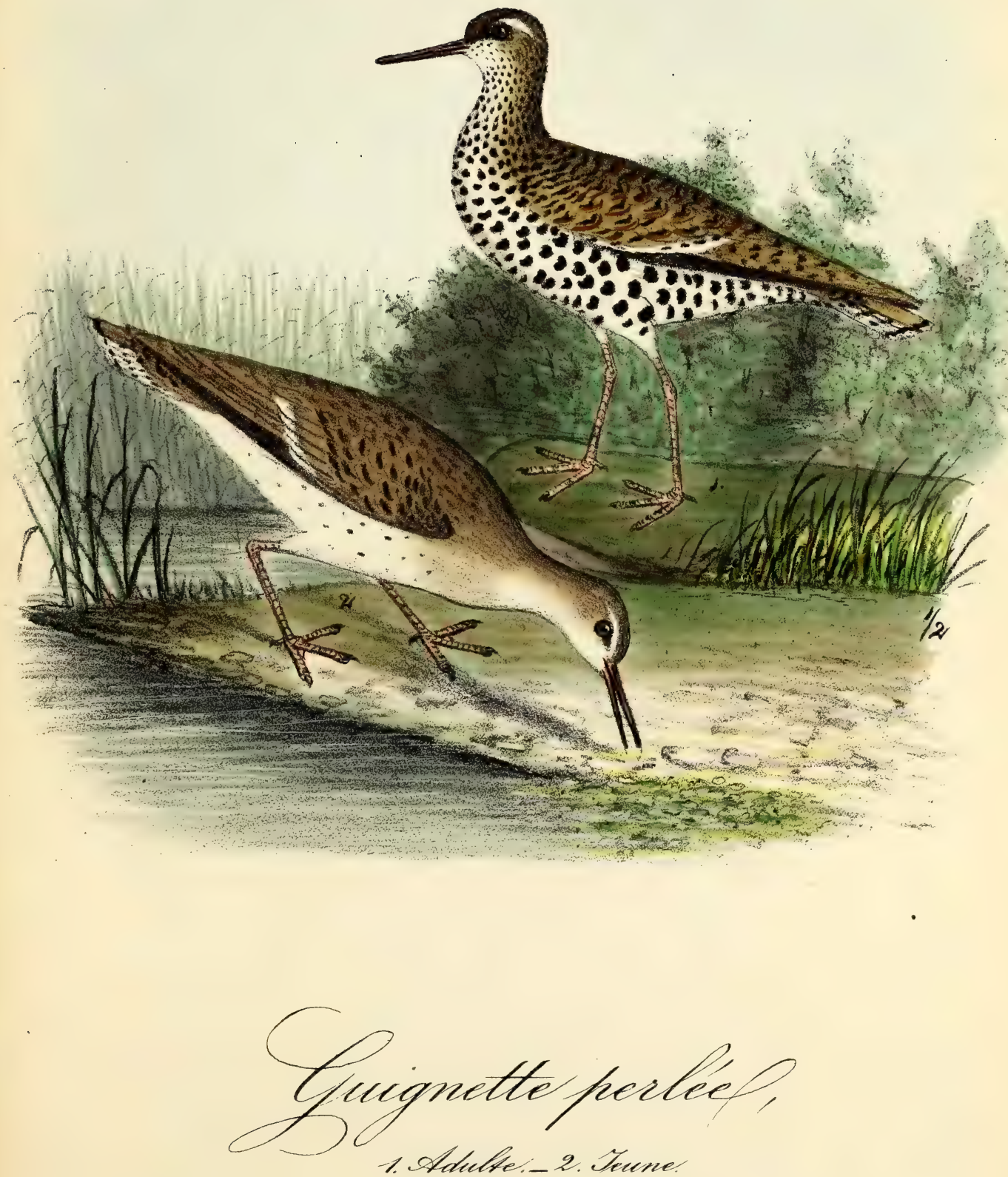



\title{
GUIGNETTE PERLÉ.
}

\author{
ACTITIS MACULARIA, NaUmann.
}

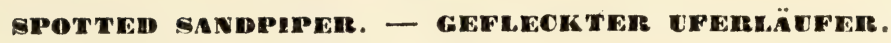

Temm., t. II, p. 656. - Gould., t. IV, pl. 514. - Naum., t. VIII, pl. 226. - Degl., t. II, p. 196. - Thien., pl. LXV, fig. 4. - Dr Rich. et Swai., Fauna Borealis, Am., p. 394. - Wilson, Am. Ornith, t. VII, pl. 60. - Totanus macularius, Temm. - T. macularius, Vieill. Tringa maculata, Edw. - T. macularia, Linné. - Turdus aquaticus, Briss. - Actitis macularius, Bonap.

Cette guignette est très-commune au Canada, au Labrador, et dans la baie d'Hudson, mais elle devient plus rare aux Etats-Unis et au Nexique. On la rencontre encore dans les Grandes et dans les Petites-Antilles et au Brésil. Dans leurs migrations, les guignettes perlées viennent quelquefois jusqu'en Europe. En Allemagne, où l'on en a déjà tué plusieurs, leur apparition a toujours été considérée comme une grande rareté, car lorsqu'elles viennent en Europe, elles se dirigent ordinairement vers la Grande-Bretagne. En Belgique, elles sont aussi rares qu'en Allemagne, et je n'ai eu qu'une seule fois occasion de les y observer; ce fut en mars 1847 où j'en vis trois chez un marchand de gibier; elles étaient encore jeunes, avaient très-peu de taches et une même était entièrement blanche. Je ne puis ici m'empêcher de faire une réflexion : c'est que la guignette perlée a, lorsqu'elle est jeune et qu'elle a ses plumes d'hiver, beaucoup de ressemblance avec notre guignette de rivière, surtout quand ses taches sont peu visibles, on est porté à les confondre; car il est probable que la guignette perlée vient souvent en Belgique, mais qu'on la méconnait et qu'on la prend facilement pour une guignette de rivière. Elles vivent sur les bords des fleuves, des étangs et des lacs; mais elles aiment surtout les rivages boisés où elles peuvent courir tout à leur aise dans les broussailles et s'y livrer à leurs joyeux ébats. En marchant, elles inclinent continuellement la tête. Pour se poser, elles choisissent ordinairement un endroit un peu élevé, soit une pierre, soit un poteau ou une branche suspendue sur l'eau. D'un caractère peu sociable et craintif elles recherchent la solitude où leur présence n'est guère trahie que par leur voix retentissante. Elles se nourissent d'insectes, de larves et de vermisseaux. Leur timidité excessive rend leur chasse ennuyeuse et difficile.

Ces oiseaux nichent dans le nord de l'Amérique, et placent ordinairement leur nid sur les grèves et les rivages, au milieu des broussailles pour mieux le cacher. Leur ponte est de trois ou quatre oufs. 


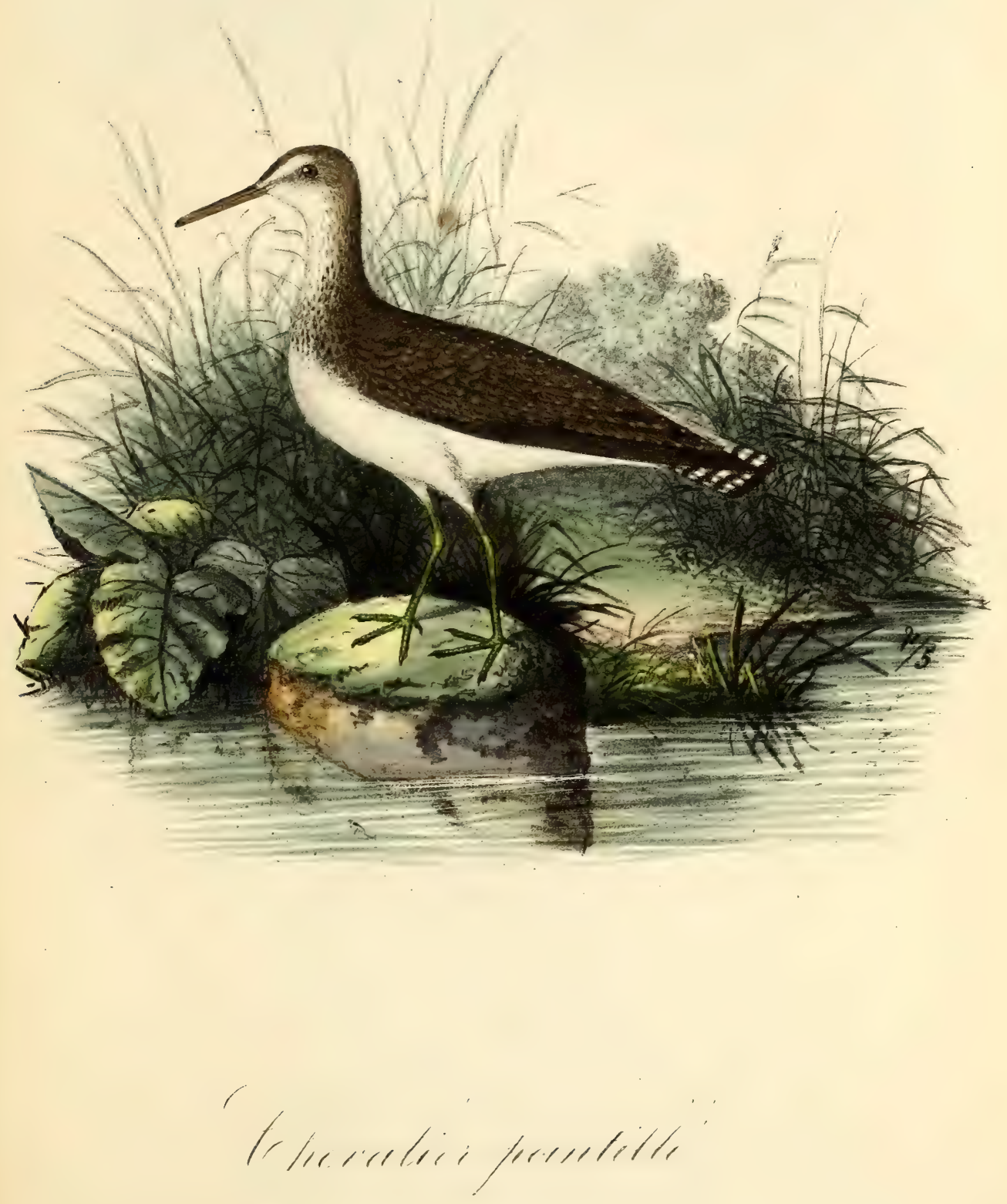

Qesure Chevalier. - Totamus, Temminck.

\section{CHEVALIER POINTILLÉ.}

TOTANUS PUNGTULATUS, DUBols.

GIEEN GANDPIPER. - GETÜPERLTER WAGETHËUFER.

Temm., MaN., t. II, p. 651. - Naum., t. VIII, pl. 228. - Gould, t. IV, pl. 3I5. - Degl., t. II, p. 192. - Thien., pl. XVII, fig. 6. - De Selys-Longch., Faune Belge, no 203. - Malh., Faune Sicile, p. 189. - Savi, Ornith. Toscana, t. II, p. 273. - V. d. Mühle, Ornith. Griechenlands, no 228. - Malh., Ois. d’Algérie, p. 21. - Rüpp. Vg. N. O. Afrika's, no 460. - Rich. et Swains., Fauna Bor. Amer., p. 392. - Tringa littorea, Brünn. - T. ochropus, Linné. Totanus Leucurus, Brehm. - T. ochropus, Temm.

Cet oiseau habite différentes parties de l'Asie, de l'Afrique et de l'Europe; on le trouve en Grèce, en Italie, en Espagne, en France, en Belgique, en Hollande, en Allemagne et en Suède. Il est, comme on le voit, dans le Nord aussi bien que dans le Midi. Ses endroits favoris sont les bords des petites rivières, des ruisseaux et des étangs qui sont abondamment pourvus de plantes aquatiques, de roseaux, de saules et d'aulnes. Mais on le voit rarement dans le voisinage des eaux dont les bords sont plats et nus. Il n'est pas très-sociable, et ce n'eșt guère qu'à l'époque de son émigration qu'il recherche la compagnie de ses semblables; encore est-il rare d'en voir plus de six ou dix ensemble. Ordinairement ces chevaliers ne vont que deux à deux, car ils aiment la solitude, et fuient la société de leur espèce, aussi bien que celle des autres oiseaux. Leur voix est sonore, modulée et assez agréable : c'est un cri ressemiblant à un : dluidluidlui fortement accentué; quand ils veulent s'appeler, leur sifflet est un dic, dic, assez agréable. Leur nourriture, qu'ils cherchent sur les bords ombragés des rivières et des étangs, consiste en insectes, vers, larves et vermisseaux aquatiques. Leur timidité est extrême et n'égale que leur prudence et leur circonspection; ils sont tellement sur leurs gardes, que dès qu'ils aperçoivent le moindre danger, ils fuient, et il leur reste toujours assez de temps pour se mettre en lieu sûr. Leur chasse est par conséquent difficile et excerce la patience du chasseur, qui ne peut les approcher à portée de fusil que lorsqu'il est caché par les arbres et les buissons.

Les femelles font leur nid dans le voisinage des eaux, sur une motte abritée de quelques broussailles; elles choisissent ordinairement un endroit très-écarté; leur nid se compose de quelques racines et brins d'herbe bien secs. L'accouplement a lieu en mai; la ponte est de quatre oeufs au plus. 


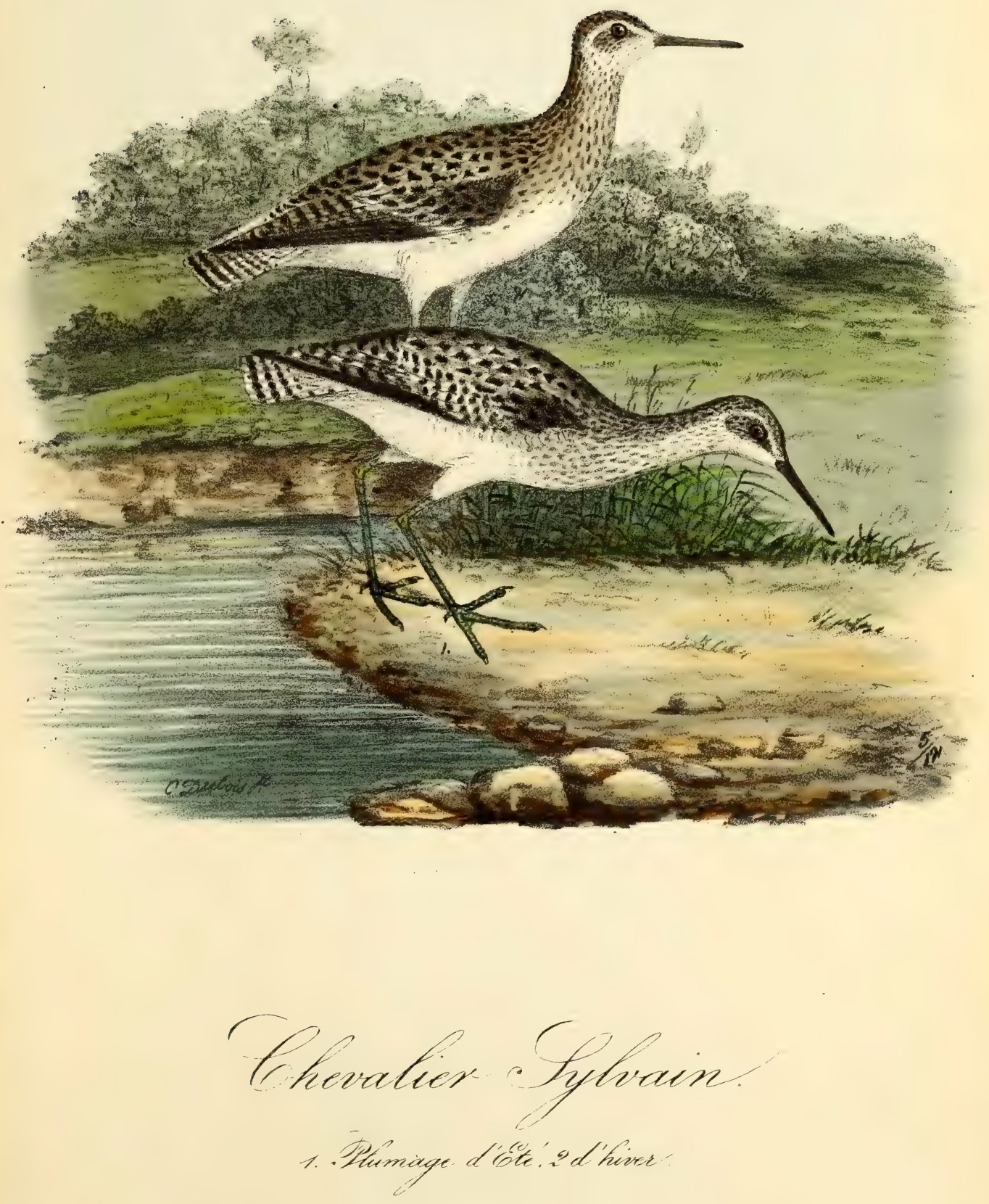



\section{CHEVALIER SYLVAIN.}

TOTANUS SYLVESTRIS, DUBoIS.

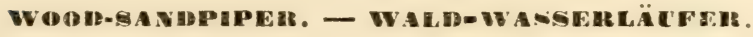

Temm., t. II, p. 654. - Naum., t. VIII, pl. 229. - Gould, t. IV, pl. 315. - Degl., t. II, p. 190.

Thien., pl. XVII, fig. 7. - De Selys-Longch., Faune Belge, no 204. - Malh., Faune Sicile, p. 190. - Savi, Ornith. Toscana, t. II, p. 277. - V. d Mühle, Ornith. Griechenlands, no 227. - Rüpp. Vg. N. 0. Afrika's, no 457. - Tringa glareola et littorea, Linné. - Totanus glareolus, Vieill. - T. glariola, Temm.

Cet oiseau habite toute l'Europe; on le voit même en Norwége; en Asie, on le trouve au Nord et au Midi, en Sibérie, aussi bien que dans le Bengale, et en Afrique, où le climat brûlant de la Nubie et de l'Égypte ne lui est pas plus contraire que la douce chaleur qui règne au cap de BonneEspérance. En Europe. on le rencontre surtout beaucoup en Allemagne, en Hollande, dans la Grande-Bretagne, en France et en Belgique. Il aime à se tenir dans les grands marais environnés d'arbres et entrecoupés de grandes flaques d'eau, comme aussi dans les forêts où se trouvent de petits lacs sur les bords desquels il aime à jouer et à patauger dans la vase. Il recherche souvent les endroits les plus retirés, les plus inabordables, où un chasseur ne peut s'aventurer sans danger de s'enfoncer dans la vase. Il visite aussi les étangs et les petits marais qui se trouvent au milieu des champs cultivés, et son plus grand plaisir est d'en parcourir les bords en tout sens et de jouer dans la vase; il y fait aussi une ample moisson d'insectes aquatiques, de larves, de vermisseaux et de limaçons. Très-sociable, mais il n'aime que la compagnie de ses pareils, et on le voit rarement avec d'autres espèces d'oiseaux aquatiques que la sienne. $\mathrm{Si}$, par hasard, il lui arrive de se trouver avec d'autres oiseaux, il ne tarde pas à s'en séparer. L'émigration des chevaliers sylvains commence en automne; ils se mettent en route par petites troupes de dix à quinze individus; quelquefois on en voit jusqu'à cent, et même plus, ensemble. Ils se tiennent trèsserrés, lorsqu'il leur arrive de s'abattre dans un marais ou sur les bords d'un étang, pour y prendre quelque repos. Au moment de leur départ, leur cri de ralliement giff, giff, giff, résonne dans les airs; mais c'est surtout vers le soir, au moment de commencer leurs courses nocturnes, qu'on les entend crier le plus; ils s'élèvent alors à une grande hauteur. Leur méfiance est extrême, et, comme ils se tiennent presque toujours dans des lieux dégarnis d'arbres, il est difficile de les approcher à portée de fusil sans qu'ils s'en aperçoivent. Leur chasse est donc difficile, le plus léger bruit, le moindre mouvement leur parait suspect et les met en fuite; ils s'envolent à une grande distance et ne mettent pied à terre que quand ils se croient bien en sûreté.

La femelle se retire dans de vastes marais pour nicher; elle place son nid sur une petite élévation entourée d'eau et de vase pour en rendre l'abord difficile; elle le garnit de racines flexibles et de petites graminées sèches et arrangées sans art. Sa ponte a lieu au commencement de mai et se compose rarement de plus de quatre œufs. Après l'éclosion, les petits courent çà et là, quittent leur nid et savent, en cas de danger, si bien se cacher, qu'il n'y a que les cris d'angoisse des parents qui font connaitre au chasseur le lieu de leur retraite. 


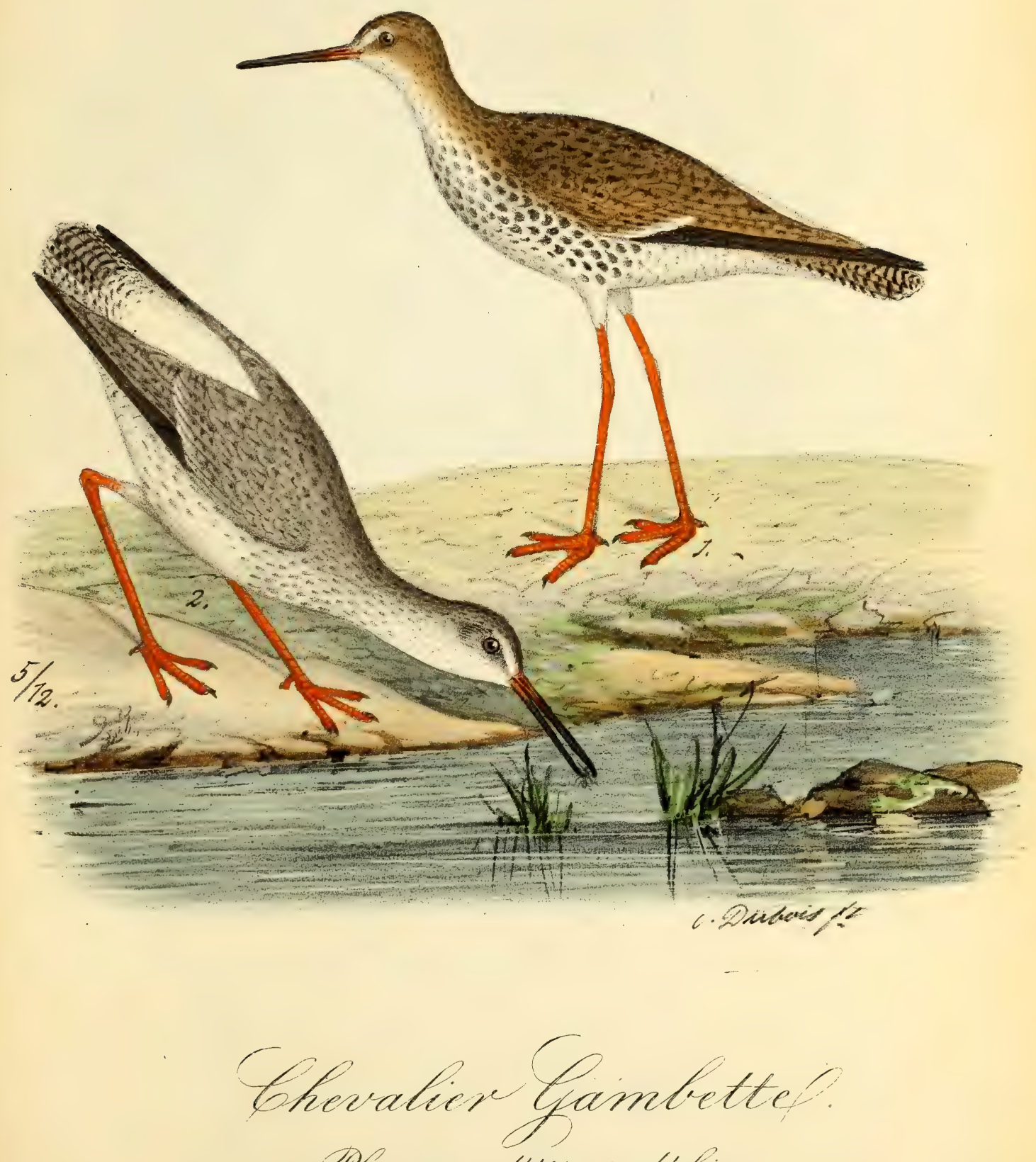
1. Dumage d'ete'-is d'tiever. 



\section{CHEVALIER GABETTE.}

TOTANUS GAMBETTUS, DUBoIs.

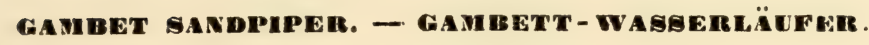

LA GAMBETTE, Buff., t. VII, p. 513. - Temm., t. II, p. 643. - Gould, t. IV, pl 309. Naum., t. VIII, pl. 199. - Degl., t. II, p. 187. - Thienem., pl. XVII, fig. 5. - Selys-Longch., Faune belge, no 206. - Malh., Faune Sicile, p. 189. - Savi, Ornith. Toscana, 1. II, p. 271. - v. d. Mühle, Vg. Griechenlands, no 226. - Faber, Island. Ornith, p. 25. - Rüpp., Vg. N. 0. Afrika's, no 459. - Rich. et Swainson, p. 391. - Scolopax calidris, Linné. - Tringa gambetta et striata, Gmel. - Totanus Calidris, Bechs. - T. striatus et naevius, Briss.

Cet oiseau est répandu dans toute l'Europe jusqu'aux confins de l'Afri. que et de l'Asie, en Sibérie, en Perse et en Chine; dans l'Amérique du nord; en Islande, en Norwége et en Danemark; dans plusieurs parties de l'Allemagne; il est aussi abondant dans les Iles Britanniques, en France et en Belgique; et commun en Hollande. Il quitte le pays pendant le printemps pour nicher plus vers le Nord; la plupart restent pendant toute l'année en France, en Hollande et en Belgique. Cet oiseau vit aussi bien aux bords de la mer que dans les grands marais et les bourbiers, les prairies humides, les pâturages pourvus d'étangs ou de marais dans lesquels il s'enfonce parfois jusqu'au ventre; il est farouche et prudent, aussi le chasseur peut-il rarement en approcher à portée de fusil, car il s'envole à temps en jetant des cris. Ils émigrent pendant la nuit en petites sociétés de deux à six, plus rarement en plus grandes de vingt à trente. Leur chant est agréable, court et perçant, on l'entend ordinairement quand il vole. Ce n'est que dans les nuits fort obscures qu'ils dorment pendant quelques heures, près de l'eau, couchés sur le ventre ou se tenant sur une jambe, le bec entre les plumes des épaules; sinon ils ne dorment que pendant le jour vers le midi, posés sur les deux jambes. Ils se tiennent assez bien en captivité pourvu qu'ils aient abondamment de la vase au fond de leur eau.

Nourriture : coléoptères, insectes d'eau et leurs larves, limaces d'eau et vers de terre, aussi les parties tendres des mousses aquatiques.

Ils nichent ordinairement au mois d'avril, dans les marais, à terre sur une élévation sèche ou dans le voisinage de la mer dans la société des mouettes ou autres oiseaux aquatiques. Le nid est dans un petit enfoncement, et bourré d'herbe sèche; on y trouve ordinairement trois ou quatre cufs qui sont un peu plus petits que ceux des vanneaux quoiqu'ils leur ressemblent beaucoup. Aussitôt qu'on s'approche d'un nid, on est poursuivi à grands cris par ces oiseaux, tantôt se reposant, ou courant puis volant encore, ils suivent même à peu de distance lorsqu'on s'éloigne. Les petits courent aussitôt qu'ils ont quitté l'œuf sous la conduite de la mère toujours tendre et attentive; elle leur apprend à chercher leur nourriture et à se cacher en cas de danger; aussi les écrase-t-on plutôt qu'on ne les découvre; lorsqu'ils savent voler, ils s'envolent avec les vieux. 



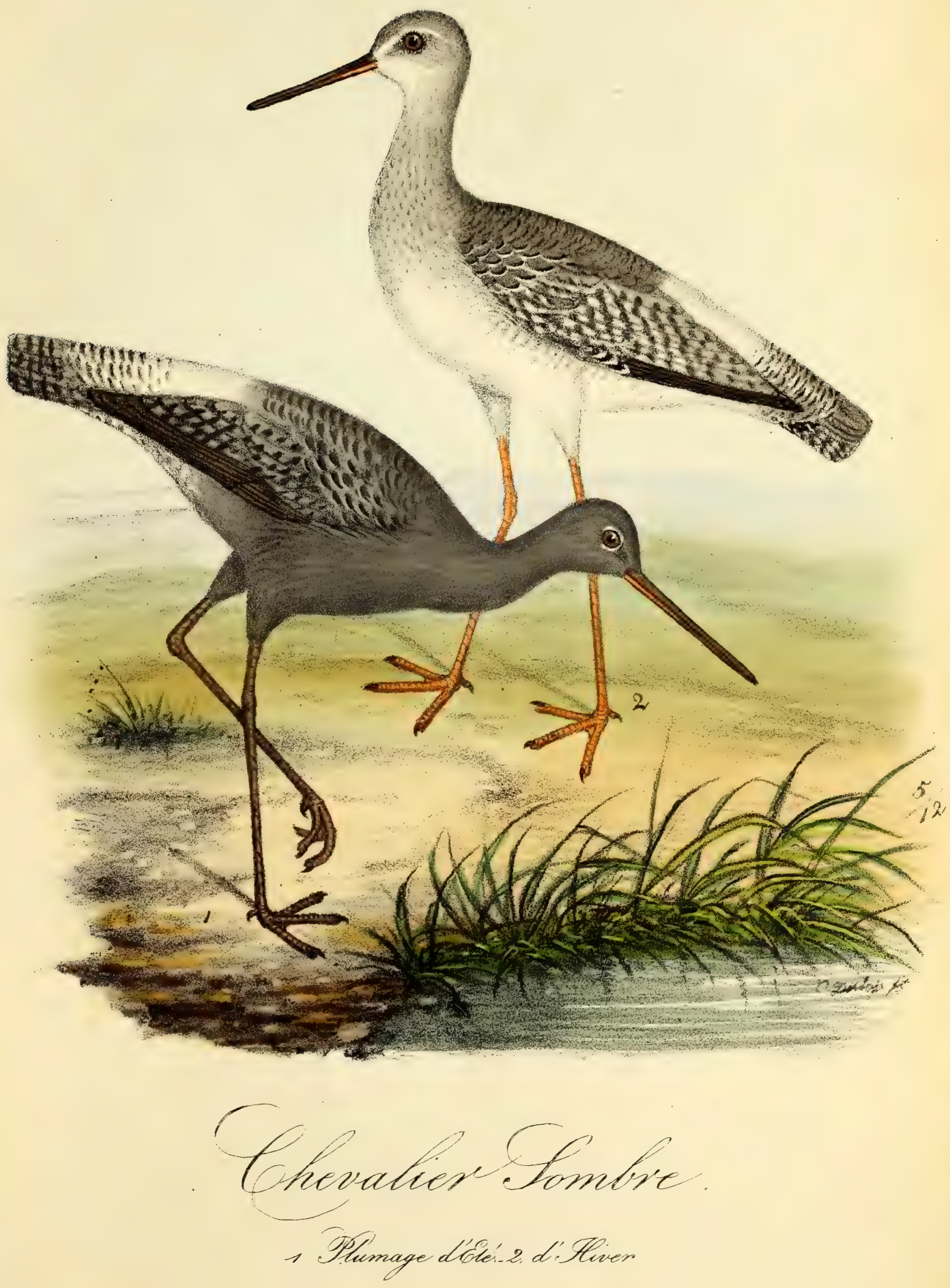





\section{CHEVALIER SOMBRE.}

TOTANUS OBSCURUS, DUBoIs.

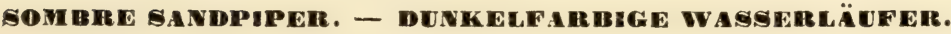

BARGE BRUN, Buff., t. VII, p. 508. - Temm., t. II, p. 639. - Gould, t. IV, pl. $315 .-$ Naum., t. VIII, pl. 200. - Degl., t. II, p. 182. - Thienem., pl. LXIV, fig. 2. - Selys-Longch., Faune belge, no 20כ. - Meyer, Vg. Liv.-v. Esthlands, p. 200. - Malh., Faune Sicile, p. 188. - Savi, Ornith. Toscana, t. II, p. 269. - v. d. Mühle, Vg. Griechenlands, p. 220̃. - Scolopax totanus et S. fuscus, Linné. - S. natans, Otto. - S. Cantabrigiensis el curonica, Gmel. S. fuscus, Linné. - Tringa totanus, Meyer, - T. Longipes, Meis. - T. atra, Gmel. - Totanus fuscus, Leisler. - T. natans et maculatus, Bechs. - T. ater, Brehin.

Cet oiseau est assez répandu, quoiqu'il y ait des contrées en Europe où il soit fort rare. On le trouve en Norwége, en Laponie, en Finlande, en Islande, aux îles Feroë, en Russie, en Sibérie, dans le Groenland ainsi que dans plusieurs parties de l'Amérique septentrionale. A son double passage en automne et au printemps, il parait en Allemagne, en Italie, en Espagne, en France et en Belgique, mais nulle part il n'est en abondance. Il vit aux bords des fleuves. des lacs, des marais, des localités marécageuses ou sur les terrains bourbeux qui n'ont ni arbres, ni roseaux, ni d'autres plantes élevées; on les y trouve par troupes de six à vingt, marchant aussi profondément dans l'eau que le leur permettent leurs longues jambes; lorsque l'eau est trop profonde, ils nagent. Leur voix se compose d'un son fort et perçant, que l'on entend au loin et surtout lorsqu'ils volent. Ils dorment toujours tout près de l'eau, à découvert, et pendant le jour à l'heure du midi, ou se tenant sur une jambe, ou couchés sur le ventre le bec caché sous les ailes; ils ne dorment que pendant les nuits très-obscures.

Le chevalier sombre est un des oiseaux les plus farouches et les plus craintifs; et comme il se trouve presque toujours à découvert, le chasseur n'en approche que difficilement, mais s'il y parvient il peut en abattre plusieurs d'un seul coup, car ils se tiennent toujours ensemble pour chercher leur nourriture qui consiste en insectes et leurs larves, en trèspetits coquillages, vers et frai de grenouilles.

Ils nichent au nord dans les marais sur une place sèche où l'on trouve dans un petit enfoncement, sur un peu d'herbe sèche, deux ou trois œufs. 


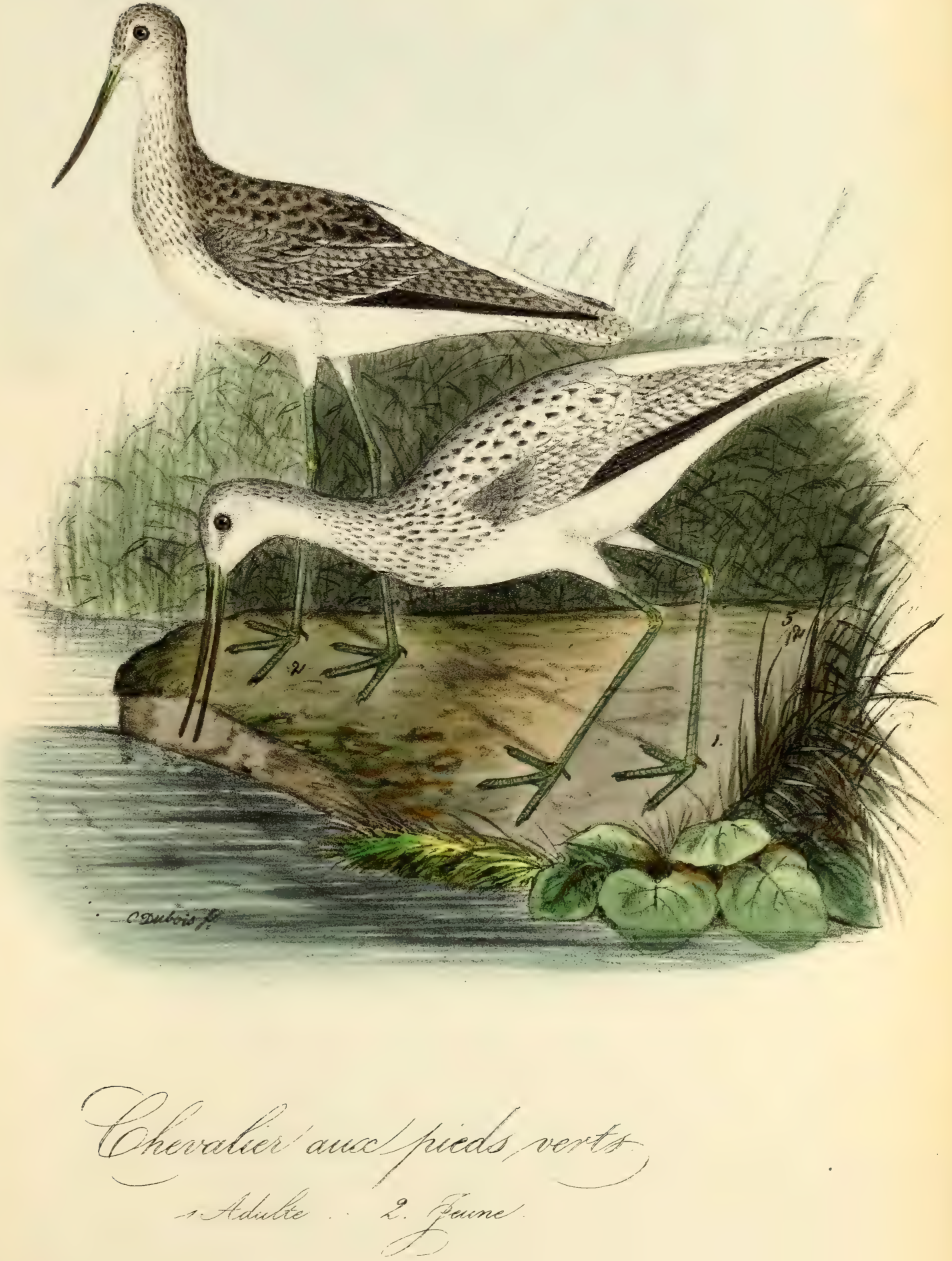



\section{CHEVALIER AUX PIEDS VERTS.}

TOTANUS CHLOROPUS, MEYER.

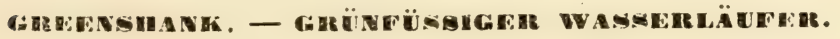

Temm., t. II, p. 659. - Gould., t. IV, pl. 312. - Naum., t. VIII, pl. 232. - Degl., t. II, p. 180. - Thien., pl. XVII, fig. 9. - De Selys-Lonch., Faune Belge, no 207. - Malh., Faune Sicile, p. 191. - V. d. Mühle, Ornith. Griechenlands, no 223. - Savi, Ornith. Toscana, t. II, p. 267.-Rüpp., Vg., N. 0. Afrika's, nº 4ว̆4.-Scolopax glottis, Linné. - Tringa fistulans et T. griseus, Bechist. - Limosa grisea, Briss. - Glottis chloropus, Nils. - G. Fistulans, Brehm. - T. gLotTis, Temm.

C'est un des oiseaux les plus répandus; on le voit dans toute l'Europe, en Asie, en Afrique et dans l'Amérique septentrionale et méridionale. Les contrées de l'Europe où on le trouve le plus sont : la Russie, l'Allemagne, la Hollande, la Grande-Bretagne, la Belgique et la France. Il vit principalement sur les bords des lacs, des étangs et des eaux stagnantes. Il fréquente aussi les grands marais et les bords des rivières; mais on le rencontre rarement sur le rivage de la mer. Il s'éloigne, autant que possible, des bois et des bruyères. Les chevaliers aux pieds verts ont un caractère très-sociable, et ils recherchent non-seulement la société de leur espèce, mais encore celle des chevaliers appartenant à d'autres espèces. Au printemps, les mâles font entendre leur voix; leur cri ressemble a un hiululu et tuqué, tuqué, légèrement modulé et qui n'est pas précisément désagréable. Lorsque les mâles veulent appeler les femelles, leur sifflet prend alors une articulation plus saccadée : ce n'est plus qu'un dic, dic souvent répété et assez peu mélodieux. Ils commencent leurs émigrations en automne, et ne voyagent que pendant la nuit. Ils se réunissent pour éinigrer, et leur nombre varie de quatre jusqu'à vingt; s'ils arrivent dans un endroit marécageux qui leur plaise, ils s'y arrêtent souvent pendant plusieurs jours pour s'amuser à courir dans la vase ou dans l'eau jusqu'au ventre. En cas de besoin, ils savent nager. Leur nourriture consiste en insectes aquatiques, larves, vermisseaux, petits escargots et frai de grenouilles, mais rarement de petits poissons; ils avalent aussi du sable et de petites pierres. D'un caractère remuant, changeant, ils ne peuvent rester longtemps à la même place, et la vivacité de tous leurs mouvements est vraiment extraordinaire; mais on a observé que le temps n'est pas sans influence sur eux, car le froid et l'humidité les rendent tristes, mornes et silencieux. Leur timidité est extrême, et aussitôt qu'ils aperçoivent un chasseur, ils s'enfuient à tire-d'aile et en criant beaucoup ; car leur prudence et leur prévoyance sont remarquables. Ils ont aussi une vue excellente, et ils aperçoivent tout ce qui se passe à une distance de deux cents pas. Le moindre bruit les alarme, et, dès qu'ils entendent des pas d'homme, ils se tiennent cois et écoutent pour savoir si l'on se dirige de leur côté. D'après ce que nous venons de dire, leur chasse est fort difficile, et le seul moyen qui reste à un chasseur adroit, quand il a découvert le lieu de leur retraite, c'est de se tenir dans leur voisinage et d'imiter leur cri jusqu'à ce qu'il parvienne à les attirer à portée de fusil pour les tirer.

Ils construisent leurs nids dans les marais ou sur les bords des étangs. Une petite excavation garnie de quelques brins d'herbe desséchés suffit à la femelle pour y déposer ses oufs, qui dépassent rarement le nombre de trois ou quatre. 


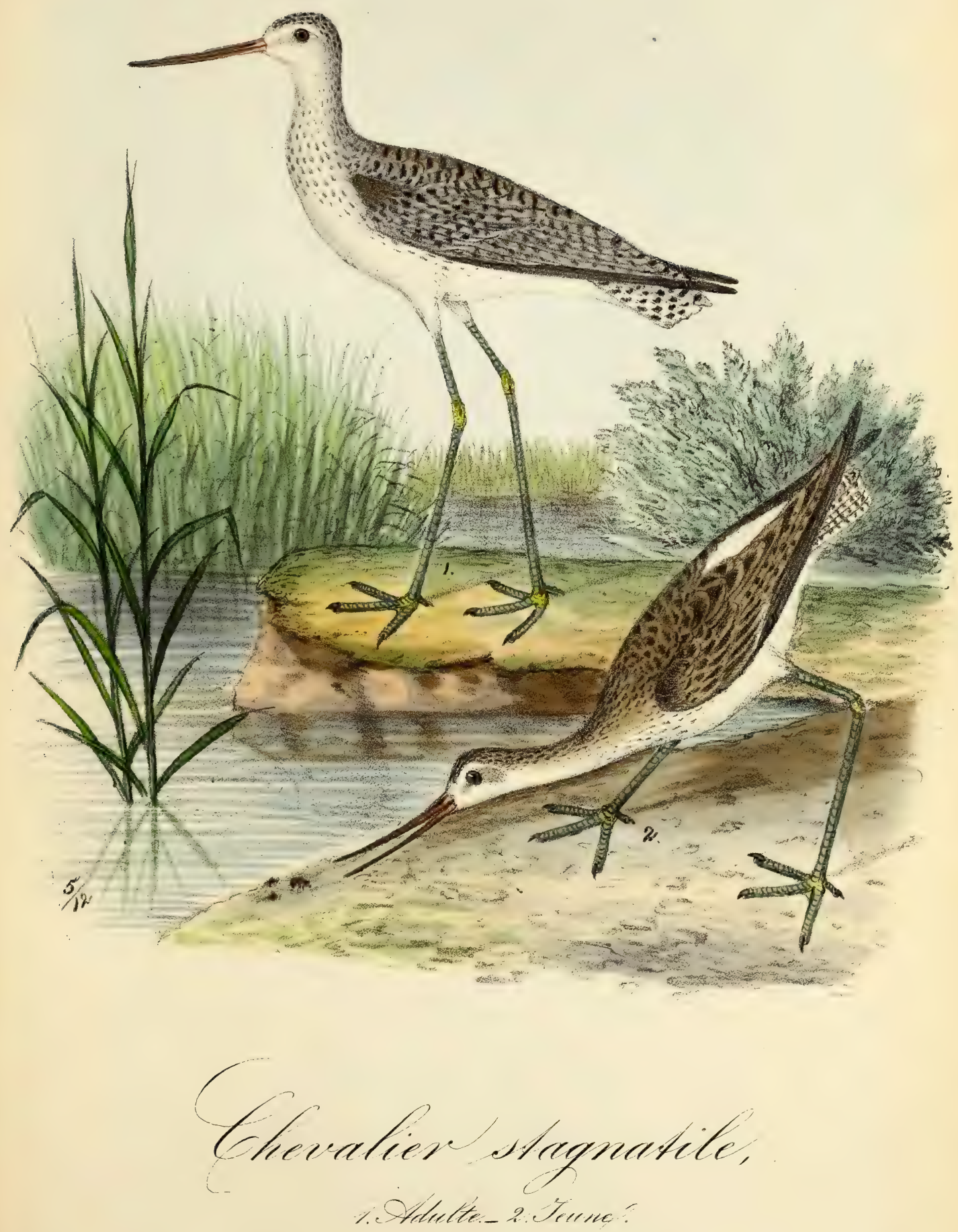



\section{CHEVALIER STAGNATILE.}

TOTANUS STAGNATILIS, BECIISTEIN.

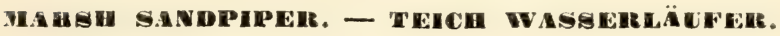

Temm., 1. II, p. 649. - Gould., t. IV, pl. 314. - Naum., 1. VIII, pl. 23̈3. - Degl., ı. II, p. 183. Thien., pl. LXIV, fig. 4.-Malh., Faune Sicile, p. 189. - Savi, Ornith. Toscana, t. II, p. 278. - v. d. Mülhe, Orvith. Griechenlands, no 224. - Rüpp., Vg. N. 0. Afrika's, no 4506. - Scolofax totanus, Linné. - Triga guinette, Pallas. - Totanus longipes, Leisl.

Cet oiseau habite diverses parties de l'Asie et de l'Afrique. En Europe il est assez rare et on ne le voit guère que dans les contrées méridionales, telles que la Grèce, l'Espagne, la Hongrie et l'Italie. Souvent on le rencontre aussi dans quelques parties de l'Allemagne, en Autriche, dans le Wurtemberg et même en Prusse, tandis qu'en France et en Belgique on ne le voit que fort rarement. Le chevalier stagnatile vit pour la plupart du temps sur les rivages et les bords des eaux stagnantes, des lacs et des grands étangs, quelquefois on le trouve aussi dans le voisinage des grandes rivières, mais il fréquente surtout les grands marais entrecoupés d'immenses flaques d'eau. Il est en proportion de sa taille le plus élancé et le plus mince de toutes les espèces de chevaliers, ses jambes sont aussi les plus longues; il est donc facile à reconnaître, même à distance. Ses mouvements sont gracieux, sa démarche aisée et son vol rapide. Doué d'un caractère timide, il se laisse difficilement approcher et la vue d'un homme l'effraye de suite; même en volant, il évite de passer près d'une habitation. Il est donc difficile de le tirer, et ce n'est guère qu'en employant beaucoup de ruse et d'adresse qu'on peut y parvenir. Il court souvent au bord de l'eau et même il y entre de toute la hauteur de ses jambes; sa principale occupation alors est de chercher des insectes aquatiques, des larves et des vermisseaux. En cas de danger, ou d'attaque imprévuc, il sait se soustraire à son ennemi par la nage, quoiqu'il ait rarement recours à ce moyen.

Le chevalier stagnatile niche dans les marais où il cherche par terre une place sèche et légèrement excavće, qu'il remplit d'herbes sèches arrangées sans art. Il pond ordinairement trois ou quatre ocufs. C'est seulement en Ilongrie ef en Allemagne qu'on a découvert des nids appartenant à cet oiseau. 



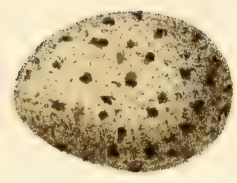

i)

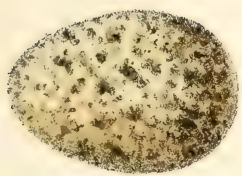

Irefing.1

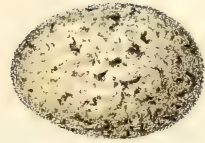

Q1
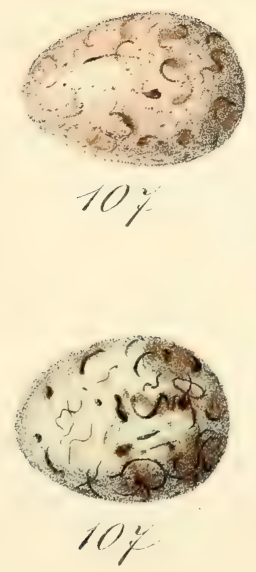
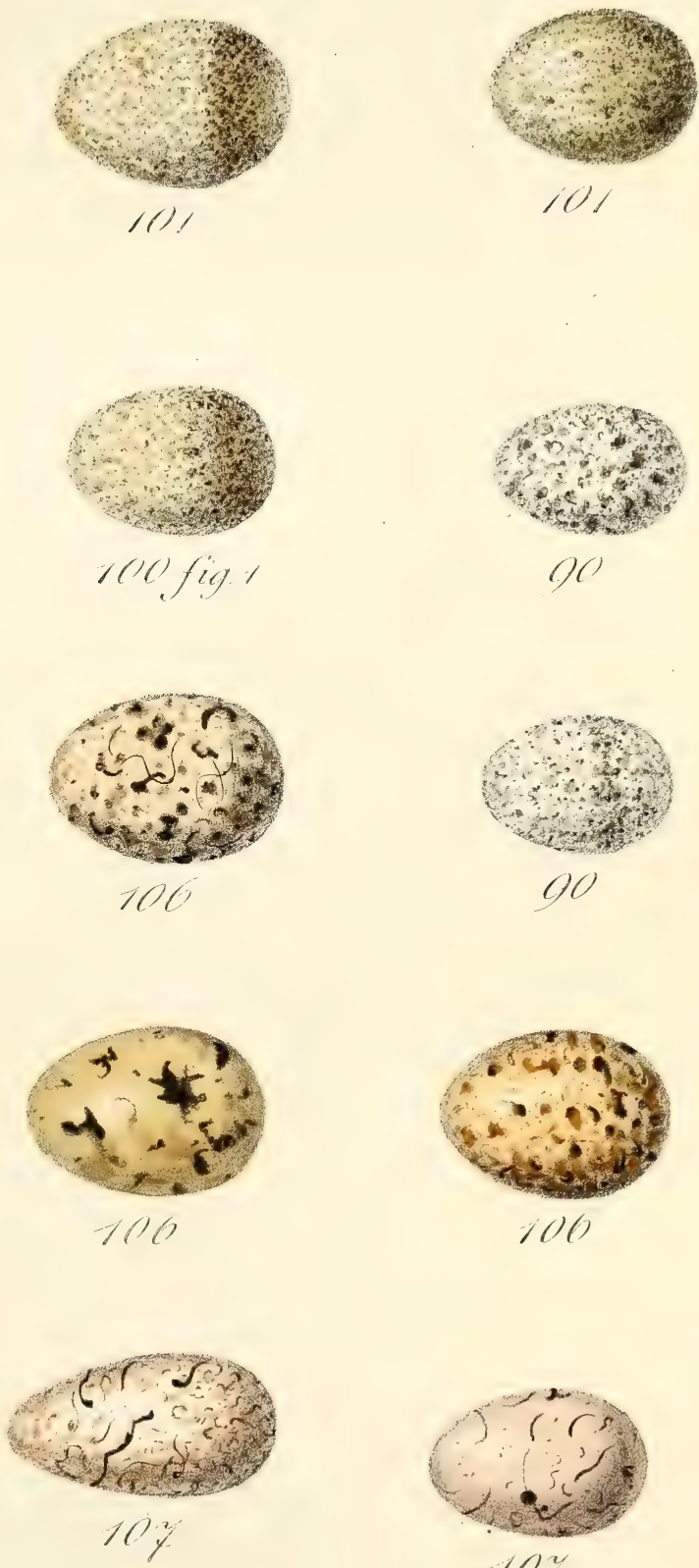
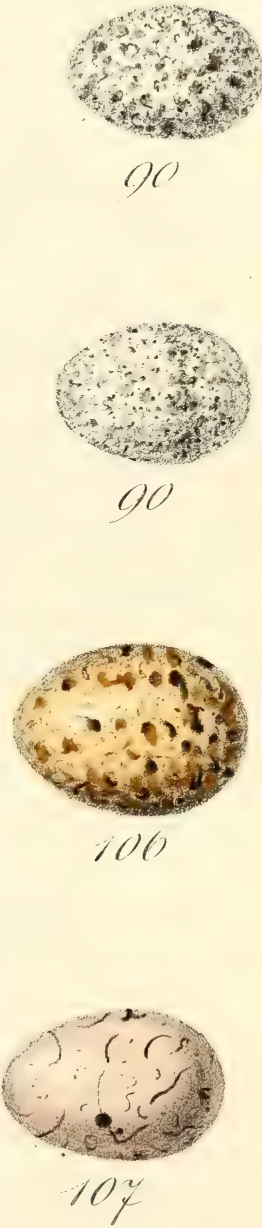

XIX
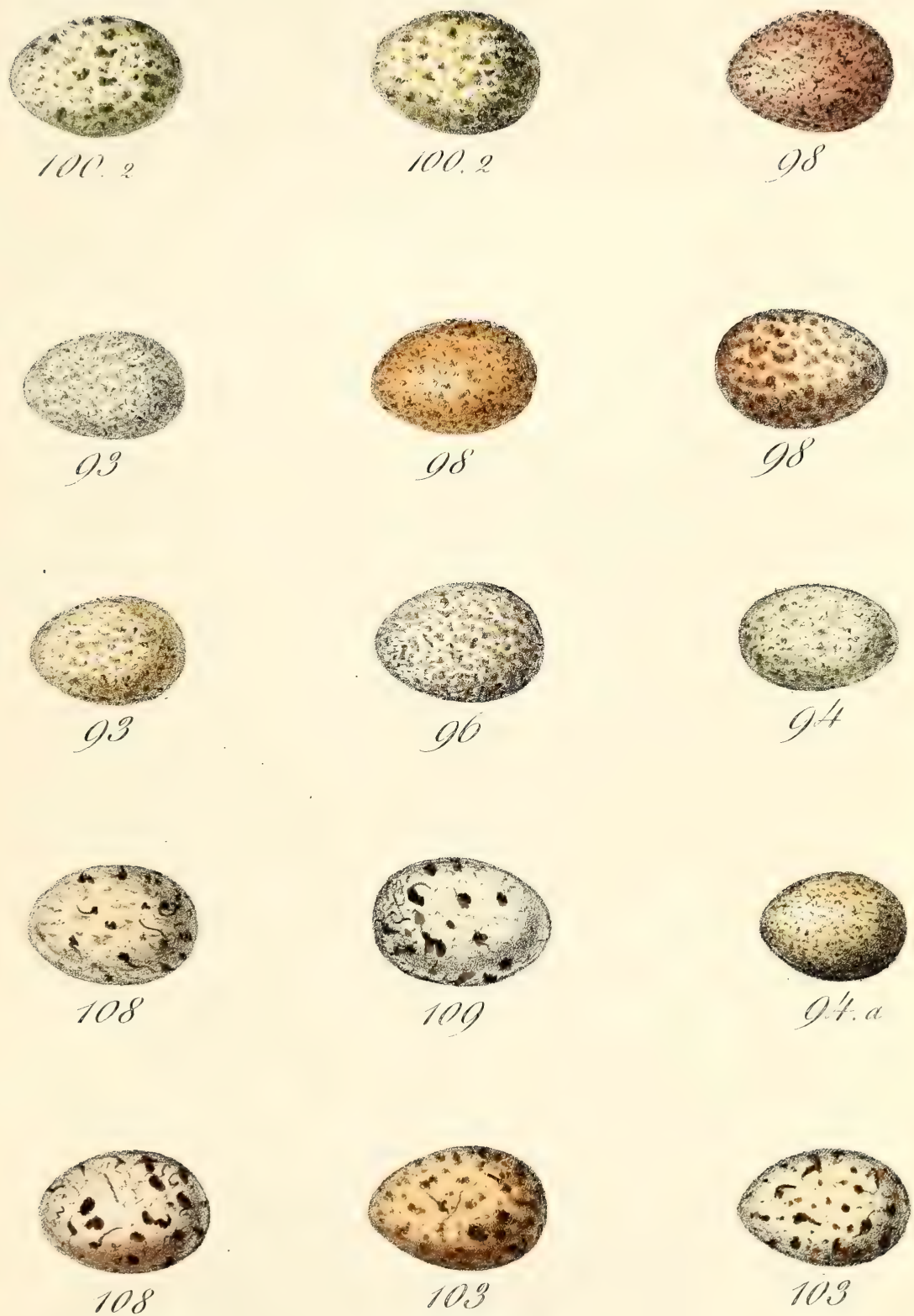

XX
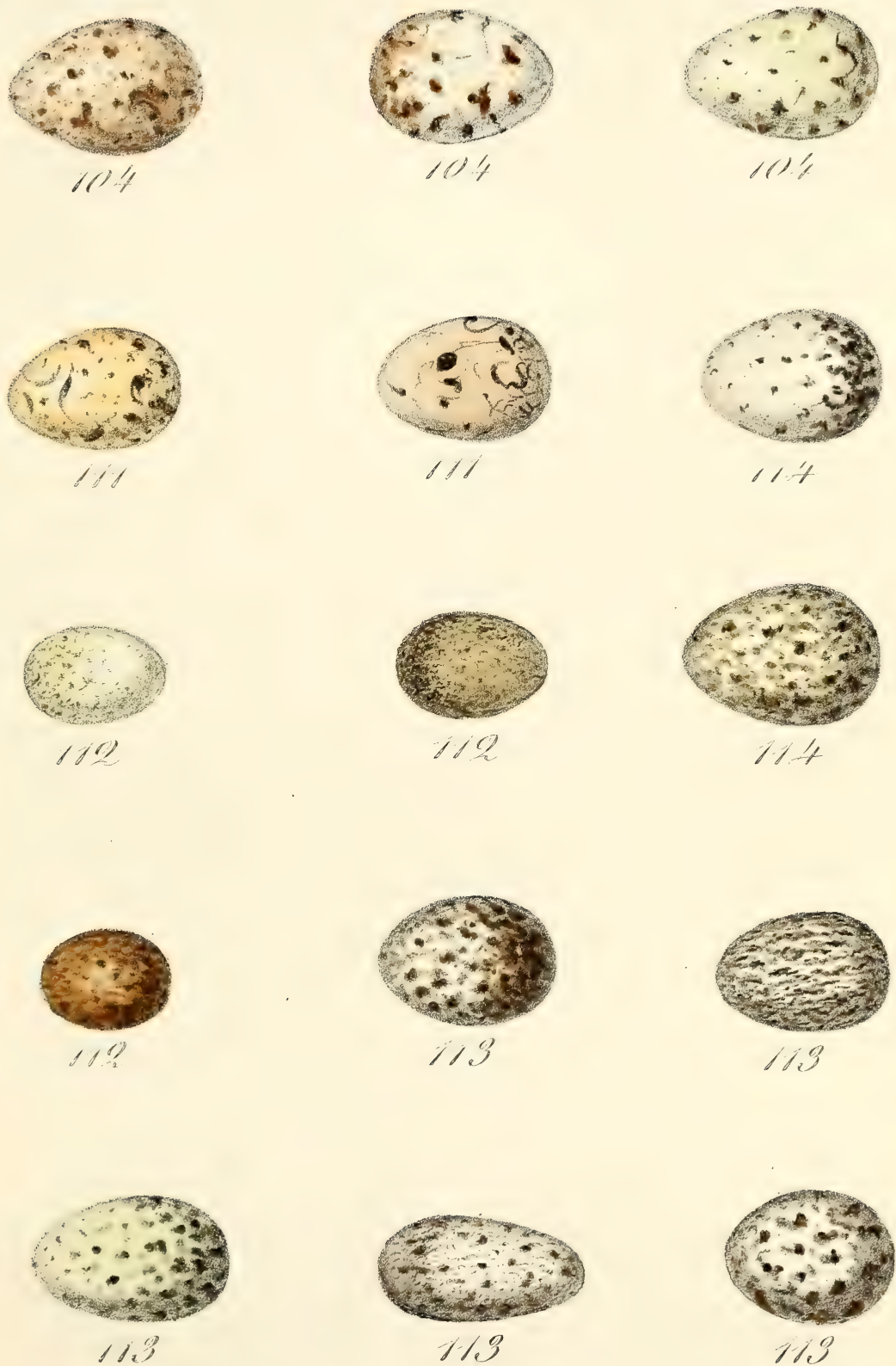


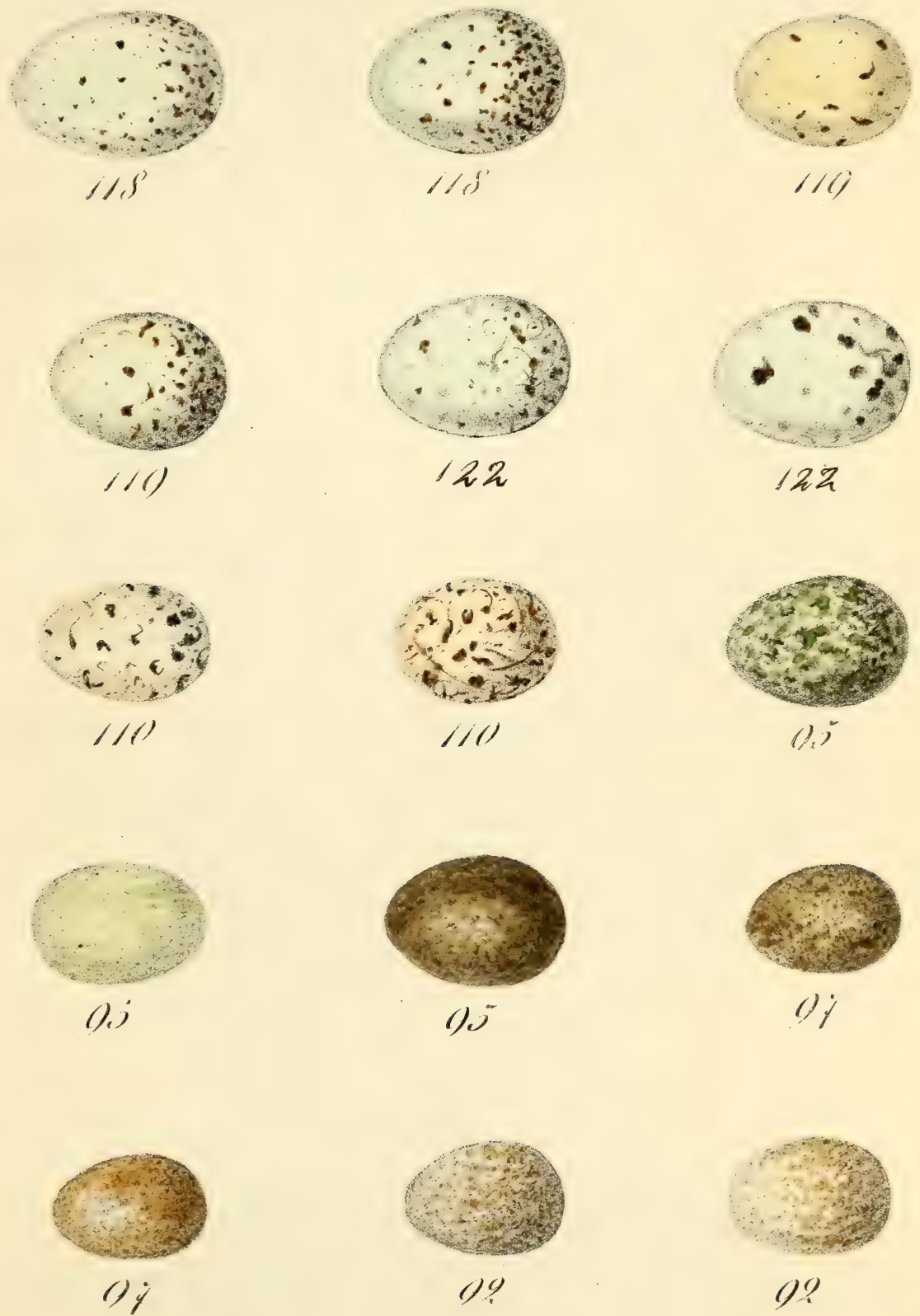

VIII.
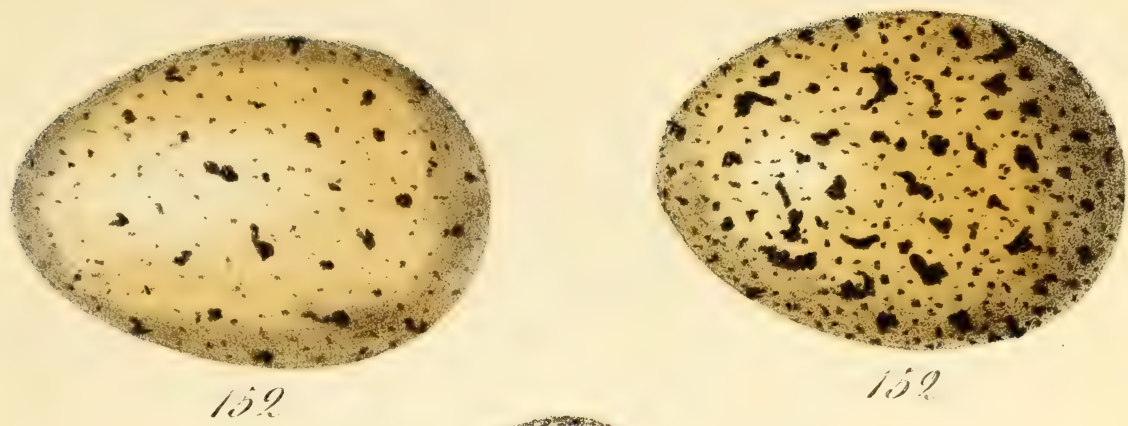

woxthe

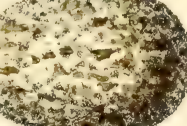

(I)?
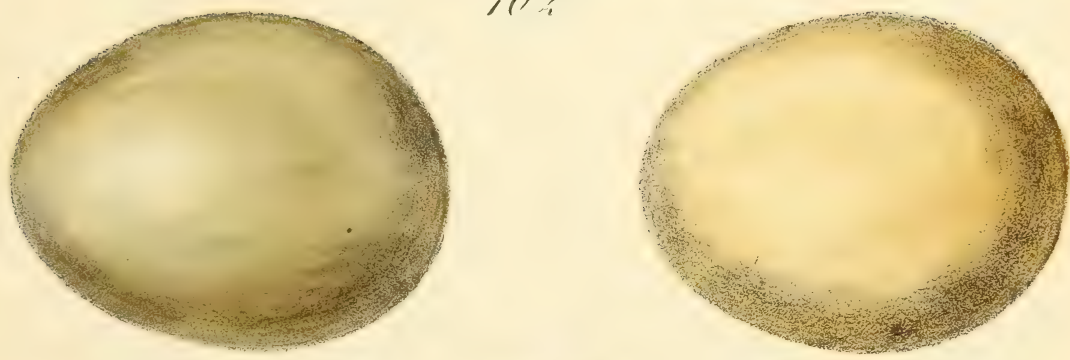

biol
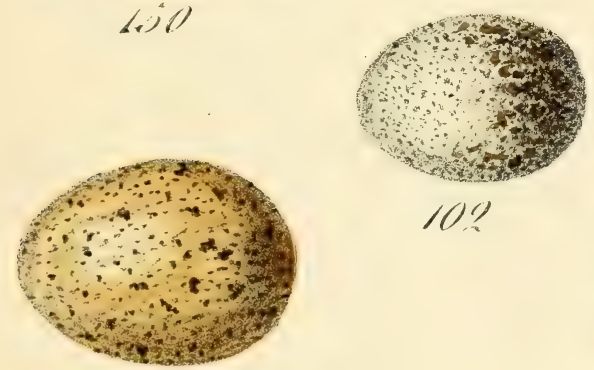

iob
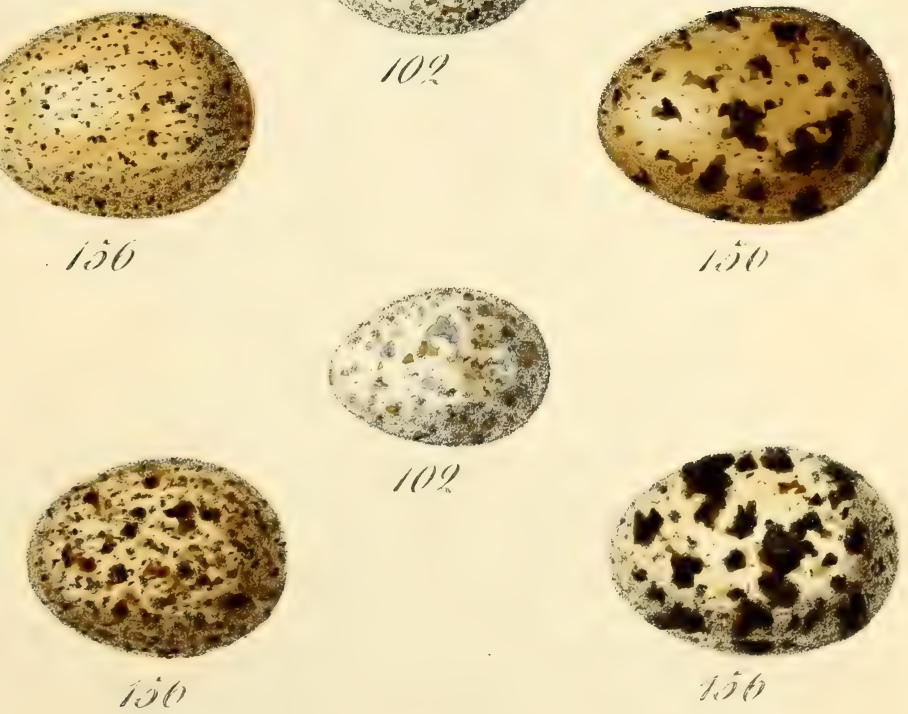



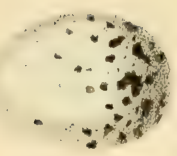

(अ)

$$
\text { ('), }
$$

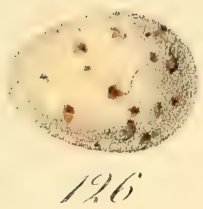

$-4$
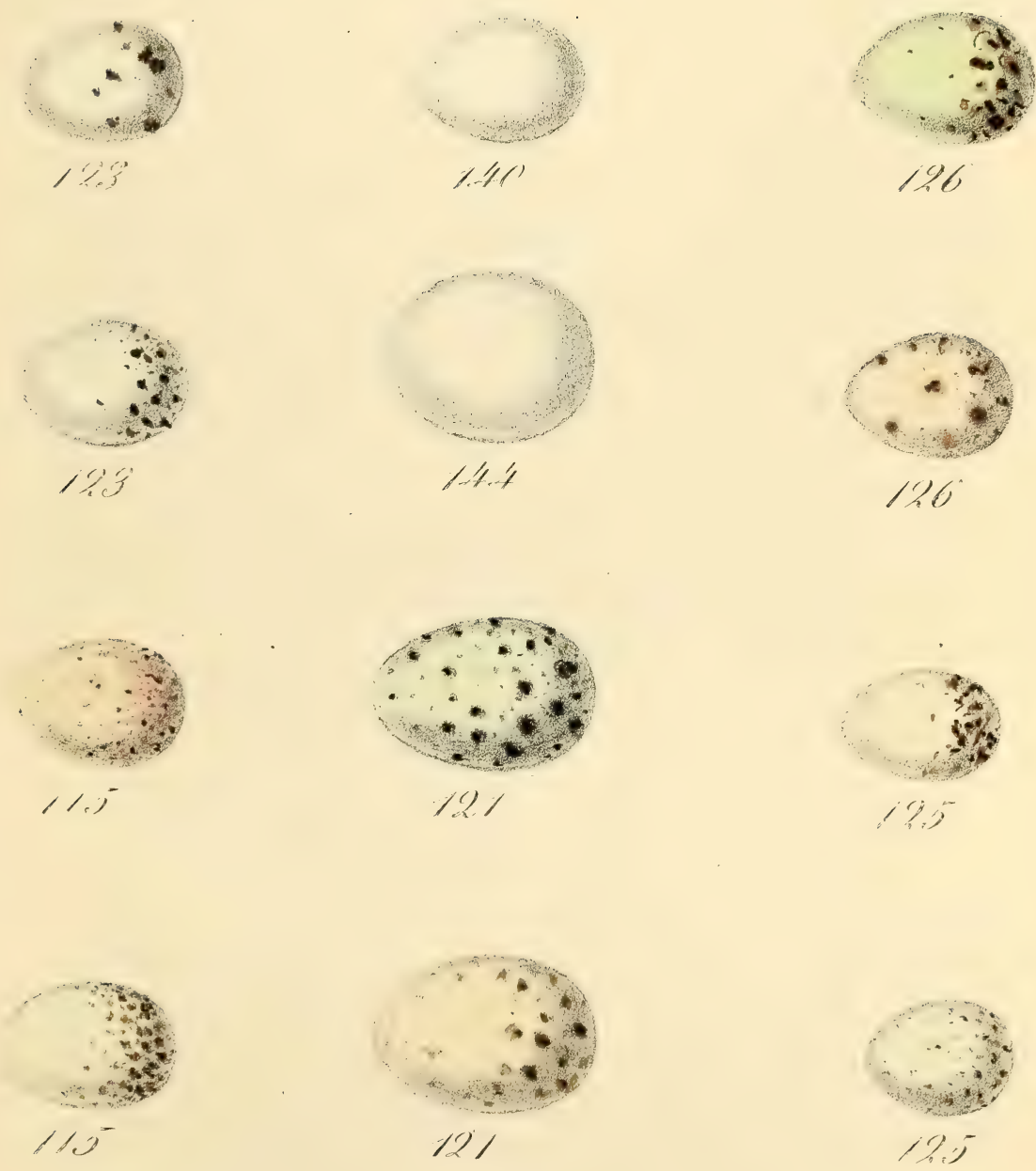

XXIV.

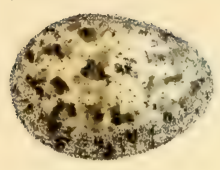

$143 \mathrm{Cl}$
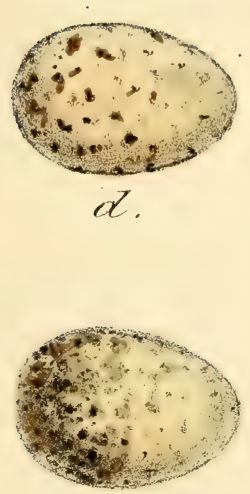

9
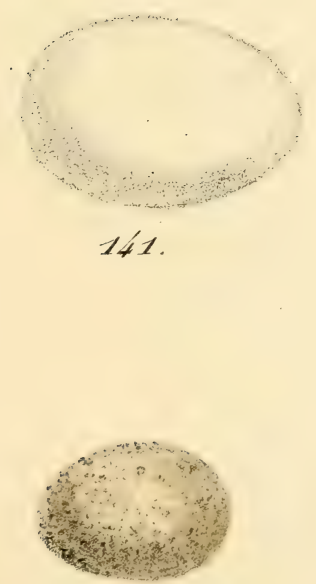

$9.5 \alpha$
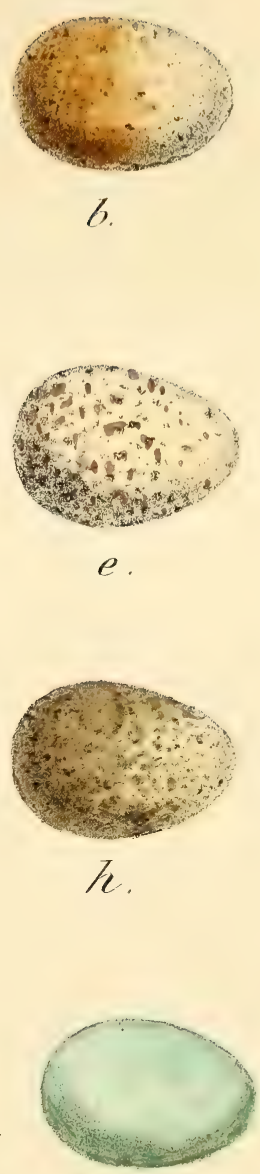

$k$

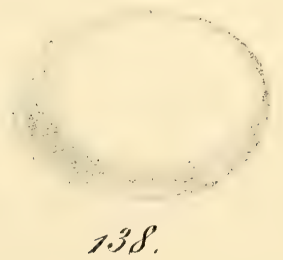

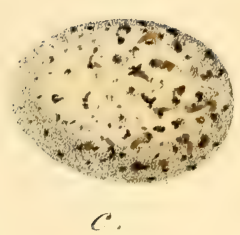
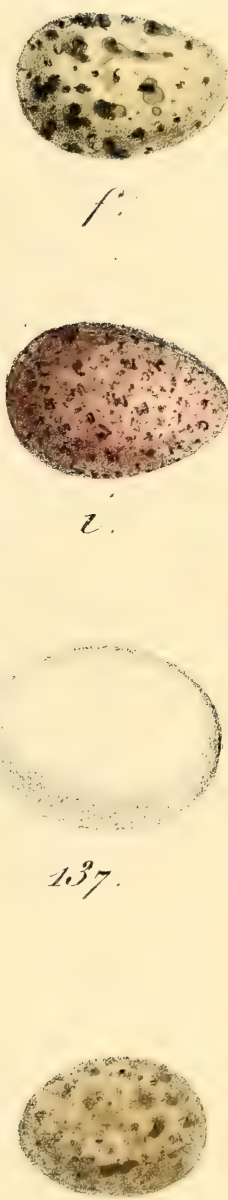

$9.5 a$ 


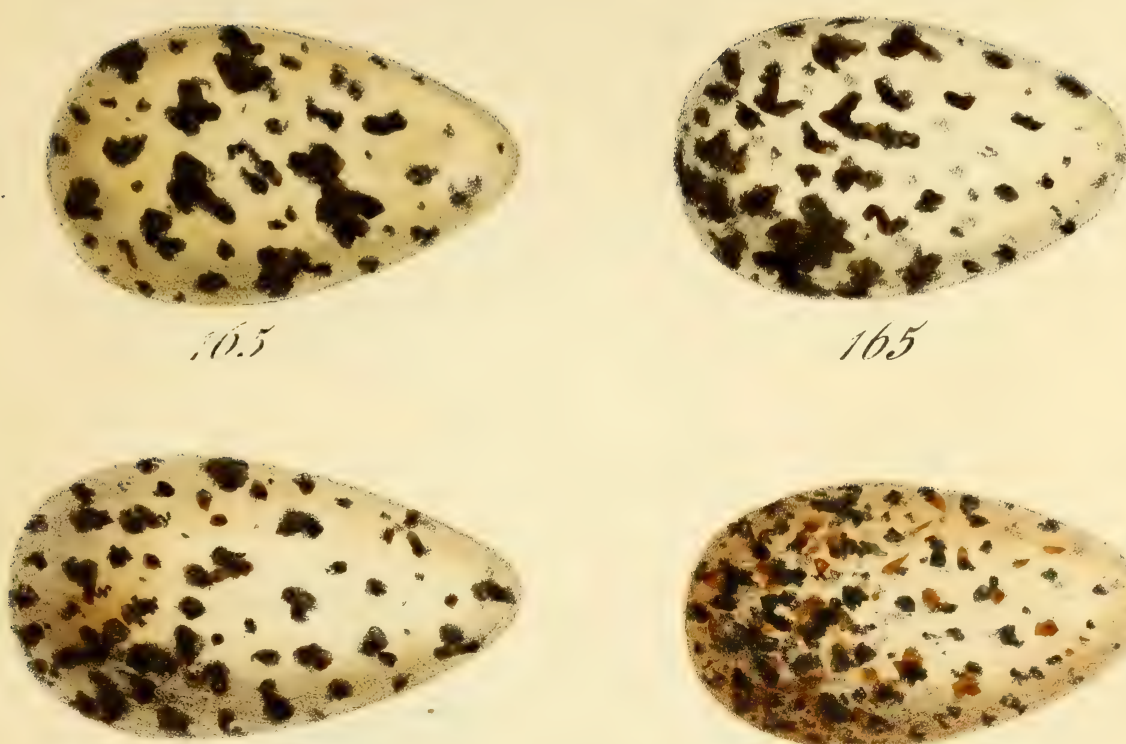

165
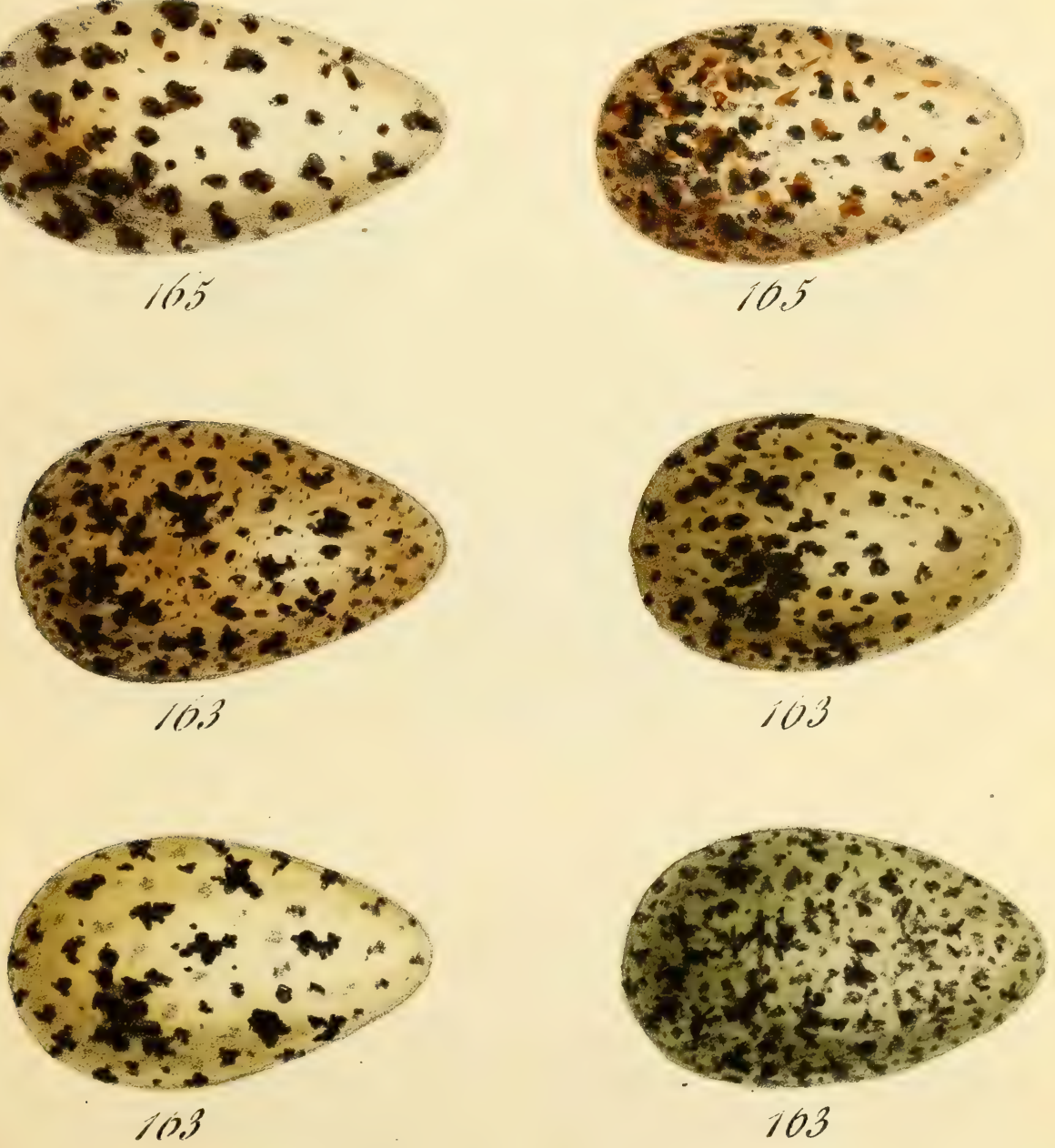


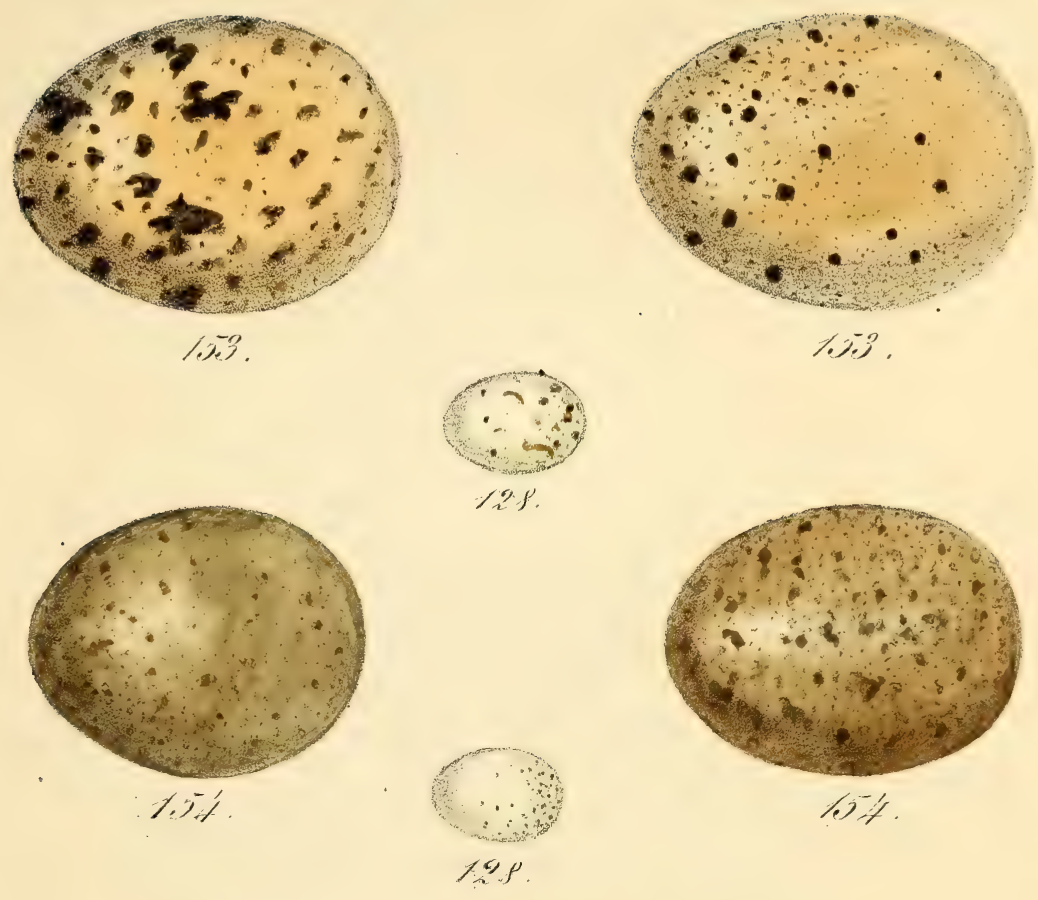

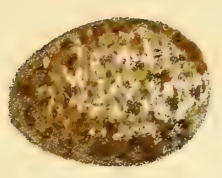

ubia
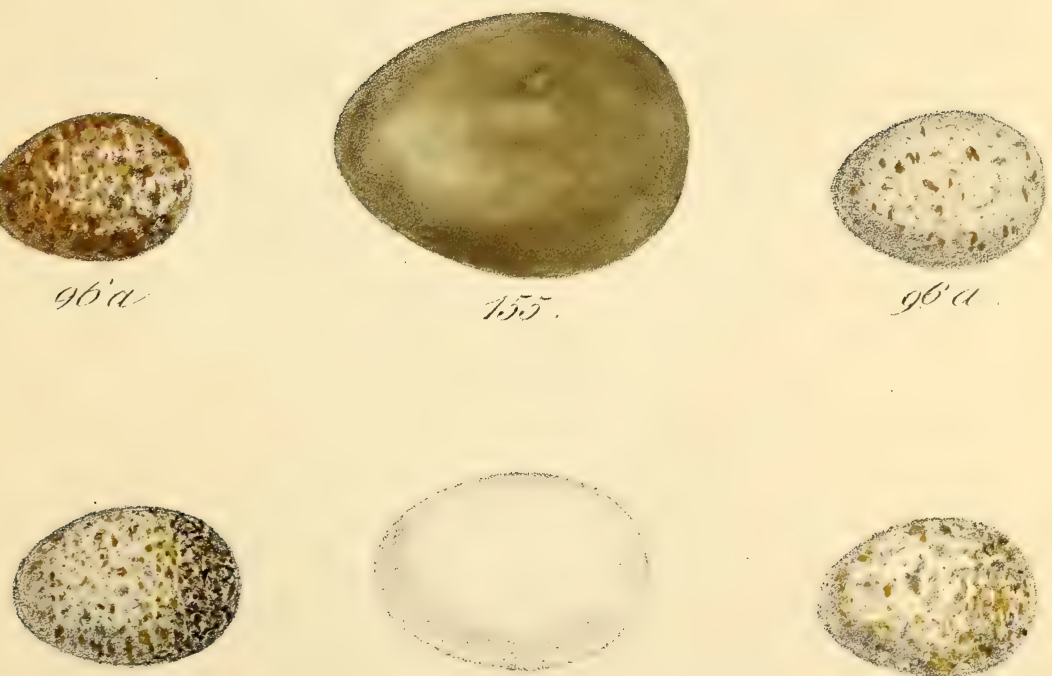

99
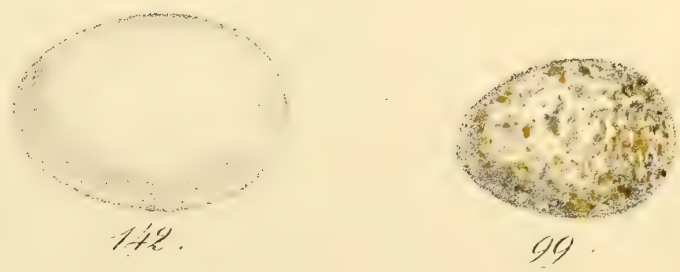



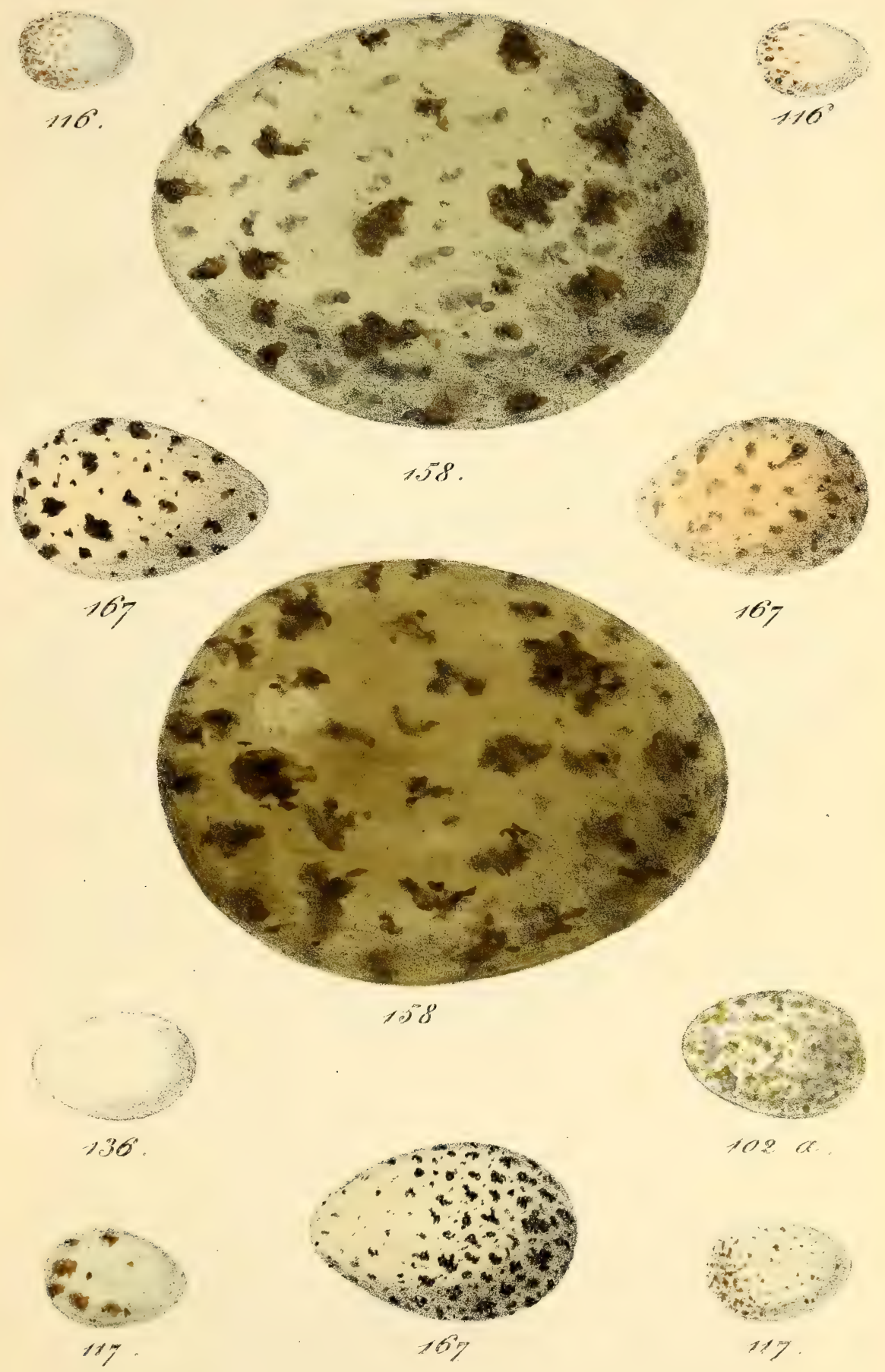


<smiles>C1CC1</smiles> 

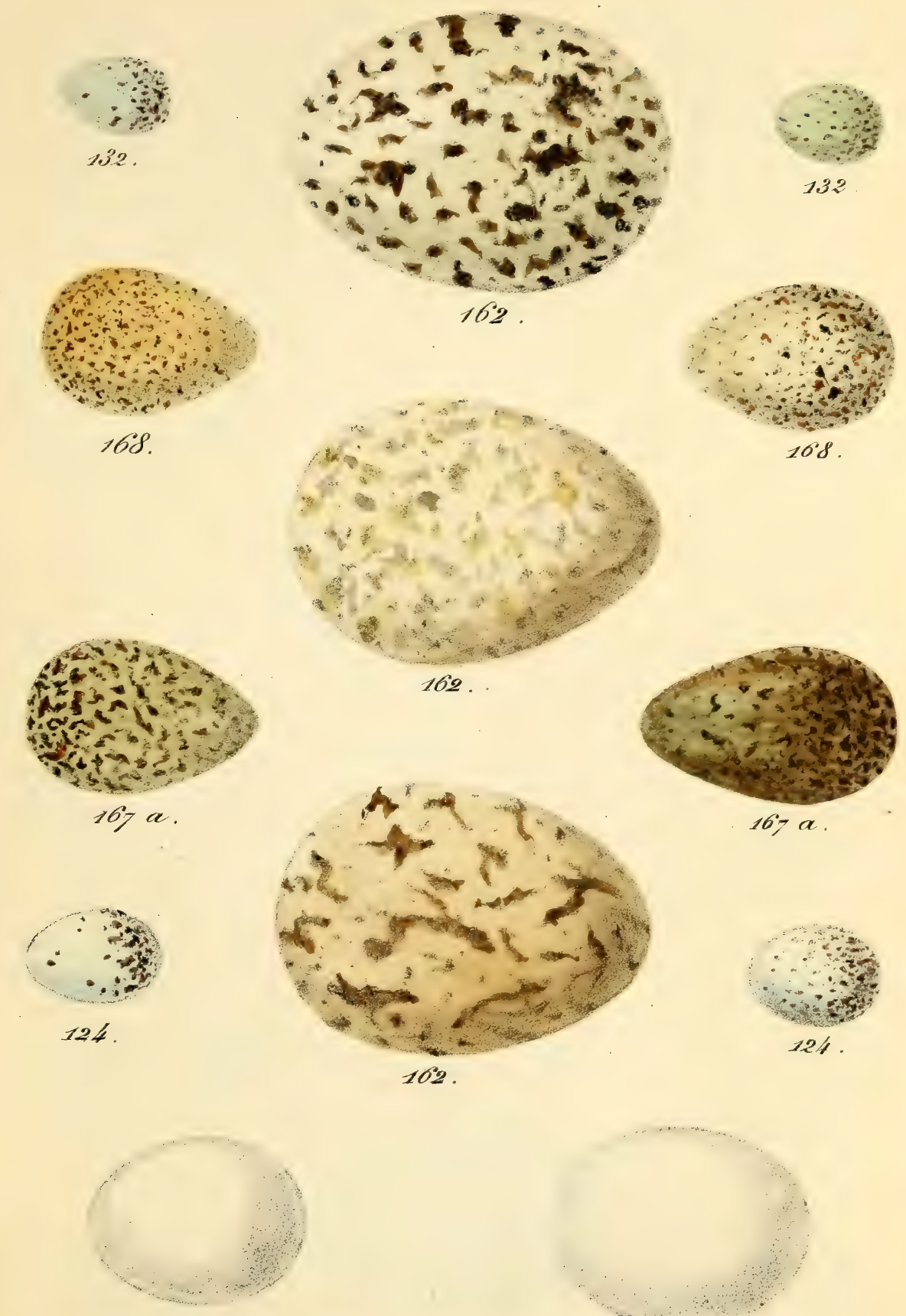

149.

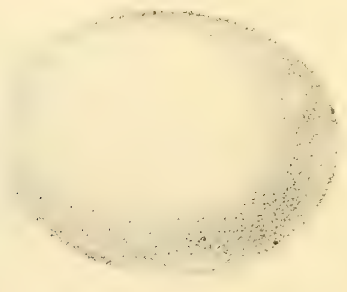

147. 

XYTX

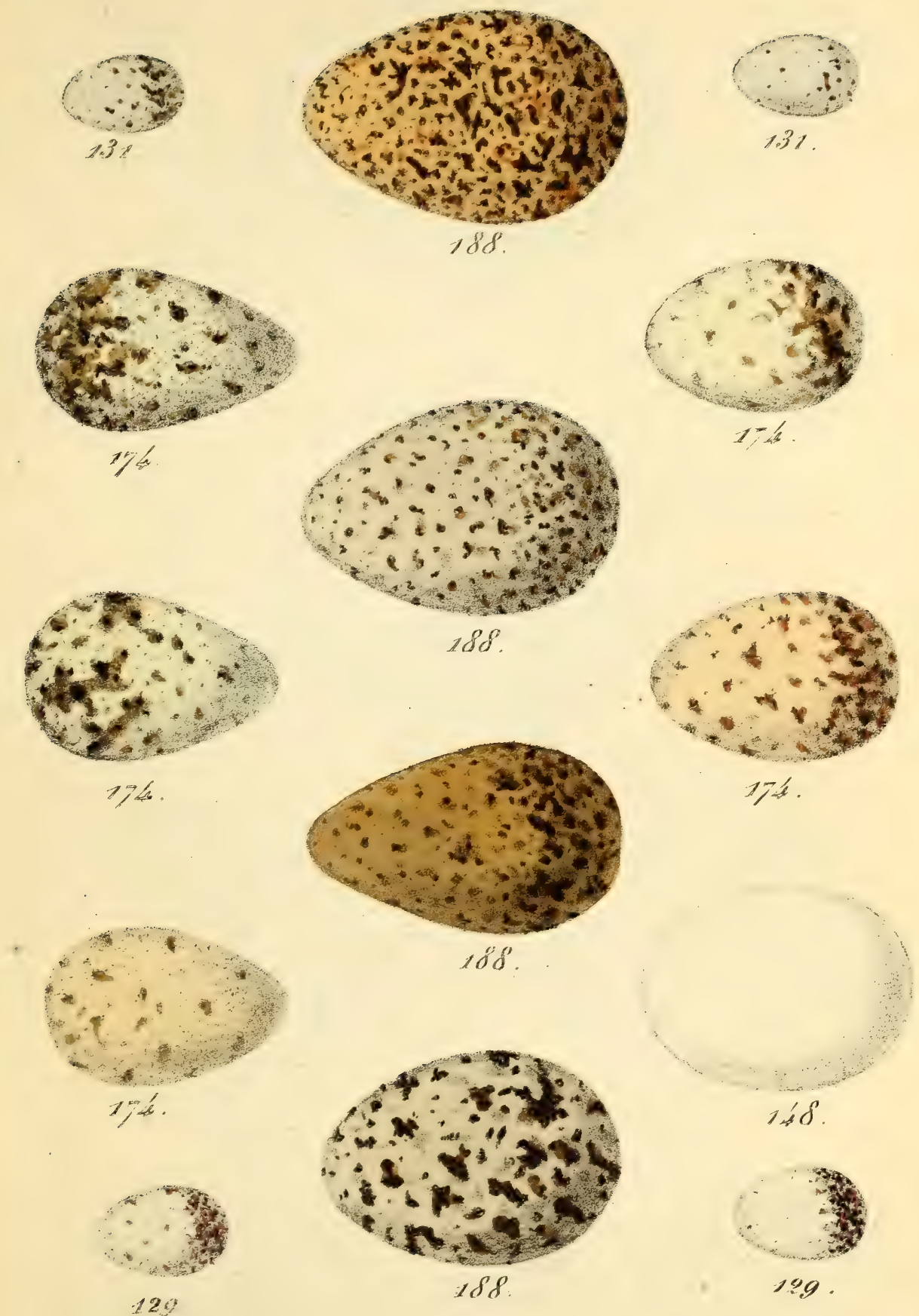





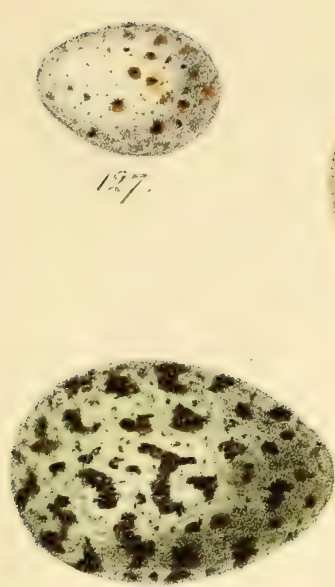

1.57
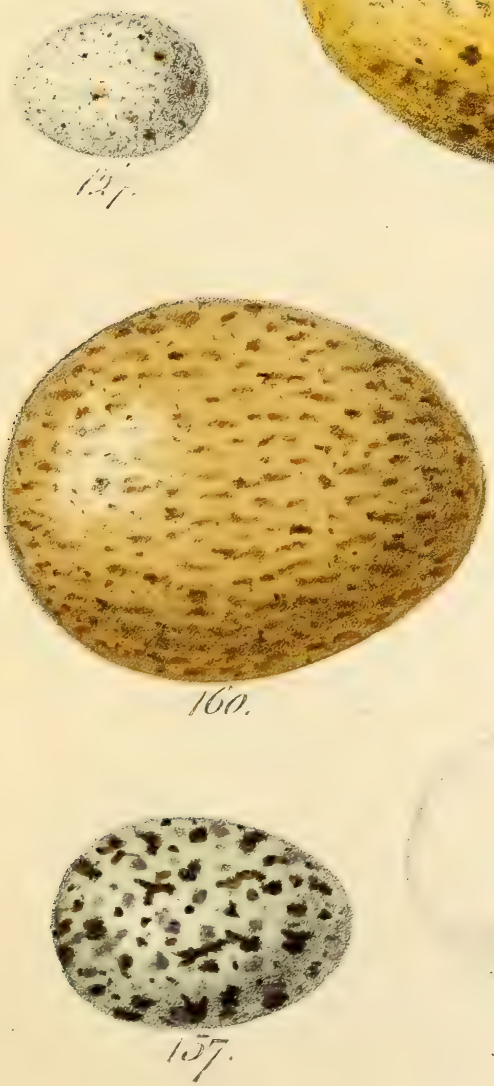

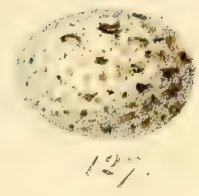

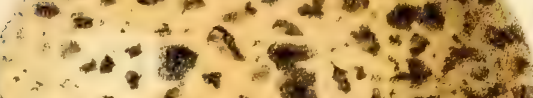

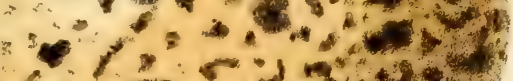

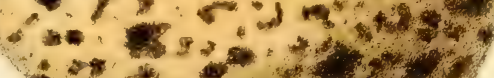

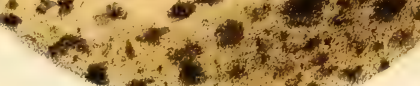

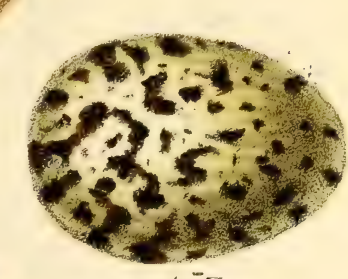

10.5

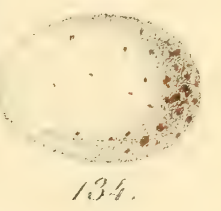

$15 \%$
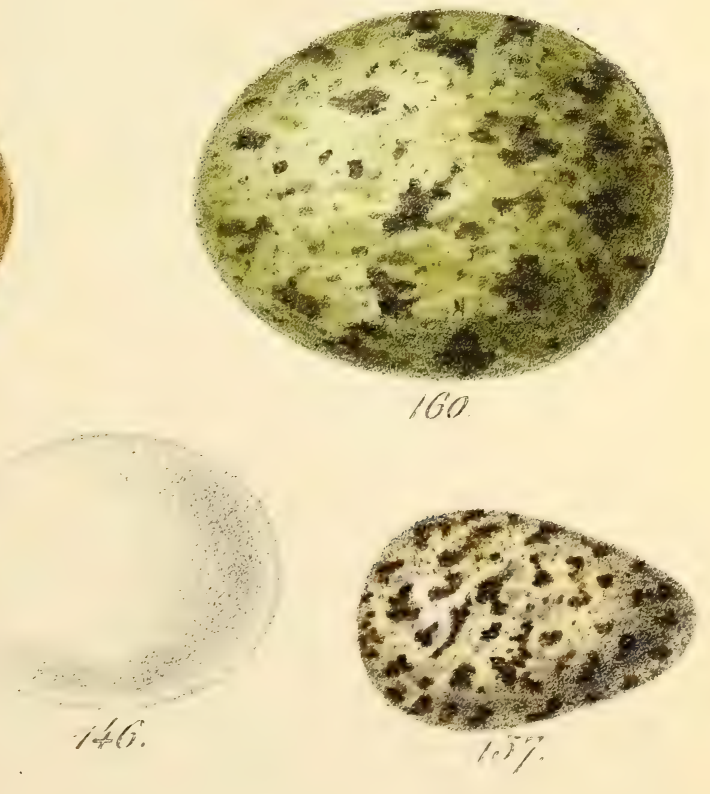

XXXI.

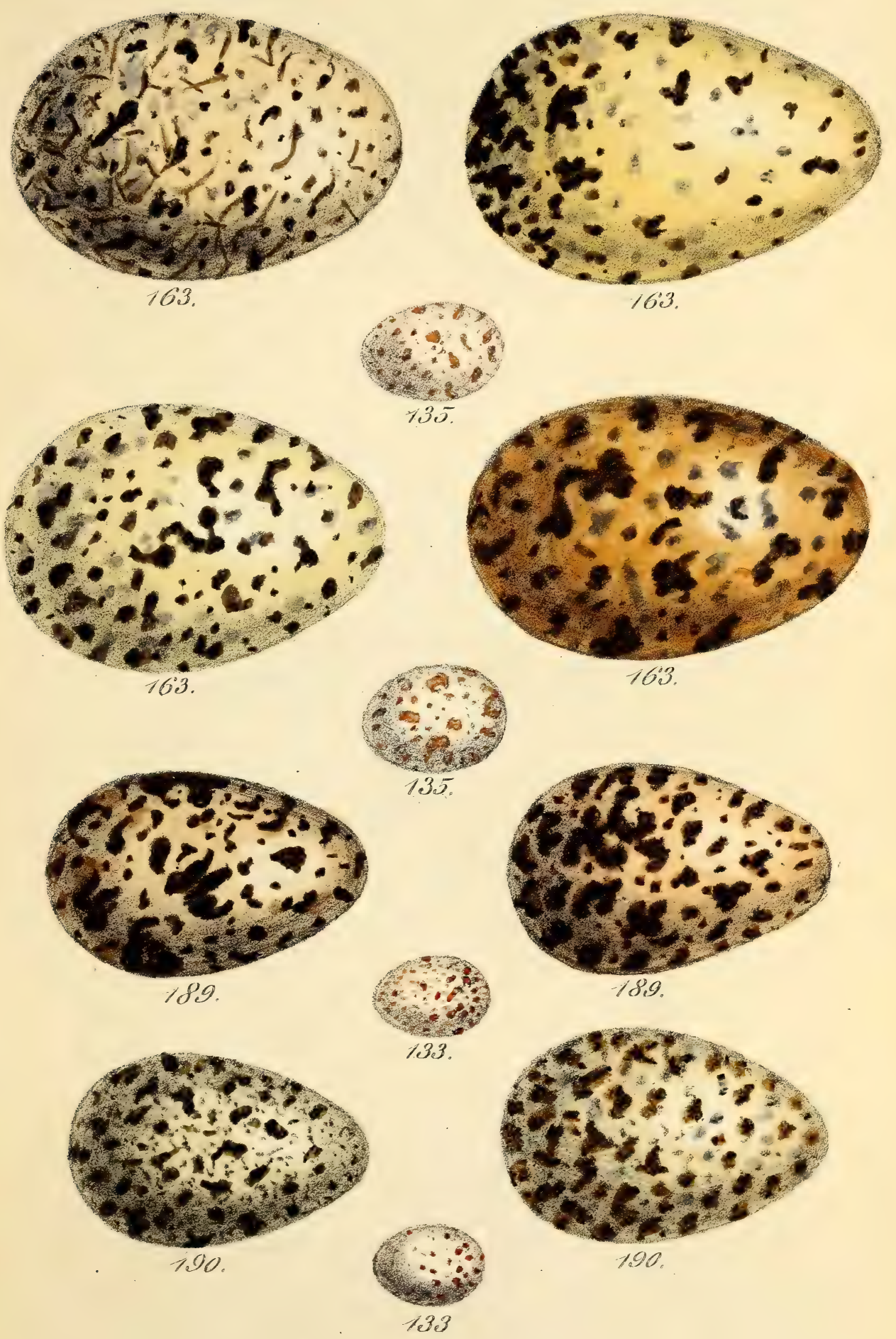





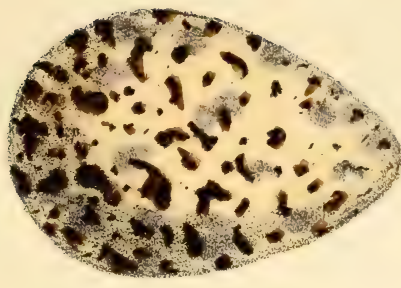

AR.

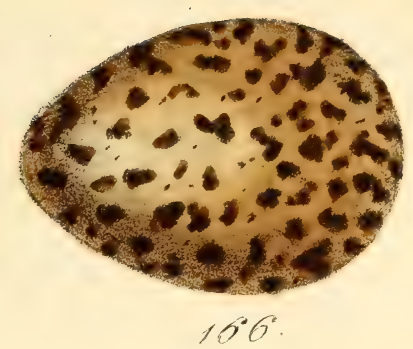

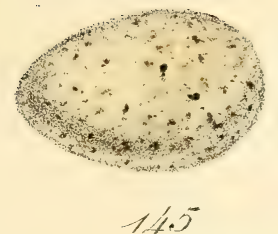
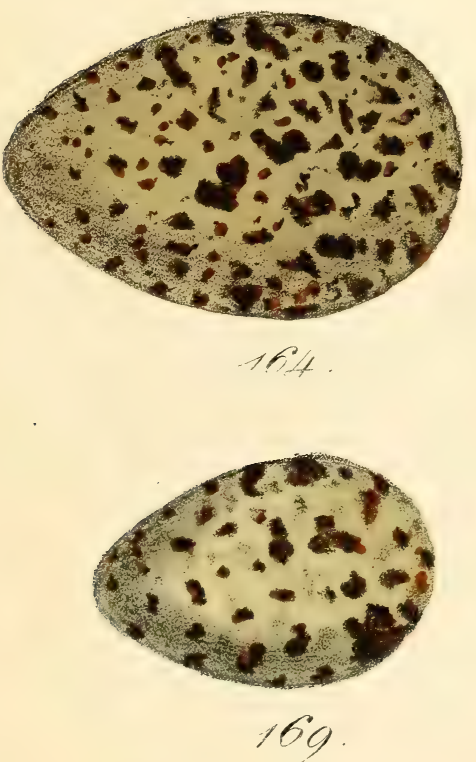
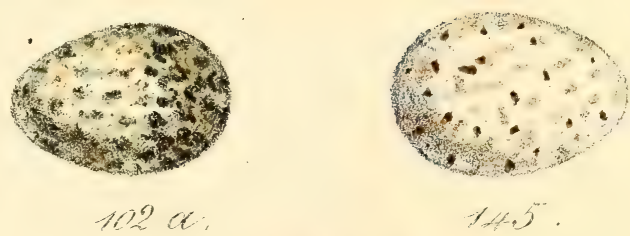
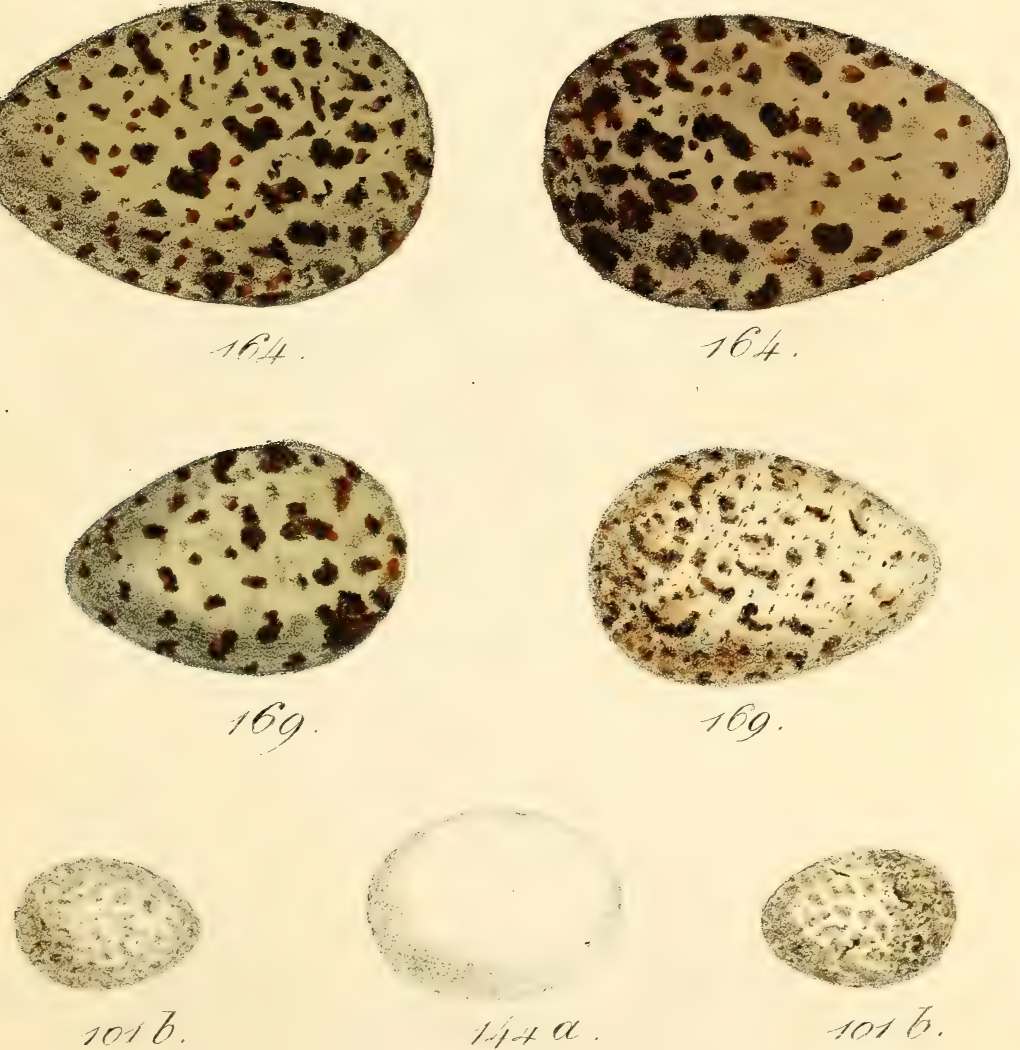

1016 .

$x+d$

1016. 


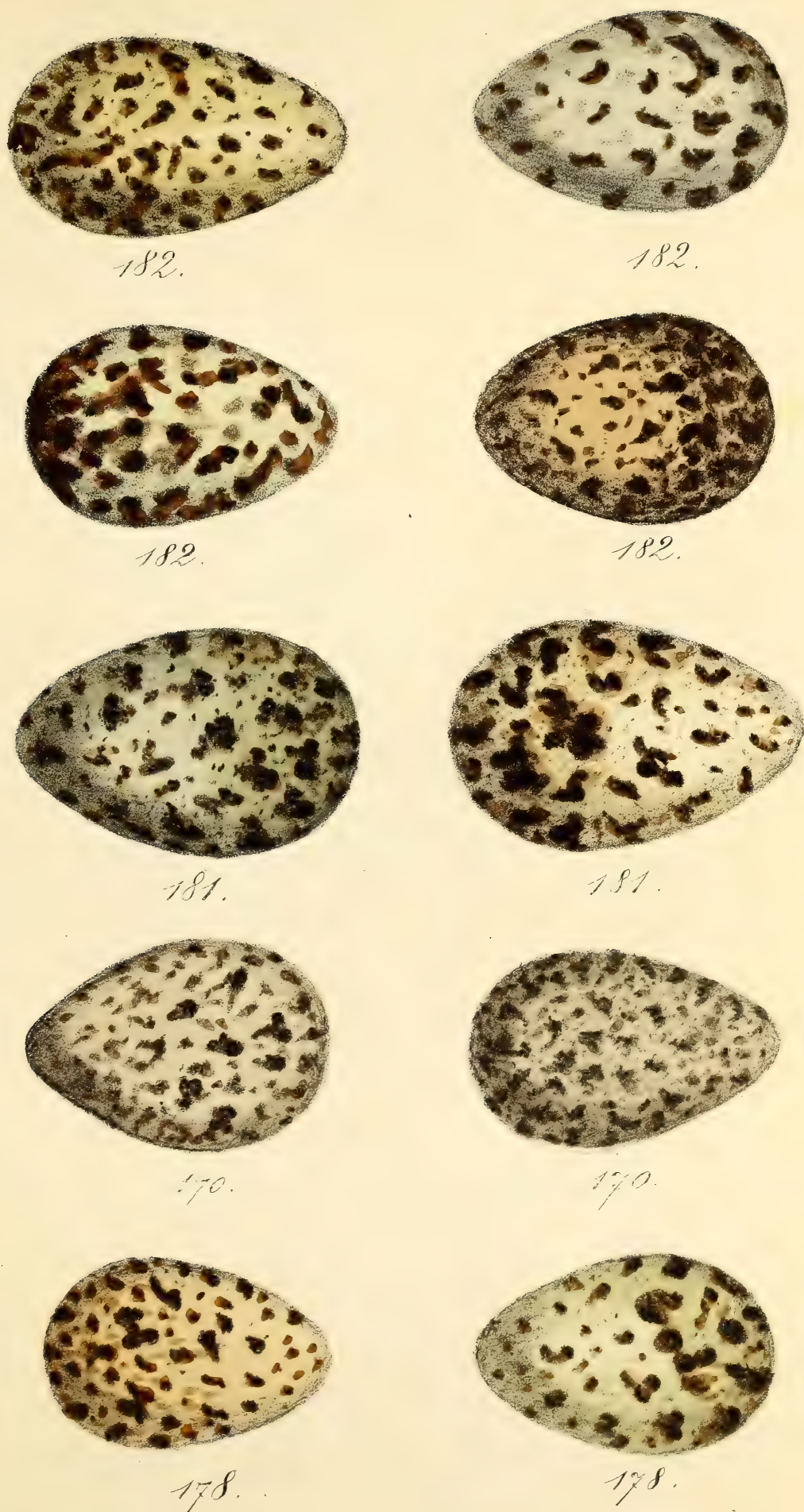



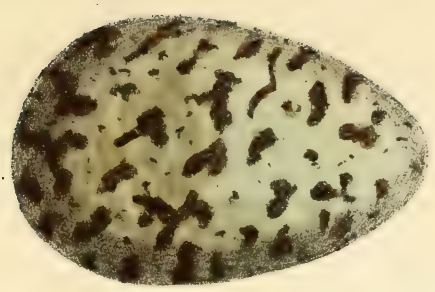

if?

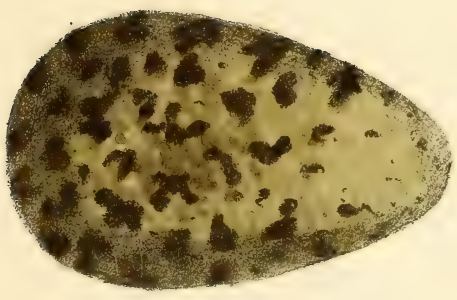

lon

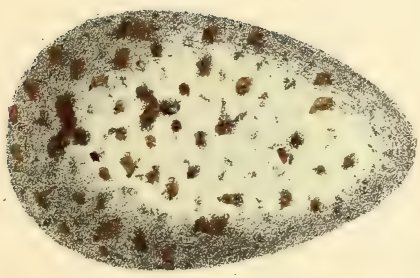

fop

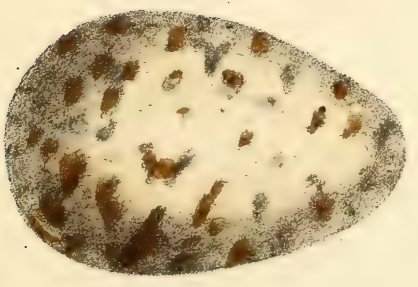

1824

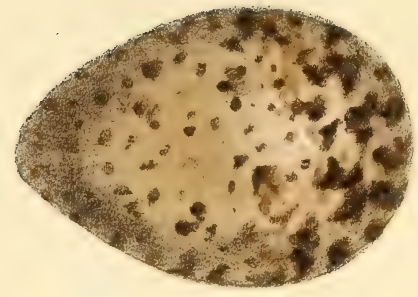

IPL

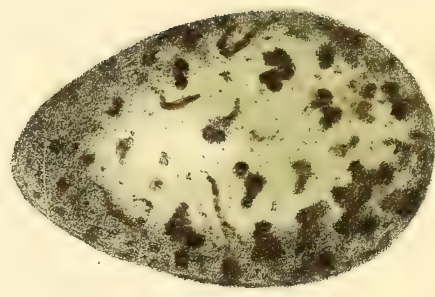

Ifo

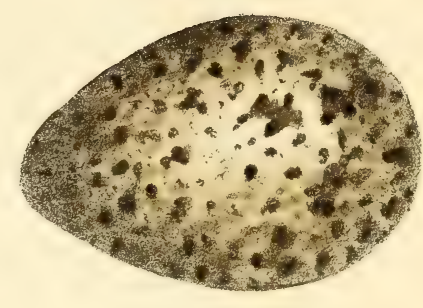

(f)

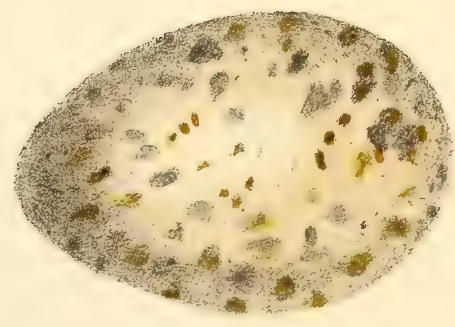

$18-12$ 

XXXV.
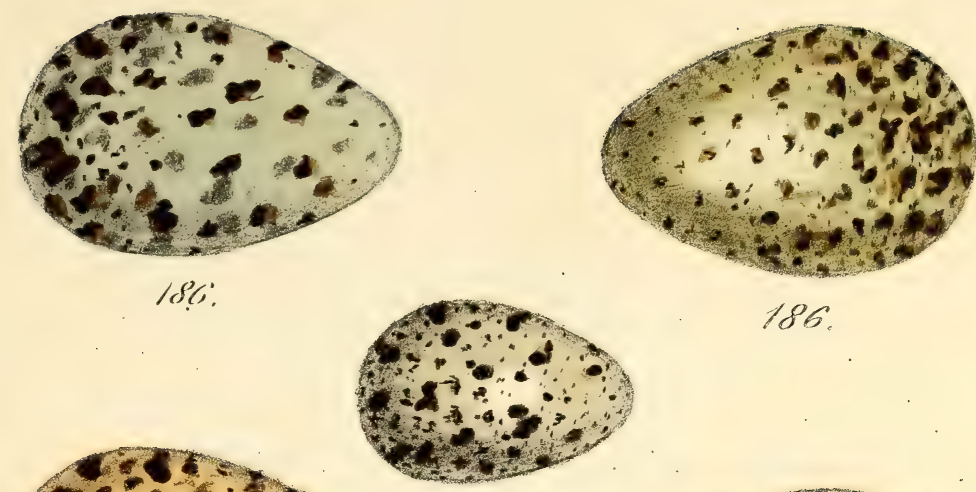

186.

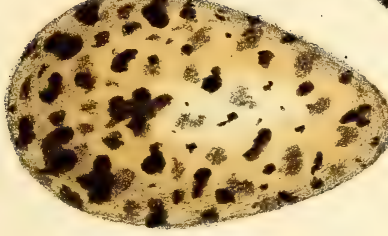

186.
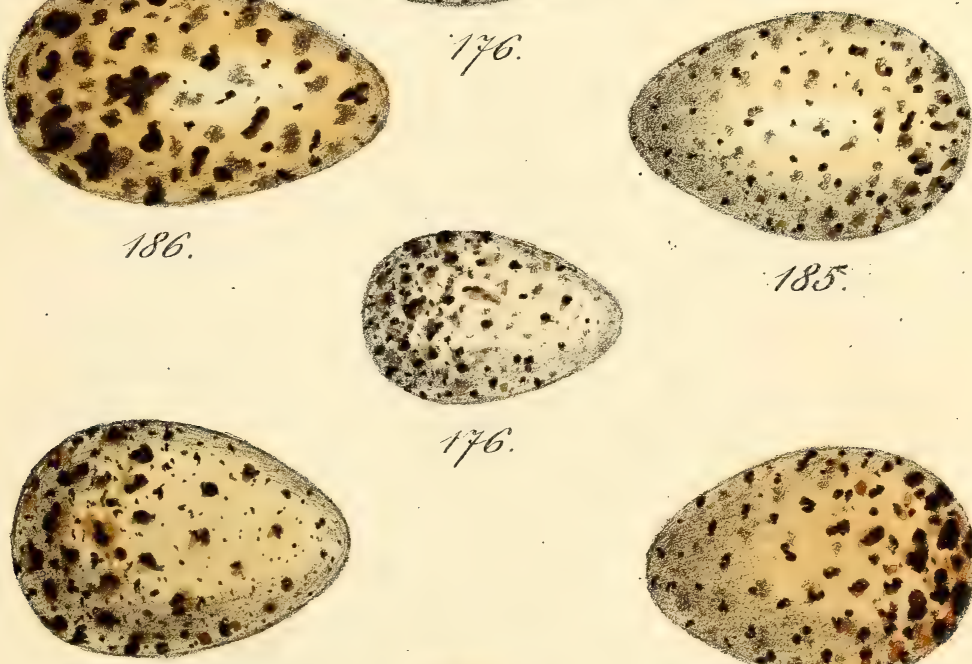

176

185.

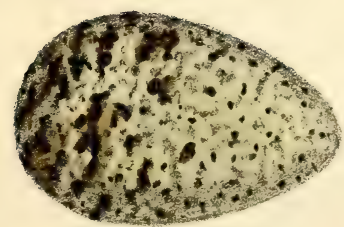

146.
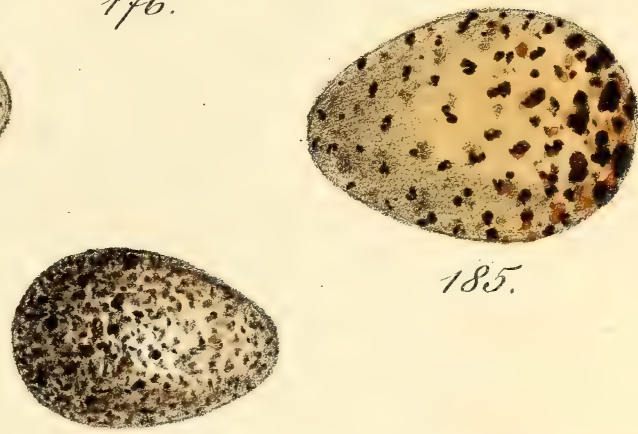

185.

183.

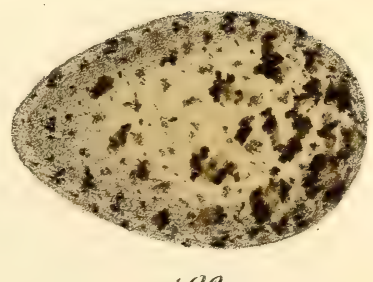

183. 



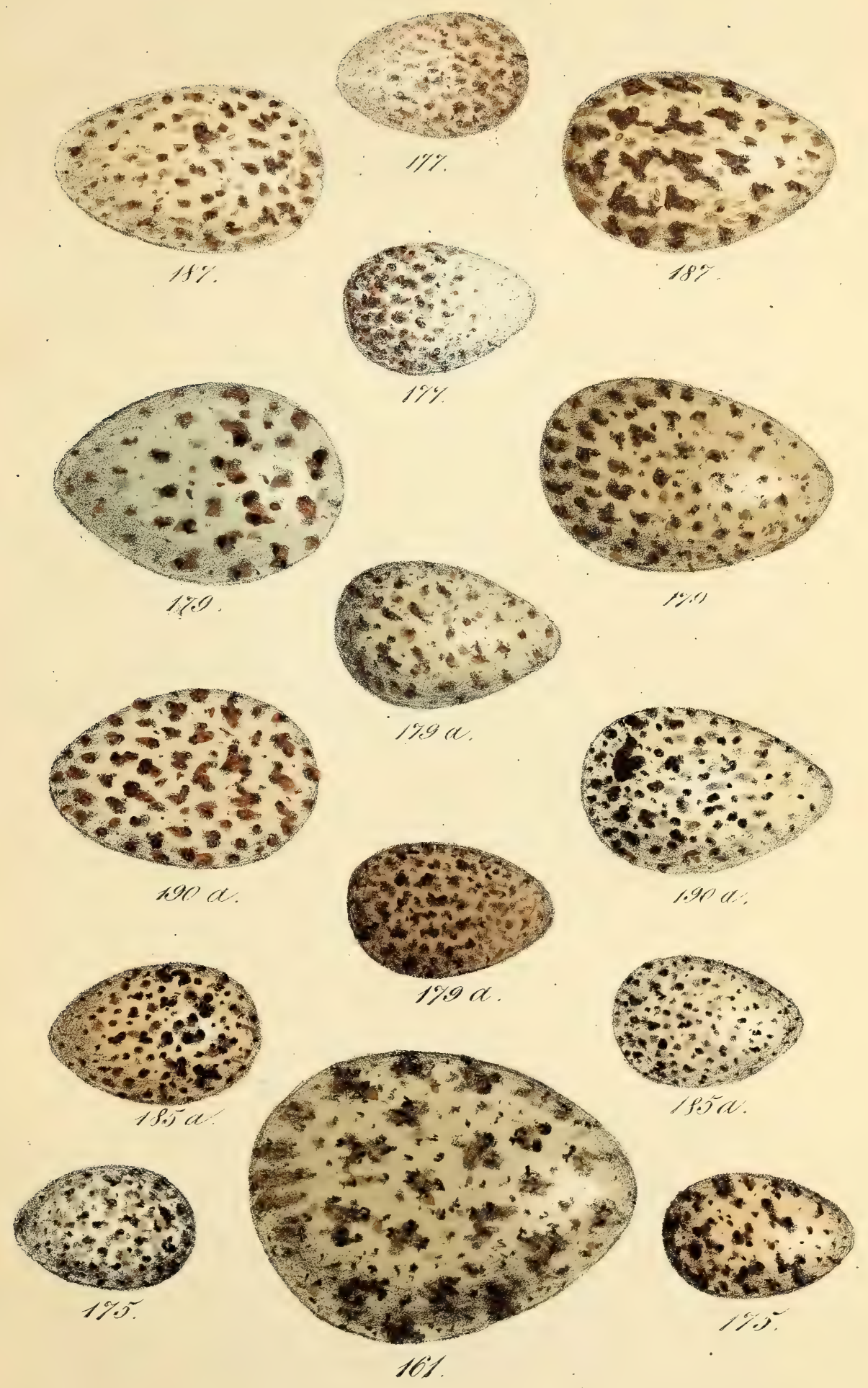




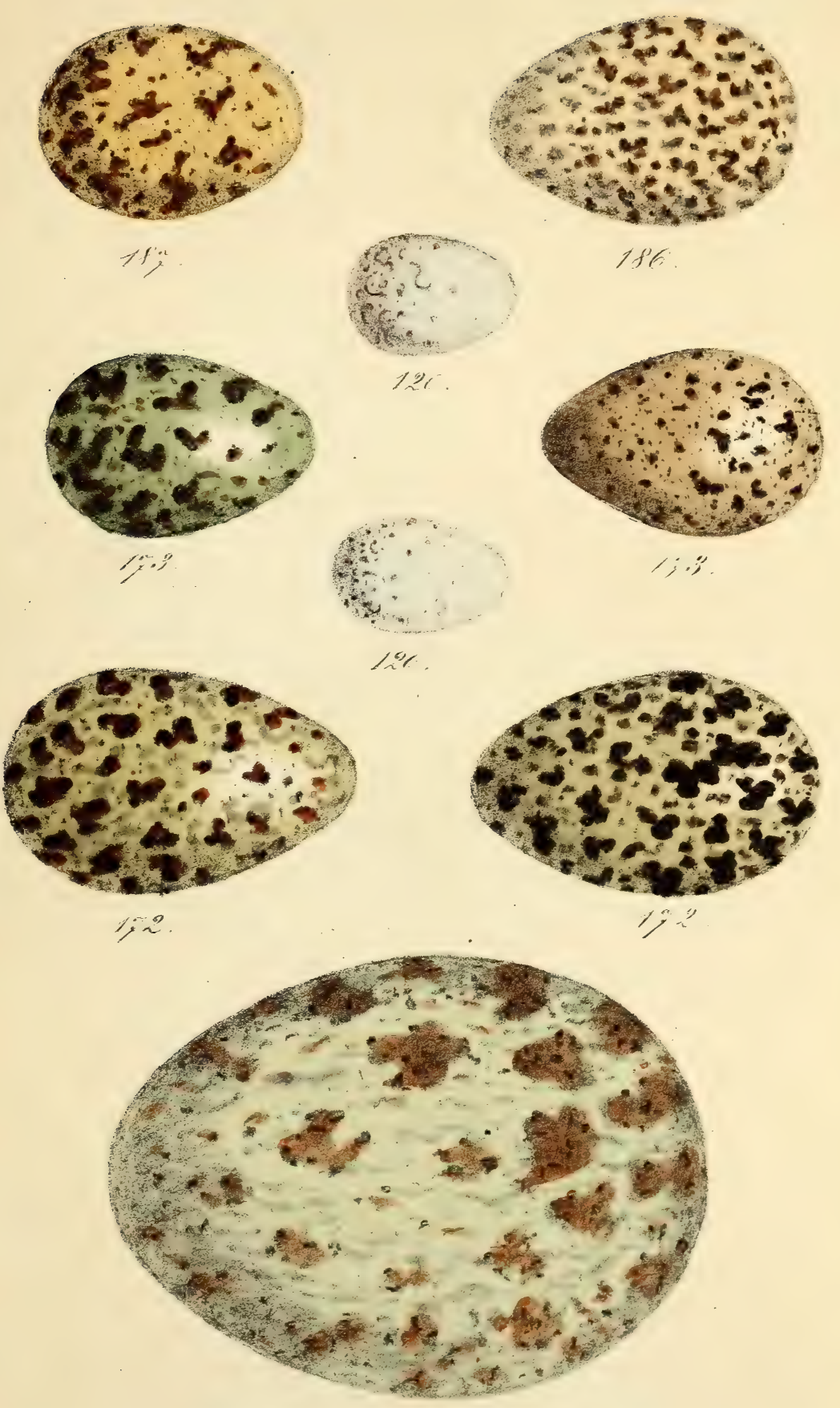

i) 




